Johannes Zuber

\title{
Gegenwärtiger Rassismus in Deutschland
}

Zwischen Biologie und kultureller Identität

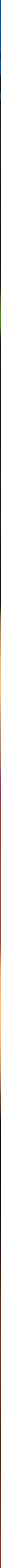

Universitätsdrucke Göttingen 

Johannes Zuber

Gegenwärtiger Rassismus in Deutschland

Dieses Werk ist lizenziert unter einer

Creative Commons

Namensnennung - Weitergabe unter gleichen Bedingungen

4.0 International Lizenz.

(ㄷ) (1) ( ) 
erschienen in der Reihe der Universitätsdrucke im Universitätsverlag Göttingen 2015 
Johannes Zuber

Gegenwärtiger Rassismus in Deutschland

Zwischen Biologie

und kultureller Identität

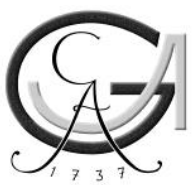

Universitätsverlag Göttingen 2015 


\section{Bibliographische Information der Deutschen Nationalbibliothek}

Die Deutsche Nationalbibliothek verzeichnet diese Publikation in der Deutschen Nationalbibliographie; detaillierte bibliographische Daten sind im Internet über $<$ http://dnb.dnb.de $>$ abrufbar.

Autorenkontak.t

Johannes Zuber

E-Mail: johannes.zuber@web.de

Dissertationsschrift

„Analyse des modernen Rassismus - Verbreitung, Ursachen und wissenschaftliche Realität des biologisch-genetischen Rassismus im heutigen Deutschland“, eingereicht an der Sozialwissenschaftlichen Fakultät der Georg-August-Universität Göttingen

Dieses Buch ist auch als freie Onlineversion über die Homepage des Verlags sowie über den Göttinger Universitätskatalog (GUK) bei der Niedersächsischen Staats- und Universitätsbibliothek Göttingen (http://www.sub.uni-goettingen.de) erreichbar. Es gelten die Lizenzbestimmungen der Onlineversion.

Satz und Layout: Johannes Zuber Umschlaggestaltung: Petra Lepschy

Titelabbildung: blvdone/Shutterstock.com

(C) 2015 Universitätsverlag Göttingen

http://univerlag.uni-goettingen.de

ISBN: 978-3-86395-193-1 


\section{Inhalt}

Abkürzungsverzeichnis ...................................................................................... 5

Abbildungs- und Tabellenverzeichnis.......................................................................... 11

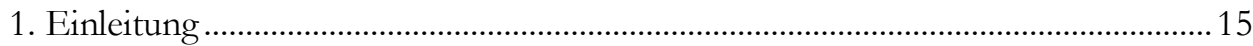

1.1 Theoretische Einordnung......................................................................23

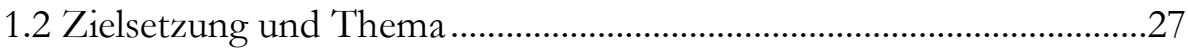

1.3 Methodische Vorgehensweise ...............................................................30

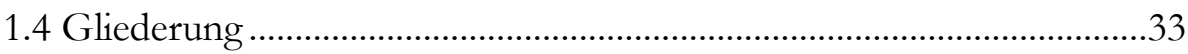

2. Zur Theorie des gegenwärtigen Rassismus................................................................ 35

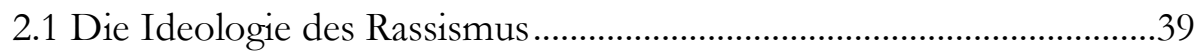

2.1.1 Vielfalt von Rassismusdefinitionen ............................................................. 41

2.1.2 Der ,Rassebegriff' aus sozialwissenschaftlicher Perspektive .................... 43

2.1.3 Rassismus - Versuch einer begrifflichen Eingrenzung .............................. 49

2.2 Rassismustheorien: Eine exemplarische Übersicht ................................54

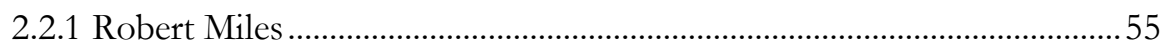

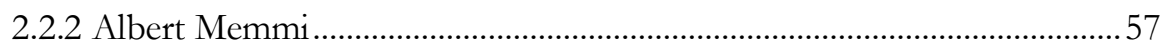

2.2.3 Étienne Balibar und Pierre-André Taguieff .................................................. 60

2.2.4 Enggeführte, biologisch argumentierende Rassismustheorien

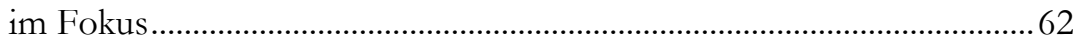

2.3 Historische Entwicklungslinien des Rassismus ......................................62

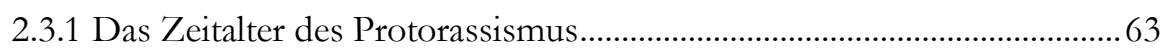

2.3.2 Die Etablierung des pseudowissenschaftlichen Rassismus

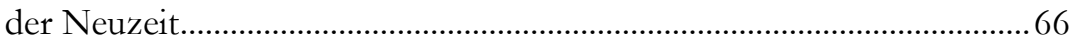

2.3.3 Historische Formen des Rassismus ........................................................... 72

2.4 Biologistischer Rassismus im 21. Jahrhundert .......................................73

2.5 Zwischenfazit: Rassismusbegriff im 21. Jahrhundert............................78

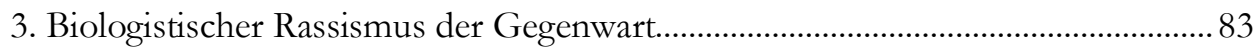

3.1 Thilo Sarrazin - ein Rassist des 21. Jahrhunderts? ................................89

3.1.1 Methodische Vorgehensweise ................................................................... 91

3.1.2 Materialanalyse: Fundstellen und Fundstellenbezeichnung...................... 94 
3.1.3 Inhaltsanalyse: Rassismus, Fremdenfeindlichkeit oder Offenheit? ........95

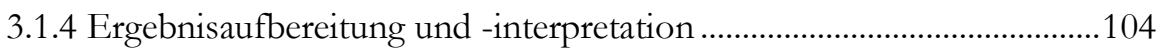

3.2 Rassistische Einstellungen in Deutschland .........................................109

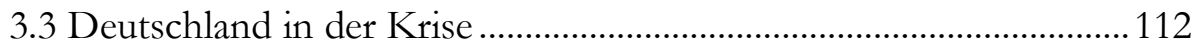

3.4 ALLBUS - Bevölkerungsumfrage der Sozialwissenschaften ............125

3.5 Datenreporte 2008/2011 für die Bundesrepublik Deutschland ...... 131

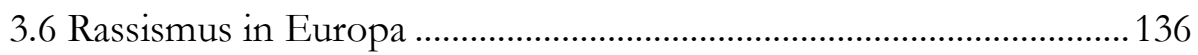

3.7 Zwischenfazit: Rassismus als Alltag?....................................................144

4. Phänomenologie des gegenwärtigen Rassismus...................................................151

4.1 Rassismus im politischen Alltag? ........................................................154

4.1.1 Ausländerpolitik Deutschlands: Vergangenheit und Gegenwart..........156

4.1.2 Neorassismus und deutsche Wiedervereinigung ......................................168

4.1.3,Einwanderungsland‘ Deutschland:

Ein Teil des Rassismusproblems?............................................................177

4.1.4 ,Überflutung' und ,Überfremdung' Deutschlands?

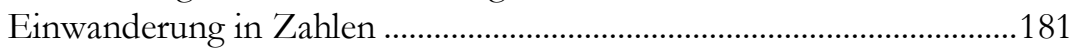

4.1.5 Rassismus und Rechtspopulismus: Deutschland und Europa ...............190

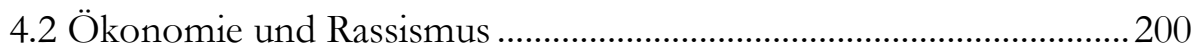

4.3 Die deutsche Gesellschaft im Umbruch? ...........................................205

4.3.1 Die, Ängste‘ der bundesrepublikanischen Bürgerinnen und Bürger....206

4.3.2 Mediale Einflüsse auf Rassismus und Rassismuskritik ...........................211

4.4 Zwischenfazit:

Phänomenologie des Rassismus im 21. Jahrhundert..........................215

5. Naturwissenschaften und Rassismus ....................................................................219

5.1 Charles Darwin: Evolution und Rassismus ........................................228

5.1.1 Die Evolutionstheorie: Von Darwin bis in die Gegenwart ....................230

5.1.2 Missbrauch der Evolutionstheorie im Rahmen des Rassismus..............234

5.1.3 Charles Darwin - kein Rassist! ................................................................237

5.2 Missbrauch eines biologischen Begriffes: Die sogenannte ,Rasse‘ ..239

5.2.1 Rassismus und das Konzept der ,Rasse‘.

5.2.2 Biologischer Art- und Rassebegriff:

Klassifikation in Botanik und Zoologie....................................................243

5.2.3 Phylogenese des modernen Menschen: Das Out-of-Africa-Modell ....250 
5.2.4 ,Rasse ${ }^{6}$ - Missbrauch eines biologischen Fachbegriffs ...........................264

5.3 Rassistische Ressentiments aus molekulargenetischer Perspektive. 267

5.3.1 Mendel-Regeln als theoretische Grundlage der modernen Genetik ....272

5.3.2 Mutationen als Voraussetzung der Evolution ........................................2.273

5.3.3 Bedeutung von Genmutationen und Reparaturmöglichkeiten .............279

5.3.4 Chromosomen- und Genommutationen.................................................283

5.3.5 Rekombinationsereignisse als Ursache von Mutationen ........................286

5.3.6 Zusammenhang von induzierten Mutationen und Umweltfaktoren ...290

5.3.7 Umwelt und Gene 293

5.3.8 Molekulargenetik und biologisch-genetisch

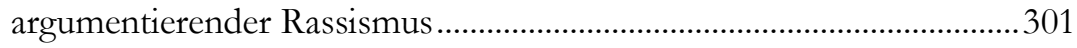

5.4 Intelligenz-Phänomen im Kontext von Genen und Umwelt .......... 306

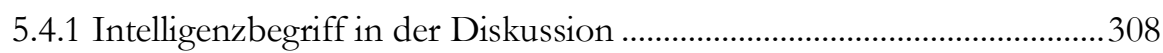

5.4.2 Missverständnis Intelligenz: Intelligenztests und Intelligenzquotient..311

5.4.3 Intelligenz im Kontext

von Verhaltens-, Molekular- und Humangenetik ..................................318

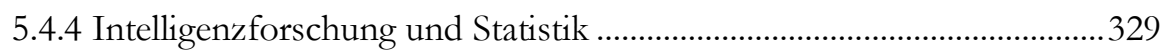

5.4.5 Biologische Forschung und Intelligenzphänomen .................................331

5.5 Zwischenfazit: Biologie contra Rassismus ....................................... 334

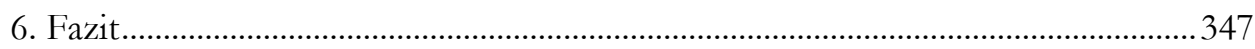

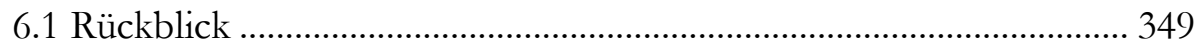

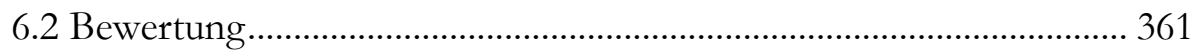

6.3 Ausblick: Rassismusforschung in Deutschland............................... 364

6.4 Ausblick: Biologie und Rassismus ................................................... 366

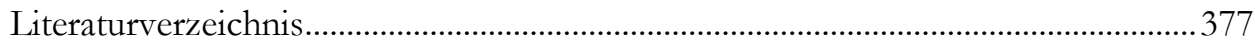




Abkürzungsverzeichnis
AGG
AIDS
ALLBUS
ANOVA
BGB
BRD
BZÖ
CERD
CDU
CSU
DDR
DESTATIS
DNA
EG
EU
FDP
FPÖ
FRA
G
GG
GMF
G2C
$\mathrm{HBP}$
HUGO
IA
IMF
IQ
LA
$\mathrm{mtDNA}$
NPD
NSU
OECD
ÖVP
QTL
PDL
PISA
RFLP
SOEP
SPD
UN
Allgemeines Gleichbehandlungsgesetz
Aquired immunodeficiency syndrome
Allgemeine Bevölkerungsumfrage der Sozialwissenschaften
Analysis of Variance
Bürgerliches Gesetzbuch
Bundesrepublik Deutschland
Bündnis Zukunft Österreich
Committee on the Elimination of Racial Discrimination
Christlich Demokratische Union Deutschlands
Christlich-Soziale Union
Deutsche Demokratische Republik
Statistisches Bundesamt
Desoxyribonucleic acid/Desoxyribonukleinsäure
Europäische Gemeinschaft
Europäische Union
Freie Demokratische Partei
Freiheitliche Partei Österreichs
European Union Agency for Fundamental Rights
General cognitive ability
Grundgesetz der Bundesrepublik Deutschland
Gruppenbezogene Menschenfeindlichkeit
Genes to Cognition Programme
Human-Brain-Project
Human-Genome-Project
Intelligenzalter
International Monetary Fund/Internationaler Währungsfonds
Intelligenzquotient
Lebensalter
Mitochondriale Desoxyribonukleinsäure
Nationaldemokratische Partei Deutschlands
Nationalsozialistischer Untergrund
Organization for Economic Co-operation and Development
Österreichische Volkspartei
Quantitative Trait Loci
Popolo della Libertà
Programme for International Student Assessment
Restriktionsfragment-Längenpolymorphismen-Analyse
Sozioökonomisches Panel
Sozialdemokratische Partei Deutschlands
United Nations/Vereinte Nationen 
UNESCO United Nations Educational, Scientific and Cultural Organization USA United States of America

UV Ultraviolettstrahlung 


\section{Abbildungs- und Tabellenverzeichnis}

Tab. 1: Rassismusdefinitionen (exemplarische Auswahl) ....................................... 42

Tab. 2: Historische Formen des Rassismus nach Jost Müller .............................. 73

Tab. 3: Kodier-Leitfaden nach Mayring.................................................................. 93

Tab. 4: Ergebnisübersicht der Inhaltsanalyse nach Kodier-Leitfaden ............... 105

Tab. 5: Ergebnisse zu Ausländerfeindlichkeit, Antisemitismus und

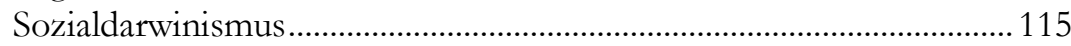

Abb. 1: Zustimmung zur Dimension der „Fremdenfeindlichkeit“ (in Prozent)

Abb. 2: Zustimmung zur Dimension des „Sozialdarwinismus“ (in Prozent) .118

Abb. 3: Fremdenfeindlichkeit - Entwicklung im Zeitverlauf (in Prozent) .......119

Abb. 4: Antisemitismus - Entwicklung im Zeitverlauf (in Prozent) ................. 120

Abb. 5: Sozialdarwinismus - Entwicklung im Zeitverlauf (in Prozent) ............121

Tab. 6: Interessenkonflikte Ausländer (Gastarbeiter) vs. Deutsche (in Prozent)

Tab. 7: „Die in Deutschland lebenden Ausländer sollten ihren Lebensstil ein bisschen besser an den der Deutschen anpassen“ (in Prozent)

Tab. 8: „Wenn die Arbeitsplätze knapp werden, sollte man die in Deutschland lebenden Ausländer wieder in ihre Heimat zurückschicken“" (in Prozent)

Tab. 9: „Haben Sie persönliche Kontakte zu in Deutschland lebenden Ausländern?" (in Prozent)

Tab. 10: Einstellungen gegenüber den in Deutschland lebenden Ausländern in ausgewählten Bevölkerungsgruppen 2006 (Anteil derjenigen, die den Aussagen zustimmen).

Abb. 6: Diskriminierende Einstellungen gegenüber Ausländern in Deutschland (Zustimmung in Prozent)..... 134

Tab. 11: Fremdenfeindliche Aussagen (Zustimmung in Prozent)........................138

Abb. 7: Fremdenfeindlichkeit im europäischen Vergleich (Mittelwertskala)... 139

Tab. 12: Antisemitische Aussagen (Zustimmung in Prozent) .............................. 140

Abb. 8: Antisemitismus im europäischen Vergleich (Mittelwertskala) .............. 141

Tab. 13: Rassistische Aussagen (Zustimmung in Prozent) ....................................141

Abb. 9: Rassismus im europäischen Vergleich (Mittelwertskala) ......................... 142

Abb. 10: Entwicklung der ausländischen Bevölkerung Deutschlands seit 1961

Tab. 14: Wanderungen zwischen Deutschland und dem Ausland ...................... 185

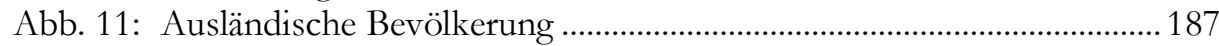

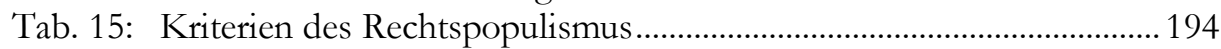

Abb. 12: Hierarchische Klassifizierung der Biologie ...............................................243

Tab. 16: Artkonzepte der Biologie (eigene Darstellung) ....................................... 245

Tab. 17: Überblick über die Fortpflanzungsbarrieren zwischen Arten............... 246 
Tab. 18: Allopatrische und sympatrische Artbildung im Überblick ....................248

Tab. 19: Herkunftsmodelle des anatomisch modernen Menschen ......................252

Abb. 13: Wanderungsbewegungen des modernen Menschen .............................256

Tab. 20: Genetische Distanzen zwischen den Kontinenten..................................259

Abb. 14: Genetischer Stammbaum des modernen Menschen (ausgehend von Tab. 20) ......................................................................259

Tab. 21: Zusammenhang zwischen genetischen Distanzen und Besiedlungsdaten.............................................................................2261

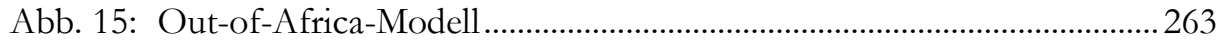

Tab. 22: Biologische Aufgaben der DNA ...........................................................269

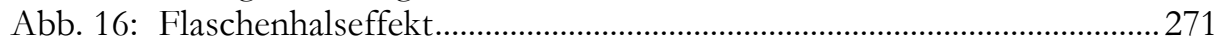

Abb. 17: Auswirkung von positiven, neutralen und negativen Mutationen ......277

Tab. 23: Mutationen am Beispiel der handschriftlichen Kopie von Gedichten ...................................................................................... 280

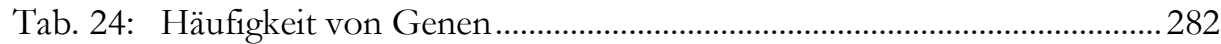

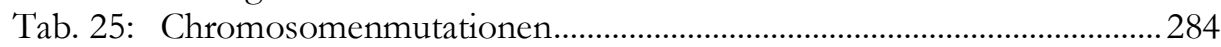

Abb. 18: Möglichkeiten der interchromosomalen Rekombination während der

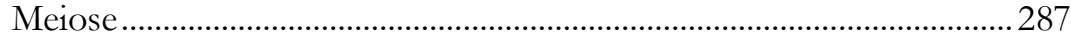

Tab. 26: Umwelteinflüsse auf Weitergabe und Ausprägung von Eigenschaften ..................................................................................2295

Abb. 19: Adoptionsstudien im Überblick.................................................................2296

Tab. 27: Exemplarischer Überblick über Intelligenztheorien...............................309

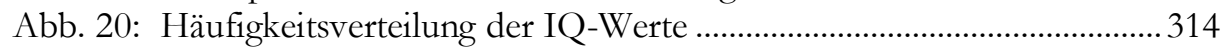

Tab. 28: Exemplarische Items aus dem Stanford-Binet-Intelligenztest.............. 316

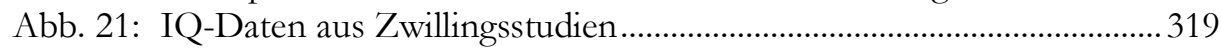

Tab. 29: Häufigkeit von Zwillingsgeburten pro 1000 Geburten............................321

Tab. 30: Beispiele von Heritabilitätsschätzungen bei Tieren und Pflanzen .......322

Abb. 22: Gen- und Umwelteinfluss während der Individualentwicklung...........326

Abb. 23: Gen- und Umwelteinfluss im Kindes- und Erwachsenenalter ..............327

Tab. 31: Current understanding of genetic contribution to group differences 359 
„But visitors from Mars - or from Malawi - unfamiliar with the Western concept of racism could be excused if they had some difficulty in identifying what exactly racism was. We see it everywhere, but rarely does anyone stop to say what it is, or to explain what is wrong with it."

Kwame Anthony Appiah Appiah, Kwame Anthony (1990): Racisms, in: Goldberg, David Theo (Hrsg.): Anatomy of racism, Minneapolis, S. 3. 



\section{Einleitung}

Kaum ein Ereignis führte zu solch einer Erregung der deutschen Gesellschaft, wie die Diskussion der Thesen des ehemaligen Bundesbankvorstandes Thilo Sarrazin im Sommer 2010. Die Causa Sarrazin illustriert zu Beginn des 21. Jahrhunderts exemplarisch, dass rassistische Ressentiments Rückhalt in weiten Teilen der bundesrepublikanischen Gesellschaft genießen. ${ }^{1}$ „Heute sind solche Denkweisen in der Mitte der Gesellschaft angekommen und dürfen laut beklatscht werden." 2 Ein Einblick in die gegenwärtige Rassismusdebatte verdeutlicht, dass insbesondere die Rückkehr biologisch-genetisch konnotierter, rassistischer Vorurteile, wie das angebliche Phänomen der angeborenen bzw. vererbbaren Intelligenz, nachhaltigen Zuspruch findet. Die außerordentlich hohen Verkaufszahlen von Thilo Sarrazins „Deutschland schafft sich $\mathrm{ab}^{\text {"3 } 3}$ belegen diese These augenscheinlich: Es ist mit etwa 1,5 Millionen verkaufter Exemplare das meist verkaufte politische Sachbuch

$1 \quad$ Vgl. Haller, Michael/Niggeschmidt, Martin (2012): Einführung, in: ebd. (Hrsg.): Der Mythos vom Niedergang der Intelligenz. Von Galton zu Sarrazin: Die Denkmuster und Denkfehler der Eugenik, Wiesbaden, S. 7. | Vgl. Decker, Oliver/Kiess, Johannes/Brähler, Elmar (2012): Die Mitte im Umbruch. Rechtsextreme Einstellungen in Deutschland 2012, Bonn.

2 Haller/Niggeschmidt 2012, ebd., S. 7.

Die Begrifflichkeit ,Mitte der Gesellschaft' verdeutlicht, dass die genannten Vorurteile und Stereotype im 21. Jabrbundert in allen Ebenen der bundesrepublikanischen Gesellschaft vorzufinden sind. Die genannten Denkweisen sind folglich keinesfalls nur in gesellschaftlichen Randgruppen zu verorten (s. Kapitel 3).

3 Sarrazin, Thilo (2010): Deutschland schafft sich ab. Wie wir unser Land aufs Spiel setzen, 13. Auflage, München. 
der Nachkriegsgeschichte und das, obwohl „[d]as Hauptargument des Buchs [von Sarrazin] [...] aus der eugenischen Mottenkiste des späten 19. und frühen 20. Jahrhunderts [stammt]." ${ }^{4}$ Thilo Sarrazin bedient sich demzufolge inhaltlich und fachlich überholter Ansichten. ${ }^{5}$

An dieser dringlichen und brisanten Problemstellung, die die gesellschaftliche Stabilität und Integrität Deutschlands im 21. Jahrhundert gefährden könnte, setzt dieses Forschungsvorhaben an. Untersucht werden soll die Verbreitung biologisch-rassistischer Vorurteile und Ressentiments: In welchen gesellschaftlichen Ebenen können diese diagnostiziert werden? Kann von einem neuen biologischgenetischen Rassismusproblem in Deutschland gesprochen werden? Und diesbezüglich zentral: Wie sieht die naturwissenschaftliche Realität biologischgenetischer Argumentationen des Rassismus aus? Hierzu verbindet diese Arbeit in so bisher noch nicht vorhandener Weise die Forschungsbereiche der Sozial- und der Naturwissenschaften - insbesondere der Biologie -, um das Phänomen des biologisch konnotierten Rassismus mithilfe verschiedener wissenschaftlicher Disziplinen bzw. Perspektiven zu analysieren. Die Integration von naturassoziierten bzw. biologischen Thesen in sozialwissenschaftlich-rassistische Argumentationen bestätigen den essentiellen Sinn dieses kombinierten Forschungsansatzes, der sich die Frage stellt, welche Argumente gegenwärtige biologische Forschungserkenntnisse hinsichtlich des sozialbiologisch argumentierenden Rassismus liefern.

Das Konzept der Kombination von sozial- und naturwissenschaftlicher Forschung zeigt sich dabei als größtenteils methodisch als auch fachwissenschaftlich zukunftsweisend konstruiert, da sich nur so vielfältige Interdependenzen zwischen Sozial- und Naturwissenschaften gewinnbringend nutzen lassen, die für eine umfassende Untersuchung der biologistischen Rassismuskomponente unabdinglich erscheinen. Doch warum auf biologische Grundlagen zurückgreifen und diese falsifizieren, wenn es auch vor dem Hintergrund der Causa Sarrazin vor allem um gesellschaftliche Herrschaftsverhältnisse und soziale Zuschreibungen geht, möge man sich fragen? Die Basis dieser Unterscheidung zwischen Herrschenden und Beherrschten bzw. der sozialen Hierarchisierung von Bevölkerungsgruppen wurde in der Vergangenheit aufgrund biologischer Zuschreibungen, beispielsweise des ,blauen', reinen Blutes u. a., gelegt. ,Rasse', Rassismus, Rassifizierung, soziale Ungleichheit, Herrschaftsverhältnisse und Macht sind aufgrund dessen eng miteinander verwoben; sie verleihen sich erst gegenseitig Sinn und sind dementsprechend

$4 \quad$ Weingart, Peter (2012): Ist Sarrazin Eugeniker?, in: Haller, Michael/Niggeschmidt, Martin (Hrsg.): Der Mythos vom Niedergang der Intelligenz. Von Galton zu Sarrazin: Die Denkmuster und Denkfehler der Eugenik, Wiesbaden, S. 19. | Vgl. Haller/Niggeschmidt 2012, a. a. O., S. 8. | Vgl. Dernbach, Andrea (2013): ,Bundesregierung antwortet auf Sarrazin-Kritik der UN", in URL: http://www.zeit.de/ politik/deutschland/2013-07/sarrazin-unbundesregierung $<23.07 .2013>$.

5 Vgl. Weingart 2012, ebd., S. 25. | Vgl. Etzemüller, Thomas (2012): Die Angst vor dem Abstieg - Malthus, Burgdörfer, Sarrazin: eine Ahnenreihe mit immer derselben Botschaft, in: Haller, Michael/Niggeschmidt, Martin (Hrsg.): Der Mythos vom Niedergang der Intelligenz. Von Galton zu Sarrazin: Die Denkmuster und Denkfehler der Eugenik, Wiesbaden, S. 177. 
schwer zu entwirren. ${ }^{6}$ Weiterhin wurde der biologistisch argumentierende Rassismus bis in die Gegenwart nicht ausreichend widerlegt. ${ }^{7}$ Der Rekurs auf die Biologie des Menschen im Rahmen des Rassismus ist so auch heute noch allgegenwärtig - denn er ist funktional, da gesellschaftliche Konflikte so hinter einer vermeintlich nicht hinterfragbaren Natur versteckt werden können. ${ }^{8}$ In diesem Zusammenhang kann insbesondere in der englischsprachigen Forschung von einer ReEtablierung des ,Rassenglaubens' gesprochen werden, der in Deutschland als „Unwort der letzten 60 Jahre“9 gilt. Gerade die Genetik ermöglicht hier als neuere Disziplin der Biologie multiple Anknüpfungspunkte.

Aufgrund dieser Verknüpfungen zwischen Biologie und Rassismus ist auch von Seiten der sozialwissenschaftlichen Forschung eine gewisse Multiperspektivität gefragt: Das Konzept des Rassismus verbindet biologische, genetische, körperliche, kulturelle und soziale Zuschreibungen. ${ }^{10}$ Für eine umfassende, multiperspektivische und möglichst objektive Analyse des gegenwärtigen, modernisierten Rassismusphänomens bedarf es daher unter anderem Kenntnisse der Biowissenschaften als Voraussetzung, um dessen einzelne Bestandteile bzw. dessen Bedeutung für den gegenwärtigen Rassismus zu untersuchen. ${ }^{11}$ Insofern kann die methodische Vorgehensweise nochmals zusätzlich legitimiert werden.

Darüber hinaus unterstreicht und legitimiert die skizzierte, aktuelle bundesrepublikanische Situation zugleich den bedeutsamen Charakter dieses Forschungsprojektes sowie den dringend notwendigen Forschungsbedarf. Die primäre Zielsetzung dieser Arbeit fokussiert demnach Verbreitung, Phänomenologie und Erklärungsansätze sowie die naturwissenschaftliche Realität des biologischgenetischen Rassismusphänomens im Deutschland des 21. Jahrhunderts. Unter dem Begriff des biologisch-genetisch konnotierten Rassismus wird dabei in der folgenden Untersuchung die Differenzierung und Hierarchisierung bzw. die Konstruktion und Diskriminierung von spezifischen menschlichen Gruppen anhand biologischer Merkmale verstanden.

Seitens der politischen Arena gilt diese Ideologie des Rassismus in Deutschland zwar seit dem Ende der fremdenfeindlichen, gewalttätigen Unruhen der 1990er Jahre tendenziell als nicht mehr existent, was sich jedoch erst kürzlich mit den rassistisch motivierten Morden des ,Nationalsozialistischen Untergrundes' (NSU) als fehlerhafte Annahme herausstellte. Von europäischer Seite bemerkt beispielsweise die FRA (European Union Agency For Fundamental Rights) in ihrem Jahresbericht 2010, dass rassistisch motivierte Gewalt in der Bundesrepublik Deutschland wieder im Anstieg begriffen ist: Zwischen den Jahren 2007 und 2008 wird dem-

$6 \quad$ Vgl. Plümecke, Timo (2013): Rasse in der Ära der Genetik. Die Ordnung des Menschen in den Lebenswissenschaften, Bielefeld, S. 12f.

Vgl. Plümecke 2013, ebd., S. 22.

Vgl. Plümecke 2013, ebd., S. 20.

Plümecke 2013, ebd., S. 12.

Vgl. Plümecke 2013, ebd., S. 33.

Vgl. Plümecke 2013, ebd., S. 33ff. 
nach ein tendenzieller Anstieg um 16,0 Prozent identifiziert. ${ }^{12}$ Der bundesrepublikanische Rassismus des 21. Jahrhunderts im europäischen Spitzenfeld? ${ }^{13}$ Stellvertretend hierfür seien die gesellschaftspolitischen Interpretationen Sarrazins genannt, der vor allem auch wieder biologistische Grundprinzipien des Rassismus auf der gesellschaftlichen Tagesordnung positionierte: Genetisch bedingte Vererbungsschemata, die Unterscheidung von ,nützlicheren' und ,unnützlicheren' Menschengruppen, biologistische Ungleichheiten oder die Gefahr einer angeblichen kulturell-biologischen ,Überfremdung' der bundesrepublikanischen Gesellschaft durch die zunehmende Anzahl von ausländischen Mitbürgerinnen und Mitbürgern. ${ }^{14}$ Erschreckend stellen sich vor diesem Hintergrund insbesondere die bevölkerungsübergreifend hohen Zustimmungswerte zu Sarrazins pseudowissenschaftlicher Rückkehr biologistisch-rassistischer Vorurteile dar. ${ }^{15}$ Besorgt muss so nachgefragt werden, ob sich die überholt geglaubten sozialbiologischen Ansichten und Erklärungsschemata des 19. und 20. Jahrhunderts auch im 21. Jahrhundert wieder partiell im gesellschaftlichen Meinungsbild etabliert haben? ${ }^{16}$ Werden Menschengruppen abermals auf der Grundlage pseudobiologischer Klassifikationsmerkmale in unterschiedliche Gruppen bzw. ,Rassen ${ }^{6}$ hierarchisiert? ${ }^{17}$ Kann weiterhin ,[...] an unproved assumption of the biological and perpetual superiority of one human group over another" 18 identifiziert werden? Festzustellen ist sicherlich, dass die Folgen des gesellschaftlichen Rassismus im Gegensatz zum 19. und 20. Jahrhundert heute differieren: Die offen biologische sowie explizite Diskriminierung und Abwertung von spezifischen Menschengruppen scheint aktuell größtenteils zu fehlen bzw. vor allem in der Nicht-Öffentlichkeit stattzufinden. ${ }^{19}$

Diese skizzierten gesellschaftlichen Tendenzen in Deutschland schockieren, da die Gleichheit aller Menschen als Grundlage der Europäischen Union (EU) verstanden werden kann. Zusätzlich ist die Richtlinie zur Gleichbehandlung der Menschen ohne Unterschied der ,Rasse' seitens der FRA aus dem Jahr 2000 zu nennen, die als EU-weites Ziel die Bekämpfung und Prävention von Diskriminierung, Abwertung und Ausgrenzung von Menschengruppen aufgrund deren angeblicher

12 Vgl. Agentur der Europäischen Union für Grundrechte (2010): Jahresbericht 2010. Konferenzausgabe, Wien, S. 41.

13 Vgl. Winkler, Jürgen R. (2003): Ursachen fremdenfeindlicher Einstellungen in Westeuropa, in: Aus Politik und Zeitgeschichte, Beilage zur Wochenzeitung Das Parlament, 26/2003, Bonn, S. 38.

14 Der auf soziale Verbältnisse übertragene biologische, Rassebegriff kann einzig als Ergebnis einer fragwürdigen gesellschaftlichen Konstruktion verstanden werden, wie die nachfolgenden Kapitel illustrieren werden. Deshalb wird der Begriff, Rasse" nachfolgend jeweils mit Anführungszeichen gekennzeichnet.

15 Vgl. Buchmann, Jonas et al. (2011): ,Sind Deutsche klüger als Türken?“, in: Frankfurter Neue Presse, Jahrgang 66 Nr. 223, 24.11.2011, S. 4-5.

16 Vgl. Weingart, Peter (1992): Politik und Vererbung, in: Propping, Peter/Schott, Heinz (Hrsg.): Wissenschaft auf Irrwegen. Biologismus - Rassenhygiene - Eugenik, Bonn u. a., S. 34.

17 Vgl. Messerschmidt, Astrid (2009): Rassismusanalyse in einer postnationalsozialistischen Gesellschaft, in: Melter, Claus/Mecheril, Paul (Hrsg.): Rassismuskritik. Band 1: Rassismustheorie und -forschung, Schwalbach/Taunus, S. $63 \mathrm{ff}$.

18 Benedict, Ruth (1983): Race and racism, London, S. VII.

19 Vgl. Weingart 1992, ebd., S. $37 \mathrm{ff}$. 
biologischer ,Rasse' ausgibt. ${ }^{20}$ Zudem gilt in einer demokratischen Gesellschaft wie der bundesrepublikanischen die Gleichwertigkeit aller Menschen als zentraler Wertbaustein, was durch die in der bundesrepublikanischen Verfassung zementierten Grundrechte bestätigt wird. ${ }^{21}$ Problematisch erscheint jedoch, dass die Gesetzes- und Verordnungslage Deutschlands viele Jahre den Mythos der ,fremdartigen', ,andersartigen' Nicht-Staatsbürgerinnen und -Staatsbürger selbst forciert und reproduziert hat, da eine transparente, strukturierte und verständliche Migrations-, Integrations- und Einwanderungspolitik lange Zeit fehlte. ${ }^{22}$ Erst 2005 wurde dies im Rahmen des novellierten Zuwanderungsgesetzes geändert. ${ }^{23}$ Trotzdem enthält beispielsweise das Grundgesetz (GG) in Art. 3 Abs. 3 im Rahmen der sogenannten Diskriminierungsverbote den fragwürdigen biologischen ,Rassebegriff', obwohl dieser im 21. Jahrhundert bezüglich des modernen Menschen wissenschaftlich falsifiziert werden kann.

Die elementare Bedeutung von einwandernden Menschen nach Deutschland und in die EU wird aktuell verkannt. In Zeiten des Facharbeitskräftemangels in bestimmten Arbeitsfeldern sowie eines sich abzeichnenden, kritischen demographischen Wandels ist die europäische Staatengemeinschaft - und damit auch Deutschland - in hohem Maße von ausländischen Bürgerinnen und Bürgern abhängig, die für den Erfolg der bundesrepublikanischen Wirtschaft in der Vergangenheit und auch in der Zukunft unabdingbar erscheinen. Menschen mit Migrationshintergrund stellen heute einen wichtigen Bestandteil Deutschlands dar. ${ }^{24}$ Migration und Integration stehen demnach seitens der EU an primärer Stelle der politischen Agenda, die umsetzungsbedingten Differenzen zwischen den einzelnen Mitgliedstaaten zeigen sich jedoch immer noch deutlich. ${ }^{25}$

Das Thema Rassismus kann im 21. Jahrhundert auf europäischer und bundesrepublikanischer Ebene als von herausragender Bedeutung für die zukünftige gesellschaftliche, politische und ökonomische Entwicklung charakterisiert werden. Der angebliche Rückzug der rassistischen Ideologie in der Bundesrepublik Deutschland nach den Schreckensereignissen des Nationalsozialismus und des

20 Vgl. Agentur der Europäischen Union für Grundrechte (2012): Die Richtlinie zur Gleichbehandlung ohne Unterschied der Rasse: Anwendung und Herausforderungen, Wien, S. 7, 9.

21 Vgl. Groß, Eva/Zick, Andreas/Krause, Daniela (2012): Von der Ungleichwertigkeit zur Ungleichheit: Gruppenbezogene Menschenfeindlichkeit, in: Aus Politik und Zeitgeschichte, Beilage zur Wochenzeitung Das Parlament, 16-17/2012, 62. Jahrgang, Bonn, S. 11. | Vgl. Bundeszentrale für politische Bildung (2011): Grundgesetz für die Bundesrepublik Deutschland, Bonn, S. 13ff.

22 Vgl. Terkessidis, Mark (2004): Die Banalität des Rassismus. Migranten zweiter Generation entwickeln eine neue Perspektive, Bielefeld, S. 55.

23 Vgl. Terkessidis 2004, ebd., S. 55.

24 Vgl. Terkessidis 2004, ebd., S. 8.

25 Vgl. Bendel, Petra (2009): Die Migrationspolitik der Europäischen Union. Inhalte, Institutionen und Integrationsperspektiven, in: Butterwegge, Christoph/Hentges, Gudrun (Hrsg.): Zuwanderung im Zeichen der Globalisierung. Migrations-, Integrations- und Minderheitenpolitik, 4. Auflage, Wiesbaden, S. 123ff. 
Zweiten Weltkrieges kann nur als vordergründig identifiziert werden. ${ }^{26}$ Rassismus darf demnach nicht als ,[...] vergangenes Problem [...]“27 bzw. gesellschaftliches Randphänomen gekennzeichnet werden, sondern muss als besorgniserregende Entwicklung Beachtung finden. Zu Beginn des 21. Jahrhunderts zeigt er sich nach wie vor als Element von Gegenwart und Zukunft, nicht nur in Deutschland, sondern tendenziell weltweit. ${ }^{28}$ Demzufolge kann er keinesfalls als überholtes, historisches Konstrukt präsentiert werden. ${ }^{29}$ Darüber hinaus scheinen die diskriminierenden, rassistischen Vorurteile insbesondere wieder mithilfe von Biologie und neuerdings - Genetik legitimiert zu werden. ${ }^{30}$

Für die im weiteren Verlauf zu untersuchende Entwicklung des gegenwärtigen, bundesrepublikanischen Rassismusphänomens spricht teilweise ebenfalls die europaweite Verbreitung des sogenannten Rechtspopulismus. ${ }^{31}$ Denn auch dessen Annahmen basieren größtenteils auf der rassistischen Ideologie, die die Kernelemente zur Ab- und Ausgrenzung von ,Fremden“ bereitstellt: Sie gilt als „Lebenselixier“32 von Rechtspopulismus und Rechtsextremismus. ${ }^{33}$ Diese grundsätzlich fremdenfeindlichen sowie rassistischen Theoreme sprechen die Bürgerinnen und Bürger direkt an. ${ }^{34}$ Sie identifizieren vorhandene soziale oder beispielsweise politische Probleme in der Bedrohung durch ,Fremde' und ,Andersartige', welche die Lebensqualitäten der eigenen ,arbeitsamen', ,fleißigen“ Menschengruppe angeblich gefährde. Die Gesellschaft knüpft an diese verwissenschaftlichten bzw. biologistischen Falschinterpretationen oftmals an, um die tatsächlichen Ursachen der eigenen Fehlentwicklungen zu verschleiern. Die Diskriminierung von ausländischen Mitbürgerinnen und Mitbürgern sowie die Statuszuschreibung, Sündenbock ${ }^{6}$ und ,Sozialschmarotzer' scheint jedoch tendenziell wieder als Normalität angesehen zu

Vgl. Barth, Boris (2010): „Rassismus“, in URL: http://www.ieg-ego.eu/de/threads/europaund-die-welt/rassismus/boris-barth-rassismus $<23.09 .2012>$.

Messerschmidt 2009, a. a. O., S. 59.

Vgl. Hong, Eun-Young (2011): Rassismus als Problem kritischer Bildung. Widersprüche von Aufklärung, Solidarität und Vielfalt, Diss. Pädagogische Hochschule, Karlsruhe, S. 44. | Vgl. Panahi, Badi (1980): Vorurteile. Rassismus, Antisemitismus, Nationalismus... in der Bundesrepublik heute. Eine empirische Untersuchung, Frankfurt/Main, S. 31.

Vgl. Hong 2011, ebd., S. 49ff.

Vgl. Sesín, Claus-Peter (2012): Sarrazins dubiose US-Quellen, in: Haller, Michael

/Niggeschmidt, Martin (Hrsg.): Der Mythos vom Niedergang der Intelligenz. Von Galton zu Sarrazin: Die Denkmuster und Denkfehler der Eugenik, Wiesbaden, S. 31.

1 Beacbtet werden muss jedoch, dass Rechtspopulisten insbesondere in Osteuropa nicht zwangsläufig hauptsächlich mit rassistischen Aspekten argumentieren. Das ,Fremde' können auch Gruppierungen im eigenen Land bespielsweise die sogenannte Elite eines Staates - darstellen, die nur schwerlich ,rassistisch" zu definieren sind. Zick, Andreas/Küpper, Beate/Hövermann, Andreas (2011): Die Abwertung der Anderen. Eine europäische Zustandsbeschreibung zu Intoleranz, Vorurteilen und Diskriminierung, Berlin, S. 187.

33 Vgl. Decker, Frank (2006): Die populistische Herausforderung. Theoretische und länderübergreifende Perspektiven, in: ebd. (Hrsg.): Populismus in Europa. Gefahr für die Demokratie oder nützliches Korrektiv?, Bonn, S. 9ff. | Vgl. Jaschke, Hans-Gerd (2006): Politischer Extremismus, Wiesbaden, S. 80ff.

Vgl. Spier, Tim (2006): Populismus und Modernisierung, in: Decker, Frank (Hrsg.): Populismus in Europa. Gefahr für die Demokratie oder nützliches Korrektiv?, Bonn, S. 37. 
werden. Damit reproduziert die Gesellschaft direkt als auch indirekt rassistische Vorurteile und Ressentiments, die sich vorausblickend eher als Gefährdung des Zusammenhalts der Gesellschaft darstellen. ${ }^{35}$

Die avisierte Fokussierung auf das biologisch-genetische Rassismuskonstrukt im Rahmen der Kombination von sozial- und naturwissenschaftlicher Forschung generiert jedoch nicht nur die schon skizzierten Chancen, sondern auch ungeahnte analytische Probleme bzw. Anforderungen: Auf der politischen und gesellschaftlichen Handlungsebene ist der Begriff des Rassismus in Deutschland seit den weltweiten Auswirkungen des Nationalsozialismus ,,[... ein rotes Tuch.“36 „Die Spuren der Vergangenheit schrecken in Deutschland mehr als in jedem anderen Land. “37, so eine verständliche Einschätzung des Genetikers Peter Propping. Der Begriff und das Konzept des Rassismus gelten in Deutschland nach wie vor als mit der nationalsozialistischen Herrschaft eng verbunden - in unserer heutigen demokratischen Gesellschaft haben diese demnach keinen Platz. ${ }^{38}$ Vor diesem Hintergrund wird verständlich, warum in den offiziellen Arenen von Politik und Gesellschaft im 21. Jahrhundert größtenteils unzulängliche, aber gesellschaftlich konsensfähigere, Ersatztermini für das Rassismusphänomen konstruiert werden, wie Ausländerfeindlichkeit, Fremdenfeindlichkeit oder Ethnozentrismus, um sämtliche Parallelen mit den sozialbiologischen Vorgehensweisen der Nationalsozialisten zu vermeiden. ${ }^{39}$ Kritisch muss diesbezüglich jedoch angemerkt werden, dass diese Begrifflichkeiten einerseits als definitorisch vollkommen unangemessen, das Rassismuskonzept verfälschend, charakterisiert werden müssen sowie andererseits lediglich überholte und antiquierte Worthülsen darstellen. Der Begriff Ausländerfeindlichkeit zeigt sich beispielsweise als per se diskriminierend, da hier Inund Ausländer differenziert und segregiert werden. ${ }^{40}$ Zusätzlich findet in der unscharfen Verwendung dieser Ersatzbegrifflichkeiten eine unzulässige juristische Vermischung von ,Fremden', ,Ausländern', ,Einwanderern', ,Migranten', ,Asylsuchenden' und ,Flüchtlingen's statt, die meist generalisierend als ,Fremde' bezeichnet werden. ${ }^{41}$ Auch die Begrifflichkeit des sogenannten Ethnozentrismus visualisiert vielfach die fehlenden Parallelen zum Rassismuskonzept: Eine identische Übertragung des aus dem US-amerikanischen (USA, United States of America) Sozialdarwinismus stammenden Ethnozentrismus-Begriffes auf das bundesrepublikanische Rassismusphänomen verbietet sich demnach grundlegend. ${ }^{42}$ Alle Ersatztermini

35 Vgl. Zick/Küpper/Hövermann 2011, a. a. O., S. 11. | Vgl. Terkessidis 2004, a. a. O., S. 9.

36 Terkessidis 2004, a. a. O., S. 7.

37 Propping, Peter (1992): Was müssen die Wissenschaft und die Gesellschaft aus der Vergangenheit lernen? Die Zukunft der Humangenetik, in: Propping, Peter/Schott, Heinz (Hrsg.): Wissenschaft auf Irrwegen. Biologismus - Rassenhygiene - Eugenik, Bonn u. a., S. 114.

38 Vgl. Terkessidis 2004, a. a. O., S. 8.

39 Bussink-Becking, Elke Marie (2013): Identitäten in Bewegung. Ausländische Adoptierte, Rassismus und hybride kulturelle Identität. Eine biographieanalytische Studie, Diss. Universität Göttingen, Göttingen, S. 46ff.

40 Vgl. Terkessidis 2004, a. a. O., S. $19 f$.

41 Vgl. Terkessidis 2004, a. a. O., S. 14.

42 Vgl. Terkessidis 2004, a. a. O., S. 61, 66. 
verschleiern vor allem die Biologie als Grundlage und Kernkomponente des ursprünglichen, biologistischen ,Rasserassismus'. Denn gerade dieser scheint, obwohl mit kulturellen Worthülsen verdeckt, wieder gesellschaftsweit als integraler Baustein des Rassismuskonzeptes akzeptiert zu werden. Leider sind diese Ersatztermini heute im politischen und gesellschaftlichen Wortschatz nachhaltig etabliert, sollen in dieser Forschungsarbeit aufgrund ihres Charakters jedoch weitgehend vermieden - bzw. in nicht-diskriminierendem Sinn benutzt - werden. Nichtsdestotrotz bleibt der begriffliche Rahmen des Rassismuskonzeptes auch innerhalb der Sozialwissenschaften weiterhin umstritten und vielfältig debattiert, ebenso wie das ,Rassekonstrukt ${ }^{t}$ in der biologischen Forschung. ${ }^{43}$

Das Problem der zahlreichen rassismusähnlichen Bezeichnungen ist augenscheinlich: Die rassistische Ideologie ist aufgrund ihrer begrifflichen Verschleierungen, zum Beispiel Euphemismen, schwieriger zu identifizieren sowie präventiv zu entgegnen. ${ }^{44}$ Hinzu kommen erschwerend die zahlreich vorhandenen, unterschiedlichen Rassismusdefinitionen, die das Rassismusphänomen jeweils aus differierenden Perspektiven betrachten und einordnen. Eher eingeschränkt integriert werden muss in diesem Zusammenhang die amerikanische und britische Rassismusforschung, da die englischsprachigen Begrifflichkeiten racism, race oder racialization aufgrund übersetzungstechnischer, semantischer und begrifflicher Schwierigkeiten nicht direkt auf die deutschen Begriffe übertragen werden können sowie darüber hinausgehend unterschiedliche Bedeutungen oder definitorische Konnotationen aufweisen. Somit zeigt sich die Einbeziehung der englischsprachigen Forschung zwar insbesondere vor dem biologisch-rassistischen Schwerpunkt dieser Arbeit als notwendig, eine uneingeschränkte Übertragung der USamerikanischen Rassismusdebatte auf die bundesrepublikanische Situation jedoch nur eingeschränkt zielführend. 45

Der profilierte Rassismusforscher Albert Memmi bewertet die Lage der 1990er Jahre - die sich tendenziell als auf die heutige Situation übertragbar zeigt - folgendermaßen trefflich:

„Nach wie vor bemühen sich die Wissenschaftler verzweiffelt, die Haltlosigkeit des Rassismus zu beweisen, indem sie die Schwäche seiner Hypothesen und die Illegitimität seiner Bestrebungen hervorbeben. [...] Das Ergebnis ist immer wieder niederschmetternd. Statt zu verschwinden, scheint der Rassismus heute unausrottbarer denn je und gleicht dem Unkraut, dessen Wurzeln man vergeblich zu zerstören versucht; verk:ümmern sie an ei-

Das Ethnozentrismus-Konzept geht von der Möglichkeit der Übernahme von kulturellen und sozialen Werten zwischen verschiedenen Menschengruppen aus, wobingegen der Rassismus die Verschiedenheit einer spezifischen Menschengruppe als nicht bzw. nur kaum veränderlich ansieht (s. Kapitel 2.1.3).

43 Vgl. Scherr, Albert (2009): Rassismus oder Rechtsextremismus? Annäherung an eine vergleichende Betrachtung zweier Paradigmen jenseits rhetorischer Scheinkontroversen, in: Melter, Claus/Mecheril, Paul (Hrsg.): Rassismuskritik. Band 1: Rassismustheorie und -forschung, Schwalbach/Taunus, S. 75.

44 Vgl. Kerner, Ina (2009): Differenzen und Macht. Zur Anatomie von Rassismus und Sexismus, Frankfurt/Main u. a., S. 44.

45 Vgl. Banton, Michael (1987): Racial theories, Cambridge u. a., S. VIII. 
nigen Stellen, so sprießen sie an anderen wieder neu hervor. Wie kommt es, dass so viel wissenschaftlicher Geist und guter Wille nichts gegen den Rassismus ausrichten können? ${ }^{\text {46 }}$

\subsection{Theoretische Einordnung}

„Kaum ein anderes Feld wissenschaftlicher Arbeit ist komplizierter, verwirrender und belasteter als jenes des Rassismus.“47 Der aktuelle, sozialwissenschaftliche Forschungsstand zum Thema Rassismus zeigt sich folglich auf nationaler und internationaler Ebene vielfach differenziert. Der Schwerpunkt der bundesrepublikanischen Rassismusforschung lag vor allem auf den fremdenfeindlichen Gewaltexzessen der 1990er Jahre. ${ }^{48}$ Nach dem scheinbaren Sieg von Politik, Gesellschaft und Wissenschaft über die damaligen angeblich gesellschaftlichen Randphänomene, blieb der Forschungsfortschritt seit Beginn des neuen Jahrtausends eher gering - denn warum sich mit einem Thema beschäftigen, welches in Deutschland offiziell nicht mehr präsent erscheint? Bestehende Veröffentlichungen der unterschiedlichen sozialwissenschaftlichen Theorierichtungen fokussieren deshalb heute vermehrt auf die zukünftige Aktualität und Brauchbarkeit des Rassismusbegriffs. Seit dem Jahr 2008 geraten jedoch vermehrt Studien und Forschungsberichte der Europäischen Union sowie von Oliver Decker und Elmar Brähler u. a. im Auftrag der Friedrich-Ebert-Stiftung in den gesellschaftlichen Fokus. Diese attestieren der bundesrepublikanischen Gesellschaft eine zunehmend fremdenfeindliche und rassistische Gesinnung, wenn auch oftmals unter verdeckten bzw. beschönigenden Worthülsen und Ersatzbegrifflichkeiten versteckt. Eine neue Rassismusdebatte etablierte sich in Deutschland erst mit den Veröffentlichungen Thilo Sarrazins im Sommer 2010, die ungeahnten Zuspruch großer Teile der deutschen Bevölkerung generierten. Seit diesem Zeitpunkt gewinnt die politik- und sozialwissenschaftliche Rassismusforschung wieder langsam an Intensität, wobei detaillierte Analyseergebnisse noch auf sich warten lassen. ${ }^{49}$

$46 \quad$ Memmi, Albert (1992): Rassismus, Hamburg, S. 29.

47 Terkessidis, Mark (1998): Psychologie des Rassismus, Opladen u. a., S. 255.

48 Im Rabmen der rassistisch sowie fremdenfeindlich motivierten Gewalttaten zu Beginn der 1990er Jabre sind beispielsweise die Angriffe auf ein Vertragsarbeiter- und Flücbtlingswohnheim in Hoyerswerda im September 1991, die Ausschreitungen von Rostock-Lichtenhagen im August 1992 oder der Brandanscblag auf das Haus einer türkischstämmigen Großfamilie in Solingen im Mai 1993 zu nennen. Diese stellten die schwerwiegendsten Übergiffe auf ausländische Menschen in Deutschland nach dem Ende der nationalsozialistischen Ära dar. Vgl. Herbert, Ulrich (2003): Geschichte der Ausländerpolitik in Deutschland, München, S. 308ff.

49 Die neuerliche Forschungsnotwendigkeit das Rassismusphänomen betreffend erlangt seit dem Jahrtausendbeginn in Gesellschaft und Wissenschaft nur zögerlich wieder an Bedeutung. Diesbezüglich sind vor allem die Studienergebnisse im Auftrag der Friedrich-Ebert-Stiftung, der Allgemeinen Bevölkerungsumfrage der Sozialwissenschaften, des Sozioökonomischen Panels (SOEP) als auch der Sozialberichte der Bundesrepublik Deutschland zu nennen. Vgl. Arndt, Susan/Ofuatey-Alazard, Nadja (2011b): Zum Geleit, in: ebd. (Hrsg.): Wie Rassismus aus Wörtern spricht. (K)erben des Kolonialismus im Wissensarchiv deutsche Sprache. Ein kritisches Nachschlagewerk, Münster, S. 15. 
Weiterhin wird hier noch vorsichtig von Fremdenfeindlichkeit oder Ethnozentrismus gesprochen, anstatt den passenderen Rassismusbegriff - der auch dessen biologische Charakteristika integriert - zu verwenden, obwohl diesen Alternativbegriffen wesentliche Komponenten des Rassismusbegriffes fehlen. Aufgrund dessen hängt die neuere bundesrepublikanische Rassismusforschung den Entwicklungen - der Flexibilität und Wandelbarkeit des gegenwärtigen Rassismusphänomens im 21. Jahrhundert - hinterher. ${ }^{50}$ Hervorzuheben sind im Rahmen der aktuelleren Rassismusforschung unter anderem die aus historischer Perspektive analysierenden Arbeiten von Christian Geulen, der psychologischpsychotherapeutische Analyseansatz von Paul Mecheril, die soziologisch bzw. sozialanalytisch argumentierenden Arbeiten von Mark Terkessidis und Albert Memmi, die kulturtheoretischen Erklärungsansätze von Pierre André Taguieff und Étienne Balibar oder der klassisch rassismustheoretische Forschungsansatz von Robert Miles. ${ }^{51}$ Vor dem Hintergrund dieser verschiedenen theoretischen Forschungsrichtungen sind dementsprechend auch verschiedene Analyseansätze zu differenzieren, um sich dem gegenwärtigen Phänomen des Rassismus zu nähern. Unterscheiden lassen sich hier beispielsweise die rassismushistorischen Forschungsansätze, die diesen mithilfe der historischen Entwicklungslinien von Protorassismus bzw. Rassismus zu erklären versuchen. Kulturtheoretische und soziologische Forschungsansätze fokussieren im Gegensatz dazu im Rahmen der Rassismusforschung vor allem kulturelle gesellschaftliche Differenzen, Identitätskonflikte, Macht- oder Herrschaftskonstruktionen, wohingegen die klassisch rassismustheoretischen Analyseansätze die Naturalisierung und Biologisierung von gesellschaftspolitischen Problem- und Fragestellungen in den Mittelpunkt des Rassismusdiskurses stellen. Dieser Untersuchung liegt ein poststrukturalistischer Forschungszugriff zugrunde. Dieser ermöglicht aufgrund seines viele Forschungsbereiche der Sozialwissenschaften umfassenden theoretischen Rahmens einen multiperspektivischen Zugriff auf das Rassismusphänomen. ${ }^{52}$ Über das Konzept des Strukturalismus hinausgehend können aus dieser Perspektive so ebenfalls historische und machttheoretische Dimensionen bzw. - gerade für das Phänomen Rassismus elementar - Fragen nach Macht- und Herrschaftsverhältnissen in die Untersuchung inkludiert werden, die eine Kernkomponente der poststrukturalistischen Theorie darstellen. ${ }^{53}$ Deren Machtkonzeption beschränkt sich nicht allein auf juristische Machtbegriffe, die eng mit den Begriffen Gesetz, Gewalt, Legalität u. a. vernetzt sind, sondern fokussiert auch psychische, emotionale oder subjekti-

$50 \quad$ Vgl. Weiß, Anja (2013): Rassismus wider Willen. Ein anderer Blick auf eine Struktur sozialer Ungleichheit, 2. Auflage, Wiesbaden, S. 27ff.

51 Bezüglich der vollständigen Literaturangaben der einzelnen Autorinnen und Autoren wird auf die detaillierten Beschreibungen im Literaturverzeichnis verviesen.

52 Vgl. Moebius, Stephan/Reckwitz, Andreas (2008): Einleitung: Poststrukturalismus und Sozialwissenschaften: Eine Standortbestimmung, in: ebd. (Hrsg.): Poststrukturalistische Sozialwissenschaften, Frankfurt/Main, S. 9, 21.

53 Vgl. Moebius/Reckwitz 2008, a. a. O., S. 15. 
vierende Facetten des Machtbegriffs. ${ }^{54}$ Auch kulturelle Interdependenzen sowie soziale Phänomene werden im Rahmen von poststrukturalistischen Forschungsansätzen aufgegriffen, wie die Diskursanalyse Michel Foucaults vergegenwärtigt, die darüber hinausgehend ebenfalls historische Entwicklungsbedingungen integriert. ${ }^{55} \mathrm{Da}$ auch das Rassismusphänomen in biologisierter und kulturalistischer Ausprägung einerseits eng mit dem Machtbegriff - zwischen herrschenden und beherrschten bzw. diskriminierten Bevölkerungsgruppen - und andererseits mit historischen und postkolonialen Entwicklungstendenzen vernetzt ist, bietet sich ein poststrukturalistischer Forschungszugriff hinsichtlich des Rassismus in Deutschland an.

Der Journalist und Migrationsforscher Mark Terkessidis kritisiert diese unstrukturierte Vorgehensweise der sozialwissenschaftlichen Forschung vor allem hinsichtlich Deutschlands:

„,...] [So] hat die deutsche Forschung geradezu erschreckende Defizite: Sie ist theoretisch inkohärent und methodisch fragwürdig. Zudem weist sie keinerlei Kontinuität auf. Geforscht wird gewissermaßen stoßweise - nämlich immer dann, wenn sich in der Gesellschaft Gewalt oder Extremismus zeigt. Zudem sind Bezüge auf die Forschung im Ausland böchst selten. " 56

Auch die biologische sowie die biopolitische Forschung zum Themenbereich des Rassismus und zu biologistischer Diskriminierung von Minderheiten kann im 21. Jahrhundert nur vereinzelt im Bereich der Verhaltensgenetik sowie der Biopsychologie identifiziert werden. Die biologische Rassismuskomponente wurde tendenziell als nicht mehr existent bzw. nicht mehr von Bedeutung angesehen. Die Modifizierung und Korrektur dieser Bewertung erfolgt seit wenigen Jahren nur langsam, wird jedoch in Zukunft noch nachhaltige Forschungsfragen zu klären haben, da die biologische Forschung zu pseudorassistischen Theoremen insbesondere im Bereich der Molekular- und Evolutionsgenetik neue, interessante Erkenntnisse verspricht.

Die bundesrepublikanischen Forschungsverhältnisse zeigen sich also vor allem nach den 1990er Jahren äußerst mäßig, lückenhaft und unstrukturiert. Insbesondere der jüngeren Forschung fehlen jegliche historische bzw. übergreifende und kontinuierliche Dimensionen - sie bleibt lediglich ,konjunkturorientiert ${ }^{6}{ }^{57}$ Einzig die theoretischen Charakteristika und Besonderheiten des Rassismusbegriffes

\footnotetext{
54 Vgl. Moebius, Stephan (2008): Macht und Hegemonie: Grundrisse einer poststrukturalistischen Analytik der Macht, in: Moebius, Stephan/Reckwitz, Andreas (Hrsg.): Poststrukturalistische Sozialwissenschaften, Frankfurt/Main, S. 159, 172f.

55 Vgl. Quadflieg, Dirk (2008): Sprache und Diskurs: Von der Struktur zu différance, in: Moebius, Stephan/Reckwitz, Andreas (Hrsg.): Poststrukturalistische Sozialwissenschaften, Frankfurt/Main, S. 106.

56 Terkessidis 2004 , a. a. O., S. 9.

57 Vgl. Terkessidis 2004, a. a. O., S. 87 f.
} 
scheinen mehr oder weniger ausreichend erforscht. ${ }^{58}$ Doch ist das Rassismusphänomen als mehrdimensionales System per se jeweils neu untersuchungswürdig. ${ }^{59}$ Vor diesem Hintergrund muss also konstatiert werden, dass das Phänomen des Rassismus zwar vielfach analysiert wurde, jedoch auch weiterhin noch ein weitgehend unbekanntes Terrain darstellt: Eindeutige Erklärungsansätze und Entwicklungsbedingungen oder eine transparente Definition fehlen ebenso wie - gerade hinsichtlich des biologistischen Rassismustypus - eine Kombination von sozialund naturwissenschaftlichen Untersuchungsmethoden, was die notwendige Intention dieser Arbeit bestätigt. Die intensive Analyse des Rassismus muss deshalb auch in Zukunft dazu beitragen, die Aufmerksamkeit ihm gegenüber zu erhalten. ${ }^{60}$ Nur so kann ein Verständnis bezüglich der unwissenschaftlichen Misskonzepte der rassistischen Ideologie innerhalb der Bevölkerung erlangt werden. ${ }^{61}$ Der Bildungsforscher Paul Mecheril und die Soziologin Karin Scherschel bemerken ebenso:

\section{„Auch wenn von einzelnen Forscherinnen und Forschern in Deutschland die Perspektive ,Rassismus' theoretisch und empirisch aufgegriffen und untersucht wird, so steht die aka- demische Etablierung der Rassismusforschung im deutschsprachigen Raum doch noch am Anfang. "“2}

Auf internationaler Ebene zeigt sich hingegen ein teilweise differenziertes Bild. Insbesondere die englischsprachige Rassismusforschung ist mit aktuellen Untersuchungen im Rahmen von EU und UN (United Nations) kontinuierlich vorhanden, jedoch ebenfalls keineswegs detailliert ausgeprägt. Im Gegensatz zur deutschen Debatte muss zusätzlich konstatiert werden, dass der in Deutschland meist tabuisierte Rassismusbegriff in der internationalen Forschung immer gebräuchlich war, auch die Fokussierung auf den biologistischen Rassismustypus. Daraus ergeben sich natürliche Defizite in der bundesrepublikanischen Rassismusanalyse. Die Hauptschwierigkeit der aktuellen Rassismusforschung bleibt jedoch das Fehlen einer einheitlichen, Disziplinen übergreifenden Definition. ${ }^{63}$ Es existieren zwar zahlreiche Vorschläge, die jedoch jeweils alternierende Perspektiven des Rassismusphänomens hinsichtlich seines inhaltlichen und strukturellen Umfangs fokussieren. ${ }^{64}$ Vor allem in der bundesrepublikanischen Forschung kommt das schon angesprochene Problem der Begrifflichkeit des Rassismus hinzu, die vielfach

58

Vgl. Miles, Robert (1991): Die Idee der „Rasse“ und Theorien über Rassismus: Überlegungen zur britischen Diskussion, in: Bielefeld, Uli (Hrsg.): Das Eigene und das Fremde. Neuer Rassismus in der Alten Welt, Hamburg, S. 189.

59 Vgl. Miles 1991, ebd., S. 214.

60 Vgl. Butterwegge, Christoph/Jäger, Siegfried (1993): Einleitung, in: ebd. (Hrsg.): Rassismus in Europa, 2. Auflage, Köln, S. 14ff.

61 Vgl. Memmi 1992, a. a. O., S. 139.

62 Mecheril, Paul/Scherschel, Karin (2009): Rassismus und „Rasse“, in: Melter, Claus/Mecheril, Paul (Hrsg.): Rassismuskritik. Band 1: Rassismustheorie und -forschung, Schwalbach/Taunus, S. 41.

63 Vgl. Terkessidis 2004, a. a. O., S. 91.

64 Vgl. Terkessidis 2004, a. a. O., S. 92. 
durch mangelnde und unpassende, kompensatorische Termini ersetzt wird. Meist bleibt es bei einer mehr oder weniger oberflächlichen Debatte über die Eigenschaften des Rassismus. ${ }^{65}$ Sowohl Phänomen als auch Begrifflichkeit dessen haben demnach national und international multiple sozialwissenschaftliche, naturwissenschaftliche und auch alltägliche Bedeutungen, was eine transparente sowie strukturierte Forschung einerseits erschwert, andererseits nochmals die Bedeutung dieses Forschungsprojektes unterstreicht. ${ }^{66}$

Zusammenfassend kann so festgestellt werden, dass die mit dieser Arbeit avisierte kombinierte Analysemethode vor dem Hintergrund der Wandelbarkeit, der Flexibilität und der kontinuierlichen Erneuerung des Rassismusphänomens auch im Zusammenhang mit dem Fortschritt von Biologie und Genetik - den Kerngrundlagen der rassistischen Ideologie - im 21. Jahrhundert notwendig erscheint, so dass eines der bislang bestehenden Forschungsdesiderate aufgearbeitet wird. ${ }^{67}$

\subsection{Zielsetzung und Thema}

Der Schwerpunkt dieser Untersuchung liegt eindeutig auf dem biologischgenetisch konnotierten Rassismusphänomen des 21. Jahrhunderts, welches einerseits aus der heutigen Perspektive sowie andererseits mithilfe des avisierten interdisziplinären Forschungsansatzes - der Kombination von Sozial- und Naturwissenschaften - bisher noch nicht näher erforscht wurde. Diese Forschungslücke zeigt sich gerade vor dem Hintergrund der heutigen gesellschaftlichen Situation in Deutschland als dringend notwendig zu füllen (s. Kapitel 1, 1.1). Der Analysezeitraum wird auf die Jahre 2007 - den Beginn der heutigen Krisenentwicklungen mit der Immobilienkrise in den USA - bis 2013 eingegrenzt, um die Aktualität und die gegenwärtige Brisanz des Forschungsansatzes herauszustellen. ${ }^{68}$ Rassismusforschungen sowie das Problem des Rassismus existieren zwar schon einen längeren Zeitraum, neue bzw. gewandelte politische, gesellschaftliche und ökonomische Umgebungsbedingungen generieren jedoch eine gegenwärtige Situation, die mit vorherigen Rassismusproblematiken keineswegs zu vergleichen ist - deshalb auch die Bezeichnung als ,modernisiertes' bzw. ,gegenwärtiges' biologisch-genetisch konnotiertes Rassismuskonstrukt. ${ }^{69}$ Insbesondere der Fokus auf die heutige biolo-

65 Vgl. Terkessidis 2004, a. a. O., S. 98.

66 Vgl. Miles, Robert (1999): Rassismus. Einführung in die Geschichte und Theorie eines Begriffs, 3. Auflage, Hamburg, S. 7.

67 Vgl. Kerner 2009, a. a. O., S. $166 f$.

68 Vor dem Hintergrund der empirischen Analyse der aktuellen Verbreitung von rassistischen Vorurteilen und Stereotypen innerhalb der bundesrepublikanischen Gesellschaft wird schwerpunk.tmäßig auf qualitative sowie quantitative Datenmaterialien der Jabre 2006 bis 2012 zurückgegriffen (s. Kapitel 3).

69 Der gegenwärtige Rassismus wird somit nicht als mit dem Zeitalter der Moderne - was der Begriff, moderner Rassismus implizieren könnte - gleichgesetz̨. Er beschreibt die aktuellen Entwicklungen im 21. Jabrbundert. Gerade die Unterschiede zu den rassistischen Problemphasen der 1960er oder 1990er Jabre gestalten sich enorm. Die im Rabmen der Globalisierung gewandelten ökonomischen Voraussetzungen, Rabmenbedingungen und Zielsetzungen des 21. Jabrbunderts stellen Politik, und Gesellschaft vor vollkommen neue Herausforderungen. Hinzukommend trägt auch die politische Situation - das Ende des Kalten Krieges sowie die zunehmende 
gisch-genetische Rassismuskomponente sowie die interdisziplinäre Arbeit zwischen sozial- und naturwissenschaftlicher Forschung erfordern größtenteils neue Untersuchungswege. Von einer Kontinuität des Rassismus in Deutschland zu sprechen ist demnach weniger zielführend. Aufgrund dessen bedarf es für den oben vorgestellten Untersuchungszeitraum auch eines modernisierten sowie innovativen Analyse- und Forschungskonzepts, um sich den gewandelten Rahmenbedingungen des heutigen Rassismusphänomens zu nähern, was mithilfe dieser Arbeit gelingen soll. Für das Forschungsdesign ist zum einen ein aktueller Definitionsrahmen bzw. eine begriffliche Einordnung des biologisch konnotierten Rassismusbegriffes zwingend notwendig sowie zum anderen eine Analyse der aktuellen gesellschaftlichen Situation: Haben sich biologisch-rassistische Vorurteile und Ressentiments wirklich wieder in der bundesrepublikanischen Gesellschaft nachhaltig etabliert? Inwieweit sind rassistische Diskriminierungen und Abwertungen gesellschaftsweit vorhanden? Kann abermals in der deutschen Geschichte von einem Rassismusproblem gesprochen werden? Grundlegend erscheint in diesem Zusammenhang ebenso eine Untersuchung der möglichen Hintergründe und Wirkungszusammenhänge, die die heutige bundesrepublikanische Entwicklung bezüglich Rassismus und Fremdenfeindlichkeit generieren. Denn nur ein ursachenanalytischer Forschungsansatz bzw. eine Analyse vorstellbarer Erklärungsansätze ermöglicht eine umfassende und detaillierte Untersuchung dieses Phänomens. Bisher schien die Ideologie des Rassismus jeweils auf der aktuellen gesellschaftlichen Agenda aufzutauchen, wenn für gesellschaftliche, soziale, ökonomische oder politische Probleme keine Lösung vorhanden schien. Aus gegebenem Anlass - verwiesen sei auf die Morde des NSU - stellt sich die Frage, ob dies auch auf die aktuelle Situation in Deutschland zutrifft? ${ }^{70}$ Weiterhin geht es auch darum, welche Faktoren heute ursächlich das Phänomen des biologisch konnotierten Rassismus konstruieren und regenerieren. Aufgrund der gegenwärtigen finanzpolitischen und ökonomischen Krisenlage in den europäischen Nachbarstaaten sowie der gefühlten Krise bzw. der gefühlten Bedrohung durch die europäische Krisenlage in Deutschland treten vor allem die durch das Wirtschafts- und Bankenwesen entstandenen Probleme in das Zentrum der Aufmerksamkeit, die als „Nährboden“"71 für rassistische Ansichten gegenüber spezifischen Menschengruppen gelten könnten. ${ }^{72}$

supra- sowie internationale Zusammenarbeit zimischen den ehemaligen West- und Ostblockstaaten - zu einer gewandelten Lage bei. Innen- und Außenpolitik sorgen ebenso wie eine supranationale Finan₹- und Wirtschaftspolitik, für gewandelte Ansprüche und Herausforderungen. Auch die weiterentwickelte Gesellschaft ist mit den veränderten politischen sowie wirtschaftlichen Voraussetzungen intensiv verknüpft: Unsicherheiten, Lebensziele, Lebensalltag und Lebenserwartung sind im Vergleich zu vorherigen Jahrzehnten verändert.

70 Vgl. Elfferding, Wieland (1989): Funktion und Struktur des Rassismus. Eine Theorieskizze, in: Autrata, Otger/Kaschuba, Gerrit/Leiprecht, Rudolf (Hrsg.): Theorien über Rassismus. Eine Tübinger Veranstaltungsreihe, 3. Auflage, Hamburg, S. 101f.

71 Butterwegge, Christoph (1993): Der Funktionswandel des Rassismus und die Erfolge des Rechtsextremismus, in: Butterwegge, Christoph/Jäger, Siegfried (Hrsg.): Rassismus in Europa, 2. Auflage, Köln, S. 184.

72 Vgl. Metin, Mehmet (1990): Rassismus in der Sprache, Frankfurt/Main, S. 53. 
Selbstverständlich darf ebenfalls ein Blick auf die europäische Ebene nicht fehlen, da die EU als supranationales Gefüge sowie ihre Mitgliedstaaten ebenfalls großen politischen, wirtschaftlichen und gesellschaftlichen Einfluss auf die bundesrepublikanische Entwicklung ausüben könnten. Der Fokus liegt jedoch eindeutig auf nationalstaatlicher Ebene.

Im Mittelpunkt dieser Arbeit steht der biologisch-genetisch begründete Rassismustypus. Dieser unterstreicht die Brisanz dieses Forschungsprojektes im Untersuchungszeitraum von 2007 bis 2013. Der biologistische Rassismus gilt zwar auf sozialwissenschaftlicher Ebene seit der Fokussierung kultureller Rassismusbestandteile in den 1990er Jahren als nur noch partiell existent, die Realität des 21. Jahrhunderts sowie die naturwissenschaftlichen Grundlagen des Rassismusbegriffes scheinen jedoch ein differierendes Bild zu generieren. Der Schwerpunkt dieser Untersuchung liegt folglich auf der Analyse der Besonderheiten und Charakteristika des biologisch-genetischen Rassismuskonstrukts sowie auf dessen ReEtablierung in der Bundesrepublik Deutschland. Hier findet neben der sozial- und politikwissenschaftlichen Perspektive auch die naturwissenschaftliche Sichtweise bezüglich des Rassismusphänomens ihre besondere Bedeutung. Vor allem die Fragestellung nach neuesten biologischen Erkenntnissen zur endgültigen Falsifizierung der rassistischen Theoreme erscheint brisant: Welche Ergebnisse und Erkenntnisse tragen moderne molekulargenetische, neurobiologische, human- und evolutionsbiologische sowie biopsychologische Forschungsdesigns bezüglich der rassistischen Theorie bei? Kann die Biologie und speziell die Genetik die Theoriekonstrukte des Rassismus endgültig diskreditieren? Welche Rolle spielt die Biologie heute innerhalb der rassistischen Ideologie?

Der Rassismusforscher Christian Delacampagne skizzierte die Problemstellung des biologisch begründeten Rassismus in den 1990er Jahren so treffend, als würde er bereits prognostizierend in das 21 . Jahrhundert blicken:

„Das Problem des Rassismus in unserer Zeit wird durch den folgenden Widerspruch
charakterisiert: einerseits sind seine wichtigsten intellektuellen Urbeber der vergangenen
Jahrbunderte, das heißt die Anthropologen und ganz allgemein die Wissenschaftler in ih-
rer überwältigenden Mehrheit zu seinen hartnäckigsten Bekämpfern geworden; anderer-
seits jedoch bestehen die psychologischen und sozialen Faktoren, denen er seine Dynamik
verdankt, nämlich die Mischung von Völkern verschiedener Kulturen in großem Maß-
stab, die Spannungen des modernen Lebens und seine beängstigende Problematik noch
immer und nebmen obne Zweifel von Jabrzehnt zu Jabrzehnt ständig zu. "73

Das Ziel dieser wissenschaftlichen Untersuchung ist demnach eine detaillierte Analyse des heutigen Rassismusphänomens in Deutschland unter biologischgenetischem Schwerpunkt. Im Zentrum dieser wissenschaftlichen Untersuchung steht folglich die sozial- und naturwissenschaftliche Erforschung des biologischgenetisch konnotierten Rassismusphänomens. Nur mit diesem dringend notwen-

73 Poliakov, Léon et al. (1992): Rassismus. Über Fremdenfeindlichkeit und Rassenwahn, Hamburg u. a., S. 204. 
digen Verständnis des heutigen Rassismus haben Präventions- und Aufklärungsmaßnahmen eine realistische Erfolgschance. Die übergreifende bzw. zentrale Fragestellung lautet demzufolge: Analyse des gegenwärtigen Rassismus - Wie stellen sich Verbreitung, Hintergründe und wissenschaftliche Realität des biologisch-genetischen Rassismus im heutigen Deutschland dar? Folgende forschungsleitende Hypothesen sollen im Verlauf dieser Untersuchung analysiert und auf ihre Validität kontrolliert werden:

- Rassistische Vorurteile zeigen sich insbesondere in biologisch-genetischer Ausprägung im Deutschland des 21. Jahrhunderts auf allen gesellschaftlichen Ebenen etabliert.

- Die Entstehungs- und Erklärungsansätze des gegenwärtigen biologistischen Rassismusphänomens liegen insbesondere in der fehlerhaften sowie unzureichenden Integrations-, Migrations- und Einwanderungspolitik Deutschlands und werden zusätzlich noch durch die wirtschaftlichen, fiskal- und europolitischen Krisensymptome seit dem Jahr 2007 verstärkt: Der Finanzund Staatsschuldenkrise, den damit verbunden Unsicherheiten des Arbeitsmarktes und den daraus resultierenden Zukunftsängsten.

- Biologie und Genetik sind als Kernelemente der pseudowissenschaftlichen, rassistischen Ideologie direkt und indirekt als Legitimationsgrundlage präsent, obwohl neuere Forschungsbefunde jegliche naturwissenschaftliche Zusammenhänge zwischen Rassismus und Biologie ausschließen.

\subsection{Methodische Vorgehensweise}

Aufgrund der Interdisziplinarität dieser Untersuchung sind die einzelnen methodischen Vorgehensweisen an den jeweiligen Fachdisziplinen - Sozial- oder Naturwissenschaften - orientiert, die in den spezifischen Kapiteln schwerpunktmäßig betrachtet werden. Hierauf wird jeweils detailliert nochmals in den einzelnen $\mathrm{Ka}$ piteln eingegangen, die die jeweilig angewandten methodischen Vorgehensweisen spezifizieren.

Allgemein betrachtet stehen sozial- bzw. politikwissenschaftliche Forschungsmethoden im überwiegenden Fokus dieser Untersuchung. Diese sind jedoch oftmals mit naturwissenschaftlichen Forschungsansätzen verknüpft; insbesondere die quantitative Sozialforschung orientiert sich an den methodischen Vorgehensweisen der Naturwissenschaften, wie Reliabilität, Validität und Objektivität. ${ }^{74}$ In den Sozialwissenschaften geht es jedoch nicht um naturwissenschaftliche Objekte, sondern um aktiv handelnde, menschliche Subjekte sowie um das Verstehen der

74 Vgl. Flick, Uwe (2009): Sozialforschung. Methoden und Anwendungen. Ein Überblick für die BA-Studiengänge, Reinbek bei Hamburg, S. 23.

Insbesondere die quantitativ-empirischen Methoden der Sozialwissenschaften orientieren sich an naturwissenschaftlichen Messverfahren: Isolation, Mathematisierung, die Herstellung von allgemeinen Gesetzmäßigkeiten, Repräsentativität, Generalisierbarkeit und Reproduzierbarkeit stehen im Mittelpunkt. 
Realität - in diesem Fall der Realität des Rassismus. ${ }^{75}$ In dieser Arbeit stehen aus sozial- bzw. politikwissenschaftlicher Perspektive demzufolge auf der einen Seite empirische sowie hermeneutische Analysemethoden im Mittelpunkt: Bezüglich der Analyse der Ausprägung rassistischer Vorurteile und Ressentiments in der bundesrepublikanischen Gesellschaft - insbesondere von biologisch-genetisch konnotierten Erklärungsschemata - bieten sich zahlreiche aktuelle, qualitative und quantitative Datenmaterialien an, die im gewählten Untersuchungszeitraum von 2007 bis 2013 publiziert wurden. Für die Präferenz von empirischen, sowohl qualitativen als auch quantitativen Untersuchungsdaten spricht eindeutig, dass keine der beiden methodischen Vorgehensweisen klar als sinnvollere bzw. schwierigere oder leichtere identifiziert werden kann. ${ }^{76}$ Im Gegenteil: Die Abwechslung von qualitativen und quantitativen Forschungsdesigns im Rahmen der präferierten Datensätze garantiert beim Themenbereich des Rassismus sinnvolle und notwendige gegenseitige Ergänzungen, die ein umfangreicheres und valideres Gesamtbild der aktuellen Gesellschaftslage - einen möglichst objektiven empirischen Befundermöglichen. ${ }^{77}$ Dies entspricht ebenfalls dem Komplementaritätsmodell sowie dem Phasenmodell des Methodenmixes. ${ }^{78}$ Gerade letzteres wird aufgrund der individuellen Grenzen von qualitativer sowie quantitativer Forschung als aktueller Trend gesehen und aufgrund der positiven Kompatibilität mit der hier vorgenommenen interdisziplinären Kooperation auf die nachfolgende Untersuchung im Hinblick auf die Auswahl der Datenmaterialien angewandt. ${ }^{79} \mathrm{Zu}$ Beginn stehen, bezugnehmend auf die Zustandsanalyse der deutschen Gesellschaft, qualitative, nicht standardisierte Untersuchungsergebnisse im Zentrum. Diese bieten zwar im Rahmen von Interviews und Diskussionen nur eine äußerst geringe Anzahl an Auswertungsfällen sowie keine quantitativen bzw. metrischen Daten, dienen jedoch zur Identifizierung und Visualisierung typischer Deutungs-, Handlungs- und Interaktionsmuster hinsichtlich offener und verdeckter biologisch-rassistischer Verhaltensweisen. ${ }^{80}$ Die Datenaufbereitung bzw. Transkription ist im Rahmen der vorzustellenden Studien überwiegend schon erfolgt, so dass sich im Rahmen dieser Untersuchung schwerpunktmäßig sekundäre Analyseoptionen anschließen. Im Bereich der Datenanalyse erfolgen einerseits am Beispiel Thilo Sarrazin eine qualitative Inhaltsanalyse sowie andererseits ein studienübergreifender Datenvergleich. Somit kann eine Systematisierung, Strukturierung und Visualisierung der Datensätze für die Ziele und Schwerpunkte dieser Untersuchung ermöglicht werden. Abschließend folgen quantitative Analyseergebnisse der ausgewählten Datensätze, mithilfe derer die qualitativen Daten bzw. Ergebnisse validiert und bestätigt wer-

75 Vgl. Lamnek, Siegfried (2010): Qualitative Sozialforschung. Lehrbuch, 5. Auflage, Weinheim, S. 13.

76 Vgl. Brauner, Detlef Jürgen/Vollmer, Hans-Ulrich (2006): Erfolgreiches wissenschaftliches Arbeiten. Seminararbeit. Diplomarbeit. Doktorarbeit, Sternenfels, S. 43.

77 Vgl. Brauner/Vollmer 2006, ebd., S. 44.

78 Vgl. Brauner/Vollmer 2006, ebd., S. 44. | Vgl. Behnke, Joachim/Baur, Nina/Behnke, Nathalie (2010): Empirische Methoden der Politikwissenschaft, 2. Auflage, Paderborn, S. 45.

$79 \quad$ Vgl. Flick 2009, a. a. O., S. 217ff, 228ff, 233, $237 f$.

80 Vgl. Behnke/Baur/Behnke 2010, ebd., S. 45. | Vgl. Lamnek 2010, a. a. O., S. 3. 
den können. ${ }^{81}$ Diese werden hinsichtlich des zu untersuchenden biologischgenetischen Rassismusphänomens unter einer neuen Perspektive ausgewertet. Der Vorteil dieser quantitativen Datensätze liegt in der Vielzahl an Auswertungsfällen und damit in der Möglichkeit der Verallgemeinerung und Generalisierung der Ergebnisse. ${ }^{82}$

Bei der Untersuchung des Rassismusbegriffes sowie einer möglichen Rassismusdefinition für die bundesrepublikanische Situation des 21. Jahrhunderts werden vornehmlich hermeneutische, theoretische und textanalytische Instrumente angewandt, um die Besonderheiten und Kerncharakteristika des Rassismusbegriffes von begrifflicher und theoretischer Perspektive zu erörtern. Da die diesbezügliche Forschungsliteratur relativ breit gefächert aufgestellt ist, kann hier zwar größtenteils auf Erkenntnisse und Ergebnisse aus Primär- und Sekundärliteraturvorlagen zurückgegriffen werden, jedoch müssen diese für die heutige Situation in Deutschland modifiziert werden, insbesondere vor dem Hintergrund des biologischen Schwerpunktes. Dies bedingt die Verknüpfung von sozial- und naturwissenschaftlicher Forschung. Ähnliches gilt teilweise für die Betrachtung der Phänomenologie des Rassismusphänomens in Deutschland. Auch hier kann partiell auf rassismustheoretische Veröffentlichungen zurückgegriffen werden - die Fokussierung auf das 21. Jahrhundert sowie die sozialwissenschaftlich-naturwissenschaftliche Betrachtung müssen jedoch neu aufbereitet und systematisiert werden.

Auf der naturwissenschaftlichen Forschungsebene stehen teilweise primär biologische Analyse- und Auswertungsoptionen zur Verfügung, mit denen wichtige Ergebnisse und Erkenntnisse fachlich korrekt erarbeitet und untersucht werden können. Diese zielen, im Unterschied zur sozialwissenschaftlichen Herangehensweise, weniger auf die gesellschaftlichen und politischen Strukturen des gegenwärtigen Rassismuskonstrukts, sondern auf die Überprüfung der naturwissenschaftlichen Realität von rassistisch-biologistischen Argumentationszusammenhängen. Diesbezüglich wird größtenteils auf die quantitativ-genetische Forschung der letzten zehn Jahre zurückgegriffen, da sich qualitative, humanbiologische sowie experimentelle Untersuchungen am Menschen aufgrund der ethischen Verantwortung verbieten. Im Mittelpunkt stehen so Analysen hinsichtlich der Struktur sowie der Funktionsweise der menschlichen Erbinformationen. Diese müssen hinsichtlich des biologistischen Rassismusphänomens aus einer neuen Perspektive gewichtet und interpretiert werden. Selbstverständlich kommen jedoch auch sprachwissenschaftliche Verfahren zur Anwendung, die - wie die Textanalyse - zur empirischtheoretischen Untersuchung und Aufbereitung der Daten sowie der fachlichen Grundlagen unabdinglich erscheinen.

Gerade für den naturwissenschaftlichen Untersuchungsabschnitt wird hinsichtlich des biologisch-genetischen Rassismusphänomens eine Herangehensweise entwickelt, die bisher aufgrund des überwiegenden Nichtvorhandenseins von sozialwissenschaftlich-naturwissenschaftlich-kombinierten Forschungsdesigns feh- 
lte. Die gegenseitige - fachliche und methodische - Implementierung der Untersuchungs-, Auswertungs- und Interpretationsergebnisse von Sozial- und Naturwissenschaften zeigt sich demnach neu.

\subsection{Gliederung}

Die Gliederung folgt den Schwerpunktsetzungen der vorangegangenen Einleitung. Auch die methodische Vorgehensweise generiert zusätzlich unterstützend eine verständliche, logische und transparente Strukturierung dieser wissenschaftlichen Untersuchung.

Das zweite Kapitel fokussiert eine theoretische Einführung über die Charakteristika und Besonderheiten des Rassismus, die Entwicklung des Rassismusbegriffes, die verschiedenen Definitionsansätze des Rassismusphänomens sowie eine begriffliche Zentrierung auf das 21. Jahrhundert und den biologisch-rassistischen Schwerpunkt dieser Arbeit. Bedeutsam ist hier vor allem eine zwingende biologisch konnotierte Begriffsbestimmung des Rassismus, denn diese ist unerlässlich für den weiteren Untersuchungs- und Analyseverlauf bzw. -beginn. ${ }^{83}$ Hieran schließt sich im dritten Kapitel eine Analyse der gesellschaftlichen Situation in Deutschland sowie die der europäischen Einflüsse an, um eine Vorstellung von der Verbreitung rassistischer Vorurteile und Ressentiments im 21. Jahrhundert insbesondere mit biologistischer Konnotation - herauszuarbeiten. Es folgt eine ursachenanalytische Betrachtung sowie eine Untersuchung der Entwicklung und Re-Etablierung bzw. der Phänomenologie und der Erklärungsansätze des heutigen Rassismusphänomens in der bundesrepublikanischen Bevölkerung. In diesem Rahmen werden sowohl gesellschaftliche und soziale als auch politische und wirtschaftliche Faktoren differenziert. Im vorletzten Schwerpunktkapitel findet dann die Analyse der naturwissenschaftlichen Realität des biologisch-genetischen Rassismusphänomens statt: Wie stehen moderne biologische und molekulargenetische Erkenntnisse zu heutigen rassistischen Argumentationen? Bestehen eventuelle Parallelen und Zusammenhänge mit fachbiologischen Grundsätzen? Resümierend folgen dann am Ende dieser Arbeit sowohl ein umfassendes Fazit sowie ein Ausblick auf die zukünftigen Entwicklungstendenzen des Rassismusphänomens in Deutschland. 



\section{Zur Theorie des gegenwärtigen Rassismus}

In den folgenden Kapiteln wird das Phänomen des heutigen Rassismus eingehend untersucht. Wie konstruiert sich der heutige Rassismusbegriff bzw. eine gegenwärtige Rassismustheorie? Welche theoretischen Komponenten werden in das Rassismuskonstrukt integriert? Wie charakterisiert sich Rassismus heute in Politik und Gesellschaft?

Das Rassismusphänomen ist insbesondere vor dem Hintergrund biologistischer Konnotationen kein Problemfeld, welches sich auf das Territorium der Bundesrepublik Deutschland oder den deutschen Sprachraum beschränkt. Vielmehr kann heute von einer weiten supra- bzw. internationalen Verbreitung gesprochen werden. ${ }^{84}$ „Rassismus betrifft alle, wenn auch in unterschiedlicher Weise." ${ }^{\text {"85 }}$ Aber gerade in Deutschland stellt sich die Suche nach einer einheitlichen und von wissenschaftlicher Seite einstimmig akzeptierten Definitionsgrundlage des Rassismusbegriffs als äußerst kontrovers heraus. Dies liegt zum Großteil an der in der Vergangenheit oft praktizierten Tabuisierung des Rassismusbegriffes aufgrund der durch das sogenannte Dritte Reich belasteten deutschen Historie. 86

$84 \quad$ Vgl. Terkessidis 1998, a. a. O., S. 10.

85 Mecheril, Paul/Melter, Claus (2009): Rassismustheorie und -forschung in Deutschland. Kontur eines wissenschaftlichen Feldes, in: ebd. (Hrsg.): Rassismuskritik. Band 1: Rassismustheorie und -forschung, Schwalbach/Taunus, S. 14.

86 Vgl. Rieger, Günter (2005): Art. „Rassismus“, in: Nohlen, Dieter/Schultze, Rainer-Olaf (Hrsg.): Lexikon der Politikwissenschaft. Band 2 N-Z. Theorien, Methoden, Begriffe, 3. Auflage, München, S. 813. 
In diesem Zusammenhang kann ein „Nachkriegstabu“67 des Rassismusbegriffes in Deutschland diagnostiziert werden. Der Historiker Léon Poliakov folgert diesbezüglich noch drastischer: „Es ist, als hätte sich der Westen entschlossen, die offene und schändliche Wunde mit glühendem Eisen auszubrennen." 88 Gerade diese Tabuisierung des Rassismusphänomens stellt die Forschung jedoch vor große Herausforderungen, da eine detaillierte Begriffsdefinition unter den genannten Rahmenbedingungen realitätsfern ist, obwohl rassistische Vorstellungen in der deutschen Bevölkerung immer noch weit verbreitet sind (s. Kapitel 3). ${ }^{89}$ Demzufolge hat die bundesrepublikanische Rassismusforschung im Vergleich zu anderen (Nachbar-)Staaten eine relativ kurze Vergangenheit, ,[w]eil nicht sein konnte, was nicht sein durfte, $[\ldots]^{“ 90}$. In der Folge zeigt sich selbstverständlich auch die analytische Sprache den Rassismus betreffend nicht in dem Maße präzisiert, wie in anderen Staaten. In Deutschland werden oftmals umschreibende, beschönigende Ersatztermini genutzt, die das Rassismusphänomen sprachlich jedoch nicht vollkommen treffen, wie der weitere Verlauf visualisieren wird. ${ }^{91}$ Insbesondere im englischen Sprachraum zeigt sich die Benutzung des originären Rassismusbegriffes häufiger, weshalb auch die nicht-deutschen Autoren aufgrund ihrer intensiven Forschungstätigkeiten beachtet werden müssen. Teilweise wird der Rassismusbegriff hier jedoch in unterschiedlichen Zusammenhängen verwendet, beispielsweise im Rahmen von naturwissenschaftlichen, sozialwissenschaftlichen oder auch alltagsspezifischen Gesichtspunkten. ${ }^{92}$

Vor diesem Hintergrund muss schon einführend akzeptiert werden, dass kein gesellschaftlicher sowie wissenschaftlicher Konsens bezüglich einer Definition oder Begriffsbestimmung des Rassismus existiert. ${ }^{93}$ Einzig die engen Verknüpfungen des Begriffes mit biologistischen und - seit den 1990er Jahren tendenziell ansteigend - mit kulturellen Eigenschaften scheinen einen Minimal-Konsens zu ermöglichen. ${ }^{94}$ Daher kann subsummierend eine wahre Definitionsvielfalt konstatiert werden. ${ }^{95}$ In der Folge existiert eine fast unüberblickbare Vielfalt an Rassismustheorien und -konzepten, die sich dem Phänomen aus unterschiedlichen theoretischen Perspektiven nähern. Differenziert werden können engere bzw. weitere

87

Singer, Mona (1997): Fremd. Bestimmung. Zur kulturellen Verortung von Identität, Tübingen, S. 53.

88 Poliakov et al. 1992, a. a. O., S. 136.

89 Vgl. Räthzel, Nora (1992): Vorwort, in: Institut für Migrations- und Rassismusforschung e. V. (Hrsg.): Rassismus und Migration in Europa. Beiträge des Kongresses „Migration und Rassismus und Europa" Hamburg, 26. bis 30. September 1990, Hamburg, S. 8.

90 Mecheril/Melter 2009, a. a. O., S. 14.

91 Vgl. Ruf, Werner (1989): Ökonomie des Rassismus, in: Autrata, Otger/Kaschuba, Gerrit/Leiprecht, Rudolf (Hrsg.): Theorien über Rassismus. Eine Tübinger Veranstaltungsreihe, 3. Auflage, Hamburg, S. 63.

92 Vgl. Miles, Robert (2000): Bedeutungskonstitution und der Begriff des Rassismus, in: Räthzel, Nora (Hrsg.): Theorien über Rassismus, Hamburg, S. 17.

93 Vgl. Poliakov et al. 1992, a. a. O., S. 44.

$94 \quad$ Vgl. Koller, Christian (2009): Rassismus, Paderborn, S. 7ff.

95 Vgl. Koller 2009, ebd., S. 8ff. | Vgl. Delacampagne, Christian (2005): Die Geschichte des Rassismus, Düsseldorf u. a., S. 8. 
Definitionsrahmen sowie Konzepte mit eher biologischem oder eher kulturellgesellschaftlichem Fokus. Exemplarisch sind diesbezüglich die Rassismuskonzepte von Étienne Balibar, Ruth Benedict, Christian Delacampagne, Patrick Girard, Christian Koller, Albert Memmi, Robert Miles, George L. Mosse, Léon Poliakov, Mark Terkessidis oder Johannes Zerger zu nennen. Der überwiegende Anteil der bundesrepublikanischen Rassismusforschung ist jedoch in den 1980er und 1990er Jahren des vergangenen Jahrhunderts verortet, während man heutzutage in Europa tendenziell einen neuerlichen Anstieg der rassistischen Ideologie beobachten kann. Nichtsdestotrotz muss demgegenüber für das erste Jahrzehnt des 21. Jahrhunderts größtenteils eine Stagnation der Rassismusforschung festgestellt werden, da man annahm, rassistische Vorurteile und Ressentiments in Deutschland bis auf wenige Randgruppen der Gesellschaft für die Zukunft verbannt zu haben - ein Fehler, wie sich nun herausstellt.

In den nachfolgenden Kapiteln muss dieser umstrittene Begriff des Rassismus folglich für die weitere Untersuchung detailliert analysiert sowie für das 21. Jahrhundert modifiziert bzw. angepasst werden. Die folgenden Kapitel sollen dabei eine strukturierte Einführung in das Konzept des Rassismus ermöglichen. Hier muss illustriert werden, dass sich das Rassismusphänomen als vielschichtig, zeitlich anpassungsfähig, variabel und flexibel darstellt. So kann eine mögliche Eingrenzung des Rassismusbegriffs aus dem 20. Jahrhundert nicht gleichsam für das 21. Jahrhundert übernommen werden. Anhand der multiplen sowie deutlich differenzierten Forschungs- und Untersuchungsdesigns zur Begrifflichkeit des Rassismus muss weiterhin - trotz der wissenschaftlichen Kontroversität - eine Rassismusdefinition gefunden werden, die für den hier fokussierten, biologischen Rassismustyp als Arbeitsgrundlage verwendet werden kann. Nicht fehlen darf in diesem Zusammenhang auch ein Einblick in die historischen Entwicklungslinien des Rassismus, um mithilfe der in der Vergangenheit geschaffenen, rassistischen Grundmerkmale die Existenz des heutigen Rassismusphänomens umfassend verstehen zu können. Als Primärziel zeigt sich so die Engführung des Rassismusbegriffes zur Anwendung auf die Gegenwart: Was bedeutet Rassismus im 21. Jahrhundert?

Im literarischen Fokus der folgenden Untersuchung stehen insbesondere die Grundlagenwerke von Robert Miles, Albert Memmi und Étienne Balibar. Alle drei Autoren prägen mit ihren theoretischen Überlegungen den Rassismusbegriff verschiedener Forschungsrichtungen: Der Soziologe und Politikwissenschaftler Robert Miles vor dem biologisch-genetischen Hintergrund des Rassismus, der Philosoph Étienne Balibar vor dem kulturellen Hintergrund des Rassismus sowie Albert Memmi im Versuch einer Synthese von engen und weiteren Rassismustheorien (s. Kapitel 2.2). ${ }^{96}$ Hinzukommend ist selbstverständlich noch zahlreiche Se-

96 Im Zentrum der Rassismusdefinition von Robert Miles steht die Differenzierung bzw. Konstruktion spezifischer Menschengruppen anhand biologischer Merkmale. Étienne Balibar und Albert Memmi stellen hingegen eher kulturelle Unterschiede in den Mittelpunkt: Unterschiedliche Menschengruppen werden nach deren Rassismusdefinitionen überwiegend durch differierende kulturelle Merkmale, wie Religion, Herkunft,... generiert (s. Kapitel 2.2). 
kundärliteratur zu nennen, die sich zukunftsgerichtet mit dem Rassismusbegriff befasst, beispielsweise von Siegfried Jäger, Ina Kerner oder Mark Terkessidis.

Der methodische Schwerpunkt der nachfolgenden Kapitel liegt in der theoretischen und empirischen Analyse rassismusfokussierender Theorien der vergangenen Jahrzehnte. Auf der einen Seite sollen hier die unterschiedlichen Erklärungsund Begründungszusammenhänge des Rassismusbegriffes identifiziert sowie theoretisch vergleichend differenziert und systematisiert werden. Auf der anderen Seite sollen die zahlreichen Charakteristika des Rassismusbegriffes ausgewertet und darauf aufbauend eine für das 21. Jahrhundert passende Rassismusdefinition fokussiert werden, die insbesondere die biologistischen Bestandteile der rassistischen Ideologie wieder integriert.

$\mathrm{Zu}$ Beginn der theoretischen Betrachtung des Rassismusphänomens ist nachfolgend eine einführende Analyse des Rassismusbegriffes für das Verständnis der weiteren Untersuchungsschritte notwendig. Sowohl die sich anschließende Untersuchung der Verbreitung des Rassismusphänomens innerhalb der bundesrepublikanischen Gesellschaft des 21. Jahrhunderts, als auch die Identifizierung möglicher Erklärungszusammenhänge des Rassismus bedingen eine präzise, begriffliche Grundlage, der im folgenden Kapitel Rechnung getragen werden soll. „Die präzise Bestimmung des Gegenstandes bildet [...] die Basis für eine differenzierte Analyse des Phänomens Rassismus.“97, so auch Rassismusforscher Johannes Zerger.

Im ersten Teil müssen folglich die zahlreichen Charakteristika sowie die vielfältigen Erscheinungsformen des Rassismus erörtert werden. In diesem Zusammenhang soll ein umfassender Begriffs-Pool erstellt werden, um die Kernaussagen der unterschiedlichen Forschungs- und Argumentationsansätze aus den Geschichtswissenschaften, der Psychologie, der Soziologie, der Philosophie, der Politikwissenschaft und den Naturwissenschaften zu strukturieren. ${ }^{98}$ Von besonderem Interesse sind dabei die naturwissenschaftlichen Erklärungskomponenten des Rassismusphänomens. Diesbezüglich darf auch der sogenannte ,Rassebegriff' nicht ausgeblendet werden, da er - als naturwissenschaftliches Relikt - noch immer zur Begründung vielfältiger gesellschaftlicher und sozialer Konflikte herangezogen wird. ${ }^{99}$ Eine transparente, auf wissenschaftlichen Fakten basierende Begründung, warum Menschengruppen in angebliche ,Rassen' klassifiziert werden sollen, versuchen rassistische Gruppierungen schon seit der Begriffseinführung im Mittelalter - natürlich - vergeblich zu finden (s. Kapitel 5). ${ }^{100}$ Als ein Beispiel sei hier die physische und kulturelle ,Rassifizierung' von heutigen Arbeitsmigrantinnen und migranten genannt: Diesbezüglich steht „,...] für den Rassisten [scheinbar fest], dass die Billig-Arbeitskräfte, welcher Nation, Kultur oder Rasse sie entstammen mögen, den Schritt zum mitteleuropäischen Kulturmenschen allesamt noch nicht geschafft haben."101

\footnotetext{
97 Zerger 1997, a. a. O., S. 8.

98 Vgl. Koller 2009, a. a. O., S. $11 \mathrm{ff}$.

99 Vgl. Miles, Robert (1993): Racism after, race relations', London, S. 3.

100 Vgl. Terkessidis 1998, a. a. O., S. 27. | Vgl. Zerger 1997, a. a. O., S. 13

101 Ruf 1989, a. a. O., S. 78.
} 
Aufgrund der historischen Flexibilität des Rassismusbegriffes darf darüber hinaus eine Einführung in die historische Entstehung und Entwicklung des Rassismusbegriffes nicht fehlen, da sich verschiedene Rassismuskonzeptionen voneinander differenzieren lassen. ${ }^{102}$

„Man muss den verschlungenen Pfaden seiner wirklichen Geschichte folgen, seine verschiedenen Veränderungen im Laufe der Jabrbunderte nachvolliziehen, erkennen, wie viele Gestalten sozialer und kultureller Art er annabm, um zu verstehen, für welche Probleme er angeblich Lösungen anzubieten [...] [hat]. "103 „Will man die jeweiligen rassistischen Zuschreibungen, ibre Begründungen und die daraus abgeleiteten Folgerungen analysieren, muss man immer auch den entsprechenden bistorischen [...] Kontext betrachten. "104

Besonders vor dem Hintergrund der angestrebten Analyse des gegenwärtigen Rassismusphänomens im 21. Jahrhundert scheinen die historischen Dimensionen des Rassismusbegriffs bedeutend. ${ }^{105}$

Abschließend folgt dann ein Zwischenfazit zur Visualisierung des heutigen Rassismusverständnisses bzw. -Begriffes, insbesondere unter Einbeziehung der biologistischen Elemente.

\subsection{Die Ideologie des Rassismus}

Das folgende Kapitel ermöglicht einen Einblick in die kontroverse Rassismusforschung. Der Schwerpunkt liegt hierbei auf dem 21. Jahrhundert, jedoch müssen ebenfalls maßgebliche Forschungsarbeiten aus den vorherigen Jahrzehnten integriert werden. Im Fokus steht folglich eine umfangreiche Darstellung des heutigen Verständnisses des Rassismusbegriffes in der Bundesrepublik Deutschland, einschließlich seiner Charakteristika und Erscheinungsformen.

Was wird unter dem Begriff ,Rassismus‘ verstanden? Trotz der vielfältigen Forschungsperspektiven lässt sich einführend feststellen, dass Rassismus nicht nur als individuelle Vorstellung oder pseudowissenschaftlich begründete Theorie, sondern vielmehr als Ideologie bezeichnet werden kann. ${ }^{106}$ Albert Memmi ver-

102 Vgl. Miles 2000, a. a. O., S. 27. | Vgl. Benedict 1983, a. a. O., S. 97.

103 Delacampagne 2005, a. a. O., S. 15-16.

104 Zerger 1997, a. a. O., S. 70.

105 Vgl. Mosse, George L. (1993): Die Geschichte des Rassismus in Europa, Frankfurt/Main, S. 23.

Diesbezüglich kann jedoch nur von einer überblickartigen Einleitung zur Verständnisförderung der nachfolgenden Analysen und Untersuchungen gesprochen werden, da allein die Betrachtung des historischen Rassismusaspekts den thematischen Rabmen dieser Arbeit bei Weitem übertreffen würde.

106 Vgl. Appiah, Kwame Anthony (1990): Racisms, in: Goldberg, David Theo (Hrsg.): Anatomy of racism, Minneapolis, S. 8.

Der Begriff, Ideologie" wird in dieser Arbeit als Lehre von Ideen - in diesem Fall der Ideen des Rassismus verstanden. Die Ideologie des Rassismus dient dabei zur Begründung und Legitimation des Handels rassistischer Akteure, um deren Zielsetzungen zu erreichen bzw. deren Absichten und Interessen zu verwirklichen. Vgl. Weiß, Ulrich (2011a): Art. „Ideologie“, in: Nohlen, Dieter/Grotz, Florian (Hrsg.): Kleines 
merkt demnach folgerichtig, dass „,[d]er Rassismus [...] keine Theorie [ist], sondern eine Pseudotheorie. " 107 Der Historiker George L. Mosse charakterisiert den Rassismus weitergehend als umfassendes „Denksystem“108, als weit verbreitete Ideologie, die ihren Ursprung in Europa hat und mit der systematischen Judenvernichtung im sogenannten Dritten Reich ihren Höhepunkt fand. ${ }^{109}$ „Der Rassismus [ist] [...] eine auf Klischees oder Stereotypen basierende visuelle Ideologie $[\ldots]$ “110, die ,[...] die von der Moderne entwurzelten und verängstigten Menschen

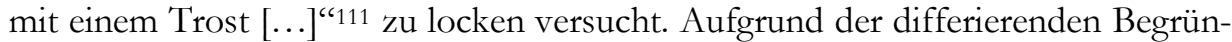
dungszusammenhänge kann der Rassismus darüber hinaus auch als Typus einer interdisziplinären Ideologie dargestellt werden. Er integriert Vorstellungen aus den Sozialwissenschaften, der Psychologie, der Biologie oder der Medizin; damit konstruiert er Ressentiments, Stereotype und Klischees, wie beispielsweise bezüglich der Differenzierung von angeblich ,anormalen', ,minderwertigen' sowie ,normalen', ,überlegenen“ Menschengruppen. ${ }^{112}$ Diesbezüglich sind insbesondere die scheinbar engen Verknüpfungen von Rassismus und Humanbiologie hervorzuheben, die beispielsweise im Zuge der neu entstehenden Sexualkunde am Ende des 19. Jahrhunderts sogenannte ,jüdische Krankheiten“113 zu identifizieren versuchten. ${ }^{114}$ Der Rassismus zeigt sich hier lediglich als pseudowissenschaftliche Ideologie, da Theorien validierte Erkenntnisse illustrieren, die auf einer systematischen, geordneten, kategorialen Beobachtung bzw. Erklärung der Realität basieren - der Rassismus kann jedoch keinesfalls als eine wissenschaftliche Aussage kategorisiert werden. ${ }^{115}$

Was kennzeichnet nun diese Ideologie des Rassismus? Der Rassismus gilt, wie bereits erwähnt, als Übertreibung, als überzogene Darstellung der scheinbaren Realität. ${ }^{116}$ Überblickartig betrachtet, kann Rassismus als Hass, Ausgrenzung und Abwertung von anderen Menschen oder Personengruppen angesehen werden, weil diese ,anders' sind - eine eindeutige Begründung bleibt offen. ${ }^{117}$ „Rassismus ist auch eine Geisteshaltung $[\ldots]^{\text {"118 }}$, mithilfe derer Individuen aufgrund angeblicher psychischer, kultureller oder biologisch-genetischer Störungen diskriminiert

Lexikon der Politik, 5. Auflage, München, S. 257f. | Vgl. Schubert, Klaus/Klein, Martina (2011): Art. „Ideologie“, in: ebd. (Hrsg.): Das Politiklexikon. Begriffe, Fakten, Zusammenhänge, 5. Auflage, Bonn, S. $142 \mathrm{f}$.

107 Memmi 1992, a. a. O., S. 30.

108 Mosse 1993, a. a. O., S. 7.

109 Vgl. Mosse 1993, a. a. O., S. 7.

110 Mosse 1993, a. a. O., S. 9.

111 Mosse 1993, a. a. O., S. 10.

112 Vgl. Mosse 1993, a. a. O., S. $11 \mathrm{ff}$.

113 Mosse 1993, a. a. O., S. 14.

114 Vgl. Mosse 1993, a. a. O., S.14ff.

115 Vgl. Schubert, Klaus/Klein, Martina (2011): Art. „Theorie“, in: ebd. (Hrsg.): Das Politiklexikon. Begriffe, Fakten, Zusammenhänge, 5. Auflage, Bonn, S. 297.

116 Vgl. Geulen 2007, a. a. O., S. 7.

117 Vgl. Delacampagne 2005, a. a. O., S. 7.

118 Delacampagne 2005, a. a. O., S. 8. 
werden. ${ }^{119}$ Vor diesem Hintergrund kann Rassismus als Setting von biologischen, sozialen oder kulturellen Unterschieden aufgrund willkürlicher Kriterien bezeichnet sowie als Legitimationsgrundlage der Ungleichbehandlung von Menschen verstanden werden. ${ }^{120}$ Zurückgreifend auf die naturwissenschaftliche Forschung wird hierfür auch heute noch mehr oder weniger direkt der sogenannte ,Rassebegriff' integriert, um der Abwertung bzw. Diskriminierung von spezifischen Menschengruppen einen wissenschaftlichen Anstrich zu geben:121 „,Rasse ist die bestimmte Form einer Grenzziehung, mittels derer die Nicht-/Zugehörigkeit von Personen zu einer Gruppe oder Bevölkerung festgelegt wird.“122 Den auszugrenzenden Menschen werden folglich ihre Menschenwürde und damit auch ihre Grundrechte entzogen (s. Kapitel 5.2). ${ }^{123}$ Ein Ziel des Rassismus ist schlussfolgernd, dass als ,normal' angesehene, primär biologische Werte und Unterschiede festgelegt werden, mithilfe derer die eigene ,höherwertige' Position des Lebens gerechtfertigt werden kann. ${ }^{124}$ Der ,Rassebegriff' existiert demnach auch heute noch direkt und indirekt im gesellschaftlichen Umfeld. So illustriert Schriftsteller Volker Weiß, dass Thilo Sarrazin diesen im ersten Manuskript seines Werkes „Deutschland schafft sich ab. Wie wir unser Land aufs Spiel setzen“125 anwandte. ${ }^{126}$ Nur auf Drängen der publizierenden Deutschen Verlagsanstalt wurde er durch den unaufdringlicheren, beschönigenden Begriff der ,Ethnie' ersetzt - die Intention bleibt jedoch unverändert. ${ }^{127}$

\subsubsection{Vielfalt von Rassismusdefinitionen}

Aus den vorhergehenden Darstellungen wird schon ansatzweise deutlich, dass eine allumfassende Rassismusdefinition aufgrund der facettenreichen Charakteristika und Merkmale komplex und unrealistisch erscheint. ${ }^{128}$ In der folgenden Übersicht stehen exemplarisch einige repräsentative Rassismusdefinitionen, die die multiplen Erklärungs- und Begründungszusammenhänge offenlegen.

119 Vgl. Delacampagne 2005, a. a. O., S. 8ff.

120 Vgl. Rommelspacher, Birgit (2009): Was ist eigentlich Rassismus?, in: Mecheril, Paul/Melter, Claus (Hrsg.): Rassismuskritik. Band 1: Rassismustheorie und -forschung, Schwal-

bach/Taunus, S. 25ff.

121 Vgl. Jäger, Siegfried (1992b): BrandSätze. Rassismus im Alltag, Duisburg, S. 15.

122 Anthias, Floya (1992): Parameter kollektiver Identität: Ethnizität, Nationalismus und Rassismus, in: Institut für Migrations- und Rassismusforschung e. V. (Hrsg.): Rassismus und Migration in Europa. Beiträge des Kongresses „Migration und Rassismus in Europa“ Hamburg, 26. bis 30. September 1990, Hamburg, S. 96.

123 Vgl. Poliakov et al. 1992, a. a. O., S. 72.

124 Vgl. Terkessidis 1998, a. a. O., S. 71.

125 Sarrazin 2010 , a. a. O.

126 Vgl. Weiß 2011b, a. a. O., S. 117.

127 Vgl. Weiß 2011b, a. a. O., S. 117.

128 Vgl. Mecheril/Melter 2009, a. a. O., S. 16. | Vgl. Weiß 2013, a. a. O., S. 23. 
Tab. 1: Rassismusdefinitionen (exemplarische Auswahl)

„Ein übersteigertes Rassenbewusstsein, das aufgrund äußerlicher Merkmale die Über- oder Unterlegenheit einer ethnischen Gruppe gegenüber einer anderen behauptet, wird als Rassismus bezeichnet." ${ }^{129}$

„Von Rassismus spricht man, wenn in einem Land ganze Gruppen von Menschen wegen ihrer angeblichen rassischen Minderwertigkeit von anderen Gruppen wirtschaftlich, gesellschaftlich und rechtlich benachteiligt werden." 130

„Rassismus, übersteigertes Rassenbewusstsein und Rassendenken, das in der Regel mit der Akzeptanz von Diskriminierung und Unterdrückung anderer ethnischer Gruppen oder mit aktiver Gegnerschaft gegen Mitglieder anderer ethnischer Gruppen einhergeht.“131

„Rassismus, eine Ideologie, die soziale Phänomene mit Hilfe pseudowissenschaftlicher Analogieschlüsse aus der Biologie zu erklären sucht." 132

„Rassismus, eine Ideologie, die eine prinzipielle, mit biologistischen Argumentationen begründete Ungleichheit zwischen Menschen unterschiedlicher Abstammung behauptet, daraus den Überlegenheitsanspruch der jeweils eigenen Rasse oder Gruppe ableitet und aggressives, diskriminierendes Verhalten gegenüber Fremden fördert."133

Einige der Definitionen beinhalten den sozialwissenschaftlich als diskreditiert erscheinenden ,Rassebegriff', wohingegen andere schwerpunktmäßig mit den ideologischen Aspekten des Rassismus operieren; auch gesellschaftliche, wirtschaftliche, rechtliche und vor allem biologische Begründungsansätze kommen in unterschiedlichen Ausprägungen zur Anwendung. Gefolgert werden kann demnach: „Nicht immer [folgt] der Rassismus in seinen verschiedenen Formen den gleichen Eingebungen, nicht immer führt er zu den gleichen Ergebnissen. “134 Der „[...] Rassismus [hat empirisch viele Gesichter.“"135 Es existieren keine ,[...] einheitlichen Trennlinien [...]“136, sondern eine Vielzahl von „,[...] Abstufungen oder Schattierungen." ${ }^{137}$ Hinzukommend sind der Charakter sowie der definitorische Hintergrund des Rassismusbegriffs äußerst wandlungs- und anpassungsfähig. Man kann hier von keiner einheitlichen, unveränderbaren Ideologie sprechen, sondern vielmehr von einem äußerst flexiblen, historisch und zeitlich anpassungsfähigen

129 Rittershofer, Christian (2007): Art. „Rasse/Rassismus“, in: ebd. (Hrsg.): Lexikon Politik, Staat, Gesellschaft, München, S. 563.

130 Drechsler, Hanno/Hilligen, Wolfgang/Neumann, Franz (2003): „Rasse/Rassismus“, in: ebd. (Hrsg.): Gesellschaft und Staat. Lexikon der Politik, 10. Auflage, München, S. 802.

131 Schmidt, Manfred G. (2010b): Art. „Rassismus“, in: ebd. (Hrsg.): Wörterbuch zur Politik, 3. Auflage, Stuttgart, S. 657.

132 Rieger 2005, a. a. O., S. 810.

133 Nohlen, Dieter/Schultze, Rainer-Olaf/Schüttemeyer, Suzanne (1998): Art. „Rassismus“, in: ebd. (Hrsg.): Lexikon der Politik. Band 7. Politische Begriffe, München, S. 530-531.

134 Mosse 1993, a. a. O., S. 24.

135 Mecheril/Melter 2009, a. a. O., S. 16.

136 Memmi 1992, a. a. O., S. 16.

137 Memmi 1992, a. a. O., S. 16. 
Konstrukt. ${ }^{138}$ Dieses wird mithilfe biologistischer oder kultureller Argumentationsversuche immer wieder neu konstruiert und situationsgerecht an aktuelle Erfordernisse angepasst. ${ }^{139}$ Trotz der weit differenzierten Definitionsansätze des rassistischen Phänomens zeigt sich jedoch ein Aspekt in den exemplarischen Definitionsversuchen weitgehend konstant: Die Integration der biologistischen bzw. der ,rassischen' Erkenntnisse als Grundlage der rassistischen Argumentationen. Die Biologie ist und bleibt folglich auch definitorisch ein essentieller Grundbaustein des Rassismus.

Zusammenfassend muss vor dem Hintergrund der vielfältigen Erklärungsansätze und der ebenso multiplen Begriffsanalysen des Rassismus auch für die Gegenwart festgestellt werden, dass nach wie vor keine einheitliche Definition des Rassismusphänomens existiert. Der Historiker Imanuel Geiss erklärte in diesem Zusammenhang schon in den 1980er Jahren prognostisch treffend, ,[...] dass eine befriedigende Definition von [...] Rassismus noch nicht gefunden ist. Daher ist hier nur eine ungefähre Umschreibung möglich [...]."140 Auch Alfred Memmi spricht diesbezüglich von einer Mehrdeutigkeit des Rassismusbegriffes. ${ }^{141}$ Robert Miles warnt sogar vor einer ,[...] begrifflichen Inflation $[\ldots]^{“ 142}$, einer zu starken Erweiterung der begrifflichen Konnotation der rassistischen Ideologie. ${ }^{143}$ Denn Konsequenz der fehlenden Zustimmung zu einer gemeinsamen Rassismusdefinition ist die im 21. Jahrhundert in Politik und Gesellschaft sehr weitläufige Verwendung des Terminus auch in fragwürdigen Zusammenhängen, wie zahlreiche Rassismustheoretiker diagnostizieren. Der Philosoph Kwame Anthony Appiah folgert so fragend:

„But visitors from Mars - or from Malawi - unfamiliar with the Western concept of racism could be excused if they had some difficulty in identifying what exactly racism was. We see it everywhere, but rarely does anyone stop to say what it is, or to explain what is wrong with it. "'44

\subsubsection{Der ,Rassebegriff‘ aus sozialwissenschaftlicher Perspektive}

Ein zentrales Schlüsselelement sowie Namensgeber des Rassismus ist auch im 21. Jahrhundert der sogenannte ,Rassebegriff‘, der sich schon in der vergangenen Weltgeschichte als bedeutsames Gelenkstück des ,Rassen-` bzw. des Rassismus-

\footnotetext{
138 Vgl. Glanninger, Peter (2009): Rassismus und Rechtsextremismus. Rassistische Argumentationsmuster und ihre historischen Entwicklungslinien, Frankfurt/Main u. a., S. 22. | Vgl. Mecheril/Scherschel 2009, a. a. O., S. 47.

139 Vgl. Glanninger 2009, ebd., S. 47.

140 Geiss, Imanuel (1988): Geschichte des Rassismus, Frankfurt/Main, S. 9.

141 Vgl. Glanninger 2009, ebd., S. $20 \mathrm{ff}$.

142 Glanninger, ebd., S. 20.

143 Vgl. Glanninger 2009, ebd., S. 20ff.

144 Appiah 1990, a. a. O., S. 3.
} 
konzeptes zeigte. ${ }^{145}$ Dieser stammt ursprünglich aus der lateinischen sowie italienischen Sprache und steht für die in den Naturwissenschaften, insbesondere in der Haustierkunde der Zoologie, benötigten Begrifflichkeiten Subspezies, Unterart und Form (s. Kapitel 5.2). ${ }^{146}$ Ein historischer Rückblick als Orientierungshilfe sei gestattet: Die erste Verwendung des Begriffs geht auf den französischen Arzt und Philosophen François Bernier am Ende des 17. Jahrhunderts zurück, der ,Rasse‘ wertfrei zur Unterscheidung von körperlichen Merkmalen benutzte. ${ }^{147}$ Die europäischen Eroberer führten den ,Rassebegriff' mit dem Beginn des Zeitalters der Kolonialisierung wieder ein, um damit eine Erklärungs- und Rechtfertigungsideologie der Überlegenheit der Europäer weltweit pseudowissenschaftlich zu belegen. ${ }^{148}$ Somit wurde versucht, ,[...] eine physiologische Dimension in den Ungleichheiten von Menschen herauszustellen."149 Insbesondere der Nationalsozialismus prägte die antisemitische Verwendung des ,Rassebegriffs' in Deutschland. Bis zum Ende des nationalsozialistischen Terrorregimes kamen bezüglich der Existenz und des Vorhandenseins von unterschiedlichen menschlichen ,Rassen“ keine Zweifel auf. ${ }^{150}$ Selbst für die Gegenwart wird im weiteren Verlauf deutlich werden, dass der ,Rassebegriff' bzw. die ,Rassekategorisierung' auch heute noch eine umstrittene Rolle spielt, wenn auch größtenteils verborgen und indirekt vorhanden.

Ein Kernelement der ,Rasse 'innerhalb der Ideologie des Rassismus bleibt das übersteigerte ,Rassebewusstsein' und die damit einhergehende Überhöhung der eigenen ,Rasse' bzw. Menschengruppe. ${ }^{151}$ Die einzelnen, scheinbaren ,Menschenrassen' zeichnen sich durch angebliche morpho-physiologische, genetische, soziale, symbolische und intellektuelle Unterschiede aus. ${ }^{152}$ Diese Unterscheidungselemente konstruieren letztlich den sogenannten ,Rassebegriff'. Mithilfe der Einbeziehung der biologisch-genetischen Komponente wird seitens der ,Rassebefürworter versucht, dem aus den Naturwissenschaften entliehenen Begriff auch in sozialwissenschaftlicher Anwendung einen angeblich unwiderlegbaren, wissenschaftlichen ,Anstrich' zu verschaffen, um so eventuellen Kritikern mit dem Verweis auf naturwissenschaftliche Erkenntnisse zuvorzukommen. Die Verabsolutierung des ,Rasse'- bzw. des Rassismusbegriffes beförderten in der ersten Hälfte des 20. Jahrhunderts die Nationalsozialisten, die sich pseudowissenschaftlicher, biologi-

145 Vgl. Rex, John (1990): „Rasse“ und „Ethnizität“ als sozialwissenschaftliche Konzepte, in:

Dittrich, Eckhard J./Radtke, Frank-Olaf (Hrsg.): Ethnizität. Wissenschaft und Minderheiten, Opladen, S. 141.

146 Vgl. Delacampagne 2005, a. a. O., S. 130.

147 Vgl. Poliakov et al. 1992, a. a. O., S. 72.

148 Vgl. Geiss 1988, a. a. O., S. 14. | Vgl. Becker, Peter Emil (1990): Sozialdarwinismus, Rassismus, Antisemitismus und Völkischer Gedanke. Wege ins Dritte Reich. Teil II, Stuttgart u. a., S. 514.

149 Geulen 2007, a. a. O., S. 14.

150 Vgl. Geulen 2007, a. a. O., S. 14ff.

151 Vgl. Rittershofer 2007, a. a. O., S. 563.

152 Vgl. Guillaumin, Colette (1991): Rasse. Das Wort und die Vorstellung, in: Bielefeld, Uli (Hrsg.): Das Eigene und das Fremde. Neuer Rassismus in der Alten Welt?, Hamburg, S. 167. 
scher Belege zahlreicher selbsternannter ,Rassekundler' bedienten, um mit deren Hilfe Gemeinsamkeiten des Erbmaterials sowie die erbliche Zusammengehörigkeit der deutschen Bürgerinnen und Bürger nachzuweisen. ${ }^{153}$ So konnten Angehörige angeblich minderwertiger ,Rassen“ identifiziert, systematisch ausgrenzt und grausam ermordet werden - ein Verstoß gegen die Naturgesetze. ${ }^{154}$ Unterschiedliche ,[...] phantasmatische Merkmale [...]“155 wurden folglich zu dem Gesamtprodukt ,Rasse“ zusammengefügt. Da diese gesellschaftlichen, biologistischen, kulturalistischen, religiösen oder herkunftsspezifischen Merkmale jedoch zum Großteil willkürlich, ohne jegliche wissenschaftliche Begründung oder Verifizierung, gewählt werden, ist auch der ,Rassebegriff‘ - ähnlich wie das Rassismusphänomen - von einer hohen Wandlungs- und Anpassungsfähigkeit sowie von einer außerordentlichen Vielseitigkeit und Dehnbarkeit geprägt. ${ }^{156}$ Zusätzlich gelangt die ,Rasseidee' durch das Fehlen von jeglichen semantischen Grenzen - trotz ihrer „Antiquiertheit"“157 - zu einer enormen Flexibilität. ${ }^{158}$ Dem wurde insbesondere im 19. und 20. Jahrhundert Rechnung getragen, da in diesem Zeitfenster eine große Anzahl von ,Rassenklassifizierungen“ stattfanden. „Der Einfallsreichtum der Forscher war grenzenlos $[\ldots]^{\text {“159 }}$.

Das ,Rassekonzept' ist und bleibt also biologisch konnotiert. ${ }^{160}$ Jedoch muss ebenfalls festgestellt werden, dass das erbbiologische ,Rassenkonzept ${ }^{6}$ auch gewisse kulturelle Komponenten beinhaltet. ${ }^{161}$ Überwiegend stellen jedoch auch diese Argumentationen lediglich eine Naturalisierung kultureller und sozialer Merkmale dar. Mit der Verbreitung des ,Rassekonzeptes' in den Gesellschafts- und Sozialwissenschaften wurde so fälschlicherweise ein naturwissenschaftliches Konzept der Kategorisierung von Organismen auf die gesellschaftliche Ebene übertragen eine fatale Entscheidung, da der ,Rassebegriff' im politischen und gesellschaftlichen Alltag nach wie vor keine wissenschaftliche Verankerung aufweist. ${ }^{162}$ Das bedeutet folglich, dass erst die illegitime Generalisierung des ,Rassebegriffes` auf die menschliche Gesellschaft letztlich zu dem Phänomen des ideologischen Ras-

153 Vgl. Guillaumin, Colette (1992): Zur Bedeutung des Begriffs ,Rasse`, in: Institut für Migrations- und Rassismusforschung e. V. (Hrsg.): Rassismus und Migration in Europa. Beiträge des Kongresses „Migration und Rassismus in Europa“ Hamburg, 26. bis 30. September 1990, Hamburg, S. 81 ff. | Vgl. Propping 1992, a. a. O., S. 121.

154 Vgl. Guillaumin 1992, ebd., S. 81 ff. | Vgl. Schott, Heinz (1992): Die Stigmen des Bösen kulturgeschichtliche Wurzeln der Ausmerze-Ideologie, in: Propping, Peter/Schott, Heinz (Hrsg.): Wissenschaft auf Irrwegen. Biologismus - Rassenhygiene - Eugenik, Bonn u. a., S. 20.

155 Guillaumin 1992, ebd., S. 83.

156 Vgl. Geulen 2007, a. a. O., S. $15 \mathrm{ff}$.

157 Guillaumin 1992, ebd., S. 79.

158 Vgl. Guillaumin 1992, ebd., S. 80ff.

159 Poliakov et al. 1992, a. a. O., S. 16.

160 Vgl. Benedict 1983, a. a. O., S. 10.

161 Vgl. Hund, Wulf D. (2007): Rassismus, Bielefeld, S. $15 \mathrm{ff}$.

Religion, Herkunft oder Sprache werden so beispielweise im Rabmen der rassistischen Ideologie mit biologischen Eigenschaften, wie sperifischen Vererbungsmustern und -wahrscheinlichkeiten oder kognitiven Fäbigkeiten, verknüpft.

162 Vgl. Rex 1990, a. a. O., S. 141. 
sismus und - weitergedacht - zu den Entwicklungslinien von Sozialbiologismus und Eugenik führte. ${ }^{163}$

Mithilfe dieses biologischen Konzeptes der ,Rasse' werden im Sinne des Rassismus Pseudodifferenzen und -unterschiede von Menschengruppen verifiziert. In den 1990er Jahren wurden hierfür auch die alternativen Ersatzbegriffe der ,Kultur ${ }^{6}$ sowie der ,Ethnie' geprägt, um den negativ belasteten ,Rassebegriff‘ zu substituieren - die hinter den Begrifflichkeiten stehende Bedeutung sowie deren Sinnzusammenhang bleibt jedoch größtenteils auch im 21. Jahrhundert ähnlich: ${ }^{164}$ Menschen werden anhand dieser Wortkonstruktionen in spezifische Bevölkerungsgruppen - ,Rassen“ - hierarchisiert, die auf haltlosen, vornehmlich biologistischen Merkmalen basieren. Auf der Grundlage von angeblichen biologischen, genetischen oder kulturellen - wie in den 1990er Jahren vermehrt konstatiert - Unterschieden werden ,Menschenrassen' quasi konstruiert. ${ }^{165}$

\section{„Der Rassismus ist in Wirklichkeit diejenige Haltung, die die intellektuellen oder mora- lischen Merkmale einer gegebenen Menschengruppe als direk.te Folge ibrerphysischen oder biologischen Merkmale ansieht [...]. " "66}

Die Konstruktion von angeblich höher- bzw. minderwertigen ,Menschenrassen“ wird als Legitimationsgrundlage einer Hierarchisierung der Gesellschaft verwendet. Die erste historisch belegte Abgrenzung von Menschengruppen mithilfe der ,Rassenschemata' ist für die griechische Antike - hier jedoch noch tendenziell wertneutral - belegt. Hier wurde der, Rassebegriff' zur Abgrenzung des Adels von der bürgerlichen Gesellschaftsschicht benutzt. ${ }^{167}$ Auch vor dem Hintergrund der Kolonialisierungsbestrebungen der Europäer - der Kolonialmächte Spanien, Portugal, Großbritannien, Frankreich, den Niederlanden und dem damaligen Deutschen Reich - im 19. und 20. Jahrhundert kam die künstliche Konstruktion von ,Menschenrassen' sehr gelegen. So konnten die abwertende und menschenunwürdige Behandlung der in den Kolonien lebenden Menschen sowie die Sklaverei mithilfe der amateur-naturwissenschaftlichen Grundlage des anthropologisierten ,Rassekonzeptes' begründet werden. Aufgrund von angeblich vererbten biologischen - insbesondere einfachen äußeren, phänotypischen Merkmalen, wie Hautfarbe und Körpergestalt - Unterschieden wurde der ausgrenzende, diskriminierende und menschenverachtende Umgang mit ,den Fremden' legitimiert. Gleichzeitig kam so auch der Machtanspruch der europäischen Bevölkerung als der angeblich am weitesten und besten - biologisch wie kulturell - entwickelten ,Menschenrasse $^{6}$ zustande: „Der Rassismus impliziert eine Hierarchie zwischen

\footnotetext{
163 Vgl. Marten, Heinz-Georg (1983): Sozialbiologismus. Biologische Grundpositionen der politischen Ideengeschichte, Frankfurt/Main u. a., S. 25 im sozialwissenschaftlichen Diskurs, in: Dittrich, Eckhard J./Radtke, Frank-Olaf (Hrsg.): Ethnizität. Wissenschaft und Minderheiten, Opladen, S. $179 \mathrm{ff}$.

165 Vgl. Poliakov et al. 1992, a. a. O., S. $24 \mathrm{ff}$.

166 Poliakov et al. 1992, a. a. O., S. 27.

167 Vgl. Hund 2007, a. a. O., S. 13.
} 
menschlichen Gruppen [... $]^{\text {“168 }}$ und „,...] dient bis heute der Legitimation von Herrschaft."169 Gleichzeitig ermöglichte diese Argumentationsstruktur auch die Einordnung von möglichen Nachkommen einer Menschengruppe von Geburt an aufgrund deren „[...] als erblich geltenden ,Makeln'““170 in eine feste Zugehörigkeit - das biologistisch determinierte ,Rassekonzept ${ }^{`}$ fungiert so als rassenkonstruierendes Element.

Als Folge des ,Rassekonzeptes“ lassen sich demnach Diskriminierung, Trennung, Segregation, Unterwerfung, Unterordnung oder Auslöschung von spezifischen Menschengruppen scheinbar wissenschaftlich legitimieren. ${ }^{171}$ Die Hierarchisierungsfunktion des ,Rassekonzeptes‘ bedingt darauf aufbauend immer zweier Perspektiven: Auf der einen Seite die der Abwertung, Ausgrenzung und Diskriminierung von angeblich durch vererbte biologische Prädispositionen ,minderwertigen“ Menschengruppen sowie auf der anderen Seite die der „Selbstüberhöhung“"172 und Glorifizierung der eigenen biologisch und kulturell scheinbar vollkommensten ,Rasse'. Kennzeichen des kulturell geprägten Ideologietheorems ist so eine „[...] ideologische Verhüllung [...]“173 dessen mithilfe angeblich wissenschaftlich validierter, biologischer, das heißt natürlicher, Differenzen zwischen spezifischen Menschengruppen. ${ }^{174}$ Vor diesem Hintergrund kann von einer Naturalisierung der kulturellen Elemente gesprochen werden, da ,[... , auch die Kultur [...] als eine solche Natur fungieren' [...]"175 kann:176 Zentrales Steuerelement bleibt trotz des engen Zusammenhangs von biologischen und kulturellen Erklärungsansätzen das biologistische Kernelement des Rassismus zur pseudowissenschaftlichen Begründung der ,Rassifizierung ${ }^{6}$ von Menschengruppen. Nichtsdestotrotz wird jedoch illustriert, dass eine Unterscheidung in biologistische und kulturelle Elemente des Rassismus zwar insbesondere für den naturwissenschaftlichen Schwerpunkt dieser Untersuchung wichtig, aber nicht immer eindeutig und klar differenzierbar erscheint. ${ }^{177}$

Die biologische Forschung wird im Rahmen des Rassismus also nicht nur absichtlich falsch interpretiert, sondern faktisch missbraucht. Die Biologie wird als objektives Validierungs- und Begründungsinstrument der rassistischen Ideologie zweckentfremdet. ${ }^{178}$ Gerade in dieser ,[...] Verschränkung von Wissenschaft und

\footnotetext{
168 Dettmar, Erika (1987): Rassismus, Vorurteile, Kommunikation. Afrikanisch-europäische Begegnung in Hamburg, Berlin u. a., S. 42.

169 Hund 2007, a. a. O., S. 15.

170 Taguieff, Pierre-André (2000): Die Macht des Vorurteils. Der Rassismus und sein Double, Hamburg, S. 12.

171 Vgl. Taguieff 2000, ebd., S. 12ff.

172 Kalpaka, Annita/Räthzel, Nora (2000): Die Schwierigkeit, nicht rassistisch zu sein, in: Räthzel, Nora (Hrsg.): Theorien über Rassismus, Hamburg, S. 180.

173 Hund 2007, a. a. O., S. 15.

174 Vgl. Hund 2007, a. a. O., S. $15 f f$.

175 Jäger, Margret/Jäger, Siegfried (2000): Rassistische Alltagsdiskurse, in: Räthzel, Nora (Hrsg.): Theorien über Rassismus, Hamburg, S. 278.

176 Vgl. Scherr 2009, a. a. O., S. 78.

177 Vgl. Hund 2007, a. a. O., S. $15 \mathrm{ff}$.

178 Vgl. Geulen 2007, a. a. O., S. $63 \mathrm{ff}$.
} 
Politik [... ]“179 kann ein ursächlicher Faktor der Rassismusausbreitung im 20. und 21. Jahrhundert gesehen werden. ${ }^{180}$

Die aufgezeigten Entwicklungen visualisieren im Zusammenhang mit dem Phantasma der ,Rasse eindrucksvoll, dass es sich hierbei um keine biologisch begründete Tatsache, sondern lediglich um eine gesellschaftliche Konstruktion mit pseudonaturwissenschaftlichem Rückgriff handelt. Robert Miles bezeichnet diese gesellschaftlich und politisch motivierte ,Rassenbildung' treffend als „Rassenkonstruktion“181, einen „[...] Prozess der Beschreibung von Gruppengrenzen und der Verortung von Personen innerhalb dieser Grenzen durch den vorrangigen Bezug auf (möglicherweise) angeborene und/oder biologische (meist phänotypische) Merkmale." "182 ,Rasse' kann so als gesellschaftliche Konstruktion der Realität, als „,...] gesellschaftliche Fiktio[n] [...]“183 angesehen werden, keinesfalls als biologische Wirklichkeit. Die ,Rassenkonstruktion“ wird einzig zur Abgrenzung, Ausgrenzung sowie Diskriminierung von Menschengruppen benutzt und konzipiert in ihrer Gesamtheit die Wirklichkeit des Rassismus. ${ }^{184}$ Gesellschaft und soziales Milieu generieren ,die Fremden', die Anderen', die Minderwertigen' eigenständig. Rassismus wird demnach alleine im sozialen und gesellschaftlichen Kontext erzeugt und reproduziert - ,Rasse ${ }^{6}$ kann so als ,ideologisches Konstrukt ${ }^{\text {"185 }}$, als „soziale Kategorie“"186, als Praxisform des Rassismus angesehen werden. ${ }^{187}$ Auch die Sozialwissenschaftlerin Mona Singer folgert diesbezüglich, dass „,Rasse“ im weiteren Sinne [...] über die morphologisch-physiognomischen Kennzeichen hinaus [geht] [...].“"188 - sie identifiziert ein von der Gesellschaft erschaffenes und etabliertes „Unterdrückungssystem“189. Der Rassismus bestreitet also zwar nicht vorrangig das Mensch-Sein von spezifischen Menschengruppen, vollzieht aber ihre systematische Abwertung aufgrund ihrer angeblichen primär biologischen Andersartigkeit - er entzieht ihnen damit faktisch ihre Menschenwürde. ${ }^{190}$

179 Geulen 2007, a. a. O., S. 91.

180 Vgl. Geulen 2007, a. a. O., S. $91 \mathrm{ff}$.

181 Miles 1999, a. a. O., S. 99.

182 Miles 1999, a. a. O., S. 100.

183 Glanninger 2009, a. a. O., S. 34.

184 Vgl. Kalpaka, Annita/Räthzel, Nora (1994c): Wirkungsweisen von Rassismus und Ethnozentrismus, in: ebd. (Hrsg.): Die Schwierigkeit, nicht rassistisch zu sein. Rassismus in Politik, Kultur und Alltag, Köln, S. 13ff.

185 Cohen, Philip (1994): Gefährliche Erbschaften: Studien zur Entstehung einer multirassistischen Kultur in Großbritannien, in: Kalpaka, Annita/Räthzel, Nora (Hrsg.): Die Schwierigkeit, nicht rassistisch zu sein. Rassismus in Politik, Kultur und Alltag, Köln, S. 97.

186 Dettmar 1987, a. a. O., S. 43.

187 Vgl. Kalpaka/Räthzel 1994c, a. a. O., S. 14ff. | Vgl. Anthias 1992, a. a. O., S. 90.

188 Singer 1997, a. a. O., S. 56.

189 Bojadžijev, Manuela (2008): Die windige Internationale. Rassismus und Kämpfe der Migration, Münster, S. 55.

190 Vgl. Geiss 1988, a. a. O., S. 35.

Im Zeitalter des Nationalsozialismus muss jedoch neben einer entmenschlichenden Praxis gegenüber der jüdischen Bevölkerung - dem Tod durch Zyklon B - auch eine entmenschlichende Sprache - die Juden' als , Ungeziefer'- festgestellt werden. 
Abschließend kann so vor dem Hintergrund der rassistischen Ideologie festgehalten werden, dass speziell die Biologie nach wie vor eine nicht zu unterschätzende Rolle im Erklärungssystem des Rassismus einnimmt. Obwohl der biologistische Deutungsansatz des Rassismus und das ,Rassephänomen“ ihren Schwerpunkt im 19. sowie der ersten Hälfte des 20. Jahrhunderts - dem , [...] Jahrhundert des Sozialdarwinismus [...]"191 - hatten, zeigen sich multiple biologistische, rassistische Vorurteile noch bis heute präsent (s. Kapitel 3). ${ }^{192}$ Die Biologie bleibt als quasi-wissenschaftliche Grundlage des Rassismus sowie des ,Rassekonzeptes ein wichtiger Bestandteil, was sich auch an der im 21. Jahrhundert noch zum Teil kontrovers diskutierten, naturwissenschaftlichen Rassismusforschung zeigt (s. Kapitel 5). ${ }^{193}$ Die Biologie wird auch weiterhin einen essentiellen Kristallisationspunkt des Rassismusphänomens darstellen, insbesondere, wenn auch in der heutigen Zeit eher indirekt und verdeckt, die Lehre der sogenannten ,reinen Rassen ' als Visualisierung der angeblichen biologischen Überlegenheit spezifischer Menschengruppen. ${ }^{194}$ Bei der Betrachtung des Forschungshintergrundes wird hier nochmals deutlich, dass der ,Rassebegriff' keine einheitliche Definition aufweist, so dass eine ,[...] , größtmöglichste [sic!] Meinungsverschiedenheit' [...]“195 auch bei den Vertreterinnen und Vertretern des Rassismus existiert. Eine detaillierte Analyse dieser ,Rassenproblematik' aus biologischer Perspektive erfolgt im weiteren Verlauf (s. Kapitel 5). Das Konstrukt der ,Rasse“ bleibt resümierend im Rahmen des Rassismus „,[...] eines der konstitutiven Elemente der biologisierenden (szientifisch-naturalistischen) Ideologie der gegenwärtigen Gesellschaften." "196

\subsubsection{Rassismus - Versuch einer begrifflichen Eingrenzung}

Oftmals wird der Rassismusbegriff, insbesondere im 21. Jahrhundert seitens der politischen Führungsebene, mit Synonymen ersetzt, beispielsweise ,Ausländerfeindlichkeit', ,Fremdenfeindlichkeit', ,Xenophobie' oder ,Ethnozentrismus'. Sicherlich zeigen alle diese Begrifflichkeiten vielfältige Überschneidungen und Ähnlichkeiten (s. Kapitel 1). Obwohl das Rassismuskonstrukt „[...] als Begriff schwer abgrenzbar ist. “197, ist es nichtsdestotrotz aus sozialwissenschaftlicher Perspektive notwendig, um den Begriff nicht zu verfälschen. Auch auf der internationalen

191 Dittrich, Eckhard J./Radtke, Frank-Olaf (1990): Der Beitrag der Wissenschaften zur Konstruktion ethnischer Minderheiten, in: ebd. (Hrsg.): Ethnizität. Wissenschaft und Minderheiten, Opladen, S. 19.

192 Vgl. Dittrich/Radtke 1990, ebd., S. $19 \mathrm{ff}$.

193 Vgl. Solomos, John (2002): Making sense of racism: Aktuelle Daten und politische Realitäten, in: Bojadžijev, Manuela/Demirović, Alex (Hrsg.): Konjunkturen des Rassismus, Münster, S. $158 \mathrm{ff}$.

194 Vgl. Glanninger 2009, a. a. O., S. 29f. | Vgl. Weingart 1992, a. a. O., S. 23.

195 Geiss 1988, a. a. O., S. 38.

196 Guillaumin 1992, a. a. O., S. 84.

Die biologische Seite bleibt hierbei mit verschiedenartigen Facetten variantenreich, als praktische Haltung, als rechtliche Struktur oder als politisches Projekt. Vgl. Guillaumin 1992, a. a. O., S. 84f.

Rommelspacher 2009, a. a. O., S. 33. 
Ebene scheint eine eindeutige Abgrenzung des Rassismusbegriffes komplex. ${ }^{198}$ Die genannten Äquivalente sind sicherlich nicht klar vom Rassismusbegriff zu unterscheiden - es sind jedoch Abwandlungen und Variationen vorhanden, die definitorisch zwar Parallelen enthalten, aber deutlich differenziert werden müssen. ${ }^{199}$

Trotz aller Herausforderungen kommt eine wissenschaftliche Untersuchung nicht umhin, eine begriffliche Abgrenzung bzw. Eingrenzung des Rassismusbegriffes anzustreben, um eine eindeutige Arbeitsgrundlage für die weitere Analyse des heutigen Rassismusphänomens in Deutschland zu ermöglichen bzw. zu erleichtern (s. Kapitel 2.2.4). Auf sozialwissenschaftlicher Ebene wird vielfach vor einer synonymen Verwendung der skizzierten Ersatztermini gewarnt. Publizist Wieland Elfferding mahnt vor allem eine begriffliche Trennung der in Deutschland häufig fälschlicherweise parallel gebrauchten Begriffe Fremden-, Ausländerfeindlichkeit und Xenophobie an. ${ }^{200}$ Auch zwischen Rassismus und dem Konstrukt des Ethnozentrismus ist eine eindeutige Differenzierung unabdingbar:

\section{„Die entscheidende Differen z zwischen beiden Phänomenen besteht darin, dass im Ras- sismus die Verschiedenheit anderer Gruppen als nicht oder kaum veränderlich angesehen wird, während beim Ethnozentrismus die Übernabme der eigene Werte durch die Fremdgruppen als durchaus möglich erachtet wird. "201}

Der Ethnozentrismus definiert Kultur und Sozialisation als zentrale Merkmale von ähnlichen Menschengruppen, konstatiert jedoch gleichzeitig, dass sich spezifische Menschengruppen auch durch ihren biologischen Selbsterhalt bzw. ihre Fortpflanzung charakterisieren.202 Primär sind jedoch soziale Faktoren für die Angehörigkeit zu spezifischen ethnischen Gruppen ausschlaggebend; kulturelle Eigenschaften dienen theoretisch nicht als Unterscheidungsmerkmal, ohne diese sind jedoch Verwandtschaftsbeziehungen schwierig zu konstruieren. ${ }^{203}$ Nichtsdestotrotz werden die vom Ethnozentrismus fokussierten sprachlichen und kulturellen Abgrenzungscharakteristika von Menschengruppen schon durch das pseudobiologische Konstrukt der ,Rasse“ eingeschlossen (s. Kapitel 2.1.2). ${ }^{204}$ Der Ethno-

\footnotetext{
198 Vgl. Bojadžijev 2008, a. a. O., S. 28.

199 Vgl. Kerner 2009, a. a. O., S. 59.

200 Vgl. Elfferding 1989, a. a. O., S. $106 \mathrm{ff}$.

201 Zerger 1997, a. a. O., S. 90.

202 Vgl. Barth, Fredrik (1998): Ethnic Groups and Boundaries. The Social Organization of Culture Difference, Long Grove/Illinois, S. 6, $10 \mathrm{ff}$.

203 Vgl. Barth 1998, a. a. O., S. 13ff, 38, 84, 99.

Ethnische Gruppen definieren sich als eine Form sozialer Organisation, die von Einflüssen aus Politik, Wirtschaft, Umwelt und Gesellschaft abhängig sind. Aufgrund dieser multiplen Einflussfaktoren ist eine direkte Übertragung von ethnischen Gruppen auf spezifische kulturelle Differenzen nicht möglich bzw. nicht ausreichend zu begründen. Die Fragen um ethnische Gruppen sind demnach nicht einfach zu lösen, da ein vielfältiges Spektrum an ethnischen Grenzen sowie inter-ethnischen Beziehungen existiert. 
zentrismus-Begriff kennzeichnet sich folglich durch eine fehlende Trennschärfe und ist demnach im Rahmen dieser Untersuchung nicht zu gebrauchen. ${ }^{205}$

Auch bezüglich der Fremden- und Ausländerfeindlichkeit sowie der Xenophobie ist eine eindeutige Trennung zum Rassismusbegriff anzumahnen. Insbesondere beim Terminus der Xenophobie liegt die Fokussierung eher auf den Bedrohungsängsten, die durch andere Menschengruppen ausgelöst werden. ${ }^{206} \mathrm{Hinzu}$ kommend existieren ebenso in der vorhandenen Standardliteratur nur ungenaue Definitionen sowie begriffliche Annäherungen. Ein ähnliches Fazit zieht Johannes Zerger auch für die Begriffe Fremdenfeindlichkeit und Ausländerfeindlichkeit: Fremdenfeindlichkeit umfasst vielfältige und unterschiedliche Formen der Ablehnung, Ausgrenzung und Diskriminierung ausländischer Mitbürgerinnen und Mitbürgern. ${ }^{207}$ Diese werden schon allein durch die Begrifflichkeit ,Fremde` als ,fern der Heimat' sowie ,anders' wahrgenommen. ${ }^{208}$

„Die entscheidende Differenz zwischen Fremdenfeindlichkeit und Rassismus sehe ich vor allem darin, dass die Begründungen der ablehnenden Haltung bei der Fremdenfeindlichkeit unspezifischer sind und weder der Zuschreibung noch der Bewertung spezifischer Merkmale der Fremdgruppe bedürfen. "209

Auch der Begriff Ausländerfeindlichkeit kann ,,[...] nicht einfach durch den Rassismusbegriff ersetzt werden [...], weil entscheidende Kriterien des Rassismus in der Ausländerfeindlichkeit nicht vorhanden sein müssen. Da der Begriff in allgemeiner Verwendung zu unpräzise ist, sollte seine Anwendung auf den Bereich beschränkt bleiben, bei dem die Staatsangehörigkeit tatsächlich das entscheidende Kriterium von Ablehnung oder Ausschlussmechanismen bildet [... $]^{\text {‘"210. }}$.

Hinzukommend muss auch eine differenzierte Verwendung der Begrifflichkeiten Antisemitismus und Rassismus angemahnt werden, obwohl bezüglich beider Theorien Parallelen erkennbar sind. Hinsichtlich beider Phänomene ist so eine schwierige Theoriefindung zu konstatieren, die auf der gewandelten bürgerlichen Gesellschaft und damit einhergehend auch auf den veränderten antisemitischen bzw. rassistischen Ressentiments basiert. ${ }^{211}$ Der Antisemitismus muss darüber hinausgehend jedoch als integrativer Teil der modernen Gesellschaft, als „,...] negative Leitidee der Moderne [... $]^{\text {“212 }}$, wie Politikwissenschaftler Samuel Salzborn ihn charakterisiert, verstanden werden, der sich grundlegend vom vormodernen Antijudaismus unterscheidet und aufgrund seiner Vieldimensionalität nicht an sozialstrukturelle oder ökonomische Entwicklungen gekoppelt ist. ${ }^{213}$ Sowohl

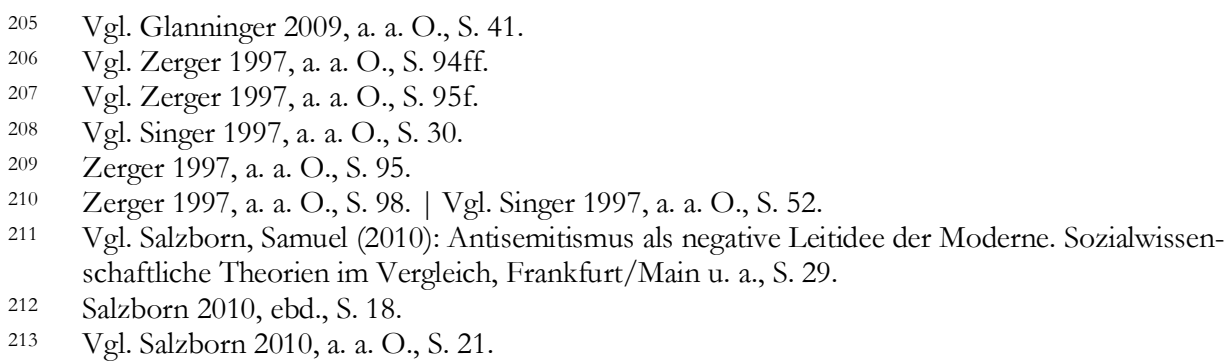


diese Verknüpfung von Antisemitismus und Moderne, die auch Max Horkheimer und Theodor W. Adorno konstatieren, als auch die bewusste Wahl bzw. die bewusste Fokussierung auf die jüdische Bevölkerung im Rahmen des Antisemitismus verbieten eine theoretische Gleichsetzung von Rassismus und Antisemitismus. ${ }^{214}$

Die politische und gesellschaftliche Realität in der Bundesrepublik zeigt so eine Vermischung bzw. eine Umschreibung des Rassismusphänomens durch beschönigende Ersatztermini wie Ausländer- und Fremdenfeindlichkeit, da die Tabuisierung des Rassismusbegriffs immer noch anhält (s. Kapitel 2). ${ }^{215}$ Ein Ersatz oder gar eine perspektivische Verdrängung des Rassismusbegriffes, beispielsweise durch die angesprochenen Ersatztermini, ist jedoch aufgrund der teilweise diametralen begrifflichen und definitorischen Differenzen nicht zielführend, da jeweils unterschiedliche soziale und politische Phänomene illustriert werden. ${ }^{216}$ Die Alternativbegrifflichkeiten treffen das Phänomen des Rassismus größtenteils nicht und sind sogar eher irreführend. ${ }^{217}$ Trotz des von Sozialforscher Ulrich Bielefeld diagnostizierten Nachkriegstabus des Rassismus- und ,Rassebegriffs“ scheinen beide nach wie vor die brauchbarsten Begrifflichkeiten zur eindeutigen Beschreibung und Identifizierung des Phänomens. ${ }^{218}$

Die aufgezeigten Nuancen, Facetten und Besonderheiten des Rassismus bestätigen so dessen Disziplinen übergreifende, flexible, wandelbare und vielfältige ideologische Charakteristika. Er integriert demzufolge beispielsweise einerseits die Gedanken einer biologischen Ungleichheit und angeblichen Reinheit von sogenannten ,Menschenrassen' sowie andererseits eine damit zusammenhängende Hierarchisierung von Menschengruppen aufgrund pseudowissenschaftlicher Unterscheidungsmerkmale. ${ }^{219}$,Rasse' zeigt sich hierbei als zentrales, konstitutives Element, als Phantasma der rassistischen Ideologie.220 Nicht vergessen werden

Antisemitismus kann damit nicht, nur' als ein Bestandteil der modernen Gesellschaft begriffen werden, sondern ist mit dieser unzertrennbar verbunden. Hannah Arendt zitierend, skizziert Samuel Salzborn vor dem Hintergrund des aktuell forcierten Entwicklungsprozesses des Antisemitismus eine Entkopplung der antijüdischen Ressentiments von der gesellschaftlichen Realität: Der Antisemitismus der Moderne basiert so im Unterschied zum vormodernen Antijudaismus auf einer potenzierten Abstraktionsleistung. Antisemitische Argumentationen basieren nicht mehr auf, realen 'Jüdinnen und Juden, sondern auf von antisemitisch argumentierenden Personen konstruierten , [...] fiktiven, völkisch fremd bestimmten ,Juden ' [...]“. (Vgl.) Salzborn 2010, a. a. O., S. 317f., 320.

214 Vgl. Salzborn 2010, a. a. O., S. 317, 322ff.

215 Vgl. Kalpaka/Räthzel 2000, a. a. O., S. 178ff.

216 Vgl. Glanninger 2009, a. a. O., S. $24 \mathrm{ff}$.

217 Vgl. Singer 1997, a. a. O., S. 51.

218 Vgl. Singer 1997, a. a. O., S. $53 \mathrm{ff}$.

219 Vgl. Rieger 2005, a. a. O., S. 811.

220 Vgl. Guillaumin 1992, a. a. O., S. 84.

Imanuel Geiss entriffert in diesem Zusammenhang mehrere zentrale, verwandte Elemente des Rassismus: Die Xenophobie als eine auf, Rassen' bezogene Fremdenfeindlichkeit; die Endogamie mit dem Ziel der, Reinheit des Blutes' und der Verbinderung der angeblichen Degeneration von ,Menschenrassen' durch ,Blutmischung; die Hierarchisierung von Menschengruppen aufgrund deren ethnischen Eigenschaften; sowie die Sklaverei in ihren unterschiedlichen Rassismus fördernden V arianten. Aus heutiger Perspektive kann die vorangegangene Auflistung noch mit weiteren Faktoren ergänそ̨t werden, die in ibrer Gesamtheit als Erklärungsphänomene für 
darf vor diesem Hintergrund auch die Bedeutung der Sprache als Charakteristikum des Rassismus. Denn gerade mit sprachlichen Ausdrucksformen lassen sich gesellschaftliche und soziale Missstände besonders naturalisieren und damit der alltägliche Rassismus forcieren. ${ }^{221}$ Die Sprache trägt somit als kulturelles Merkmal zur Legitimation und Regeneration des alltäglichen Rassismus bei. 222 Diesbezüglich können vielfältige sprachliche Rassismen in den europäischen Alltagssprachen diagnostiziert werden. 223 Mit Léon Poliakov bleibt so zu folgern, dass die Ideologie des Rassismus definitiv nicht auf wissenschaftlichen Grundlagen basiert, sondern eine Art ,Übersetzung“ der zwischen den Menschen bestehenden kulturellen Konflikte in naturgegebene bzw. biologische Konflikte darstellt. ${ }^{224}$

Auch der Politikwissenschaftler und Soziologe Pierre-André Taguieff differenziert resümierend unterschiedliche Perspektiven in der Ideologie des Rassismus: Auf der einen Seite die Sichtweise des ,,[...] Rassismus als Weltanschauung oder Metaphysik der Geschichte [... “ $]^{\text {¿225 }}$ sowie auf der anderen Seite die Perspektive des Rassismus als zukunftsorientiertes, gesellschaftliches und politisches Ideal mit dem Ziel der Umgestaltung der Bevölkerung auf der Grundlage eines diskriminierenden ,Rassen'-, Werte- und Normensystems. ${ }^{226}$ So kann der heutige Rassismus trotz seiner unterschiedlichen Ausprägungen vielfach als ,[...] eine Frage des Andersseins.“"227, als „[...] Bestätigung der Differenz [...]“228 zwischen Menschen sowie als ,rassenbildende‘ Behandlung anderer Gruppen mit dem Ziel der Ausgrenzung, Abgrenzung oder Eliminierung dieser begriffen werden. ${ }^{229}$ Rassismus war, ist und bleibt auch zukünftig ein komplexes, biologisch konnotiertes Phänomen, welches keine eindeutige definitorische Zuordnung ermöglicht. ${ }^{230}$

die Entstehung und Wirkung des Rassismus herangezogen werden können (s. Kapitel 4). Vgl. Geiss 1988, a. a. O., S. $27 \mathrm{ff}$.

221 Vgl. Jäger, Siegfried (1992a): Alltäglicher Rassismus in Deutschland. Erste Ergebnisse einer diskursanalytischen Studie, in: Jäger, Siegfried/Januschek, Franz (Hrsg.): Der Diskurs des Rassismus. Ergebnisse des DISS-Kolloquiums November 1991, Osnabrück, S. 135.

Vgl. Skutnabb-Kangas, Tove/Phillipson, Robert (1992): Linguizismus, in: Institut für Migrations- und Rassismusforschung e. V. (Hrsg.): Rassismus und Migration in Europa. Beiträge des Kongresses „Migration und Rassismus in Europa“ Hamburg, 26. bis 30. September 1990, Hamburg, S. 204. | Vgl. Arndt/Ofuatey-Alazard 2011b, a. a. O., S. 11. | Vgl. Stefanowitsch, Anatol (2012): Sprache und Ungleichheit, in: Aus Politik und Zeitgeschichte, Beilage zur Wochenzeitung Das Parlament, 16-17/2012, 62. Jahrgang, Bonn, S. 27.

Die Herstellung von Unterscheidungen oder Kategorien ist eine Hauptfunktion von Sprache. Die deutsche Sprache gilt als wesentlicher Bestandteil bezüglich der Reproduktion des Rassismusphänomens sowie der rassistischen Ideologie. Nur durch die regelmäßige Anwendung rassistischer Sprachbestandteile und -muster im Wissenschafts- und Gesellschaftsalltag werden rassistische Argumentationsansätze sukzessive abermals etabliert. Vgl. Arndt/Ofuatey-Alazard 2011b, a. a. O., S. $11 \mathrm{ff}$.

223 Vgl. Geiss 1988, a. a. O., S. 18.

224 Vgl. Poliakov et al. 1992, a. a. O., S. 166.

225 Taguieff 2000 , a. a. O., S. 29.

226 Vgl. Taguieff 2000, a. a. O., S. $29 \mathrm{ff}$.

227 Guillaumin 1992, a. a. O., S. 85.

228 Taguieff 2000 , a. a. O., S. 39.

229 Vgl. Taguieff 2000, a. a. O., S. $37 \mathrm{ff}$.

230 Vgl. Poliakov et al. 1992, a. a. O., S. 145. 
Hier sollen nachfolgende Kapitel mit einem exemplarischen Blick über für das 21. Jahrhundert relevante Rassismustheorien und -definitionen anknüpfen, um multiple Beispiele einer begrifflichen Engführung zu demonstrieren. Aufgrund der Einengung des Rassismusbegriffes dieser Arbeit auf biologische Schwerpunkte stehen insbesondere biologisch-genetisch argumentierende Rassismuskonzepte im Vordergrund (s. Kapitel 2.2.4).

\subsection{Rassismustheorien: Eine exemplarische Übersicht}

Im vorhergehenden Kapitel wurde ersichtlich, dass der Begriff Rassismus eine große Flexibilität, Wandelbarkeit und Anpassungsfähigkeit aufweist. Je nach zeitlicher Epoche und Anwendungsgebiet des Rassismusphänomens, ändern sich auch partiell seine Erklärungs- und Deutungszusammenhänge. Da die Erforschung des Rassismusphänomens in den vergangenen Jahrzehnten vielfältige Rassismusdefinitionen und -Theorien hervorgebracht hat, ist es nicht möglich diese im Rahmen der vorliegenden Arbeit vorzustellen. In diesem Zusammenhang sind die „[...] Vielfältigkeit der rassismustheoretischen Debatte [...]“231 und die multiplen ,,[...] [unterschiedlichen] Möglichkeiten, sich dem Phänomen Rassismus zu nähern. "232 zu konstatieren. Aus diesem Grund werden lediglich die wichtigsten Rassismustheorien den pseudobiologischen Begründungszusammenhang betreffend fokussiert, die gleichzeitig die prägnantesten Theorien des 20. Jahrhunderts darstellen. Die Rassismusforschung des 21. Jahrhunderts greift größtenteils auf diese Analyseansätze zurück, da hier vielfach noch keine weiterführenden Forschungsarbeiten vorhanden sind. Im primären Fokus stehen daher im Folgenden die Theorien von Robert Miles, Albert Memmi, Étienne Balibar und Pierre-André Taguieff. ${ }^{233}$ Hierbei muss zwischen engeren und weiteren Rassismusdefinitionen unterschieden werden, wobei beide Vor- und Nachteile aufweisen. Wie schon mehrmals aufgezeigt, scheint eine zu weite, zu viele rassistische Perspektiven integrierende Definition überfordert sowie mit einer mangelnden Trennschärfe versehen. Jede Diskriminierung als rassistisch zu bezeichnen verfehlt den dargestellten ideologischen Kern des Rassismus, sodass definitorische Mischformen wahrscheinlich sind. ${ }^{234}$ Andererseits zeigen sich Forschungsansätze mit weiteren begrifflichen Konturen auf ein breiteres Spektrum der rassistischen Alltagsbeobachtungen anwendbar. ${ }^{235}$ Demgegenüber favorisieren enge Rassismusdefinitionen eine Fokussierung und Präzisierung des Begriffes. Sowohl der engere als auch der weiter gefasste Rassismusbegriff haben im gesellschaftlichen und politischen Umfeld jedoch ihre Legitimation.

231 Kerner 2009, a. a. O., S. 56.

232 Kerner 2009, a. a. O., S. 56.

233 Weitere wichtige Rassismustheorien brw. Beiträge zur neueren Rassismusdebatte stammen unter anderem von Detlef Claussen, Annita Kalpaka, Ina Kerner, Léon Poliakov, Nora Räthzel, Mark Terkessidis und Johannes Zerger.

234 Vgl. Singer 1997, a. a. O., S. 55.

235 Vgl. Kerner 2009, a. a. O., S. 57 ff. 


\subsubsection{Robert Miles}

Der Soziologe und Politikwissenschaftler Robert Miles hat die Rassismusforschung mit seinen Untersuchungs- und Analyseansätzen am Ende des 20. Jahrhunderts nachhaltig geprägt. Er kann zu den Vertretern der enger gefassten Rassismusdefinitionen gezählt werden. Miles warnt eindringlich vor einer zu starken Erweiterung des Rassismusbegriffes, insbesondere im Zusammenhang mit den kulturbezogenen, neorassistischen Forschungsansätzen der 1990er Jahre, die er als „[...] begrifflich[e] Inflation [...]“236 charakterisiert. Miles kritisiert die teilweise Überdehnung des Rassismusbegriffes, die zu einer ,„[...] unscharfen Verwendung

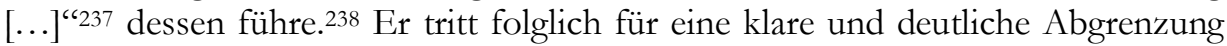
von den in den 1980er und 1990er Jahren vorherrschenden weiten, überdehnten Begriffsbestimmungen ein, vor allem unter Fokussierung des eigentlichen, biologistischen Kerns der rassistischen Ideologie. ${ }^{239}$ Alle eher kulturellen und sozialen Formen des Rassismusphänomens ohne konkrete Bezugnahme auf das biologische Konstrukt der ,Rasse“ verortet Miles als Ethnozentrismus. Dies führt in der Folge zu einer eindeutigen Abgrenzung des Rassismusbegriffes: Miles unterscheidet klar zwischen dem biologistisch begründeten, auf dem Konzept der ,Rasse ${ }^{6}$ basierenden, Rassismus auf der einen Seite und dem eher kulturell begründeten Rassismusphänomen auf der anderen Seite. ${ }^{240}$ Er plädiert so für eine eindeutige Fokussierung und Beschränkung des Rassismusbegriffes einzig auf phänotypische und genotypische Merkmalszuschreibungen bei Menschengruppen. Das ,Rassekonstrukt ${ }^{`}$ stellt für Miles folglich die zentrale begriffliche Basis des Rassismus dar. ${ }^{241}$

Die Entstehung des Rassismus sowie der ,Rasse' als kategoriales System zur Einordnung und Hierarchisierung von Menschengruppen verortet Miles in der sogenannten ,Rassenkonstruktion“ (s. Kapitel 2.1). Diese wird durch die Kombination von vornehmlich biologischen Merkmalen gebildet. ${ }^{242}$

\section{„Ich verwende von daher den Begriff der Rassenkonstruktion für jene Fälle, in denen ge- sellschaftliche Beziehungen zwischen Menschen durch die Bedeutungskonstruktion biolo- gischer Merkmale dergestalt strukturiert werden, dass sie differenzierte gesellschaftliche Gruppen definieren und konstruieren. "243}

Miles verdeutlicht so grundlegend, dass die ,Rassenklassifizierung' des Homo sapiens auf keiner wissenschaftlich validierten Basis existiert. Darauf aufbauend verbietet sich ebenfalls eine Verknüpfung rassistischer Theoreme mit biologischen Erkenntnissen - es bestehen keinerlei Zusammenhänge zwischen Biologie und Na-

\footnotetext{
236 Glanninger 2009, a. a. O., S. 20.

237 Terkessidis 1998, a. a. O., S. 71.

238 Vgl. Terkessidis 1998, a. a. O., S. $71 \mathrm{ff}$.

239 Vgl. Kerner 2009, a. a. O., S. 51.

240 Vgl. Kerner 2009, a. a. O., S. $51 \mathrm{ff}$.

241 Vgl. Kerner 2009, a. a. O., S. $52 \mathrm{ff}$.

242 Vgl. Terkessidis 1998, a. a. O., S. $72 \mathrm{ff}$.

243 Miles 1999, a. a. O., S. 100.
} 
tur einerseits sowie Gesellschaft, Sozialstruktur und Realität andererseits. „,Rassen“ sind gesellschaftliche Fiktionen, keine biologischen Realitäten." 244 Sie beruhen einzig und allein auf der phantasmatischen Zuschreibung von negativ konnotierten, scheinbar realen oder fiktiven biologischen sowie genetischen Faktoren auf spezifische Menschengruppen, so dass auf dieser Grundlage ein ,rassifiziertes“, hierarchisiertes Gruppengefüge legitimiert werden kann. ${ }^{245}$ Daher kann der Rassismus als ein rein ideologisches Konstrukt bezeichnet werden (s. Kapitel 2.1). ${ }^{246}$ Die Realisierung der fiktiven ,Rassenkonstruktion' stellt dabei eine Hauptkomponente des Rassismus dar. ${ }^{247}$

Vor diesem Hintergrund identifiziert Robert Miles zusätzlich sechs Hauptmerkmale des Rassismus, die diesen gemeinsam generieren: Der Prozess der ,Rassenkonstruktion'; die Zuschreibung von negativ konnotierten Eigenschaften gegenüber bestimmten ,rassifizierten' Gesellschaftsgruppen; die Reflektion der Darstellung der ,anderen' auf sich selbst; die ,praktische Angemessenheit“"248 des Rassismus; sowie die Wandelbarkeit und Anpassungsfähigkeit des rassistischen Phänomens. ${ }^{249}$

Der in den 1990er Jahren begonnenen Verschiebung der Analyseansätze des Rassismus weg von der direkt biologischen Konnotation sowie dem ,Rassekonstrukt', hin zu einem - jedoch größtenteils ebenfalls biologisierten und naturalisierten - kulturellen, ethnischen Erklärungsmodell, steht Miles äußerst kritisch gegenüber. Die begriffliche Ausdehnung des Rassismus auf den sogenannten Neorassismus oder ,Rassismus ohne Rassen“ der 1990er Jahre lehnt er vehement ab. ${ }^{250}$ Er identifiziert diese Entwicklungen als „,...] formal nicht-rassistische Diskurse [...].“251 Auf sozialen oder kulturellen Faktoren beruhende Ausgrenzungsund Abwertungspraktiken sieht Miles demzufolge nicht als integralen Bestandteil des Rassismusphänomens an, da diese nur auf die ideologische Kern-Dimension beschränkt bleiben, nicht aber die biologische Dimension fokussieren. ${ }^{252}$ Zusammenhänge und Überlappungen seien zwar möglich, jedoch existiere keine direkte Verknüpfung. ${ }^{253}$ Robert Miles‘ Rassismusansatz beschränkt sich folglich vollkommen auf den mit biologistischen Faktoren begründeten Rassismus und grenzt die neorassistisch-kulturelle Rassismuskomponente sowie den sogenannten ,Rassismus ohne Rassen“ komplett aus. ${ }^{254}$ Dies beschneidet zwar „[...] selbst die Reichweite [...] seiner Aussagekraft." ${ }^{255}$, wie die Sozialwissenschaftlerin Ina Ker-

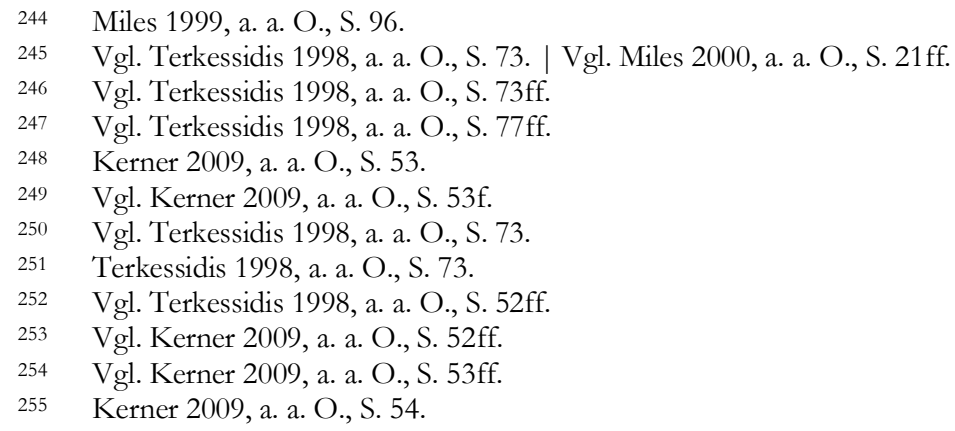


ner kritisiert, ermöglicht jedoch eine präzise, definitorische Klarheit. Da darüber hinausgehend die kulturellen Erklärungsfaktoren oftmals wiederum naturalisiert bzw. biologisiert werden - ohne selbstverständlich den tabuisierten ,Rassebegriff zu gebrauchen - scheint Robert Miles‘ enggeführter Ansatz als eine praktikable und logische Ausgangsbasis für eine Rassismusanalyse mit biologischem Schwerpunkt (s. Kapitel 2.1.2).

\subsubsection{Albert Memmi}

Auch der französische Rassismusforscher Albert Memmi gehört zu den profiliertesten Rassismusforschern des 20. Jahrhunderts, ebenfalls in der bundesrepublikanischen Rassismusdebatte. Für das Verständnis seiner theoretischen Arbeiten ist es wichtig zu wissen, dass seine persönlichen Hintergründe zur Erforschung des Rassismusphänomens auf den Ereignissen des französischen Kolonialismus sowie des französischen Antisemitismus basieren. ${ }^{256}$ Der Soziologe Detlev Claussen beschreibt die Rassismusforschung somit als „Lebensthema“257 Memmis und sein Wirken als „Grundlegung““258 der Rassismusanalyse.

„Ihm gelingt [...] das Kunststück, den Rassismus nicht zu eng als Vorurteil oder Legitimation eines Vorteils noch zu weit als eine Allergie gegen alles andere zu fassen. "259

Insbesondere die individuellen Erfahrungen mit ,anderen` Menschen stellt Memmi in den Fokus seiner Rassismusdefinition. ${ }^{260}$ Das negative Verhalten sogenannter Rassisten gegenüber diskriminierten Menschengruppen typisiert er als rassistisches Vorgehen, um dadurch ein scheinbar gefährdetes bzw. verlorenes Gleichgewicht zwischen ,Einheimischen“ und ,den Anderen“ herzustellen. ${ }^{261}$ „Der Rassismus ist

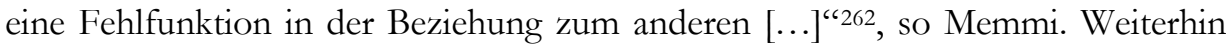
geht er, ähnlich wie Robert Miles, von einer Rassismuskonstruktion durch das gesellschaftliche und soziale Umfeld aus: „Der Rassismus beginnt erst mit der Interpretation der Unterschiede [...]."263 Folglich werden rassistische Vorurteile und Ressentiments erst durch die, über die bloße Wahrnehmung von biologischen oder kulturellen Unterschieden hinausgehende, Interpretation dieser festgestellten Differenzen generiert. 264 Die wahrgenommenen, gesellschaftlich konstruierten Unterschiede stellen so die Hauptmerkmale des alltäglichen Rassismus dar. Jedoch konstruiert nicht das bloße Vorhandensein der Unterschiede, sondern erst die Interpretation, Wertung und Anwendung dieser Unterschiede auf die Diskriminierung anderer sowie, damit zusammenhängend die eigene Vorteilsnahme, das Prin-

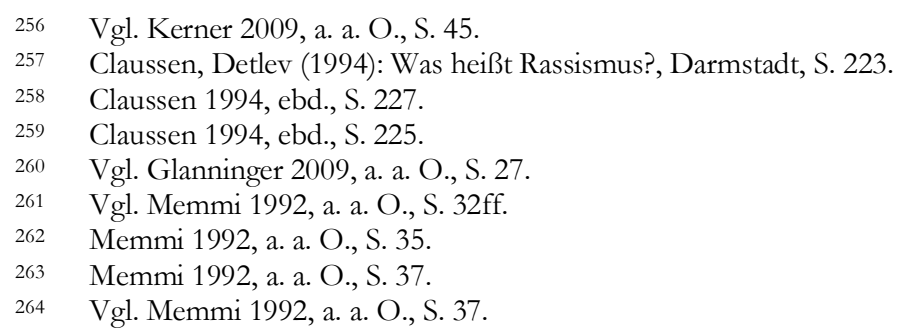


zip des Rassismus. ${ }^{265}$ Die Feststellung von Differenzen und Unterscheidungsmerkmalen zwischen Menschengruppen ist laut Memmi also eines der Hauptelemente des Rassismus. ${ }^{266}$ Wichtig dabei: „Die Differenzen, die zum Zweck der Begründung solcher Ungleichbehandlungen und Ausschlüsse herangezogen werden, können [...] faktisch bestehen [...] oder aber fiktiv sein. "267 Zusätzlich bedeutet Rassismus nach Memmi jedoch auch Angst:

„Der Rassist ist ein Mensch der Angst hat; er hat Angst, weil er der Angreifer ist, und er greift an, weil er Angst hat; ein Mensch, der Angst vor einem potentiellen Angriff hat oder glaubt, man greife ibn tatsächlich an; der schließlich angreift, um seine Angst zu bannen. [...] Wie man sieht, ist die Behauptung der Rasse ein Mittel zu dieser Behauptung des Ichs. "268

Darüber hinausgehend sei Rassismus jedoch nicht nur eine individuelle Erfahrung und Einstellung, sondern vielmehr eine gemeinsam gelebte, von vielen geteilte Erfahrung. Erst im gesellschaftlichen und sozialen Kontext könne sich das Phänomen des Rassismus voll entfalten - es besteht folglich primär aus gesellschaftlichen, kulturellen und teilweise auch historischen Elementen. ${ }^{269}$ Gemeinsam wird anhand von rassistischen Erklärungs- und Argumentationsansätzen die ,Sündenbockfunktion' der ,anderen' erschaffen. ${ }^{270}$ Mithilfe des Rassismus wird folglich versucht, ein Positiv-Negativ-Schema bzw. ein Überlegenheits-UnterlegenheitsSchema zu konstruieren, welches sich zeitneutral in Vergangenheit, Gegenwart und Zukunft auf eine bestimmte Gesellschaftsgruppe generalisieren und verabsolutieren lässt: Die ,anderen' weichen von einer festgelegten Norm ab. ${ }^{271}$
„Der Antisemit geht von der unterstellten Geldgier dieses oder jenes Juden aus, um zu dem Schluss zu gelangen, dass alle Juden habgierig seien, oder er befindet, man könne keinem einzigen Juden trauen, weil alle habgierig seien. Derselbe Mechanismus greift im Hinblick auf die notorische Faulheit des Kolonialisierten oder die Gewalttätigkeit der Schwarzen." 272

Trotzdem steht auch Albert Memmi vor dem Hintergrund einer definitorischen Begriffsbestimmung vor dem Dilemma des weiter oder enger zu fassenden Rassismusbegriffs. Beide Seiten weisen Gefahren auf: Bei einer zu weiten Fassung des Rassismus verliert er seinen besonderen Erklärungsstatus, bei einer zu engen Fassung besteht hingegen die Gefahr, dass grundlegende Elemente der Begriffsrealität unbeachtet bleiben. ${ }^{273}$ Eine Synthese von enggeführter und weiter Rassismusdefinition könnte nach Memmi wie folgt aussehen:

\footnotetext{
265 Vgl. Memmi 1992, a. a. O., S. 48, 56ff.

266 Vgl. Kerner 2009, a. a. O., S. $47 \mathrm{ff}$.

267 Kerner 2009, a. a. O., S. 47.

268 Memmi 1992, a. a. O., S. 100.

269 Vgl. Memmi 1992, a. a. O., S. $38 f f$.

270 Vgl. Memmi 1992, a. a. O., S. 68.

271 Vgl. Kerner 2009, a. a. O., S. $47 \mathrm{ff}$.

272 Memmi 1992, a. a. O., S. 170.

273 Vgl. Memmi 1992, a. a. O., S. 103.
} 
„Der Rassismus ist die verallgemeinerte und verabsolutierte Wertung tatsächlicher oder fiktiver Unterscbiede zum Vorteil des Anklägers und zum Nachteil seines Opfers, mit der seine Privilegien oder seine Aggressionen gerechtfertigt werden sollen. "274

Diese tendenziell eher weite Definitionsmöglichkeit schließt vier Hauptcharakteristika des Rassismus ein: Das Vorhandensein von tatsächlichen oder fiktiven Unterschieden, die der Rassismus aufnimmt; die Wertung der Unterschiede zum Nachteil der ,anderen' und zum Vorteil der eigenen Gruppe; die Verallgemeinerung und Verabsolutierung dieser Unterschiede; sowie die Legitimierung der durch rassistische Verhaltensweisen hervorgerufenen Handlungskonsequenzen. ${ }^{275}$ Für die weite Definition spräche die Tatsache, dass sich der Rassismus als ein vielfältiges, multiples, flexibles und wandelbares Phänomen präsentiert, welches sich nur unter schwierigsten Bedingungen in einen engen Definitionsrahmen einpassen lassen würde. Memmi konzentriert sich folglich eher auf die Zielsetzung, die Formenvielfalt und Variabilität des Rassismusbegriffes zu erfassen, was eine eindeutige und transparente Definition erschwert: Umfassende Reichweite statt Eindeutigkeit steht hier im Mittelpunkt.276

Nichtsdestotrotz sieht Albert Memmi ebenfalls die angesprochenen Kritikpunkte bezüglich seiner eventuell zu weiten Rassismusdefinition und konzipiert so zusätzlich vergleichend eine engere Begriffsbestimmung, die - wie bei Robert Miles - primär die biologischen Unterscheidungsmerkmale fokussiert. Hier ist jedoch anzumerken, dass Memmi im Gegensatz zu Robert Miles die kulturelle Rassismuskomponente auch in seiner weiteren Forschung nie aufgegeben hat, da er auch diese zu den wesentlichen Elementen des Rassismus zählt. ${ }^{277}$ Die biologische Komponente sieht er am Phänomen des Rassismus zwar als primär an, jedoch ,[...] lediglich als Vorwand und Entschuldigung ${ }^{\prime 278}$, als Legitimation von Hierarchisierung, Machtanspruch und Diskriminierung..279 Des Weiteren konstatiert Memmi eine „,...] organische Verbindung zwischen Rassismus und Herrschaft.“" 280 Von der biologischen Seite kann Rassismus so als Negativierung der biologischen Unterscheidungsmerkmale der ,anderen' und als positive Selbstpositionierung gesehen werden. ${ }^{281}$ Im Unterschied zu Robert Miles vermeidet Memmi jedoch größtenteils die Benutzung des ,Rassebegriffs', den er als unhaltbar und nicht begründbar diskreditiert. ${ }^{282}$ Trotzdem sieht Memmi die „,...] besondere Wirksamkeit $[\ldots]^{\text {“ } 283}$ biologischer Begründungsschemata im Gegensatz zu kultu-

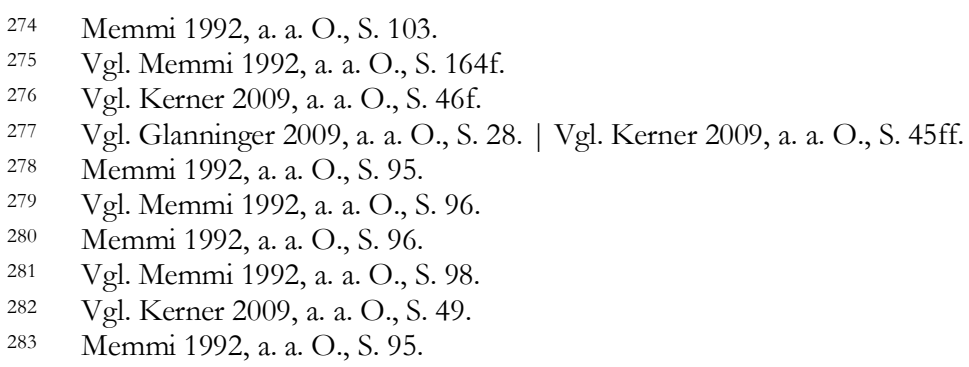


rellen Erklärungsansätzen: „,[...] sie liefer[n] das beste Unterpfand von allen. [...] Denn die Biologie ist eine Abbildung der Schicksalshaftigkeit.“284

Schlussfolgernd kann so festgestellt werden, dass Albert Memmi sowohl biologistische als auch kulturelle Elemente in seine Rassismusvorstellung integriert. ${ }^{285}$ Er charakterisiert Rassismus als die Hervorhebung von realen oder fiktiven Unterschieden zwischen Menschengruppen, der Wertung dieser Unterschiede sowie den Gebrauch dieser Unterschiede zur Abwertung der ,anderen` und der Überhöhung der eigenen Persönlichkeit. ${ }^{286}$ Vor dem Hintergrund der Verbreitung und der Expansion des Rassismus am Ende des 20. Jahrhunderts folgert Albert Memmi, dass es zum ureigenen Wesen des Rassismus gehöre, Vorurteile und Diskriminierungen auf alle Mitglieder einer Menschengruppe zu verallgemeinern - zeitlich unbegrenzt. ${ }^{287}$ Nur auf dieser Grundlage konstruiere sich das Phänomen des Rassismus, Unterschiede allein reichten nicht aus. ${ }^{288}$

Rassismus scheine manifest zu sein, da ,[...] sich die allgemeinen Mechanismen des Rassismus fast identisch überall in der ganzen Gesellschaft wieder[finden lassen]. “289 Er habe jedoch weltweit immer einen Nutzen ökonomischer, politischer oder gesellschaftlicher Art - „[...] er ist eine vielseitige Beschuldigung [...]." ${ }^{290}$ Man finde den biologischen Rassismus, so Memmi, überall wieder, auch verschleiert und verborgen. ${ }^{291}$ Er benutze alles, ,[...] was ihm durch die Entwertung des anderen einen Vorteil einbringt." 292 Somit bestätigt Memmi nochmals die führende Rolle der biologistischen Elemente der rassistischen Ideologie.

\subsection{3 Étienne Balibar und Pierre-André Taguieff}

Im Gegensatz zu Robert Miles und Albert Memmi liegt die Rassismusforschung des Philosophen Étienne Balibar schwerpunktmäßig in den 1980er und den 1990er Jahren, dem Zeitalter des besonders in Deutschland neu aufkommenden Neorassismus. Balibar charakterisiert diesen als rein kulturell begründeten Rassismus und bezeichnet ihn folglich nach dem Soziologen Stuart Hall als „Rassismus ohne Rassen“293. Dieser „[...] kulturelle Rassismus [rekurriert] nicht mehr auf die Biologie, sondern auf unterschiedliche Kulturen. "294 Er stellt nicht mehr die Überlegenheit von angeblichen ,Rassen', sondern die Gleichwertigkeit von Menschengruppen oder Kulturen in den Mittelpunkt, indem er die angebliche Unvereinbar-

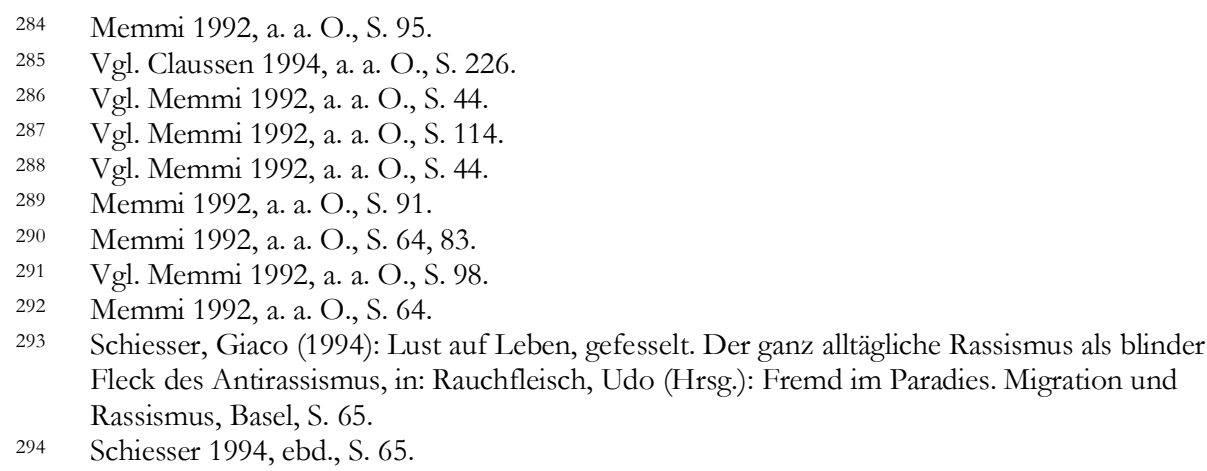


keit von Lebensweisen, Traditionen oder religiösen Metaphern fokussiert. ${ }^{295}$ Rassismus kann so als „,[...] Ensemble typischer [...] Einstellungen und Haltungen

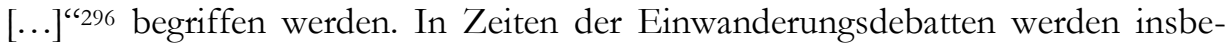
sondere die angeblich kulturellen Unterschiede von Bürgerinnen und Bürgern mit Migrationshintergrund sowie die Unvereinbarkeit des Zusammenlebens von Menschen verschiedener Kulturen in das Zentrum gestellt. ${ }^{297}$ Bestärkt wird Étienne Balibar unter anderem vom Politikwissenschaftler und Soziologen Pierre-André Taguieff, der vor dem Hintergrund des Rassismusphänomens der 1990er Jahre von einem ,differentialistischen Rassismus' spricht. ${ }^{298}$

„Wie Balibar deutlich macht, besteht die Strategie des differentialistischen Rassismus darin, sich als nicht-rassistisch darzustellen und gleichzeitig eine Legitimation rassistischen Verhaltens zu liefern. Insoweit handelt es sich um einen ,Meta-Rassismus', der den Rassismus legitimiert, indem er ,nicht die rassische Zugehörigkeit, sondern das rassistische Verhalten zu einem natürlichen Faktor erklärt. "299

Taguieff visualisiert, dass das Rassismuskonstrukt den ,Rassenbegriff‘ bzw. die ,Rassentheorie' nicht unbedingt benötige. ${ }^{300}$ Die Begrifflichkeiten ,Rasse ${ }^{6}$ und ,Blut ${ }^{6}$ werden durch einen kulturalisierten Rassismusdiskurs ersetzt. ${ }^{301}$ Unterschieden wird so deutlich zwischen dem biologistischen, ,rassentheoretischen' sowie dem kulturell-sozialen Rassismusphänomen, obwohl beide Erklärungsansätze von vielfach überlappenden und sich gegenseitig beeinflussenden Interdependenzen geprägt sind. 302 Taguieff macht hiermit jedoch schon einschränkend deutlich, dass der erklärte definitorische Verzicht auf eine biologische Rassismuskomponente nicht unwiederbringlich stattfinden kann, da auch am Konzept des Neorassismus in ,zweiter Reihe ${ }^{6}$ biologische Faktoren beteiligt sind. ${ }^{303}$ Die ,Kultur ${ }^{6}$ kann hier teilweise als ,[...] Stellvertreter oder Platzhalter [...]“304 für den ,Rassebegriff agieren, da auch die angeblichen kulturellen Differenzierungscharakteristika von Menschengruppen weiterhin biologisiert und naturalisiert verstanden werden können. ${ }^{305}$ Darüber hinaus muss beachtet werden, dass der originäre Rassismusbegriff eigentlich auf den pseudobiologischen, eugenischen und sozialdarwinistischen Theoremen des sogenannten Dritten Reiches basiert. So stellt sich schlussfolgernd die begründete Frage, ob die Darstellung des Neorassismus der 1990er Jahre wirklich als ,Rassismus ohne Rassen“ bezeichnet werden kann, da die biologische Komponente sowie der ,Rassebegriff‘ trotzdem weiterhin im Phänomen des Ras-

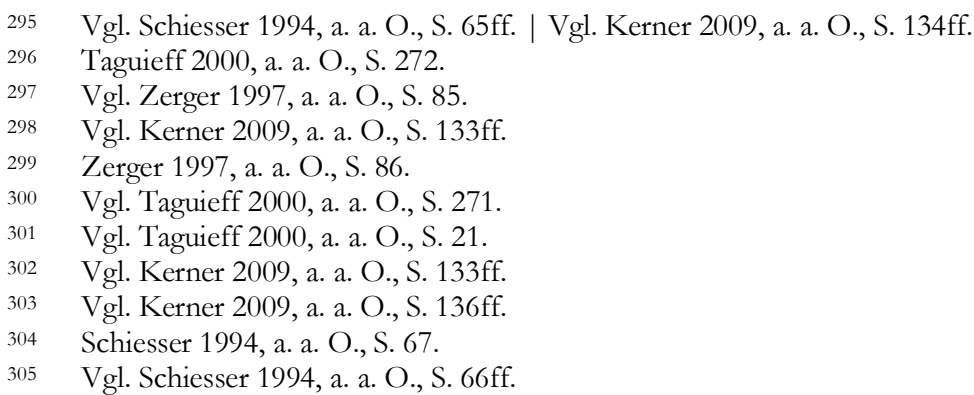


sismus vorhanden bleiben und somit ein tragendes Element des rassistischen Konzeptes darstellen.

\subsubsection{Enggeführte, biologisch argumentierende Rassismustheorien im Fokus}

Die exemplarischen Rassismustheorien und -definitionen von Robert Miles, Albert Memmi, Étienne Balibar und Pierre-André Taguieff - allesamt mit dem zeitlichen Fokus auf das Ende des 20. bzw. den Beginn des 21. Jahrhunderts - visualisieren die Vielfältigkeit und Flexibilität, die Wandelbarkeit und Anpassungsfähigkeit des Rassismusbegriffs. Aufgrund der multiplen Facetten und Nuancen ist eine eindeutige, übergreifende sowie interdisziplinäre Rassismustheorie unwahrscheinlich.

Sprachwissenschaftler Siegfried Jäger sieht die eindeutige Trennung zwischen kulturellem und biologischem Rassismus sowie den Ersatz der biologischen durch rein kulturelle Erklärungsansätze schon allein aufgrund des gesellschaftlichen Alltages als nicht haltbar an, „,[...] weil für die meisten Menschen in unserer Gesellschaft das Soziale ohnedies naturalisiert ist und insofern alles Soziale und Kulturelle biologistisch-natürlich gesehen wird.“306 Folglich spielt auch der biologistische Rassismus im Alltag noch eine entscheidende Rolle. ${ }^{307}$

Die vorliegende Arbeit wird sich im weiteren Verlauf vornehmlich auf die den biologischen Schwerpunkt fokussierende Rassismustheorie von Robert Miles konzentrieren. Die Vorteile seiner Definition liegen in ihrer eindeutigen, enggeführten, transparenten Formulierung, der biologischen Präzisierung hinsichtlich des ,Rassekonstrukts' sowie in ihrer begrifflichen Abgrenzung, ohne dabei die Wandlungsfähigkeit und Flexibilität eines möglicherweise zu eng gefassten Rassismusbegriffs zu ignorieren. ${ }^{308}$ Als wissenschaftlich-diagnostisches Instrument eignen sich Robert Miles' umfangreiche sowie aktuelle Forschungsansätze ideal für eine die Biologie fokussierende Untersuchung des Rassismusphänomens. Sie unterstützen die fachliche und methodische Passung sowie die Verzahnung der sozial- und naturwissenschaftlichen Forschungsperspektiven.

\subsection{Historische Entwicklungslinien des Rassismus}

Im weiteren Verlauf soll nun ein Überblick über die historischen Entwicklungen gegeben werden, die zur Entstehung des Rassismusphänomens führten. Zum Verständnis der begrifflichen Eigenschaften und Charakteristika sowohl des ,Ras$\mathrm{se}^{6}$ - als auch des Rassismuskonstrukts ist diese Betrachtung der historischen Geschehnisse unabdingbar (s. Kapitel 2). Im folgenden Kapitel werden folglich die wichtigsten Stationen der Entwicklung des Rassismusphänomens in Deutschland skizziert, die letztlich zur aktuellen Situation im 21. Jahrhundert führen. Zur detail-

\footnotetext{
306 Jäger 1992b, a. a. O., S. 220ff, 221.

307 Vgl. Jäger 1992b, a. a. O., S. $221 \mathrm{ff}$.

308 Vgl. Weiß 2013, a. a. O., S. 23, 25.
} 
lierten und umfangreichen Analyse der historischen Entwicklungslinien der rassistischen Ideologie wird auf die entsprechende Fachliteratur verwiesen, da diese den fachlichen und thematischen Schwerpunkt dieser Arbeit bei weitem überschreiten würde. ${ }^{309}$

\subsubsection{Das Zeitalter des Protorassismus}

Der eigentliche Rassismusbegriff etablierte sich in Forschung, Wissenschaft und Gesellschaft erst im 18. Jahrhundert. Die Merkmale und Charakteristika des Rassismus lassen sich jedoch bis in die Antike zurückverfolgen. Schon im Griechenland der Antike lässt sich so von einem „Protorassismus“310 sprechen, der sich insbesondere gegen als „Barbaren“311 klassifizierte Perser und Ägypter richtete. Weiterhin wurden beispielsweise auch Frauen aufgrund ihrer angeblich biologischen Unvollkommenheit in der griechischen Gesellschaft kategorisch aus- und abgegrenzt. ${ }^{312}$ Ähnliches galt für Sklaven, die nicht nur ausgegrenzt, sondern denen darüber hinaus auch ihr Menschsein abgesprochen wurde:

„Der wahre Grund für die Sklaverei war [...] im weitesten Sinne biologischer Natur: Er bestand darin, dass es den Sklaven bis zu einem bestimmte Grad an einer Seele gebrach - eine angeborene und selbstverständlich erbliche Schwäche. Während jeder Mann Leib und Seele besaß und die Seele bei dem Freien dem Körper befahl, beherrschte bei dem Sklaven der Körper die Seele. Äußerstenfalls konnte der Körper die Seele ersticken: Der Sklave ähnelte dann einem Tier. "313

Demzufolge etablierten sich schon in der Antike protorassistische Argumentationslinien. Mithilfe des Rückbezuges auf Biologie und Natur wurden Menschengruppen systematisch - in diesem Fall Frauen und Sklaven - aufgrund pseudobiologischer Nachteile, beispielsweise einer angeblich niedrigeren Intelligenz, diskriminiert und ausgegrenzt. ${ }^{314}$ Zusätzlich kann schon bei den theoretischen Reflexionen des Aristoteles ein gewisser ,,[...] rassistischer Beigeschmack [...]“315 identifiziert werden. 316

Darüber hinaus lassen sich jedoch auch ähnliche Entwicklungen im römischen Imperium oder in China beobachten, in denen ganze Kultur- und Gesellschaftsgruppen systematisch verachtet wurden - bezüglich China spricht Imanuel Geiss

Für die detaillierte, wissenschaftliche Analyse und Untersuchung der Entstehungs-, Entwicklungs- und Evolutionsschritte des Rassismusphänomens steht eine große Anzabl an Forschungswerken zur Verfügung. Nachfolgend eine exemplarische Auswahl: Delacampagne 2005, a. a. O. | Geiss 1988, a. a. O. | Geulen 2007, a. a. O. | Mosse 1993, a. a. O. | Poliakov et al. 1992, a. a. O. | Weingart, Peter et al. (1988): Rasse, Blut und Gene. Geschichte der Eugenik und Rassenhygiene in Deutschland, Frankfurt/Main.

310 Delacampagne 2005, a. a. O., S. 20.

311 Delacampagne 2005, a. a. O., S. 21.

312 Vgl. Delacampagne 2005, a. a. O., S. $51 \mathrm{ff}$.

313 Delacampagne 2005, a. a. O., S. 54.

314 Vgl. Delacampagne 2005, a. a. O., S. 54ff.

315 Delacampagne 2005, a. a. O., S. 60.

316 Vgl. Delacampagne 2005, a. a. O., S. $57 \mathrm{ff}$. 
sogar von einem ,[...] quasi-rassistischen Überlegenheitskomplex [...]“317. Weiterhin kann auch das indische Kastensystem zu den ältesten protorassistischen Entwicklungen gezählt werden, da hier ab etwa 1500 v. Chr. vorgeblich niedrigere Kasten organisiert diskriminiert und ausgegrenzt wurden. ${ }^{318}$ Ebenfalls der antike Antijudaismus kann als Vorläufer des heutigen, rassistisch geprägten Antisemitismus aufgefasst werden. Insbesondere in Ägypten herrschte um 170 v. Chr. eine regelrechte Judenverfolgung, ausgelöst durch den monotheistischen jüdischen Glauben, der im Gegensatz zur etablierten polytheistischen ägyptischen Religion stand. Jedoch war der frühe Antijudaismus noch von religiösen Unterschieden geprägt, da die scheinbar biologischen Differenzierungsmerkmale noch nicht bekannt waren. ${ }^{319}$ Hier standen noch theologische Rechtfertigungen aufgrund der verschiedenen Vorväter der Bibel im Mittelpunkt. ${ }^{320}$ Die Instrumentalisierung und Politisierung der Naturwissenschaften etablierte sich erst im 13. Jahrhundert, in dem die jüdische Bevölkerung durch die Integration der Biologie mit phänotypischen Negativa, wie einer ,Hakennase', dicken Lippen` oder ,Gestank', belegt wurden. ${ }^{321}$ Aus dem religiösen Antijudaismus entwickelte sich so bis zum 19. Jahrhundert der pseudobiologisch begründete Antisemitismus, um letztlich ,,[...] aus dem Judentum ein krankhaftes ,Gen' zu machen.“322 In diesem Zusammenhang wurde das Judentum nun weg von der Religion in eine politische, angeblich minderwertige ,semitische Rasse ${ }^{6}$ umfunktioniert, die als vorgebliche „Schädlinge“"323 von Politik und Gesellschaft für sämtliche Krisensituationen verantwortlich gemacht wurden. ${ }^{324}$ Insbesondere vor dem Hintergrund des Auftretens verschiedener totalitärer Regime in Europa, wie das faschistische Regime in Italien und der Nationalsozialismus in Deutschland, konnten sich der rassistische Antisemitismus sowie das Phänomen des Rassismus an sich auf politischer Ebene etablieren. ${ }^{325}$

Diese Entwicklungen lassen sich jedoch schon im Mittelalter beobachten, wo beispielsweise Krankheiten auf biologische oder körperliche Störungen zurückgeführt und Gesellschaftsmitglieder aufgrund dessen diskriminiert wurden. ${ }^{326}$ Allerdings kann hier kein direkter Rassismus identifiziert werden. ${ }^{327}$

Einen forcierenden Einfluss auf das moderne Phänomen des Rassismus hatte Spanien im 15. und 16. Jahrhundert, welches hier das Prinzip der „Reinheit des Blutes“‘328 gegenüber der jüdischen Bevölkerung etablierte. ${ }^{329}$ Nach dem Zusam-

\footnotetext{
317 Geiss 1988, a. a. O., S. 55.

318 Vgl. Geiss 1988, a. a. O., S. 49ff.

319 Vgl. Delacampagne 2005, a. a. O., S. 32ff.

320 Vgl. Delacampagne 2005, a. a. O., S. 32ff. | Vgl. Poliakov et al. 1992, a. a. O., S. $74 \mathrm{ff}$.

321 Vgl. Delacampagne 2005, a. a. O., S. $72 \mathrm{ff}$.

322 Delacampagne 2005, a. a. O., S. $72 \mathrm{ff}, 79$.

323 Poliakov et al. 1992, a. a. O., S. 119.

324 Vgl. Poliakov et al. 1992, a. a. O., S. $111 \mathrm{ff}$.

325 Vgl. Poliakov et al. 1992, a. a. O., S. $123 \mathrm{ff}$.

326 Vgl. Poliakov et al. 1992, a. a. O., S. 60.

327 Vgl. Poliakov et al. 1992, a. a. O., S. 52.

328 Koller 2009, a. a. O., S. 16.
} 
menbruch des muslimisch-christlichen Gleichgewichts in Spanien hatte man in ,den Juden' einen neuen Sündenbock gefunden, dessen diskriminierende Einordnung in einzelnen Facetten mit der ,Rassengesetzgebung der Nationalsozialisten verglichen werden kann. ${ }^{330}$ Einen besonderen Schub des europäischen Rassismus bedeutete zudem die Entdeckung des amerikanischen Kontinents im Jahr 1492: Vor dem Hintergrund der religiösen Urbarmachung der neu entdeckten Einwohner wurden die ,wilden' Indianer ohne Gesetz, Staat oder Religion von den angeblich ,überlegenen' Europäern messianisiert. ${ }^{331}$ Dies bedeutete im 16. und 17. Jahrhundert in der Folge faktisch den Massenmord an der indianischen Bevölkerung. 332

Der beginnende Kolonialismus kann demnach als Grundlage des modernen, europäischen Rassismus verstanden werden. ${ }^{333}$ Er diente unter anderem als Basis des Dreiecks-Sklavenhandels zwischen Nordamerika, Europa und Afrika sowie als Ausgangspunkt der Etablierung einer ,Rassengesellschaft ${ }^{`}$ mit der Hautfarbe als Klassifikationsmerkmal. ${ }^{334}$ Insbesondere die großen Entdeckungen der Europäer bereiteten so „[...] dem Rassismus den Weg.“335 Das Rassismusphänomen kann demnach für die vergangenen Jahrhunderte als Rechtfertigungs- und Legalisierungsideologie für Kolonialisierung und Sklaverei betrachtet werden. ${ }^{336}$ Mark Terkessidis identifiziert in der Kolonialisierung sogar die ,[... , Wiege ${ }^{\varsigma}$ des Rassismus

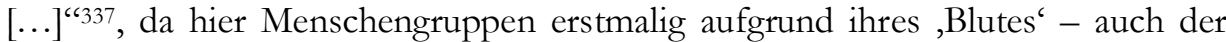
,Rassebegriff' ist hier synonym anwendbar - sowie weiterer phänotypischer Merkmale differenziert und systematisch diskriminiert wurden. ${ }^{338}$ In diesem Zusammenhang bildete sich im Zeitalter des europäischen Kolonialismus auch der ,Rassebegriff' heraus, der durch die an Bedeutung gewinnenden Naturwissenschaften fälschlicherweise an das biologisch konnotierte Rassismuskonzept entliehen wurde. Verantwortlich hierfür waren unter anderem die europäische Expansion in die neue Welt, die Aufspaltung des christlichen Glaubens durch die Reformation, die Vervielfältigung des Wissens durch den aufkommenden Buchdruck, die Herausbildung der neuzeitlichen Wissenschaften und der schon beschriebene ansteigende Hass auf die jüdische Bevölkerung. ${ }^{339}$ Auf den religiösen Glauben als Unterscheidungsmerkmal folgte also der aus der Pferdezucht entliehene biologische ,Rassebegriff', obwohl die eigentliche Biologisierung und ,Rassifizierung' der Bevölkerung erst im 18. Jahrhundert ihren Höhepunkt fand, da der hiesige

329 Vgl. Geiss 1988, a. a. O., S. $121 \mathrm{ff}$. | Vgl. Laqueur, Walter (2006): Gesichter des Antisemitismus. Von den Anfängen bis heute, Berlin, S. 109ff.

330 Vgl. Koller 2009, a. a. O., S. $17 \mathrm{ff}$.

331 Vgl. Delacampagne 2005, a. a. O., S. 96ff.

332 Vgl. Delacampagne 2005, a. a. O., S. 96ff.

333 Vgl. Koller 2009, a. a. O., S. $19 \mathrm{ff}$.

334 Vgl. Koller 2009, a. a. O., S. $20 \mathrm{ff}$.

335 Poliakov et al. 1992, a. a. O., S. 65.

336 Vgl. Mecheril/Scherschel 2009, a. a. O., S. 42.

337 Terkessidis 1998, a. a. O., S. 85.

338 Vgl. Terkessidis 1998, a. a. O., S. 85ff.

339 Vgl. Geulen 2007, a. a. O., S. $32 \mathrm{ff}$. 
Schwerpunkt noch auf dem Sklaven- und Schwarz-Weiß-Rassismus in den neuen Kolonien lag. 340

Gewisse protorassistische Diskurse und Phänomene gingen dem heutigen Rassismus also voraus, ,[e]rst der Rassismus der Neuzeit jedoch bündelte und verarbeitete sie theoretisch zu ganzen Gedankensystemen.“"341

\subsubsection{Die Etablierung des pseudowissenschaftlichen Rassismus der Neuzeit}

Bis zum 18. Jahrhundert entwickelten sich unterschiedliche Rassismen, die jeweils an die vorherrschenden, spezifischen Umstände angepasst waren. Ihnen fehlte jedoch noch ein gemeinsamer „,[...] ideologischer Mörtel [...]“342, gemeinsame Charakteristika und Merkmale, die das heutige Phänomen des Rassismus konstruieren. Eine gemeinsame theoretische Basis sowie eine wissenschaftliche Systematisierung erfolgten erst durch die scheinbare Verwissenschaftlichung im Zeitalter der Aufklärung. ${ }^{343}$ Hier etablierte sich unter Bezugnahme auf das ,Rassenkonstrukt ${ }^{6}$ der biologistisch begründete Rassismus. Ab dem 18. Jahrhundert kann folglich von dem heute noch existierenden Rassismusphänomen sowie auch von der Begrifflichkeit des Rassismus gesprochen werden:

„Vor dem 18. Jahrbundert haben wir verschiedene Formen von Rassismus, die in die Sprache des Mythos gekleidet werden, ab dem 18. Jahrbundert haben wir einen Rassismus, der vorgibt, in der Sprache der Wissenschaften zu sprechen. Der Rassismus entstand also nicht im 18. Jahrhundert. Aber gewissermaßen nabmen doch gerade in diesem Jahrbundert seine ,modernen'V arianten Gestalt an. "344

Vor diesem Hintergrund entwickelte sich die sogenannte ,Rassenforschung“ ebenso wie die Kraniologie, die Anthropologie, die Physiognomie und die Schädelbzw. Gesichtskunde zur Klassifizierung und Hierarchisierung von angeblichen ,Rassen'.345 Ihr einziger Zweck war die Konstruktion von pseudobiologischen Unterscheidungsmerkmalen zwischen sogenannten ,Rassen'.346 Ab hier begann man nun nicht mehr aufgrund religiöser oder kultureller Merkmale, sondern explizit auf der Basis angeblicher naturwissenschaftlicher Wahrheiten, Menschen anhand ihres phänotypischen Aussehens in ein Kategoriensystem zu systematisieren; im 21. Jahrhundert nur noch ergänzt durch die scheinbaren Erkenntnisse der modernen molekulargenetischen Forschung. ${ }^{347}$

\footnotetext{
340 Vgl. Geulen 2007, a. a. O., S. 35ff. | Vgl. Geiss 1988, a. a. O., S. $127 \mathrm{ff}$.

341 Geiss 1988, a. a. O., S. 49.

342 Delacampagne 2005, a. a. O., S. 125.

343 Vgl. Delacampagne 2005, a. a. O., S. $125 \mathrm{ff}$.

344 Delacampagne 2005, a. a. O., S. 126.

345 Vgl. Delacampagne 2005, a. a. O., S. $129 \mathrm{ff}$.

346 Vgl. Koller 2009, a. a. O., S. 41ff.

347 In diesem Zusammenhang etablierte sich auch die Suche nach der europäischen, Herrenrasse; ausgelöst durch den forcierten Kolonialismus der europäischen Nationalstaaten. So sollte die Überlegenheit der Europäer als ,reine Rassen' gegenüber den kolonialisierten Einheimischen - auch die ,Arier'Vorstellung etablierte sich in dieser Zeit- nun auch wissenschaftlich validiert werden. Vgl. Delacampagne 2005, a. a. O., S. $140 \mathrm{ff}$.
} 
Das Zeitalter der Aufklärung kann demnach als Grundlage des heutigen pseudowissenschaftlich bzw. pseudobiologisch begründeten Rassismus identifiziert werden. Die phänotypische und genotypische Entwicklung sowie die Vererbung und Ausprägung von Merkmalen bzw. Genen der Menschen - wie Intelligenz, Aussehen oder Ausdauer -, wurden im 18. Jahrhundert in den Naturwissenschaften verankert und ohne Einschränkungen auf die Sozial- und Gesellschaftsordnung ausgeweitet. ${ }^{348}$ In Deutschland wurde diese Entwicklung im 18. und 19. Jahrhundert noch durch die Einführung des sogenannten ,Degenerations'Begriffes verstärkt, der politisch, gesellschaftlich und biologisch zur gesellschaftlichen Stimmungsmache gegen die Mischung von angeblich ,minderwertigen ${ }^{6}$ und ,höherwertigen Rassen“ mit der Folge der Degeneration der scheinbar überlegenen ,Rassen“ eingesetzt wurde. ${ }^{349}$
„,Die Degenerationen sind krankhafte Abweichungen vom normalen menschlichen Typ, sind erblich übertragbar und entwickeln sich progressiv bis zum Untergang. 'Dabei [ist] [...] das Degenerationskonzept nicht nur auf einzelne Familien und deren Geschichte [zu beziehen], sondern auch auf Rassen, vor allem aber auf die ganze moderne Gesell- schaft." 350

Diese biologische Systematisierung des Rassismus sowie dessen pseudowissenschaftliche Begründung wurden direkt und indirekt, gewollt und ungewollt durch viele namhafte Naturforscher unterstützt. Hier sind unter anderem die ersten klassischen Naturwissenschaftler Jean-Baptiste de Lamarck, Charles Darwin, Carl von Linné und Gregor Mendel zu nennen. Deren für diese Zeit sowie für die gesamten Naturwissenschaften bahnbrechende Forschungsergebnisse wurden von selbsternannten ,Rassenforschern' übernommen und ,rassifiziert' ${ }^{6}$ - kurz: missbraucht. Die neu etablierten wissenschaftlichen Forschungsergebnisse wurden als scheinbare Erklärungsansätze für das Vorhandensein von erblichen Unterschieden zwischen ,Menschenrassen“ herangezogen. Eigentlich schwerpunktmäßig für die Pflanzen- und Tierwelt gedacht, wurden deren Forschungs- und Analyseansätze ohne Modifizierungen auf das menschliche und gesellschaftliche Zusammenleben übertragen. Beispielsweise wurden angebliche ,Rassenunterschiede', wie Hautfarbe, Körperform, Nasenstruktur oder Schädelinhalt, als von Generation zu Generation erblich und damit als ,Rassenmerkmal' festgeschrieben. ${ }^{351} \mathrm{Im}$ Rahmen dieser Verwissenschaftlichung des Rassismus von einer Ideologie zu einer scheinba-

\footnotetext{
348 Vgl. Dittrich/Radtke 1990, a. a. O., S. $17 \mathrm{ff}$.

349 Vgl. Weingart et al. 1988, a. a. O., S. $42 \mathrm{ff}$.

Die Verbreitung der Degenerations-Ideen im 19. Jahrhundert lässt sich insbesondere als Folge des schwerwiegenden wirtschaftlichen und sozialen Strukturwandels in gan z Europa, schwerpunktmäßig in Deutschland, seben. Die industrielle Revolution führte zu einem gänzlichen Wandel der traditionellen Lebensverbältnisse: Armut, Mangelernährung, menschenunwürdige Arbeitsbedingungen sowie Arbeitslosigkeit beherrschten die negative Stimmung der Gesellschaft. Mithilfe des Degenerations-Aspektes war nun ein neuer, SündenbockMechanismus' für die kerisenhaften nationalen Entwicklungstrends gefunden.

350 Weingart et al. 1988, a. a. O., S. 47. | Vgl. Ackerknecht, Erwin (1985): Kurze Geschichte der Psychiatrie, 3. Auflage, Stuttgart, S. 54f.

351 Vgl. Poliakov et al. 1992, a. a. O., S. 109 f.
} 


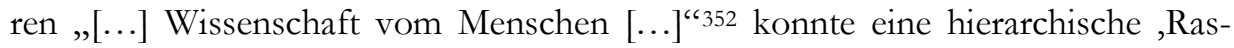
senskala' konstruiert werden, die insbesondere auf der Falschinterpretation der einzigartigen Forschungsergebnisse des Naturforschers Charles Darwin basierte. ${ }^{353}$ Darwins Forschungen wurden durch die missbräuchliche Spiegelung auf das Phänomen des Rassismus entstellt (s. Kapitel 5.1). 354 „Von nun an behauptete man, das Schicksal der Menschen werde von einem biologischen Determinismus gelenkt, und er wurde zum Schlüssel der Geschichte. "355 Charles Darwin wies hingegen sogar einen monozentrischen Lösungsansatz bezüglich der Entstehung, Entwicklung und Verbreitung der Menschen nach, der dem Rassismusphänomen eigentlich diametral zu widersprechen schien. ${ }^{356}$ Denn rassistische Argumentationen stützen sich zur Legitimierung und Begründung der Sklaverei schwerpunktmäßig auf ein polyzentrisches Entwicklungsmodell des modernen Menschen (s. Kapitel 5). ${ }^{357}$ Bis zum Beginn des 20. Jahrhunderts lässt sich so eine Akademisierung sowie eine Biologisierung des ,Rassedenkens' feststellen, obwohl auch weiterhin Mythen und Stereotype bezüglich der spezifischen ,Rassen` existierten. ${ }^{358}$ Bedeutende Vertreter der Erforschung des ,Rassediskurses' waren Georges-Louis Leclerc de Buffon, Johann Friedrich Blumenbach, Peter Camper, Francis Galton, Arthur de Gobineau, Christoph Meiners, Houston Stewart Chamberlain und Ernst Haeckel, die vor allem großen Einfluss auf das deutsche ,Rassekonzept ${ }^{6}$ entwickelten und so im weiteren Verlauf den Gedankengängen des Nationalsozialismus den Weg ebneten. Besonders bedeutend waren vor diesem Hintergrund der rassistischen Argumentation die pseudowissenschaftlichen Werke des französischen Schriftstellers Arthur de Gobineau, der als Begründer der modernen ,Rassentheorie' gesehen werden kann. ${ }^{359}$ Er etablierte keine neuen Forschungsergebnisse bezüglich der ,Rasseanalyse', sondern vereinte und integrierte lediglich die zahlreichen vorhandenen ,Rassekonzepte‘ zu einer pseudobiologischen Gesamttheorie. „Rasse wurde hier zur geschichtsmächtigen Kraft erhoben.“360 Gobi-

352 Poliakov et al. 1992, a. a. O., S. 109.

353 Hier sei jedoch anzumerken, dass Charles Darwin seine evolutions- und vererbungsbiologischen Erkenntnisse in erster Linie für Fauna und Flora entwickelte. Überlegungen hinsichtlich des Menschen folgten erst später in eingeschränktem Maße.

354 Vgl. Poliakov et al. 1992, a. a. O., S. 109 f.

355 Poliakov et al. 1992, a. a. O., S. 109.

356 Vgl. Koller 2009, a. a. O., S. 30ff.

357 Vgl. Koller 2009, a. a. O., S. $30 \mathrm{ff}$.

Anthropologen und Evolutionsbiologen diskutieren mehrere Szenarien zur Entstebung des Menschen. Das monozentrische Entstehungsmodell besagt dabei, dass sich der moderne Mensch einzig auf dem afrikanischen Kontinent entwickelt bat und dann im weiteren Verlauf von Afrika aus die restliche $W$ elt besiedelte. Für eine ,Rassenbildung' aufgrund schwerwiegender genetischer und morphologischer Unterschiede bleibt also kaum Zeit. Das heute eher im Hintergrund stehende polyzentrische Evolutionsmodell besagt hingegen, dass sich der moderne Mensch multiregional, das heißt an vielen Orten der Erde, mehr oder weniger gleichreitig entwickelte. Aufgrund dessen scheint eine Bildung von menschlichen Untergruppen - ,Rassen"- möglich (s. Kapitel 5). Vgl. Kerner 2009, a. a. O., S. $81 \mathrm{f}$.

359 Vgl. Meier-Mesquita, Cintia (1994): Rasse, Rassismus und Rassentheorien. Die Entstehung des Rassismus und das Bild der außereuropäischen Völker in Europa, in: Rauchfleisch, Udo (Hrsg.): Fremd im Paradies. Migration und Rassismus, Basel, S. 49. 
neau schlussfolgerte aus dem Vorhandensein von ,starken“ und ,schwachen“ "Rassen', dass sich diese natürliche Ungleichheit mithilfe des ,Rassenkonzeptes` lösen lasse, um die Degeneration der ,reinen Rasse ${ }^{6}$ - die größte von ihm postulierte Gefahr - zu verhindern. ${ }^{361}$ Seine Prognose für die ,reine weiße Rasse': Diese sei aufgrund der schon seit Jahrhunderten stattfindenden ,Rassenmischung' mit angeblich ,minderwertigen Rassen` zum Scheitern verurteilt. ${ }^{362}$ Arthur de Gobineau kann somit als indirekter Vorläufer und Wegbereiter des nationalsozialistischen Regimes in Deutschland gesehen werden. ${ }^{363}$

Insbesondere für Deutschland und dessen institutionalisierten Rassismus während des nationalsozialistischen Regimes war Schriftsteller Houston Stuart Chamberlain und seine im Buch ,Die Grundlagen des 19. Jahrhunderts“ erörterten Argumentationen die Basis des rassistischen und ,rassentheoretischen' Agierens. ${ }^{364}$

„Für tausende von Deutschen wurde ,Die Grundlagen des 19. Jabrhunderts' zur Bibel, und auch in den angelsächsischen Ländern fand das Buch beifällige Aufnahme. Der moderne Rassismus hatte in Chamberlain seinen Herold gefunden, und was dann die Nazis daraus machten, ist bekannt. Das man der Rassenfrage, die zur treibenden Kraft der Geschichte und zum einzigen wichtigen Problem geworden war, solche Wichtigkeit zuschrieb, ist nicht ausschließlich den verschwommenen Schriften von Theoretikern zuzuschreiben. Sie lag in doppelter Weise in der Luft; einmal in der Welt der Wissenschaft jener Zeit und sodann in der Politik. "365

Für das 19. und 20. Jahrhundert ist demnach eine Zunahme der ,Rassifizierung` der Gesellschaft und deren Hierarchisierung durch das ,Rassekonzept ${ }^{6}$ zu konstatieren, was dann letztlich in der sogenannten ,völkischen Rassentheorie‘ sowie der nationalsozialistischen Eugenik endete, die eine „,...] rassische Reinheit [...]“366 sowie die Ablehnung der Rassenmischung propagierten. ${ }^{367}$ Die irreguläre Übertragung des darwinistischen Konzeptes ,Survival of the fittest' auf die menschliche Population ermöglichte der britische Naturforscher Francis Galton, der die praktische Anwendung des darwinistischen Selektionsprinzips auf die Menschheit zur

\footnotetext{
361 Vgl. Singer 1997, a. a. O., S. 55 f.

362 Vgl. Panahi 1980, a. a. O., S. 37.

Weitere Literaturempfehlungen zum Gedanken des unwiederbringlichen Scheiterns der, reinen Rasse' nach Gobineau: Claussen 1994, a. a. O., S. 32-40. | Weingart et al. 1988, a. a. O., S. 47.

363 Vgl. Claussen 1994, a. a. O., S. 40.

Die ,Rassetheorien'von Arthur de Gobineau könnten aufgrund ibrer angeblichen Brisanz und ibrer essentiellen Bedeutung für den weiteren Verlauf der deutschen Geschichte noch weitere Kapitel ergänzen. Da der Schwerpunkt dieser Ausarbeitung jedoch weniger auf dem historischen Aspekt des Rassismus liegt, wird zur weiteren Recherche bezüglich des, Rassekonzeptes" von Gobineau auf folgende ergänzende Literaturempfehlungen verwiesen: Delacampagne 2005, a. a. O., S. 143-151. | Dettmar 1987, a. a. O., S. 131. | Geiss 1988, a. a. O., S. 169. | Geulen 2007, a. a. O., S. 70. | Kerner 2009, a. a. O., S. 72-76. | Mosse 1993, a. a. O., S. 76-85. | Poliakov et al. 1992, a. a. O., S. 98 . | Zerger 1997, a. a. O., S. 35-36. Vgl. Kerner 2009, a. a. O., S. $71 \mathrm{f}$.

Vgl. Poliakov et al. 1992, a. a. O., S. $102 \mathrm{ff}$.

Poliakov et al. 1992, a. a. O., S. 104.

Kerner 2009, a. a. O., S. 71.

Vgl. Kerner 2009, a. a. O., S. $71 \mathrm{f}$.
} 
Kontrolle der eigenen Evolution sowie zur biologischen Verbesserung der Menschen vorschlug (s. Kapitel 5.1). ${ }^{368}$ Die Nationalsozialisten griffen dann die verschiedenen ,Rassetheorien“ auf: ${ }^{369}$ „Die Perversion biologischen Denkens findet im nationalsozialistischen Rassenbiologismus, im biologisch gerechtfertigten, planmäßigen Mord ihren Höhepunkt. “370 Doch was zeichnete die Attraktivität der rassistischen und ,rassentheoretischen“ Ideologie für die deutschen Bürgerinnen und Bürger damals wie heute aus (s. Kapitel 4)?371

„Er versprach, einen jeden vor allen seinen Feinden zu schützen. Wissenschaftlicher Anstrich, eine puritanische Lebensauffassung, die erfolgreiche Mittelstandsmoral, christliche Religion, das Schönheitsideal als Symbol für eine bessere und heilere Welt, das waren die wesentlichen Bestandteile des Rassismus. Rassismus verteidigte Utopia gegen seine Feinde. Nur wenn man die Rasse bewahrte und ibre Feinde besiegte, nur dann konnten so behre Ideale wie Freiheit, Gleichbeit und Toleranz verwirklicht werden. Rassismus versprach den unterschiedlichen Menschengruppen jedwede Wobltat. "372

Die Biologie ersetzte so sukzessive im Verlauf des 18. und 19. Jahrhunderts die Religion bzw. den Glauben als Begründung und Legitimationsgrundlage des Rassismus:
„Die neue wissenschaftlich orientierte Geisteshaltung, die in dieser Zeit aufkam und gleichbedeutend mit Fortschrittsglauben war, neigte dazu, vornebmlich biologische Sach- verhalte als bestimmend anzusehen. Anstelle der alten religiösen und kulturellen Klassi- fizierungen traten solche, die von der Beobachtung physischer Merkmale (Hautfarbe usw.) abgeleitet wurden. Diese galten als unabänderlich und beeinflussten, wie man glaubte, das Verhalten der betreffenden Völker. "373

Vor diesem Hintergrund kann von einer Neuschreibung der Geschichte durch das neue, biologistische Rassismusphänomen gesprochen werden. ${ }^{374}$ In diesem Zusammenhang steht auch die weltweite Verbreitung des Antisemitismus, der sich ebenfalls von einer auf religiösen Vorurteilen basierenden Ideologie zu einer ,Rassenideologie ${ }^{6}$ wandelte. ${ }^{375}$ Primäre Aufgabe dieses biologischen ,Rassenrassismus des 18. und 19. Jahrhunderts war die Legitimation des europäischen Kolonialismus. ${ }^{376}$ Mithilfe des pseudowissenschaftlichen ,Rassekonzeptes` konnten die Diskriminierung und Entmenschlichung der kolonisierten Einwohner sowie die Sklaverei verschleiert werden. ${ }^{377}$

\footnotetext{
368 Vgl. Weingart et al. 1988, a. a. O., S. $32 \mathrm{ff}$.

369 Vgl. Jäger 1992a, a. a. O., S. 136.

370 Marten 1983, a. a. O., S. 26.

371 Vgl. Terkessidis 1998, a. a. O., S. 155.

372 Mosse 1993, a. a. O., S. 23-24.

373 Poliakov et al. 1992, a. a. O., S. 89.

374 Vgl. Poliakov et al. 1992, a. a. O., S. 93.

375 Vgl. Koller 2009, a. a. O., S. 53.

376 Vgl. Cohen 1994, a. a. O., S. 91.

377 Vgl. Rex 1990, a. a. O., S. 145.
} 
Schlussendlich kann konkludiert werden, dass die Grundlagen des heute wieder auftretenden, biologistischen Rassismustypus schon im Zeitalter der Aufklärung gelegt wurden, insbesondere die systematische Hierarchisierung der Menschen mithilfe des ursprünglich zoologischen ,Rassekonzepts‘.378 „Die Geburt der modernen Rassenkonzepte liegt im 18. Jahrhundert.“379 Die Ursachen für die dortige Entstehung des modernen Rassismus sind vielfältig: Kolonialismus, Nationalismus, Wirtschaft oder Kapitalismus scheinen einige der forcierenden Elemente gewesen zu sein. ${ }^{380}$ Christian Delacampagne folgert vor diesem Hintergrund noch drastischer:

„Das 18. Jabrhundert glaubte, den rassistischen Diskurs in die ,sicheren Babnen der Wissenschaft gelenk.t' zu haben. Das 19. Jahrbundert war - von Gobineau bis Chamberlain - das Jabrhundert der ersten Synthesen dieser Lebre. Und das 20. Jabrbundert kann für sich das traurige Privileg beanspruchen, die praktischen Konsequenzen aus diesen Thesen gezogen zu haben. Anders gesagt: Im gerade vergangenen Jabrhundert wurden die größten Verfolgungen und Deportationen, ja die Ausrottung von ganzen Völkern verübt, nur aus einem einzigen Grund: dem Hass auf den Anderen [...]. Das 20. Jabrhundert wird als das Jahrbundert der großen Massaker in die Geschichte eingeben." 381

Zuvor existierten, wie dargestellt, zwar auch schon protorassistische Handlungsund Argumentationsschemata, ihnen fehlte jedoch noch das verbindende, systematische Element des modernen Rassismusphänomens. ${ }^{382}$ Folglich generiert das ,Rassekonzept ${ }^{6}$ allein noch keinen Rassismus, dies erfolgt erst durch dessen Anwendung zur Hierarchisierung der menschlichen Gesellschaft. 383 Zweifel an der biologischen Erklärungskomponente des Rassismus kamen erst nach dem Zweiten Weltkrieg und den Schrecken des nationalsozialistischen Terrorregimes auf, so dass die UN in mehreren wissenschaftlichen Konferenzen spezifische biologistische Kernelemente des Rassismus als unmenschlich diskreditierte (s. Kapitel 5.3).384 Dies abstrahierte die heutige Bundesrepublik mit der Aufnahme dieser UN-Entscheidungen in den Grundkanon der rechtlichen Voraussetzungen des deutschen Staates, dem Grundgesetz. ${ }^{385}$ Insofern zeigt sich der Begriff des Rassismus in Deutschland als tabuisiert:

\footnotetext{
378 Vgl. Meier-Mesquita 1994, a. a. O., S. $48 \mathrm{f}$.

379 Koller 2009, a. a. O., S. 24.

380 Vgl. Miles 1993, a. a. O., S. 21.

381 Delacampagne 2005, a. a. O., S. 159.

382 Vgl. Geiss 1988, a. a. O., S. 78.

383 Vgl. Geiss 1988, a. a. O., S. $142 \mathrm{ff}$.

384 Vgl. Terkessidis 1998, a. a. O., S. 17. | Vgl. Claussen 1994, a. a. O., S. 1. Speziell in Deutschland verfolgten die alliierten Besatzungsmächte nach dem Zweiten Weltkrieg das Ziel einer „Entnazifizierung", ,Entrassifizierung" der deutschen Gesellschaft, so dass die deutschen Bürgerinnen und Bürger bei dem Eintritt in den öffentlichen Dienst dezidiert dem Rassismus offiziell entsagen mussten. Delacampagne 2005, a. a. O., S. 235, 235ff.

385 Vgl. Delacampagne 2005, a. a. O., S. $235 \mathrm{ff}$.
} 
„Für sämtliche Verwendungen des Begriffs Rassismus nach 1945 gilt [...], dass damit immer auch [...] ein Bezug zur historischen Erfahrung des rassistisch begründeten industriellen Massenmordes der Nationalsozialisten hergestellt wurde. Entsprechend war [beziehungsweise ist der Begriff immer noch] stark, normativ aufgeladen [...]. "386

Erst mit dem Anstieg der rechtsextremistischen Gewalt in den 1990er Jahren wurde der Rassismusbegriff vereinzelt wieder auf der politischen und gesellschaftlichen Agenda präsentiert. 387

Trotz der schrecklichen und menschenverachtenden, rassistischen Geschehnisse im nationalsozialistischen Deutschland ist jedoch auch nach 1945 in der Bundesrepublik partiell eine Verbindung von Politik und Biologie festzustellen. ${ }^{388}$ Ebenfalls auf der internationalen Ebene können immer wieder vereinzelt Natursowie angebliche ,Rassenwissenschaftler ${ }^{6}$ beobachtet werden, die sozialbiologische und eugenische Maßnahmen präferieren (s. Kapitel 5). ${ }^{389}$ Kritisch anzumerken bleibt so: „Eine ,Stunde Null ' hat es nicht gegeben [...].“390 Der ,Rassenbegriff“ verschwand zwar zunehmend aus dem sprachlichen Repertoire, ist aber nach wie vor auch im 21. Jahrhundert noch als Denkweise vorhanden, wie die vorhergehenden Kapitel visualisieren (s. Kapitel 3).391 Prognostizierend warnte Imanuel Geiss schon 1988 vor der Gefahr des Ausbrechens neuer ,Rassenkonflikte', beispielsweise zwischen Bevölkerungsanteilen mit unterschiedlicher Hautpigmentierung oder zwischen Einwanderungsländern und Einwanderern - aus der Perspektive des 21. Jahrhunderts gesehen, lassen sich die von Geiss prognostizierten Konflikte teilweise als existent bestätigen. ${ }^{392}$

\subsubsection{Historische Formen des Rassismus}

Die historische Entstehung des Rassismus überblickend kann schlussfolgernd konstatiert werden, dass sich der moderne Rassismus aus verschiedenen, in ganz Mitteleuropa entstandenen Elementen entwickelte:

„Der moderne Rassismus, diese Hydra mit tausend Köpfen, dieser Proteus in immer wechselnder Gestalt, dessen Ursprünge nicht genau zu greifen sind, nährte sich aus verscbiedenen Quellen, deren jewvilige Bedeutung nicht immer genau erkennbar ist." "393 „[Er] hatte ein Bündnis mit den Hauptströmen des [20.] Jabrbunderts gesucht: Nationalismus, Spiritualismus, Mittelstandsmoral und Wissenschaftsglaube. "394

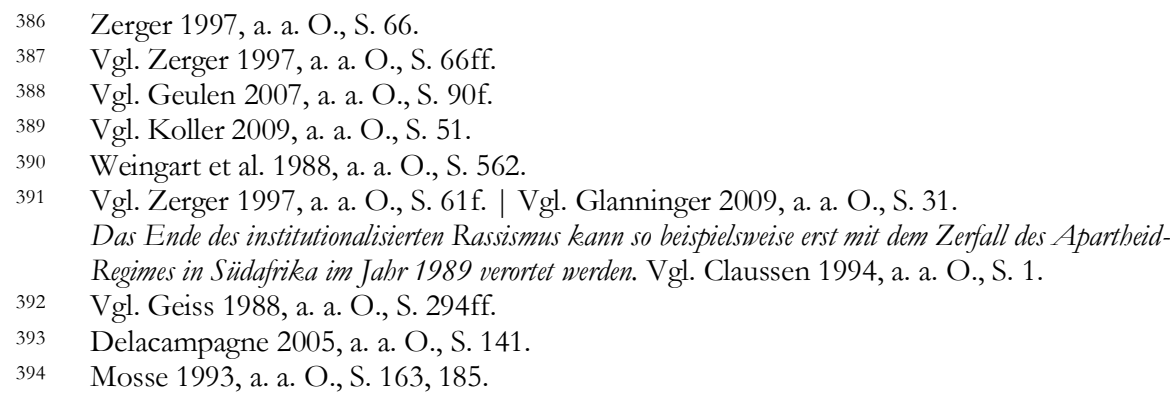


Tab. 2: Historische Formen des Rassismus nach Jost Müller ${ }^{395}$

\begin{tabular}{|c|c|}
\hline Historische Formen & Charakteristika \\
\hline $\begin{array}{l}\text { Universeller } \\
\text { Rassismus } \\
\text { 15. Jhd. - 18. Jhd. }\end{array}$ & $\begin{array}{l}\text { Varianten: } \\
\text { - „missionarischer Rassismus“: Kolonialismus } \\
\text { - "naturgeschichtlicher Rassismus“: Begründung von ,Rassenun- } \\
\text { terschieden“ } \\
\text { - „rationaler Rassismus“: John Locke, alle Menschen sind frei } \\
\text { und gleich }\end{array}$ \\
\hline $\begin{array}{l}\text { Superiorer Rassismus } \\
\text { 19. Jhd. - 20. Jhd. }\end{array}$ & $\begin{array}{l}\text { Ziel: } \\
\text { Kulturelle bzw. biologische Hierarchisierung der ,schöpferischen“ } \\
\text { Europäer sowie Menschen anderer Kontinente/innerer ,Feinde“ } \\
\text { Varianten: } \\
\text { - „typologischer Rassismus“: Rassismus vor der darwinistischen } \\
\text { Forschungsära (Verwissenschaftlichung des Rassismus: Aner- } \\
\text { kennung des ,Rassephänomens“) } \\
\text { - „sozialdarwinistischer Rassismus“: Rassismus infolge der } \\
\text { darwinistischen Forschungsergebnisse (Entstehung von Sozi- } \\
\text { aldarwinismus und Eugenik) }\end{array}$ \\
\hline $\begin{array}{l}\text { Differentieller } \\
\text { Rassismus } \\
\text { 20. Jhd. }\end{array}$ & $\begin{array}{l}\text { Ziel: } \\
\text { Paradigmenwechsel: „Kulturalistische Wende“ der Rassismusbe- } \\
\text { gründung; anstatt biologisch-genetischen Unterscheidungsmerk- } \\
\text { malen wird die kulturelle Komponente als Differenzierungsmerkmal } \\
\text { herangezogen }\end{array}$ \\
\hline
\end{tabular}

\subsection{Biologistischer Rassismus im 21. Jahrhundert}

Sowohl die Begriffsbestimmung als auch die historischen Entwicklungslinien des Rassismus zeigen sich, wie die vorherigen Kapitel illustrieren, extrem facettenreich und vielfältig. Eine eindeutige Definition sowie auch ein eindeutiger Ursprung scheinen nicht gegeben. Das letzte Kapitel der theoretisch-empirischen Begriffsanalyse des Rassismus stellt sich nun die für diese Untersuchung essentielle Frage, wie sich das Rassismusphänomen unter biologischem Fokus im 21. Jahrhundert theoretisch entwickelt, bzw. ob von wissenschaftlicher Seite überhaupt noch von einem biologisch-genetischen Rassismustypus gesprochen werden kann?

Die Schwierigkeit der Rassismusbetrachtung in Deutschland ergibt sich vor allem aufgrund der immer noch vorhandenen tendenziellen Tabuisierung und Ver-

Als weiterer tabellarischer Kurұüberblick über die historischen Entwicklungslinien des Rassismus ist folgender Literaturvorschlag zu empfeblen: Mecheril/Scherschel 2009, a. a. O., S. 44-45. 
drängung des Rassismusbegriffes. Imanuel Geiss spricht diesbezüglich treffend von einem „[...] verleugnete[n], aber praktizierte[n] Rassismus“396. Vielfach wird das Phänomen seitens politischer oder gesellschaftlicher Akteure eher mit verharmlosendem und beschönigendem Vokabular umschrieben, statt den Rassismusbegriff dezidiert anzuwenden (s. Kapitel 1, 2). ${ }^{397}$ Ungeachtet dessen bleibt Rassismus der originäre und zutreffende Begriff.398 Auch der Ersatz des ,Rassebegriffes‘ durch den tarnenden ,Kultur'- oder ,Ethnien'-Begriff beinhaltet definitorische Schwierigkeiten. Ebenso zeigt sich das ,Rassekonzept ${ }^{6}$ nach wie vor - wenn auch indirekt - präsent, wie die vorhergehenden Kapitel mit einer Untersuchung der Verbreitung von biologisch-rassistischen Vorstellungen innerhalb der bundesrepublikanischen Bevölkerung illustrieren (s. Kapitel 3). 399 Rassismusforscher Teun A. van Dijk diagnostiziert diesbezüglich schon in den 1990er Jahren die Tendenz einer wieder erstarkenden, jedoch indirekten Verbreitung von biologistisch - teilweise auch kulturell - begründeten, rassistischen Motiven in Politik, Medien und Gesellschaft. ${ }^{400}$ „Die Leugnung von Rassismus ist einer der taktischen Züge $[\ldots]^{\text {“401 }}$ zur „Gesichtswahrung oder positiven Selbstdarstellung [...]“402, um den etablierten gesetzlichen, normativen und wertgebundenen Vorstellungen zu entsprechen. ${ }^{403}$ Insbesondere in der Politik kann auch im Zuge der Debatte um Einwanderung, Migration und Fremdenfeindlichkeit des letzten Jahrzehnts eine Verschleierungstaktik rassistischer Befunde identifiziert werden. ${ }^{404}$ Van Dijk stellt hier eine ,[...] Leugnung und Umkehrung des Rassismus“405 fest. 406

Eine besondere Bedeutung des - wenn auch verdeckten - Rassismus kommt in diesem Zusammenhang auch der medialen Gewalt zu, die mithilfe ,semantischer Tricks“" 407 eine negative Fremddarstellung von Minderheiten als Bedrohung oder Überflutungswelle popularisiert. Die Medien haben folglich zusätzlich einen bedeutenden Anteil am Wiederaufstieg des Rassismus im 21. Jahrhundert (s. Kapitel 4.3.2). ${ }^{408}$

396 Geiss 1988, a. a. O., S. 315.

397 Vgl. Rommelspacher 2009, a. a. O., S. 32 f.

398 Vgl. Kalpaka/Räthzel 1994c, a. a. O., S. 12. | Vgl. Glanninger 2009, a. a. O., S. $24 f$.

399 Vgl. Glanninger 2009, a. a. O., S. 38. | Vgl. Rommelspacher 2009, a. a. O., S. 34.

400 Vgl. Dijk, Teun A. van (1992b): Rassismus-Leugnung im Diskurs, in: Jäger, Sieg-

fried/Januschek, Franz (Hrsg.): Der Diskurs des Rassismus. Ergebnisse des DISS-

Kolloquiums November 1991, Osnabrück, S. $105 \mathrm{ff}$.

401 Dijk 1992b, ebd., S. 105.

402 Dijk 1992b, ebd., S. 105.

403 Vgl. Dijk 1992b, ebd., S. 105.

$404 \quad$ Vgl. Dijk 1992b, ebd., S. $206 f f$.

405 Dijk, Teun A. van (1991): Rassismus heute: Der Diskurs der Elite und seine Funktion für die Reproduktion des Rassismus, 2. Auflage, Duisburg, S. 18.

406 Vgl. Dijk 1991, ebd., S. 18ff. | Vgl. Dijk, Teun A. van (1993): Subtiler Rassismus in westlichen Parlamenten, in: Butterwegge, Christoph/Jäger, Siegfried (Hrsg.): Rassismus in Europa, 2.

Auflage, Köln, S. $206 \mathrm{ff}$.

407 Dijk 1991, a. a. O., S. 17.

408 Vgl. Dijk 1991, a. a. O., S. 20 f. 
Trotz der zahlreichen Versuche, den Rassismusbegriff in der bundesrepublikanischen Fremdenfeindlichkeitsdebatte zu vermeiden, wird dieser durch die europäische und internationale Ebene - auf der der Begriff eine regelmäßige Anwendung findet - schrittweise wieder nach Deutschland „reimportiert“409. So kann eine Rückkehr des Rassismusbegriffes in die politische, gesellschaftliche und wissenschaftliche Debatte identifiziert werden: „Über den Umweg der EU-Politik hat die Thematisierung von Rassismus und rassistisch motivierter Gewalt [wieder] Eingang in den politischen und medialen Mainstream gefunden." ${ }^{410}$ Siegfried Jäger stellte demgegenüber in den 1990er Jahren fest, dass der biologisch-genetische Rassismus immer weiter in den Hintergrund verdrängt bzw. verdeckt werden würde. ${ }^{411}$ Wie die vorherigen Kapitel veranschaulichen, kann hier aus der Perspektive der Gegenwart nur teilweise zugestimmt werden: Verdeckung ja, Verdrängung nein (s. Kapitel 3). ${ }^{412}$ Denn heute steht zumeist nicht der offene ,rassentheoretische' Rassismus im Vordergrund, sondern eher subtil verpackte, rassistische Vorurteile. 413 Vor diesem Hintergrund darf die Untersuchung und Diskussion des biologisch konnotierten Rassismus in Deutschland - das Ziel dieser Arbeit - kein Tabuthema mehr sein.

Biologisch und kulturell konnotierter Rassismus gehen zwar auch heute noch überwiegend fließend ineinander über. ${ }^{414}$ „Hier vermischen sich zeitlich-soziale Sichtweisen mit naturbezogenen unveränderlichen." 415 Étienne Balibar und PierreAndré Taguieff diagnostizierten so vor dem Jahrtausendwechsel einen neuen kulturell geprägten Neorassismus, einen ,Rassismus ohne Rassen', der sich primär kultureller und sozialer Items bediene, um Differenzen zwischen Menschengruppen zu identifizieren (s. Kapitel 2.2.3).416 Deutlich wurde jedoch, dass diese sozialen und kulturellen Zuschreibungen der Rassismusdebatte vielfach naturalisiert werden, um mithilfe der Biologie den scheinbar validen, nachhaltigen bzw. endgültigen Charakter der Diskriminierungsstrategien zu bestätigen (s. Kapitel 2.1.2).417 Die Biologie bleibt nach wie vor ein fundamentales Erklärungsmoment des gegenwärtigen Rassismus. ${ }^{418}$

\footnotetext{
409 Rommelspacher 2009, a. a. O., S. 33.

410 Scherr 2009, a. a. O., S. 83.

411 Vgl. Jäger 1992b, a. a. O., S. 14.

412 Vgl. Jäger 1992b, a. a. O., S. 14.

413 Vgl. Jäger 1992b, a. a. O., S. 52.

414 Vgl. Glanninger 2009, a. a. O., S. 36.

415 Jäger 1992a, a. a. O., S. 135.

416 Vgl. Glanninger 2009, a. a. O., S. $40 \mathrm{ff}$.

417 Vgl. Bojadžijev, Manuela/Demirović, Alex (2002): Vorwort, in: ebd. (Hrsg.): Konjunkturen des Rassismus, Münster, S. 16.

418 Vgl. Reinfeldt, Sebastian/Schwarz, Richard/Foucault, Michel (1993): Bio-Macht, 2. Auflage, Duisburg, S. 5. | Vgl. Jäger, Siegfried/Januschek, Franz (1992): Einleitung: ,Der Diskurs des Rassismus', in: ebd. (Hrsg.): Der Diskurs des Rassismus. Ergebnisse des DISS-Kolloquiums November 1991, Osnabrück, S. 9. | Vgl. Solomos 2002, a. a. O., S. 158.

Teilweise wird sogar indirekt eine genetische Andersartigkeit der Fremden in der gesellschaftlichen Debatte angesprochen, wie die vorhergehenden Kapitel zeigen - dies kann eindeutig in das Phänomen des biologischen Rassismus reintegriert werden. Vgl. Jäger 1992b, a. a. O., S. $92 \mathrm{f}$.
} 
„Auf diese Weise wird Kultur ein nach außen bin sichtbarer Parameter für die biologisch determinierte, psychische Leistungsfähigkeit einer Rasse und demnach auch als indirekt durch Vererbung beeinflusst interpretiert."

Lediglich in der wissenschaftlichen Debatte der 1990er Jahre kann von einem Paradigmenwechsel hin zu kulturellen und sozialen Untersuchungsdesigns bezüglich des Rassismus gesprochen werden. ${ }^{420}$ Die Biologie bleibt jedoch systematischer Kern der rassistischen Argumentation. Die Kultur dient sozusagen lediglich als Platzhalter für den ,Rassebegriff ${ }^{6}$ - fraglich bleibt nur, ob der Begriff ,Kultur auch den Fokus des ehemaligen ,Rassenkonstrukts' korrekt wiedergeben kann. ${ }^{421}$ Die Vermeidung und angebliche Abschaffung des ,Rassebegriffes` scheint so nur ein „Oberflächeneffekt ${ }^{“ 422} \mathrm{zu}$ sein.
„Unter dem Deckmantel kultureller ,Inkompatibilität" wird [...] die eigene Gruppe ge- gen Einwanderung anderer ethnischer Gruppen, die allerdings bäufig ,zufällig' farbig sind, abgeschottet. Mit anderen Worten: Was implizit gefürcbtet wird und wovor mit Hilfe einer Rhetorik kultureller, Autonomie' gewarnt wird, das ist in Wirklichkeit die Rassen,mischung; um ,Rassenreinheit" und natürlich die rassische Vorberrschaft der Weißen zu verteidigen. " 423

Die angebliche Transformation des biologisch begründeten Rassismus in einen vornehmlich kulturell begründeten Rassismus, wie beispielsweise Politikwissenschaftlerin Manuela Bojadžijev argumentiert, scheint tendenziell nur partiell zutreffend. ${ }^{424}$ Die biologistisch-rassistischen Argumentationen kommen heute statt auf der Grundlage von biologischen Fachbegriffen lediglich in einem modernisierten, sozialwissenschaftlichen Gewand vor. ${ }^{425}$ Von Seiten der Sozialwissenschaften hat man den ,Rassebegriff' schon Ende des 20. Jahrhunderts größtenteils endgültig aufgegeben und zurück an die Natur- und Humanwissenschaften verwiesen. ${ }^{426}$ Anders verhält es sich mit der gesellschaftlichen Rassismusdebatte, in der „, $[\ldots]$ im banalen täglichen Gebrauch eine metaphorische Ausweitung der Begriffsverwen-

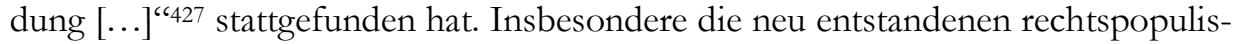
tischen Strömungen bedienen sich, selbstverständlich verdeckt, wieder dem biologischen ,Rassenrassismus', mit dem Ziel einer - um mit den Worten des französischen Philosophen, Soziologen und Psychologen Michel Foucault zu sprechen nationalen ,Bio-Politik' der Bevölkerung. ${ }^{428}$

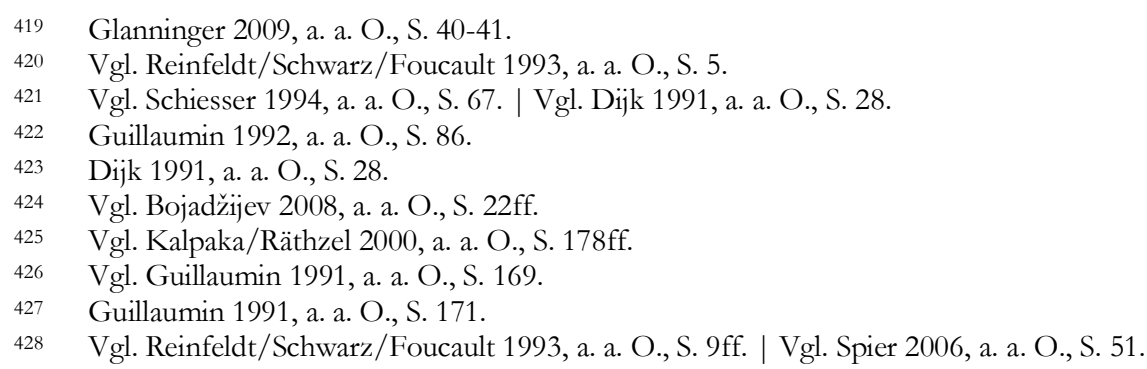


Die biologistischen Elemente des Rassismus sind resümierend auch heute noch implizit und explizit verbreitet vorhanden - lediglich die Argumentation der Rassisten hat sich dem Denken des 21. Jahrhunderts flexibel angepasst und hat die Tabuisierungs- und Leugnungsstrategie des biologistischen Rassismus sowie des Rassismusphänomens insgesamt übernommen. ${ }^{429}$ Die Kennzeichen und Charakteristika des gegenwärtigen Rassismus im 21. Jahrhundert scheinen also nicht gänzlich neu bzw. vollkommen kulturalisiert zu sein.
„Übergreifendes Kennzeichen der neuen, heutigen Formen des Rassismus ist der explizite Wechsel vom dogmatischen Weltbild zur praktischen Weltveränderung, mithin die Wie- derbolung eines Strukturwandels, der am Ausgang des 19. Jabrbunderts schon einmal stattgefunden hat. Das wird nicht zuletzit in dem von der jüngeren Forschung festgestell- ten Trend rassistischer Denkweisen deutlich, nicht mehr die rassische Ungleichbeit, son- dern rassistisches Verbalten zum natürlichen Faktor zu erklären. "430

Weiterhin kann vor diesem Hintergrund auch der prognostizierte heutige ,[...] Kampf der Kulturen $[\ldots]^{“ 431}$, vor allem seit den weltverändernden Terroranschlägen vom September 2001 in den USA, als nichts anderes als der ,[...] Mythos vom Rassenkampf $[\ldots]^{\text {" } 432}$ begriffen werden. ${ }^{433}$ Wichtig ist an dieser Stelle nur, auch im 21. Jahrhundert wieder explizit von einem biologistischen Rassismusproblem zu sprechen, um schon möglichst frühzeitig und wissenschaftlich eindeutig präventiv forschen zu können. 434

Als Ausblick kann festgestellt werden, dass insbesondere die zunehmende Etablierung des islamischen Glaubens in Deutschland und Europa zu einem neuen, europäischen Rassismusphänomen führen könnte bzw. aktuell schon vorhanden ist, in dem auch das gesellschaftliche bzw. sozialisierte ,Rassenkonzept ${ }^{\star}$ wieder eine essentielle Rolle spielen wird. ${ }^{435}$ Robert Miles prognostizierte diesbezüglich schon 1993 ein gewandeltes Rassismusproblem in den Staaten der Europäischen

429 Vgl. Veit, Barbara/Wiebus, Hans-Otto (1993): Hass macht die Erde kalt. Die Wurzeln des Rassismus, Wuppertal, S. 47f.

Das Rassismusphänomen des 21. Jabrbunderts zeigt sich flexibler und anpassungsfähiger denn je und folglich auch schwieriger definitorisch und begrifflich zu fassen. Paul Mecheril und Karin Scherschel haben eine tabellarische Zusammenstellung der aktuellen Funktionen und Charakteristika des gegenwärtigen Rassismus generiert, auf die in diesem Zusammenhang verviesen wird. Vgl. Mecheril/Scherschel 2009, a. a. O., S. 53. Geulen 2007, a. a. O., S. 112.

431 Geulen 2007, a. a. O., S. 115.

Die politische Theorie des ,Kampfes der Kulturen' geht auf den Politikwissenschaftler Samuel Huntington zurück, der Spannungen im Bereich der internationalen Beziebungen auf die Konflikte verschiedener Kulturkreise zurückführt. Vgl. Huntington, Samuel P. (2007): Kampf der Kulturen. Die Neugestaltung der Weltpolitik im 21. Jahrhundert, Hamburg.

432 Geulen 2007, a. a. O., S. 115.

433 Vgl. Geulen 2007, a. a. O., S. 115.

434 Vgl. Geulen 2007, a. a. O., S. 117.

435 Vgl. Miles 1993, a. a. O., S. 18.

Die zunehmende Etablierung des islamischen Glaubens in Deutschland zeigt sich beispielsweise an der sukzessiven Einfübrung des islamischen Religionsunterrichts an Scbulen. So existiert in Nordrhein-Westfalen seit 2012 ein Modellprojekt zum islamischen Religionsunterricht an Grundschulen. Auch Niedersachsen plant, diesen ab dem Scbuljabr 2013/2014 anzubieten. 
Union, was heute, wie die vorhergehenden Kapitel visualisieren, tendenziell bestätigt werden muss (s. Kapitel 3).436 Auch die Psychologin Birgit Rommelspacher illustriert so:

$$
\begin{aligned}
& \text { „Der antiislamische Rassismus gründet auch auf einer langen Vorgeschichte, nämlich } \\
& \text { dem jahrhundertealten politischen und kulturellen Kampf zwischen Orient und Ok.zi- } \\
& \text { dent. [...] So ist, der' Islam heute zum eigentlichen Gegenspieler, des' Westens geworden } \\
& \text { [...]. " } 437
\end{aligned}
$$

Darüber hinaus wird auch die ,Andersartigkeit' und ,Verschiedenheit' der islamischen Gläubigen wieder im Sinne des biologistischen Rassismus ihrer Natur zugeschrieben - der kulturelle Faktor Religion wird also ebenfalls biologisiert, sodass eindeutig von einem biologisch konnotierten Rassismus gesprochen werden kann. ${ }^{438}$ Denn gerade für diese interkulturellen und globalisierungsspezifischen Konfliktsituationen liefert das Rassismuskonstrukt die passenden pseudowissenschaftlichen Denk- und Systematisierungskategorien. ${ }^{439}$ Insbesondere in Zeiten krisenhafter Weltwirtschaftstrends sowie eines instabilen Arbeitsmarktes bieten die Argumentationsstrukturen des biologistischen Rassismus abermals passende Antworten, wie beispielsweise die altbekannte ,Sündenbockfunktion' - heute der Einwanderer vornehmlich des muslimischen Glaubens. ${ }^{440}$ Folglich kann im 21. Jahrhundert tendenziell nicht von einem gänzlichen ,Rassismus ohne Rassen` gesprochen werden, da die biologischen Erklärungsansätze des Rassismus und auch der ,Rassebegriff ${ }^{6}$ - wenn auch indirekt - weiterhin präsent erscheinen. Diese konstruieren immer noch das originäre Zentrum des Rassismusphänomens.

\subsection{Zwischenfazit: Rassismusbegriff im 21. Jahrhundert}

Die theoretisch-empirische Diskussion des Rassismusbegriffs in den vorherigen Kapiteln zeigt, dass sich eine eindeutige Beschreibung sowie Definition des Phänomens auch weiterhin komplex darstellt. ${ }^{441}$ Die Begrifflichkeit ist mit vielen Merkmalen, Charakteristika, Bedeutungszuschreibungen sowie multiplen Facetten und Ausprägungen verbunden. Rassismus stellt vornehmlich ein Pool von individuellen Einstellungen und Haltungen dar. ${ }^{442}$

In diesem Zusammenhang muss notwendigerweise auch auf die zahlreichen gesetzlichen und vertraglichen Grundlagen hingewiesen werden, die sämtliche pseudowissenschaftliche Theoreme der rassistischen Ideologie eigentlich ausschließen bzw. für inexistent erklären. Zu nennen sind diesbezüglich insbesondere zwei UNESCO-Erklärungen (United Nations Educational, Scientific and Cultural Orga-

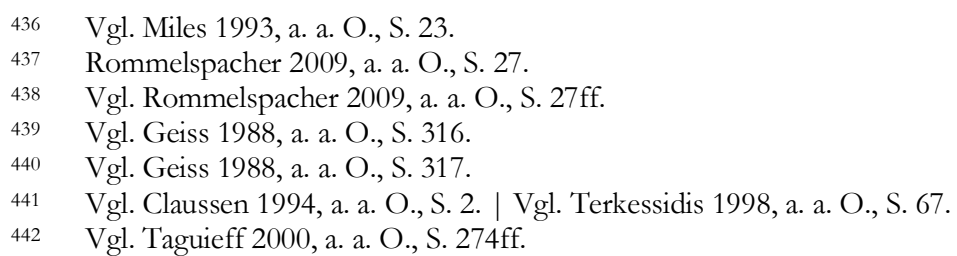


nization) von 1950 und 1978 zur Existenz und Anwendbarkeit des sogenannten ,Rassebegriffs' in Wissenschaft, Politik und Gesellschaft. Diese weisen explizit auf die Nicht-Existenz von verschiedenen ,Menschenrassen' hin. ${ }^{443}$ Auch ein UNÜbereinkommen von 1966 setzt sich die Beseitigung jeder Form der ,Rassendiskriminierung، als Ziel.444 Zusätzlich werden die ,Rassendiskriminierung' und der ,Rassepopulismus‘ ebenfalls als wissenschaftlich falsch, moralisch fragwürdig sowie als sozial ungerecht und gefährlich charakterisiert. ${ }^{445}$

Auf europäischer Ebene sind Rassismus und ,Rassendiskriminierung ${ }^{6}$ in der Charta der Grundrechte der EU ebenfalls diskreditiert: In Art. 3 werden beispielsweise eugenische Praktiken verboten, in Art. 21 das Antidiskriminierungsgebot festgesetzt sowie in Art. 22 die Achtung der kulturellen Vielfalt angemahnt. 446 Auf bundesrepublikanischer Ebene sind schließlich das Grundgesetz sowie das Bürgerliche Gesetzbuch (BGB) hervorzuheben. Im GG sind in Art. 1 die unantastbare Würde aller Menschen, die Achtung der Menschenrechte in Deutschland sowie in Art. 3 die Diskriminierungsverbote festgehalten. ${ }^{447}$ Das BGB setzt mit dem im August 2006 verabschiedeten Allgemeinen Gleichbehandlungsgesetz (AGG) in Art. 1 ebenfalls ein Argument gegen ,[...] Benachteiligungen aus Gründen der Rasse oder wegen der ethnischen Herkunft [...]“448. Kritisch muss

443 Die UNESCO-Erklärung vom Juli 1950 weist explizit darauf hin, dass alle Menschen zur gleichen Speques Homo sapiens gebören, eine Existen z von Subspezies bzw. ,Rassen' somit nicht vorhanden ist. Lediglich kulturelle Einflüsse bewirken die Entstehung vielfältiger ethnischer Gruppen, nicht jedoch differenter, biologischer ,Rassen: Der, Rassebegriff wird demnach schon hier als Mythos klassifiziert. Vgl. UNESCO (1950): "The race question", in URL:

http://unesdoc.unesco.org/images/0012/001282/128291eo.pdf <25.11.2012>. | Vgl. UNESCO (1978): „Erklärung über ,Rassen“ und rassistische Vorurteile“, in URL:

http://www.unesco. de/erklaerung_rassist_vorurteile.html <25.11.2012>.

444 Vgl. UN (1966): „Internationales Übereinkommen zur Beseitigung jeder Form von Rassendiskriminierung“", in URL: http://www.auswaertiges-

amt.de/cae/servlet/contentblob/360838/publicationFile/3632/BeseitigungRassendiskr.pdf $<25.11 .2012>$.

Vor dem Hintergrund der rassistischen Äußerungen Thilo Sarrazins wurde Deutschland im April 2013 vom Committee on the Elimination of Racial Discrimination (CERD) der Vereinten Nationen gerügt, durch die Einstellung des Strafverfahrens gegen Thilo Sarrazin gegen das Übereinkommen zur Beseitigung von Rassendiskeriminierung verstoßen zu haben. Der Türkische Bund Berlin-Brandenburg hatte den Fall bei CERD vorgebracht. Die Bundesregierung erklärte daraufhin im Juli 2013 an CERD, die bundesrepublikanische Gesetzgebung gegen Rassismus zu prüfen. Vgl. Spiegel Online (2013): „Rassismusvorwürfe wegen Sarrazin: Uno rügt Deutschland - und setzt Ultimatum“, in URL:

http://www.spiegel.de/politik/deutschland/uno-ruegt-deutschland-wegen-sarrazin-und-setztultimatum-a-895208.html <07.07.2013>. | Vgl. Committee on the Elimination of Racial Discrimination (2013): „Communication No. 48/2010. Opinion adopted by the Committee at its eighty second (11 February to 8 March 2013)“, in URL:

http://www2.ohchr.org/English/bodies/cerd/docs/CERD-C-82-D-48-2010-English.pdf $<07.07 .2013>$. | Vgl. Dernbach 2013, a. a. O.

445 Vgl. UN 1966, ebd.

446 Vgl. Bundeszentrale für politische Bildung (2008): Vertrag von Lissabon. Mit einer Einführung von Elmar Brok und Jo Leinen, Bonn, S. $207 \mathrm{ff}$.

447 Vgl. Bundeszentrale für politische Bildung 2011, a. a. O., S. 13.

448 Deutscher Taschenbuch Verlag (2010): Bürgerliches Gesetzbuch, München, 66. Auflage, S. 709 . 
jedoch bezüglich BGB und GG konstatiert werden, dass beide den sowohl sozialals auch naturwissenschaftlich diskreditierten ,Rassebegriff‘ weiterhin verwenden. Diese von zahlreichen Gesetzesgrundlagen auf internationaler, supranationaler und nationaler Ebene festgelegten Diskriminierungs- und Rassismusverbote scheinen in der deutschen Gesellschaft jedoch nur partiell akzeptiert zu sein.

Wie schon skizziert, wird sich die weitere Ausarbeitung auf die enggeführte Rassismusdefinition von Robert Miles konzentrieren, die konkret die biologischgenetischen Argumentationsschemata des Rassismus fokussiert. ${ }^{49}$ Miles spricht von Rassismus, wenn andere Menschengruppen aufgrund scheinbarer biologischer - phänotypischer und genotypischer - Differenzen abgewertet, ausgegrenzt, abgelehnt und diskriminiert werden. 450 Seine Theorie bildet hinsichtlich der Identifizierung von biologisch-rassistischen Einstellungen die ideale Ausgangsbasis für eine Untersuchung dieses biologistischen Rassismusphänomens der Gegenwart. Birgit Rommelspacher stellt diese biologischen Konnotationen nochmals deutlich heraus:

„Rassismus im modernen westlichen Sinn basiert auf der, Theorie" der Unterschiedlich-
keit menschlicher, Rassen" aufgrund biologischer Merkmale. Dabei werden [auch] soziale
und kulturelle Differenzen naturalisiert und somit soziale Beziebungen zwischen Men-
schen als unveränderliche und vererbbare verstanden [...]. Die Menschen werden dafür
in jeweils homogene Gruppen zusammengefasst und vereinheitlicht [...] und den anderen
als grundsätzlich verschieden und unvereinbar gegenüber gestellt [...] und damit zugleich
in eine Rangordnung gebracht [...]. "451

Aufmerksamkeit sollte jedoch in diesem Zusammenhang auch die Rassismusdefinition von Albert Memmi erlangen, da er enge und weite Ansätze in einem Definitionsversuch miteinander zu kombinieren versucht, also sowohl Kultur als auch Biologie in seinen Erklärungsansatz integriert. ${ }^{452}$ Gewarnt werden muss jedoch eindringlich - und deswegen hier auch die eindeutige Präferenz der engeren, biologisch konnotierten Rassismusdefinitionen - vor einer ,Verwässerung des Rassismusbegriffs; ohne die biologische Komponente bleiben die Definitionsversuche angreifbar, weniger griffig sowie theoretisch nur schwierig klassifizierbar. ${ }^{453}$

Weiterhin konnte im Verlauf der vorherigen Kapitel visualisiert werden, dass das Phänomen des Rassismus auch nicht einfach entstanden ist, sondern sich als ein von vielen Faktoren beeinflusstes, ideologisches System etablierte, das auch heute noch von Gesellschaft, Wissenschaft und Medien reproduziert und verbreitet wird (s. Kapitel 4). ${ }^{454}$

\footnotetext{
449 Vgl. Memmi 1992, a. a. O., S. $120 \mathrm{ff}$.

450 Vgl. Memmi 1992, a. a. O., S. 124.

451 Rommelspacher 2009, a. a. O., S. 29.

452 Vgl. Claussen 1994, a. a. O., S. $225 \mathrm{ff}$.

453 Vgl. Poliakov et al. 1992, a. a. O., S. 43. | Vgl. Weiß 2013, a. a. O., S. 29.

454 Vgl. Butterwegge 1993, a. a. O., S. 194f. | Vgl. Kalpaka/Räthzel 1994c, a. a. O., S. 16.
} 
„Rassismus lässt sich nur von seiner Kontinuität und Hartnäckigkeit aus begreifen. Das bedeutet nicht, dass es keine tiefen Einschnitte in der Geschichte des Rassismus gegeben hat, aber es bedeutet, dass Rassismus eng mit der Geschichte der Moderne verwoben ist." 455

Die historischen Dimensionen des Rassismus reichen demnach weit in das Zeitalter der Antike zurück, in denen sich die ersten proto-rassistischen Verhaltensweisen etablierten, auch wenn diese noch ohne den expliziten ,Rassebegriff' existierten. 456 Bis heute schreiben sich die Entwicklungen des Rassismus in Deutschland fort, wenn auch teilweise mit mangelhaften und irreführenden Ersatztermini. ${ }^{457}$ Zumindest historisch gesehen kann Deutschland als Kernland des Rassismus bezeichnet werden, als ,[...] Gelobtes Land der europäischen Rassenphantasien

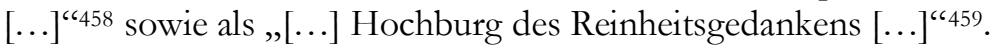

Der bundesrepublikanische Rassismus des 21. Jahrhunderts kann, um mit den Worten Robert Miles' zu sprechen, als ,soziale Konstruktion' bezeichnet werden, jedoch in einer ,[...] neue[n] Konfiguration." ${ }^{460}$ Bevölkerungsgruppen werden systematisch diskriminiert, naturalisierend und biologisierend ,rassifiziert', obwohl der negativ konnotierte ,Rassebegriff' weitestgehend vermieden wird und so eher indirekt, verborgen und verdeckt erscheint. ${ }^{461}$

„[... [ an Wirkungsmacht und Überzeugung hat der Rassismus bis heute leider wenig eingebüßt $[\ldots]^{\text {“462 }}$. Viele vergangenen Kriege und Krisenfelder weltweit gründeten auf Rassismus- und ,Rassenkonflikten“.463 „Manches deutet sogar darauf hin, dass wir an der Schwelle einer Epoche stehen, in der eine regelrechte Renaissance des Rassismus zumindest möglich erscheint." 464 Wie die vorhergehenden Kapitel bestätigen, scheint diese Prognose des Historikers Christian Geulens durchaus zuzutreffen (s. Kapitel 3). Die Entstehung und Entwicklung neuer wieder deutlich biologisch konnotierter - Formen des Rassismus stellen sich als wahrscheinlich dar. ${ }^{465}$

Rassismus charakterisiert sich so immer mehr als gesamtgesellschaftliches Problem, welches große Teile der Bevölkerung betrifft - von der Gesellschaft

\footnotetext{
455 Terkessidis 1998, a. a. O., S. 118.

456 Vgl. Kerner 2009, a. a. O., S. 59.

457 Vgl. Kerner 2009, a. a. O., S. 127.

458 Poliakov, Léon (1993): Der arische Mythos. Zu den Quellen von Rassismus und Nationalismus, Hamburg, S. 270.

459 Poliakov 1993, ebd., S. 270.

460 Balibar, Étienne (1992): „Es gibt keinen Staat in Europa“. Rassismus und Politik im heutigen Europa, in: Institut für Migrations- und Rassismusforschung e. V. (Hrsg.): Rassismus und Migration in Europa. Beiträge des Kongresses „Migration und Rassismus und Europa“ Hamburg, 26. bis 30. September 1990, Hamburg, S. 18.

461 Vgl. Glanninger 2009, a. a. O., S. 42. | Vgl. Kerner 2009, a. a. O., S. 125.

462 Geulen 2007, a. a. O., S. 8.

463 Vgl. Benedict 1983, a. a. O., S. 3.

464 Geulen 2007 , a. a. O., S. 9.

465 Vgl. Geulen 2007, a. a. O., S. 11.
} 
reproduziert und verbreitet. ${ }^{466}$ Rassistisches Wissen wird zunehmend als gesellschaftliche Normalität angesehen. ${ }^{467}$ Die Anthropologin Ruth Benedict folgerte vor diesem Hintergrund schon in den 1980er Jahren: „In other words, racism is a creation of our own time. It is a new way of separating the sheep from the goats. “" 468

Schlussfolgernd kann so gewissermaßen von einer Kontinuität des Rassismusterminus in Deutschland gesprochen werden. ${ }^{469}$ Die Geschichte des Rassismus bleibt weiterhin lebendig: ${ }^{470}$

„,...] [So] hat der Rassismus auch beute noch seine Verteidiger, die an seinen objektiven Wert glauben. Und er ist nicht nur nicht tot, sondern tötet immer noch jeden Tag Menschen auf unserer Erde." 471

466 Vgl. Kerner 2009, a. a. O., S. 59. | Vgl. Mühlen, Patrik von zur (1977): Rassenideologien. Geschichte und Hintergründe, Berlin u. a., S. $11 \mathrm{ff}$.

467 Vgl. Terkessidis 1998, a. a. O., S. 109.

468 Benedict 1983, a. a. O., S. 2.

469 Vgl. Demirovic, Alex (1992a): Vom Vorurteil zum Neorassismus. Das Objekt ,Rassismus ‘ in Ideologiekritik und Ideologietheorie, in: Jäger, Siegfried/Januschek, Franz (Hrsg.): Der Diskurs des Rassismus. Ergebnisse des DISS-Kolloquiums November 1991, Osnabrück, S. 14.

470 Vgl. Veit/Wiebus 1993, a. a. O., S. 88.

471 Delacampagne 2005, a. a. O., S. 17. 


\section{Biologistischer Rassismus der Gegenwart}

Die rassistische Ideologie rekurriert im 21. Jahrhundert auf keinen grundsätzlich neuen Erkenntnissen, Vorurteilen oder Ressentiments. Sie bedient sich zahlreicher bekannter Annahmen aus dem 18., 19. und 20. Jahrhundert, um ihre Theoreme auf eine scheinbar validierte Grundlage zu stellen. Die nachfolgenden Kapitel werden anhand unterschiedlicher empirischer Datenmaterialien visualisieren, dass sich im 21. Jahrhundert insbesondere der biologisch-genetisch argumentierende Rassismus wieder in der gesellschaftlichen Realität etabliert, obwohl dieser nach den Schreckensereignissen des Zweiten Weltkrieges eigentlich als auf den Scheiterhaufen pseudowissenschaftlicher Theoreme verbannt angesehen wurde. Illustrieren diese Annahmen jedoch die Realität des 21. Jahrhunderts? Vor allem die neueren Erfolge rechtspopulistischer Parteien in mehreren Nachbarstaaten der Europäischen Union, die Thesen Thilo Sarrazins sowie die rassistisch motivierten Anschläge der rechtsextremen, terroristischen Vereinigung ,Nationalsozialistischer Untergrund' demonstrieren, dass biologisch-rassistische Ressentiments direkt und indirekt vorhanden zu sein scheinen. ${ }^{472}$ Rechtspopulistische Argumentationen, die ebenfalls auf der Ideologie des Rassismus basieren, könnten auch in der Bundesrepublik Deutschland eine nachhaltige Zustimmung erreichen - trotz des bisherigen Fehlens einer rechtspopulistischen Partei auf der Bundesebene. ${ }^{473}$ Ist die Lage

\footnotetext{
472 Vgl. Zick/Küpper/Hövermann 2011, a. a. O., S. 198. | Vgl. Decker/Kiess/Brähler 2012, a. a. O., S. $7 \mathrm{ff}$.

473 Vgl. Zick/Küpper/Hövermann 2011, a. a. O., S. 198.
} 
der bundesrepublikanischen Demokratie folglich als bedenklich zu charakterisieren? 474

Ein in den vorherigen Kapiteln schon aufgezeigtes Problem der gegenwärtigen Rassismusforschung ist die tendenzielle Vermeidung der Begrifflichkeit des Rassismus, auch innerhalb von Forschungsprojekten. ${ }^{475}$ Der originäre Rassismusbegriff zeigt sich jedoch als zwingend notwendig, da tendenziell verdeckte, rassistische Verhaltensweisen und Einstellungen in der bundesrepublikanischen Gesellschaft anzutreffen sind, insbesondere die sich scheinbar regenerierenden biologistischen Argumentationsmodelle. Die nachfolgenden Kapitel visualisieren diese tendenzielle Rückkehr allgemein rassistischer sowie vor allem biologisch argumentierender Theoreme anhand unterschiedlicher Datenmaterialien.

Der aktuelle sozialwissenschaftliche Forschungsstand bezüglich repräsentativer, empirischer Rassismusstudien in Deutschland ist ausreichend, aber erweiterbar. Er firmiert jedoch größtenteils unter dem Phänomen bzw. der Begrifflichkeit des Rechtsextremismus oder der Fremdenfeindlichkeit. Aufgrund dessen wird im weiteren Verlauf vor allem auf Rechtsextremismus-Studien zurückgegriffen. Da der Rechtsextremismus jedoch auf der Grundidee des völkisch-rassistischen Denkens aufbaut und sich im Kern aus einer Ideologie der kulturellen als auch biologischen Ungleichheit - dem Rassismus - konstituiert, können die Rechtsextremismus-Studien zur Analyse des gegenwärtigen Rassismus herangezogen werden. ${ }^{476}$ Auch die Abschlusspublikation des deutschen XENOS-Sonderprogramms „Ausstieg zum Einstieg“"477 bestätigt die Ideologie des Rassismus als ein Hauptkriterium von Rechtsextremismus bzw. von rechtsradikalen Diskursen sowie den verschiedenen Varianten rechtsradikaler Kräfte. ${ }^{478}$ Unterstützt wird diese Vorgehensweise ebenfalls in den einzelnen Studien durch eine dezidierte Fokussierung auf das Rassismusphänomen in einzelnen Frageitems oder Befragungsschwerpunkten, wie beispielsweise der Forschungsansatz zur gruppenbezogenen Menschenfeindlichkeit (GMF) aufzeigt.

Nichtsdestotrotz bedarf eine Analyse des biologischen Rassismusschwerpunktes einer Fokussierung der Datenmaterialien unter neu zu skizzierenden Parametern. Für den Untersuchungszeitraum dieser Arbeit von 2007 bis 2013 existieren auf nationaler und supranationaler Ebene mehrere qualitative und quantitative Untersuchungsdaten. Insbesondere sind hier die zahlreichen Studien von Oliver

Diese Vermutung wird von mebreren statistischen Datenmaterialien gestïtrt, die aufgrund des Zustimmungs-

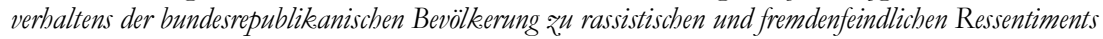
durchschnittlich eine besorgniserregende Perspektive aufzeigen (s. Kapitel 3.3, 3.4, 3.5, 3.6, 4.1.5).

474 Vgl. Zick/Küpper/Hövermann 2011, a. a. O., S. 198.

475 Vgl. Terkessidis 2004, a. a. O., S. 8.

476 Vgl. Salzborn, Samuel (2014): Rechtsextremismus, Baden-Baden, S. 20.

477 Melzer, Ralf/Serafin, Sebastian (Hrsg.): Rechtsextremismus in Europa. Länderanalysen, Gegenstrategien und arbeitsmarktorientierte Ausstiegsarbeit, Berlin.

478 Vgl. Minkenberg, Michael (2013): Die europäische radikale Rechte und Fremdenfeindlichkeit in West und Ost: Trends, Muster und Herausforderungen, in: Melzer, Ralf/Serafin, Sebastian (Hrsg.): Rechtsextremismus in Europa. Länderanalysen, Gegenstrategien und arbeitsmarktorientierte Ausstiegsarbeit, Berlin, S. 12ff. 
Decker und Elmar Brähler u. a. im Auftrag der Friedrich-Ebert-Stiftung sowie die Datenreporte des Statistischen Bundesamtes DESTATIS hervorzuheben. ${ }^{479}$ Für eine empirische Analyse gelangt weiterhin das populärwissenschaftliche Werk Thilo Sarrazins „Deutschland schafft sich ab. Wie wir unser Land aufs Spiel setzen“"480 in den Fokus, welches in der deutschen Bevölkerung ungeahnt hohe Zustimmungswerte erhielt. ${ }^{481}$ Kein anderes Autorenwerk hat in den letzten Jahren eine solch langanhaltende Debatte auf medialer, gesellschaftlicher und politischer Ebene ausgelöst. Die außerordentlich hohen Verkaufszahlen seines Bestsellers bestätigen das auch heute, drei Jahre nach der Erstveröffentlichung, noch große Interesse an Sarrazins Inhalten (s. Kapitel 1, 3.1). ${ }^{482}$ Darüber hinaus kann gerade an Sarrazins Thesen auf ideale Weise das Vorhandensein und die Akzeptanz von biologisch-rassistischen Ressentiments bewiesen werden - deswegen die Auswahl seines Werkes im Rahmen dieser Untersuchung. Für die späten 1990er Jahre sowie den Beginn des neuen Jahrtausends können jedoch fast keine wissenschaftlichen Forschungsvorhaben zum Rassismus identifiziert werden. Zwischen den rassistischen Gewalttaten von 1990 bis 1996 - während eine hohe Forschungsaktivität zu verzeichnen war - und dem Ende des ersten Jahrzehnts des 21. Jahrhunderts kann so eine gewisse Forschungslücke konstatiert werden (s. Kapitel 1.1, 1.2). Eventuell war man der Ansicht, das Problem des Rassismus“ in Deutschland endgültig überwunden zu haben - ein gefährlicher Trugschluss, der die Forschungsnotwendigkeit dieser Untersuchung nochmals herausstellt.

Vor diesem Hintergrund greift in vielen vorhandenen Forschungsprojekten die schon angesprochene Problematik der begrifflichen Unschärfe des Rassismusphänomens: Nur wenige Untersuchungen verwenden den wissenschaftlich transparenten Begriff des Rassismus. ${ }^{483}$ Dies stellt die empirische Auswertung rassisti-

479 Eine exemplarische Auswahl der publizierten Studien und Datensätze zu Rassismus, Rechtsextremismus und Fremdenfeindlichkeit in Deutschland: Decker, Oliver/Rothe, Katharina/Weissmann, Marliese/Geißler, Norman/Brähler, Elmar (2008): Ein Blick in die Mitte. Zur Entstehung rechtsextremer und demokratischer Einstellungen in Deutschland, Berlin. | Statistisches Bundesamt Destatis et al. (2008a): Datenreport 2008. Ein Sozialbericht für die Bundesrepublik Deutschland, Bonn. | Decker, Oliver/Weißmann, Marliese/Kiess, Johannes/Brähler, Elmar (2010): Die Mitte in der Krise. Rechtsextreme Einstellungen in Deutschland 2010, Berlin. | Zick/Küpper/Hövermann 2011, a. a. O. | Statistisches Bundesamt Destatis et al. (2011): Datenreport 2011. Ein Sozialbericht für die Bundesrepublik Deutschland. Band I, Bonn. | GESIS Leibniz-Institut für Sozialwissenschaften (2011): ,Supplement zur Fragebogendokumentation ALLBUS 2010", in URL: Anforderung via http://www.gesis.org/allbus (Originaldatensatz, <30.07.2011>). | Decker/Kiess/Brähler 2012, a. a. O. | Terwey, Michael/Baltzer, Stefan (2013): „GESIS-Variable Reports 2013/16. ALLBUS 2012 - Variable Report. StudienNr. 4614, Version: 1.1.0, doi: 10.4232/1.11634“, in URL: Anforderung via http://www.gesis.org/allbus $<26.05 .2013>$. Sarrazin 2010, a. a. O., München.

481 Vgl. Sarrazin 2010, a. a. O.

482 Vgl. Dernbach 2013, a. a. O.

483 Definitorisch bzw. rechtlich lassen sich verschiedene Gruppen von ausländischen Personengruppen differenzieren, die sowobl im gesellschaftlichen Alltag als auch partiell in vielfältigen Studien mit dem Begriff der. Ausländerinnen und Ausländer' vermischt werden. Unterschieden wird zwischen Personen mit Migrationshintergrund, 
scher Phänomene in der Bundesrepublik vor elementare Schwierigkeiten, insbesondere die Auswertung und Interpretation empirischer Datenmaterialien. Im weiteren Verlauf werden fremdenfeindliche, antisemitische und sozialbiologistische Tendenzen mit den Prinzipien der rassistischen Ideologie verknüpft - jedoch nicht gleichgesetzt -, da diese vielfach auf rassistischen Grundeinstellungen basieren (s. Kapitel 1). Demnach zeigen sich mögliche Probleme bzw. Gefahren der Datenanalyse, beispielsweise bei ungenauen Begriffsdefinitionen, fehlerhafter Transkribierung oder unzureichender Interpretation der Daten, als vorhanden. Dies erfordert in der Folge einen kritischen und differenzierten Umgang.

Die nachfolgenden Kapitel sollen mithilfe qualitativer sowie quantitativer, empirischer Datenmaterialien - trotz methodischer Einschränkungen - einen detaillierten Einblick in die aktuelle Verbreitung des bundesrepublikanischen Rassismusphänomens ermöglichen. Ein besonderer Fokus wird dabei auf das Vorhandensein biologisch-genetisch begründeter, rassistischer Argumentationsmuster gelegt. Wie verhält es sich mit biologistischen Erklärungsansätzen? Inwieweit stehen eher kulturalistische Elemente im Vordergrund?

Bezüglich der Datenbasis, greifen die folgenden Kapitel - wie schon angemerkt - auf unterschiedliche Datensätze bzw. sozialwissenschaftliche sowie bevölkerungsstatistische Datengrundlagen zurück. Erforderlich ist jedoch eine neue Fokussierung dieser unter für dieses Forschungsdesign passenden Parametern, um die illustrierten Fragestellungen und Ziele erfolgreich bearbeiten zu können. Auf der qualitativen Seite wird zum einen auf die Ergebnisse der gruppendiskursiven Studie „Ein Blick in die Mitte. Zur Entstehung rechtsextremer und demokratischer Einstellungen in Deutschland“"484 aus dem Jahr 2008 sowie zum anderen auf eine inhaltsanalytische Untersuchung des Werkes von Thilo Sarrazin aus dem Sommer 2010 zurückgegriffen, das aufgrund seiner hohen bevölkerungsweiten Zustimmungswerte für dieses Forschungsvorhaben unabdingbar erscheint. ${ }^{485}$ Eine qualitative Inhaltsanalyse dient dabei einerseits der Identifikation von inhaltlichen bzw. typisierenden Strukturen sowie andererseits der expliziten Aufklärung von Textpassagen hinsichtlich deren biologistisch-rassistischen Charakters. ${ }^{486}$ Dadurch können - von der sprachlichen auf die nicht-sprachliche Ebene - Rückschlüsse auf gesellschaftliche Phänomene getroffen werden. ${ }^{487}$ Diese Inhaltsanalyse des Buches von Thilo Sarrazin zeigt sich weitgehend neu, da von medialer sowie gesellschaftlicher Seite bisher nur über einzelne inhaltliche Aspekte debattiert, das Werk jedoch nie in seiner Gänze analysiert und interpretiert wurde. Die Engführung auf das biologistische Rassismusphänomen ermöglicht zusätzlich eine weitere

Zuwanderinnen und Zuwanderem, Flüchtlingen sowie Asylsuchenden, die jeweils einen differierenden, rechtlichen Status inne baben (s. Kapitel 4, 4.1.4)

484 Decker/Rothe/Weissmann/Geißler/Brähler 2008, a. a. O.

485 Aufgrund der zeitlichen Eingrenzung des Forschungszeitraumes hinsichtlich der Aktualität auf die Jahre 2007 bis 2013 sind weniger qualitative als quantitative Datensätze vorhanden, da in diesem Zeitraum die quantitativ erbobenen Datenmaterialien überwiegen.

486 Vgl. Flick 2009, a. a. O., S. 150ff. | Vgl. Lamnek 2010, a. a. O., S. $434 \mathrm{ff}, 443$.

487 Vgl. Lamnek 2010, a. a. O., S. 434ff. 
Fokussierung und Präzisierung der Thematik. Dies unterstreicht den Disziplinen übergreifenden Charakter dieses Forschungsansatzes. Auf der quantitativen Seite werden die Untersuchungsergebnisse der supranationalen Bevölkerungsbefragung „Die Abwertung der Anderen. Eine europäische Zustandsbeschreibung zu Intoleranz, Vorurteilen und Diskriminierung“"488 aus dem Jahr 2011, der nationalen Studie „Die Mitte in der Krise. Rechtsextreme Einstellungen in Deutschland 2010“489, der Studie „Die Mitte im Umbruch. Rechtsextreme Einstellungen in Deutschland 2012“490, der Datenreporte des Statistischen Bundesamtes DESTATIS 2008 und 2011491, der Allgemeinen Bevölkerungsumfragen der Sozialwissenschaften 2010 und $2012^{492}$ (ALLBUS) fokussiert sowie auch die Ergebnisse des Projektes „Gruppenbezogene Menschenfeindlichkeit in Deutschland“493 in den Mittelpunkt gestellt. Die Studien wurden auf der einen Seite ausgewählt, da sie zeitlich ideal zum gewählten Untersuchungszeitraum von 2007 bis 2013 passen und diesen mit den Erhebungsjahren 2008, 2010, 2011 und 2012 gleichmäßig sowie mit jeweils umfassendem Daten- und Vergleichsmaterial abdecken. Auf der anderen Seite sind die ausgewählten Studien ebenfalls alle durch einen ähnlichen Untersuchungsschwerpunkt gekennzeichnet. Dieser fokussiert jeweils das Phänomen des Rechtsextremismus bzw. diskriminierende, menschenfeindliche oder menschenabwertende Einstellungen. Aufgrund ähnlicher methodischer Zugänge wie beispielsweise Fragebogenanalysen oder individuelle Befragungen bzw. Interviews -, ähnlicher Untersuchungs- oder Frageitems - wie beispielweise bei den ,Mitte'-Studien, den ALLBUS-Daten oder den Datenreporten - sowie größtenteils homologer Zielformulierungen ist ebenfalls die Passung und Vergleichbarkeit der einzelnen Studienergebnisse gewährleistet. Weiterhin weisen die genannten quantitativen Untersuchungen jeweils eine hohe Teilnehmerzahl - die hinzukommend möglichst repräsentativ aus ganz Deutschland sowie aus verschiedenen sozialen Schichten zusammengesetzt sind - und damit auch auf ausreichendem Datenmaterial begründete Häufigkeitsverteilungen auf, sodass die Gefahr einer zu geringen Anzahl von Merkmalsträgern bei der Interpretation prozentualer Häufigkeitsverteilungen minimiert werden kann. ${ }^{494}$ Nichtsdestotrotz muss beachtet werden, dass die prozentualen Häufigkeitsverteilungen vordergründig nur einen quantitativen

\footnotetext{
488 Zick/Küpper/Hövermann 2011, a. a. O.

489 Decker/Weißmann/Kiess/Brähler 2010, a. a. O.

490 Decker/Kiess/Brähler 2012, a. a. O.

491 Vgl. Statistisches Bundesamt Destatis et al. 2008a, a. a. O. | Vgl. Statistisches Bundesamt Destatis et al. 2011, a. a. O.

492 Vgl. GESIS Leibniz-Institut für Sozialwissenschaften 2011, a. a. O. | Vgl. Terwey/Baltzer 2013, a. a. O.

493 Heitmeyer, Wilhelm/Zick, Andreas/Groß, Eva/Krause, Daniela/Küpper, Beate/Klein, Anna/Mansel, Jürgen (2012): „Das Projekt Gruppenbezogene Menschenfeindlichkeit in Deutschland. Eine 10-jährige Langszeituntersuchung mit einer fährlichen Bevölkerungsumfragezur Abwertung und Ausgrenzung von schwachen Gruppen“, in URL: http://www.unibielefeld.de/\%28de\%29/ikg/projekte/GMF/index.htm <01.08.2013>.

494 Vgl. Kähler, Wolf-Michael (2011): Statistische Datenanalyse. Verfahren verstehen und mit SPSS gekonnt einsetzen, 7. Auflage, Wiesbaden, S. 13.
} 
Querschnitt der Befragungsergebnisse einer zuvor ausgewählten Befragungsgruppe vergegenwärtigen. Zur Analyse, Auswertung und wissenschaftlichen Einordnung der Forschungsbefunde hilft zusätzlich neuere Sekundärliteratur zu den Themen Rassismus, Fremdenfeindlichkeit und Migration, unter anderem von Mark Terkessidis.495 Nichtsdestotrotz müssen die Datensätze anhand neu festgelegter Parameter auf den gewählten biologisch-rassistischen Schwerpunkt zentriert werden, um dem Rassismusschwerpunkt dieser Arbeit gerecht zu werden.

Im Mittelpunkt der methodischen Vorgehensweise stehen im weiteren Verlauf zu Beginn qualitative Datenmaterialien (s. Kapitel 1.3): Die Untersuchungsergebnisse des Interview-Materials sowie die Ergebnisse der qualitativen Inhaltsanalyse, die am Textmaterial unter Einbeziehung von politikwissenschaftlichen und biologischen Schwerpunkten durchgeführt wird. Der Vorteil der qualitativen Untersuchungen bzw. der qualitativen Ergebnisse am Anfang dieses Kapitels liegt in der einführenden Visualisierung und Identifizierung von typischen Deutungs-, Handlungs-, Argumentations-, Erklärungs- und Interaktionsmustern der biologisch konnotierten, rassistischen Ideologie. ${ }^{496}$ In der Folge kann ein Überblick geleistet werden, der die vorhandenen Vorurteile, Ressentiments und Stereotype einführend illustriert. Hierfür bieten sich nicht-standardisierte Interviews bzw. nichtstandardisierte, analytische Vorgehensweisen mit relativ wenigen Auswertungsfällen an.

Im weiteren Verlauf folgt die Inkludierung differenter quantitativer, standardisierter Forschungsergebnisse unter dem neuen Schwerpunkt des biologischgenetischen Rassismusphänomens. Hierzu müssen die vorhandenen Datensätze verglichen sowie an diesen Untersuchungsansatz angepasst werden. ${ }^{497}$ Aufgrund deren standardisierten, strukturierten Beobachtungen können repräsentative Aussagen ermöglicht und darauf aufbauend eine Generalisierung und Verallgemeinerung dieser Erkenntnisse realisiert werden. ${ }^{498}$ Somit können mithilfe der quantitativen Datenmaterialien die Befunde der qualitativen Datengrundlagen validiert werden. ${ }^{499}$ Diese Abfolge der Implementierung von qualitativen sowie quantitativen Datensätzen und Untersuchungsergebnissen erhöht faktisch die wissenschaftliche Validität dieser empirischen Analyse. ${ }^{500}$ Multiple Argumentationen können sich dementsprechend gegenseitig optimal ergänzen.

Diese präsentierte Vorgehensweise dient gleichzeitig als Strukturierungshilfe der Gliederung. Zu Beginn werden die qualitativen Analysen bezüglich biologischrassistischer Vorurteile in der bundesrepublikanischen Gesellschaft unter modifizierten Forschungsparametern fokussiert. Die hier gewonnenen Erkenntnisse

\footnotetext{
495 Vgl. Terkessidis 2004, a. a. O.

496 Vgl. Behnke/Baur/Behnke 2010, a. a. O., S. $45 \mathrm{ff}$.

497 Vgl. Flick 2009, a. a. O., S. 129.

498 Vgl. Brauner/Vollmer 2006, a. a. O., S. $43 \mathrm{ff}$.

499 Vgl. Behnke/Baur/Behnke 2010, a. a. O., S. 46.

500 Vgl. Behnke/Baur/Behnke 2010, a. a. O., S. 45ff. | Vgl. Flick 2009, a. a. O., S. 27.

Zusätzlich können durch die Kombination von qualitativen und quantitativen Datenmaterialien die jeweiligen methodischen Grenzen und Schwächen ausgeglichen sowie positive Synergieeffekte genutat werden.
} 
können dann mithilfe der unterschiedlichen quantitativen Datenmaterialien validiert und verifiziert werden. Abschließend folgt dann ein umfassendes Zwischenfazit bezüglich der Interpretation der Ergebnisse sowie der Verbreitung von insbesondere biologistisch argumentierenden, rassistischen Ressentiments in der bundesrepublikanischen Bevölkerung. Auch ein Blick auf die EU darf aufgrund der multiplen supra- und internationalen Verflechtungen Deutschlands keinesfalls vergessen werden, da diese sich gegenseitig auf vielfältige Weise beeinflussen.

\subsection{Thilo Sarrazin - ein Rassist des 21. Jahrhunderts?}

Der gegenwärtige Rassismus im 21. Jahrhundert kommt vielfach ohne den ,Rassebegriff‘ aus, sodass , „[...] stattdessen von Nation, Klasse oder Kultur die Rede ist und dennoch die Geschichte des Phänomens Rassismus unverkennbar fortgeschrieben wird."501 Diese neuen Argumentationsmuster des Rassismus werden auch durch die im Sommer 2010 auf politischer und gesellschaftlicher Ebene neu angestoßene Migrations-, Integrations- und Rassismusdebatte in Deutschland bestätigt. Als deren Auslöser ist die Veröffentlichung des Buches „Deutschland schafft sich ab. Wie wir unser Land aufs Spiel setzen“"502 des damaligen Bundesbankvorstandes Thilo Sarrazin zu diagnostizieren. Dieser skizziert in seinem Werk ein Untergangsszenario der Bundesrepublik Deutschland. Sarrazin identifiziert zahlreiche angebliche Krisen- und Fehlentwicklungen der letzten Jahrzehnte, sowohl politischer, gesellschaftlicher als auch wirtschaftlicher Art. Angefangen bei der durch die PISA-Studien (Programme for International Student Assessment) forcierten Bildungsdebatte zu Beginn des neuen Jahrtausends und die noch immer nicht überwundene Wirtschafts-, Finanz- und Eurokrise, über die vielseitigen negativen Auswirkungen der Globalisierung auf dem Arbeitsmarkt, dem scheinbar unaufhaltbaren demografischen Wandel der deutschen Bevölkerung, der fehlgeleiteten bundesrepublikanischen Ausländer- und Migrationspolitik, der Debatte des ,Einwanderungslandes Deutschland' bis hin zu den finanziell unterfinanzierten sozialen Sicherungssystemen der Bundesrepublik. ${ }^{503}$

Die mediale Aufmerksamkeit erlangte Thilo Sarrazin jedoch erst durch ein Vorab-Interview, in dem er die Theorie aufstellte: „Alle Juden teilen ein bestimmtes Gen, Basken haben bestimmte Gene, die sie von anderen unterscheiden. " 504

\footnotetext{
501 Geulen, Christian (2007): Geschichte des Rassismus, Bonn, S. 16.

502 Sarrazin 2010, a. a. O.

503 Vgl. Sarrazin 2010, a. a. O., S. 7-21.

Die PIS A-Studie ist eine internationale Schulleistungsstudie der OECD (Organisation for Economic Cooperation and Development). Die Studie untersucht, inwieweit Schülerinnen und Schüler gegen Ende ihrer Pflichtschulzeit die Kenntnisse und Fähigkeiten für eine volle Teilhabe an der Wissensgesellschaft erworben haben. Vgl. OECD (2010): PISA 2009 Ergebnisse. Was Schülerinnen und Schüler wissen und können: Schülerleistungen in Lesekompetenz, Mathematik und Naturwissenschaften, Paris.

504 Seibel, A./Schuhmacher, H./Fahrun, J. (2010): „Mögen Sie keine Türken, Herr Sarrazin“, in URL: http://www.welt.de/politik/deutschland/article9255898/Moegen-Sie-keine-TuerkenHerr-Sarrazin.html $<10.02 .2013>$.
} 
Diese mit fragwürdigen Datensätzen belegte Aussage verknüpfte Sarrazin mit der angeblichen genetischen Vererbbarkeit von ,niederer' Intelligenz, insbesondere bei Menschen aus dem muslimischen Kulturkreis. Dies eröffnete einen folgenreichen, gesellschaftlichen und politischen Diskurs. ${ }^{505}$ Sarrazin knüpft mit diesen Aussagen direkt an die rassistische Ideologie nationalsozialistischer sowie eugenischer Zeiten an. Für die vielfältigen Missstände in der bundesrepublikanischen Entwicklung identifiziert er generalisierend, die ${ }^{6}$ Menschen mit Migrationshintergrund - in diesen hat er scheinbar einen gegenwärtigen ,Sündenbock ${ }^{6}$ gefunden. Weiterhin belebt Sarrazin das Phantasma der biologischen Determination von menschlichen Eigenschaften und Fähigkeiten neu, indem er die unveränderbare, genetische Weitergabe von erworbenen, menschlichen Eigenschaften an nachfolgende Generationen proklamiert. ${ }^{506}$

Mithilfe einer qualitativen Inhaltsanalyse auf der Grundlage sozial- und naturwissenschaftlicher Rassismuskategorien, sollen diese biologisch-rassistischen Vorurteile und Ressentiments Sarrazins im weiteren Verlauf veranschaulicht werden. Im Mittelpunkt stehen hierbei vor allem naturalisierte, kulturelle, diskriminierende sowie abwertende Begrifflichkeiten und Begriffsintentionen aus dem definitorischen Umfeld des Rassismusphänomens, die dieser Analyse als Schlüsselbegriffe dienen (s. Kapitel 3.1.1). Auf der einen Seite zeigen sich anhand dieser Positionierungen die Wiederkehr sowie die wieder vorhandene Akzeptanz von überholt geglaubten, biologischen und genetischen Vorurteilen in Deutschland. Auf der anderen Seite entsprechen diese Argumentationen tendenziell großen Teilen der gesellschaftlichen Stimmung, wie der nachhaltige Zuspruch zu den Theoremen Thilo Sarrazins suggeriert. ${ }^{507}$ In der Folge können mithilfe einer qualitativen Inhaltsanalyse des exemplarischen Beispiels Sarrazin typische Deutungs- und Erklärungsmuster identifiziert werden, die die Verbreitung gesellschaftlicher, biologisch-rassistischer Ressentiments illustrieren. Das Ziel ist die belegbare Feststellung, dass man bezüglich der Causa Sarrazin einen modernen Rassisten identifizieren kann, der dem biologistischen Rassismusphänomen - trotz zahlreicher Verschleierungs- und Verharmlosungsversuche - heute wieder eine restaurierte, semiwissenschaftliche Grundlage verschafft. Dies kann insbesondere anhand fehlinterpretierter und laienhaft verwendeter Datensätze aus der sozial- und naturwis-

505 Vgl. Seibel/Schuhmacher/Fahrun 2010, a. a. O.

506 Vgl. Sarrazin 2010, a. a. O., S. 258ff.

507 Dass viele von Thilo Sarrazin genannten Ressentiments und Vorstellungen auch von großen Teilen der bundesrepublikanischen Bevölkerung geteilt werden, belegen die nachfolgenden Datenmaterialien (s. Kapitel 3.3, 3.4, 3.5, 3.6). Auch die bohen Verkaufszablen seines Buches - die detaillierten Zablen wurden seitens des Verlages jedoch nicht veröffentlicht - bestätigen diese Tatsache. Schätzungen gehen von mindestens 1,5 Millionen verkeauften Exemplaren aus. Vgl. Krieger, Regina (2012): „Lukratives Buch. Wie Sarrazin Millionär wurde", in URL: http://www.handelsblatt.com/unternehmen/it-medien/lukratives-buch-wiesarrazin-millionaer-wurde/ 6647994.html <03.07.2013>. | Vgl. De-

cker/Weißmann/Kiess/Brähler 2010, a. a. O. | Vgl. De-

cker/Rothe/Weissmann/Geißler/Brähler 2008, a. a. O. | Vgl. Decker/Kiess/Brähler 2012, a. a. O. | Vgl. Dernbach 2013, a. a. O. | Vgl. Ahlheim, Klaus (2011): Sarrazin und der Extremismus der Mitte. Empirische Analysen und pädagogische Reflexionen, Hannover, S. 12ff. 
senschaftlichen Forschung visualisiert werden, was die in der Einleitung skizzierte Disziplinen übergreifende, methodische Vorgehensweise unterstützt und bestätigt. Sarrazin nutzt an vielen Stellen stark vereinfachte Positionierungen, schwer zu fassende Argumentationen, eine propagandistische Gedankenführung sowie gängige Vorurteile, um seine Theoreme öffentlichkeitswirksam mittels einer aggressiven Werbestrategie zu vermarkten: Er stilisiert sich als Märtyrer einer angeblich „[...] guten Sache $[\ldots]^{\text {‘ } 508.509}$

\subsubsection{Methodische Vorgehensweise}

Zur Analyse und Auswertung von Thilo Sarrazins Argumentation hinsichtlich insbesondere biologistisch-rassistischer Strukturen wird im Folgenden aufgrund multipler methodisch-inhaltlicher Passungen und Parallelen eine qualitativinhaltsanalytische Vorgehensweise nach Philipp Mayring präferiert. ${ }^{510}$ Diese ermöglicht es, das Ausgangsmaterial auf die wesentlichen Inhalte zu reduzieren und zu komprimieren. Sie eignet sich folglich für die Inhaltsanalyse eines, wie im Falle Sarrazins, 400 Seiten langen Autorenwerkes. Darüber hinaus erleichtert sie durch eine kategoriale, inhaltsanalytische Vorgehensweise die systematische Textbearbeitung sowie darauf folgend ebenfalls die Textanalyse und -interpretation. ${ }^{511}$ Die Vorteile der qualitativen Inhaltsanalyse nach Mayring - gleichzeitig auch die Grundlage für die hier getroffene methodische Entscheidung - gegenüber quantitativen, inhaltsanalytischen Methoden liegen in der zusätzlich möglichen Erfassung der verbalen und non-verbalen Eigenschaften der Kommunikation, dem Extrapolieren von Kommunikationszusammenhängen - die zwischen den verschriftlichten Ausformulierungen zu identifizieren sind - und in der nicht vorhandenen Beschränkung auf feste Kommunikationsinhalte, was zu einer vorschnellen Quantifizierung dieser führen könnte. ${ }^{512}$ Das heißt, dass bei der qualitativen Inhaltsanalyse nach Mayring auch nicht explizite, latente Kommunikationsinhalte bzw. Kontexte im Fokus stehen: Dies passt insofern zu einer Rassismusanalyse sowie zur sarrazinschen Argumentation, da auch hier oftmals nicht-direkte Formulierungen oder Sprachformeln verwendet werden, um der gesellschaftlichen Konformität oder dem gesellschaftlich festgesetzten Normen- und Wertegefüge formal zu entsprechen. Insofern zeigt sich eine, von der qualitativen Inhaltsanalyse gebotene, allumfassende, ganzheitliche Textanalyse als praktikabel sowie ziel-

508 Bade, Klaus J. (2013): Kritik und Gewalt. Sarrazin-Debatte, ,Islamkritik‘ und Terror in der Einwanderungsgesellschaft, Schwalbach/Taunus, S. 48.

509 Vgl. Bade 2013, ebd., S. 41ff.

510 Vgl. Mayring, Philipp (2002): Einführung in die qualitative Sozialforschung. Eine Anleitung zu qualitativem Denken, Weinheim u. a. | Vgl. Mayring, Philipp (2013): Qualitative Inhaltsanalyse, in: Flick, Uwe/Kardorff, Ernst von/Steinke, Ines (Hrsg.): Qualitative Forschung. Ein Handbuch, 10. Auflage, Reinbek bei Hamburg, S. 468-475.

511 Vgl. Mayring, Philipp (2000): Qualitative Inhaltsanalyse, in: Forum Qualitative Sozialforschung/Forum Qualitative Social Research, Volume 1 No. 2, Art. 20, http://nbnresolving.de/urn:nbn:de:0114-fqs0002204.

512 Vgl. Mayring 2000, a. a. O. 
führend. Mögliche Kritikpunkte an qualitativ-inhaltsanalytischen Vorgehensweisen, die des Öfteren hinsichtlich einer zu vorschnellen Kategorie-Bildung argumentieren, kann insofern entgegen gewirkt werden, als dass das Kategoriensystem im Verlauf der Analyse gebildet wird. Im Rahmen mehrerer Analysevorgänge sind somit auch Korrekturen und deutlichere Abgrenzungen der einzelnen Kategorien möglich. ${ }^{513}$ Zusätzlich erfolgen drei hintereinander geschaltete Sach- bzw. Analysedurchgänge durch das Textmaterial, die einer möglichen Beliebigkeit der Deutung sowie der Kategorisierung entgegen wirken und somit faktisch deren Reliabilität erhöhen. ${ }^{514}$

Der Ablauf der qualitativen Inhaltsanalyse folgt der von Philipp Mayring festgelegten schrittweisen Systematik, die ein theoriegeleitetes, am Analysematerial entwickeltes Kategoriensystem als Ziel hat. ${ }^{515}$

Zu Beginn steht die Festlegung des Materials im Fokus, welches im weiteren Verlauf analysiert werden soll. Hier wurde Thilo Sarrazins „Deutschland schafft sich ab. Wie wir unser Land aufs Spiel setzen"516 in der Gesamtschau untersucht und nach der Materialsichtung einzig Kapitel 2 „Ein Blick in die Zukunft“ ${ }^{\text {" } 517}$ nicht in die Analyse inkludiert, da sich dieses ausschließlich mit statistischen Prognosen hinsichtlich der Entwicklung von Wirtschaft und Arbeitsmarkt beschäftigt, demnach keine relevanten Inhalte für die hier angestrebten Analyseziele enthält. Trotz der Aussparung eines Kapitels bleibt so mit dem Großteil des Werkes eine repräsentative Teilmenge zur Untersuchung bezüglich rassistischer Inhalte und Formulierungen vorhanden, welche insbesondere das angebliche Spannungsverhältnis zwischen Deutschen und Einwanderern in Politik, Gesellschaft und Wirtschaft erörtert.

Hinsichtlich der Analyse der Entstehungssituation von Thilo Sarrazins Werk müssen die wirtschaftlichen, euro- und fiskalpolitischen Krisensymptome in Europa seit den Jahren 2007/2008 identifiziert werden (s. Kapitel 1). Diese verknüpft Sarrazin mit der angeblich zusätzlichen Problemstellung der Einwanderung und Migration nach Deutschland sowie deren Folgen. Hieraus skizziert er multiple Empfehlungen für die Gestaltung eines zukünftigen, nachhaltigen Politikstils in Deutschland.

Vor dem Hintergrund der formalen Charakterisierung des Materials ist bei Sarrazins Schriftstück von einer Monographie zu sprechen, welche er nach eigenen Angaben 2008 beginnend verfasst hat. ${ }^{518}$

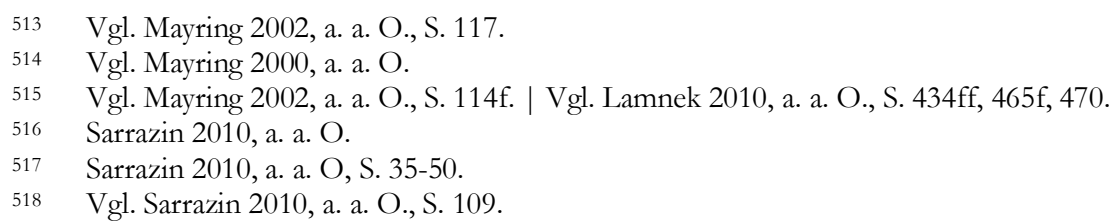


Tab. 3: Kodier-Leitfaden nach Mayring 519

\begin{tabular}{|c|c|c|c|}
\hline Kategorie & Definition & Ankerbeispiel & Kodier-Regeln \\
\hline $\begin{array}{l}\text { K1: } \\
\text { Gesell- } \\
\text { schaftliche } \\
\text { Offenheit }\end{array}$ & $\begin{array}{l}\text { Keine Diskriminierung, } \\
\text { Ausgrenzung oder Abwertung } \\
\text { von spezifischen Menschen } \\
\text { oder Menschengruppen auf } \\
\text { der Basis von Religion, } \\
\text { Herkunft, Kultur, Biologie u. a. } \\
\text { identifizierbar. }\end{array}$ & $\begin{array}{l}\text { "Bildungserfolge und Arbeits- } \\
\text { marktdaten zeigen, dass } \\
\text { deren Integration [Anm.: der } \\
\text { Aussiedler] bereits in der } \\
\text { zweiten Generation sehr gut } \\
\text { gelingt." } 520\end{array}$ & $\begin{array}{l}\text { Sobald tendenzielle Über- } \\
\text { einstimmungen mit den } \\
\text { Definitionen von K2, K3 oder } \\
\text { K4 auftreten, Kodierung in K2- } \\
4 .\end{array}$ \\
\hline $\begin{array}{l}\text { K2: } \\
\text { Fremden- } \\
\text { feindlichkeit }\end{array}$ & $\begin{array}{l}\text { Ablehnung von ausländischen } \\
\text { Mitbürgerinnen und Mitbür- } \\
\text { gern, Einwanderern oder } \\
\text { Asylsuchenden, die als } \\
\text {,anders', ,fremd' oder ,nicht zu } \\
\text { uns passend' wahrgenommen } \\
\text { werden. (Noch) keine biologi- } \\
\text { sche oder kulturelle Zuschrei- } \\
\text { bung bzw. Bewertung und } \\
\text { Beurteilung von spezifischen } \\
\text { Menschengruppen vorhan- } \\
\text { den. }{ }^{521}\end{array}$ & $\begin{array}{l}\text { „[Gesellschaftliche] Vielfalt ist } \\
\text { grundsätzlich erwünscht. Die } \\
\text { damit verbundenen Reibun- } \\
\text { gen erhöhen aber nicht } \\
\text { zwangsläufig die Leistungsfä- } \\
\text { higkeit einer Gesellschaft."522 }\end{array}$ & $\begin{array}{l}\text {,Fremd-' bzw. ,Anders- } \\
\text { Empfinden' von Einwanderern } \\
\text { u. a. muss vorhanden sein. } \\
\text { Bei fehlenden Ablehnungser- } \\
\text { scheinungen Kodierung in K1. } \\
\text { Bei vorhandenen kulturellen } \\
\text { oder biologischen Zuschrei- } \\
\text { bungen zur Diskriminierung } \\
\text { von spezifischen Menschen } \\
\text { oder Menschengruppen } \\
\text { Kodierung in K3 oder K4. }\end{array}$ \\
\hline $\begin{array}{l}\text { K3: } \\
\text { Kulturalisti- } \\
\text { sches } \\
\text { Rassis- } \\
\text { musphäno- } \\
\text { men }\end{array}$ & $\begin{array}{l}\text { Diskriminierung und Abwer- } \\
\text { tung von Einwanderern } \\
\text { mithilfe von kulturellen bzw. } \\
\text { kulturalisierten Erklärungs- } \\
\text { momenten, wie } \\
\text { (1) Religion, } \\
\text { (2) spezifische Herkunft, } \\
\text { (3) kulturelles Umfeld. }\end{array}$ & $\begin{array}{l}\text { "Die Zuwanderer aus dem } \\
\text { ehemaligen Jugoslawien, der } \\
\text { Türkei und den arabischen } \\
\text { Ländern bilden den Kern des } \\
\text { Integrationsproblems. [...] Ihre } \\
\text { Schwierigkeiten im Schulsys- } \\
\text { tem, am Arbeitsmarkt und } \\
\text { generell in der Gesellschaft } \\
\text { ergeben sich aus den Grup- } \\
\text { pen selbst, nicht aus der sie } \\
\text { umgebenden Gesellschaft."523 }\end{array}$ & $\begin{array}{l}\text { Mindestens ein Aspekt der } \\
\text { genannten Definition muss } \\
\text { vorhanden sein, kein Aspekt } \\
\text { darf auf K1 oder K2 hinwei- } \\
\text { sen, ansonsten Kodierung in } \\
\text { K1 oder K2. Bei biologischen } \\
\text { bzW. naturalisierten Erklä- } \\
\text { rungsansätzen Kodierung in } \\
\text { K4. }\end{array}$ \\
\hline $\begin{array}{l}\text { K4: } \\
\text { Biologisti- } \\
\text { sches } \\
\text { Rassis- } \\
\text { musphäno- } \\
\text { men }\end{array}$ & $\begin{array}{l}\text { Diskriminierung und Abwer- } \\
\text { tung von Einwanderern mit } \\
\text { Rückgriff auf biologistische } \\
\text { Argumentationsschemata } \\
\text { bzw. Erklärungsansätzen: } \\
\text { (1) spezifische Vererbung von } \\
\text { Fähig- und Fertigkeiten } \\
\text { (bspw. Intelligenz, Bildungs- } \\
\text { grad, Arbeitsintensität u. a.) } \\
\text { (2) genetische Unterschiede } \\
\text { zwischen spezifischen Men- } \\
\text { schengruppen, die ,qualitativ' } \\
\text { (genetisch) positiv bzw. } \\
\text { negativ (,Rasse') klassifiziert } \\
\text { werden } \\
\text { (3) Verknüpfung der Argu- } \\
\text { mentation mit biologischen } \\
\text { Konzepten oder Theorien }\end{array}$ & $\begin{array}{l}\text { „Die jeweils unterschiedliche } \\
\text { kulturelle und zivilisatorische } \\
\text { Entwicklung führt zu unter- } \\
\text { schiedlichen Fortpflanzungs- } \\
\text { und Überlebensmustern und } \\
\text { bringt auch unterschiedliche } \\
\text { genetische Ausprägungen } \\
\text { hervor."524 }\end{array}$ & $\begin{array}{l}\text { Mindestens ein biologi- } \\
\text { scher/naturalisierter Aspekt } \\
\text { der genannten Definition } \\
\text { muss vorhanden sein, kein } \\
\text { Aspekt darf auf K1, K2 oder } \\
\text { K3 hinweisen, ansonsten } \\
\text { Kodierung in K1-K3. }\end{array}$ \\
\hline
\end{tabular}

Eigene Darstellung nach: Vgl. Mayring 2000, a. a. O.

Sarrazin 2010, a. a. O., S. 59.

Vgl. Zerger, Johannes (1997): Was ist Rassismus? Eine Einführung, Göttingen, S. 95.

Sarrazin 2010, a. a. O., S. 57.

Sarrazin 2010, a. a. O., S. 59.

Sarrazin 2010, a. a. O., S. 173. 
Die Richtung der Inhaltsanalyse zielt auf die Beurteilung des expliziten und nichtexpliziten Inhalts hinsichtlich rassistischer - vornehmlich von biologistischrassistischen - Argumentationsmustern ab. Diesbezüglich soll anhand von Kategorien (s. Tab. 3) möglichst eindeutig differenziert werden, ob kulturell- oder biologisch-rassistische Erörterungen vorliegen, oder ob es sich hierbei ,nur um Fremdenfeindlichkeit bzw. um keinerlei Anzeichen von rassistischen Bestrebungen - also um eine gesellschaftliche, Offenheit' oder Toleranz - handelt.

Bezugnehmend auf die zu untersuchende Forschungsfrage muss selbstredend wieder auf die übergreifende Fragestellung dieser Untersuchung verwiesen werden: Wie stellen sich Verbreitung, Hintergründe und wissenschaftliche Realität des biologisch-genetischen Rassismus im heutigen Deutschland dar (s. Kapitel 1.1)? Diese kann in diesem Zusammenhang noch hinsichtlich des Vorhandenseins von rassistischen bzw. biologistisch-rassistischen Formulierungen und Inhalten konkretisiert werden (s. Tab. 3).

Zur Untersuchung dieses Forschungsziels wird im Rahmen der Analysetechnik das gesamte Material im Rahmen einer inbaltlichen Strukturierung nach Themen und Inhalten analysiert, welche argumentatorische Parallelen bzw. direkte Verknüpfungen mit dem Rassismusphänomen aufweisen. Als Analyseeinheiten dienen hierbei sowohl einzelne Sätze, Aussagen oder Formulierungen als Kodier-Einheiten. Jedoch werden auch größere Textabschnitte, wie einzelne Absätze oder gedankliche bzw. inhaltliche Einheiten, als Kontexteinheit integriert. Die Auswertungseinheiten basieren letztlich auf den einzelnen Kapiteln, die, mit Ausnahme des Kapitels 2, schrittweise im Rahmen der skizzierten Forschungsfrage untersucht werden (s. Kapitel 3.1.3). Hieran schließt sich dann abschließend die Ergebnisaufbereitung und interpretation an, die sowohl eine Beurteilung der kategorisierten Ergebnisse als auch eine Quantifizierung der Ergebnisse einschließt (s. Kapitel 3.1.4).525

\subsubsection{Materialanalyse: Fundstellen und Fundstellenbezeichnung}

Im Anschluss an die Einführung in den methodischen Ablauf sowie die Vorstellung der Kodierungsregeln werden im folgenden Absatz die einzelnen Kapitel von Thilo Sarrazins Werk vorerst nochmals thematisch und inhaltlich strukturiert, um die einzelnen Kerngegenstände im Überblick darzustellen und hinsichtlich des textlichen Umfangs einzuordnen. Auf dieser Grundlage kann dann im anschlieBenden Kapitel 3.1.3 die qualitative Inhaltsanalyse aufbauen.

Diese beschränkt sich auf die Einleitung, das Kapitel 1 sowie die Kapitel 3-9. Die Einleitung sowie Kapitel 1 zu „Staat und Gesellschaft“ 526 (Seiten 7-22 und 2334) enthalten vor allem eine thematische Hinführung und Präzisierung hinsichtlich des vorgeblich gefährlichen demografischen Wandels in Deutschland sowie der in Deutschland vorhandenen Einwanderungsprobleme und deren Entwicklung, die

\footnotetext{
525 Vgl. Mayring 2002, a. a. O., S. 117, 149 f. Somit stellt die qualitative Inhaltsanalyse nach Philipp Mayring im Rabmen der Quantifizierung der Ergebnisse auch eine Verflechtung mit der quantitativen Forschung dar. Sarrazin 2010, a. a. O, S. 23.
} 
Thilo Sarrazin hauptsächlich in der mangelnden Intelligenz und Bildungsfähigkeit unterer bzw. migrantischer Bevölkerungsschichten verortet. ${ }^{527}$ Vom Umfang sowie auch vom Inhalt ausführlich ausgeführt sind insbesondere die nachfolgenden Schwerpunktkapitel des Werkes. Kapitel 3 „Zeichen des Verfalls“528 (Seiten 51102) skizziert die Folgen des vermeintlichen Gegensatzpaares ,Talentierte versus Untalentierte' zwischen verschiedenen Bevölkerungsgruppen auf der Grundlage unterschiedlicher Erblichkeitswerte von Intelligenz mithilfe unterschiedlicher biologischer Theorien und Konzepte. ${ }^{529}$ Hieran knüpfen im weiteren Verlauf die Kapitel 4 „Armut und Ungleichheit“530 (Seiten 103-150), Kapitel 5 „Arbeit und Politik“"531 (Seiten 151-186), Kapitel 6 „Bildung und Gerechtigkeit“532 (Seiten 187254) und Kapitel 7 „Zuwanderung und Integration“533 (Seiten 255-330) an, die sich intensiv mit Ursachen und Folgen der größtenteils, so das Fazit Sarrazins, durch Einwanderung hervorgerufenen Probleme der Bundesrepublik Deutschland beschäftigen. Unter anderem werden hier Einwanderer - insbesondere Einwanderer islamischen Glaubens - als Ursache für die mangelhaften Bildungsergebnisse Deutschlands in internationalen Vergleichsstudien sowie als Hauptverantwortliche für Kriminalität und Terrorismus identifiziert. ${ }^{534}$ Grundlage dieser Feststellung ist ein vorgeblich biologisches Erklärungsgefüge, welches eine genetisch bedingt begrenzte Gehirn- und Intelligenzentwicklung bei unteren sozialen Schichten, vor allem bei Einwanderern aus der Türkei, Afrika sowie dem Nahen bzw. dem Mittleren Osten, konstatiert. In den letzten Kapiteln 8 „Demografie und Bevölkerungspolitik“"535 (Seiten 331-390) und 9 „Ein Traum und ein Alptraum“536 (Seiten 391-408) zeigt Sarrazin abschließend Notwendigkeiten und Umsetzungsmöglichkeiten der politischen und gesellschaftlichen Entwicklung auf, um die von ihm in den vorherigen Kapiteln skizzierten Probleme entschärfen zu können.

Wie ersichtlich, sind insbesondere die Kapitel 1 sowie 3 bis 7 als Schwerpunkte der nachfolgenden Inhaltsanalyse zu betrachten, da der oben stehende inhaltliche und thematische Umriss vor allem hier Hinweise auf die erstellten Kodierungskategorien aufzeigt (s. Kapitel 3.1.1).

\subsubsection{Inhaltsanalyse: Rassismus, Fremdenfeindlichkeit oder Offenheit?}

In seiner populärwissenschaftlichen Ausarbeitung präsentiert Thilo Sarrazin in verschiedenen Kapiteln (s. Kapitel 3.1.2) zu unterschiedlichen Schwerpunktthemen zahlreiche angebliche Krisensymptome des bundesrepublikanischen Staa-

\footnotetext{
527 Vgl. Sarrazin 2010, a. a. O., S. 7-34.

528 Sarrazin 2010, a. a. O., S. 51.

529 Vgl. Sarrazin 2010, a. a. O., S. 51-102.

530 Sarrazin 2010, a. a. O., S. 103.

531 Sarrazin 2010, a. a. O., S. 151.

532 Sarrazin 2010, a. a. O., S. 187.

533 Sarrazin 2010, a. a. O., S. 255.

534 Vgl. Sarrazin 2010, a. a. O., S. 187-254.

535 Sarrazin 2010, a. a. O., S. 331.

536 Sarrazin 2010, a. a. O., S. 391.
} 
tes. ${ }^{537}$ Über allen historischen und zukünftigen Entwicklungen der Bundesrepublik Deutschland sieht Sarrazin - wie viele selbsternannte Untergangsapokalyptiker vor ihm - die Gefahr des Zerfalles: ${ }^{538}$, „[...] die Jahrzehnte des fast ungetrübten Erfolgs [nach dem Zweiten Weltkrieg] haben [...] die Sehschärfe der Deutschen getrübt für die Gefährdungen und Fäulnisprozesse im Innern der Gesellschaft. [...] Die Deutschen [...] schaffen sich allmählich ab. "539 Damit belebt er das Schreckgespenst einer angeblich biologischen sowie kulturellen Zukunftsgefahr für die bundesrepublikanische Gesellschaft neu. Der Rückgriff sowie die Verknüpfung mit der Biologie wird insbesondere durch die Metapher ,Fäulnisprozess deutlich - diese symbolisiert einen biologischen, organischen Zerfall. Diese Aussage ist demnach der Kodierungskategorie K4 zuzuordnen, da hier auf originär biologische Konzepte zurückgegriffen wird. Sarrazin reaktiviert diesbezüglich folglich sowohl direkt als auch indirekt biologistische Rassismusargumentationen.

Als zentrale Gelenkstelle seines Theoriemodells präsentiert Sarrazin die negativen Auswirkungen der demografischen Bevölkerungsentwicklung in Deutschland: Die ,intelligenteren' Frauen aus den oberen Bevölkerungsschichten bringen demnach immer weniger Kinder zu Welt, so dass ,[...] wir als Volk an durchschnittlicher Intelligenz verlieren [...]. “540 Aufgrund einer höheren „Nettoreproduktionsrate“541 der Einwanderer sowie der unteren Bevölkerungsschichten identifiziert Sarrazin hierin eine ,[...] qualitativ[e] demografisch[e] Verschiebung [...]“542 _ also eine biologisierte ,Verschlechterung' der bundesrepublikanischen Gesellschaft auf der Grundlage „Systematische[r] Unterschiede in der Fruchtbarkeit [...]“543 von Mitbürgerinnen und Mitbürgern aus den unteren sozialen Schichten bzw. mit Migrationshintergrund (K3, K4). ${ }^{544}$ Kurz: eine Gefahr für die ,Bestandserhaltung - wiederum ein biologischer Rückgriff - der bundesrepublikanischen Gesellschaft (K4). ${ }^{545}$ In Kapitel 7 skizziert Sarrazin diesen angeblichen Tatbestand ausführlich am Beispiel der türkischen und afrikanischen Einwanderer sowie am Beispiel der Menschen aus dem Nahen und Mittleren Osten: Die ,schicksalshafte', niedrige Geburtenrate der höheren sozialen Bevölkerungsschichten in Deutschland enthielten die Gefahr, dass „[...] Staat und Gesellschaft im Laufe weniger Generationen von den Migranten übernommen“ 546 werde. ${ }^{547}$ Ein Theorieansatz, bei dem abermals Sarrazins Schwarz-Weiß-Denken zum Vorschein kommt: Auf der einen Seite die biologisch und kulturell belastenden ausländischen Bevölkerungsteile, die

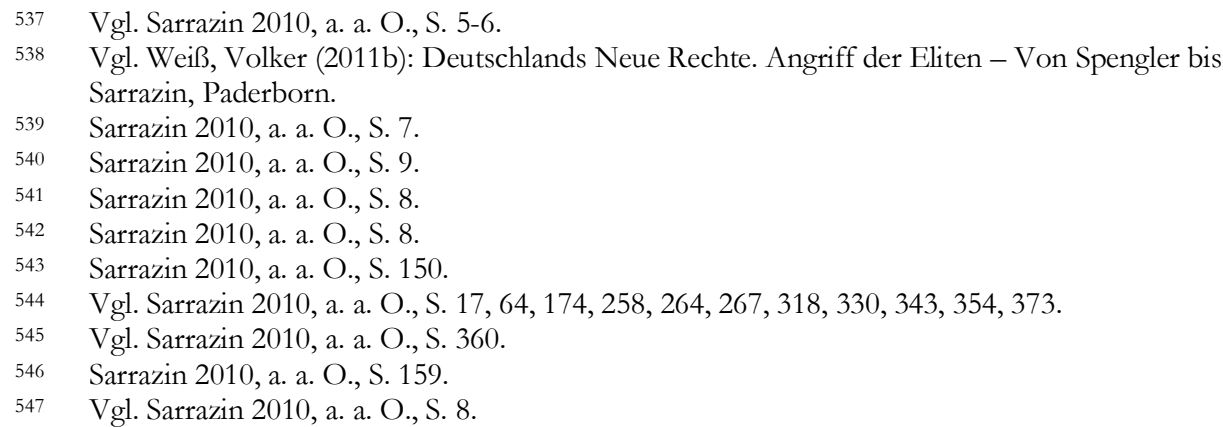


„unsere[n] Lebenssti[1]“548 bedrohen, und auf der anderen Seite das gefährdete deutsche bzw. europäische Volk. ${ }^{549}$ Für das gesamte Europa bedeute diese Gefahr durch Einwanderer: „Wer sich stärker vermehrt, wird am Ende Europa besitzen. "550 Eine Übertragung dieser Umschreibungen auf den biologistischen ,Rassebegriff‘ sowie das nationalsozialistische Konstrukt der ,arischen Rasse“ scheint hier nicht fern. Auch die vor diesem Hintergrund postulierten gesellschaftlichen Bedrohungen der „Strukturverschlechterungen“"551 bzw. der „Bestandserhaltung““552 der deutschen Bevölkerung bestätigen Sarrazins Rückgriff auf biologischgenetische sowie rassistische Zuschreibungen, welche auf die Abwertung und Diskriminierung einzelner Bevölkerungsgruppen abzielen (K4). An einzelnen Stellen lassen sich hier ebenfalls mögliche gedankliche Kontextualisierungen hinsichtlich einer aktiven Geburtensteuerung oder -kontrolle ermitteln, wenn Sarrazin vorschlägt, ,[...] dass es dringend, zwingend und alternativlos ist, die Geburtenrate in Deutschland erheblich zu steigern und gleichzeitig die Anteile der Mittel- und Oberschicht an den Geburten deutlich zu erhöhen. Wenn darüber Einigkeit herrscht, lässt sich ganz anders über die zu ergreifenden Maßnahmen diskutieren." 553 Eine inhaltliche Verbindung mit dem Begriff der Eugenik scheint demnach nahe zu liegen. Sarrazin verknüpft hier demzufolge vorgebliche kulturelle Eigenheiten, wie Bildungsgrad oder Herkunft, mit einem scheinbar besonderen generativen Verhalten von Einwanderern und konstruiert aus dieser kulturellbiologischen Vernetzung ein Untergangsszenario für Deutschland und Europa. Folglich muss diese Argumentation aufgrund sowohl kultureller als auch biologischer Konnotationen in die Kodierungskategorien K3 und K4 eingeordnet werden.

Den schon erörterten Intelligenzverlust der bundesrepublikanischen Bevölkerung manifestiert Sarrazin darüber hinausgehend an der ,[...] kontinuierliche[n] Zunahme der weniger Stabilen, weniger Intelligenten und weniger Tüchtigen [...]. “554 Er unterscheidet so unzweideutig zwischen ,tüchtigen' und ,untüchtigen', also für die gesellschaftliche Entwicklung ,nützlicheren` und ,unnützen` Bürgerinnen und Bürgern in der Bundesrepublik. Vor allem letztere seien für die Entwicklung der bundesrepublikanischen Gesellschaft eher nachteilig: „[...] aber die [Untalentierten] tragen ohnehin nichts zur [...] wirtschaftlichen und gesellschaftlichen Entwicklung bei.“555 Weiterhin konstatiert Sarrazin diesbezüglich vertiefend eine „qualitativ[e] Veränderung“556 der zukünftigen Entwicklungsmöglichkeiten Deutschlands. Verantwortlich hierfür seien insbesondere die unteren bzw. sozial

Sarrazin 2010, a. a. O., S. 266.

Vgl. Sarrazin 2010, a. a. O., S. 258-260.

Sarrazin 2010, a. a. O., S. 320.

Sarrazin 2010, a. a. O., S. 343.

Sarrazin 2010, a. a. O., S. 343.

Sarrazin 2010, a. a. O., S. 373.

Sarrazin 2010, a. a. O., S. $258 \mathrm{ff}$.

Sarrazin 2010, a. a. O., S. 11.

Sarrazin 2010, a. a. O., S. 53.

Sarrazin 2010, a. a. O., S. 11. 
schwächeren Bevölkerungsschichten, da sich „,...] die Bildungsfähigkeit und die Bildungsvoraussetzungen der Neugeborenen kontinuierlich verschlechter[n] und die Mentalität zu verkümmern scheint, die die Grundlage jeden produktiven Aufbruchs ist." ${ }^{557}$ - ein düsteres Szenario bezüglich der zukünftigen Entwicklungstendenzen. Verantwortlich für diesen destabilisierenden Trend sei die forcierte Einwanderung nach Deutschland. Für ihn ist bewiesen, dass sich Staat und Gesellschaft in Deutschland mit den Einwanderern unterschiedlicher Herkunft übernommen habe. ${ }^{558}$ Die Einwanderungspolitik der vorausgegangenen Jahrzehnte bezeichnet er schlussfolgernd als einen ,gigantischen Irrtum“559. Somit verknüpft Sarrazin den konstatierten Intelligenzverlust und die qualitativ nachteiligen Veränderungen der deutschen Gesellschaft mit der Zunahme der Migration nach Deutschland. Den „[...] Keim für diese Fehlentwicklungen, die unsere Zukunft verdüstern [... ] $]^{\text {560 }}$ sieht er unter anderem in der Frage ,[...] um die Qualität, die Struktur und den kulturellen Hintergrund der Migranten in Deutschland. "561 Und weiter: „Der Umstand, dass bei unterschiedlicher Fruchtbarkeit von Bevölkerungsgruppen unterschiedlicher Intelligenz eugenische oder dysgenische Effekte auftreten können, wird daher nicht grundsätzlich bestritten. "562 Hierbei greift Sarrazin direkt, wie auch sein Literaturverzeichnis signalisiert, auf biologische Theoriekonzepte zurück, indem er beispielsweise Charles Darwin oder Francis Galton und deren Forschungsergebnisse hinsichtlich Intelligenz und Vererbung bei Tieren veranschaulicht sowie darauf aufbauend - unausgesprochen - auf den Menschen verweist. ${ }^{563}$ Auf dieser biologisierten Grundlage identifiziert er den Schuldigen bzw. den Sündenbock für diese, die gesellschaftliche Stabilität gefährdenden, Entwicklungen hinsichtlich ,Qualität ${ }^{6}$ und ,Intelligenz ${ }^{6}$ insbesondere im Anstieg der Einwanderer nach Deutschland. ${ }^{564}$ In dieser Verbindung von kognitiven Fähigkeiten sowie Menschenqualität können eindeutig sowohl direkte als auch indirekte biologisch-genetisch geprägte, rassistische Argumentationsmuster identifiziert werden (K4). Die Frankfurter Allgemeine Zeitung titelt diesbezüglich treffend, wenn sie von einer „Prosa biologistischer Fälscher“ 565 spricht.

Sarrazins Fokus liegt, wie schon angesprochen, vor allem auf dem besorgniserregenden demografischen Wandel der bundesrepublikanischen Bevölkerungsstruktur. Somit greift er ein aktuell gesellschaftlich und politisch hoch brisantes Themengebiet auf, welches er emotionalisiert und popularisiert darstellt, indem er

\footnotetext{
557 Sarrazin 2010, a. a. O., S. 12.

558 Vgl. Sarrazin 2010, a. a. O., S. $258 f f$.

559 Sarrazin 2010, a. a. O., S. 259.

560 Sarrazin 2010, a. a. O., S. 16.

561 Sarrazin 2010, a. a. O., S. 17.

562 Sarrazin 2010, a. a. O., S. 93.

563 Vgl. Sarrazin 2010, a. a. O., S. $92 \mathrm{ff}$.

564 Vgl. Sarrazin 2010, a. a. O., S. 9, 10, 11, 24, 53, 76, 234, 245, 347, 353, 357.

565 Müller-Jung, Joachim (2010): „Sarrazins Biologismus. Phantasma ,Juden-Gen“،, in URL: http://www.faz.net/aktuell/feuilleton/debatten/2.1763/die-thesen/sarrazins-biologismusphantasma-juden-gen-11028466.html <09.02.2013>.
} 
fortwährend vor den hierdurch entstehenden „Gefährdungen“566 warnt. Die Bestätigung seiner Argumentation sucht er dabei immer wiederkehrend in den $\mathrm{Na}$ turwissenschaften. Hinsichtlich der genannten Unterschiede die ,Qualität ${ }^{\star}$ einzelner Bevölkerungsgruppen in Deutschland betreffend erklärt er ausführlich: „Zwar ist die genetische Ausstattung der Menschen aller Länder und Völker von großer Ähnlichkeit [...]“567, jedoch gebe es nachweislich „,...] Unterschiede in der Mentalität der Völker und Gesellschaften [... $]^{\text {“568 }}$. Diese divergierenden kulturellen Merkmale unterschiedlicher Gesellschaften basierten evolutiv auf ,[...] dem weiten Rahmen, den die genetische Programmierung der Menschen [... $]^{\text {"569 }}$ zulasse. Denn „Grundsätzlich [...] [gelte dies] auch für körperliche Fähigkeiten, mentale Dispositionen und intellektuelle Eigenschaften." 570 Damit verknüpft Thilo Sarrazin die ,genetische Ausstattung - dementsprechend die Gene - bestimmter Menschengruppen in Deutschland mit deren mentalen und intellektuellen Fähig- und Fertigkeiten. Dies entspricht deutlich sozialdarwinistischen und nationalsozialistischen Argumentationsmustern, die einem biologisch-rassistischen Milieu - und demnach der Kodierungskategorie K4 - zugeordnet werden können.

Darüber hinausgehend verstärkt Sarrazin die genannten biologistischen Argumentationen mit der Verknüpfung von unterdurchschnittlicher kognitiver Leistungsfähigkeit - der Intelligenz - und den Migrationstendenzen in Deutschland, wobei er vor allem die von Migration geprägten (unteren) Bevölkerungsschichten sowie deren mangelhafte Bildungserfolge fokussiert. ${ }^{571}$ Darauf bezugnehmend identifiziert er die Ursache des schlechten bundesrepublikanischen Abschneidens in den ersten PISA-Studien in der scheinbar mangelnden Bildungsfähigkeit und Intelligenz der in Deutschland lebenden Menschen mit Migrationshintergrund, was er ausführlich in Kapitel 3 behandelt. ${ }^{572}$ „Es könnte also sein, dass es [...] systematische Unterschiede in der Bildungsfähigkeit einer Population gibt [...]. “573 Auch hier findet eine notwendige Differenzierung sowie eine Beachtung der spezifischen Rahmenbedingungen nicht statt - Sarrazin konzentriert sich auf ,die „bildungsferne Unterschicht" ${ }^{\text {"574, }}$ ohne deren individuelle oder kulturelle Hintergründe zu beachten. Er spricht undifferenziert und generalisierend von einem „[...] bildungsfernen migrantischen Milieu [... $]^{6 / 575}$. Davon ausgehend skizziert er das Szenario einer Verdummung bzw. Überfremdung und Abschaffung der deutschen Bevölkerung, wie der nachfolgende Textausschnitt belegt. Ursächlich hierfür sei die anwachsende Population der Bürgerinnen und Bürger, insbesondere aus

\footnotetext{
566 Sarrazin 2010, a. a. O., S. 7.

567 Sarrazin 2010, a. a. O., S. $32 \mathrm{ff}$.

568 Sarrazin 2010, a. a. O., S. 32.

569 Sarrazin 2010, a. a. O., S. 32.

570 Sarrazin 2010, a. a. O., S. 173.

571 Vgl. Sarrazin 2010, a. a. O., S. 64ff.

572 Vgl. Sarrazin 2010, a. a. O., S. 76f., $91 \mathrm{ff}$.

573 Sarrazin 2010, a. a. O., S. 76.

574 Sarrazin 2010, a. a. O., S. 212.

575 Sarrazin 2010, a. a. O., S. 245.
} 
muslimisch geprägten Kultur- und Gesellschaftskreisen. ${ }^{576}$ Diese kulturelle Zuschreibung weist augenscheinlich auf eine Einordnung in die Kodierungskategorie K3 hin, die weiteren Ausführungen bestätigen jedoch das biologisierte Basiskonzept der sarrazinschen Argumentation.

„Bei den Migranten wurde [...] gezeigt, dass jene Migrantengmppen besonders viele
Nachkommen haben, die als besonders bildungsfern eingestuft werden müssen, also vor
allem die Migranten aus der Türkei, dem Nahen Osten und aus Afrik.a. [...] Die
schulische Bildung und Erziehung dieser Kinder aus sogenannten bildungsfernen Schich-
ten ist wesentlich schwieriger zu bewerkstelligen und mit geringeren Erfolgen verbunden
als bei anderen Kindern. [...] Folgerichtig dient der hohe Anteil von Kindern aus bil-
dungsfernen Schichten [...] als Erklärung für die überaus schlechten Pisa-Ergebnisse
[...]. Intelligenz ist [...] zu 50 bis 80 Prozent erblich. Deshalb bedeutet ein schichtab-
bängig unterschiedliches generatives Verhalten leider auch, dass sich das vererbte intellek-
tuelle Potential der Bevölkerung kontinuierlich verdünnt." "577

Seine biologische Argumentation verstärkend, weist Thilo Sarrazin in diesem Zusammenhang ebenfalls auf eine Erblichkeit von sogenannten ,Intelligenz-Genen“ hin. ${ }^{578}$ Hierbei verstrickt sich jedoch im Verlauf seiner Argumentation in mehrere Widersprüche, indem er die Vererbbarkeit von Intelligenz mit unterschiedlichen Prozentwerten illustriert: Zu Beginn spricht Sarrazin von einer Erbkomponente von 60 bis 80 Prozent, im weiteren Verlauf nur noch von 40 bis 60 Prozent oder gar bloß noch ,zum Teil erblich'.579 Hierbei bedient er sich fehlinterpretierter Datenmaterialien, die, wie der weitere Verlauf noch diagnostizieren wird, keinesfalls als wissenschaftlich absolute Erkenntnisse angesehen werden können. ${ }^{580}$ Der Vererbungsverlauf menschlicher Gene kann molekulargenetisch gesehen nicht in dieser Form mit festen, unveränderbaren Prozentwerten angegeben werden - dies ist wissenschaftlich unhaltbar (s. Kapitel 5). Insbesondere vielfältige externe sowie umweltbedingte Einflüsse setzen gemeinsam die Rahmenbedingungen für die Vererbung von Genen an nachfolgende Generationen (s. Kapitel 5.3.6, 5.3.7). Dies verkennt Sarrazin jedoch vollkommen bzw. sieht über diese genetische Erkenntnis hinweg. ${ }^{581}$ Mithilfe der fehlinterpretierten Theorien der Naturforscher Charles Darwin, Alfred Russel Wallace und Johann Gregor Mendel versucht Sarrazin, Rückschlüsse auf die Vererbung des Intelligenz-Phänomens herzustellen, ohne darauf zu achten, dass sich die wissenschaftlichen Grundlagen - die humanund evolutionsbiologischen Erkenntnisse - sowie auch die gesellschaftlichen

\footnotetext{
576 Vgl. Sarrazin 2010, a. a. O., S. $91 \mathrm{ff}$.

577 Sarrazin 2010, a. a. O., S. 91-92.

578 Vgl. Sarrazin 2010, a. a. O., S. 28ff, $98 \mathrm{ff}$.

579 Vgl. Sarrazin 2010, a. a. O., S. 28ff, $97 \mathrm{ff}$.

580 Vgl. Stern, Elsbeth (2010): „Was heißt hier erblich? Die Intelligenzforscherin Elsbeth Stern widerspricht der Verdummungsthese", in URL: http:/ /www.zeit.de/2010/36/IntelligenzSarrazin $<09.08 .2013>$.

Exemplarisch zeigt die Psychologin Elsbeth Stern Sarrazins mangelndes Verständnis der Intelligenzforschung auf (s. Kapitel 5.4).

581 Vgl. Sarrazin 2010, a. a. O., S. 97, 98, 215.
} 
Rahmenbedingungen in den vergangenen 150 Jahren naturwissenschaftlicher und gesellschaftlicher Entwicklung verändert haben. ${ }^{582}$ Darüber hinaus zeigen sich gerade die Mendelschen Vererbungsregeln nicht uneingeschränkt auf das menschliche Intelligenz-Phänomen anwendbar (s. Kapitel 5). Insbesondere sein Bezug auf die semi-wissenschaftlichen Studien von Francis Galton, Detlef Rost, Gunnar Heinsohn, Heiner Rindermann, Richard Lynn, Hans Jürgen Eyseneck oder Volkmar Weiss müsste die Strittigkeit seiner aufgestellten Theoreme eigentlich verdeutlichen. ${ }^{583}$ „Das Erbintelligenz-Paradigma ist rassistisch. “584 Sarrazin agiert diesbezüglich intellektuell $\mathrm{zu}$ reduziert, $\mathrm{zu}$ einseitig, zu vorurteilsbelastet und biologisch - ob mit Absicht oder nicht - größtenteils falsch (s. Kapitel 5). Die folgende Aussage bestätigt diese Perspektive: „Für einen großen Teil dieser Kinder [der Unterschicht] ist der Misserfolg mit ihrer Geburt bereits besiegelt: Sie erben [...] gemäß den Mendelschen Gesetzen die intellektuelle Ausstattung ihrer Eltern und werden [...] durch deren Bildungsferne und generelle Grunddisposition benachteiligt [...]. “585 Demzufolge ist durchaus folgerichtig zu fragen, ,[...] was ist rassistisch, wenn nicht die Zuweisung von Eigenschaften wie mangelnde Intelligenz an einzelne Menschen aufgrund ihrer Zugehörigkeit zu einer Gruppe?"586 Unterstützt wird diese Annahme weitergehend durch die Verknüpfung der mit mangelnden intellektuellen Fähig- und Fertigkeiten beschriebenen Einwanderer mit dem Verweis auf deren überproportionale Geburtenrate. Dies führe über einzelne Generationen hinweg zu einer ,Verdünnung' des vererbten intellektuellen Potenzials. ${ }^{587}$

„Die drei Migrantengruppen mit den größsten Bildungsdefiziten und den höchsten Sorialkosten sind auch jene, die sich am stärksten vermehren. Menschen mit Migrationshintergrund aus Jugoslawien, Türkei, Nah- und Mittelost sowie Afrika stellen sechs Prozent der Bevölkerung in Deutschland, auf sie entfallen aber gut 11 Prozent aller unter 15-Jährigen und ein noch deutlich höherer Anteil an den Geburten. Die Gruppen mit der höchsten Bevölkerungsdynamik haben also die niedrigste Bildung und weisen auch die niedrigsten Bildungszuwächse in der Generation der hier Geborenen auf. Damit stellen sie nicht einen Teil der demografischen Lösung, sondern des demografischen Problems dar. Es ist nämlich zu befürchten, dass sie zur überdurchschnittlichen Vermehrung jener bildungsfernen und von Transfers abhängigen Unterschicht beitragen, welche die Entwicklungsaussichten Deutschlands verdüstert. "

582 Vgl. Sarrazin 2010, a. a. O., S. 175, 350ff, 373.

583 Vgl. Sarrazin 2010, a. a. O., S. 92ff. | Vgl. Kemper, Andreas (2012): Sarrazins deutschsprachige Quellen, in: Michael/Niggeschmidt, Martin (Hrsg.): Der Mythos vom Niedergang der Intelligenz. Von Galton zu Sarrazin: Die Denkmuster und Denkfehler der Eugenik, Wiesbaden, S. 50 .

584 Kemper 2012, ebd., S. 65.

585 Sarrazin 2010, a. a. O., S. 175.

586 Schmidt, Christoph M. (2010a): Falsch verstandene Statistik und Rassismus, in: Deutschlandstiftung Integration (Hrsg.): Sarrazin. Eine deutsche Debatte, München, S. 135.

587 Vgl. Sarrazin 2010, a. a. O., S. 91f., 93, 97, 98, 99, 100, 215

588 Sarrazin 2010, a. a. O., S. 64. 
Dies markiert abermals die biologisch-rassistische Tendenz des modernisierten, sarrazinschen Rassismus, der schlussfolgernd mit der Kodierungskategorie K4 klassifiziert werden muss. Zusätzlich nimmt Sarrazin dabei auf sozialdarwinistische und teilweise eugenische Argumentationsmodelle Bezug, indem er zu genetischen Prädispositionen in den Bereichen der Bildung und der Intelligenz eine erhöhte Erkrankungswahrscheinlichkeit von Einwanderern an Erbkrankheiten hinzuzieht, was die - biologische - Qualität der bundesrepublikanischen Bevölkerung in weiterem Maße beeinträchtigen würde. ${ }^{589}$
„Das Muster des generativen Verhaltens in Deutschland seit Mitte der sechiger Jahre ist nicht nur keine Darwin'sche natürliche Zuchtwahl im Sinne von, survival of the fit- test', sondern eine kulturell bedingte, vom Menschen selbst gesteuerte negative Selektion, die den einzigen nachwachsenden Rohstoff, den Deutschland hat, nämlich Intelligenz, re- lativ und absolut in hohem Tempo vermindert. [...] So spielen bei Migranten aus dem Naben Osten auch genetische Belastungen, bedingt durch die dort übliche Heirat qwi- schen Verwandten, eine erhebliche Rolle und sorgen für den überdurchschnittlich bohen Anteil an angeborenem Schwachsinn und anderen Erbkrankheiten. "590

Jedoch stellt diese von Sarrazin konstatierte Abnahme der geistigen und intellektuellen Fähigkeiten durch die unterdurchschnittliche Bildungsfähigkeit der Bürgerinnen und Bürger mit Migrationshintergrund sowie deren höhere Nachkommensrate mitnichten einen intellektuellen ,Mehrwert', sondern eher eine Gefahr für die gesellschaftliche Integrität und damit für die Zukunft Deutschlands dar. ${ }^{591}$ Eine Verknüpfung von „[...] biologische[r] [...][ [und] kulturelle[r] Evolution $[\ldots]^{\text {“592 }}$ - allein die Begrifflichkeit der Evolution deutet schon auf einen naturwissenschaftlichen bzw. biologischen Hintergrund hin -, also faktisch eine Biologisierung von Kultur verbietet sowohl die sozial- und erziehungswissenschaftliche als auch die neuere genetische Forschung. Nichtsdestotrotz sind diese Ausführungen Sarrazins demnach in die Kodierungskategorie K4 einzuordnen.

Jedoch lassen sich aus einer weiteren Perspektive auch multiple Argumente ermitteln, die eher der kulturalistisch-orientierten Kodierungskategorie K3 zuzuordnen sind. Dies bestätigt auch die Verknüpfung der angeblich weniger intelligenteren sowie genetisch bzw. gesundheitlich beeinträchtigten Einwanderer, vor allem aus dem muslimischen Kulturkreis, mit Wirtschaftlichkeitsaspekten. Denn Sarrazin verortet das grundsätzliche Problem der bundesrepublikanischen Zukunftsentwicklung nicht nur in der seiner Meinung nach katastrophalen Lage von Migration und Integration in Deutschland, sondern auch in der Wirtschaftlichkeit bzw. der ökonomischen Leistungsfähigkeit von Einwanderern. ${ }^{593}$ Hier identifiziert

\footnotetext{
589 Vgl. Jörges, Hans-Ulrich (2010): Ein Ungeheuer wird freigesetzt, in: Deutschlandstiftung Integration (Hrsg.): Sarrazin. Eine deutsche Debatte, München, S. 154.

590 Jörges 2010, ebd., S. 154.

591 Vgl. Sarrazin 2010, a. a. O., S. 64, $234 \mathrm{ff}$.

592 Sarrazin 2010, a. a. O., S. 24.

593 Vgl. Schirrmacher, Frank (2010): Ein fataler Irrweg, in: Deutschlandstiftung Integration (Hrsg.): Sarrazin. Eine deutsche Debatte, München, S. 23.
} 
er eine mangelnde Qualität sowie eine - aus integrationsspezifischer Perspektive nicht passende Struktur sowie einen nicht passenden kulturellen Hintergrund der Einwanderer. ${ }^{594}$ Hierzu trügen auch ,[...] regional[e] und national[e] Eigenheiten der Völker“"595 sowie Differenzen bezüglich deren kultureller Traditionen bei. 596 Weiterhin verbindet Sarrazin diese scheinbaren Erkenntnisse mit Schwierigkeiten bei der Bildungsfähigkeit, der Arbeitsplatzsuche oder der Integration von Einwanderern, was auf nicht überwindbare - im Vergleich zur bundesrepublikanischen Bevölkerung stark differierende - kulturelle und zivilisatorische Entwicklungen zurückzuführen sei.597 Insbesondere die ,[...] keinerlei ,wirtschaftlichen Mehrwert $^{6}[\ldots]^{\text {“598 }}$ bringenden muslimischen Einwanderer stellen für ihn das Kernproblem der zukünftigen Gesellschaftsordnung dar: „[...] unterdurchschnittliche Beteiligung am Arbeitsmarkt, unterdurchschnittliche Erfolge im Bildungswesen und eine überdurchschnittliche Quote von Transferleistungsempfängern sowie eine überdurchschnittliche Beteiligung an der Gewaltkriminalität."599 Vor allem hinsichtlich der skizzierten Bildungsnachteile Deutschlands sei ,[...] das deutsche Bildungsproblem vor allem ein Problem der muslimischen Migranten." 600 So stilisiert Sarrazin hauptsächlich die Religion des Islams als antidemokratische Gefahr und Bedrohung der westlichen Welt.
„Das westliche Abendland sieht sich durch die muslimische Immigration und den wach- senden Einfluss islamistischer Glaubensrichtungen mit autoritären, vormodernen, auch antidemokratischen Tendenzen konfrontiert, die nicht nur das eigene Selbstverständnis herausfordern, sondern auch eine direkte Bedrobung unseres Lebensstils darstellen. "601

Insbesondere Kriminalität, Aggressivität und Terrorismus verknüpft Sarrazin eng mit islamisch gläubigen Einwanderern aus Afrika, der Türkei oder dem Nahen und Mittleren Osten, und sieht in ihnen die eigentliche Integrationsproblematik in Europa. ${ }^{602}$ Jedoch spielt er hier weiterhin auch Herkunft bzw. Gene gegen ökonomische Produktivität aus - ein nochmaliger Hinweis auf die Kodierungskategorie K4. ${ }^{603}$ Hiermit knüpft er insbesondere an das in letzter Zeit wieder neu belebte wirtschaftswissenschaftliche Forschungsgebiet der sogenannten Genoeconomics an, das eine Abhängigkeit zwischen genetischer Ausstattung und wirtschaftlicher Leistungsfähigkeit von Menschen konstatiert. ${ }^{604}$

\footnotetext{
594 Vgl. Sarrazin 2010, a. a. O., S. 17, 258, 393.

595 Sarrazin 2010, a. a. O., S. 20.

596 Vgl. Sarrazin 2010, a. a. O., S. 237, 32, 295.

597 Vgl. Sarrazin 2010, a. a. O., S. 59, 173, 212, 234, 245, 269, 331, 347, 369.

598 Bullion, Constanze von (2010): Am warmen Ofen der Völkerfreundschaft, in: Deutschlandstiftung Integration (Hrsg.): Sarrazin. Eine deutsche Debatte, München, S. 14.

599 Sarrazin 2010, a. a. O., S. 262.

600 Sarrazin 2010, a. a. O., S. 235.

601 Sarrazin 2010, a. a. O., S. 266.

602 Vgl. Sarrazin 2010, a. a. O., S. 236, 259, 260, 2625, 264, 266, 267, 277, 278, 292, 297, 330.

603 Vgl. Bullion 2010, ebd., S. 15.

604 Vgl. Callaway, Ewen (2012): Economics and genetics meet in uneasy union, in: Nature, Vol. 490, London u. a., S. $154 \mathrm{f}$.
} 
Thilo Sarrazin rechnet jedoch abschließend nicht nur mit der Bundespolitik und der politischen Führungsriege Deutschlands ab, sondern fällt auch bezüglich der europäischen Nachbarstaaten ein vernichtendes Urteil. Hier habe eine ,[...] überwiegend unhistorisch[e], naiv[e] und opportunistisch[e] staatlich[e] Migrationspolitik [...]“605 stattgefunden. Aufgrund dessen unterstellt Sarrazin so nicht nur der Bundesrepublik Deutschland ein von Zerfallsprozessen geprägtes Zukunftsszenario, sondern weitet diese Prognose auch auf die europäische Staatengemeinschaft aus. Er steht damit in der Tradition zahlreicher rassistisch motivierter Untergangstheoretiker. ${ }^{606}$

\subsubsection{Ergebnisaufbereitung und -interpretation}

Die Frage nach biologistisch-rassistischen Elementen in Thilo Sarrazins Werk sollte so definitiv beantwortet werden können: Festzuhalten sind vielfältige direkt rassistische Äußerungen Sarrazins sowie vielfältige indirekte Verweise, die zu groBen Teilen biologistischen Argumentationen zugesprochen werden können. Dies visualisiert ebenfalls die nachfolgende, quantifizierende Auswertung der qualitativen Inhaltsanalyse von Thilo Sarrazins Werk „Deutschland schafft sich ab. Wie wir unser Land aufs Spiel setzen“607. Hier können vor dem Hintergrund der Kodierungskategorie K4, mit welcher Elemente des biologistischen Rassismusphänomens klassifiziert wurden, viele Fundstellen verortet werden. Über die Hälfte statistisch gesehen etwa 54,8 Prozent - der analysierten Fundstellen in Sarrazins Werk enthalten direkt oder indirekt biologisierende Argumentationen oder greifen biologische Theorien dezidiert auf (s. Kapitel 3.1.3). Ebenfalls sind im Rahmen der Kodierungskategorie K3 multiple Stellen in Sarrazins Erörterung zu finden, die auf kulturalistische Rassismusthematisierungen hinweisen bzw. diese aufzeigen, vergleichsweise jedoch in geringerem Ausmaß mit statistisch gesehen etwa 37,6 Prozent der Fundstellen. Lediglich die Kodierungskategorien K1 und K2, die eine gesellschaftliche, Offenheit' bzw. Fremdenfeindlichkeit konstatierten, lassen sich mithilfe der Inhaltsanalyse nur rudimentär mit nur drei bzw. vier Fundstellen nachweisen. Dies zeigt jedoch in der Gesamtschau, dass viele der sarrazinschen Formulierungen, Gedanken und Argumente als rassistisch eingestuft werden können. Insbesondere für die nicht explizit genannten, sondern teilweise, verschleiert ${ }^{6}$ dargelegten Interpretationen und Visionen Sarrazins ist die qualitative Inhaltsanalyse nach Mayring - wie die Ergebnisse zeigen - aufgrund der methodischen und inhaltlichen Passung zu präferieren.

Hinsichtlich der formulierten Forschungsfrage (s. Kapitel 3.1.1) kann demnach zustimmend festgestellt werden, dass in Thilo Sarrazins Werk nicht nur rassistische, sondern vor allem vielfältige multiple biologistisch-rassistische Elemente

\footnotetext{
605 Sarrazin 2010, a. a. O., S. 257.

606 Vgl. Weiß 2011b, a. a. O.

Zu nennen sind an dieser Stelle beispielsweise Oswald Spengler, Edgar Julius Jung, Friedrich Sieburg, HansJürgen Syberberg, Botho Strauß oder Peter Sloterdijk. 
vorhanden sind, die eindeutig zu den Definitionsaspekten sowie zum Ankerbeispiel von Kodierungskategorie K4 passen. Insbesondere die immer wiederkehrende Verknüpfung der theoretischen Darlegungen Sarrazins mit biologischen Grundsätzen bzw. der oftmalige Rückgriff auf die Forschungsergebnisse von Biologie und Genetik bestätigen diese Einordnung.

Tab. 4: Ergebnisübersicht der Inhaltsanalyse nach Kodier-Leitfaden

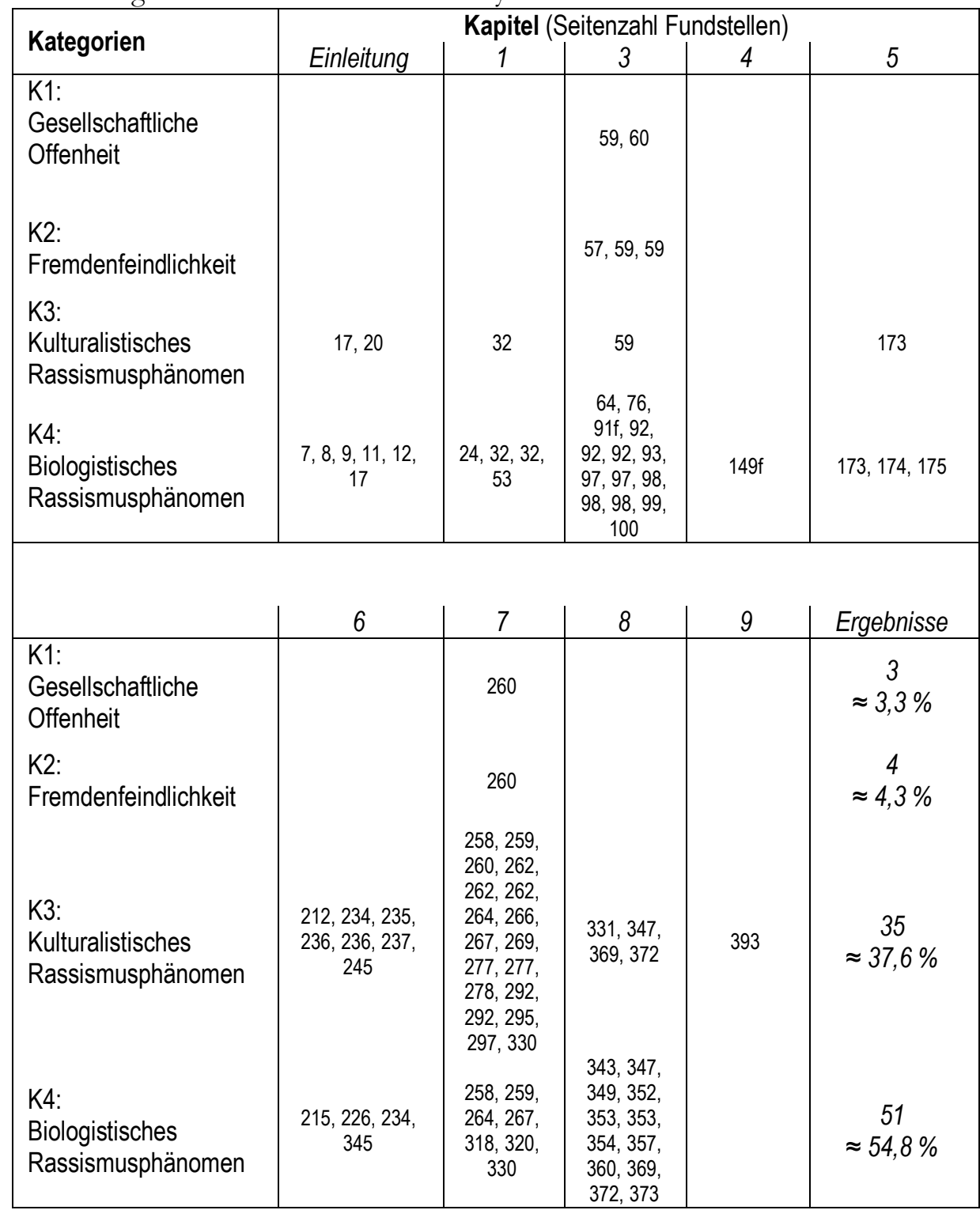


Das Problem: Diese vielfach biologistisch-kulturalistischen Rassismen in Sarrazins Argumentation sprechen weite Bevölkerungsbereiche an, was dem Wesen des gegenwärtigen Rassismus entspricht. ${ }^{608}$ Sarrazins Theoreme finden so in Deutschland ein großes Publikum sowie einen riesigen Absatzmarkt mit geschätzt mindestens 1,5 Millionen verkauften Exemplaren seines Buches. ${ }^{609}$

\section{„,...] Philosophen und Künstler, Politiker und Militärs sowie selbsternannte Rassen- kundler aus allen Ländern und Berufsschichten haben seit dem 18. Jahrhundert eine in- zwischen fast unüberschaubare Vielzahl rassentheoretischer Texte produziert. Von die- sen verschwanden viele kaum gelesen in der Versenkung, manche aber erreichten zumin- dest zeitweise eine ungeheure Popularität und ein Millionenpublikum. "610}

Thilo Sarrazins Thesen fallen bei großen Teilen der bundesrepublikanischen Bevölkerung demnach auf einen „fruchtbaren Boden“611, wie die anhaltende gesellschaftliche Zustimmung demonstriert - sie folgen dem „Ruf des Rattenfängers"612, wie Journalist Stephan Hebel treffend konstatiert. Auch weitere Kommentare aus dem medialen Umfeld bestätigen diesbezüglich: „Ein fataler Irr-

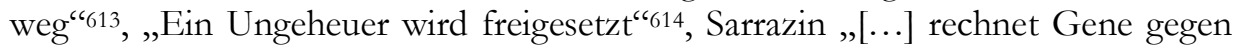
Bildung auf."615 Vor diesem Hintergrund kann so auch die Feststellung des Schriftstellers Feridun Zaimoglu bestätigt werden, der Thilo Sarrazin als einen „lupenreinen Rassist[en]“616 identifiziert. Sarrazin hat in der bundesrepublikanischen Historie abermals das Schreckgespenst des biologisch konnotierten Rassismus hoffähig etabliert, indem er die biologistische Trickkiste des Rassismus im 21. Jahrhundert wieder publikumswirksam öffnet. Somit rehabilitiert er biologistisch konnotierte Argumentationen und Gedankengänge für weite Teile der Gesellschaft. Auch der Erziehungswissenschaftler Klaus Ahlheim bestätigt diese argumentative Biologisierung, indem er Sarrazin wie folgt rezitiert: „Intelligenz, Elite, Exzellenz und [...] der sozioökonomische Status sind genetisch bedingt [...]“617. Journalistin Karen Krüger bemerkt ebenfalls bezüglich der europäischen Brisanz

Vgl. Geulen 2007, a. a. O., S.13ff.

Dass viele von Thilo Sarrazin genannten Ressentiments und Vorstellungen auch von großen Teilen der bundesrepublikanischen Bevölkerung geteilt werden, belegen die nachfolgenden Datenmaterialien (s. Kapitel 3.3, 3.4, 3.5, 3.6). Vgl. Decker/Weißmann/Kiess/Brähler 2010, a. a. O. | Vgl. De-

cker/Rothe/Weissmann/Geißler/Brähler 2008, a. a. O. | Vgl. Decker/Kiess/Brähler 2012, a. a. $\mathrm{O}$.

609 Vgl. Weiß 2011b, a. a. O., S. 90ff. | Vgl. Krieger 2012, a. a. O. | Vgl. Dernbach 2013, a. a. O.

610 Geulen 2007, a. a. O., S. 15.

611 Hebel, Stephan (2010): Der Ruf des Rattenfängers, in: Deutschlandstiftung Integration (Hrsg.): Sarrazin. Eine deutsche Debatte, München, S. 69.

612 Hebel 2010, ebd., S. 69.

613 Schirrmacher 2010, a. a. O., S. 22.

614 Jörges 2010, a. a. O., S. 154.

615 Elitz, Ernst (2010): Abregen, anpacken, in: Deutschlandstiftung Integration (Hrsg.): Sarrazin. Eine deutsche Debatte, München, S. 49.

616 Zaimoglu, Feridun (2010): Saubermann als Brandstifter, in: Deutschlandstiftung Integration (Hrsg.): Sarrazin. Eine deutsche Debatte, München, S. 56.

617 Ahlheim 2011, a. a. O., S. 36. 
des Themas kritisch: „Die Niederlande haben ihren Geert Wilders, Deutschland hat seinen Thilo Sarrazin. Im Rassismus steht keiner dem anderen etwas nach. "618 Darüber hinaus identifiziert der Journalist Arno Widmann insbesondere im Zusammenhang mit den Erfahrungen der deutschen Vergangenheit treffend:

„Solche Vorstellungen prägten rassistische und sozialdarwinistische Überlegungen des 19. Jahrbunderts. Sie waren damals schon nicht Ergebnis seriöser Forschung, sondern Ausdruck von Rassen- und Standesdünkel. Sie prägten jene Weltbilder, die im Nationalsozialismus zusammengeschmolzen wurden zu einer Phantasmagorie, in der dann von deutschen Tugenden gesprochen werden konnte im Gegensatz. zu den Charaktereigenschaften von Franzosen, Engländern und Amerikanern. Von Russen, Juden und Schwarzen ganz zu schweigen. "619

Auch vor dem Hintergrund der weiter gefassten Rassismusdefinition Albert Memmis sind in Thilo Sarrazins Aussagen zweifellos rassistische Aspekte festzustellen. ${ }^{620}$

„Rassismus ist nach dem heutigen Stand der Wissenschaft und der internationalen Diskussion keineswegs nur ein biologisch begründeter Herrenrassenwahn. Zunehmend basieren rassistische Argumentationsmuster auf Zuschreibungen, unterschiedliche Zitate wie ,Kulturen', ,Nationen', Ethnien“ oder ,Religionsqugebörigkeit'. Kennzeichnend für Rassismus ist die [biologistische baw. naturalisierende] Konstruktion vermeintlich homogener Gruppen, deren individuellen Mitgliedern pauschal bestimmte negative Eigenschaften zugeschrieben werden. "621

Folglich bleibt festzuhalten, dass Sarrazins Ausführungen vielfältige, direkte und indirekte rassistische Elemente, Modellvorstellungen und Argumentationsmuster aufnehmen, die oftmals auf biologisch-genetisch begründete Erkenntnisse zurückgreifen bzw. „[...] an der Grenze zum biologischen Rassismus [...]“622 stehen, so Politikwissenschaftler Michael Minkenberg. Die Ergebnisse der qualitativen Inhaltsanalyse bestätigen diese Einschätzung (s. Tab. 2). Selbstverständlich bedient Sarrazin sich auch verschleiernden, kulturalisierten Attributen des biologistischen Rassismusphänomens, welche bei ihm jedoch vielfach offensichtlich nur ein Ablenkungsmanöver darstellen. ${ }^{623} \mathrm{Zu}$ identifizieren sind multiple deutlich rassistische

618 Krüger, Karen (2010): Er ist nur eine Stimme unter vielen, in: Deutschlandstiftung Integration (Hrsg.): Sarrazin. Eine deutsche Debatte, München, S. 65.

$\mathrm{Zu}$ beachten ist jedoch, dass Geert Wilders einen spezifisch niederländischen Fall darstellt. Er spricht sich für das Judentum, jedoch gegen den Islam sowie gegen Antillianer aus. Aufgrund dessen ist die Gleichsetzung Wilders-Sarrazin nur eingeschränkt möglich.

619 Widmann, Arno (2010): Wider den Rassendünkel, in: Deutschlandstiftung Integration (Hrsg.): Sarrazin. Eine deutsche Debatte, München, S. 89.

620 Vgl. Vesper, Karlen (2010): Eine Gefahr für die Demokratie, in: Deutschlandstiftung Integration (Hrsg.): Sarrazin. Eine deutsche Debatte, München, S. 102ff.

621 Vesper 2010, a. a. O., S. 103.

622 Minkenberg 2013, a. a. O., S. 20.

623 Die genannten, angeblichen kulturellen Unterscheidungsfaktoren, wie Herkunft, Bildungsgrad, Wirtschaftskraft, Intelligenz oder individuelle ,Qualität', werden von Sarrazin mithilfe des Hinweises auf geburts- und 
Ansätze, die vor allem hinsichtlich tendenziell eugenischer Aussagen bzw. Vermutungen im Bereich der übermäßigen Geburten von Einwanderern Parallelen zu den menschenunwürdigen Schreckensszenarien des sogenannten Dritten Reichs geradezu aufzwingen. Verfestigt wird diese Annahme auch bezüglich seines Rückgriffs auf ,qualitative' Unterschiede zwischen einzelnen Bevölkerungsgruppen, sodass sich auch hier direkte Parallelen aus der nationalsozialistischen Ära vor dem Hintergrund des sogenannten ,Arier'-Mythos aufdrängen. Vor allem bleibt er eine notwendige Differenzierung schuldig: Er verallgemeinert seine Argumentationen auf die gesamte ausländische Bevölkerung respektive die Bürgerinnen und Bürger mit Migrationshintergrund - dies kommt der eigentlich überholt geglaubten ,Rasseklassifikation' vergangener Tage entgegen. Zwar wird der Begriff ,Rasse“ in diesem Zusammenhang nicht wortwörtlich erwähnt, jedoch ist er indirekt, mit umschreibenden Metaphern versehen, anzutreffen. Sarrazin nutzt lediglich die Begrifflichkeiten ,Kultur' oder ,Ethnie ${ }^{6}$ als Deckbegriffe für herkunftsspezifische, kulturelle oder biologische Zuschreibungen, die er vor allem auf die Einwanderer in Deutschland fokussiert. ${ }^{624}$ Nichtsdestotrotz treffen auf seine Argumente auch alle definitorischen Merkmale des enggeführten, biologisch-genetisch konnotierten Rassismusbegriffes nach Robert Miles zu (s. Kapitel 2.2.1).

Thilo Sarrazins Theoreme können resümierend als ,,[...] eindeutig rassistisch bewertet $[\ldots]^{“ 625}$ werden. „[...] Sarrazin [mobilisiert] mit einem ,bewussten Tabubruch' Vorurteile, die sonst von Rechtsradikalen geäußert w[e]rden." "626 Auch bezüglich der pseudogenetischen Betrachtung einer generationenübergreifenden Weitergabe von erworbenen Eigenschaften - von Genen - wie Bildung oder Intelligenz, kann eindeutig diagnostiziert werden: „Die Verbindung von Abstammung und einer bestimmten Schichtzugehörigkeit im Sinne von Vererbung, das ist eindeutig rassistisch."627 Das eigentliche Problem hieran ist jedoch, dass diese biologisch-rassistischen Ressentiments auch in vielfältigen Bereichen der bundesrepublikanischen Gesellschaft etabliert scheinen, was die große Zustimmung zu Sarrazins Thesen illustriert (s. Kapitel 3, 3.1). Der Politikwissenschaftler Gideon Botsch folgert - in Übereinstimmung mit den hier analysierten Ergebnissen zusammenfassend: „Meine Fragestellung war, ob sich Herr Sarrazin [...] rassistisch äußert - und da komme ich zu einem eindeutigen Ergebnis: Ja." ${ }^{\prime \prime 28}$

vererbungsspezifische Hintergründe naturalisiert und biologisiert. Der Kulturbezug dient folglich überwiegend nur als Verkleidung biologistischer Argumentationen.

624 Vgl. Bade 2013, a. a. O., S. 65.

625 Vorsamer, B. (2010): Gutachten zu Thilo Sarrazin. Rassistisch, elitär und herabwürdigend, in URL: http://www.sueddeutsche.de/ politik/gutachten-zu-thilo-sarrazin-rassistisch-elitaerund-herabwuerdigend-1.58130<17.06.2011>.

626 Vorsamer 2010, a. a. O.

627 Vorsamer 2010, a. a. O.

628 Vorsamer 2010, a. a. O. 


\subsection{Rassistische Einstellungen in Deutschland}

Die vorangegangene Analyse der Theorien Thilo Sarrazins belegt eindrücklich, dass innerhalb der bundesrepublikanischen Gesellschaft eine in den letzten Jahren stark angestiegene Akzeptanz fremdenfeindlicher bzw. rassistischer Theoreme identifiziert werden kann. ${ }^{629}$ Vor allem überholt geglaubte biologisch-genetische Argumentationsstrukturen zeigen sich in weiten Teilen der deutschen Bevölkerung präsent (s. Kapitel 3, 3.1). Besorgniserregend an dieser Entwicklung ist, dass diese Meinungstendenzen keinesfalls ein gesellschaftliches Randphänomen darstellen, sondern die breite Mitte unserer Gesellschaft im 21. Jahrhundert repräsentieren. Die qualitative Studie „Ein Blick in die Mitte. Zur Entstehung rechtsextremer und demokratischer Einstellungen in Deutschland" 630 von Oliver Decker und Elmar Brähler u. a. im Auftrag der Friedrich-Ebert-Stiftung setzt an diesen zentralen Erkenntnissen mit dem Ziel an, sowohl Ursachen und Hintergründe als auch die Zusammenhänge und Einflussfaktoren von schwerpunktmäßig rassistisch motivierten, fremdenfeindlichen Einstellungen $\mathrm{zu}$ entschlüsseln. ${ }^{631}$ Sie stellt ein vertiefendes Forschungsprojekt auf der Grundlage von zwölf Gruppendiskussionen unter den oben genannten Zieldimensionen dar. ${ }^{632}$ Sie gilt als Nachfolgestudie der Untersuchung „Vom Rand zur Mitte. Rechtsextreme Einstellungen und ihre Einflussfaktoren in Deutschland“"633 aus dem Jahr 2006. Die Diskussionen mit insgesamt 120 Teilnehmerinnen und Teilnehmern fanden von 2007 bis 2008 in West- und Ostberlin, in Sachsen, Hessen, Baden-Württemberg, NordrheinWestfalen sowie in Schleswig-Holstein statt. ${ }^{634}$ Ziel der Studie, in Anknüpfung an die zuvor genannte, vorausgehende Untersuchung, war die Ermittlung von Zusammenhängen von Einflussfaktoren für rechtsextreme Einstellungen sowie die Aufklärung der Ursachen für diesbezügliche teils/teils-Antworten. ${ }^{635}$ Aufgrund der begrenzten Teilnehmerzahl kann hierbei keinesfalls - wie bei den meisten qualitativen Analysen - von einer repräsentativen Untersuchung gesprochen werden, eher von einem gesellschaftlichen Trend, der kritisch sowie differenziert analysiert werden muss. Der Fokus liegt auf einer „[...] vertiefte[n] Rekonstruktion

${ }_{629}$ Vgl. Decker/Rothe/Weissmann/Geißler/Brähler 2008, a. a. O., S. 9.

630 Decker/Rothe/Weissmann/Geißler/Brähler 2008, a. a. O.

Die Studie ,Ein Blick in die Mitte' gilt als Nachfolgestudie des quantitativen Forschungsvorbabens „Vom

Rand zur Mitte. Recbtsextreme Einstellungen und ibre Einflussfaktoren in Deutscbland" (Decker, Oliver/Brähler,

Elmar (2006): Vom Rand zur Mitte. Rechtsextreme Einstellungen und ibre Einflussfaktoren in Deutschland, Berlin.) aus dem Jabr 2006. Sie basiert auf zwölf themenzentrierten Gruppendiskussionen von 120 Probandinnen und Probanden, die 2007/2008 in verscbiedenen, regionalen Milieus durchgeführt wurden: In Westund Ostberlin, Sachsen, Nord- und Süd-Hessen, Baden-Württemberg, Nordrhein-Westfalen und SchleswigHolstein. Die Gruppendiskussionen dauerten jeweils eineinhalb bis zwei Stunden; sie wurden per Tonband aufgezeichnet und für die Auswertung transkribiert.

631 Vgl. Decker/Rothe/Weissmann/Geißler/Brähler 2008, a. a. O., S. $15 \mathrm{ff}$.

${ }_{632}$ Vgl. Decker/Rothe/Weissmann/Geißler/Brähler 2008, a. a. O., S. $15 \mathrm{ff}$.

633 Decker/Brähler 2006, a. a. O.

634 Vgl. Decker/Rothe/Weissmann/Geißler/Brähler 2008, a. a. O., S. 47.

635 Vgl. Decker/Brähler 2006, S. $15 \mathrm{ff}$. 


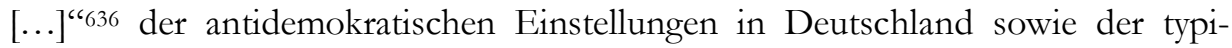
schen, gesellschaftlichen Deutungs- und Handlungsmuster. Im Mittelpunkt stehen in dieser Untersuchung die Dimensionen des Rassismus sowie der Fremdenfeindlichkeit, welche als ,[...], Einstiegsdroge ${ }^{6}$ in den Rechtsextremismus [...]“637 gelten.

Im folgenden Abschnitt werden exemplarische Argumentations- und Diskussionslinien dargestellt, um auch abseits von standardisierten Fragebogenauswertungen einen qualitativen Einblick in die partiell deutlich rassistischen Einstellungen der deutschen Gesellschaft zu geben. Schon im Voraus lässt sich konstatieren, dass innerhalb der Diskussionsrunden häufig zwischen ,nützlichen' und ,unbrauchbaren' Menschen unterschieden wird - hier werden also direkt oder indirekt Menschengruppen kategorisiert und teilweise auch offen mit dem aus der Biologie entwendeten ,Rassebegriff‘ bezeichnet. ,Fremde' und ,die Anderen' werden systematisch abgewertet, ausgegrenzt, diskriminiert und hierarchisiert.

Beispielsweise wird darauf aufmerksam gemacht, dass ,die ${ }^{6}$ Migrantenkinder sowie ,die' südländischen Typen oftmals als Bedrohung wahrgenommen werden eine notwendige Differenzierung fehlt. ${ }^{638}$ Bürgerinnen und Bürger mit Migrationshintergrund werden generalisierend negativ klassifiziert. Eine Diskussionsrunde in Dortmund greift den Themenbereich ,Ausländer ${ }^{6}$ auf, es ,[...] durchzieht die ganze Gruppendiskussion [...]“639. Ebenfalls wird pauschal von ,den“ Türken, „[...] die immer mehr zunehmen würden [...] und deren Abschottung in ,Ghettos'“640, von Ausländerinnen und Ausländern, „,[...] die von ,dubiosen Geschäften` leben würden." "641 sowie von der grundlegenden Kriminalität ,der ${ }^{6}$ Türken gesprochen. ${ }^{642}$ Hinzukommend wird explizit an die Argumentationslinien Thilo Sarrazins angeknüpft, der auch vor einer zunehmenden biologischen bzw. kulturellen ,Überfremdung' des Landes warnt. 643 So wird auf die ärgerlichen gesellschaftlichen Zustände in Deutschland hingewiesen, wo ,[...] ,über ein Drittel Ausländer $[\ldots]^{\text {“6 } 644}$ vermutet werden. Insbesondere in einer Diskussionsrunde in Gießen wird direkt zwischen ,[...] guten“ Ausländern unterschieden, die etwas leisten würden, im Gegensatz zu ,schlechten Ausländern', die ,schmarotzen“، "645 _ ein exemplarisches Beispiel für die tendenziell rassistische respektive ,rassische“ Einstellung innerhalb großer Teile der deutschen Gesellschaft (s. Kapitel 3, 3.1). Auch eine Diskussionssequenz in Berlin-Hohenschönhausen wird von fremdenfeindlichen und rassistisch-antisemitischen Äußerungen geprägt: ${ }^{646}$ Aussagen wie

\footnotetext{
636 Decker/Rothe/Weissmann/Geißler/Brähler 2008, a. a. O., S. 15.

637 Decker/Rothe/Weissmann/Geißler/Brähler 2008, a. a. O., S. 15.

638 Vgl. Decker/Rothe/Weissmann/Geißler/Brähler 2008, a. a. O., S. 63.

639 Decker/Rothe/Weissmann/Geißler/Brähler 2008, a. a. O., S. 68.

640 Decker/Rothe/Weissmann/Geißler/Brähler 2008, a. a. O., S. 68.

641 Decker/Rothe/Weissmann/Geißler/Brähler 2008, a. a. O., S. 69.

642 Vgl. Decker/Rothe/Weissmann/Geißler/Brähler 2008, a. a. O., S. 204ff.

643 Vgl. Decker/Rothe/Weissmann/Geißler/Brähler 2008, a. a. O., S. 70.

644 Decker/Rothe/Weissmann/Geißler/Brähler 2008, a. a. O., S. 99.

645 Decker/Rothe/Weissmann/Geißler/Brähler 2008, a. a. O., S. 74.

646 Vgl. Decker/Rothe/Weissmann/Geißler/Brähler 2008, a. a. O., S. $110 \mathrm{ff}$.
} 
„,Ah die boxen wir alle um Junge, die Säue “6477 oder die Bezeichnung von Ausländerinnen und Ausländern als ,[...], minderwertiges Volk ${ }^{6}[\ldots]^{\text {“648 }}$ sind auch hier im Verlauf der gesamten Sitzung anzutreffen. „Ausländerfeindliche [und rassistische] Einstellungen werden deutlich, so wird ihnen zum Beispiel pauschal Aggressivität unterstellt." 649

Fremdenfeindlichkeit sowie originärer Rassismus konnten in mehr oder weniger allen Gruppendiskussionen diagnostiziert werden, ,[...] auch wenn in den Fragebögen Ablehnung oder Teils/Teils-Zustimmung zu den entsprechenden Aussagen angegeben worden ist.“"650 „Auffällig ist, dass wir entgegen der Ergebnisse der Fragebogenerhebung auch bei Teilnehmenden ausländerfeindliche und rassistische Einstellungen antrafen, die dieser Dimension im Fragebogen nicht oder nur teilweise zugestimmt hatten." 651 Dies beweist zusätzlich, dass ausländerfeindliche bzw. rassistische Verhaltensweisen in der Gesellschaft oftmals verschleiert werden, um sich trotz seiner tendenziell rassistischen Einstellung als offiziell demokratisch und rechtsstaatlich zu präsentieren. Auch eindeutig biologistische, ,rasserassistische“ Aussagen sind zu identifizieren. ${ }^{652}$ So wird beispielsweise erwähnt, dass bei Freundschaften ,die Rasse` keine Rolle spielen sollte. ${ }^{653}$ Auch wird auf ,reine ${ }^{6}$ und ,vermischte ${ }^{6}$ - biologisch konnotierte - Ethnien aufmerksam gemacht, was eine bleibende Bedeutung des ,Rassebegriffs' impliziert: ${ }^{654}$ Hier erlebt die ,[...] Vorstellung von ,Ethnien“, die in sich gleich seien, die sich aber mit ,den/m Anderen“ vermischen könnten.“"655 eine gesellschaftliche Renaissance. „Zusammengefasst wird ein sehr deutlicher, vom Gefühl der Bedrohung gespeister offener Rassismus [...] geäußert."656

Die Datenmaterialien sind ein Beweis dafür, „[...] dass Ausländerfeindlichkeit [bzw. hier Rassismus] bis in die Mitte der Gesellschaft hineinreicht. Die Ablehnung von angeblich nicht integrierten und unnützen Ausländern ist zu einer weitgehenden Selbstverständlichkeit im gesellschaftlichen Diskurs geworden. "657 Fremdenfeindlichkeit und Rassismus stellen darüber hinaus in der Studie ,[...] sowohl quantitativ als auch qualitativ die am stärksten vertretene[n] Dimension[en] in den meisten Diskussionen dar [...].“658 Aufgrund der Untersuchungserkenntnisse lässt sich schlussfolgern, dass vor allem biologistisch-rassistische sowie fremdenfeindliche Einstellungen in der bundesrepublikanischen Bevölkerung 
noch stärker vertreten sein könnten, als es die nachfolgenden Ergebnisse quantitativer, repräsentativer Fragebogenanalysen veranschaulichen.

Weiterhin demonstriert die hier vorgenommene Fokussierung der Studienmaterialien unter biologisch-rassistischem Schwerpunkt, dass Fremdenfeindlichkeit sowie insbesondere das Rassismusphänomen im 21. Jahrhundert präsent sind. Ebenfalls zeigt sich, dass vor allem als überholt angesehene, biologisch-genetische Erklärungsversuche im Rahmen rassistischer Argumentationen integriert werden, um die Diskriminierung und Abwertung von ,Fremden' mithilfe biologisch vorgeblich valider Erkenntnisse zu legitimieren. Dem Fazit der Studienautorinnen und -autoren ist demzufolge zuzustimmen:

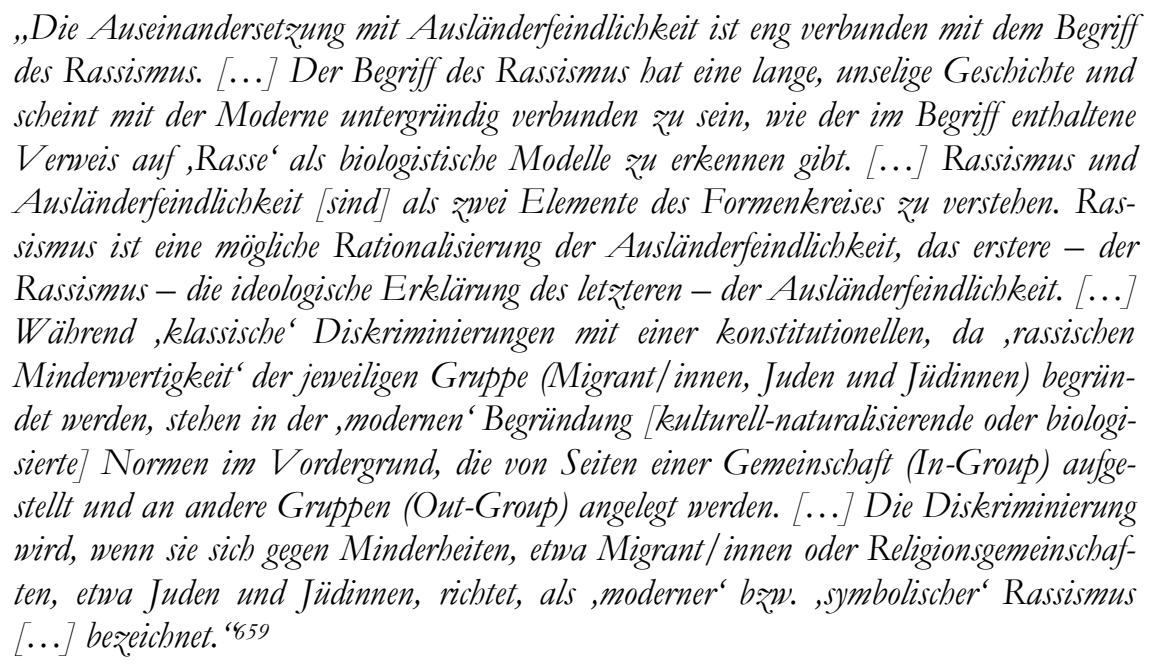

\subsection{Deutschland in der Krise}

Nach den vorausgegangenen, qualitativen Forschungsdaten werden die nun nachfolgenden, quantitativen Forschungsdesigns bzw. die Untersuchungsergebnisse dieser genutzt, um mithilfe von verallgemeinerbaren und strukturierten Beobachtungen rassistische Verhaltensweisen und Einstellungen in der deutschen Gesellschaft festzustellen. Die qualitativen Datensätze haben bereits gezeigt, dass rassistische Handlungs- und Interaktionsmuster innerhalb der deutschen Bevölkerung existent sind - mithilfe der quantitativen Daten können diese Ergebnisse nun repräsentativ validiert und bestätigt werden. Da es sich hierbei größtenteils um Rechtsextremismus-Studien handelt, müssen die Datenmaterialien jedoch kritisch sowie differenziert reflektiert werden. Die Repräsentativität der quantitativen Studienergebnisse ermöglicht zwar vielfältige Vorteile, jedoch müssen auch etwaige Nachteile bzw. Probleme - beispielsweise bei der Clusterung der Daten - beachtet werden, um mögliche irregulären Schlussfolgerungen zu vermeiden. Notwendig ist 
zudem eine neuerliche Fokussierung der Ergebnisse der Datensätze, um dem Schwerpunkt dieser Arbeit - der Kombination von sozial- und naturwissenschaftlichen Forschungsansätzen sowie der Fokussierung des biologisch-genetischen Rassismusphänomens - gerecht zu werden.

Die von 2006 bis 2012 von Oliver Decker und Elmar Brähler u. a. im Auftrag der Friedrich-Ebert-Stiftung durchgeführten ,Mitte'-Studien analysieren rechtsextreme Einstellungen in der bundesrepublikanischen Gesellschaft. ${ }^{660}$ Vor diesem Hintergrund wird nicht nur die aktuelle gesellschaftliche Situation diagnostiziert, sondern diese auch vergleichend mit den vorhergehenden Ergebnissen systematisch eingeordnet. Das Ziel der ,Mitte'-Studien ist die Identifizierung von antidemokratischen Einstellungen in der bundesrepublikanischen Gesellschaft bzw. - als Querschnittsvergleich - in der Gruppe der befragten Bürgerinnen und Bürger. ${ }^{661}$ Die publizierten Daten können unter einem modifizierten Analyseraster ebenfalls zur Darstellung biologisch-rassistischer Ressentiments in der bundesrepublikanischen Bevölkerung genutzt werden, da die rassistische Ideologie den zentralen Grundbaustein des Rechtsextremismus darstellt und dieser zudem auf rassistische Argumentationsmuster zurückgreift. Jedoch konzentrieren sich die quantitativen Studien zumeist auf die beschönigenden, rassistischen Ersatzbegriffe der ,Fremden-' und ,Ausländerfeindlichkeit'. Der originäre Rassismusbegriff steht partiell im Hintergrund, sodass auch diese Tatsache eine neue Interpretation der Datenmaterialien nötig macht.

Im folgenden Abschnitt stehen einige exemplarische Beispiele des Fragebogens der Studie „Die Mitte im Umbruch. Rechtsextreme Einstellungen in Deutschland

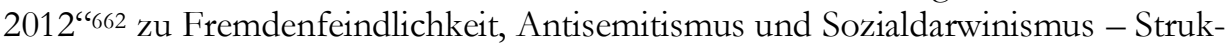
turen, auf die sich der Rassismus beruft und diese durch die Bezugnahme auf kulturalistische und biologistische Elemente zu begründen versucht. ${ }^{663}$ Hierzu wurden von Oliver Decker und Elmar Brähler u. a. im Auftrag der FriedrichEbert-Stiftung standardisierte Fragebogenuntersuchungen durchgeführt. Selbstverständlich muss sowohl mit den gesammelten Datenmaterialien als auch mit deren Interpretation kritisch umgegangen werden, da sie Stichprobenfehler sowie Auswertungsabweichungen beinhalten könnten. „Wie auch in den vorangegange-

660 Vgl. Decker/Weißmann/Kiess/Brähler 2010, a. a. O., S. 7.

661 Vgl. Decker/Kiess/Brähler 2012, a. a. O., S. 8ff.

662 Decker/Kiess/Brähler 2012, a. a. O.

Die ,Mitte $-S t u d i e n$ basieren auf quantitativen Fragebogenumfragen der bundesrepublikanischen Gesellschaft. Der Fokus wird bierbei auf die Repräsentativität der Ergebnisse gelegt. Die Studie aus dem Jabr 2012 orientiert sich demnach an unterschiedlichen, gleich verteilten Stichprobenflächen in Deutschland, um möglichst homogene sowie gleich große Stichproben zu erreichen. Die Bevölkerungserbebung wurde im Juni und Juli 2012 in 4480 Haushalten durchgeführt; aufgrund von Auskunftsverweigerungen, Krankheitsfällen oder Abwesenheit waren jedoch gewisse Ausfälle zu verzeichnen. Insgesamt wurden letztlich 56,5 Prozent der 4480 Haushalte in die Datenerhebung integriert. Die befragten Haushalte wurden dabei soziodemographisch kategorisiert, danach der Rechtsextremismusfragebogen mit 18 Fragen (,lebne ab' bis, stimme voll und ganz ₹ $u^{\prime}$ ) anonym ausgefüllt; die Interviewleiterinnen und-leiter standen dabei als Hilfestellung zur Verfïgung, falls Verständnisprobleme auftauchen sollten. Kritisch muss an dieser Stelle die verringerte Repräsentativität anfgrund der kleineren Stichprobenzabl angemerkt werden. Vgl. Decker/Kiess/Brähler 2012, a. a. O., S. 24ff, $29 \mathrm{f}$. 
nen Studien sind nicht nur die teilweise hohen Zustimmungswerte zu den einzelnen Fragen beachtenswert, sondern auch der große Anteil an ,teils/teilsAntworten'. Wir vermuten hinter diesen Antworten zumindest teilweise eine versteckte Zustimmung zu den vorgelegten Aussagen, die nicht geäußert wird, weil den Proband/innen die soziale Unerwünschtheit bewusst ist." "664, so eine von den Autorinnen und Autoren der Studie formulierte Einschränkung. Hier muss ergänzend schon im Vorhinein auf die Schwierigkeit der Auswertung und Analyse von quantitativen Daten hingewiesen werden, da die scheinbar neutrale Antwortmöglichkeit ,teils/teils' auf beide Bereiche - Zustimmung und Ablehnung, je nach der Perspektive der bearbeitenden Person - angewandt werden kann. Der Großteil der Antwortmöglichkeit ,teils/teils' kann jedoch tendenziell mit dem zustimmenden Bereich assoziiert werden, da die uneindeutige Zuordnung nur als Verschleierung angesehen werden kann, um vordergründig weiterhin gesellschaftlich etablierten Normen zuzustimmen. ${ }^{665}$ So werden in der folgenden Fokussierung der Daten ebenfalls, trotz der vorhandenen analytischen Unschärfe, die ,teils/teils ‘Antwortalternativen dem zustimmenden Bereich hinzugezählt.

Die vorliegenden, exemplarischen Untersuchungsergebnisse einzelner Studienfragen geben einen nachhaltigen Einblick in die Gedankenwelt der deutschen Gesellschaft, insbesondere der jugendlichen Mitbürgerinnen und Mitbürger. Über ein Drittel aller Befragten (35,1 Prozent), wenn die Antwortmöglichkeiten ,stimme voll und ganz $\mathrm{zu}^{6}$, ,stimme überwiegend $\mathrm{zu}^{6}$ und ,stimme teils $\mathrm{zu}$, teils nicht $\mathrm{zu}^{6}$ summiert werden, können sich tendenziell mit der sozialdarwinistisch geprägten Aussage identifizieren, wonach das von Charles Darwin adaptierte Konzept des ,Überlebens des Stärkeren` auch auf gesellschaftlicher Ebene unterstützt werden sollte. ${ }^{666}$ Demzufolge wird mithilfe einer Naturalisierung der Gesellschaft indirekt zwischen den ,stärkeren' Bürgerinnen und Bürgern einerseits, die die Gesellschaft weiterentwickeln und für deren Zukunftssicherung verantwortlich sind, sowie andererseits den angeblich ,schwächeren', ,weniger notwendigen“ Menschen differenziert. Diesbezüglich könnte man ebenfalls Parallelen zum Phänomen des sogenannten biologistischen ,Rassekonzeptes ‘ anmerken, das die Hierarchisierung der Gesellschaft in unterschiedliche Bevölkerungsgruppen vorsieht.

Diesen Trend unterstützt beispielsweise auch die aufgezeigte Argumentation nach ,wertem' und ,unwertem' Leben: Auch hier stimmt tendenziell fast ein Viertel aller Befragten (26,6 Prozent) zu - ein Indiz für die Verbreitung von biologisch konnotierten, rassistischen Perspektiven. ${ }^{667}$ Ein Drittel aller befragten Bürgerinnen und Bürger (37,7 Prozent) gibt zu erkennen, dass es das ,deutsche Volk` tendenzi-

664 Decker/Weißmann/Kiess/Brähler 2010, a. a. O., S. 72. | Vgl. Decker/Kiess/Brähler 2012, a. a. O., S. 28.

665 Vgl. Decker/Weißmann/Kiess/Brähler 2010, a. a. O., S. $72 . \mid$ Vgl. Lamnek 2010, a. a. O., S. 7. Diese Vorgehensweise unterstützen auch die Erkenntnisse der Sozialforschung. Meistens stehen, weiß nicht" b₹w. ,teils/ teils'-Antworten - trotz,prinzipiell unterschiedlicher Bedeutungen - vor allem für das Verbergen von sozial nicht akzeptierten Eigenschaften.

666 Vgl. Decker/Kiess/Brähler 2012, a. a. O., S. 29ff.

667 Vgl. Decker/Kiess/Brähler 2012, a. a. O., S. 29ff. 
ell - biologisch als auch kulturell - gegenüber anderen Völkern deutlich überlegen sieht, was nochmals die sozialdarwinistischen und rassistischen Tendenzen in der bundesrepublikanischen Bevölkerung nachdrücklich verdeutlicht. ${ }^{668}$ Letztlich stimmen 64,4 Prozent aller Befragten der rassistisch motivierten These zu, dass die Bundesrepublik Deutschland durch zu viele ausländische Einwanderer - kulturell und biologisch gesehen - ,überfremdet ${ }^{6}$ sei. ${ }^{669}$ Diese Ergebnisse skizzieren eine tendenziell problematische, wenn nicht sogar gefährliche Entwicklung in Deutschland. Auch ein zeitlicher Vergleich der Ergebnisse der vorliegenden Studien zwischen 2002 und 2012 stützt die zuvor genannten Erkenntnisse. 670

Tab. 5: Ergebnisse zu Ausländerfeindlichkeit, Antisemitismus und Sozialdarwinismus ${ }^{671}$

\begin{tabular}{|c|c|c|c|c|c|c|}
\hline \multicolumn{2}{|c|}{ Rechtsextremismus } & $\begin{array}{l}\text { lehne } \\
\text { völlig } a b \\
\%\end{array}$ & $\begin{array}{c}\text { lehne } \\
\text { überwie- } \\
\text { gend } a b \\
\%\end{array}$ & $\begin{array}{l}\text { stimme } \\
\text { teils zu, } \\
\text { teils nicht } \\
\text { zu \% }\end{array}$ & $\begin{array}{l}\text { stimme } \\
\text { überwie- } \\
\text { gend zu } \\
\%\end{array}$ & $\begin{array}{l}\text { stimme } \\
\text { voll und } \\
\text { ganz zu } \\
\%\end{array}$ \\
\hline 01 & $\begin{array}{l}\text { Wie in der Natur sollte sich in der } \\
\text { Gesellschaft immer der Stärkere } \\
\text { durchsetzen. }\end{array}$ & 44,8 & 20,2 & 20,6 & 12,0 & 2,5 \\
\hline 02 & $\begin{array}{l}\text { Die Ausländer kommen nur hierher, } \\
\text { um unseren Sozialstaat auszunutzen. }\end{array}$ & 16,8 & 16,9 & 30,4 & 21,7 & 14,3 \\
\hline 03 & $\begin{array}{l}\text { Eigentlich sind die Deutschen ande- } \\
\text { ren Völkern von Natur aus überlegen. }\end{array}$ & 42,4 & 20,0 & 19,9 & 12,6 & 5,2 \\
\hline 04 & $\begin{array}{l}\text { Wenn Arbeitsplätze knapp werden, } \\
\text { sollte man die Ausländer wieder in } \\
\text { ihre Heimat zurückschicken. }\end{array}$ & 22,8 & 18,1 & 27,5 & 18,4 & 13,2 \\
\hline 05 & $\begin{array}{l}\text { Es gibt wertvolles und unwertes } \\
\text { Leben. }\end{array}$ & 58,2 & 15,3 & 16,0 & 6,9 & 3,7 \\
\hline 06 & $\begin{array}{l}\text { Die Bundesrepublik ist durch die } \\
\text { vielen Ausländer in einem gefährli- } \\
\text { chen Maß überfremdet. }\end{array}$ & 19,4 & 16,2 & 27,2 & 22,3 & 14,9 \\
\hline 07 & $\begin{array}{l}\text { Die Juden haben einfach etwas } \\
\text { Besonderes und Eigentümliches an } \\
\text { sich und passen nicht so recht zu } \\
\text { uns. }\end{array}$ & 39,6 & 21,6 & 24,3 & 10,5 & 4,0 \\
\hline
\end{tabular}

Nachfolgend steht nun nochmals ein dezidierter Blick auf die Bereiche Fremdenfeindlichkeit, Antisemitismus und Sozialdarwinismus - Komponenten, die in vie-

668 Vgl. Decker/Kiess/Brähler 2012, a. a. O., S. 29ff.

669 Vgl. Decker/Kiess/Brähler 2012, a. a. O., S. 73ff.

Auch bier stehen die augenscheinlich kulturellen Zuschreibungen der ,Überfremdung' oder des, deutschen

Volkes" nur als vordergründige Beispiele. Im Zentrum sind jedoch die angeblichen biologisch-genetischen Besonderheiten des, deutschen Volkes'sowie die Gefahr der genetischen, Überfremdung', das heißt der negativen bzญw. nachteiligen Veränderung, zu identifizieren.

670 Im zeitlichen Vergleich kann im Bereich Fremdenfeindlichkeit brw. Rassismus erkannt werden, dass die Zustimmungswerte der Studienteilnebmerinnen und-teilnehmer, nach einem geringen Abfall von 2002 bis 2006, seit 2008 im Durchschnitt um 3,9 Prozent angestiegen sind. Ein äbnliches Bild skiziziert der thematische Schwerpunkt des Sozialdarwinismus, welcher seit 2008 um 1,2 Prozent gewachsen ist. Lediglich die Zustimmungswerte zum Antisemitismus bewegen sich in einem stabilen Feld zwischen 8,6 sowie 10 Prozent. Vgl. Decker/Kiess/Brähler 2012, a. a. O., S. $48 \mathrm{ff}$.

671 Eigene Darstellung nach: Decker/Kiess/Brähler 2012, a. a. O., S. 29-30. 
len Rassismustheorien einen bedeutenden Platz einnehmen bzw. vielfältige Parallelen zum Phänomen des Rassismus aufweisen, mit diesem jedoch nicht gleichzusetzen sind (s. Kapitel 2.1.3). Gerade die Integration der Dimensionen Antisemitismus und Sozialdarwinismus bestärkt und fundiert jedoch die Ergebnisse der Rassismusanalyse durch die Implementierung von zwei zusätzlichen Perspektiven. Diesbezüglich soll zusätzlich ein Fokus auf mögliche intragesellschaftliche Unterschiede in West- und Ostdeutschland gelegt werden. Die nachfolgende Grafik veranschaulicht die prozentuale Zustimmung der bundesrepublikanischen Bevölkerung zu fremdenfeindlichen, rassistischen Aussagen. Wie zu erkennen ist, liegen alle drei Zustimmungswerte im Bereich zwischen 31,7 und 37,2 Prozent. ${ }^{672}$ Dies bedeutet, dass durchschnittlich ein Drittel der bundesrepublikanischen Bürgerinnen und Bürger fremdenfeindlichen sowie tendenziell rassistischen Argumentationen zustimmt.

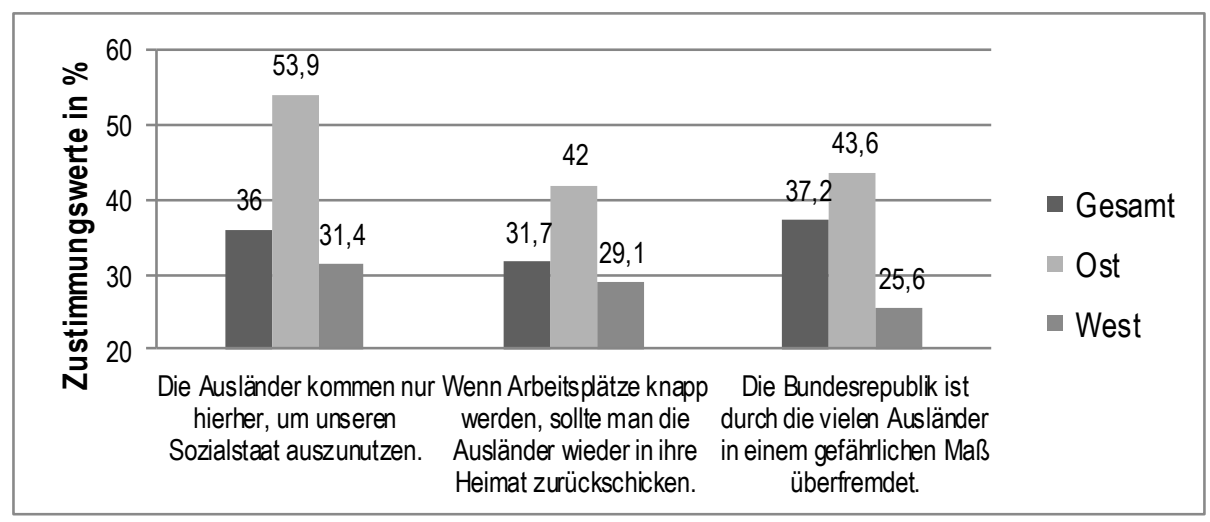

Abb. 1: Zustimmung zur Dimension der „Fremdenfeindlichkeit" (in Prozent) ${ }^{673}$

Ein eklatanter Unterschied ist im Meinungsbild von west- und ostdeutscher Bevölkerung zu identifizieren: Fast die Hälfte der ostdeutschen Bevölkerung (zwischen 42,0 und 53,9 Prozent) stimmt den dargelegten fremdenfeindlichen und rassistischen Thesen zu, wohingegen die Zustimmungsrate der westdeutschen Bevölkerung nur zwischen 25,6 und 31,4 Prozent variiert. ${ }^{674}$ Diese deutlichen Zustimmungsdifferenzen müssen in der nachfolgenden Analyse der Phänomenologie des Rassismus detailliert erörtert werden (s. Kapitel 4). Zusammenfassend kann bisher resümiert werden:

„In der Dimension, Ausländerfeindlichkeit' finden wir [vor dem Hintergrund der weiteren Studienergebnisse] konsequenterweise durchgängig hobe Zustimmungswerte [...]. Nach wie vor herausstechend ist die extrem starke Befürwortung ausländerfeindlicher Aussagen in Ostdeutschland. Mehr als die Hälfte der ostdeutschen Befragten äußert die

672 Vgl. Decker/Kiess/Brähler 2012, a. a. O., S. 34.

673 Eigene Darstellung nach: Decker/Kiess/Brähler 2012, a. a. O., S. 34.

674 Vgl. Decker/Kiess/Brähler 2012, a. a. O., S. 34. 
Ansicht, dass , die Ausländer' den Sozialstaat ausnutzen und nur deshalb nach Deutschland kommen würden. "675

Auch im Rahmen der Fokussierung auf eine weitere Ausprägungsform des Rassismus, den Antisemitismus, können hohe Zustimmungswerte bezüglich der Ablehnung der jüdischen Bevölkerungsgruppe aufgrund angeblicher kultureller bzw. biologistischer ,Eigenheiten ${ }^{6}$ diagnostiziert werden. ${ }^{676}$ Damit werden vor allem wieder biologistische Erklärungsalternativen sowie angebliche biologischgenetische Besonderheiten von jüdischen Mitmenschen bestätigt, die an nationalsozialistische Argumentationen anknüpfen. Fast jeder fünfte Bundesbürger respektive jede fünfte Bundesbürgerin stimmen so rassistisch motivierten Vorurteilen aus der biologischen Phantasma-Kiste zu. ${ }^{677}$

„Die Fremdgruppenabwertung finden wir ebenfalls in der Dimension ,Antisemitismus", auch wenn dieser nicht ähnlich hohe manifeste Zustimmung findet wie die Ausländerfeindlichkeit [...]. [...] Zunächst einmal fällt auf, dass mehr als jeder und jede sechste Deutsche keine Scheu hat, antisemitischen Vorurteilen zuzustimmen. Das gilt auch für Ostdeutschland, wo bis vor einigen Jahren der Antisemitismus deutlich geringer ausgeprägt war. "678

Auch die Zustimmungswerte zum Bereich des Sozialdarwinismus sind keinesfalls zu vernachlässigen. Biologistische Aussagen wie ,[...] in der Gesellschaft sollte [sich] immer der Stärkere durchsetzen“"679, ,[...] die Deutschen [sind] anderen Völkern von Natur aus überlegen“680 oder „Es gibt wertvolles und unwertes Leben“"681 finden durchgängig konstante Zustimmungswerte, die - bei Betrachtung der Durchschnittswerte für Gesamtdeutschland - in einem Spektrum von 10,6 bis 17,7 Prozent liegen. ${ }^{682}$ So stimmt auch diesem Themenbereich überblickend betrachtet jeder zehnte Deutsche zu, was bei einer Gesamtbevölkerung von etwa 80,3 Millionen Bürgerinnen und Bürgern immerhin ungefähr acht Millionen Menschen in Deutschland betreffen würde. In diesem Zusammenhang ist erneut eine deutliche Differenz im west- und ostdeutschen Meinungsverhalten zu konstatieren. ${ }^{683}$ Die Zustimmungswerte der ostdeutschen Bevölkerung liegen konstant um 1,5 bzw. 6,2 Prozentpunkte über den Zustimmungswerten der westdeutschen

675 Decker/Kiess/Brähler 2012, a. a. O., S. 33.

676 Vgl. Decker/Kiess/Brähler 2012, a. a. O., S. 35.

Etwa ein Sechstel der befragten Bürgerinnen und Bürger steht antisemitischen Aussagen offen gegenüber, wie die folgenden Beispiele vergegenwärtigen: 14,5 Prozent der Befragten sieht die jüdische Bevölkerung als, anders; ,nicht zu uns passend'; 15,4 Prozent der Studienteilnehmerinnen und-teilnehmer unterstellen jüdischen Mitmenschen per se ,üble Tricks:

677 Vgl. Decker/Kiess/Brähler 2012, a. a. O., S. 35.

678 Decker/Kiess/Brähler 2012, a. a. O., S. 34.

679 Decker/Kiess/Brähler 2012, a. a. O., S. 36.

680 Decker/Kiess/Brähler 2012, a. a. O., S. 36.

681 Decker/Kiess/Brähler 2012, a. a. O., S. 36.

682 Vgl. Decker/Kiess/Brähler 2012, a. a. O., S. 36.

683 Vgl. Decker/Kiess/Brähler 2012, a. a. O., S. 36. 
Bürgerinnen und Bürger. ${ }^{684}$ Auch hier muss demnach wieder auf die noch ausstehende, notwendige Analyse der Phänomenologie des Rassismus verwiesen werden (s. Kapitel 4).

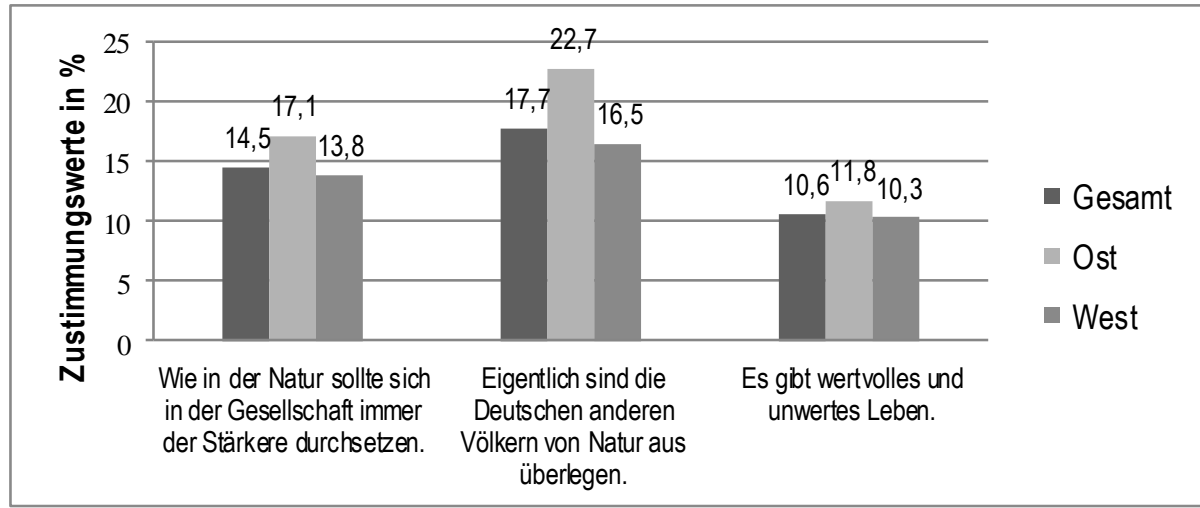

Abb. 2: Zustimmung zur Dimension des „Sozialdarwinismus“ (in Prozent)

Schlussfolgernd bleibt so festzuhalten, dass „,[a]uch die Aussagen sozialdarwinistischen Inhalts [...] von mehr als jedem bzw. jeder zehnten Deutschen befürwortet [werden]. Die mit dem völkischen Denken aufs Engste verbundene Vorstellung eines wertvollen bzw. unwerten Lebens findet die geringste Zustimmung, bleibt aber im Zeitverlauf auf diesem [besorgniserregenden] Niveau." "686 Insbesondere die biologistischen Vorurteile und Ressentiments, die angebliche biologische ,Andersartigkeit' fremdländischer Mitbürgerinnen und Mitbürger betreffend, scheinen somit wieder nachhaltig etabliert. So erleben sozialdarwinistische, eugenische und nationalsozialistische, biologisierende Ansichten eine Renaissance in Deutschland. Eine ansteigende rassistische Neigung ist trotz vornehmlich geringer Zustimmungswerte zu identifizieren, die sich schnell auf weitere Gesellschaftsbereiche ausweiten und das biologistische Rassismusphänomen in Deutschland wieder salonfähig machen könnte. Besonders die hohen Zustimmungswerte in den ostdeutschen Bundesländern skizzieren eine gefährliche Situation (s. Kapitel 3). ${ }^{687}$ Als zusätzliche Warnung dienen die im weiteren Verlauf vorgestellten zeitlichen Vergleichsanalysen zu den unterschiedlichen Dimensionen von 2002 bis 2012.

684 Vgl. Decker/Kiess/Brähler 2012, a. a. O., S. 36.

685 Eigene Darstellung nach: Decker/Kiess/Brähler 2012, a. a. O., S. 36.

686 Decker/Weißmann/Kiess/Brähler 2010, a. a. O., S. 79.

687 In diesem Zusammenhang ist auch auf die Erfolge der rechtsextremen Nationaldemokratischen Partei Deutschlands (NPD) in den ostdeutschen Bundesländern zu verweisen. In Mecklenburg-Vorpommern wurden bei den Landtagswablen 2006 7,3 Prozent, 2011 6,0 Prozent erreicht. Auch in Sachsen erreichte die NPD bei den Landtagswablen 2009 5,6 Prozent. Vgl. Bundeszentrale für politische Bildung (2013): „Parteiprofile. Wer steht zur Wahl“, in URL: http://www.bpb.de/politik/wahlen/wer-steht-zurwahl/ <04.07.2013>. | Vgl. Sontheimer, Kurt/Bleek, Wilhelm/Gawrich, Andrea (2007): Grundzüge des politischen Systems Deutschlands, München u. a., S. 245ff. | Vgl. Schmidt, Manfred G. (2007): Das politische System Deutschlands, München, S. 83. 


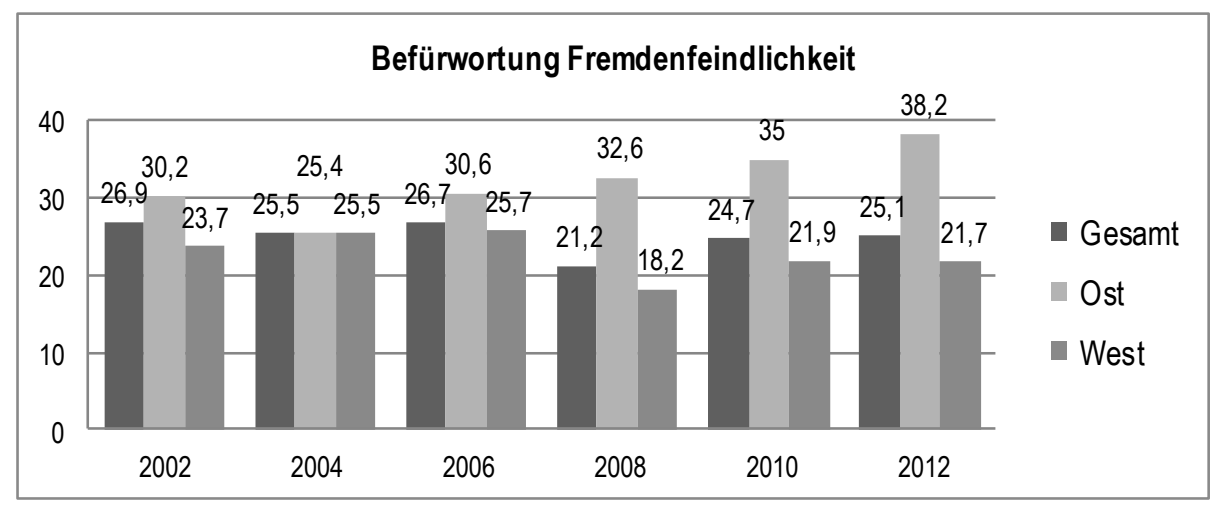

Abb. 3: Fremdenfeindlichkeit - Entwicklung im Zeitverlauf (in Prozent) ${ }^{688}$

Die vorherige Grafik illustriert die Entwicklung fremdenfeindlicher Tendenzen im Zeitraum von 2002 bis 2012. Bei der Betrachtung fällt auf, dass die Zustimmungswerte bis zum Jahr 2012 relativ konstant zwischen 21,2 und 26,9 Prozent verortet werden können. ${ }^{689}$ Auch dieser Zahlenwert scheint für eine demokratische Gesellschaft eindeutig zu hoch - ein Anstieg fremdenfeindlicher Tendenzen ist deutlich zu verifizieren. ${ }^{690}$ Hierbei kann konstatiert werden, dass die westdeutschen Bürgerinnen und Bürger fremdenfeindlichen Aussagen tendenziell in geringerem Ausmaße zustimmen. ${ }^{61}$ In den ostdeutschen Bundesländern scheint jedoch eine deutlich ausgeprägtere Fremdenfeindlichkeit vorzuliegen, was einen besorgniserregenden Trend vergegenwärtigt: Im Jahr 2012 stimmte so mehr als jeder dritte ostdeutsche Bundesbürger (38,2 Prozent) fremdenfeindlichen Thesen zu. ${ }^{692}$ Für Gesamtdeutschland kann dementsprechend resümiert werden, dass jeder vierte Bürger bzw. jede vierte Bürgerin, also etwa 20 Millionen Menschen, fremdenfeindlichen und diskriminierenden Aussagen offen gegenüber steht. ${ }^{693}$
„Eindeutiger ist die Lage bei der Dimension, Ausländerfeindlichkeit' [...]. In Gesamt- deutschland hat der Zustimmungswert wieder das Niveau der ersten Jabre erreicht, nach- dem der Wert 2008 mit 21,1\% relativ niedrig ausfiel. Viel alarmierender aber ist der Trend in Ostdeutschland. Mit jetrt 38,7\% ist der Wert so hoch wie nie zuvor, nachdem er 2004 - also zum fünften Mal in Folge - kontinuierlich anstieg. Ein Gegensteuern auf allen gesellschaftlichen Ebenen ist längst überfällig [...]. " "994

Die vergleichende Grafik zur Entwicklung des Antisemitismus-Meinungsbildes als spezifischer Rassismustypus - verdeutlicht überblickend betrachtet eine dis-

\footnotetext{
688 Eigene Darstellung nach: Decker/Kiess/Brähler 2012, a. a. O., S. 50.

689 Vgl. Decker/Kiess/Brähler 2012, a. a. O., S. 50.

690 Vgl. Decker/Kiess/Brähler 2012, a. a. O., S. 50.

691 Vgl. Decker/Kiess/Brähler 2012, a. a. O., S. 50.

692 Vgl. Decker/Kiess/Brähler 2012, a. a. O., S. 50.

693 Vgl. Decker/Kiess/Brähler 2012, a. a. O., S. $50 \mathrm{ff}$

694 Decker/Kiess/Brähler 2012, a. a. O., S. 50.
} 
kontinuierliche Entwicklung der Zustimmungswerte. Eine eindeutige Tendenz ist schwierig zu konstatieren. Das exemplarische Meinungsbild der deutschen Gesamtbevölkerung schwankt zwischen einer Zustimmungsrate von 8,4 Prozent im Jahr 2006 und 10,0 Prozent Jahr 2004.695 Seit dem Jahr 2008 ist eine mehr oder weniger stabile Zustimmungslage mit nur geringen Abweichungen zu verzeichnen: Etwa jeder zehnte Bürger bzw. jede zehnte Bürgerin stimmt antisemitischen Argumentationen zu. Eine Vorhersage bezüglich der zukünftigen Entwicklungsoptionen scheint aufgrund der oberflächlichen Datenbeschaffenheit schwierig. Aufgrund der Tendenzen der Jahre 2008 bis 2012 ist jedoch von einer gewissen Kontinuität der Zustimmungswerte auszugehen. Nichtsdestotrotz bleiben die gesellschaftlichen Zustimmungswerte besorgniserregend.

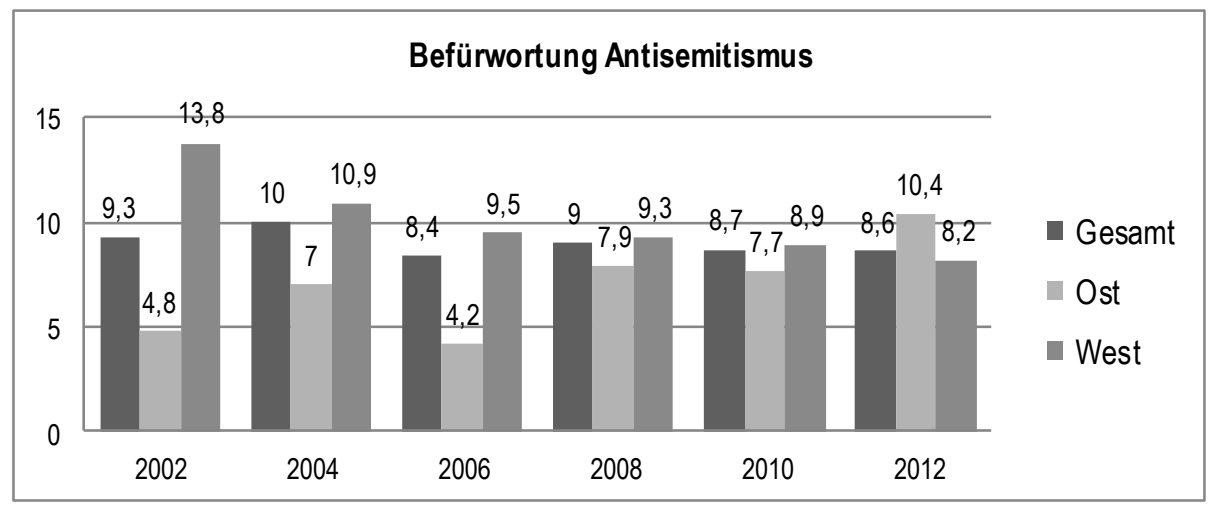

Abb. 4: Antisemitismus - Entwicklung im Zeitverlauf (in Prozent) ${ }^{696}$

„Antisemitismus ist nicht leicht messbar. Dies hängt insbesondere mit seiner öffentlichen Ächtung, aber auch mit [...] dem hohen Potenzial der damit verbundenen Befangenheit zusammen. "897 „In Gesamtdeutschland ist zwischen 2008 und 201 [2] nur ein leichter Rück.gang von $9 \%$ auf $8,[6] \%$ festzustellen, der allerdings statistisch nicht signifikant ist. Insgesamt pendelt der Wert seit 2002 zwischen mindestens 8,4\% und böchstens 10 \%. "898 "[Jedoch ist] [i]m Zeitverlauf der Dimension, Antisemitismus' [...] ein Novum zu beobachten. Das erste Mal seit Beginn der Zeitreibe im Jahr 2002 ist der Wert für Ostdeutsche höher als für Westdeutsche [...]. "699

695 Vgl. Decker/Kiess/Brähler 2012, a. a. O., S. $51 \mathrm{ff}$.

696 Eigene Darstellung nach: Decker/Kiess/Brähler 2012, a. a. O., S. 51.

Der statistische Vergleich der Entwicklung der Zustimmungswerte zu den Bereichen Fremdenfeindlichkeit, Antisemitismus und Sozialdarvinismus im Zeitverlauf von 2002 bis 2012 basiert auf sperifischen Fragenkomplexen der genannten Studie, die jeweils den drei Themenbereichen zugeordnet wurden.

697 Decker/Kiess/Brähler 2012, a. a. O., S. 76.

698 Decker/Weißmann/Kiess/Brähler 2010, a. a. O., S. 92.

699 Decker/Kiess/Brähler 2012, a. a. O., S. 51. 
Auch ist vor neuen Formen des Antisemitismus zu warnen, die in Deutschland zunehmend ,Umwege ${ }^{6}$ einschlagen: ${ }^{700}$ „Der breite politische Konsens gegen Antisemitismus führt zu seiner Äußerung in anderen Bereichen. So kommt es zu einer Verdichtung antidemokratischer Einstellungen in der Kapitalismuskritik, die auch deutlich von antisemitischen Ressentiments getragen ist." ${ }^{701}$ Darüber hinaus kann auch beim Antisemitismus - angelehnt an den biologisch konnotierten Rassismus - eine tendenzielle Verschleierungshaltung diagnostiziert werden.

Abschließend ein vergleichender Blick auf die Zustimmungswerte zum Themenaspekt des biologistischen Sozialdarwinismus von 2002 bis 2012. Hier lässt sich eine abnehmende Tendenz von den Jahren 2004 bis 2008 um 3,3 Prozent beobachten. ${ }^{702}$ Auffälliger ist die Abnahme noch bei den Datensätzen der ostdeutschen Bevölkerung zu identifizieren: Hier existiert eine Abnahme von 7,7 Prozent zwischen den Jahren 2004 mit einer Zustimmung von 9,3 Prozent und dem Jahr 2008 mit einer Zustimmungsrate von nur noch 1,6 Prozent. ${ }^{703}$

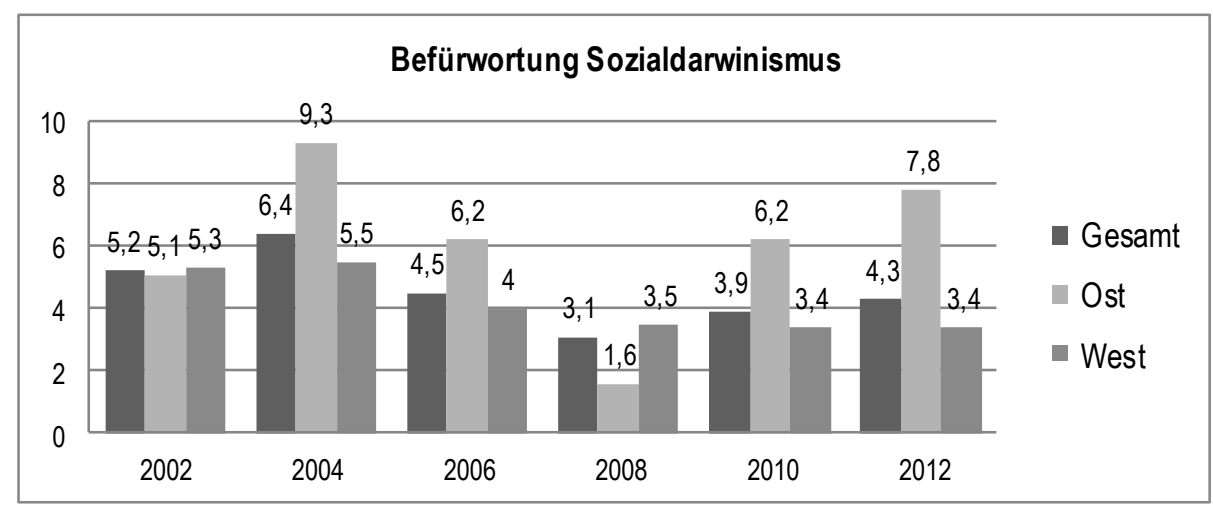

Abb. 5: Sozialdarwinismus - Entwicklung im Zeitverlauf (in Prozent) $)^{704}$

Ebenso deutlich ist der sprunghafte Anstieg der Zustimmungswerte zu sozialdarwinistischen Äußerungen zwischen den Jahren 2008 und 2012 zu konstatieren, der insbesondere auf dem extremen Zustimmungsanstieg der ostdeutschen Bevölkerung basiert. ${ }^{705}$ Dahingegen stagnieren die Zustimmungswerte der westdeutschen Bürgerinnen und Bürger in diesem Zeitraum. Diesbezüglich muss zwar ausgehend vom Jahr 2012 ein relativ niedriger Zustimmungswert zum Themenbereich des Sozialdarwinismus in der Gesellschaft festgehalten werden. Nichtsdestotrotz sollte man diesen nicht verharmlosen, sondern - vor allem den Zustimmungsanstieg in Ostdeutschland - ebenfalls einer aussagekräftigen Analyse unterziehen (s. Kapitel

\footnotetext{
700 Vgl. Decker/Weißmann/Kiess/Brähler 2010, a. a. O., S. $148 f$.

701 Decker/Weißmann/Kiess/Brähler 2010, a. a. O., S. 148.

702 Vgl. Decker/Weißmann/Kiess/Brähler 2010, a. a. O., S. 94.

703 Vgl. Decker/Weißmann/Kiess/Brähler 2010, a. a. O., S. 94.

704 Eigene Darstellung nach: Decker/Kiess/Brähler 2012, a. a. O., S. 52.

705 Vgl. Decker/Kiess/Brähler 2012, a. a. O., S. 52.
} 
4). So bleibt abschließend festzuhalten, dass „,...] der Anstieg von $2008 \mathrm{zu} 201$ [2] [...] nicht signifikant [ist] [...]. Der starke Rückgang der Zustimmung von Ostdeutschen, den wir zwischen 2006 (6,2 \%) und 2008 (1,6\%) beobachten konnten, hat sich allerdings aufgehoben, und der Wert liegt wieder bei $[7,8] \%$ \%." ${ }^{\text {"706 }}$

Vor dem Hintergrund einer resümierenden Interpretation der Datensätze hinsichtlich des biologisch konnotierten Rassismustypus kann so festgehalten werden, dass man ,[...] in 201[2] einen Anstieg von dezidiert antidemokratischen und rassistischen Einstellungen feststellen und [...] zudem eine leichte Zunahme der sozialdarwinistischen Ungleichwertigkeitsvorstellungen [erkennen muss]. "707 Zwar bewegen sich die Zustimmungswerte zu rassistischen, fremdenfeindlichen, sozialdarwinistischen und antisemitischen Äußerungen zum Teil auf niedrigem zweistelligem Niveau, sind aber durchweg existent. Vor allem die Umrechnung der Prozentwerte in die absoluten Bevölkerungszahlen verdeutlicht den bedrohlichen Entwicklungstrend. Besonders gefährlich für die Stabilität und Integrität der Gesellschaft gestaltet sich die zunehmende Fremdenfeindlichkeit und der deutlich wahrnehmbare biologistische Rassismus in der bundesrepublikanischen Bevölkerung - bis zu einem Drittel der Bundesbürgerinnen und Bundesbürger unterstützen diesbezügliche Thesen, in den ostdeutschen Bundesländern sogar tendenziell in höherem Maße. ${ }^{708}$ Ausländische Mitbürgerinnen und Mitbürger werden als eine ,Belastung' des deutschen Staates angesehen, wie durch die Auswertung der Fragen herausgefunden wurde. ${ }^{709}$ Einwanderer werden pauschal sowohl von ,keiner besonderen Bedeutung ‘ für die Weiterentwicklung der Bundesrepublik als auch der bundesrepublikanischen Gesellschaft angesehen, eher als ,Belastung', Bedrohung und ,Überfremdung. Auf diese denkwürdigen Ergebnisse weist auch die Studie hin:

„Ein Viertel der Bevölkerung stimmt den Aussagen ausländerfeindlichen Inhalts zu im Unterschied zu 2008, als diese Gruppe noch etwa ein Fünftel der Bevölkerung ausmachte. Das Ausmaß der Ausländerfeindlichkeit wird bei den Einzelaussagen deutlich. Durchgängig mehr als $30 \%$ der Deutschen stimmen folgenden Aussagen zu: ,Ausländer kommen, um den Sozialstaat auszunutzen', bei knappen Arbeitsplätzen , sollte man

706 Decker/Weißmann/Kiess/Brähler 2010, a. a. O., S. 93. | Vgl. Decker/Kiess/Brähler 2012, a. a. O., S. 52.

Insbesondere die niedrigen Zustimmungswerte der ostdeutschen Bevölkerung im Jahr 2008 von nur 1,6 Prozent stimmen jedoch weniger mit dem festgestellten Trend überein. Vermutet werden könnten hier eventuell statistische Probleme bzw. Schwierigkeiten bei der Datenerbebung.

707 Decker/Weißmann/Kiess/Brähler 2010, a. a. O., S. 139.

708 Vgl. Decker/Weißmann/Kiess/Brähler 2010, a. a. O., S. 91 ff. | Vgl. Decker/Kiess/Brähler 2012, a. a. O., S. $52 \mathrm{ff}$.

Insbesondere fremdenfeindliche Gewalt gegenüber Ausländerinnen und Ausländern ist in den ostdeutschen Bundesländern - im Vergleich zu den westdeutschen Bundesländern - wesentlich intensiver vorhanden. Vgl. Quent, Matthias (2012): Rechtsextremismus - ein ostdeutsches Phänomen?, in: Aus Politik und Zeitgeschichte, Beilage zur Wochenzeitung Das Parlament, 16-17/2012, 62. Jahrgang, Bonn, S. 39.

709 Vgl. Decker/Weißmann/Kiess/Brähler 2010, a. a. O., S. 139 ff. | Vgl. Decker/Kiess/Brähler 2012, a. a. O., S. 54 f. 
Ausländer wieder in ibre Heimat schicken' und durch, die vielen Ausländer' werde Deutschland ,in einem gefährlichen Maß überfremdet‘ " "110 „Besonders besorgniserregend ist, dass diese Tendenz. mit einer neuen Generation des Rechtsextremismus einhergeht [...]." "11

Insbesondere vor dem Hintergrund, rassentheoretischer ${ }^{6}$ Vorstellungen wird die in Deutschland steigende Fremdgruppenabwertung deutlich. Hier wird - in tendenziell steigendem Maße - zwischen ,nützlichen` und ,unnützen` Bevölkerungsgruppen differenziert. ,Deutsche ${ }^{6}$ und ,Ausländer ${ }^{6}$ werden systematisch hierarchisiert. Biologistisch und kulturalistisch wird „,[... zwischen nützlichen Migrant/innen, die ,uns` etwas bringen, und jenen Migrant/innen, die ,nicht zu uns passen ‘ und kulturell rückständig seien, $[\ldots]^{\text {“'712 }}$ unterschieden. Parallelen zum biologistischen ,Rassekonstrukt' sind demnach eindeutig nachweisbar.

Festgehalten werden kann so explizit, dass vor allem das biologistische Rassismusphänomen im Vergleich zu den Vorjahren aktuell deutlich stärker ausgeprägt und tendenziell im Wachstum begriffen ist. ${ }^{713}$ Weiterhin ist eine Besonderheit in den gewandelten Begründungsschemata rassistischer Vorurteile festzustellen: „So greifen im modernen Rassismus die biologisch-rassistischen und kulturalistischen Begründungen ineinander.“714, „[...] Rassismus, der auf biologischen Annahmen beruht, geht inzwischen mit [naturalisierter] kulturell begründeter Ausgrenzung zum Beispiel von Türken, Arabern, Muslimen einher. " 715 Im 21. Jahrhundert wird das Rassismusphänomen so wieder zunehmend mit originär biologischgenetischen Argumentationen ergänzt, bzw. diese treten direkt und indirekt in den Vordergrund.

Auch die Langzeituntersuchung zur „Gruppenbezogenen Menschenfeindlichkeit in Deutschland“7716 des Institutes für interdisziplinäre Konflikt- und Gewaltforschung der Universität Bielefeld nach dem GMF-Konzept unterstützt die bisher ermittelten Ergebnisse. Im Rahmen einer 10-jährigen Langzeituntersuchung zur Abwertung und Ausgrenzung von schwächeren Gruppen wurde hinsichtlich

710 Decker/Weißmann/Kiess/Brähler 2010, a. a. O., S. 141.

711 Decker/Kiess/Brähler 2012, a. a. O., S. 54.

712 Decker/Weißmann/Kiess/Brähler 2010, a. a. O., S. 141.

713 Vgl. Decker/Weißmann/Kiess/Brähler 2010, a. a. O., S. 141.

714 Decker/Weißmann/Kiess/Brähler 2010, a. a. O., S. 141.

715 Ruf, Christoph (2010): „Studie zu deutschen Einstellungen. Wie groß Sarrazins Basis wirklich ist", in URL: http://www.spiegel.de/ politik/deutschland/0,1518,druck-722789,00.html $<25.07 .2011>$.

716 Heitmeyer/Zick/Groß/Krause/Küpper/Klein/Mansel 2012, a. a. O.

Die GMF-Langzeituntersuchung wurde von 2002-2012 vor allem durch mebrere Stiftungen, wie die Volk.swagen-Stiftung oder die Freudenberg-Stiftung gefördert und finanziert. Über einen Zeitraum von 10 Jabren wurden hier jährlich etwa 2000 Personen zu ibren Einstellungen gegenüber schwächeren Gruppen befragt. Mit zwei Jahren Abstand wurden die befragten Personen zusätzlich wiederbolend erneut befragt, um Abweichungen oder Ursachen für Änderungen im Befragungsverhalten detaillierter analysieren zu können. Im Jahr 2008 wurde die Entwicklung von, gruppenbezogener Menschenfeindlichkeit' zusätzlich in acht europäischen Staaten vergleichend erwiert (s. Kapitel 3.6). Hinzukommend wird die gruppenbezogene Menschenfeindlichkeit" ebenfalls in Städten oder Gemeinden im Rahmen von Sozialraumanalysen untersucht, wie der weitere Verlauf vergegenwärtigt. Vgl. Heitmeyer/Zick/Groß/Krause/Küpper/Klein/Mansel 2012, a. a. O. 
der GMF-Kategorien Fremdenfeindlichkeit, Rassismus und Antisemitismus eine Stagnation bzw. Zunahme der Zustimmungswerte innerhalb der bundesrepublikanischen Bevölkerung festgestellt. Das Ziel der Langzeitstudie ist es, das jeweilige Ausmaß der ,gruppenbezogenen Menschenfeindlichkeit` gegenüber schwächeren sozialen Gruppen, die Veränderungen dieses Ausmaßes - auch im Jahresvergleich - sowie mögliche Erklärungen für diese menschenfeindlichen Positionen zu ermitteln. ${ }^{717}$ Hinsichtlich des Ausmaßes von Rassismus in Deutschland - erfasst wird nur der klassische, auf einer biologistischen bzw. natürlichen Abwertung basierende Rassismus - wird dabei eine Stagnation bzw. eine leicht abfallende Tendenz seit 2002 konstatiert. ${ }^{718}$ Stärker zeigen sich hingegen die ansteigenden Tendenzen der Kategorien Fremdenfeindlichkeit und insbesondere bei Israelbezogenem Antisemitismus. ${ }^{719}$

Bestätigt wird dieser Trend ebenfalls durch eine auf dem GMF-Konzept basierende Sozialraumanalyse in Städten und Gemeinden, die unter anderem von den Autoren des GMF-Konzeptes 2013 publiziert wurde. ${ }^{720}$ Untersucht wurden in diesem Zusammenhang verschiedene Klein-, Mittel- und Oberzentren in Deutschland hinsichtlich Diskriminierung und Demokratie-gefährdendem Potenzial, wie beispielsweise Rechtsextremismus. ${ }^{721}$ In allen untersuchten Städten und Gemeinden wurde hierbei in mehr oder weniger großer Ausprägung Zustimmung zu diskriminierenden Argumentationen identifiziert: Einerseits wurden ausgeprägte Vorstellungen von Ungleichheit und Ungleichwertigkeit als vorhanden verifiziert und andererseits ebenfalls das ,Herunter-spielen' bzw. Verdecken von diskriminierenden Äußerungen. Beispielsweise wurde so für die Dortmunder Stadtbezirke Innenstadt West und Dortmund-Eving mit etwa 20 Prozent Zustimmung ein hohes Potenzial zu rassistischen Aussagen eruiert. ${ }^{722}$

Naturalisierung, Sozialdarwinismus sowie rassistisch-antisemitische Gedankenmodelle - alles Bestandteile des zunehmend biologisch-genetisch geprägten, gegenwärtigen Rassismusphänomens des 21. Jahrhunderts - sind in der bundesrepublikanischen Bevölkerung nicht nur angekommen, sondern - unter Einbeziehung der hier vorgestellten Daten - tendenziell im Wachstum begriffen. Nach den Erklärungsansätzen dieser Entwicklungen wird im weiteren Verlauf zu suchen sein (s. Kapitel 4).

\footnotetext{
717 Vgl. Heitmeyer/Zick/Groß/Krause/Küpper/Klein/Mansel 2012, a. a. O., S. 2 ff.

718 Vgl. Heitmeyer/Zick/Groß/Krause/Küpper/Klein/Mansel 2012, a. a. O., S. 6ff.

719 Vgl. Heitmeyer/Zick/Groß/Krause/Küpper/Klein/Mansel 2012, a. a. O., S. 6ff.

720 Vgl. Grau, Andreas/Heitmeyer, Wilhelm (2013): Menschenfeindlichkeit in Städten und Gemeinden, Bielefeld.

721 Bezüglich Vorurteilen und feindseligen Mentalitäten wurden die folgenden Städte und Gemeinden untersucht: Anklam (Mecklenburg-Vorpommern), Wernigerode (Sachsen), Bad Nenndorf (Niedersachsen), Pirmasens (Rheinland-Pfali), Dortmund (Nordrhein-Westfalen), Dresden (Sachsen). Vgl. Grau/Heitmeyer 2013, ebd., S. 34ff.

722 Vgl. Grau/Heitmeyer 2013, ebd., S. 110f, $150 \mathrm{ff}$.
} 


\subsection{ALLBUS - Bevölkerungsumfrage der Sozialwissenschaften}

Der ALLBUS 2010 und 2012 befasst sich unter anderem ebenfalls in einigen Fragenkompartimenten mit fremdenfeindlichen und - direkt wie indirekt - rassistischen Einstellungen innerhalb der bundesrepublikanischen Bevölkerung. ${ }^{723}$ Auch die nachfolgenden, in regelmäßigen Abständen publizierten Sozialberichte der Bundesrepublik Deutschland basieren unter anderem auf den ALLBUSErgebnissen (s. Kapitel 3.5). Allerdings inkludieren die Sozialberichte einerseits nicht alle Ergebnisse der ALLBUS-Datenerhebungen, sondern nur diejenigen, die die einzelnen Schwerpunkte der Sozialberichte widerspiegeln und unterstützen. Andererseits fehlen darüber hinaus in den hier genutzten Sozialberichten 2008 und 2011 die aktuellen ALLBUS-Ergebnisse des Jahrgangs 2012. Aufgrund dessen werden die für den Themenbereich dieser Arbeit entscheidenden ALLBUSFragenkomplexe, die in den Sozialberichten nur lückenhaft angesprochen sind bzw. auf älteren Datensätzen basieren, im folgenden Abschnitt zusätzlich analysiert sowie mit den schon vorhandenen qualitativen und quantitativen Erkenntnissen zu einem aussagekräftigen Gesamtbild verknüpft.

Ein Fragenbereich des ALLBUS 2010 beschäftigt sich mit intragesellschaftlichen Konflikten, insbesondere zwischen ausländischen und deutschen Bevölkerungsanteilen. Hier wurde exemplarisch nach dem gefühlten Vorhandensein von möglichen Konflikten sowie Konfliktpotenzial in der bundesrepublikanischen Bevölkerung gefragt.

Tab. 6: Interessenkonflikte Ausländer (Gastarbeiter) vs. Deutsche (in Prozent) ${ }^{724}$

Es wird oft gesagt, dass es Interessenkonflikte zwischen verschiedenen Gruppen in Deutschland gibt [...] Die Konflikte sind aber nicht alle gleich stark. Sagen Sie mir bitte, ob dieser Konflikt Ihrer Meinung nach sehr stark, ziemlich stark, eher schwach ist, oder ob es gar keinen Konflikt gibt.

\begin{tabular}{|lccc|}
\hline West/Ost gewichtet & West & Ost & Gesamt \\
\hline Gibt es nicht & 4,5 & 3,1 & 4,2 \\
Eher schwach & 33,8 & 30,2 & 33,1 \\
Ziemlich stark & 46,7 & 45,7 & 46,5 \\
Sehr stark & 15,1 & 21,1 & 16,2 \\
\hline
\end{tabular}

723 Die Allgemeine Bevölkeerungsumfrage der Sozialwissenschaften (ALLBUS) erbebt mithilfe quantitativer, standardisierter Umfrageverfahren aktuelle Daten über Einstellungen, Verhaltensweisen und Sozialstrukturen der Bevölkerung in der Bundesrepublik Deutschland. Sie wird seit 1980 alle zwei Jahre alternierend durchgeführt. Hierbei wird ein repräsentativer Querschnitt der Bevölkerung mit einem teils konstanten, standardisierten, teils variablen Fragenpool befragt. Seit 1992 werden 2400 Teilnebmerinnen und Teilnehmer mittels Interviews in den alten und 1100 Teilnehmerinnen und Teilnehmer mittels Interviews in den neuen Bundesländern befragt, das heißt die ostdeutschen Bürgerinnen und Bürger sind in der ALLBUS-Stichprobe tendenqiell überrepräsentiert. Für diese Untersuchung wurden die Originaldatensätze des ALLBUS 2010 und 2012 vervendet, die vom Leibniz-Institut für Sozialwissenschaften online zur Verfügung gestellt wurden. Vgl. Blohm, Michael (2011): „Allgemeine Informationen zum ALLBUS“, in URL: http://www.gesis.org/allbus/allgemeine-informationen/ <31.07.2011>.

724 Eigene Darstellung nach: GESIS Leibniz-Institut für Sozialwissenschaften 2011, a. a. O. 
Das Ergebnis scheint die aktuelle gesellschaftliche Tendenz in Deutschland hin zu einer Renaissance fremdenfeindlicher bzw. -skeptischer Vorurteile zu bestätigen. Es wird - sowohl in Westdeutschland als auch leicht verstärkt in den ostdeutschen Bundesländern - ein deutliches Konfliktpotenzial zwischen Ausländerinnen und Ausländern sowie Deutschen vermerkt: 95,6 Prozent der westdeutschen und 97 Prozent der ostdeutschen Bevölkerung sehen tendenzielle Interessenkonflikte. ${ }^{725}$ Darüber hinaus konstatieren 61,8 bzw. 66,8 Prozent der Befragten das Vorhandensein von deutlich ausgeprägten Interessenkonflikten zwischen ausländischen Mitbürgerinnen und Mitbürgern sowie Deutschen. ${ }^{726}$ Hierunter müssen vor allem kulturelle und soziale Differenzen eingeschlossen werden. Insgesamt 95,8 Prozent der befragten Bürgerinnen und Bürger erkennen so ein Konfliktpotenzial, dessen Auswirkungen sich im 21. Jahrhundert sukzessive im Anwachsen des gegenwärtigen Rassismusphänomens visualisieren könnten. ${ }^{727}$ Vor diesem Hintergrund können die dargestellten Ergebnisse mit den anwachsenden rassistischen Vorurteilen und Ressentiments in Deutschland in Verbindung gebracht werden. Zurecht ist so zu folgern, „[...] dass unser größtes Problem [...] derzeit in der Feindlichkeit gegenüber Ausländer/innen $[\ldots]^{\text {“ } 728}$ und der zunehmend wieder als rassistisch einzustufenden Gesinnung in der bundesrepublikanischen Bevölkerung liegt.

Dass sich rassistische Tendenzen oftmals immer noch vordergründig an kulturellen, sozialen oder religiösen Differenzen manifestieren, zeigt das exemplarische Beispiel der in Deutschland vorhandenen ,Islamophobie 6 , der ablehnenden Haltung gegenüber der Religionsgemeinschaft des Islams. Auch der ALLBUS 2010 greift diesen Themenaspekt auf und fragt nach einem vorhandenen Konfliktpotenzial zwischen Christen und Muslimen. ${ }^{729}$ Diesbezüglich zeigen sich ebenfalls die zahlreichen Vorurteile und Ressentiments der bundesrepublikanischen Bevölkerung gegenüber den Muslimen, da ein Großteil - 60,1 Prozent - das Vorhandensein von starken kulturellen Konflikten zwischen Christen und Muslimen bestätigt. ${ }^{730}$ Vor dem Hintergrund der bisherigen Analyseergebnisse könnte jedoch auch hier die Biologie als eigentliche, grundlegende Erklärungs- und Legitimationsbasis vermutet werden: Die kulturellen Zuschreibungen würden auf biologistische Erklärungsmuster zurückgeführt. Viele Befragte sehen sogar ein stark vor-

725 Vgl. GESIS Leibniz-Institut für Sozialwissenschaften 2011, a. a. O.

726 Vgl. GESIS Leibniz-Institut für Sozialwissenschaften 2011, a. a. O.

727 Vgl. GESIS Leibniz-Institut für Sozialwissenschaften 2011, a. a. O.

728 Langenbacher, Nora/Molthagen, Dietmar (2010): Rechtsextremismus? Nicht mit mir! Grundwissen und Handwerkzeug für Demokratie, Berlin, S. 8.

729 Vgl. GESIS Leibniz-Institut für Sozialwissenschaften 2011, a. a. O. | Vgl. GESIS LeibnizInstitut für Sozialwissenschaften (2013): „Supplement zum Variable Report ALLBUS 2012. Nach Geschlecht getrennte Auszählungen. Studien-Nr. 4614, Version: 1.1.0, doi: 10.4232/1.11634", in URL: Anforderung via http://www.gesis.org/allbus (Originaldatensatz, $<26.05 .2013>$ ). | Vgl. Terwey/Baltzer 2013, a. a. O.

Der ALLBUS 2010 fragt nach vorhanden Konflikten zwischen Christen und Muslimen in Deutschland; der ALLBUS 2012 fragt bingegen allgemeiner nach der persönlichen Einstellung zur Aussage:; Die Anwesenheit von Muslimen in Deutscbland fübrt zu Konflikten:

730 Vgl. GESIS Leibniz-Institut für Sozialwissenschaften 2011, a. a. O. 
handenes bzw. ausgeprägtes Konfliktpotenzial. ${ }^{731}$ Auch zwischen Christen und Muslimen - respektive zwischen Christentum und Islam - scheint folglich eine deutlich negativ betonte Differenzierung zu erfolgen. Der Islam wird von der überwältigenden Mehrzahl der befragten Bürgerinnen und Bürger als konfliktbeladene, gewaltbereite sowie der Kriminalität und dem Terrorismus nahestehende Religion angesehen und in der Folge zunehmend ,abgewertet ${ }^{6}$ (s. Kapitel 3). ${ }^{732}$ Auch diese Diskriminierung einer Menschen- bzw. Religionsgruppe vergegenwärtigt, dass fremdenfeindliche Tendenzen innerhalb eines Großteils der bundesrepublikanischen Gesellschaft verankert scheinen.

Tab. 7: „Die in Deutschland lebenden Ausländer sollten ihren Lebensstil ein bisschen besser an den der Deutschen anpassen“" (in Prozent) ${ }^{733}$

Bei dieser Frage geht es um die in Deutschland lebenden Ausländer. Sagen Sie mir bitte zu dem Satz, inwieweit Sie inm zustimmen. Der Wert 1 heißt, dass Sie „überhaupt nicht zustimmen“, der Wert 7 heißt, dass Sie „voll und ganz zustimmen“. Mit den Werten dazwischen können Sie Ihre Meinung abstufen.

\begin{tabular}{|lccc|}
\hline West/Ost gewichtet & West & Ost & Gesamt \\
\hline 1 Stimme gar nicht zu & 2,3 & 1,5 & 2,0 \\
$2 \ldots$ & 3,4 & 2,5 & 3,1 \\
$3 \ldots$ & 6,0 & 4,3 & 5,4 \\
$4 \ldots$ & 15,4 & 12,9 & 14,6 \\
$5 \ldots$ & 20,8 & 14,8 & 18,8 \\
$6 \ldots$ & 15,8 & 16,8 & 16,2 \\
7 Stimme voll zu & 36,4 & 47,1 & 40,0 \\
\hline
\end{tabular}

Auch die Fragestellung nach einer zwingenden Lebensstilanpassung der ausländischen Bevölkerung greift der ALLBUS 2010 aktuell und nachdrücklich auf. ${ }^{734}$ Hierbei zeigt sich ein ähnliches Ergebnis: Ein Großteil der Befragten sieht die Notwendigkeit einer Lebensstilanpassung durch in Deutschland lebende ausländische Menschen an den der bundesrepublikanischen Bevölkerung als notwendig an. ${ }^{735}$ Die Mehrheit von 88,4 Prozent der westdeutschen Befragten stimmt der Aussage ebenso wie 91,6 Prozent der ostdeutschen befragten Bürgerinnen und Bürger mehr oder weniger zu. ${ }^{736}$ 73,0 bzw. 78,7 Prozent der befragten Bevölke-

731 Vgl. GESIS Leibniz-Institut für Sozialwissenschaften 2011, a. a. O.

732 Demnach befürworten 47,3 Prozent der befragten Bürgerinnen und Bürger aufgrund der vom Islam ausgehenden Gefahren eine kontinuierliche Beobacbtung und Überwachung der islamischen Religionsgemeinschaft durch den Staat. Vgl. Terwey/Baltzer 2013, a. a. O.

733 Eigene Darstellung nach: GESIS Leibniz-Institut für Sozialwissenschaften 2013, a. a. O. $\mid$ Terwey/Baltzer 2013, a. a. O.

734 Vgl. GESIS Leibniz-Institut für Sozialwissenschaften 2013, a. a. O.

735 Vgl. GESIS Leibniz-Institut für Sozialwissenschaften 2013, a. a. O.

736 Vgl. GESIS Leibniz-Institut für Sozialwissenschaften 2013, a. a. O.

Bei der Berechnung der mehr oder weniger positiven Zustimmungswerte wurden die Tabellenergebnisse 4 (,teils/ teils") bis 7 (,stimme voll ₹u') eingerechnet und nachfolgend summiert. Zur Vereinheitlichung der Ergebnispräsentation wurden die Auswertungsschemata der Studie, Die Mitte in der Krise. Rechtsextreme Einstellungen in Deutscbland 2010' ̈̈bernommen. „Entlang der Forschungsergebnisse unserer Studie [...] müssen 
rung zeigt eine ausdrückliche Zustimmung zur genannten Aussage - dies entspricht statistisch etwa 58-63 Millionen Menschen in Deutschland. ${ }^{737}$ Die statistische Differenz zwischen west- und ostdeutscher Bevölkerung zeigt sich demzufolge wiederum als vernachlässigbar. Im Gesamtdurchschnitt identifizieren sich 40,0 Prozent der befragten Bürgerinnen und Bürger voll mit der Auffassung, in Deutschland lebende Ausländerinnen und Ausländer sollten sich besser an die ,deutschen' Lebensumstände anpassen - mehr als jeder dritte Befragte, was im Vergleich zum ALLBUS 2010 einen Anstieg um 1,1 Prozent bedeutet. ${ }^{738}$ Auch hier offenbart sich demzufolge deutlich die tendenzielle Skepsis und Diskriminierung gegenüber ausländischen Mitbürgerinnen und Mitbürgern.

Tab. 8: „Wenn die Arbeitsplätze knapp werden, sollte man die in Deutschland lebenden Ausländer wieder in ihre Heimat zurückschicken“ (in Prozent) ${ }^{739}$

Bei dieser Frage geht es um die in Deutschland lebenden Ausländer. Sagen Sie mir bitte zu dem Satz, inwieweit Sie inm zustimmen. Der Wert 1 heißt, dass Sie „überhaupt nicht zustimmen“, der Wert 7 heißt, dass Sie „voll und ganz zustimmen“. Mit den Werten dazwischen können Sie lhre Meinung abstufen.

\begin{tabular}{|lccc|}
\hline West/Ost gewichtet & West & Ost & Gesamt \\
\hline 1 Stimme gar nicht zu & 44,6 & 31,3 & 40,1 \\
$2 \ldots$ & 18,2 & 16,1 & 17,5 \\
$3 \ldots$ & 10,7 & 11,5 & 11,0 \\
$4 \ldots$ & 13,2 & 19,5 & 15,4 \\
$5 \ldots$ & 6,3 & 8,1 & 6,9 \\
$6 \ldots$ & 2,5 & 4,6 & 3,2 \\
7 Stimme voll zu & 4,4 & 8,8 & 5,9 \\
\hline
\end{tabular}

Bezüglich der Frage nach einer Abschiebung bzw. einer Zwangsrückkehr der in Deutschland lebenden Ausländerinnen und Ausländer in deren Heimatstaaten vor dem Hintergrund einer Arbeitsplatzknappheit zeigen sich die Zustimmungswerte nun deutlich differenzierter, es lassen sich hierbei eindeutigere Unterschiede zwischen west- und ostdeutschen Bundesländern feststellen. Im Westen stimmen tendenziell 13,2 Prozent, im Osten jedoch 21,3 Prozent der Befragten der Aussage zu. ${ }^{70}$ Auch bei der detaillierten Auswertung der Zustimmungswerte im Bereich

diese ,teils/teils'-Antworten als ein Antwortverhalten im Sinne der sozialen Erwünschtheit interpretiert werden. "Decker/Weißmann/Kiess/Brähler 2010, a. a. O., S. 75. | Vgl. Lamnek 2010, a. a. O., S. 7.

737 Vgl. GESIS Leibniz-Institut für Sozialwissenschaften 2013, a. a. O. Bei der Berechnung der eindeutig positiven Zustimmungswerte wurden die Tabellenergebnisse 5 bis 7 (,stimme voll zu') eingerechnet und nachfolgend summiert.

738 Vgl. GESIS Leibniz-Institut für Sozialwissenschaften 2013, a. a. O. | Vgl. GESIS LeibnizInstitut für Sozialwissenschaften 2011, a. a. O.

739 Eigene Darstellung nach: GESIS Leibniz-Institut für Sozialwissenschaften 2013, a. a. O. Terwey/Baltzer 2013, a. a. O.

740 Vgl. Terwey/Baltzer 2013, a. a. O. 
,stimme voll $\mathrm{zu}^{\text {‘ }}$ ergeben sich deutliche Unterschiede zwischen West und Ost: Nur 4,4 Prozent der westdeutschen, aber 8,8 Prozent der ostdeutschen befragten Bürgerinnen und Bürger zeigen dieses Abstimmungsverhalten. ${ }^{741}$ Die ostdeutschen Bundesländer reagieren so ,sensibler ${ }^{\star}$ auf den vermeintlichen Arbeitsplatzmangel bzw. die vermeintliche Arbeitsknappheit. Insgesamt stimmt ungefähr jeder zehnte Deutsche der Aussage zu. ${ }^{742}$ Dies bestätigen - trotz unmaßgeblich geringerer Zustimmungswerte - unter anderem auch die zuvor betrachteten Ergebnisse der Studien „Die Mitte in der Krise. Rechtsextreme Einstellungen in Deutschland $2010^{‘ 673}$ und „Die Mitte im Umbruch. Rechtsextreme Einstellungen in Deutschland 2012“674. Die ausländische Bevölkerung wird folglich nur so lange geduldet, wie sich der Arbeitsmarkt in der Bundesrepublik stabil verhält, das heißt, wächst. ${ }^{745}$ Ökonomische Krisensymptome werden mit der ausländischen Mitbevölkerung assoziiert, der in der Folge die ,Sündenbock'-Funktion für die wirtschaftlichen und politischen Fehlentwicklungen zugeschrieben wird; eine durchweg falsche Annahme (s. Kapitel 4). Auch hier kann demnach wieder eine tendenzielle Diskriminierung gegenüber ausländischen Bevölkerungsgruppen festgestellt werden.

Tab. 9: „Haben Sie persönliche Kontakte zu in Deutschland lebenden Ausländern?" (in Prozent) ${ }^{746}$

\begin{tabular}{|l|c|c|c|c|}
\hline & $\begin{array}{c}\text { West/Ost } \\
\text { gewichtet }\end{array}$ & West & Ost & Gesamt \\
\hline \multirow{2}{*}{$\begin{array}{l}\text { In Ihrer eigenen Familie oder } \\
\text { näheren Verwandtschaft? }\end{array}$} & JA & 35,5 & 16,8 & 29,2 \\
\cline { 2 - 5 } & NEIN & 64,5 & 83,2 & 70,8 \\
\hline \multirow{2}{*}{ An Ihrem Arbeitsplatz? } & JA & 62,1 & 32,7 & 52,2 \\
\cline { 2 - 5 } & NEIN & 37,9 & 67,3 & 47,8 \\
\hline \multirow{2}{*}{ In Ihrer Nachbarschaft? } & JA & 50,8 & 18,3 & 39,9 \\
\cline { 2 - 5 } & NEIN & 49,2 & 81,7 & 60,1 \\
\hline \multirow{2}{*}{$\begin{array}{l}\text { In Ihrem sonstigen Freundes- } \\
\text { und Bekanntenkreis? }\end{array}$} & JA & 67,6 & 36,3 & 57,1 \\
\cline { 2 - 5 } & $\mathrm{NEIN}$ & 32,4 & 63,7 & 42,9 \\
\hline
\end{tabular}

Ein weiterer Fragenkomplex konstatiert, dass ausländischen Mitbürgerinnen und Mitbürgern jegliche politische Betätigung in der Bundesrepublik Deutschland untersagt werden sollte. Hier sind relativ geringe Zustimmungswerte zu beobachten, die jedoch trotzdem aufmerksam verfolgt und dokumentiert werden soll-

Bei der Berechnung der eindeutig positiven Zustimmungswerte wurden die Tabellenergebnisse 5 bis 7 (,stimme voll ₹u') eingerechnet und nachfolgend summiert.

741 Vgl. Terwey/Baltzer 2013, a. a. O.

742 Vgl. Terwey/Baltzer 2013, a. a. O.

743 Decker/Weißmann/Kiess/Brähler 2010, a. a. O.

744 Decker/Kiess/Brähler 2012, a. a. O.

745 Vgl. GESIS Leibniz-Institut für Sozialwissenschaften 2013, a. a. O.

746 Eigene Darstellung nach: GESIS Leibniz-Institut für Sozialwissenschaften 2013, a. a. O. |

Terwey/Baltzer 2013, a. a. O. 
ten. ${ }^{747}$ Nichtsdestotrotz ist dies sicherlich kein beruhigendes Ergebnis für die deutsche Demokratie.

Der letzte vorzustellende, exemplarische Fragenkomplex des ALLBUS 2012 zeigt nochmals in deutlichem Maße, dass auch seitens der bundesrepublikanischen Gesellschaft der Kontakt zu ausländischen Bürgerinnen und Bürgern zu großen Teilen - außer bei der Ausübung einer beruflichen Tätigkeit - wenig bis selten gesucht wird. ${ }^{748}$ Auf der einen Seite könnte dies als Folge rassistischer Tendenzen respektive der tendenziellen Ablehnung von Fremden, auf der anderen Seite jedoch auch als eigenverschuldete Problematik eingeordnet werden: Ohne die aktive, selbstorganisierte Suche nach Kontakt, beispielsweise mit ausländischen Nachbarinnen und Nachbarn, gestaltet es sich nachweislich schwierig neue Kulturen verstehen und akzeptieren zu lernen. Fast drei Viertel aller Deutschen (70,8 Prozent) haben so in Familie und Verwandtschaft keinen Kontakt zu ausländischen Bürgerinnen und Bürgern - bei der alleinigen Konzentration auf die ostdeutsche Bevölkerung sind es sogar fast 85 Prozent aller Bürgerinnen und Bürger. ${ }^{749}$ Auch bei der Ausübung ihrer beruflichen Tätigkeiten hat nur etwa ein Drittel (32,7 Prozent) der ostdeutschen Befragten Kontakt zu ausländischen Mitmenschen, in Westdeutschland immerhin über die Hälfte (62,1 Prozent). ${ }^{750}$ Des Weiteren besteht seitens der ostdeutschen Bevölkerung auch bezüglich Nachbarschaftskontakten mit ausländischen Mitbürgerinnen und Mitbürgern ein ernüchterndes Fazit: 81,7 Prozent der ostdeutschen Befragten verneinen dies, was jedoch auch mit der geringen Ausländerquote in Ostdeutschland im Zusammenhang steht. ${ }^{751}$ Lediglich in Westdeutschland pflegt immerhin die Hälfte (50,8 Prozent) der Bevölkerung nachbarschaftlichen Kontakt zu ausländischen Mitmenschen. ${ }^{752}$ „Kontakte mit Ausländern in den verschiedenen Bereichen sind in West und Ost

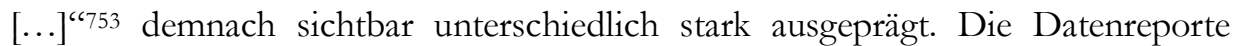
2008 und 2011 zeigen darüber hinaus noch weitere interessante Besonderheiten auf: „Es zeigt sich, dass diejenigen, die Kontakte zu Ausländern haben, den [oben vorgestellten] [...] Ausländer diskriminierenden Aussagen weitaus seltener zu-

747 Vgl. GESIS Leibniz-Institut für Sozialwissenschaften 2013, a. a. O. Im Durchschnitt stimmen 16,8 Prozent der befragten Bürgerinnen und Bürger der Aussage zu, dass Ausländerinnen und Ausländern die politische Betätigung in Deutschland untersagt werden sollte.

748 Vgl. Terwey/Baltzer 2013, a. a. O.

749 Vgl. GESIS Leibniz-Institut für Sozialwissenschaften 2013, a. a. O.

750 Vgl. GESIS Leibniz-Institut für Sozialwissenschaften 2013, a. a. O.

751 Vgl. GESIS Leibniz-Institut für Sozialwissenschaften 2013, a. a. O.

Die Verteilung der ausländischen Bevölkerung in den einzelnen Bundesländern ist deutlich unterschiedlich. In den ostdeutschen Bundesländern leben explizit weniger Ausländerinnen und Ausländer als in den westdeutschen Bundesländern (s. Kapitel 4). Vgl. Statistisches Bundesamt Destatis (2013a): „Ausländische Bevölkerung. Ausländische Bevölkerung am 31.12.2011“, in URL: https://www.destatis.de/DE/ZahlenFakten/GesellschaftStaat/Bevoelkerung/MigrationInteg ration/AuslaendischeBevolkerung/Tabellen/Bundeslaender.html $<13.01 .2013>$.

752 Vgl. GESIS Leibniz-Institut für Sozialwissenschaften 2013, a. a. O.

753 Blohm, Michael/Wasmer, Martina (2008): Einstellungen und Kontakte zu Ausländern, in: Statistisches Bundesamt Destatis et al. (Hrsg.): Datenreport 2008. Ein Sozialbericht für die Bundesrepublik Deutschland, Bonn, S. 213. 
stimmen.“754 Folglich „[...] gehen Kontakte zu Ausländern mit positiveren Einstellungen zu dieser Bevölkerungsgruppe einher." ${ }^{\text {‘755 }}$

Aufgrund der Datengrundlage des ALLBUS 2010 und 2012 lässt sich abschlieBend schlussfolgern, dass rassistische Tendenzen sowie ein deutlich negativ, vorurteilsgeprägtes Verhalten gegenüber ausländischen Mitbürgerinnen und Mitbürgern in der bundesrepublikanischen Bevölkerung etabliert sind. Eine notwendige Differenzierung fehlt meist vollständig - man geht verallgemeinernd von ,den Ausländern aus. Diese Einordnung basiert sowohl auf biologisch-rassistischen sowie kulturell-naturalisierenden Ressentiments (s. Kapitel 3.1, 3.2, 3.3).

\subsection{Datenreporte 2008/2011 für die Bundesrepublik Deutschland}

Auch die Sozialberichte bzw. Datenreporte für die Bundesrepublik Deutschland von 2008 und 2011 beschäftigen sich mit den Einstellungen der bundesrepublikanischen Gesellschaft gegenüber ausländischen Mitbürgerinnen und Mitbürgern, Flüchtlingen, Asylsuchenden oder Menschen mit Migrationshintergrund. Ihr Ziel ist die ,[...] kontinuierliche Beobachtung und Analyse der Lebensqualität und des sozialen Wandels in Deutschland. “756 Weiterhin veranschaulichen sie „[...] relevante Trends des gesellschaftlichen Wandels [... $]^{\text {‘"757 }}$ sowie „[...] individuelle Einstellungen und Verhaltensweisen $[\ldots]^{\text {‘758 }}$ der deutschen Bevölkerung. ${ }^{759}$ Als Datenquellen dienen unter anderem die quantitativen ALLBUS-Datensätze aus den Jahren 1980 bis 2006 bzw. 2010, die Ergebnisse des Sozioökonomischen Panels, die Datengrundlagen des Statistischen Bundesamtes DESTATIS sowie die Erkenntnisse des Mikrozensus. ${ }^{760}$ Mithilfe dieser bevölkerungsstatistischen Befunde sollen die zuvor illustrierten Forschungserkenntnisse weiter vertieft und bestätigt werden.

Ein Fokus der Sozialberichte liegt im Bereich der „Einstellungen und Kontakte zu Ausländern“"761 der deutschen Bürgerinnen und Bürger. Da sich einige Ergebnisse der Datenreporte 2008 und 2011 mit denen des ALLBUS 2010 - auf den die Datenreporte unter anderem zurückgreifen - überschneiden und der ALLBUS

754 Blohm/Wasmer 2008, a. a. O., S. 213.

755 Blohm/Wasmer 2008, a. a. O., S. 213.

756 Statistisches Bundesamt Destatis et al. (2008b): Einleitung, in: ebd. (Hrsg.) Datenreport 2008.

Ein Sozialbericht für die Bundesrepublik Deutschland, Bonn, S. 8.

757 Statistisches Bundesamt Destatis et al. 2008b, ebd., S. 8.

758 Statistisches Bundesamt Destatis et al. 2008b, ebd., S. 8.

759 Auch bei diesem Beispiel müssen die zu interpretierenden Datensätze jedoch differenziert betrachtet werden, um die statistischen Darstellungen korrekt sowie kritisch auszuwerten (s. Kapitel 3).

760 Das Soziö̈leonomische Panel stellt eine repräsentative Befragung von etwa 12.000 Bürgerinnen und Bürgern der Bundesrepublik Deutschland zu unterschiedlichen Themenbereichen dar. Diese wird jährlich durchgeführt. Demgegenüber ist der sogenannte Mikrozensus eine repräsentative, statistische Befragung verschiedener Haushalte, mit deren Hilfe beispielsweise die Daten aus Volkszählungen überprüft und gegebenenfalls modifiziert werden können.

761 Blohm/Wasmer 2008, a. a. O., S. $208 f f$. 
2012 zum Teil die aktuelleren Datensätze beinhaltet, werden im weiteren Verlauf dieses Kapitels lediglich die in den bisherigen Daten nicht bzw. nur teilweise betrachteten, den Rassismus des 21. Jahrhunderts betreffenden, Themenaspekte neu integriert und diskutiert.

Tab. 10: Einstellungen gegenüber den in Deutschland lebenden Ausländern in ausgewählten Bevölkerungsgruppen 2006 (Anteil derjenigen, die den Aussagen zustimmen) $)^{762}$

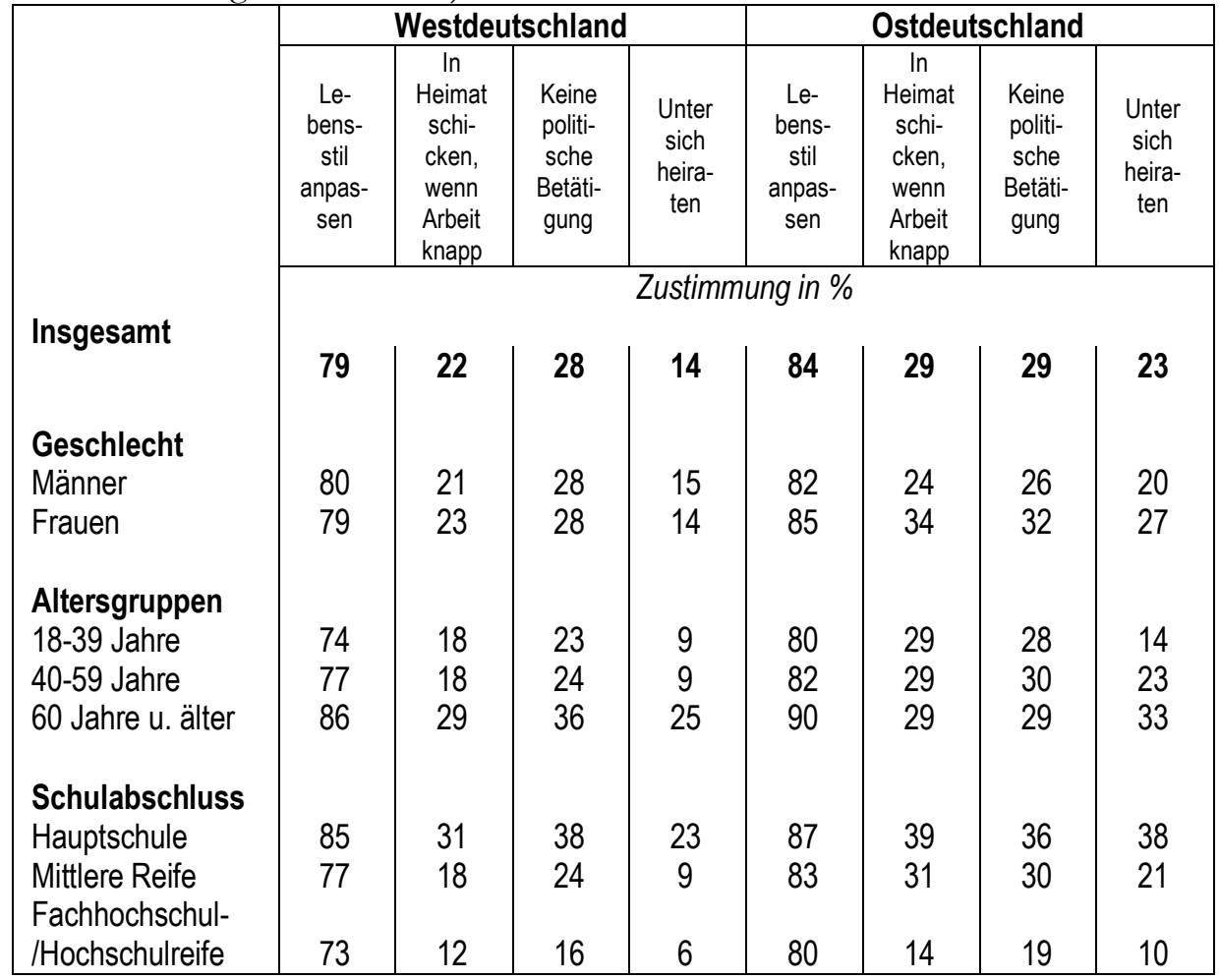

Die oben stehende tabellarische Zusammenfassung illustriert nochmals einen exemplarischen Fragenkatalog zu fremdenfeindlichen und rassistischen Einstellungen in der Bundesrepublik. ${ }^{763}$ Unter anderem werden hier auch Alters-, Geschlechts- und Bildungsunterschiede im Zusammenhang mit dem Zustimmungsverhalten zu den einzelnen Aussagen aufgelistet. Auch die hier dargestellten Befunde, die überwiegend noch auf dem ALLBUS 2006 basieren, bestätigen das partiell beunruhigende Bild gegenüber ausländischen Personengruppen, welches die schon im Zusammenhang mit dem ALLBUS 2010 vorgestellten Analyseergebnisse konstatieren. Tendenziell ist die Zustimmung zu den ausgewählten rassis-

762 Eigene Darstellung nach: Blohm/Wasmer 2008, a. a. O., S. 209.

763 Vgl. Blohm/Wasmer 2008, a. a. O., S. 209 f. 
tischen und fremdenfeindlichen Aussagen in den ostdeutschen Bundesländern stärker ausgeprägt als innerhalb der westdeutschen Bevölkerung - auch diese Ergebnisse bestätigen und unterstützen die der bisher vorgestellten Studien. ${ }^{764}$ „Im Allgemeinen äußern sich die Ostdeutschen weniger ausländerfreundlich als die Westdeutschen.“765, so ein Vorabfazit.

Was wird seitens der deutschen Bevölkerung an den ausländischen Mitbürgerinnen und Mitbürgern bzw. den Einwanderern kritisiert? Wie auch in den schon diskutierten Datensätzen erkennbar, fordert ein Großteil der befragten Bürgerinnen und Bürger - 79 Prozent im Westen sowie 84 Prozent im Osten - eine bessere Lebensstilanpassung der ausländischen Bevölkerung an die bundesdeutschen Verhältnisse:766 „Mit Abstand die meiste Zustimmung findet [...] die vergleichsweise gemäßigte Forderung nach $[. .$.$] mehr Lebensstilanpassung der hier lebenden$ Ausländer [...].“767 (s. Kapitel 3.3, 3.4). Vor diesem Hintergrund werden demzufolge eher angebliche kulturelle Eigenheiten und Besonderheiten der ,Fremden“ kritisiert.

Den weiteren - in der vorherigen Tabelle dargestellten - Aussagen stimmen die meisten befragten Bürgerinnen und Bürger zwar weniger intensiv zu, jedoch ist allein die grundsätzlich festzustellende Zustimmungsbereitschaft besorgniserregend. Demnach identifiziert sich immerhin ungefähr jeder dritte Deutsche damit, ausländischen Mitbürgerinnen und Mitbürgern eine politische Betätigung zu verweigern - statistisch gesehen also etwa 22 Millionen Menschen, eine nicht zu unterschätzende Anzahl. 768 Auch die Aussage der zwingenden Rückführung von ausländischen Bevölkerungsanteilen bei Arbeitsplatzknappheit unterstützt im Durchschnitt ein Fünftel aller deutschen Bürgerinnen und Bürger, 22 Prozent im Westen sowie 29 Prozent im Osten (s. Kapitel 3.3). ${ }^{769}$ Die Übereinstimmung mit fremdenfeindlichen und diskriminierenden Aussagen ist demnach keinesfalls zu vernachlässigen - alle Datenauswertungen liegen im deutlich zweistelligen Bereich. 770

Bei der überblickenden Analyse der Geschlechts-, Bildungs- und Altersunterschiede lassen sich drei prägnante Erkenntnisse festhalten: Bezüglich des Geschlechterverhaltens der Studienteilnehmerinnen und -teilnehmer lässt sich konstatieren, dass „Einstellungsunterschiede zwischen Männern und Frauen [...] nur vereinzelt festzustellen [sind].“"771 Jedoch ,[...] sind diskriminierende Einstellungen gegenüber in Deutschland lebenden Ausländern in verschiedenen Alters- und Bildungsgruppen unterschiedlich weit verbreitet." $" 72$ Wie zu erkennen, sind diskriminierende sowie mehr oder weniger offene rassistische Einstellungen bei älte-

\footnotetext{
764 Vgl. Blohm/Wasmer 2008, a. a. O., S. $208 \mathrm{f}$.

765 Blohm/Wasmer 2008, a. a. O., S. 208.

766 Vgl. Blohm/Wasmer 2008, a. a. O., S. 209 f.

767 Blohm/Wasmer 2008, a. a. O., S. 208.

768 Vgl. Blohm/Wasmer 2008, a. a. O., S. 209 f.

769 Vgl. Blohm/Wasmer 2008, a. a. O., S. 209 f.

770 Vgl. GESIS Leibniz-Institut für Sozialwissenschaften 2011, a. a. O.

771 Blohm/Wasmer 2008, a. a. O., S. 208.

772 Blohm/Wasmer 2008, a. a. O., S. 208-209.
} 
ren Bevölkerungsmitgliedern deutlich häufiger verbreitet als bei der jüngeren Bevölkerung, besonders bei den über 60-Jährigen. ${ }^{773}$ Für das Verhältnis von Bildungsgrad und Ausländerfreundlichkeit lässt sich eine positive Korrelation feststellen: „In West und Ost gilt: je gebildeter desto ,ausländerfreundlicher‘.“774 So stimmen die Ergebnisse der Sozialberichte 2008 und 2011 größtenteils mit den neueren Erkenntnissen der hier schon präsentierten Studien überein. Fremdenfeindlichkeit und Rassismus müssen in Deutschland abermals auf der gesellschaftlichen Tagesordnung identifiziert werden.

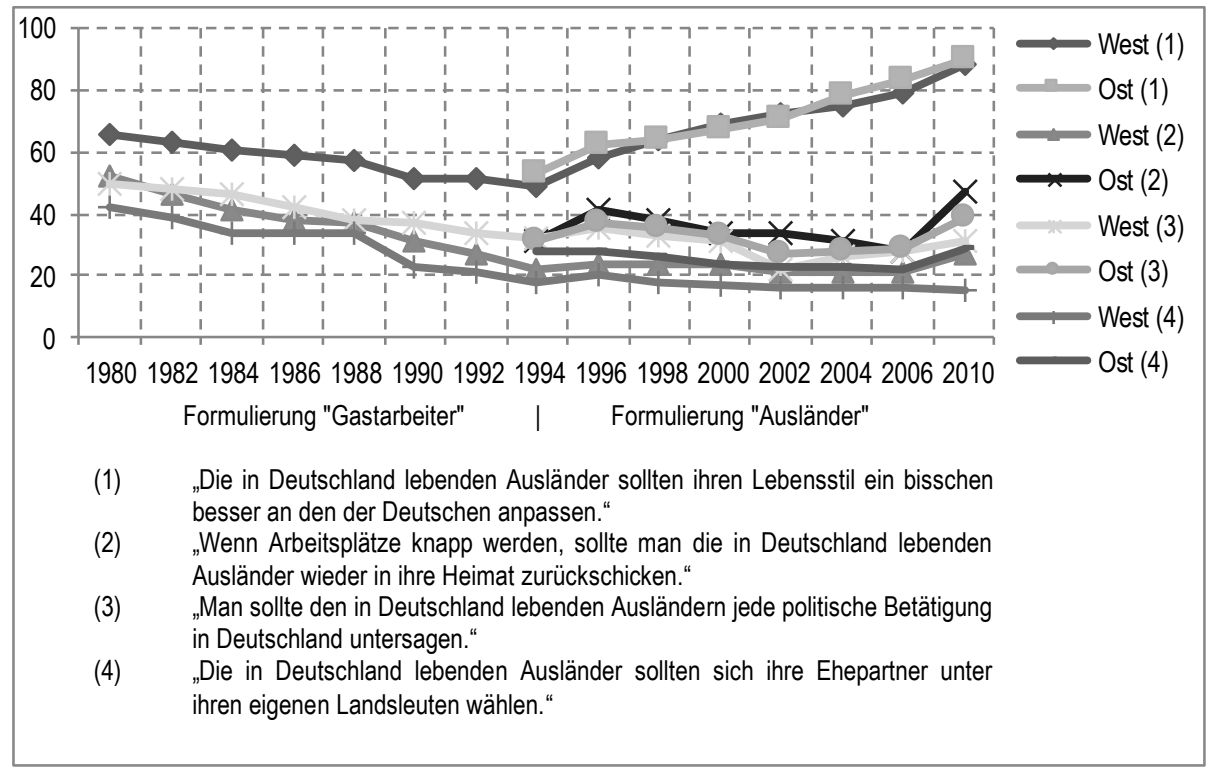

Abb. 6: Diskriminierende Einstellungen gegenüber Ausländern in Deutschland (Zustimmung in Prozent) $)^{775}$

Abschließend ein vergleichender Blick auf die Entwicklung rassistischer und diskriminierender Einstellungen in Deutschland seit 1980. In die oben stehende Grafik wurden die Datensätze der ALLBUS-Studien 1980 bis 2010 neu eingearbeitet, so dass ein umfassender Querschnittsvergleich ermöglicht wird. ${ }^{776}$ Beobachtet werden kann, dass vor allem die Zustimmungswerte der west- und ostdeutschen Bevölkerung nach der Wiedervereinigung bezüglich des Fragenkomplexes zur

773 Vgl. Blohm/Wasmer 2008, a. a. O., S. 209 f.

774 Blohm/Wasmer 2008, a. a. O., S. 209.

775 Eigene Darstellung nach: Blohm/Wasmer 2008, a. a. O., S. 209. | GESIS Leibniz-Institut für Sozialwissenschaften 2011, a. a. O. | Blohm, Michael/Wasmer, Martina (2011): Einstellungen und Kontakte zu Ausländern, in: Statistisches Bundesamt Destatis et al. (Hrsg.): Datenreport 2011. Ein Sozialbericht für die Bundesrepublik Deutschland. Band I, Bonn, S. 203.

776 Hinzuweisen ist auf die Tatsache, dass die ostdeutsche Bevölkerung in den sogenannten ,neuen 'Bundesländern erst seit 1994 in der Analysegrafik enthalten ist. 
Lebensstilanpassung angewachsen sind. ${ }^{777}$ Hier kann im Jahr 2010, vergleichend zum Jahr 1994, ein fast 40 prozentiger Anstieg konstatiert werden (s. Kapitel 3.3, 3.4). ${ }^{778}$ Darüber hinaus ist ebenfalls bei dem schon genannten Fragenkomplex zu möglichen Arbeitsplatzkrisen ein deutlicher Anstieg zu beobachten (s. Kapitel 4). ${ }^{779}$ Grundsätzlich kann demnach vermutet werden, dass Wirtschaft und Arbeitsmarkt einen nachhaltigen Einfluss auf rassistische sowie fremdenfeindliche Tendenzen haben.

So lässt sich zusammenfassend feststellen, dass „,...] von 1980 bis 1994 ein mehr oder weniger starker - kontinuierlicher Rückgang der Zustimmung zu allen vier Aussagen zu beobachten [ist], so dass man für diesen Zeitraum eine zunehmend tolerante Haltung gegenüber Ausländern konstatieren kann. Seit 1994 ist das Bild weniger eindeutig. "780 Demgegenüber ist jedoch bei direkt abwertenden und diskriminierenden Aussagen gegenüber ausländischen Mitbürgerinnen und Mitbürgern „[...] seit 1994 eine starke Zunahme der Zustimmungsquoten zu verzeichnen." 781

Die Sozialberichte der Bundesrepublik Deutschland halten zusätzlich einschränkend fest, dass es ,,[...] keine Hinweise auf ein generell ausländerfeindliches Meinungsklima in Deutschland $[\ldots]^{\text {“782 }}$ gebe. Vor dem Hintergrund des Vergleichs dieser Werte mit den aktuellen Ergebnissen aus den Jahren 2010 und 2011 ist diese Aussage jedoch nachweislich zu modifizieren: Rassistische und diskriminierende Einstellungen sind tendenziell im Ansteigen begriffen, insbesondere in biologistischer Ausprägung. Außerdem wird die ,,[...] Andersartigkeit [der ausländischen Bevölkerung] in der Regel eher negativ[er] bewertet [... “"783 als noch vor wenigen Jahren. Sicherlich ist nicht von einem ,generellen' Fremdenfeindlichkeitsbzw. Rassismusphänomen sämtlicher Gesellschaftsmitglieder zu sprechen - eine Differenzierung ist notwendig und geboten. Nichtsdestotrotz etablieren sich die Zustimmungswerte mit einem immer größeren Zuspruch der bundesrepublikanischen Gesellschaft, so dass heute durchaus von latent vorhandenen, diskriminierenden und mehr oder weniger offen rassistischen Einstellungen in einem beträchtlichen Teil der bundesrepublikanischen Gesellschaft gesprochen werden muss.

\footnotetext{
777 Vgl. Blohm/Wasmer 2008, a. a. O., S. 209. | Vgl. GESIS Leibniz-Institut für Sozialwissenschaften 2011, a. a. O.

778 Vgl. Blohm/Wasmer 2008, a. a. O., S. 209. | Vgl. GESIS Leibniz-Institut für Sozialwissenschaften 2011, a. a. O.

779 Vgl. Blohm/Wasmer 2008, a. a. O., S. 209. | Vgl. GESIS Leibniz-Institut für Sozialwissenschaften 2011, a. a. O.

780 Blohm/Wasmer 2011, a. a. O., S. 210.

781 Blohm/Wasmer 2011, a. a. O., S. 210.

782 Blohm/Wasmer 2011, a. a. O., S. 213.

783 Blohm/Wasmer 2011, a. a. O., S. 214.
} 


\subsection{Rassismus in Europa}

Die von der Friedrich-Ebert-Stiftung in Auftrag gegebene Querschnittsstudie „Die Abwertung der Anderen. Eine europäische Zustandsbeschreibung zu Intoleranz, Vorurteilen und Diskriminierung " 784 skizziert die Verbreitung von - rassistischen - Vorurteilen auf europäischer Ebene. Sie wurde 2008/2009 unter der Federführung des Bielefelder Instituts für interdisziplinäre Konflikt- und Gewaltforschung durchgeführt. ${ }^{785}$ Hierzu wurden exemplarisch via Telefonumfrage 1.000 Personen mit einem Mindestalter von 16 Jahren aus acht europäischen Staaten interviewt, um insbesondere Ausmaß, mögliche Determinanten und Ursachen von ,gruppenbezogener Menschenfeindlichkeit in Europa zu untersuchen. ${ }^{786}$ Die Studie basiert auf dem GMF-Forschungsansatz und analysiert so die einzelnen Bausteine der sogenannten, gruppenbezogenen Menschenfeindlichkeit in Europa, die vielfältige Facetten und Bestandteile des Rassismuskonstruktes aufgreift: Fremdenfeindlichkeit, Antisemitismus, originärer Rassismus, Islamfeindlichkeit, Sexismus und Homophobie - alles Aspekte, die zum erweiterten Rassismusbegriff hinzu gezählt werden können, da sie auf rassistischen - zum Teil biologisch konnotierten - Argumentationsstrukturen basieren. ${ }^{787}$

Das Ziel der Studie ist es, die aktuell vorherrschenden „[...] demokratiegefährdende[n] Tendenzen in Europa [...] $]^{\text {"788 }}$ - die Bundesrepublik Deutschland inbegriffen - kenntlich zu machen, um der Bedrohung durch neu entstehenden Rechtsextremismus, Rassismus und neu entstehende Fremdenfeindlichkeit wirkungsvoll eindämmend sowie präventiv entgegenwirken zu können. ${ }^{789}$ Beispiele für fremdenfeindlich oder rassistisch motivierte Straftaten lassen sich für die vergangenen Jahre europaweit erkennen, insbesondere vor dem Hintergrund des Anwachsens der sogenannten rechtspopulistischen Szene auf der politischen Ebene der europäischen Staatengemeinschaft (s. Kapitel 4). Als Beispiele seien hier die rechtspopulistische FPÖ (Freiheitliche Partei Österreichs) in Österreich, die Sverigedemokraterna (Schwedendemokraten) in Schweden, die Fremskrittspartiet (Fortschrittspartei) in Norwegen, die Perussuomalaiset (Wahre Finnen) in Finnland, der Front National (Nationale Front) in Frankreich, das Vlaams Belang (Flämisches Interesse) in Belgien oder Geert Wilders Partij voor de Vrijheid (Partei für die Freiheit) in den Niederlanden zu nennen, die in den letzten Jahren beachtliche Wahlerfolge auf nationaler Ebene aufweisen konnten. ${ }^{790}$ Insbesondere die schon vorgestellte

784 Zick/Küpper/Hövermann 2011, a. a. O.

785 Vgl. Zick/Küpper/Hövermann 2011, a. a. O., S. 49ff.

786 Vgl. Zick/Küpper/Hövermann 2011, a. a. O., S. 14ff, 49ff.

Zur Steigerung der Vergleichbarkeit der Ergebnisse zwischen den einzelnen teilnehmenden Staaten, wurden in diesen jeweils die gleichen Methoden, Stichprobenziehungen sowie Erhebungszeiträume abgestimmt.

787 Vgl. Zick/Küpper/Hövermann 2011, a. a. O., S. $77 \mathrm{ff}$.

788 Zick/Küpper/Hövermann 2011, a. a. O., S. 10.

789 Vgl. Zick/Küpper/Hövermann 2011, a. a. O., S. 9 f.

790 Vgl. Zick/Küpper/Hövermann 2011, a. a. O., S. 9f.

$Z u$ beachten ist jedoch, dass die skizzierten $W$ ablerfolge nicht gleichzeitig mit einer Ausweitung rassistischer

Tendenzen innerbalb der europäischen Gesellschaft gleichgesetzt werden können. Viele Belgierinnen und Belgier 
Grundrechtecharta der Europäischen Union gerät diesbezüglich immer weiter in Bedrängnis - hier existiert ein deutlicher Widerspruch zwischen Anspruch und Wirklichkeit (s. Kapitel 1). ${ }^{791}$ Die hier genannte Studie zeigt so einen „,[...] aufschlussreiche[n] als auch besorgniserregende[n] Lagebericht [...] “792. Die Medien titeln demzufolge nicht unbegründet von einem „Europa der Intoleranten“793.

Im Rahmen der Integration der Datenmaterialien wird der Schwerpunkt thematisch neu auf die exemplarischen Bereiche der diskriminierenden Fremdenfeindlichkeit, dem Antisemitismus als Spezialform von rassistischen Einstellungen sowie dem originären Rassismusphänomen ausgerichtet. So ist es möglich, dem biologisch-rassistischen Fokus dieses Forschungsansatzes gerecht zu werden. Selbstverständlich enthalten auch die weiteren untersuchten Forschungsbereiche der Islamfeindlichkeit, des Sexismus sowie der Homophobie biologischrassistische Elemente, da hierbei einzelne Bevölkerungsgruppen aufgrund von biologistischen Vorurteilen ausgegrenzt, diskriminiert und benachteiligt werden. Stellvertretend sollen die hier vorzustellenden, exemplarischen Bereiche eine einführende Zustandsdiagnose bezüglich der rassistischen Einstellungen in Deutschland bzw. Europa demonstrieren.

Wie zu erkennen ist, stimmt ein Drittel bis die Hälfte der deutschen Bürgerinnen und Bürger den nachfolgend aufgezeigten fremdenfeindlichen Aussagen zu. 50 Prozent der bundesrepublikanischen Bevölkerung sieht zu viele Einwanderer in Deutschland; über ein Drittel (37,6 Prozent) gibt darüber hinaus an, sich dadurch als ,„...] Fremder im eigenen Land [... $]^{6794} \mathrm{zu}$ fühlen. ${ }^{795}$ Über ein Drittel der deutschen Bevölkerung (40,8 respektive 39,3 Prozent) sieht die Menschen mit Migrationshintergrund in Deutschland als ,,[... Belastung für unser Sozialsystem [...]“796 und unsere Wirtschaft. ${ }^{797}$ Einzig der Frage nach der Kulturbereicherung durch ausländische Mitbürgerinnen und Mitbürger wird mit großer Mehrheit (75 Prozent) zugestimmt, was dem tendenziell ablehnenden Verhalten der bundesrepublikanischen Gesellschaft gegenüber einwandernden Menschen statistisch widerspricht. ${ }^{798}$ Als Zwischenfazit können der Bundesrepublik Deutschland so multiple fremdenfeindliche Einstellung bescheinigt werden, was die hohen Zustimmungswerte verdeutlichen.

wählen beispielsweise das Vlaams Belang, um für ein unabbängiges Flandern zu stimmen; die ,Wabren Finnen'profitierten insbesondere von der EU-Skepsis der Bürgerinnen und Bürger.

791 Vgl. Zick/Küpper/Hövermann 2011, a. a. O., S. 9f.

792 Zick/Küpper/Hövermann 2011, a. a. O., S. 12.

793 Spiegel Online (2011b): „Studie in acht Ländern. Europa der Intoleranten“, in URL: http://www.spiegel.de/politik/ausland/ 0,1518,750172,00.html <30.07.2011>.

794 Zick/Küpper/Hövermann 2011, a. a. O., S. 62.

795 Vgl. Zick/Küpper/Hövermann 2011, a. a. O., S. $62 \mathrm{ff}$.

796 Zick/Küpper/Hövermann 2011, a. a. O., S. 62.

797 Vgl. Zick/Küpper/Hövermann 2011, a. a. O., S. $62 \mathrm{ff}$.

798 Vgl. Zick/Küpper/Hövermann 2011, a. a. O., S. 62ff. 
Tab. 11: Fremdenfeindliche Aussagen (Zustimmung in Prozent) 799

\begin{tabular}{|c|c|c|c|c|c|c|c|c|c|}
\hline Nr. & Item & D & GB & $\mathbf{F}$ & NL & $\mathrm{I}$ & PT & PL & $\mathrm{HU}$ \\
\hline 01 & $\begin{array}{l}\text { Es gibt zu viele Zuwanderer } \\
\text { in (jew. Land). }\end{array}$ & 50,0 & 62,2 & 40,3 & 46,0 & 62,5 & 59,6 & 27,1 & 58,7 \\
\hline 02 & $\begin{array}{l}\text { Durch die vielen Zuwande- } \\
\text { rer fühle ich mich manch- } \\
\text { mal wie ein Fremder im } \\
\text { eigenen Land. }\end{array}$ & 37,6 & 45,8 & 31,0 & 37,7 & 27,0 & 19,1 & 19,4 & 44,6 \\
\hline 03 & $\begin{array}{l}\text { Wenn Arbeitsplätze knapp } \\
\text { sind, sollten (jew. Bevölke- } \\
\text { rung) mehr Recht auf eine } \\
\text { Arbeit haben als Zuwande- } \\
\text { rer. }\end{array}$ & 42,4 & 50,3 & 29,5 & 24,7 & 55,9 & 58,2 & 74,1 & 71,2 \\
\hline 04 & $\begin{array}{l}\text { Zuwanderer bereichern } \\
\text { unsere Kultur. }\end{array}$ & 75,0 & 71,2 & 70,8 & 74,9 & 61,0 & 73,7 & 64,2 & 57,0 \\
\hline \multicolumn{10}{|c|}{ Zusätzliche Items in einer Zufallshälfte der Stichprobe: } \\
\hline 05 & $\begin{array}{l}\text { Zuwanderer sind eine } \\
\text { Belastung für unser Sozial- } \\
\text { system. }\end{array}$ & 40,8 & 60,2 & 54,7 & 20,3 & 31,7 & 42,5 & 45,8 & 77,2 \\
\hline 06 & $\begin{array}{l}\text { Wir brauchen Zuwanderer, } \\
\text { um die Wirtschaft am Lau- } \\
\text { fen zu halten. }\end{array}$ & 60,7 & 59,5 & 66,1 & 64,5 & 70,7 & 68,1 & 42,4 & 24,2 \\
\hline
\end{tabular}

Die vorgestellte bundesrepublikanische Auswertung lässt sich auch - mit jeweils leichten Abweichungen nach oben und unten - als europäischer Trend festhalten, was die nachfolgende Grafik illustriert. Auch die tendenziell widersprüchlichen Angaben bei der Frage nach der Kulturbereicherung durch ausländische Bürgerinnen und Bürger ist in den weiteren europäischen Staaten mehr oder weniger ausgeprägt zu erkennen: ${ }^{800}$ „Hier drückt sich eine gewisse Ambivalenz aus, die Vorurteilen durchaus zu eigen ist. “" ${ }^{801}$, so eine kritische Schlussfolgerung der Autorinnen und Autoren.

Vor dem Hintergrund der Analyse der Größenordnung von Fremdenfeindlichkeit in Deutschland sowie den weiteren untersuchten Staten kann konstatiert werden, dass Ungarn vor Großbritannien und der Bundesrepublik Deutschland die höchste Fremdenfeindlichkeits-Rate aufweist. ${ }^{802}$ Die Mehrzahl der befragten ungarischen Bürgerinnen und Bürger stimmt den fremdenfeindlichen und diskriminierenden Aussagen zu. Demgegenüber weisen Frankreich und die Niederlande die geringsten Anteile an fremdenfeindlichen Stimmungen in der Bevölkerung

\footnotetext{
799 Eigene Darstellung nach: Zick/Küpper/Hövermann 2011, a. a. O., S. 62.

800 Vgl. Zick/Küpper/Hövermann 2011, a. a. O., S. 63ff.

801 Zick/Küpper/Hövermann 2011, a. a. O., S. 63.

802 Vgl. Zick/Küpper/Hövermann 2011, a. a. O., S. 64.
} 
auf. ${ }^{803}$ Diesbezüglich muss jedoch relativierend erwähnt werden, „[...] dass sich die Länder im Ausmaß der Fremdenfeindlichkeit absolut gesehen nur geringfügig unterscheiden. “804

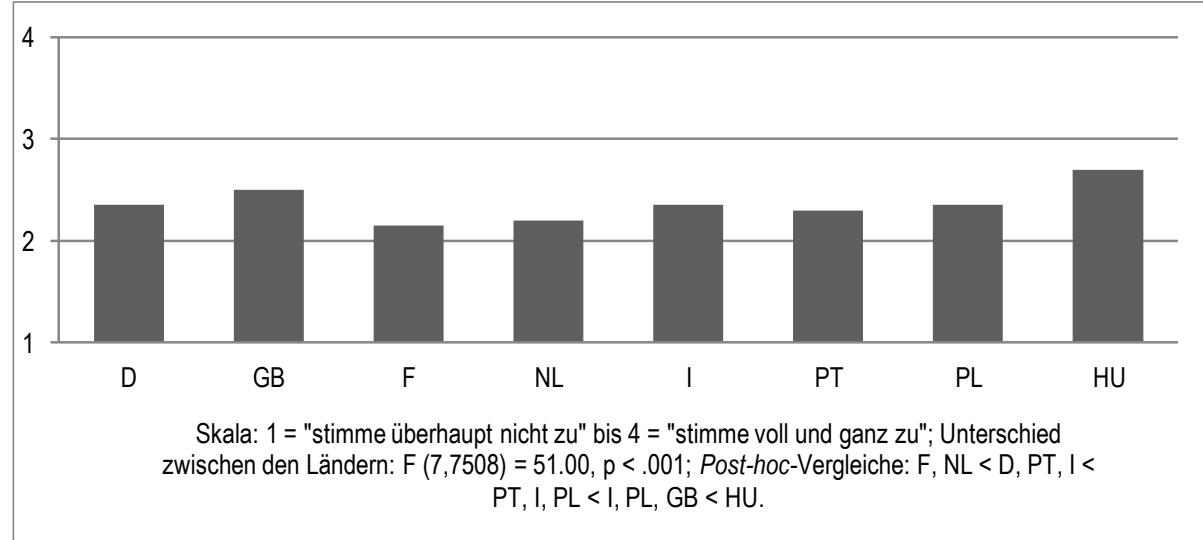

Abb. 7: Fremdenfeindlichkeit im europäischen Vergleich (Mittelwertskala) ${ }^{805}$

Die durchaus hohen Zustimmungswerte der bundesrepublikanischen und - in ausgewählten Staaten - der europäischen Bevölkerung lassen sich tendenziell auch auf den Themenbereich des Antisemitismus projizieren. Einschränkend muss jedoch gleichzeitig auf das niedrigere, jedoch immer noch besorgniserregende, Niveau der diesbezüglichen Zustimmungswerte hingewiesen werden. Bei der Frage nach dem Einfluss der jüdischen Bevölkerung in den jeweiligen Staaten sind insbesondere die Untersuchungsergebnisse Polens und Ungarns aufsehenerregend: Hier stimmt die Hälfte der Bevölkerung, 49,9 bzw. 69,2 Prozent der jeweiligen Bürgerinnen und Bürger, zu. ${ }^{806}$ Diese negative Einstellung gegenüber der jüdischen Bevölkerung zeigt sich auch in den weiteren Fragen mit erschreckend hohen Zustimmungswerten, allen voran in Polen. ${ }^{807}$ Lediglich der Bereicherung der nationalen und europäischen Kultur durch die jüdischen Mitbürgerinnen und Mitbürger wird von mehr als der Hälfte der Bevölkerung der studienteilnehmenden Staaten zugestimmt, wie auch schon im Fragenpool zur Fremdenfeindlichkeit skizziert wurde. ${ }^{808}$ Auch für die Bundesrepublik Deutschland sind die ermittelten Untersuchungsergebnisse keinesfalls befriedigend, im Gegenteil. Sie unterstützen die Ergebnisse des aktuellen gesellschaftlichen Trends hinsichtlich einer Zunahme

\footnotetext{
803 Die erhobenen Datenmaterialien widersprechen in dieser Darstellung jedoch der politischen Realität: Frankreich und die Niederlande sind die Staaten mit den größten $W$ ablerfolgen von rechtspopulistischen Parteien, wie Front National und die Partei für die Freibeit beweisen.

804 Zick/Küpper/Hövermann 2011, a. a. O., S. 64.

805 Eigene Darstellung nach: Zick/Küpper/Hövermann 2011, a. a. O., S. 64.

806 Vgl. Zick/Küpper/Hövermann 2011, a. a. O., S. $65 \mathrm{ff}$.

807 Vgl. Zick/Küpper/Hövermann 2011, a. a. O., S. 65ff.

808 Vgl. Zick/Küpper/Hövermann 2011, a. a. O., S. 65.
} 
von rassistischen und diskriminierenden Einstellungen, sowohl auf biologistischer als auch auf kulturalistischer Grundlage (s. Kapitel 3.1, 3.2, 3.3, 3.4).

Tab. 12: Antisemitische Aussagen (Zustimmung in Prozent) 809

\begin{tabular}{|c|c|c|c|c|c|c|c|c|c|}
\hline Nr. & Item & D & GB & $F$ & NL & I & PT & PL & HU \\
\hline 01 & $\begin{array}{l}\text { Juden haben in (jew. Land) } \\
\text { zu viel Einfluss. }\end{array}$ & 19,7 & 13,9 & 27,7 & 5,6 & 21,2 & 19,9 & 49,9 & 69,2 \\
\hline 02 & $\begin{array}{l}\text { Juden versuchen heute } \\
\text { Vorteile daraus zu ziehen, } \\
\text { dass sie während der Nazi- } \\
\text { Zeit die Opfer gewesen } \\
\text { sind. }\end{array}$ & 48,9 & 21,8 & 32,3 & 17,2 & 40,2 & 52,2 & 72,2 & 68,1 \\
\hline 03 & $\begin{array}{l}\text { Juden im Allgemeinen } \\
\text { kümmern sich um nichts } \\
\text { und niemanden außer um } \\
\text { ihre eigene Gruppe. }\end{array}$ & 29,4 & 22,5 & 25,8 & 20,4 & 26,9 & 54,2 & 56,9 & 50,9 \\
\hline 04 & $\begin{array}{l}\text { Juden bereichern unsere } \\
\text { Kultur. }\end{array}$ & 68,9 & 71,5 & 60,6 & 71,8 & 49,7 & 51,9 & 51,2 & 57,3 \\
\hline \multicolumn{10}{|c|}{ Zusätzliche Items in einer Zufallshälfte der Stichprobe: } \\
\hline 05 & $\begin{array}{l}\text { Bei der Politik, die Israel } \\
\text { macht, kann ich gut verste- } \\
\text { hen, dass man Juden nicht } \\
\text { mag. }\end{array}$ & 35,6 & 35,9 & - & 41,1 & 25,1 & 48,8 & 55,2 & 45,6 \\
\hline 06 & $\begin{array}{l}\text { Israel führt einen Vernich- } \\
\text { tungskrieg gegen die Paläs- } \\
\text { tinenser. }\end{array}$ & 47,7 & 42,4 & - & 38,7 & 37,6 & 48,8 & 63,3 & 41,0 \\
\hline
\end{tabular}

So stimmt jeder fünfte Deutsche der Aussage zu, dass Juden ,[... zu viel Einfluss haben. " 810 Fast die Hälfte der deutschen Bevölkerung (48,9 Prozent) stimmt darin überein, dass die jüdische Bevölkerung sich aus der grausamen deutschen Geschichte während des sogenannten Dritten Reiches heutzutage Vorteile zu verschaffen versucht. ${ }^{811}$ Jedoch erkennt die bundesrepublikanische Gesellschaft positiv an, dass die jüdischen Mitbürgerinnen und Mitbürger unsere Kultur nachhaltig bereichern und ergänzen. ${ }^{812}$

Auch diesbezüglich lässt sich wieder für die Bundesrepublik eine insgesamt negative Entwicklung bestätigen, was die nachfolgende Vergleichsskala der Studienteilnehmer unterstützt: „In Deutschland ist der Antisemitismus [...] signifikant deutlicher ausgeprägt als in den anderen westeuropäischen Ländern mit Ausnahme Portugals. “'813

\footnotetext{
809 Eigene Darstellung nach: Zick/Küpper/Hövermann 2011, a. a. O., S. 65.

810 Zick/Küpper/Hövermann 2011, a. a. O., S. 65ff.

811 Vgl. Zick/Küpper/Hövermann 2011, a. a. O., S. $65 \mathrm{ff}$.

812 Vgl. Zick/Küpper/Hövermann 2011, a. a. O., S. $65 \mathrm{ff}$.

813 Zick/Küpper/Hövermann 2011, a. a. O., S. 67.
} 


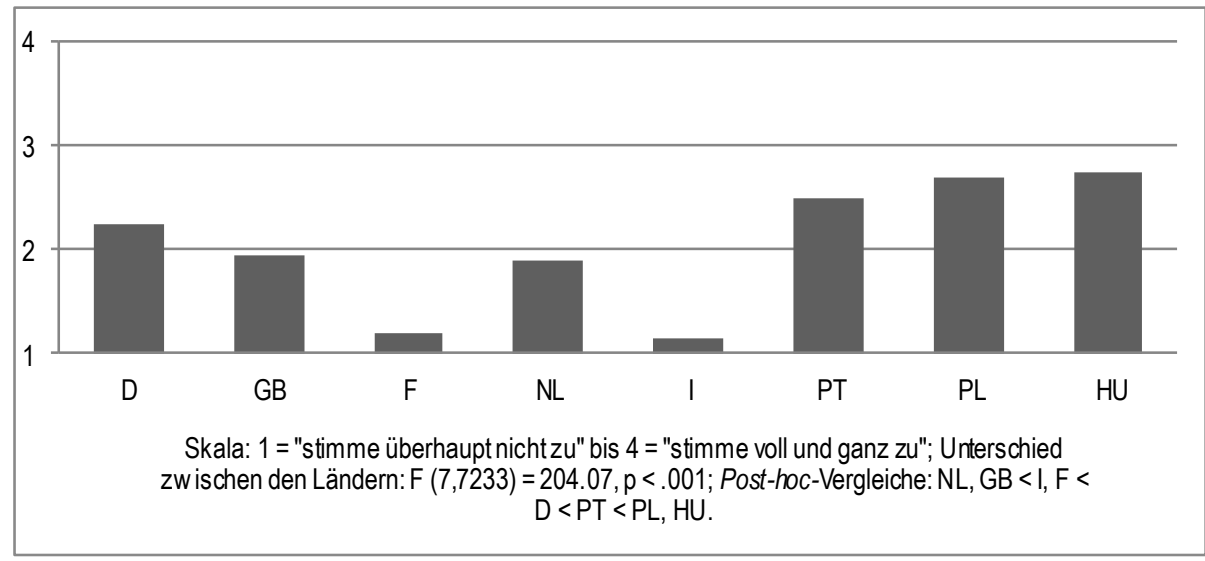

Abb. 8: Antisemitismus im europäischen Vergleich (Mittelwertskala) ${ }^{814}$

Tab. 13: Rassistische Aussagen (Zustimmung in Prozent) ${ }^{815}$

\begin{tabular}{|cccccccccc|}
\hline Nr. & \multicolumn{1}{c}{ Item } & D & GB & F & NL & I & PT & PL & HU \\
\hline 01 & $\begin{array}{l}\text { Es gibt eine natürliche } \\
\text { Hierarchie zwischen } \\
\text { schwarzen und weißen } \\
\text { Völkern. }\end{array}$ & 30,5 & 34,6 & $\begin{array}{c}38,5 \\
\star\end{array}$ & 32,4 & 18,7 & 45,1 & 41,6 & 41,8 \\
\hline 02 & $\begin{array}{l}\text { Schwarze und Weiße soll- } \\
\text { ten besser nicht heiraten. }\end{array}$ & 13,5 & 10,6 & $\begin{array}{c}13,6 \\
\star\end{array}$ & 4,7 & 7,5 & 17,9 & 23,5 & 30,3 \\
\hline Zusätzliche Items in einer Zufallshälfte der Stichprobe: & & & & & \\
\hline 03 & $\begin{array}{l}\text { Manche Kulturen sind } \\
\text { anderen klar überlegen. }\end{array}$ & 41,6 & 20,1 & 29,4 & 37,9 & 28,6 & 61,3 & 49,4 & 38,5 \\
\hline 04 & $\begin{array}{l}\text { Wir müssen unsere eigene } \\
\text { Kultur vor dem Einfluss } \\
\text { anderer Kulturen schützen. }\end{array}$ & 51,9 & 59,2 & 54,8 & 54,1 & 49,4 & 70,1 & 69,0 & 78,5 \\
\hline 05 & $\begin{array}{l}\text { Manche Völker sind begab- } \\
\text { ter als andere. }\end{array}$ & 45,0 & 27,5 & 25,0 & 43,6 & 31,2 & 57,1 & 50,4 & 53,8 \\
\hline
\end{tabular}

* In Frankreich wurde hier die positive Formulierung verwendet und nach der Zustimmung zu den Aussagen "Es gibt keine natürliche Hierarchie zwischen schwarzen und weißen Völkern“ und "Es ist kein Problem, wenn Schwarze und Weiße heiraten" gefragt. Der Wert für Frankreich gibt an, wie viel Prozent der Befragten diesen Aussagen "eher nicht" oder "überhaupt nicht" zugestimmt hat. Die Items wurden später umcodiert, sodass die Ablehnung dieser positiven Aussagen in die Berechnung einging.

Abschließend folgt nun der Fokus auf allgemein rassistische Einstellungen in den Teilnahmestaaten der Vergleichsstudie. Hier zeigen sich besorgniserregende Ten- 
denzen, sowohl in Deutschland als auch in den weiteren europäischen Staaten. Vor dem Hintergrund der Fokussierung der bundesrepublikanischen Ergebnisse kann, ohne detaillierte Analyse, umgehend festgestellt werden, dass sich die Zustimmung der befragten Bürgerinnen und Bürger zu den dargestellten Aussagen durchgehend auf einem hohen Niveau befindet. Fast jeder dritte Bundesbürger bzw. jede dritte Bundesbürgerin (30,5 Prozent) konstatiert, dass es Unterschiede zwischen weißen und schwarzen Völkern gäbe. ${ }^{816}$ Der Begriff ,Rasse' scheint indirekt impliziert zu sein, so dass sich biologistische Erklärungsansätze wieder in den Vordergrund des heutigen Rassismusphänomens zu schieben scheinen. Diese Differenzen werden als ,natürliche‘, als angeborene, biologische Unterschiede angesehen. Hiermit ist wieder zu belegen, dass der vor allem in den 1990er Jahren und zu Beginn des neuen Jahrtausends konstatierte sogenannte Kulturrassismus heute tendenziell direkt um das biologistische Element ergänzt wird. Der Weg zurück zu einem modernisierten, biologisch konnotierten ,Rassenrassismus? Dass bestimmte Kulturen anderen deutlich überlegen seien, stellen sogar 41,6 Prozent der befragten Bürgerinnen und Bürger fest und bestätigen somit die Ergebnisse der ersten Fragestellung. ${ }^{817}$ Auch die hiermit in Zusammenhang stehende Aussage, dass manche ,Völker' begabter, intelligenter als andere seien, ist von hohen Zustimmungswerten von fast der Hälfte (45 Prozent) der befragten Bevölkerung geprägt. 818

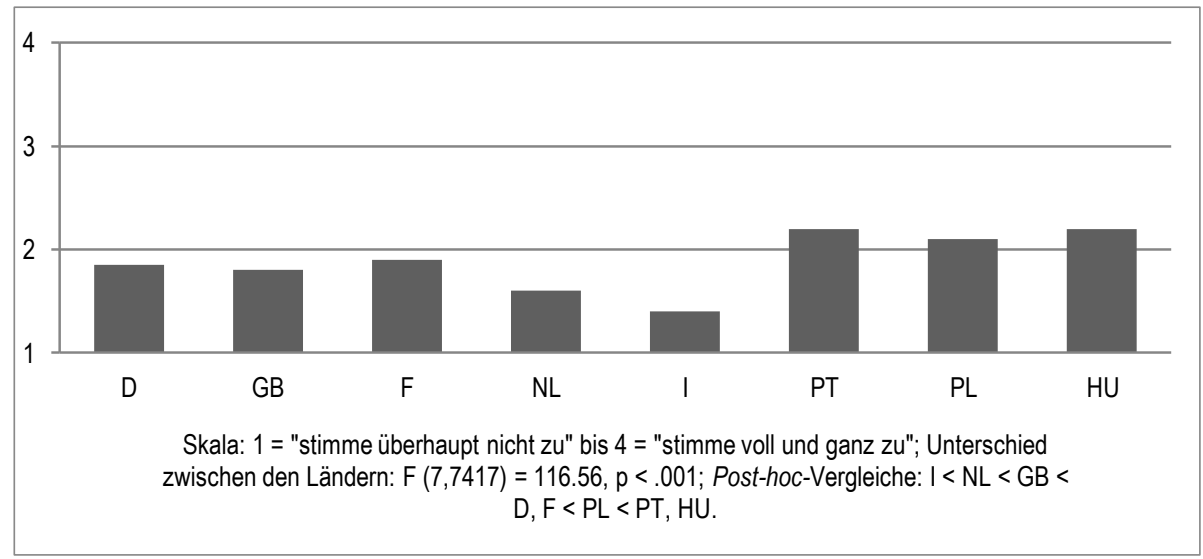

Abb. 9: Rassismus im europäischen Vergleich (Mittelwertskala) ${ }^{819}$

816 Vgl. Zick/Küpper/Hövermann 2011, a. a. O., S. 68f.

817 Vgl. Zick/Küpper/Hövermann 2011, a. a. O., S. 68f. Aufgrund der bisherigen Untersuchungserkenntnisse können die bier genannten kulturellen Differenzierungen tendenziell eher als Verschleierung der eigentlich biologistischen Argumentationsbasis rassistischer Theoreme angesehen werden, wie der folgende Verweis auf Intelligenz und Vererbung verdeutlicht.

818 Vgl. Zick/Küpper/Hövermann 2011, a. a. O., S. 68f.

819 Eigene Darstellung nach: Zick/Küpper/Hövermann 2011, a. a. O., S. 69. 
Für die Bundesrepublik Deutschland kann so eine durchweg hohe Zustimmung zu grundsätzlich biologisch-rassistischen Argumentationen festgestellt werden. Der Rassismus scheint sich in der Bundesrepublik in der Gesellschaft abermals zu manifestieren - eine potenziell gefährliche Entwicklung. Auch in den weiteren untersuchten, europäischen Staaten, allen voran Portugal, Polen und Ungarn, können ähnlich hohe bzw. höhere Zustimmungswerte zu rassistischen Einstellungsmustern identifiziert werden. ${ }^{820}$ „Rassismus grassiert signifikant am stärksten in Portugal und Ungarn, gefolgt von Polen. Auch in Deutschland und Frankreich

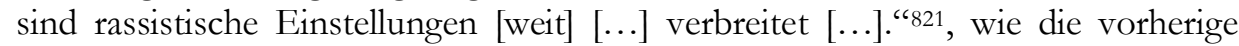
grafische Zusammenstellung demonstriert.

Als Fazit muss demzufolge eine zunehmend forcierte und gesellschaftlich weit verbreitete, gruppenbezogen menschenfeindliche Stimmung in Deutschland und Europa - zumindest in den an der Studie teilnehmenden Staaten - konstatiert werden. $^{822}$

„Abwertende Einstellungen gegenüber den bier berücksichtigten Adressatengruppen der Gruppenbezogenen Menschenfeindlichkeit sind in Europa weit verbreitet. Auffallend einig sind sich die Europäer/innen in ibrer Ablehnung von Einwanderer/innen und Muslim/innen. Hingegen unterscheiden sie sich im Ausmaß an Rassismus, Antisemitismus, Sexismus und Homophobie teilweise [...]. Die Befragten in den Niederlanden äußern sich insgesamt am wenigsten abwertend [...]. In Frankreich erfahren Fremdenfeindlichkeit und Islamfeindlichkeit im Vergleich zu den anderen Ländern weniger $Z u$ stimmung; dennoch ist das Ausmaß auch hier bemerkenswert. In Italien dagegen ist im Vergleich zu den übrigen westeuropäischen Ländern ein böheres Ausmaß an Fremdenund Islamfeindlichkeit [...] erkennbar, während Rassismus auffallend geringen $\mathrm{Zu}$ spruch erhält. In Großbritannien erreicht die Fremdenfeindlichkeit ein verhältnismäßig hohes Ausmaß. Wie auch in den Niederlanden ist der Antisemitismus dort im Vergleich zu den anderen Ländern weniger verbreitet, dennoch vertreten auch dort besorgniserregend viele Befragte antisemitische Einstellungen. In Deutschland offenbart sich ein relativ hohes Ausmaß an Islamfeindlichkeit [...] Im europäischen Vergleich fallen die osteuropäischen Länder Ungarn und Polen durch eine bohe Ablebnung aller angesprochenen Minderbeiten auf." 823

Die Diskussion über die streitbaren Thesen Thilo Sarrazins scheint folglich keine originär deutsche Debatte zu sein: „Die Sarrazin-Debatte ist kein auf Deutschland beschränktes Problem, sondern Ausdruck einer in Europa verbreiteten Gemütslage, auf die Politiker eine Antwort finden müssen. “824, so eine Schlussfolgerung des Nachrichtenportals ,Spiegel Online‘, stellvertretend für die bundesrepublikanische Mediengemeinschaft. Weiterhin muss - wie auch schon für die bundesrepublikanische Bevölkerung erörtert - nachdrücklich illustriert werden, dass die „,[...] Ab-

\footnotetext{
820 Vgl. Zick/Küpper/Hövermann 2011, a. a. O. S. 68f.

821 Zick/Küpper/Hövermann 2011, a. a. O., S. 69.

822 Vgl. Zick/Küpper/Hövermann 2011, a. a. O., S. 14f.

823 Zick/Küpper/Hövermann 2011, a. a. O., S. 75-76.

824 Spiegel Online 2011b, a. a. O.
} 
wertung und Ausgrenzung von Anderen [...] vor allem kein Phänomen von politischen Randgruppen [ist], sondern [...] sich auch in der Mitte der Gesellschaft [findet]." 825 Der Befund ist eindeutig: Die Verbreitung rassistischen Gedankenguts stellt ein gesamtgesellschaftliches Problem dar, das auch im europäischen Ausland nicht zu leugnen ist. ${ }^{826}$ Es besteht folglich nicht nur in der Bundesrepublik Deutschland, sondern nachweislich auch in weiteren Staaten der Europäischen Union ein dringender Handlungsbedarf zur Eindämmung von biologisch und vordergründig kulturell konnotierten, rassistischen und menschendiskriminierenden Einstellungen.

\subsection{Zwischenfazit: Rassismus als Alltag?}

Sowohl die qualitativen als auch die quantitativen Datensätze zeugen bezüglich biologisch-rassistischer Vorurteile und Ressentiments von einer forcierten Entwicklung in der bundesrepublikanischen Gesellschaft. ${ }^{827}$ Die vielfältigen Abgrenzungs-, Abwertungs- und Diskriminierungserscheinungen gegenüber Menschen mit Migrationshintergrund sind der statistisch fassbare Ausdruck einer Lage, deren gesellschaftlich desintegrative Einflüsse bereits spürbar sind. ${ }^{828}$ Diese vorurteilsbelasteten Einstellungen großer Teile der bundesrepublikanischen Bevölkerung bestätigen insbesondere die zahlreichen rassistischen Argumentationen, die mithilfe der qualitativen Datensätze identifiziert werden konnten (s. Kapitel 3.1, 3.2). Sowohl die Auswertung der Gruppendiskussionen als auch die Inhaltsanalyse von Thilo Sarrazins Bestseller bestätigen den enormen Zuspruch und das alltägliche Vorhandensein von fremdenfeindlichen sowie rassistischen Ressentiments. In diesem Zusammenhang zeigen sich auch biologisch-genetisch konnotierte Argumentationen als wieder präsent. Selbst der ,Rassebegriff' scheint indirekt mehr oder weniger eine Renaissance zu erlangen. Darüber hinaus bestätigen auch die quantitativ angelegten Datenmaterialien eine weitreichende gesellschaftliche Verbreitung dieser diskriminierenden Perspektiven (s. Kapitel 3.3, 3.4, 3.5, 3.6). Die ,Mitte'-Studien, die GMF-Ergebnisse, die ALLBUS-Daten sowie die Sozialberichte der Bundesrepublik quantifizieren und validieren die in den qualitativen Untersuchungen identifizierte öffentliche Wahrnehmung. Die aktuelle Zustimmung zu den Bereichen Rassismus, Fremdenfeindlichkeit, Antisemitismus oder Sozialdarwinismus ist in allen Datenmaterialien als bedenklich einzustufen: Durchschnittlich jeder fünfte Deutsche stimmt demnach fremdenfeindlichen Argumentationen

\footnotetext{
825 Spiegel Online 2011b, a. a. O.

826 Vgl. Zick, Andreas et al. (2010): „Das Projekt Gruppenbezogene Menschenfeindlichkeit in Europa. Eine kulturvergleichende Untersuchung mit einer Bevölkerungsumfrage in acht europäischen Ländern zur Abwertung und Ausgrenzung von schwachen Gruppen“, in URL: http://www.uni-bielefeld.de/\%28de\%29/ikg/projekte/GMF/index.htm <01.08.2013>.

827 Vgl. Groß/Zick/Krause 2012, a. a. O., S. 18. Angemerket werden muss nochmals die Notwendigkeit der kritischen sowie differenzierten Betrachtung der diskutierten Datensätz̨e (s. Kapitel 3). Vgl. Groß/Zick/Krause 2012, a. a. O., S. 18.
} 
zu; etwa jede zehnte Bürgerin bzw. jeder zehnte Bürger zeigt sich offen für antisemitische Aussagen; selbst sozialdarwinistische Begründungszusammenhänge erfahren in Teilen der bundesrepublikanischen Bevölkerung eine nachhaltige Zustimmung (s. Kapitel 3.3). Diskriminierende Einstellungen gegenüber ,Fremden“ sind so seit 2006 mit nur wenigen Ausnahmen deutlich im Anstieg begriffen (s. Kapitel 3.4).

Ebenfalls kann festgehalten werden, dass soziale und gesellschaftliche Konfliktlagen zunehmend ethnifiziert - bzw. ,rassifiziert ${ }^{6}$ - werden:829 Als ,Sündenbock' für wirtschaftliche und soziale Fehlentwicklungen sowie fehlende politische Lösungskonzepte stehen wieder einmal in der deutschen Geschichte ethnische Minderheiten bereit.

Auch rechtsextreme Einstellungen - als deren Grundbaustein die rassistische Ideologie zählt - sind in vielen gesellschaftlichen Gruppen etabliert (s. Kapitel 3.3). ${ }^{830}$ Kulturwissenschaftlerin Caroline Robertson-von-Trotha identifiziert diesbezüglich treffend einen ,[...] schleichende[n] Prozess der wachsenden Akzeptanz dieser Einstellungen $[. . .]^{\text {"831. }}$. Rechte und rassistische Einstellungen zeigen sich in Deutschland demnach wieder salonfähig und dürfen deshalb keinesfalls ignoriert, verharmlost oder beschönigt werden. ${ }^{832}$ Besonders gefährlich ist hierbei die nachhaltige, weite Verbreitung von rechtsextremen, rechtspopulistischen und rassistischen Einstellungen in der Mitte der bundesrepublikanischen Gesellschaft - von einem Randphänomen ist nicht mehr zu sprechen. ${ }^{83}$ Insbesondere der Erfolg der Thesen Thilo Sarrazins illustriert das Vorhandensein eines „[...] ungeheuren Reservoir[s] [...]"834 an kulturell und biologisch konnotierten, rassistischen Argumentationen in Deutschland. Vor allem die Wiederkehr zumeist verdeckter, biologistischer Vorurteile impliziert zahlreiche Erinnerungen an sozialdarwinistische, eugenische und nationalsozialistische Theoreme der deutschen Vergangenheit.

Auch die von quantitativer Seite identifizierten, intragesellschaftlichen Differenzen der rassistischen Grundeinstellungen zwischen West- und Ostdeutschland müssen als auffällig eingeordnet werden. Demnach gelten die ostdeutschen Bürgerinnen und Bürger nach den repräsentativen Datenauswertungen als tendenziell fremdenfeindlicher. ${ }^{835}$ Hintergründe und Erklärungsansätze dieser Beobachtung müssen im nachfolgenden Kapitel detailliert hinterfragt werden (s. Kapitel 4). Mit Blick auf die hier vorgestellten Ergebnisse erscheint der Befund des Sozialberichtes des Statistischen Bundesamtes 2011, nach dem es keine generelle bzw. allumfassende fremdenfeindliche und rassistische Stimmung in der Bundesrepublik

829 Vgl. Gehrs, Oliver (2012): Fremdenfeindlichkeit ist die Einstiegsdroge, in: fluter. Magazin der Bundeszentrale für politische Bildung, Frühling 2012/Nr. 42, Bonn, S. 7.

830 Vgl. Robertson-von-Trotha, Caroline Y. (2011): Rechtsextremismus in Deutschland und Europa. Einleitende Anmerkungen, in: ebd. (Hrsg.): Rechtsextremismus in Deutschland und Europa. Rechts außen - Rechts ,Mitte?, Baden-Baden, S. 13.

831 Robertson-von-Trotha 2011, ebd., S. 13.

832 Vgl. Robertson-von-Trotha 2011, ebd., S. 13 ff.

833 Vgl. Gehrs 2012, ebd., S. 5.

834 Gehrs 2012, ebd., S. 5.

835 Vgl. Blohm/Wasmer 2011, a. a. O., S. 200. 
gäbe, bestenfalls fragwürdig. ${ }^{836}$ Eventuell können diese Ergebniseinschätzungen jedoch mit der von Seiten der Politik betriebenen relativen Tabuisierung des Rassismusphänomens erklärt werden. Demnach wird hier eine beschönigende gesellschaftliche Atmosphäre vorgetäuscht, die der Realität diametral entgegensteht.

Bedenklich ist weiterhin der schleichende Politisierungsprozess rassistischer und diskriminierender Argumentationen im Rahmen des Rechtspopulismus. Auf nationalstaatlicher Ebene scheint dieser noch nicht etabliert zu sein, wohingegen sich in den europäischen Nachbarstaaten ein bedrohlicher Trend identifizieren lässt (s. Kapitel 1, 3.6, 4). Diesbezüglich kann von einem neuen Phänomen in Europa gesprochen werden, welches sich durch eine kontinuierliche Ausbreitung charakterisieren lässt. ${ }^{837}$ Hierfür sprechen ebenso die identifizierten hohen $\mathrm{Zu}$ stimmungswerte zu rassistischen, antisemitischen und fremdenfeindlichen Argumentationsmustern in ganz Europa. In diesem Zusammenhang sind insbesondere die besorgniserregenden Zustimmungswerte in Großbritannien, Italien, Polen und Ungarn zum Bereich Fremdenfeindlichkeit sowie in Polen, Portugal und Ungarn zu den Bereichen Antisemitismus und Rassismus hervorzuheben (s. Kapitel 3.6). Auch Deutschland befindet sich jeweils tendenziell im Spitzenfeld.

Weiterhin ist auch auf europäischer Ebene die Tendenz eines weit verbreiteten, neuen antiislamischen Rassismus zu konstatieren (s. Kapitel 3.4, 3.6). 838 Der ursprüngliche Anti-Gastarbeiter-Rassismus der 1950er und 1960er Jahre hat sich demzufolge über den Anti-Türken-Rassismus der 1990er Jahre zunehmend zu einem Anti-Muslime-Rassismus des 21. Jahrhunderts weiterentwickelt. ${ }^{839}$ Die muslimische Religionsgemeinschaft wird aufgrund einer angeblich mangelnden Integrierbarkeit, einer kulturell-naturalisierten sowie einer biologistischen ,Überfremdung' ihrer ,fremden' Religion abgewertet und diskriminiert. ${ }^{840}$ Das Ziel der Islamkritiker bleibt altbekannt: Die Selbstaufwertung der eigenen Gruppe mithilfe pseudowissenschaftlicher Begründungsmuster - das ursprüngliche und ureigene Rassismusprinzip. ${ }^{841}$

Ein Rückblick in die 1990er Jahre bestätigt, dass ein „[...] aktuell vorhandene [s] Potenzial fremdenfeindlicher Tendenzen und deren Hintergründe in der deutschen Gesellschaft festzustellen $[\ldots]^{\text {“842 }}$ ist. Die Bevölkerungsumfrage

Vgl. Blohm/Wasmer 2011, a. a. O., S. 205.

Vgl. Krause-Vilmar, Dietfrid (2006): „Rechtspopulismus als Herausforderung“, in URL:

http://kobra.bibliothek.uni-kassel.de / handle/urn:nbn:de:hebis:34-2006112115754 $<30.08 .2012>$.

Vgl. Shooman, Yasemin (2012): Das Zusammenspiel von Kultur, Religion, Ethnizität und Geschlecht im antimuslimischen Rassismus, in: Aus Politik und Zeitgeschichte, 16-17/2012, Bonn, S. 54.

Vgl. Shooman 2012, ebd., S. 54ff.

Vgl. Shooman 2012, ebd., S. 54ff. | Vgl. Zick/Küpper/Hövermann 2011, a. a. O., S. 145.

Vgl. Zick/Küpper/Hövermann 2011, a. a. O., S. $145 \mathrm{ff}$.

Silbermann, Alphons/Hüsers, Francis (1995): Der „normale“ Hass auf die Fremden. Eine sozialwissenschaftliche Studie zu Ausmaß und Hintergründen von Fremdenfeindlichkeit in Deutschland, München, S. 1. 
„Fremdenfeindlichkeit in Deutschland“"843 aus dem Jahr 1993 vergegenwärtigt vielfältige Parallelen zur gegenwärtigen Rassismusproblematik. Schon hier wird gefolgert, dass „,...] Fremdenfeindlichkeit in unterschiedlich starker Ausprägung für unsere Gesellschaft leider, normal" ist. "“844 Auch heute kann immer noch eine „[...] Angst vor dem Fremden [...]“"845 identifiziert werden, die als Protest gegenüber den vorherrschenden gesellschaftlichen und politischen Entwicklungen gesehen werden kann. ${ }^{846}$ Fremdenfeindlichkeit ist nichts Neues, so könnte ein Resümee aus der Perspektive des 21. Jahrhunderts lauten. ${ }^{847}$ Fremdenfeindliche Verhaltensweisen scheinen innerhalb der deutschen Gesellschaft seit den 1990er Jahren verankert zu sein - heute mehr denn je. ${ }^{848}$ Diese bieten der Entwicklung rassistischer Tendenzen eine ideale Ausgangslage. Vor diesem Hintergrund muss abschließend die Prognose des Sozialwissenschaftlers Wilfried Schubarth aus den 1990er Jahren bezüglich der weiteren gesellschaftlichen Entwicklung des Rassismusphänomens in Deutschland aus der heutigen Perspektive bestätigt werden:

„W as die Prognosen für die Zukunft betrifft, so braucht man kein Prophet zu sein, um angesichts der anbaltenden sozialen Probleme [...], der zunehmenden Wanderungsbewegungen in Europa usw. ein weiteres Anwachsen des Konfliktpotenzials zwischen Deutschen und Ausländern zu prophezeien. Ohne wirksame Konzepte in der Jugend-, Sozialund Ausländerpolitik [...], obne eine Stärkung der demokratischen politischen Kultur in Deutschland ist wobl eine Verschärfung der Probleme von Rechtsextremismus und Ausländerfeindlicbkeit, vor allem unter Jugendlichen in den neuen und alten Bundesländern nicht zu vermeiden. "849

Die vorausgegangene Datenanalyse mit der Schwerpunktsetzung auf dem biologisch konnotierten Rassismusphänomen stellt die Chancen der Kombination von sozial- und naturwissenschaftlichen Forschungsansätzen zur Identifizierung biologisch-rassistischer Einstellungen heraus. Zusammenfassend belegen die Datenmaterialien so einen , ,...] besorgniserregende[n] Lagebericht $[\ldots]^{\text {“850 }}$ der aktuellen

843 Silbermann/Hüsers 1995, a. a. O.

844 Silbermann/Hüsers 1995, a. a. O., S. 41.

845 Radtke, Frank-Olaf (1993): Multikulturalismus - Ein Gegengift gegen Ausländerfeindlichkeit und Rassismus?, in: Heßler, Manfred (Hrsg.): Zwischen Nationalstaat und multikultureller Gesellschaft. Einwanderung und Fremdenfeindlichkeit in der Bundesrepublik Deutschland, Berlin, S. 95.

846 Vgl. Demirović, Alex (1992b): Vom Vorurteil zum Neorassismus. Das Objekt „Rassismus“ in Ideologiekritik und Ideologietheorie, in: Institut für Sozialforschung (Hrsg.): Aspekte der Fremdenfeindlichkeit. Beiträge zur aktuellen Diskussion, Frankfurt/Main u. a., S. 31. Vgl. Freyberg, Thomas von (1992): Anmerkungen zur aktuellen Welle von Fremdenhass, in: Institut für Sozialforschung (Hrsg.): Aspekte der Fremdenfeindlichkeit. Beiträge zur aktuellen Diskussion, Frankfurt/Main u. a., S. 71.

848 Vgl. Demirović 1992b, ebd., S. $80 \mathrm{ff}$.

849 Schubarth, Wilfried (1993): Woher kommt der jugendliche Rechtsextremismus in Ostdeutschland?, in: Heßler, Manfred (Hrsg.): Zwischen Nationalstaat und multikultureller Gesellschaft. Einwanderung und Fremdenfeindlichkeit in der Bundesrepublik Deutschland, Berlin, S. 180181.

850 Zick/Küpper/Hövermann 2011, a. a. O., S. 12. 
gesellschaftlichen Situation in Deutschland bezüglich rassistischer Ressentiments direkt sowie auch indirekt. Ersichtlich ist insbesondere im 21. Jahrhundert die zunehmende begriffliche Verdeckung und Verschleierung vor allem von biologistisch-rassistischen Grundhaltungen, um dem gesellschaftlich etablierten Normenund Wertekanon offiziell nicht zu widersprechen. Rassistische Ausdrucksformen zeigen sich so oftmals hinter nur eingeschränkt brauchbaren Ersatztermini oder partiell verharmlosenden, kulturell konnotierten Zuschreibungen versteckt. Diese Tabuisierung des Rassismusbegriffs verfälscht jedoch zum einen dessen originäres Phänomen und verschließt zum anderen den Blick vor der gesellschaftlichen Realität. Auch die präsentierten Datenanalysen schließen sich hier größtenteils an. Rassismus scheint in der biologistischen Dimension tendenziell ansteigend vorhanden. Nichtsdestotrotz bleibt zu konstatieren, dass eine Tabuisierung rassistischer Vorurteile und Ressentiments innerhalb der bundesrepublikanischen Bevölkerung keinesfalls nutzbringend und hilfreich ist, da hiermit das Phänomen des Rassismus künstlich ausgeblendet und als nicht existent suggeriert wird. ${ }^{851}$ Dies ermöglicht der rassistischen Ideologie jedoch - direkt und indirekt - ein Anwachsen sowie eine weitgehend unbemerkte Verbreitung in vielfältigen gesellschaftlichen Sphären, ist also eher kontraproduktiv. Denn präventive Maßnahmen können aufgrund der verschleierten Verbreitung des Rassismusphänomens folglich nur suboptimal ansetzen. ${ }^{852}$ Gerade diese große Akzeptanz von Rassismus und Fremdenfeindlichkeit stellt sich somit gesellschaftlich als auch wissenschaftlich als elementares Problem dar. ${ }^{853}$

Resümierend kann insbesondere der biologistisch argumentierende Rassismus als zunehmend wieder weit verbreitetes Phänomen in der Bundesrepublik Deutschland sowie im Europa des 21. Jahrhunderts identifiziert werden. ${ }^{854}$ Insbesondere im Untersuchungszeitraum dieser Arbeit von 2007 bis 2013 kann eine deutlich ansteigende Verbreitung rassistischer Einstellungen und Verhaltensweisen bestätigt werden. ${ }^{855}$ Einen gewichtigen Anstoß erlebte in diesem Zusammenhang vor allem das offen sowie verdeckt biologistisch argumentierende Rassismusphänomen durch die Ausführungen Thilo Sarrazins, der dieses nachhaltig forciert hat. ${ }^{856}$ Sein - um kritisch mit den Worten des Politikwissenschaftlers Christoph Butterwegge zu sprechen - „[...] erfolgreichste[s] Sachbuch des Jahrzehnts $[\ldots]^{\text {‘657 }}$ steht wie kein anderes Werk für die Regeneration und Re-Etablierung

851 Vgl. Geyer, Oliver (2012): Du Grammatik-Hitler, in: fluter. Magazin der Bundeszentrale für politische Bildung, Frühling 2012/Nr. 42, Bonn, S. 17.

852 Vgl. Blohm/Wasmer 2011, a. a. O., S. 202.

853 Vgl. Robertson-von-Trotha 2011, a. a. O., S. 13.

854 Vgl. Süddeutsche Zeitung (2011): „Studie. Europas Sehnsucht nach dem ,starken Mann““, in URL: http://www.sueddeutsche.de/ politik/studie-europas-sehnsucht-nach-dem-starkenmann-1.1070820<25.08.2011>.

855 Vgl. Groß/Zick/Krause 2012, a. a. O., S. 15.

856 Vgl. Blohm/Wasmer 2011, a. a. O., S. 200.

857 Butterwegge, Christoph (2013): Sarrazynismus. Eine Katastrophe für die politische Kultur der Bundesrepublik und eine Gefahr für die Demokratie, in: Bathke, Peter/Hoffstadt, Anke 
biologistischer sowie naturalistischer Ressentiments auf sozialer Ebene. Hierzu instrumentalisiert und dramatisiert er die Sorgen und Ängste der Bürgerinnen und Bürger aufgrund von Finanz-, Wirtschafts- und Eurokrise, um Sozialdarwinismus und Rassismus den Weg in die Gegenwart zu ebnen. ${ }^{858}$ Aufgrund dieser manifestierten Vorurteilsstrukturen bestätigen beispielsweise über ein Drittel der europäischen Bürgerinnen und Bürger die Überlegenheit von hell pigmentierten gegenüber dunkel pigmentierten Menschenpopulationen - ein exemplarischer Beweis für die Re-Etablierung biologisch-genetischer Misskonzepte. ${ }^{859}$ Gewarnt werden muss folglich vor einer eindeutigen Gefahr dieser zunehmend rassistischen Grundeinstellung innerhalb der europäischen Bevölkerung: ${ }^{600}$ „Darauf verweisen auch die starken, einstellungsbasierten Diskriminierungsabsichten, die vor allem in Deutschland [...] auffallen."861 Dies offenbart einen bedrohlichen, gesellschaftlichen Entwicklungstrend auf gesamteuropäischer Ebene, so dass auch die Etablierung neuer politischer Organisationen mit rassistischem Hintergrund in Deutschland in Zukunft möglich erscheint.

(Hrsg.): Die neuen Rechten in Europa. Zwischen Neoliberalismus und Rassismus, Köln, S. 206.

858 Vgl. Butterwegge 2013, a. a. O., S. $217 f$.

859 Vgl. Süddeutsche Zeitung 2011, a. a. O.

860 Vgl. Zick/Küpper/Hövermann 2011, a. a. O., S. 188.

861 Zick/Küpper/Hövermann 2011, a. a. O., S. 195. 



\section{Phänomenologie des gegenwärtigen Rassismus}

Die vorhergehenden Kapitel haben mithilfe multiperspektivischer Untersuchungsdaten verdeutlicht, dass rassistische Einstellungen in weiten Teilen der bundesrepublikanischen Gesellschaft - insbesondere die als überwunden geglaubten biologisch-genetischen Erklärungsmodelle - wieder fest verwurzelt sind. ${ }^{862}$ Seit den 1990er Jahren - der ,[...] Hochphase des erneuten Erstarkens der gegenwärtigen Form von Rassismus $[\ldots]$ in Deutschland $[\ldots]^{\text {"863 }}$ - ,[...] hat sich ein Rassismus aufgebaut, der scheinbar der Vergangenheit angehörte." ${ }^{864}$ Keinesfalls kann hier einschränkend von einem Randphänomen gesprochen werden, sondern von Vorurteilen und Ressentiments, welche in vielen gesellschaftlichen Sphären präsent sind (s. Kapitel 3). Jürgen Trittin von Bündnis 90/Die Grünen warnte in diesem Zusammenhang schon in den 1990er Jahren vor einer neuen ,[...] Welle der Gewalt $[\ldots]^{\text {“865 }}$ - die im Jahr 2011 aufgedeckte rechtsextreme, rassistische

862 Vgl. Arndt, Susan (2001c): Vorbemerkung, in: ebd. (Hrsg.): AfrikaBilder. Studien zu Rassismus in Deutschland, Münster, S. 10f.

863 Bojadžijev 2008, a. a. O., S. 25.

864 Müller, Jost (1992): Rassismus und die Fallstricke des gewöhnlichen Antirassismus, in: Redaktion diskurs (Hrsg.): Die freundliche Zivilgesellschaft. Rassismus und Nationalismus in Deutschland, Berlin u. a., S. 25.

865 Trittin, Jürgen (1993): Gefahr aus der Mitte. Die Republik rutscht nach rechts, Göttingen, S. 62. 
Mordserie der sogenannten Zwickauer Terrorzelle geben Trittin heute tendenziell recht. 866

Folglich muss eine Analyse der Phänomenologie und der Erklärungsansätze des gegenwärtigen Rassismusphänomens auch an der Gesamtheit der deutschen Gesellschaft ansetzen: „Da Rassismus in der bundesdeutschen Gesellschaft fest verwurzelt ist, kann eine Debatte darüber eben auch nur unter Einbeziehung der gesamten Gesellschaft wirksam geführt werden [...]“867. Die folgenden Kapitel untersuchen die multiplen Erklärungs- und Ursachenfaktoren des neueren Rassismus ,in altem Gewand' im 21. Jahrhundert unter verschiedenen Perspektiven. Welche Faktoren haben zur Renaissance der biologistisch-rassistischen Ressentiments in der Bundesrepublik Deutschland geführt? Welche Bedeutung kommt politischen, wirtschaftlichen sowie gesellschaftlichen Akteuren zu? Welche Rolle spielen nationale, supra- und internationale Entwicklungen, die die Ausgestaltung nationalpolitischer Entscheidungen nachhaltig beeinflussen?

Doch warum überhaupt eine Analyse der Entstehungsbedingungen des Rassismusphänomens im Rahmen der Erforschung des heutigen, wieder zunehmend biologistisch konnotierten Rassismuskonstrukts? Diese ist elementar notwendig, da erst auf der Grundlage umfassender Kenntnisse, die Hintergründe der Entwicklung des bundesrepublikanischen Rassismus betreffend, eine Diagnose des heutigen Rassismusphänomens ermöglicht wird. Nur auf der Basis des Verständnisses der ursächlichen Entstehungsfaktoren rassistischer Ausformungen kann das aktuelle Rassismuskonstrukt detailliert und korrekt analysiert werden. Vor diesem Hintergrund ist eine Analyse der Entstehungs- und Erklärungsansätze des Rassismusphänomens der Gegenwart im Rahmen dieser Arbeit unerlässlich.

Aus dem 21. Jahrhundert existieren bisher vornehmlich Untersuchungen, die sich im Rahmen der Diskussion bezüglich einer modernisierten Einwanderungsgesetzgebung mit den historischen und neueren Entwicklungslinien der bundesrepublikanischen Migrations- und Ausländerpolitik beschäftigen. Selbstverständlich berühren diese ebenfalls den Themenbereich des Rassismusphänomens in Deutschland, der die zum Teil sehr emotionalisierte Debatte um die Einwanderung nach Deutschland intensiv begleitet. Direkte Forschungsansätze zu den Hintergründen des heutigen Rassismusphänomens sind bisher jedoch nur ansatzweise vorhanden. Auch vor diesem Hintergrund füllt diese Untersuchung so im weiteren Verlauf eine Forschungslücke.

Eine eindeutige Differenzierung in kulturalistische sowie biologistische Erklärungsmodelle gestaltet sich komplex, da beide Modelle voneinander abhängig sind

866 Dies bestätigen auch partiell die Daten des Bundesamtes für Verfassungsschutz, die einen Anstieg der rechtsextremistischen Kriminalität identifizieren. Der Verfassungsschutzbericht 2011 konstatiert einen Anstieg der rechtsextremistisch motivierten Straftaten um 1,5 Prozent, lediglich der Anteil der rechtsextremistisch motivierten Gewalttaten sank. um 1,0 Prozent. 46,4 Prozent der Gewalttaten wiesen dabei einen fremdenfeindlichen Hintergrund auf - ein Anstieg um 22,8 Prozent im Vergleich zum Jahr 2010. Der Anteil der Straftaten mit antisemitischem Hintergrund blieb indessen mit 1162 Straftaten gleich hoch. Vgl. Bundesministerium des Innern (2012): Verfassungsschutzbericht 2011. Vorabfassung, Berlin, S. $27 \mathrm{ff}$. 
und sich vielfach beeinflussen (s. Kapitel 2, 3). Trotzdem soll der Schwerpunkt auch im weiteren Verlauf auf den Erklärungsansätzen und Entwicklungslinien der biologisch-genetischen Rassismusargumentationen liegen. Nichtsdestotrotz erschwert dies den folgenden Forschungsansatz, so dass nachstehend eine äußerst bedachte Verwendung dieser Begrifflichkeiten erfolgen muss (s. Kapitel 2).

Von Seiten der Politikwissenschaft bietet sich methodisch eine text- bzw. literatur- und inhaltsanalytische Vorgehensweise an, um mithilfe des vorhandenen Forschungsmaterials einen Erklärungsansatz für das Rassismusphänomen des 21. Jahrhunderts zu erstellen. Dieser ermöglicht Rückschlüsse auf die gesellschaftliche bzw. soziale Realität. Grundlegend ist in diesem Zusammenhang ebenfalls ein historischer Rückblick auf die bundesrepublikanische Ausländerpolitik, um deren Bedeutung für die Renaissance der rassistischen Ideologie im 21. Jahrhundert offen zu legen: „Eine Rassismusanalyse [kann] nicht umhin, den historischen Prozess zu berücksichtigen $[\ldots]^{\text {"868 }}$. Mit integriert werden muss darüber hinaus die Sonderstellung der Deutschen Demokratischen Republik (DDR), in der am Vorabend der Wiedervereinigung „Ausländerfeindlichkeit [...] nicht mehr aus den Schlagzeilen $[\ldots]^{\text {“6869 }}$ geriet.

Zur Sicherung einer strukturierten, verständlichen und transparenten Vorgehensweise wird in den weiteren Kapiteln eine weitgehende Differenzierung der Themenbereiche Politik, Wirtschaft und Gesellschaft angestrebt. Eine eindeutige Trennung der Erklärungsansätze scheint aufgrund deren multiplen Vernetzung jedoch schwierig.

Vor dem Hintergrund der verwendeten Literatur, wird in den folgenden Kapiteln schwerpunktmäßig auf Forschungsdokumentationen sowie empirische Studien der 1990er Jahre zurückgegriffen, die sich im Zusammenhang mit dem hier verbreiteten sogenannten Neorassismus teilweise mit möglichen Entstehungsansätzen der rassistischen Ideologie beschäftigen. Hierbei kann vor allem auf Forschungsergebnisse von Klaus J. Bade, Étienne Balibar, Friedrich Balke, Uli Bielefeld oder Edith Bronzinsky-Schwabe zurückgegriffen werden. ${ }^{870}$ Eine dezidierte Analyse von Erklärungsstrukturen des gegenwärtigen, tendenziell wieder biologistischen Rassismusphänomens fehlt jedoch bisher weitgehend bzw. ist nur vereinzelt vorhanden. Diesbezüglich kann lediglich auf Teilergebnisse der genannten Autoren zurückgegriffen werden, da diese sich mit dem Rassismusphänomen des 21. Jahrhunderts größtenteils nur am Rande beschäftigen. In diesem Zusammenhang muss das Forschungsmaterial der 1990er Jahre neu modifiziert und an den

\footnotetext{
868 Bojadžijev 2008, a. a. O., S. 15.

869 Krüger-Potratz, Marianne/Jasper, Dirk (1991): Vorwort, in: Krüger-Potratz, Marianne (Hrsg.): Anderssein gab es nicht. Ausländer und Minderheiten in der DDR, Münster u. a., S. I.

870 Weiterbin bieten sich auch die Forschungsansätze von Klaus Farin, Colette Guillaumin, Manfred Heßler, Siegfried Jäger, Annita Kalpaka, Sanem Kleff, Ute Knight, Wolfgang Kowalsky, Marianne Krüger-Potrat\%, Claus Leggewie, Reinhard Lobrmann, Nora Räthzel, Irene Runge, Barbara Veit oder Hans-Otto Wiebus an. Für die jeweils detaillierten Literaturangaben wird auf die umfangreichen Hinweise im Literaturverzeichnis vermiesen.
} 
hier fokussierten Untersuchungszeitraum angepasst werden, um es auf das heutige Rassismuskonstrukt anwenden zu können.

Zur strukturierten und transparenten Auseinandersetzung mit dem skizzierten Forschungsbereich soll die Gliederung beitragen, die auch die methodische Vorgehensweise unterstützt. Im ersten Teil werden schwerpunktmäßig die vielfältigen politischen Erklärungsansätze und Hintergründe der heutigen rassistischen Vorurteile und Ressentiments untersucht, die zum Teil bis zur Gründung der Bundesrepublik Deutschland zurückreichen. Hieran schließen sich im weiteren Verlauf die Analysen von wirtschaftlichen und gesellschaftlichen Faktoren sowie ein umfassendes Zwischenfazit an.

Vorausblickend kann schon kritisch festgestellt werden, dass „[d]as Thema ,Ausländer [seit den 1980er Jahren] [...] im Brennpunkt heftiger gesellschaftspolitischer Auseinandersetzung[en] [...]“871 steht - auch in der Gegenwart. Im Fokus der folgenden Kapitel steht so die Fragestellung nach den Hintergründen, die zum Wiedererstarken des zunehmend biologistisch konnotierten Rassismus im heutigen Deutschland führten. Mit anderen Worten soll es um die Beantwortung der Frage gehen, welche Charakteristika für die Verbreitung rassistischer Vorurteile gegenüber Fremden als ursächlichen zu gelten haben. Die Beantwortung dieser Frage ist umso wichtiger, als sich rassistische Vorurteile gegenüber ,Fremden wieder großflächig ausbreiteten, die nach den fremdenfeindlichen Übergriffen im Zuge der deutschen Wiedervereinigung in den Jahren 1990 bis 1996 eigentlich als ,besiegt' galten. ${ }^{872}$

\subsection{Rassismus im politischen Alltag?}

Das folgende Kapitel konzentriert sich auf die politische Ebene und deren Beteiligung an wiedererstarkenden biologisch-genetischen Argumentationsmustern des Rassismus in Deutschland. Dieser zeigt sich an mehr oder weniger offenen rassistischen Ressentiments in vielen Bereichen der deutschen Gesellschaft verbreitet und geht weit über die sogenannte Fremdenfeindlichkeit hinaus: Ausgrenzung und Abwertung von ,Fremden' scheinen alltäglich (s. Kapitel 3). Welche Bedeutung und Beteiligung hat die politische Arena am bundesrepublikanischen Rassismusphänomen des 21. Jahrhunderts? Existieren Zusammenhänge zwischen dem wiedererstarkenden Rassismus und spezifischen, politischen Entscheidungen? Wie schon illustriert, ist für eine ursächliche Analyse ein theoretisch-empirischer Überblick über die gegenwartsbezogenen Entwicklungen der Ausländer-, Migrationsund Einwanderungspolitik Deutschlands unerlässlich, da die direkt und indirekt gezeigten biologisch-rassistischen Tendenzen innerhalb der bundesrepublikanischen Bevölkerung eine längere Entwicklungsgeschichte durchlaufen haben müs-

871 Knight, Ute/Kowalsky, Wolfgang (1991): Deutschland nur den Deutschen? Die Ausländerfrage in Deutschland, Frankreich und den USA, 2. Auflage, Erlangen u. a., S. 8.

872 Vgl. Finkelstein, Kerstin E. (2006): Eingewandert. Deutschlands Parallelgesellschaften, Bonn, S. 20. 
sen. ${ }^{873}$ Denn Rassismus entwickelt sich nicht einfach zufällig - aufgrund der belasteten Geschichte schon gar nicht in Deutschland -, sondern wird durch vielfältige Entstehungs- und Entwicklungsfaktoren beeinflusst und forciert. Der Historiker Ulrich Herbert folgert korrekt, dass ,,[o]hne die Auseinandersetzung mit den kollektiven Erfahrungen, die eine Gesellschaft in der Vergangenheit mit [...] Ausländern gemacht hat, [...] die Art und Weise des Umgangs mit Ausländern in der Gegenwart nicht zu verstehen [ist].“"874 Dies unterstützt ebenfalls Manuela Bojadžijev: ${ }^{875}$

„Für ein Verständnis der Konjunkturen des Rassismus und [...] der Migration sind die Kämpfe und Praktiken der Migrantinnen und Migranten und ibre Geschichte konstitutiv."

Rassismus gilt insbesondere in der Ausländer- und Migrationspolitik der Bundesrepublik Deutschland als „,[...] ein merkwürdig beschwiegenes Thema.“877 Meist wird dieser Problembereich in der politischen Debatte mit beschönigenden Begriffen, wie ,Diskriminierung ${ }^{6}$,Ausländerfeindlichkeit ${ }^{\star}$ oder ,Fremdenfeindlichkeit', umschrieben (s. Kapitel 2). ${ }^{878}$ Bis in die 1990 er Jahre galt die den Rassismus betreffende Ursachenforschung in Deutschland aufgrund der einzigartigen historischen Belastung als ,tabu' ${ }^{879}$ Diese politische Vorgehensweise kann als fragwürdig angesehen werden, da „Seit fast drei Jahrzehnten [...] die Debatte um die Ausländerpolitik die innenpolitische Auseinandersetzung in Deutschland wie kein anderes Thema [bestimmt]." 880 Die rassistische Fragestellung nach einer möglichen Bedrohung durch die Einwanderung von ,andersartigen' Zugezogenen mit Migrationshintergrund zeigt sich so schon seit etwa 120 Jahren als politisch aktuelle Debatte. ${ }^{881}$ Insbesondere die pseudobiologische Komponente der angeblichen

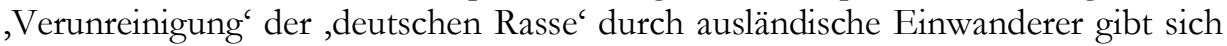
als quasi zeitlos.

Im weiteren Verlauf muss weiterhin die Einbindung der Bundesrepublik Deutschland in das Staatenbündnis der Europäischen Union beachtet werden, welches zusätzlich zahlreiche Einflüsse auf die rassistischen Strömungen innerhalb der bundesrepublikanischen Bevölkerung bewirkt. Denn vor allem im 21. Jahrhundert spielt die Europäische Union im politischen und gesellschaftlichen Alltag aufgrund forcierter Kompetenzen - ausgelöst durch die angestiegene Abgabe von nationalen Souveränitätsrechten - eine entscheidende Rolle. Abschließend darf ebenfalls die Integration der Migrationsdebatte in der Bundesrepublik, insbesondere um die Anerkennung Deutschlands als Einwanderungsland, nicht fehlen.

\footnotetext{
873 Vgl. Herbert 2003, a. a. O., S. 10 f.

874 Herbert 2003, a. a. O., S. 10.

875 Vgl. Bojadžijev 2008, a. a. O., S. 285.

876 Bojadžijev 2008, a. a. O., S. 285.

877 Bojadžijev 2008, a. a. O., S. 89.

878 Vgl. Bojadžijev 2008, a. a. O., S. 90.

879 Vgl. Kalpaka/Räthzel 1994c, a. a. O., S. 18.

880 Herbert 2003, a. a. O., S. 9.

881 Vgl. Herbert 2003, a. a. O., S. 9.
} 
Denn diese kann auch heute noch als Kristallisationspunkt biologistischer sowie kulturalistischer, rassistischer Argumentationen identifiziert werden. Für eine detaillierte Analyse der Phänomenologie und der Erklärungsansätze zeigt sich dies folglich als unbedingt notwendig.

\subsubsection{Ausländerpolitik Deutschlands: Vergangenheit und Gegenwart}

Ausländer-, Einwanderungs-, Migrations- und Integrationspolitik stehen, wie das Rassismusphänomen, schon seit vielen Jahren auf der politischen und gesellschaftlichen Agenda. Dies gilt insbesondere für die 1960er Jahre im Rahmen der sogenannten Gastarbeiterdebatte, für die 1990er Jahre vor dem Hintergrund der diskutierten Anerkennung Deutschlands als Einwanderungsland sowie aktuell für die durch die Wirtschafts-, Finanz- und Eurokrise ausgelösten Unsicherheiten. Die Vorgehensweise der Politik und das Phänomen des Rassismus müssen deshalb in einem mehr oder weniger direkten Zusammenhang stehen. Erste deutsche und europäische Rassismusdiskussionen lassen sich bis in das Zeitalter des Kolonialismus zurückverfolgen, der einen Grundstein für den europäischen Rassismus legte: 882, „[...] der Kolonialismus [wäre] ohne Rassismus nicht denkbar gewesen

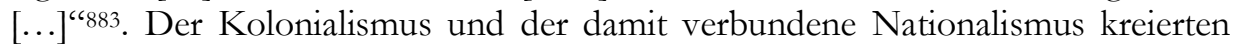
im 19. Jahrhundert sowohl den ,Rassebegriff', als auch den originären, pseudobiologisch begründeten Rassismus (s. Kapitel 2.1.2, 5.2). ${ }^{884}$ Mithilfe des Rassismus konnten die Kolonialisierungsbestrebungen mit dem Hinweis auf eine „zivilisatorische Mission" 885 legitimiert werden. Aufgrund dessen war schon lange vor der Gründung der Bundesrepublik Deutschland im Jahr 1949 auf deren gegenwärtigem Territorium das Phänomen des biologistischen Rassismus in Politik und Gesellschaft präsent. Im Unterschied zum heutigen politischen Alltag war der ,Rassebegriff' in Zeiten der Kolonialisierung nachhaltig etabliert - heute ist er zwar im Rahmen des zurückkehrenden, biologisch konnotierten Rassismusphänomens zumeist wieder indirekt vorhanden, jedoch im öffentlichen sowie gesellschaftlichen Leben ,[...] weitgehend tabu.“"886

Nach der Gründung der Bundesrepublik Deutschland galt der Rassismus als elementares Element des Nationalsozialismus und wurde in seiner gegenwärtigen Relevanz eher verdrängt. Aufgrund der Ereignisse und traumatischen Erfahrungen des Zweiten Weltkrieges schien er aus den Köpfen der bundesrepublikanischen Bevölkerung verbannt. Spätestens die Flüchtlingsbewegungen der Nachkriegszeit sowie die zunehmende Beschäftigung von ausländischen Fachkräften in deutschen Industrieunternehmen ließen jedoch die als nicht mehr existent gelten-

\footnotetext{
882 Vgl. Trittin 1993, a. a. O., S. 70.

883 Arndt, Susan (2001b): Impressionen. Rassismus und der deutsche Afrikadiskurs, in: ebd. (Hrsg.): AfrikaBilder. Studien zu Rassismus in Deutschland, Münster, S. 15.

884 Vgl. Guillaumin 1992, a. a. O., S. $81 \mathrm{f}$.

885 Cohen 1994, a. a. O., S. 91.

886 Räthzel 1992, a. a. O., S. 8.

Die heutige Perspektive beschränkt sich auf den Zeitraum von 2007 bis 2013 (s. Kapitel 1.2).
} 
de, rassistische Fremdenfeindlichkeit wieder erstarken. ${ }^{887}$ Vor diesem Hintergrund ist nach einer ,Tradition des Rassismus' in Deutschland zu fragen. 888 Die Ära der sogenannten Gastarbeiterinnen und Gastarbeiter ab den 1960er Jahren könnte als rassistische Kontinuität, als rassistische Fortsetzung der deutschen Ausländerpolitik identifiziert werden, anknüpfend an die vorwiegend zwangsverpflichteten, polnischen Land- und Industriearbeiter durch Deutschland vor 1933.889 Auch diese Importe von ausländischen Arbeitskräften waren seitens der deutschen Bevölkerung von Diskriminierung, Abwertung und Ausgrenzung geprägt, da hier meist einfache, weniger komplexe Arbeiten vergeben wurden. Unterbrochen wurde diese ,kontinuierliche' Ausländerpolitik lediglich durch die nationalsozialistische, radikalisierte und menschenverachtende Terrormaschinerie, die ein Zwangsarbeitersystem gegenüber „niedere[n] Rassen“890 etablierte. ${ }^{891}$ Letzte Reste dieser verachtenden Terrormaschinerie sind noch bis heute im politischen Alltag der Bundesrepublik Deutschland präsent, da die Entschädigungsfrage von ehemaligen Zwangsarbeiterinnen und Zwangsarbeitern immer noch nicht gänzlich gelöst ist, dieser Teil der deutschen Geschichte somit noch nicht endgültig abgeschlossen werden kann - eine für die Bundesrepublik Deutschland schwierige Hypothek. ${ }^{892}$

Wie kam es zu diesem Anstieg an ausländischen Arbeitskräften in den Anfangsjahren der Bundesrepublik und damit verbunden zur Wiederkehr des rassistisch motivierten Fremdenhasses sowie des offenen biologisch begründeten Rassismus? Nach dem Ende des Zweiten Weltkrieges 1945 und der nachfolgenden Gründung der Bundesrepublik Deutschland 1949 konnten zunächst heimkehrende Flüchtlinge und Vertriebene die Arbeitskräftelücke in Deutschland füllen, die durch die im Kriegsverlauf gefallenen Bürger im arbeitsfähigen Alter entstanden war. 893

\section{„Mehr als $90 \%$ des Bevölkerungszuwachses zwischen 1950 und 1960 entfallen auf die Zuwanderung von Flüchtlingen und Vertriebenen, die 1960 fast ein Viertel der Ge- samtbevölkerung der Bundesrepublik ausmachten. " 894}

In der Folge konnten in der noch jungen Bundesrepublik zwar riesige ökonomische Wachstumsraten erzielt werden - die Zeit des sogenannten,Wirtschaftswunders $^{6}$-, einher ging dies jedoch mit einer zunehmenden Abwehrreaktion und Feindseligkeit gegenüber den Einwanderern. ${ }^{895}$ Nichtsdestotrotz kann man dies-

Vgl. Ganßloser, Dagmar (1992): „Wir riefen Arbeitskräfte, es kamen Menschen“. Migrationspolitik und verschärftes Ausländergesetz in der BRD, Berlin u. a., S. 45ff.

Vgl. Frankenberg, Günter (1992): Drinnen vor der Tür. Stichworte zur Asyldebatte, in: Institut für Sozialforschung (Hrsg.): Aspekte der Fremdenfeindlichkeit. Beiträge zur aktuellen Diskussion, Frankfurt/Main u. a., S. $91 \mathrm{ff}$.

Vgl. Herbert 2003, a. a. O., S. 184.

Herbert 2003, a. a. O., S. 187.

Vgl. Herbert 2003, a. a. O., S. $187 f$.

Vgl. Herbert 2003, a. a. O., S. 189.

Vgl. Herbert 2003, a. a. O., S. 193.

Herbert 2003, a. a. O., S. 193.

Vgl. Herbert 2003, a. a. O., S. $195 \mathrm{ff}$. 
bezüglich nicht von Rassismus bzw. einer ,rassischen' Abwehr sprechen, da die zahlreichen Flüchtlinge und Vertriebenen aufgrund der deutschen Sprache - in Anlehnung an biologisch-rassistische Argumentationsschemata - noch als ,Deutsche' anerkannt wurden. ${ }^{896}$

Erst im Zuge der politisch initiierten Aufnahme von sogenannten ausländischen Gastarbeiterinnen und Gastarbeitern zur Deckung des enorm angewachsenen Arbeitskräftebedarfs der bundesrepublikanischen Wirtschaft, entwickelten sich aus zunächst zurückhaltenden Abwehrtendenzen offene und direkte rassistische Ausgrenzungs- und Abwertungserscheinungen. Auch die Regierungsebene hatte der Aufnahme von ausländischen Gastarbeitern lediglich unter der Annahme zugestimmt, dass diese per Rotationsprinzip jeweils nur für kurzzeitige wirtschaftliche Aushilfsmaßnahmen in der Bundesrepublik verweilen sollten. ${ }^{897}$ Vor diesem Hintergrund kann auch auf der politischen Ebene eine eher ambivalente und für die Gesamtbevölkerung wenig vorbildliche Haltung festgestellt werden. Ob diesbezüglich von rassistischen Tendenzen gesprochen werden kann, sei dahingestellt. Das nicht einkalkulierte Problem bestand jedoch darin, dass viele Arbeitsmigrantinnen und Arbeitsmigranten keine Anstrengungen zur Rückkehr in ihre Heimatländer unternahmen. ${ }^{898}$ Insbesondere die türkischen Einwanderer waren danach bestrebt in Deutschland zu bleiben. ${ }^{899}$

„[...] die Mebraabl der hier lebenden Ausländer [kann oder will] keinen konkreten Zeitpunkt für die beabsichtigte Rück.kehr nennen [...]. Analysen von Hierbleibeabsichten und Rückkehrwünschen von Türken zeigen, dass, wie auch bei anderen ausländischen Arbeitsmigranten, zwischen der bei der Einreise in die BRD [Bundesrepublike Deutschland] geplanten Aufenthaltsdauer, die 2/3 der Migranten auf böchstens fünf Jahre veranschlagt hatten, und der tatsächliche Zeitspanne, während der sie sich in der Bundesrepublik aufhalten, eine beträchtliche Diskrepanz besteht. "90o

Das sich hieraus ergebende, langfristige Problem des Daueraufenthaltes der sogenannten Gastarbeiterinnen und Gastarbeiter war jedoch von der Politik nicht beachtet worden, da von deren Seite nur ein kurzfristiger Einsatz der ausländischen Arbeitskräfte als ,Konjunkturpuffer' eingeplant war. ${ }^{901}$ Der Begriff ,Gastarbeiter‘ war für die Politik demnach Name und Botschaft zugleich: „[...] denn

896 Vgl. Herbert 2003, a. a. O., S. 197.

897 Vgl. Matter, Max (1987): Fremde im eigenen Land. Zur Situation türkischer Arbeitnehmer und ihrer Familien nach der Rückkehr aus der Bundesrepublik Deutschland, in: Kuntz, Andreas/Pfleiderer, Beatrix (Hrsg.): Fremdheit und Migration, Berlin u. a., S. 221.

898 Vgl. Matter 1987, ebd., S. 232.

Die kurze Aufenthaltsdauer war jedoch auch von vielen Arbeitgebern nicht gewollt, die auf die angelernten ausländischen Arbeitskerätte nicht verzichten wollten.

899 Vgl. Matter 1987, ebd., S. 232.

$900 \quad$ Matter 1987, ebd., S. 222.

901 Vgl. Bade, Klaus J. (1992b): Einheimische Ausländer: ,Gastarbeiter ${ }^{\star}$ - Dauergäste - Einwanderer, in: ebd. (Hrsg.): Deutsche im Ausland - Fremde in Deutschland. Migration in Geschichte und Gegenwart, München, S. 394f. 
,Gast" ist nur, wer nicht auf Dauer bleibt.“"902 Vor diesem Hintergrund lässt sich zumindest eine Mitverantwortung der politischen Arena an den ansteigenden fremdenfeindlichen sowie offen rassistischen Tendenzen im Zuge der Einwanderung von Arbeitsmigrantinnen und -migranten konstatieren. Denn selbst ein Großteil der politischen Ebene stand einer dauerhaften Ansiedlung von Einwanderern in der Bundesrepublik Deutschland ablehnend gegenüber.

Die ersten Planungen des Bundeswirtschaftsministeriums zu einem gesteuerten Ausländerzuzug waren ursächlich „[...] prophylaktische Überlegungen $[. . .]^{“ 903}$ für den Fall eines Arbeitskräftemangels, da die Arbeitslosigkeit in der Mitte der 1950er Jahre noch bei durchschnittlich 5,1 Prozent lag. ${ }^{904}$ Erst im November 1955 kam es dann in Rom zum ersten deutsch-italienischen Anwerbeabkommen, welches eine kurzfristige Versorgung der deutschen Landwirtschaft mit italienischen Arbeitskräften zum Ziel hatte. ${ }^{905}$ Die ausländischen Arbeitskräfte waren nun sozialpolitisch mit den bundesrepublikanischen Arbeitnehmerinnen und Arbeitnehmern gleichgestellt - eine für viele Bürgerinnen und Bürger der Bundesrepublik Deutschland inakzeptable Entscheidung, die die rassistischen Tendenzen innerhalb der Gesellschaft nachdrücklich verstärkte. ${ }^{906}$ Andererseits wurde insbesondere bei der Begrüßung des millionsten sogenannten Gastarbeiters in der Bundesrepublik angemerkt, dass die ausländischen Arbeitnehmerinnen und Arbeitnehmer im Vergleich zur Zeit vor 1945 keine „[...] volkstumspolitischen Nachteile

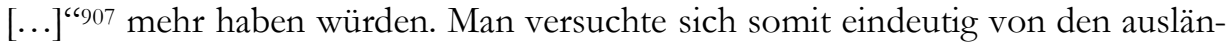
derpolitischen Agitationen der nationalsozialistischen Vergangenheit zu distanzieren, um die bundesrepublikanische Ausländer- und Migrationspolitik für einen gesellschaftlich und international beachteten Neuanfang auszurichten. ${ }^{908}$

Offene fremdenfeindliche und rassistische Gewalt zeigte sich mit dem erstmaligen Wirtschaftsrückgang seit der Gründung der Bundesrepublik Deutschland in den Jahren 1966 und 1967, in dessen Verlauf Befürchtungen nach einer „,...] Renaissance des Rechtsextremismus [...] “909 in der Bundesrepublik bestätigt wurden. ${ }^{910}$ Obwohl die ausländischen Arbeitnehmerinnen und Arbeitnehmer durch den schnellen Rückgang der ökonomischen Rezession ihre Stellung als „,[...] kon-

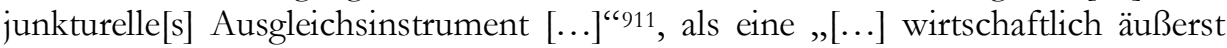

902 Bade 1992b, a. a. O., S. 394.

903 Herbert 2003, a. a. O., S. 202.

904 Vgl. Herbert 2003, a. a. O., S. $202 \mathrm{ff}$.

905 Auf das italienische Anwerbeabkommen folgten in zeitlicher Nähe Anwerbeabkommen mit Griechenland und Spanien (1960), der Türkei (1961), Portugal (1964) und Jugoslawien (1968). Politisch und gesellschaftlich existierte zu diesem Zeitpunkt noch keine öffentliche Debatte, da die ausländischen Arbeitsmigrantinnen und Arbeitsmigranten als unumstrittene Bedingung für eine weiterbin wachsende bundesrepublikeanische Wirtschaft angesehen wurden. Vgl. Herbert 2003, a. a. O., S. 208.

906 Vgl. Herbert 2003, a. a. O., S. 206.

907 Herbert 2003, a. a. O., S. 211.

908 Vgl. Herbert 2003, a. a. O., S. 211.

909 Herbert 2003, a. a. O., S. 200.

910 Vgl. Herbert 2003, a. a. O., S. $220 \mathrm{ff}$.

911 Herbert 2003, a. a. O., S. 220. 
flexibel einsetzbar[e] Reservearmee $[\ldots]^{\text {“ } 912}$ bestätigten, entstanden in der bundesrepublikanischen Gesellschaft neue Ängste vor ansteigender Arbeitslosigkeit, einer zu starken Konkurrenz durch die sogenannten Gastarbeiterinnen und Gastarbeiter sowie auch altbekannte Vorurteile, wie die angebliche Gefahr einer zunehmenden Überfremdung der bundesrepublikanischen Gesellschaft.913 Dieser - durch eine fehlgeleitete und suboptimal organisierte Wirtschafts- und Ausländerpolitik ausgelöste - neu entstehende Rassismus löste in der Folge auch auf der politischen Ebene eine Kehrtwende aus. ${ }^{914}$ Der Startschuss zur Wiedereinführung bzw. zur Wiederetablierung des mehr oder weniger verdeckten Rassismusphänomens war somit gelegt.

\section{„Der Wendepunkt der Ausländerpolitik [...] wurde im Verlaufe des Jabres 1973 er- reicht. Schon in seiner Regierungserklärung im Januar 1973 batte Bundeskanqler Brandt die Notwendigkeit betont, ,dass wir sehr sorgsam überlegen, wo die Aufnabmefä- higkeit unserer Gesellschaft erschöpft ist und wo soziale Vernunft und Verantwortung Halt gebieten! " 915}

Aus der gesellschaftlichen Ausgrenzung und Abwertung der sogenannten Gastarbeiterinnen und Gastarbeiter entwickelte sich folglich auch eine gewisse politische Ablehnung. Dies zeigen die politischen Agitationen in der Folge des sogenannten Anwerbestopps: Mit vielfältigen Diskriminierungen der sogenannten Gastarbeiterinnen und Gastarbeiter wurde versucht zu verhindern, dass sich diese dauerhaft in der Bundesrepublik Deutschland niederließen. ${ }^{916}$ Auch in der politischen Debatte wurden sie zu ,Ausländern',zurückgestuft'.917 Schon allein diese Begrifflichkeit vermittelt, dass die Gastarbeiterinnen und Gastarbeiter nicht mehr zur bundesrepublikanischen Gesellschaft zugehörig sind - dies könnte man als politisch forcierte Ausgrenzung und Diskriminierung verstehen. ${ }^{918}$

Der Anwerbestopp entwickelte sich jedoch immer mehr zu einem politischen „Bumerang“"919, der eine verstärkte Tendenz zum Daueraufenthalt der ausländischen Arbeitskräfte zur Folge hatte. ${ }^{920}$ Dies forcierte weiterhin auch den Wandel von einem Arbeitskräfteimport hin zu einem politisch entstandenen Einwanderungsproblem, welches die bundesrepublikanische Ausländerpolitik die nächsten Jahrzehnte prägen sollte. ${ }^{921}$ Hierbei half auch die ab 1983 im Zuge des Rückkehrförderungsgesetzes angebotene Rückkehrhilfe für in ihre Heimatländer zurückkehrende Gastarbeiterinnen und Gastarbeiter nicht weiter. ${ }^{922}$ Zum einen waren die

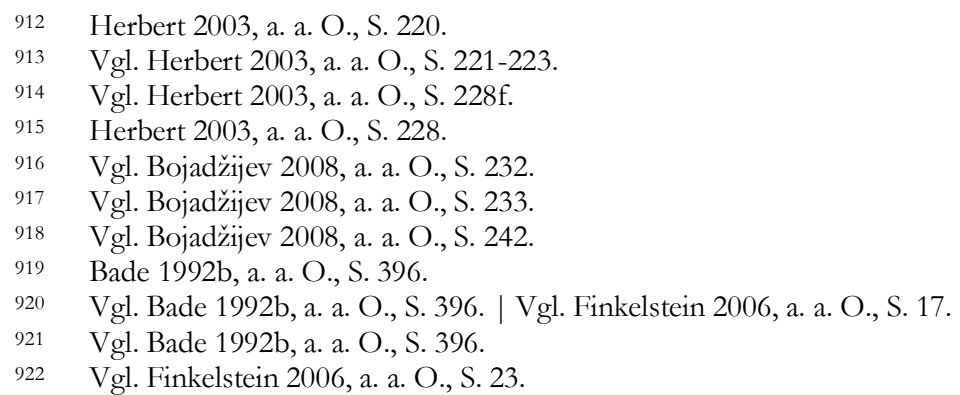


finanziellen Anreize zu niedrig angesetzt, zum anderen kristallisierten sich neue Reintegrationsprobleme in den ursprünglichen Heimatländern der Gastarbeiterinnen und Gastarbeiter heraus. ${ }^{923}$

„Die Aufenthaltsdauer der Gastarbeiter stieg stetig an, und folglich nabmen auch die Fälle, in denen Gastarbeiter ibre Familien nachbolten, beständig zu. Seit Mitte der 60er Jabre begann zudem die Zahl der beschäftigten ausländischen Frauen stetig zu wachsen. [...] Vor allem aber: Die Anzabl der nichterwerbstätigen Ausländer wurde beständig größser. Waren es 1967 noch 815000 nichterwerbstätige Ausländer gewesen, die in der Bundesrepublik. Deutschland lebten, (und 1961 gar nur 137200 gegenüber ca. 550 000 erwerbstätigen), waren es 1973 schon 1,37 Millionen - alles gleichermaßen Hinweise auf einen längerfristigen oder gar Daueraufenthalt einer zunehmenden Anzabl von Ausländern in Deutschland. "224

Vielfältige Sekundärliteratur skizziert die Diskriminierung der sogenannten Gastarbeiterinnen und Gastarbeiter durch die bundesrepublikanische Gesellschaft in unterschiedlichen Bereichen. ${ }^{925}$ Die Bürgerinnen und Bürger ,[...] reagierte[n] mit zunehmender [...] Feindlichkeit [...] "926, die auch als Rassismus bezeichnet werden kann. Hier entstanden die für das biologistische Rassismusphänomen typischen Begriffspaare ,Einheimisch`versus ,Fremde' bzw. ,Deutsche versus ,Ausländer ${ }^{6}$ wieder. ${ }^{927}$

Vor diesem Hintergrund etablierte sich in den 1970er Jahren auf der politischen und gesellschaftlichen Ebene eine umfassende Diskussion um Vor- und Nachteile der Ausländerbeschäftigung in Deutschland. ${ }^{228}$ Währenddessen produzierte die zunehmende Ausländerbeschäftigung in der Bundesrepublik vielfältige Folgeprobleme: Die Entwicklung von „,[...] sozialen Spannungen und Auseinandersetzungen zwischen Deutschen und Ausländern [... $]^{\text {“929 }}$, von Existenz- und Zukunftsängsten, einer weitgehenden Ablehnung der sogenannten Gastarbeiter, eine neu entstehende, rassistisch motivierte Fremdenfeindlichkeit sowie die angebliche Bedrohung durch eine Unterwanderung und Überfremdung der bundesrepublikanischen Gesellschaft.930 Schon während der Nachkriegsära kann so ein intensiver Anstieg des mit verschiedensten Vorurteilen begründeten Rassis-

923 Vgl. Matter 1987, a. a. O., S. 226 ff.

924 Herbert 2003, a. a. O., S. 225.

925 Vgl. Bojadžijev 2008, a. a. O., S. 198.

Die Diskriminierung der Gastarbeiterinnen und Gastarbeiter basierte unter anderem auf deren sprachlichen

Barrieren, deren differierender Lebensweise sowie unterschiedlichen kulturellen Hintergründen, wie beispielsweise einer anderen religiösen Glaubenszugehörigkeit. Die Ausgrenzung dieses ,Fremden‘ zeigte sich in einer zunehmenden Ghettobildung. Unterstüt?t wurde diese Diskriminierung noch durch Medien, die die Nicht-

Staatsangehörigen immer wieder mit kriminellen Agitationen in Verbindung brachten.

926 Finkelstein 2006, a. a. O., S. 20.

927 Vgl. Bade, Klaus J. (1992a): Einführung: Das Eigene und das Fremde - Grenzerfahrungen in Geschichte und Gegenwart, in: ebd. (Hrsg.): Deutsche im Ausland - Fremde in Deutschland. Migration in Geschichte und Gegenwart, München, S. 16.

928 Vgl. Herbert 2003, a. a. O., S. 226.

929 Herbert 2003, a. a. O., S. 235.

930 Vgl. Herbert 2003, a. a. O., S. 239. 
musphänomens - in Form der zunehmenden Ablehnung der ,fremden' Einwanderer - identifiziert werden. Im Rahmen des enggeführten Rassismuskonzepts nach Robert Miles können die ,Fremden“ als Ortsbedeutung für eine angeblich ,fremde', , andersartige', biologisch unterschiedliche ,Rasse' angesehen werden (s. Kapitel 2.2.1). Der biologisch konnotierte Rassismus zeigt sich so in den Folgejahrzehnten des Zweiten Weltkrieges immer noch indirekt existent.

Die Regierung Helmut Kohls setzte in den 1980er und 1990er Jahren ihren Arbeitsschwerpunkt im Bereich der Ausländer- und Migrationspolitik - die auch den Wahlkampf im Jahr 1987 prägte -, verfolgte jedoch immer noch die Devise, dass die Bundesrepublik Deutschland kein Einwanderungsland sei. ${ }^{931}$ Dabei muss beachtet werden, dass die „[...], Geburt des Einwanderungslandes Deutschland“

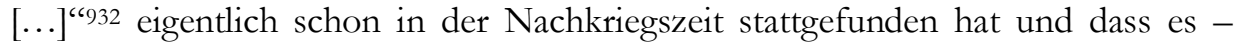
noch viel wichtiger - Migrations- und Einwanderungsbewegungen auch schon im 19. Jahrhundert sowie zu Beginn des 20. Jahrhunderts in das Territorium der heutigen Bundesrepublik Deutschland gegeben hatte. ${ }^{933}$ Trotzdem wurde die bundesrepublikanische Bevölkerung nicht mit dem Gedanken vertraut gemacht, zukünftig mit Einwanderern zusammenzuleben. Zusätzlich steigerte die politisch angemahnte Angst „[...] vor einer drohenden Masseneinwanderung aus der Türkei

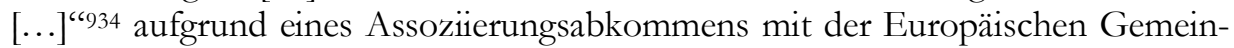
schaft (EG) die rassistischen Tendenzen innerhalb der bundesrepublikanischen Gesellschaft.935 Vor diesem Hintergrund kann die im 21. Jahrhundert erneut intensivierte Debatte bezüglich der angeblichen ,Andersartigkeit' sowie der ,Nichtintegrationsfähigkeit‘ von ausländischen Mitbürgerinnen und Mitbürgern aufgrund von vermeintlich natürlichen Unterschieden - was direkt auf biologistische Ressentiments hinweist - auch nicht verwundern. ${ }^{936}$

Für die bundesrepublikanische Ausländerpolitik bis zum Ende der 1980er Jahre kann so deren eindeutiges Scheitern konstatiert werden. Auch der Zusammenbruch der Deutschen Demokratischen Republik 1989 und die Wiedervereinigung Deutschlands konnte die Ausländerdebatte nur zeitweise in den Hintergrund drängen.937 Denn spätestens mit dem Aufflammen der rassistischen Gewalttaten in der Folge der deutschen Wiedervereinigung ist abermals eine intensivierte Debatte zur deutschen Ausländerpolitik entstanden. ${ }^{938}$ Diese zieht ihre Kreise bis in das 21. Jahrhundert.

Damit einhergehend ist primär die Änderung des bundesrepublikanischen Asylrechts vom Mai 1993 zu nennen, welches stellvertretend für die Negierung

Vgl. Herbert 2003, a. a. O., S. 249ff, 272.

Bojadžijev 2008, a. a. O., S. 98.

Vgl. Bojadžijev 2008, a. a. O., S. 98.

Herbert 2003, a. a. O., S. 250.

Vgl. Herbert 2003, a. a. O., S. $250 \mathrm{ff}$.

Vgl. Herbert 2003, a. a. O., S. 259.

Vgl. Herbert 2003, a. a. O., S. $281 \mathrm{ff}$.

Vgl. Herbert 2003, a. a. O., S. $281 \mathrm{ff}$. 
des Einwanderungsstatus Deutschlands steht: „Angeblich war ,das Boot voll“““939 Vor diesem Hintergrund wurde die amtierende Bundesregierung unter Helmut Kohl vielfach für den neu entstehenden Neorassismus aufgrund der mangelhaften Ausländer- und Asylpolitik verantwortlich gemacht. ${ }^{940}$ Jürgen Trittin konstatierte daher in den 1990er Jahren, dass durch die Quasi-Abschaffung des Asylrechtes im Zuge der Asylrechtsreform auch der Rassismus in der Bundesrepublik Deutschland wieder politisch animiert ,hoffähig“ gemacht wurde: ${ }^{941}$ „Mit der Abschaffung des Grundrechts auf Asyl ist das Feindbild des Fremden zur Verfassungsnorm erhoben worden. "942 Auch Ulrich Herbert vermerkt diesbezüglich, dass Deutschland mit der novellierten Asylgesetzgebung , ,...] gegenüber Einwanderung über das Asylrecht praktisch abgeriegelt [...]“943 war. „Der gängige Alltagsrassismus

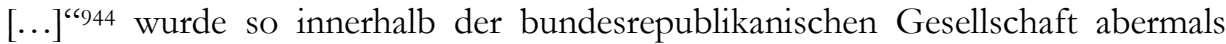
von Seiten der Politik forciert, was folgerichtig zu einer drastisch sinkenden Akzeptanz von ,Fremden ${ }^{6}$ - die eher als ,Bedrohung' ${ }^{6}$ angesehen wurden - führte. ${ }^{945}$ Das Resultat war so blutig wie deutlich: In den Pogromen von RostockLichtenhagen und Mölln zeigte der lange verdrängte gesellschaftliche Rassismus sein hässliches Antlitz. ${ }^{946}$

939 Leo, Gerhard (2001): Tausende Ausländer/innen in Abschiebehaft. Gedanken zu einem Gefängnis besonderer Art in Berlin, in: Arndt, Susan (Hrsg.): AfrikaBilder. Studien zu Rassismus in Deutschland, Münster, S. 384.

940 Vgl. Trittin 1993, a. a. O., S. 24.

Dafür spricht ebenfalls die Veröffentlichung geheimer Aufzeichnungsprotokolle aus den Jabren 1982 und 1983 von Treffen zwischen dem damaligen Bundeskan₹ler Helmut Kobl und der britischen Regierungschefin Margaret Thatcher im August 2013. Die bisher geheim gehaltenen Dokumente illustrieren, dass nicht nur Mitglieder der Regierung Kobl, sondern Politiker verschiedener Parteien insbesondere die , [...] Zabl der Türken um 50 Prozent [...]" in Deutschland reduzieren wollten. Diese seien überwiegend „, [n] icht integrationsfähig und [...] nicht integrationswillig [...]“, so die Gesprächsmitschriften. Hecking, Claus (2013): „Britische Geheimprotokolle. Kohl wollte offenbar jeden zweiten Türken loswerden“, in URL: http://www.spiegel.de/politik/deutschland/kohl-wollte-jeden-zweiten-tuerken-indeutschland-loswerden-a-914318.html <03.08.2013>.

941 Vgl. Trittin 1993, a. a. O., S. 27.

942 Trittin 1993, a. a. O., S. 27.

943 Herbert 2003, a. a. O., S. 319.

944 Trittin 1993, a. a. O., S. 76.

945 Vgl. Finkelstein 2006, a. a. O., S. 28. | Vgl. Jäger 1992b, a. a. O., S. 10.

946 Vgl. Schneider, Jan (2009): Die Organisation der Asyl- und Zuwanderungspolitik in Deutschland, Paper 25, Nürnberg, S. 31. | Vgl. Herbert 2003, a. a. O., S. $315 \mathrm{ff}$.

Die Folgen und Reaktionen auf die rassistischen Gewaltexzesse, die ein neues Zeitalter in der Nachkriegsära einläuteten, zeigten sich vielfältig. Seitens der Politik gab es zwar scharfe Verurteilungen, jedoch unterschiedliche Bewertungen der einzelnen Parteien binsichtlich der Schwere und der Hintergründe der Verbrechen.

Nichtsdestotrotz. wurde dadurch die Asylrechtsdebatte wieder forciert, welche im Dezember 1992 mit der Änderung der Asylgesetzgebung im Grundgesetz im Rabmen des sogenannten Asylkompromisses ibr vorläufiges Ende fand. Hierdurch wurde das Grundrecht auf Asyl auf vielfältigen Ebenen stark eingescbränkt sowie die Leistungen für die Asylsuchenden in Deutschland maßgeblich verschlecbtert, was in den Folgejabren zu einer drastisch absinkenden Anzabl der Asylanträge führte. In diesem Zusammenhang ist insbesondere die Rolle der CDU nachdrücklich $z u$ kritisieren, die mit tendenziell fremdenfeindlichen, rassistischen Parolen immer wieder auf den angeblichen Asylmissbrauch der Asylsuchenden binwies und so die gesellschaftlichen Ängste und Unsicherheiten weiter verstärkte. Von gesellschaftlicher Seite entstanden jedoch vielerorts spontane Demonstrationen, Schweigemärsche und Gedenkveranstaltungen, die sich insbesondere durch charakteristische Lichterketten aus- 


\section{„Der Bericht des Europaparlaments über Rassismus und Fremdenfeindlichkeit in Eu- ropa vom Juli 1990 konstatierte der Bundesrepublik. Deutschland bereits ein beängsti- gendes Ausmaß an rassistischem und fremdenfeindlichem Denken und Handeln in der Bevölkerung [...]. " 947}

Diese Gewalttaten nur mit kulturellen Faktoren zu begründen scheint auch aufgrund der historischen Hintergründe unrealistisch. Die biologistische bzw. naturalisierte Kernkomponente des Rassismus bleibt ebenso wie das ,Rassekonzept ${ }^{6}$ lediglich unausgesprochen im Hintergrund. Beschönigende und verharmlosende Begrifflichkeiten ersetzen diese scheinbar - Sinn sowie Intention bleiben jedoch identisch. Parallel zur heutigen Situation der bundesrepublikanischen Gesellschaft kann so ein hohes $\mathrm{Ma}$ an direktem, aber auch, verdecktem kulturalistischen und biologistischen Rassismus identifiziert werden - kein neues Phänomen in der Bundesrepublik, wie die vorangegangenen Entwicklungen illustrieren. ${ }^{948}$ Der Sportwissenschaftler Lutz Hoffmann diagnostiziert im heutigen Rassismus so folgerichtig eine neue ,Konjunktur ${ }^{6}$ desselben in Deutschland - als eine Konjunktur unter vielen vorausgegangenen rassistischen Tendenzen:
„Nur weil das deutsche Staatsangehörigkeitsrecht die nichtdeutschen Inländer dauerhaft in ibrem Status als Ausländer gefangen bält, kann der Eindruck entstehen, es handele sich bei der aktuellen, Ausländerfeindlichkeit" um eine Erscheinung, die ohne historische $V$ orgänger ist. Nimmt man aber nicht die fehlende deutsche Staatsangehörigkeit, sondern die fehlende deutsche Volkesqugehörigkeit als das die Diskriminierung auslösende Krite- rium an, so zeigt sich sofort, dass die ,Ausländerfeindlichkeit' [und der Rassismus] so alt [...] [sind] wie die Idee des deutschen Nationalstaats. "949

Die Asyl- und Ausländerpolitik nimmt im bundesrepublikanischen Politikgeschäft auch heute noch eine bedeutsame Rolle ein, da sie als Querschnittsthema viele weitere Politikbereiche beeinflusst. ${ }^{950}$ Folglich lässt sich vor diesem Hintergrund auch begründen, dass „[...] Zuwanderung und Asyl in Deutschland seit vielen Jahren wichtige und kontrovers diskutierte innenpolitische Themen $[\ldots]^{\text {“991 }}$ sind sowohl in der Politik als auch in der Gesellschaft.

„,Asylpolitike" wurde [...] für viele Deutsche zum Symbol für den bis dahin vielfach noch zurückgehaltenen Verdruss über die Zuwanderung überhaupt, über die vermeintli-

zeichneten. Vor allem die ausländischen Medien stilisierten vor diesem Hintergrund neue Verbindungen zwischen der nationalsozialistischen Ära und dem damaligen Deutschland und zeichneten das neuerliche Bild einer durchweg fremdenfeindlichen, rassistischen deutschen Gesellschaft.

947 Jäger 1992b, a. a. O., S. 9.

948 Vgl. Jäger 1992b, a. a. O., S. 9.

949 Hoffmann, Lutz (1993): Nationalstaat, Einwanderung und „Ausländerfeindlichkeit, in: Heßler, Manfred (Hrsg.): Zwischen Nationalstaat und multikultureller Gesellschaft. Einwanderung und Fremdenfeindlichkeit in der Bundesrepublik Deutschland, Berlin, S. 44.

950 Vgl. Schneider 2009, a. a. O., S. 9.

951 Schneider 2009, a. a. O., S. $10 \mathrm{f}$. 
che Privilegierung anderer und die sozialen Schieflagen im Gefolge der Wirtschaftskrise der frühen 80 er Jahre generell. "'552

Nicht lange nach dem Ende der Asylrechtsdebatte formierte sich im 21. Jahrhundert eine neue Diskussion bezüglich einer Novellierung der allgemeinen Ausländergesetzgebung. ${ }^{953}$ Innerhalb großer Teile der deutschen Bevölkerung verbreiten sich zunehmend negative Einstellungen bezüglich der ausländischen Mitbürgerinnen und Mitbürger.954 Diese „Ausländerphobie“955 gründet auch heute noch in vielfältigen Ängsten vor Arbeitsplatzverlusten, zunehmender Überfremdung, Kriminalität oder Wohnungsknappheit.956 Die Einwanderer galten und gelten wieder einmal als willkommene „Sündenböcke“957 in einer instabilen einwanderungspolitischen und wirtschaftlichen Situation. Folglich wandelte sich die bundesrepublikanische ,Ausländerfeindlichkeit‘ auch hin zu einer ,,[...] allgemeinen Fremdenfeindlichkeit $[\ldots]^{\text {“958, }}$, die ohne essentielle Unterbrechungen an die heutigen Verhältnisse anknüpft. Der Politikwissenschaftler Claus Leggewie konstatiert ernüchternd, dass rassistisch motivierte Fremdenfeindlichkeit in den 1990er Jahren zum „Zeitgeist" ${ }^{\text {“959 }}$ wurde, was sich aus der Perspektive des wieder etablierenden, biologistischen Rassismusphänomens zu Beginn des 21. Jahrhunderts tendenziell bestätigen lässt.

Diese gesellschaftliche Atmosphäre unterstützt auch die These, dass Gedanken der nationalsozialistischen Ära immer noch bzw. wieder in der Mitte der bundesrepublikanischen Gesellschaft präsent sind. ${ }^{960}$ Die Einwanderung in die Bundesrepublik Deutschland verbunden mit deren Status als modernes Einwanderungsland, löst negative historische Assoziationen an die nationalsozialistische Zeit aus: „[...] [Sie] lässt an Chaos, Unsicherheit, Zusammenbruch der alten Ordnung, Not, Mangel, Bürgerkrieg, Hunger, Elend denken." 961 Vor diesem Hintergrund wird ersichtlich, dass die Agitationen der Politik, insbesondere das zögerliche, unkoordinierte und von Fehlplanungen gekennzeichnete Verhalten der Bundesregierung bezüglich der Asyl-, Ausländer- und Migrationspolitik, eine entscheidende Rolle spielen, was die weit verbreitete Etablierung von kulturalistischem und biologistischem Rassismus innerhalb der bundesrepublikanischen Gesellschaft betrifft. Ob in diesem Zusammenhang innerhalb der Bundesrepublik eventuell ein sogenann-

952 Herbert 2003, a. a. O., S. 269-270.

953 Vgl. Jäger 1992b, a. a. O., S. 10.

954 Vgl. Heßler, Manfred (1993a): Ausländerbeschäftigung, Ausländerpolitik und Einstellungswandel, in: ebd. (Hrsg.): Zwischen Nationalstaat und multikultureller Gesellschaft. Einwanderung und Fremdenfeindlichkeit in der Bundesrepublik Deutschland, Berlin, S. 145.

955 Heßler 1993a, ebd., S. 140.

956 Vgl. Heßler 1993a, ebd., S. $138 f f$.

957 Heßler 1993a, ebd., S. 139.

958 Bade 1992b, a. a. O., S. 400.

959 Leggewie, Claus (1992): ,Stolz, ein Deutscher zu sein...'- die neue Angst vor den Fremden, in: Bade, Klaus J. (Hrsg.): Deutsche im Ausland - Fremde in Deutschland. Migration in Geschichte und Gegenwart, München, S. 428.

960 Vgl. Schubarth 1993, a. a. O., S. $173 \mathrm{ff}$.

961 Knight/Kowalsky 1991, a. a. O., S. 10. 
ter „Institutioneller Rassismus“"962 - trotz der vorhandenen begrifflichen und wissenschaftlichen Streitigkeiten - diagnostiziert werden kann, bleibt auch weiterhin diskutiert. ${ }^{963}$ Nicht vergessen werden darf diesbezüglich die zweifelhafte Ausländergesetzgebung der Regierung Kohl, die institutionell-rassistische Tendenzen zweifellos verstärkt hat. ${ }^{964}$ In diesem Zusammenhang kann keinesfalls, wie von der Regierung Kohl propagiert, von einer ,[...] freundliche[n] Zivilgesellschaft" ${ }^{\text {" } 965}$ in Deutschland gesprochen werden. Die bundesrepublikanische Situation in den 1990er Jahren kennzeichnete sich durch rassistische Gewalt und rassistische Übergriffe, forciert durch die zögerliche Haltung der politischen Entscheidungsträger. ${ }^{966} \mathrm{Ob}$ letztlich schon von einem institutionellen Rassismus gesprochen werden kann, bleibt jedoch umstritten: Die Sprachwissenschaftler Siegfried Jäger und Margarete Jäger sehen diesen für die 1990er Jahre in der Bundesrepublik Deutschland noch nicht nachhaltig etabliert, da hier größtenteils verharmlosend von einer latenten Fremdenfeindlichkeit gesprochen wird. ${ }^{967}$ In der Gesamtschau scheint die Bundesrepublik zumindest einzelne Tendenzen des institutionellen Rassismus aufzuweisen: ,[...] eine verfestigte Form von Rassismus [...] “968 sowie einen ,[...] Rassismus, der sich hinter Gesetzen und Normen etc. verschanzt. “969

Als ein Erklärungsansatz des im 21. Jahrhundert wiederkehrenden biologistischen als auch kulturalistischen Rassismusphänomens kann in der Folge der partiell „,[...] in der Politik vertreten[e] Rassismus [...]“970 der vergangenen Jahrzehnte diagnostiziert werden. ${ }^{971}$ Zukünftig dringend notwendig ist demnach ein ,[...] Konzept für eine zusammenhängende Ausländerpolitik. “972 Für die Zukunft muss perspektivisch ein Umdenken in Politik und Gesellschaft gefordert werden, unter anderem ein intensiver gesellschaftlicher Diskurs zur Notwendigkeit einer aktiven Einwanderungspolitik sowie eine konsequente Integrationspolitik. ${ }^{973}$ Denn nur gemeinsam können Politik und Gesellschaft ein nachhaltiges Zeichen gegen rassistische Vorurteile und Ressentiments setzen.

\section{„Die politischen Rabmenbedingungen bewirken für sich allein jedoch keine Integration.}

Integration kann nur durch die Gesellschaft geleistet werden. Es gilt Vorurteile zu über-

962 Bojadžijev 2008, a. a. O., S. 39.

963 Vgl. Bojadžijev 2008, a. a. O., S. 39f.

964 Vgl. Kalpaka/Räthzel 1994c, a. a. O., S. 19.

965 Redaktion diskurs (1992): Die freundliche Zivilgesellschaft. Rassismus und Nationalismus in Deutschland, Berlin u. a.

966 Vgl. Bojadžijev 2008, a. a. O., S. 246, 249.

967 Vgl. Jäger, Siegfried/Jäger, Margarete (2002): Das Dispositiv des Institutionellen Rassismus. Eine diskurstheoretische Annäherung, in: Bojadžijev, Manuela/Demirović, Alex (Hrsg.): Konjunkturen des Rassismus, Münster, S. 214ff.

968 Jäger/Jäger 2002, ebd., S. 216.

969 Jäger/Jäger 2002, ebd., S. 218.

970 Jäger/Jäger 2002, ebd., S. 219.

971 Vgl. Jäger/Jäger 2002, ebd., S. $218 f$.

972 Funcke, Liselotte (1993): Konzept für eine zusammenhängende Migrations- und Integrationspolitik, in: Heßler, Manfred (Hrsg.): Zwischen Nationalstaat und multikultureller Gesellschaft. Einwanderung und Fremdenfeindlichkeit in der Bundesrepublik Deutschland, Berlin, S. 23. 
winden und die äußeren und inneren Voraussetzungen für Begegnung und Verständigung zu treffen. " 974

Problematisch scheint diesbezüglich jedoch, dass in der Ausländerpolitik kein optimaler Lösungsweg sowie keine objektiv ,richtigen“ und ,falschen' Lösungen existieren - es erfordert ein gewisses Engagement von Seiten der Bevölkerung sowie der Politik. ${ }^{975}$ Das novellierte Zuwanderungsgesetz der rot-grünen Bundesregierung im Jahr 2005 kann als erstes Signal zu einem umfangreichen Migrationsmanagement gesehen werden. ${ }^{976}$ Die Bundesrepublik kann sich ihrem Status als Einwanderungsland sowie der damit einhergehenden Migrationsbewegungen also auch in Zukunft keinesfalls verschließen. ${ }^{977}$

Diese einführende Analyse der bundesrepublikanischen Ausländer- und Migrationspolitik veranschaulicht eindrücklich, dass die politische Ebene sowohl mittelbar als auch unmittelbar am wieder etablierten Rassismus in der deutschen Gesellschaft mit beteiligt ist - sowohl in der Vergangenheit als auch in der Gegenwart. Jürgen Trittin geht sogar so weit, dass er das Wiedererstarken des Rassismus in den 1990er Jahren als „[...] politische[s] Programm.“ 978 der damaligen Bundesregierung identifiziert. Auch die insbesondere im 21. Jahrhundert wieder auf der gesellschaftlichen Agenda etablierten biologistischen Ressentiments scheinen partiell mit von der politischen Entwicklung unbewusst bekräftigt worden zu sein. ${ }^{979}$ Obwohl der Begriff des Rassismus in der Bundesrepublik auch heute noch politisch tabuisiert wird, ,[...] haben wir es [also] mit Rassismus zu tun." "980 Vermieden werden sollte jedoch eine unzulässige Überdehnung des Begriffes auf weitere Themenbereiche (s. Kapitel 2). Die Wiederkehr des gegenwärtigen Rassismus hat also vielfältige historische und aktuelle politische Entstehungs- bzw. Erklärungsfaktoren. ${ }^{981}$ Die politische Arena kann resümierend als ein Akteur diagnostiziert werden, der den kulturell-naturalisierenden als auch den originär pseudobiologischen Rassismus in Deutschland - direkt sowie indirekt - wieder mit in die Mitte der Gesellschaft verholfen hat. ${ }^{982}$

\footnotetext{
974 Funcke 1993, a. a. O., S. 26-27.

975 Vgl. Knight/Kowalsky 1991, a. a. O., S. 29.

976 Vgl. Bojadžijev 2008, a. a. O., S. 251.

977 Vgl. Bojadžijev 2008, a. a. O., S. 251.

Der beutige politische und institutionelle Rabmen der Ausländer-und Asylpolitik geht auf das novellierte

Zuwanderungsgesetz vom 01. Januar 2005 zurück. Hier wurden neue rechtliche und gesetzliche Rabmenbedingungen geschaffen, um insbesondere dem Art. 16 a Abs. 1 GG Rechnung zu tragen: „Politisch Verfolgte genießen Asylrecht" (Detaillierter Wortlaut: Bundesżentrale für politische Bildung 2011, a. a. O., S. 20.). Zur detaillierten Organisation der novellierten Asyl-und Zuwanderungspolitik der Bundesrepublik Deutschland wird auf folgende Literatur verwiesen: Vgl. Schneider 2009, a. a. O. 


\subsubsection{Neorassismus und deutsche Wiedervereinigung}

Wie in den vorhergehenden Kapiteln schon angemerkt, nimmt in der bundesrepublikanischen Rassismusdebatte die deutsche Wiedervereinigung im Jahr 1990 eine bedeutende Stellung ein. Die ostdeutsche Bevölkerung war in der DDR lediglich mit einer Ausländerquote von unter einem Prozent konfrontiert. ${ }^{983}$ Der Kontakt mit der kulturell vielschichtigen bundesrepublikanischen Bevölkerung löste bei zahlreichen ostdeutschen Bürgerinnen und Bürgern vielfach eine radikale Ausländerfeindlichkeit, Rassismus, Ablehnung, Feindseligkeit, kurz „,[...] Terror gegen Ausländer $[\ldots]^{\text {‘984 }}$ aus. ${ }^{985}$ Als Beispiel hierfür mag etwa die deutsch-polnische Grenzöffnung vom April 1991 gelten. ${ }^{986}$ Hunderte deutsche Jugendliche empfingen die einreisenden Polen in Frankfurt an der Oder mit einem Steinhagel. ${ }^{987}$ Aufgrund dessen darf der Prozess der Wiedervereinigung im Rahmen einer Analyse der Entstehungsfaktoren des heutigen Rassismusphänomens nicht fehlen.

Ein „Anstieg von Fremdenfeindlichkeit und Rechtsradikalismus im zeitlichen Kontext der deutschen Einheit [...]"988 ist zu beobachten - was sind die Hintergründe? Christoph Butterwegge spricht in diesem Zusammenhang von einer „Renationalisierung “989 in Deutschland: Durch die Wiedervereinigung wurden Nationalismus, Fremdenfeindlichkeit und Rassismus wieder auf der gesellschaftlichen Tagesordnung etabliert. ${ }^{990}$ Die mit der Wiedervereinigung in die neuen Bundesländer umsiedelnden Zugezogenen mit Migrationshintergrund - insbesondere aus der zerfallenden Sowjetunion - lösten aufgrund der fehlenden Erfahrung der ostdeutschen Bevölkerung mit ausländischen Mitbürgerinnen und Mitbürgern einen „,...] Schub rassistischer Stimmungen [...]“991 aus. ${ }^{992}$ Denn schon seit dem Ende der 1980er Jahre hatten sich in der ostdeutschen Bevölkerung multiple Vorurteile entwickelt, wie die folgenden exemplarischen Beispiele visualisieren. ${ }^{993}$

Vgl. Herbert 2003, a. a. O., S. 296.

Herbert 2003, a. a. O., S. 304.

Vgl. Herbert 2003, a. a. O., S. 301.

Vgl. Herbert 2003, a. a. O., S. 302.

Vgl. Herbert 2003, a. a. O., S. 302.

Heßler, Manfred (1993b): Einleitung, in: ebd. (Hrsg.): Zwischen Nationalstaat und multikultureller Gesellschaft. Einwanderung und Fremdenfeindlichkeit in der Bundesrepublik Deutschland, Berlin, S. 7.

Butterwegge, Christoph (2001): Rassismus und Rechtsextremismus im Zeichen der Globalisierung, in: Arndt, Susan (Hrsg.): AfrikaBilder. Studien zu Rassismus in Deutschland, Münster, S. 109.

Vgl. Butterwegge 2001, ebd., S. 109ff.

Wagner, Bernd (2001): Zu rechtsextremen Entwicklungen in den neuen Bundesländern, in: Arndt, Susan (Hrsg.): AfrikaBilder. Studien zu Rassismus in Deutschland, Münster, S. 170. Vgl. Geiger, Klaus (1992): Nationalistische und postnationalistische Diskurse im Verteilungskampf der Bundesrepublik Deutschland, in: Institut für Migrations- und Rassismusforschung e. V. (Hrsg.): Rassismus und Migration in Europa. Beiträge des Kongresses „Migration und Rassismus in Europa“" Hamburg, 26. bis 30. September 1990, Hamburg, S. 273.

Vgl. Wagner 2001, ebd., S. $170 \mathrm{ff}$. 
„Ausländer versauen uns die Lebensbedingungen, die auch obne Ausländer schon schlecht genug sind. Ausländer nehmen uns den obnebin knappen Wohnraum weg. Die Polen kaufen unsere Kaufballen leer, um Spekulationsgescbäfte zu machen und sich als Schmarotzer zu bereichern. Die Afrikaner schleppen AIDS [Aquired immunodeficiency syndrome] in die DDR ein und begrapschen deutsche Frauen. Die ,dreckigen' Türken kommen aus West-Berlin mit der D-Mark und machen Frauen zu Prostituierten. Die Türken und die ,Neger' kommen bierher und machen mit ibrem dicken Portmonee Randale; ibre Aggressivität fordert nicht selten sogar Todesopfer unter den DDR-Bürgern. Und für das alles wird ibnen von der Regierung noch Zucker in den Hintern geblasen. Die Bürger und insbesondere die Jungen gehen immer leer aus. Da man keinen Einfluss auf diese Regierung ausüben kann, muss man sich eben direkt zur Webr setzen. Jedem Ausländer muss klar gemacht werden, dass er von hier so schnell wie möglich zu verschwinden hat." "g94

In den geschilderten Vorurteilen sind sowohl aus dem kulturalistischen Rassismustypus stammende Argumente vorhanden, wie Kriminalität oder Gewalt, als auch den biologisch-genetisch konnotierten Rassismus betreffende Elemente, wie beispielsweise die Implikation einer genetischen Minderwertigkeit oder der krankhaften, ,minderwertigen Fremden'. Fremdenfeindlichkeit und Rassismus galten so Ende der 1980er Jahre in der DDR als alltägliche Normalität.995

Demzufolge kann festgestellt werden, dass im Zuge der Wiedervereinigung fremdenfeindliche und rassistische Einstellungen zu einem aktuellen Thema in den neuen ostdeutschen Bundesländern wurden, obwohl sich auf dem Territorium der ehemaligen DDR relativ wenige Bürgerinnen und Bürger mit Migrationshintergrund niedergelassen hatten.996 Durch die neu hinzukommende ,fremde Bevölkerung, stellte sich seitens der ostdeutschen Bürgerinnen und Bürger „,[d]as Gefühl, einer überlegenen Kultur anzugehören $[\ldots]^{“ 997}$ und damit einhergehend eine Abwertung der ,Fremden' ein. Diesbezüglich können Parallelen zum biologischen ,Rassekonzept ${ }^{\star}$ hergestellt werden, da spezifische Menschengruppen systematisch ausgegrenzt und hierarchisiert werden. Zusätzlich impliziert auch das Überlegenheitsgefühl gegenüber, den Anderen' biologistische Merkmale.

Der ehemalige politische Feind, die Bundesrepublik Deutschland und deren Bürgerinnen und Bürger, waren auf einen Schlag verschwunden - ein neues ,Feindbild‘ wurde geschaffen: die Bürgerinnen und Bürger mit Migrationshintergrund. ${ }^{998}$ Vor 1990 gab es durch die rigorose Abschottung der Bevölkerung durch

\footnotetext{
994 Wagner 2001, a. a. O., S. 171.

995 Vgl. Wagner 2001, a. a. O., S. 175.

996 Vgl. Runge, Irene (1990): Ausland DDR. Fremdenhass, Berlin, S. 7ff. | Vgl. Ayim, May (2001): Die afro-deutsche Minderheit, in: Arndt, Susan (Hrsg.): AfrikaBilder. Studien zu Rassismus in Deutschland, Münster, S. 82.

997 Runge 1990, ebd., S. 7.

998 Vgl. Bergmann, Werner (1993): Antisemitismus und Ausländerfeindlichkeit - Eine empirische Überprüfung ihres Zusammenhangs, in: Heßler, Manfred (Hrsg.): Zwischen Nationalstaat und multikultureller Gesellschaft. Einwanderung und Fremdenfeindlichkeit in der Bundesrepublik Deutschland, Berlin, S. 121. | Vgl. Trittin 1993, a. a. O., S. 14.
} 
das DDR-Regime nur seltene Gelegenheiten des Kontaktes mit NichtStaatsangehörigen, sodass der Bevölkerung der ehemaligen DDR ein komplexer und schwieriger Lernprozess bevorstand. ${ }^{999}$

\begin{abstract}
„Noch vor einem Jahr war die DDR eine geschlossene, abgeschlossene Gesellschaft, heute ist sie Teil eines vereinten Deutschland auf dem Weg in ein geeintes Europa. Zur Normalität des Alltags wird nun auch in diesem Teil Deutschlands das Zusammenleben unterschiedlicher Nationen, Nationalitäten, ethnischer und religiöser Gruppen mit unterschiedlichen Traditionen der Lebensweise und Wertvorstellungen. In diese Situation kurzfristig hineingeworfen entstehen für ehemalige DDR-Bürger Berührungsängste und Kontaktschwierigkeiten im Umgang mit ,Fremden; eskalieren Formen der Intoleran₹. und Aggressivität." "1000
\end{abstract}

Demzufolge bleibt festzustellen, dass die Abschottung der DDR-Bevölkerung von als kulturfremd empfundenen Menschen im Verlauf des Zusammenbruchs der DDR relativ plötzlich und unkontrolliert aufgehoben wurde, was in der heutigen Lesart ein bedeutsamer Faktor für das Entstehen fremdenfeindlichen bzw. rassistischen Gedankenguts in weiten Teilen der ostdeutschen Bevölkerung zu gelten hat. ${ }^{1001}$ Selbstverständlich kann dies nicht als alleiniger Erklärungsansatz für die fremdenfeindlichen und rassistischen Tendenzen in der ostdeutschen Bevölkerung identifiziert werden. Eine wichtige Rolle kommt ebenfalls dem politischen System der DDR zu, welches verdeckten Rassismus reproduzierte. ${ }^{1002}$ Die rassistischen Einstellungen und Verhaltensmuster der ostdeutschen Bevölkerung sind also in großem Maße vor allem das Ergebnis der Geschichte der DDR sowie der Gastarbeiterpolitik des DDR-Regimes in den 1980er Jahren, welches von Ignoranz, Intoleranz und Unverständnis gegenüber ,den Fremden' geprägt war. ${ }^{1003}$

Vor dem Hintergrund einer strukturierten Analyse der Ausländersituation in der DDR fällt auf, dass sich Fremdenfeindlichkeit und Rassismus der DDRBevölkerung gegenüber Einwanderern erst gegen Ende der 1980er Jahre entwickelten, da hier die Anzahl der sogenannten Arbeitsmigrantinnen und Arbeitsmigranten rasant anstieg. ${ }^{1004}$ Zuvor gab es innerhalb der DDR schon in den 1950er Jahren eine erste Einwanderungswelle von Jugendlichen mit dem Ziel eines Studiums. ${ }^{1005}$ Jedoch verstärkten sich erst ab den 1970er Jahren sowohl die zunehmende Berufsausbildung als auch die Beschäftigung von ausländischen Arbeitskräf-

\footnotetext{
999 Vgl. Broszinsky-Schwabe, Edith (1990): Die DDR-Bürger im Umgang mit „Fremden“ Versuch einer Bilanz der Voraussetzungen für eine Leben in einer multikulturellen Welt, in: Kleff, Sanem et al. (Hrsg.): BRD - DDR. Alte und neue Rassismen im Zuge der deutschdeutschen Einigung, Frankfurt/Main, S. 18f.

1000 Broszinsky-Schwabe 1990, a. a. O., S. 18.

1001 Vgl. Broszinsky-Schwabe 1990, a. a. O., S. 18f.

1002 Vgl. Broszinsky-Schwabe 1990, a. a. O., S. 18f.

1003 Vgl. Staud, Toralf (2012): „Generation Nazi“, in URL: http://www.zeit.de/2012/45/NSUSozialisation <13.08.2013>. | Vgl. Broszinsky-Schwabe 1990, a. a. O., S. 18f.

1004 Vgl. Broszinsky-Schwabe 1990, a. a. O., S. $20 \mathrm{ff}$.

1005 Vgl. Broszinsky-Schwabe 1990, a. a. O., S. $19 \mathrm{ff}$.
} 
ten. ${ }^{1006}$ Über verschiedene Regierungsabkommen, unter anderem mit Kuba (1978), Mosambik (1979), Vietnam (1980) oder Angola (1985), wurden für die Einhaltung der Planziele der DDR-Wirtschaft dringend benötigte Gastarbeiterinnen und Gastarbeiter seitens der politischen Führung in die DDR geholt. ${ }^{1007}$

„Der in der DDR-Geschichte intensivste und massenhafteste Kontakt von DDRBürgern mit Ausländern im Alltag vollzog sich seit Mitte der 80er Jahre, als ausländische Arbeitsmigranten zu Tausenden ins Land geholt wurden. "1008

Jedoch kann vor diesem Hintergrund - vergleichend zur bundesrepublikanischen Situation - keinesfalls von einem Einwanderungsland gesprochen werden, da die Einwanderung in die DDR seitens der politischen Führung strikt kontrolliert sowie durch vertraglich aufgestellte Richtlinien und Rahmenbedingungen konsequent geregelt wurde. ${ }^{1009}$ Unter anderem wurde so beschlossen, dass die Arbeitsmigration überwiegend auf vier bis fünf Jahre begrenzt und in deren Rahmen „[...] keine Möglichkeit, die Familie nachkommen zu lassen."1010 eröffnet und genehmigt werden würde. ${ }^{1011}$

„Die Arbeit in der DDR dient deshalb vorrangig dem Ziel, sich bessere Startbedingungen für die Zeit nach der Heimkehr zu sichern, einen möglichen Grundstock für einen eigenen Haushalt zu legen und die Familie - entweder im engeren Sinne oder die arbeitsund erwerbslosen Angehörigen der Großfamilie - zu unterstützen. "1012

Ein weiteres Indiz der außerordentlichen Kontrolle der Beschäftigung der Arbeitsmigrantinnen und Arbeitsmigranten war eine umfassende ,Isolation' dieser von den Bürgerinnen und Bürgern der DDR. ${ }^{1013}$ Demzufolge ist es auch verständlich, dass durch den weitgehend fehlenden Kontakt kein kultureller und gesellschaftlicher Austausch stattfinden konnte, sodass dieser nach der Wiedervereinigung übereilt, unkontrolliert und mit zahlreichen Ressentiments verknüpft stattfinden musste. Die Arbeitsmigrantinnen und Arbeitsmigranten wurden in der Folge als Konkurrenten um Arbeitsplätze, als ,Fremde ${ }^{6}$ und ,Unbekannte innerhalb der Bevölkerung der DDR wahrgenommen. ${ }^{1014}$ So konnten verdeckt rassistische Denk- und Handlungsmuster innerhalb der Gesellschaft entstehen und sich - je nach der eigenen wirtschaftlichen Situation - verstärken.

\footnotetext{
1006 Vgl. Broszinsky-Schwabe 1990, a. a. O., S. $19 \mathrm{ff}$.

1007 Vgl. Broszinsky-Schwabe 1990, a. a. O., S. $20 \mathrm{ff}$.

1008 Broszinsky-Schwabe 1990, a. a. O., S. 18.

1009 Vgl. Broszinsky-Schwabe 1990, a. a. O., S. $21 \mathrm{ff}$.

1010 Broszinsky-Schwabe 1990, a. a. O., S. 23.

1011 Vgl. Broszinsky-Schwabe 1990, a. a. O., S. 23.

1012 Broszinsky-Schwabe 1990, a. a. O., S. 27.

1013 Vgl. Broszinsky-Schwabe 1990, a. a. O., S. $29 \mathrm{ff}$.

1014 Vgl. Broszinsky-Schwabe 1990, a. a. O., S. 29 ff.
} 
Von Seiten der DDR-Führung wurden hingegen sämtliche rassistische Strö-

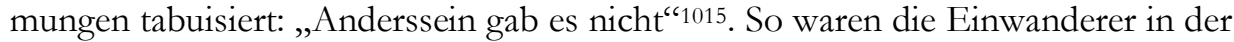
DDR auch nicht als Minderheiten anerkannt. ${ }^{1016}$ Folglich wurden gleichermaßen gesellschaftliche Phänomene, wie Rassismus und Fremdenfeindlichkeit, als nicht existent angesehen. ${ }^{1017}$ Ebenfalls vor dem Hintergrund der sozialistischen Ideologie galten diese Vorurteilsstrukturen mit der Gründung der DDR als, ausgerottet'.1018 Diese skizzierte Situation spiegelt sich auch auf sozialwissenschaftlicher Ebene im Forschungsfeld die Ausländer-, Migrations- und Rassismusforschung betreffend wieder, das nicht geduldet wurde. ${ }^{1019}$ Aufgrund dessen konnte bzw. kann bezüglich des Rassismusphänomens zum Großteil nur aus der Post-DDRÄra forschend und untersuchend angesetzt werden, sodass die meisten detaillierten und umfassenden Forschungsprojekte auch erst nach der Vollendung der deutsch-deutschen Wiedervereinigung beginnen. Vor dem Hintergrund einer Analyse der gesamtdeutschen Rassismusentwicklungen im 21. Jahrhundert gestaltet es sich demnach kompliziert, die gesellschaftliche Dynamik der DDR umfassend zu integrieren.

Durch die staatliche Negierung des Rassismus sowie durch die mangelnde Transparenz in der DDR wurde das ,alt-neue ' Thema Rassismus zum Großteil verdrängt. ${ }^{1020}$ „Sichtbar rassistische und nationalistische Erscheinungen wurden je nach politischer Brauchbarkeit verfolgt, vertuscht oder uminterpretiert." ${ }^{1021}$ Die fehlenden politischen Entschlüsse zu einer transparenten Ausländerpolitik hatten innerhalb der Gesellschaft der DDR in der Folge drastische Auswirkungen: Eine steigende Aggressivität und Gewaltbereitschaft, die zunehmende Diskriminierung von ,Fremden' im Alltag sowie ein offener Rassismus aufgrund mangelnden Wissens und fehlender Erfahrungen gegenüber ausländischen Mitbürgerinnen und Mitbürgern. ${ }^{1022}$ Die unbedachte Politik des DDR-Regimes bezüglich der vertraglichen Arbeitsabkommen veranschaulicht einige Parallelen zu der im vorigen Kapitel dargestellten Situation in der benachbarten Bundesrepublik Deutschland. In der west- und ostdeutschen Gesellschaft wurde ein enormes Konfliktpotenzial geschaffen, welches sich im Zuge der deutschen Wiedervereinigung summierte und direkt im gesellschaftlichen Alltag zeigte. ${ }^{1023}$ Dies belegen seitens der DDR auch zahlreiche Leserbriefe der Bevölkerung in den Printmedien. ${ }^{1024}$ Schlussfolgernd lässt sich demnach feststellen, dass Ablehnung, Ausgrenzung, Diskriminie-

1015 Krüger-Potratz, Marianne (1991b): Das hässliche Gesicht der einen Welt - Zur Einleitung, in: ebd. (Hrsg.): Anderssein gab es nicht. Ausländer und Minderheiten in der DDR, Münster u. a., S. 1.

1016 Vgl. Krüger-Potratz 1991b, ebd., S. 2.

1017 Vgl. Krüger-Potratz 1991b, ebd., S. 6.

1018 Vgl. Krüger-Potratz 1991b, ebd., S. 6.

1019 Vgl. Krüger-Potratz 1991b, ebd., S. 15.

1020 Vgl. Runge 1990, a. a. O., S. $12 \mathrm{ff}$.

1021 Runge 1990, a. a. O., S. 11.

1022 Vgl. Runge 1990, a. a. O., S. $12 \mathrm{ff}$.

1023 Vgl. Runge 1990, a. a. O., S. 15.

1024 Vgl. Runge 1990, a. a. O., S. 17-34. 
rung und Aggressivität gegenüber Einwanderern in der DDR latent vorhanden waren, durch den erdrückenden Propagandaapparat der Staatspartei jedoch erfolgreich unterdrückt werden konnten. ${ }^{1025}$ Seit den deutlich erkennbaren Zerfallserscheinungen der DDR traten rassistische Tendenzen aufgrund der zahlreichen Zukunftsängste dann offen zutage. ${ }^{1026}$ Angelehnt an das biologische ,Rassekonzept ${ }^{\star}$ wurden ausländische Mitbürgerinnen und Mitbürger als unerwünschte, ,andersartige‘ Bevölkerungsgruppe systematisch abgewertet und diskriminiert.

Welche Folgen hatten die dargestellten neorassistischen Tendenzen nun im Zuge der deutsch-deutschen Wiedervereinigung für die Menschen mit Migrationshintergrund in der DDR? Diese wurden meist schon mit ihrer Ankunft in der DDR aufgrund zahlreicher Limitierungen von Rechten mit dem neu-alten biologistisch-kulturalistischen Rassismus- und ,Rasseproblem' konfrontiert, was für diese eine ,[...] Situation fortwährenden Beobachtens und des Herausfallens aus der Allgemeinheit [...] “1027 bedeutete. Die Ausgrenzung und Diskriminierung sowohl durch die Bürgerinnen und Bürger der DDR als auch durch die politischen Rahmenbedingungen der Arbeitsmigration waren deutlich zu erkennen. ${ }^{1028}$ Alle Personen mit „fremdländischem“1029 Aussehen wurden als „Nichtdazugehörige" ${ }^{\text {"1030 }}$ abgestempelt und mit einem steigenden Potenzial rassistischer Ressentiments konfrontiert. Dieser fremdenfeindliche und rassistische Trend lässt sich auch im Rahmen der Feierlichkeiten zur deutschen Wiedervereinigung erkennen. ${ }^{1031}$ Einwanderer waren mit an den Einigungsfeierlichkeiten beteiligt, jedoch wurde ihnen deutlich gezeigt, dass ,Deutsche' hier ,unter sich' feiern wollten, wie das folgende exemplarische Beispiel illustriert. ${ }^{1032}$

„Auf allen Fotos von diesen ersten Tagen nach der Maueröffnung kann frau auffallend viele offensichtlich nicht-deutsche (meist männliche) Jugendliche sehen. Sogar unter den ersten, die auf das Brandenburger Tor kletterten, waren viele aus der zweiten Generation der Migrantinnen dabei. Auch Schülerinnen [...] beteiligten sich an diesen spontanen Straßenfesten, den Empfängen an jeder neuen Maueröffnung. Schließlich waren mit am stärksten durch die neuen Übergänge die Wohngebiete der ausländischen Bevölkerung betroffen. Die Jugendlichen hatten vor allem die Angst vor den Augen, dass hier etwas passiert. Was ibre Wohngegend, ihre Straße, ihre Stadt verändert. Also dass etwas passiert,

1025 Vgl. Broszinsky-Schwabe 1990, a. a. O., S. 35.

1026 Vgl. Broszinsky-Schwabe 1990, a. a. O., S. 35, 42.

1027 Krüger-Potratz, Marianne (1991c): Ihre Sorgen - unsere Sorgen, in: ebd. (Hrsg.): Anderssein gab es nicht. Ausländer und Minderheiten in der DDR, Münster u. a., S. 223.

1028 Vgl. Krüger-Potratz 1991c, a. a. O., S. 223 ff.

1029 Kleff, Sanem (1990): „Wir sind auch das Volk!“ Die letzten zwölf Monate des geteilten Berlin aus der Sicht nicht-deutscher Berlinerinnen, in: Kleff, Sanem et al. (Hrsg.): BRD - DDR. Alte und neue Rassismen im Zuge der deutsch-deutschen Einigung, Frankfurt/Main, S. 5.

1030 Kleff 1990, ebd., S. 5.

1031 Vgl. Elsner, Eva-Maria/Elsner, Lothar (1993): Ausländerpolitik und Ausländerfeindlichkeit in der DDR, in: Heßler, Manfred (Hrsg.): Zwischen Nationalstaat und multikultureller Gesellschaft. Einwanderung und Fremdenfeindlichkeit in der Bundesrepublik Deutschland, Berlin, S. $201 \mathrm{ff}$.

1032 Vgl. Kleff 1990, ebd., S. 7 ff. 
was ganz eng mit ihnen, ibrem Alltag, ihrem Lebensumfeld zu tun hat. Sie merkten jedoch sehr schnell, welche eingeschränkte Rolle ibnen von der deutschen Mebrheit nur zugebilligt wurde bei den Umwandlungen. Sie bekamen zu bören, dass sie,... uns Deutsche doch mal unter uns lassen sollten, damit wir auch mal für uns feiern können. Denn schließlich ist das ja unsere Vereinigung!" "1033

Vor dem Hintergrund dieser Entwicklungen protestierten die Menschen mit Migrationshintergrund gegen das diskriminierende Bild der bundesrepublikanischen Bevölkerung gegenüber ausländischen Minderheiten: „Wir sind auch das Volk“"1034, war die Losung.

Insbesondere die Bevölkerung der ehemaligen DDR war über die „Massen von Ausländern"1035 in Westdeutschland überrascht. Sie schien überzeugt, dass diese „[...] fremde Lebensart [...] $]^{“ 1036}$ nicht zur Gesellschaft des neuen, wiedervereinigten Deutschlands passe. Dieses negative Bild forcierte in der Folge zusätzlich das fremdenfeindlich-rassistische Potenzial innerhalb großer Teile der ostdeutschen Bevölkerung, was zu einer „,...] besonders gefährlich[en] heimtückisch[en] und durchorganisiert[en] [...]“1037 Fremdenfeindlichkeit - mit vielfach rassistischen Tendenzen - führte. Zu Beginn der 1990er Jahre sorgte dies für regelrechte Hetzjagden gegenüber eingewanderten Personen. ${ }^{1038}$ Auch an dieser Stelle kann folglich die mangelnde präventive Vorbereitung der ostdeutschen Bevölkerung auf ein vereinigtes Deutschland mit vielfältigen neuen und unbekannten Strukturen konstatiert werden. In diesem Zusammenhang könnte schlussfolgernd auch die Frage aufgeworfen werden, ob die Wiedervereinigung vor dem Hintergrund der Skepsis gegenüber ,Fremden` nicht zu ,übereilt' bzw. mit zu wenig Vorbereitung erfolgt ist?

Als weiterer Erklärungsansatz von Fremdenfeindlichkeit und Rassismus innerhalb der DDR kann die ausgewiesene Ausländerfeindlichkeit des sozialistischen Systems identifiziert werden: ,Fremde`, wie beispielsweise der ,Klassenfeind' sowie die ausländischen Arbeitsmigrantinnen und -migranten, galten hier als ,Bedrohung' der Nation und des sozialistischen Herrschaftssystems. ${ }^{1039}$ Auch aus der Perspektive der Bürgerinnen und Bürger der DDR war der - durch zahlreiche staatliche Restriktionen - seltene Kontakt sowie die mangelnden Erfahrungen mit Einwanderern stets eher unfreiwillig, von ,oben' diktiert: „Kontakt und Umgang außerhalb der staatlich festgelegten Regeln waren nicht vorgesehen, entweder

\footnotetext{
1033 Kleff 1990, a. a. O., S. $7 \mathrm{ff}$.

1034 Kleff 1990, a. a. O., S. 10.

1035 Kleff 1990, a. a. O., S. 15.

1036 Kleff 1990, a. a. O., S. 16.

1037 Kleff 1990, a. a. O., S. 16.

1038 Vgl. Herbert 2003, a. a. O., S. 316

1039 Vgl. Poutrus, Patrice G. et al. (2001): Fremd-Sein in der sozialistischen Diktatur. Zu historischen Ursachen von Fremdenfeindlichkeit und rassistischer Gewalt in den Neuen Bundesländern, in: Arndt, Susan (Hrsg.): AfrikaBilder. Studien zu Rassismus in Deutschland, Münster, S. 184.
} 
explizit verboten, zumindest aber unerwünscht.“1040 Der Historiker Patrice Poutrus folgert so treffend, dass die Expansion des Rassismus sowie allgemein fremdenfeindlicher Strömungen bereits lange vor der Wiedervereinigung in der DDR vorhanden waren. Die Tilgung dieser Hypothek der 40jährigen staatssozialistischen Herrschaft sollte sich - wie die Ergebnisse zur Verbreitung rassistischen Gedankenguts gezeigt haben - als äußerst schwierig und derzeit noch immer offenes gesellschaftliches Problem darstellen (s. Kapitel 3). ${ }^{1041}$

„Alle ,Fremde' trafen in der DDR auf eine Gesellschaft, in der politisch motivierte Ausgrenzungsmechanismen eine historische Kontinuität darstellten, die älter war als der sozialistische Staat. " 042

Im Rahmen der erweiterten Recherche nach Hintergründen der - offen biologistisch und kulturalistisch konnotierten - rassistischen Tendenzen in der ostdeutschen Bevölkerung lassen sich weitere multiple Ursachenkomplexe identifizieren. Auch das ,[...] gravierende Unkenntnis [...]"1043 produzierende Bildungssystem der DDR muss in besonderem Maße kritisiert werden - gegenseitiges Verständnis, Toleranz und Akzeptanz hatten hier keinen Platz. Darüber hinaus wurden die Bürgerinnen und Bürger der DDR durch das sozialistische System per se nur als zweitklassige Bürger angesehen. ${ }^{1044}$

„Diese Minderwertigkeitsgefühle nabmen nach dem 9. November [1989] und der Grenzöffnung noch zu, als sie dem BRD-Konsum staunend, aber obne Geld gegenüberstanden. Dieses Minderwertigkeitsgefühl versuchten zuerst einige, später zunehmend mehr, dadurch zu kompensieren, dass sie ihrerseits eine ,Klasse' unter sich aufmachten, andere Schwächere, die Ausländer. "045

Hinzukommend verstärkten die sozialistische Erziehung zur Meidung von Einwanderern, fehlende und falsche Informationen seitens der politischen Führung der DDR bezüglich der Arbeitsmigration, aktive Maßnahmen der sozialistischen Führung zur Diskriminierung und Abwertung von Fremden sowie die Ausgrenzung von Zugezogenen mit Migrationshintergrund im Prozess der deutschdeutschen Wiedervereinigung die zunehmend rassistische Atmosphäre im gesellschaftlichen Alltag der DDR. ${ }^{1046}$

Die latente Fremdenfeindlichkeit sowie die anwachsenden rassistischen Tendenzen der Bürgerinnen und Bürger der DDR sind so auf multiple Hintergründe zurückzuführen: Zum einen auf das sozialistische Herrschafts- und Gesellschaftssystem und zum anderen auf die sozialen Verunsicherungen durch den Zusam-

\footnotetext{
1040 Poutrus et al. 2001, a. a. O., S. 191.

1041 Vgl. Poutrus et al. 2001, a. a. O., S. 197.

1042 Poutrus et al. 2001, a. a. O., S. 196.

1043 Broszinsky-Schwabe 1990, a. a. O., S. 36.

1044 Vgl. Broszinsky-Schwabe 1990, a. a. O., S. 36f.

1045 Broszinsky-Schwabe 1990, a. a. O., S. 37.

1046 Vgl. Broszinsky-Schwabe 1990, a. a. O., S. 37 ff.
} 
menbruch der DDR und die Folgen der deutschen Wiedervereinigung. ${ }^{1047}$ Insbesondere die sich durch die Wiedervereinigung verstärkenden Zukunfts- und Existenzängste der jungen DDR-Bevölkerung spielen in diesem Zusammenhang eine bedeutende Rolle. ${ }^{1048}$ Vorausblickend muss demzufolge für das 21. Jahrhundert gleichzeitig vermerkt werden, dass Rassismus seit langem zum alltäglichen Bild in der deutschen Gesellschaft gehört, insbesondere aufgrund der gravierenden „[...] Defizite der DDR-Geschichte [...]"1049 in den ostdeutschen Bundesländern. ${ }^{1050}$ Fragwürdig sind diese Reaktionen der ostdeutschen Bevölkerung durchaus, da insbesondere ausländische Unternehmen zu Beginn der 1990er Jahre bei dem Wiederaufbau der ostdeutschen Wirtschaft und Industrie investieren wollten, jedoch vielfach durch den wachsenden Rassismus und Fremdenhass abgeschreckt wurden. ${ }^{1051}$ Die skizzierten Entwicklungslinien in der DDR verdeutlichen jedoch, dass die heutigen hohen Zustimmungswerte der ostdeutschen Bevölkerung zu fremdenfeindlichen, antisemitischen und rassistischen Vorurteilen keinen neuartigen Trend, sondern eine gewisse Kontinuität repräsentieren (s. Kapitel 3).

Vergleichend betrachtet können so in der bundesrepublikanischen Gesellschaft als auch in der ehemaligen Bevölkerung der DDR unterschiedliche Erklärungsansätze bezüglich des heutigen Rassismusphänomens identifiziert werden. ${ }^{1052}$ Diese sind sowohl auf Strukturen der Vergangenheit - deshalb auch die herausragende Bedeutung der ursächlich, an der modernen historischen Entwicklung ansetzenden Analyse - als auch auf Faktoren der gesellschaftlichen und politischen Gegenwart zurückzuführen. ${ }^{1053}$ Jedoch ist in beiden Fällen klar zu konstatieren, dass die politische Ebene jeweils eindeutige Fehleinschätzungen bzw. nachhaltig problematische Entscheidungen getroffen hat, die rassistische Tendenzen innerhalb der Bevölkerung bis heute reproduzieren und forcieren. Hervorzuheben bleibt nochmals die Bedeutung des Rassismusphänomens, welches der sozialistische Staatsapparat sicherlich indirekt verstärkt hat, indem er die originäre Bevölkerung der DDR einerseits sowie die Arbeitsmigrantinnen und -migranten andererseits faktisch in verschiedene Menschengruppen - Grundlage bleibt das ,Rassekonzept $^{6}$ - differenziert hat: Die ,wertvolle , ,profitable ${ }^{6}$ Bevölkerung der DDR sowie

1047 Vgl. Krüger-Potratz 1991b, a. a. O., S. 3. | Vgl. Quent 2012, a. a. O., S. 40.

1048 Vgl. Thierse, Wolfgang (1992): Deutsch-deutsche Gewalt, in: Nirumand, Bahman (Hrsg.): Angst vor den Deutschen. Terror gegen Ausländer und der Zerfall des Rechtsstaates, Reinbek bei Hamburg, S. 71.

1049 Broszinsky-Schwabe 1990, a. a. O., S. 42.

1050 Vgl. Farin, Klaus/Seidel-Pielen, Eberhard (1992): Rechtsruck. Rassismus im neuen Deutschland, 3. Auflage, Berlin, S. 9. | Vgl. Marburger, Helga (1990): Interkulturelles Lernen in Europa - Aufgaben und Ansätze, in: Kleff, Sanem et al. (Hrsg.): BRD - DDR. Alte und neue Rassismen im Zuge der deutsch-deutschen Einigung, Frankfurt/Main, S. 67.

1051 Vgl. Neubauer, Ralf (1992): Fremdenhass als Konjunkturbremse, in: Nirumand, Bahman (Hrsg.): Angst vor den Deutschen. Terror gegen Ausländer und der Zerfall des Rechtsstaates, Reinbek bei Hamburg, S. 194 ff.

1052 Vgl. Hoffmann 1993, a. a. O., S. 35. | Vgl. Quent 2012, a. a. O., S. 43 Diesbezüglich müssen desweiteren auch mikeroregionale Effekte, Ursachen und Unterschiede beachtet werden, die zu verschiedenen Ausprägungen von Rassismus und Fremdenfeindlichkeit fübren können. 
demgegenüber die als Arbeitskräfte ausgenutzten, angeblich ,minderwertigen“, ausgegrenzten Einwanderer. Demzufolge visualisieren auch diese rassistischen Zuschreibungen das Vorhandensein naturalisierter Erklärungsgrundlagen - die Begriffe ,Minderwertigkeit' oder, Wert' intendieren genetische bzw. humanbiologische Differenzen, so dass kulturelle Zuschreibungen eher in den Hintergrund rücken.

Insbesondere das „[...] Erbe des Realsozialismus [...]“1054 hat also Rassismus und Fremdenhass nicht nur geduldet, sondern zum Großteil auch unterstützt und forciert. Demnach kann vor diesem Hintergrund auch für die Zukunft resümiert werden:

„Ausländerfeindlichkeit hat [, wie der Rassismus,] immer dann Hochkonjunktur, ,wenn sich Krisensymptome bäufen, militärische Niederlagen und/oder Systemkrisen drohen sowie benachteiligte Schichten existentiell gefährdet sind und durch eine Herabsetzung fremder Menschengruppen den auf ibnen lastenden Druck nach unten weitergeben. "1055

\subsection{3 ,Einwanderungsland‘ Deutschland: Ein Teil des Rassismusproblems?}

Schon die vorherigen Kapitel illustrieren, dass das Phänomen der Einwanderung als integrativer Bestandteil der bundesrepublikanischen Geschichte angesehen werden muss. „Wanderung nach Deutschland hat es zu allen Zeiten gegeben. “1056, beginnend mit den ersten Bevölkerungsbewegungen im Rahmen der Kolonialisierung. ${ }^{1057}$ Folglich erscheint auch die Weigerung der bundesrepublikanischen Regierung bis in die 1990er Jahre, Deutschland als Einwanderungsland anzuerkennen, wissenschaftlich vollkommen unverständlich. ${ }^{1058}$ Wenn so aus heutiger Sicht die Schwierigkeiten oder das angebliche Scheitern der Integration der ausländischen Mitbürgerinnen und Mitbürger angemahnt wird, muss beachtet werden, dass dies auch von der lange Zeit fehlenden Akzeptanz der bundesrepublikanischen Bevölkerung sowie auch der Politik abhängig ist. Ohne das Ablegen des rassistischen und fremdenfeindlichen Schleiers der bundesrepublikanischen Gesellschaft sowie auch - in einzelnen Ebenen - der Politik, ist eine erfolgreiche Einwanderungspolitik nicht möglich, wie die in den vorherigen Kapiteln skizzierten historischen Erfahrungen belegen. ${ }^{1059}$ Darüber hinaus muss ergänzt werden, dass die ökonomische sowie die innergemeinschaftliche (EU) und international politische Vorreiterrolle der Bundesrepublik Deutschland heute ohne die Mithilfe und Unterstützung der ausländischen Mitbürgerinnen und Mitbürger nicht ermöglicht worden wäre, was sich insbesondere in der starken Stellung Deutschlands in

\footnotetext{
1054 Schubarth 1993, a. a. O., S. 180.

1055 Elsner/Elsner 1993, a. a. O., S. 205.

1056 Funcke 1993, a. a. O., S. 21.

1057 Vgl. Meier-Mesquita 1994, a. a. O., S. 47.

1058 Vgl. Funcke 1993, a. a. O., S. 24.

1059 Vgl. Funcke 1993, a. a. O., S. 26 f.
} 
der aktuellen Eurokrise zeigt. ${ }^{1060}$ Die ausländische Bevölkerung hat sich zu einem permanenten und fördernden Bestandteil Deutschlands entwickelt. 1061

Einwanderung ist folglich ein Charakteristikum der heutigen Bundesrepublik Deutschland sowie schon ihrer historischen Vorfahren. Die ,Einwanderungswelle“ in den 1990er Jahren, die den Neorassismus in Deutschland wieder auf der politischen und gesellschaftlichen Agenda positionierte, ist vor allem dem Zerfall der Sowjetunion, des ehemaligen sogenannten Ostblocks, zuzuschreiben. ${ }^{1062}$ Durch die vermehrte Einwanderung aus der ehemaligen Sowjetunion, die sich im Westen bessere Lebensverhältnisse erhofften, entstanden insbesondere in der ostdeutschen Bevölkerung neue fremdenfeindliche und rassistische Tendenzen (s. Kapitel 4.1.2). ${ }^{1063}$ Darüber hinaus wurde die ausländische Bevölkerung seitens großer Teile der ostdeutschen Bevölkerung als ,Sündenböcke' für die trotz der Integration in die Bundesrepublik Deutschland immer noch anhaltenden, schlechten Lebensverhältnisse verantwortlich gemacht. ${ }^{1064}$

Nichtsdestotrotz beharrte die Regierung der Bundesrepublik - trotz des ersichtlichen Anstiegs der Einwanderungszahlen - auf dem Standpunkt, Deutschland sei kein Einwanderungsland. Der Historiker Klaus J. Bade kommentierte diese Verweigerungshaltung 1990 folgendermaßen:

\section{„Im Giftschrank amtlich tabuisierter Zeitbegriffe steht eine Flasche mit der Aufschrift ,Einwanderungsland: Darin hocket ein Geist. Wer ihn befreit, so geht die Rede politi- scher Weisheiten seit vielen Legislaturperioden, der ist verloren und mit ibm Land und Leute, von denen der Geist dann Besitz ergreift. Deshalb warnt vor solchem Tun seit je- her ein amtliches Dementi: ,Die Bundesrepublik Deutschland ist kein Einwanderungs- land!" "065}

Sogar im Vergleich zum klassischen Einwanderungsland USA wies die wiedervereinte Bundesrepublik in den 1990er Jahren mehr Einwanderer auf. ${ }^{1066}$ Selbstver-

1060 Vgl. Hoffmann 1993, a. a. O., S. 36ff.

Die wirtschaftlich starke Stellung Deutschlands in der Gegenwart ist neben den bundesrepublikanischen Arbeitnehmerinnen und Arbeitnehmern auch den ausländischen Facharbeitskräften zu verdanken. Nur gemeinsam konnte die aktuell herausragende wirtschaftliche Position der Bundesrepublik Deutschland innerbalb der EU realisiert werden.

1061 Vgl. Rürup, Bert/Sesselmeier, Werner (1993): Einwanderung: Die wirtschaftliche Perspektive, in: Balke, Friedrich et al. (Hrsg.): Schwierige Fremdheit. Über Integration und Ausgrenzung in Einwanderungsländern, Frankfurt/Main, S. 287.

1062 Vgl. Herbert 2003, a. a. O., S. 273.

1063 Vgl. Radtke 1993, a. a. O., S. 91.

1064 Vgl. Heßler 1993b, a. a. O., S. 8.

1065 Bade, Klaus J. (1990): Die Einwanderungssituation: Erfahrungen - Probleme - Perspektiven, in: Beauftragte der Bundesregierung für die Integration der ausländischen Arbeitnehmer und ihrer Familienangehörigen (Hrsg.): Bericht ,99. Zur Situation der ausländischen Arbeitnehmer und ihrer Familien - Bestandsaufnahme und Perspektiven für die 1990er Jahre, 2. Auflage, Bonn, S. 307.

1066 Vgl. Leggewie, Claus (1993): Vom Deutschen Reich zur Bundesrepublik - und nicht zurück. Zur politischen Gestalt einer multikulturellen Gesellschaft, in: Balke, Friedrich et al. (Hrsg.): Schwierige Fremdheit. Über Integration und Ausgrenzung in Einwanderungsländern, Frankfurt/Main, S. 3ff. 
ständlich hatte diese Jahrzehnte anhaltende „[...] Realitätsverweigerung von Öffentlichkeit und Politik [...] “1067 Folgen, die sich in zunehmenden rassistischen Ressentiments zeigten. Relativierend muss vor diesem Hintergrund jedoch ebenfalls festgestellt werden, dass sich diese gesellschaftliche und politische Angst vor einer ,Überfremdung ' durch Einwanderer nicht nur auf die Bundesrepublik Deutschland beschränkte - der abermals grassierende Rassismus kann als Folge des zunehmenden Einwanderungsdrucks in allen europäischen Staaten identifiziert werden. ${ }^{1068}$

Die Folgen und Auswirkungen dieser andauernden Negierung des Einwandererstatus der Bundesrepublik Deutschland waren anhand multipler Faktoren im gesellschaftlichen Umfeld zu erkennen, die in ihrer Gesamtheit den neorassistischen Strömungen einen neuen Aufschwung ermöglichten. Insbesondere die aufkeimenden Debatten über Zugehörigkeit und Nicht-Zugehörigkeit zur deutschen Gesellschaft sowie die ideologischen Auseinandersetzungen mit migrationsbeeinflussten Mitbürgerinnen und Mitbürgern sind in diesem Zusammenhang zu nennen. ${ }^{1069}$ Ähnliche Diskussionen lassen sich als Kontinuität im 21. Jahrhundert antreffen, wie beispielsweise die Causa Sarrazin vergegenwärtigt (s. Kapitel 3.1).

In der Gesamtschau kann also auch hierbei wieder die Politik als mittelbarer Akteur verstanden werden, der fremdenfeindliche und rassistische Ressentiments in der bundesrepublikanischen Gesellschaft aufgrund der verweigerten Anerkennung des Einwanderungsstatus forcierte. ${ }^{1070}$ Folge dieser Verweigerungshaltung war nicht nur eine ,[...] unwürdige politische Pariastellung $[\ldots]^{\text {(1071 }}$ der in der Bundesrepublik lebenden Bürgerinnen und Bürger mit Migrationshintergrund, sondern auch eine Ausgrenzung und „Super-Diskriminierung“'1072 dieser.

Die Voraussetzungen der Ausländerpolitik der Bundesrepublik Deutschland waren so vor dem Jahrtausendwechsel alles andere als optimal und förderlich für den gesellschaftlichen und sozialen Frieden. Durch die Wirtschaftskrise im Jahr 1994 konnte die Einwanderungsdebatte zwar überlagert bzw. minimiert werden, jedoch bedeutete dies keinesfalls das Ende der Diskussionen um Migration und Einwanderung, wie die heutige gesellschaftliche Situation beweist. ${ }^{1073}$ Die Streitthemen wurden kurzzeitig lediglich durch neue Fragen nach Einbürgerungspraktiken und doppelter Staatszugehörigkeit überlagert, keinesfalls jedoch endgültig

\footnotetext{
1067 Leggewie 1993, a. a. O., S. 5.

1068 Vgl. Herbert 2003, a. a. O., S. $321 \mathrm{ff}$.

1069 Vgl. Bukow, Wolf-Dietrich (1992): Ethnisierung und nationale Identität, in: Institut für Migrations- und Rassismusforschung e. V. (Hrsg.): Rassismus und Migration in Europa. Beiträge des Kongresses „Migration und Rassismus in Europa“ Hamburg, 26. bis 30. September 1990, Hamburg, S. 139.

1070 Vgl. Balke, Friedrich et al. (1993): Vorwort, in: Balke, Friedrich et al. (Hrsg.): Schwierige Fremdheit. Über Integration und Ausgrenzung in Einwanderungsländern, Frankfurt/Main, S. IX.

1071 Balke et al. 1993, ebd., S. X.

1072 Balke et al. 1993, ebd., S. X.

1073 Vgl. Herbert 2003, a. a. O., S. $330 \mathrm{ff}$.
} 
gelöst. ${ }^{1074}$,Deutschsein“ und ,nicht-deutschsein' aufgrund sowohl biologistischer als auch sozialer und kultureller Argumentationsschemata bleibt bis heute ein debattiertes Themengebiet:

\section{„So befand sich die Diskussion um die Zuwanderung von Ausländern wieder dort, wo} sie immer endete - bei der Frage: ,W as ist deutsch?" "1075

Jedoch konnte die rot-grüne Bundesregierung unter Bundeskanzler Gerhard Schröder im Jahr 1998 einen Entwurf bezüglich einer Novellierung des Staatsangehörigkeitsrechts vorlegen und damit einen neuen Elan in der Ausländer- und Einwanderungsdebatte ermöglichen. ${ }^{1076}$ Seit Januar 2005 existiert weiterhin ebenfalls angestoßen durch die rot-grüne Koalition - das erste Mal in der Geschichte der Bundesrepublik Deutschland ein Zuwanderungsgesetz, welches die gesamte Migrationspolitik umfasst. ${ }^{1077}$ Seit 2005 kann demzufolge offiziell festgestellt werden, dass die Bundesrepublik in den Status der Einwanderungsländer auch politisch akzeptiert - aufgestiegen ist. ${ }^{1078}$ Dies markiert sozusagen den Höhepunkt der politischen Bemühungen um eine transparente Ausländergesetzgebung in Deutschland, jedoch keinesfalls das Ende der rassistischen und einwanderungskritischen Tendenzen in der bundesrepublikanischen Bevölkerung.

Nichtsdestotrotz kann am Ende des ersten Jahrzehnts des 21. Jahrhunderts eine neue Konjunktur des Rassismusphänomens identifiziert werden (s. Kapitel 3). Bezüglich der auch politisch umstrittenen Frage nach einem neuen angeblichen Ausländerproblem in der Bundesrepublik kann heute folglich direkt an die 1990er Jahre angeknüpft werden: Deutschland als Einwanderungsland? Wilfried Schubarth lag demzufolge mit seiner zu Beginn der 1990er Jahre getroffenen Zukunftsprognose mehr oder weniger richtig:

„W as die Prognosen für die Zukunft betrifft, so braucht man kein Prophet zu sein, um angesichts der anbaltenden sozialen Probleme insbesondere in Ostdeutschland, der sich eventuell verschärfenden Verteilungskonflikte zwischen Ost und West, der zunehmenden $W$ anderungsbewegungen in Europa usw. ein weiteres Anwachsen des Konfliktpoten zials zwischen Deutschen und Ausländern zu prophezeien. "1079

Die in den 1990er Jahren geäußerte Gefahr, dass sich der Neorassismus in Deutschland etabliere, ist so zum Großteil eingetreten. Jedoch muss heute wieder der originäre Rassismusbegriff angewandt werden, da zusätzlich zu den eher kul-

1074 Vgl. Herbert 2003, a. a. O., S. 330ff.

1075 Herbert 2003, a. a. O., S. 334.

1076 Vgl. Herbert 2003, a. a. O., S. 332ff. | Vgl. Rahner, Sven (2011): Fachkräftebedarf und Zuwanderung: Geschichte und Perspektiven, in: Aus Politik und Zeitgeschichte, Beilage zur Wochenzeitung Das Parlament, 43/2011, 61. Jahrgang, Bonn, S. 32.

1077 Vgl. Finkelstein 2006, a. a. O., S. 34.

1078 Vgl. Tanner, Jakob (1994): Nationalmythos und „Überfremdungsängste“. Wie und warum die Immigration zum Problem wird, dargestellt am Beispiel der Schweizer Geschichte des 19. und 20. Jahrhunderts, in: Rauchfleisch, Udo (Hrsg.): Fremd im Paradies. Migration und Rassismus, Basel, S. $11 \mathrm{ff}$.

1079 Schubarth 1993, a. a. O., S. 180-181. 
turell begründeten Vorurteilen des Neorassismus wieder pseudobiologische Differenzen zwischen ,Deutschen' und ,Fremden' - direkt und indirekt - eine gewichtige Rolle spielen (s. Kapitel 3, 5). Folglich ist es weniger geboten von einer Etablierung des Neorassismus der 1990er Jahre, sondern vielmehr von einem gewandelten, modernisierten Rassismusphänomen zu sprechen. Die zunehmende öffentliche Fokussierung auf das Problem des Rassismus mag im 21. Jahrhundert neu sein, nicht aber das Problem selbst, wie der bisherige Verlauf illustriert. ${ }^{1080}$ Grundsätzlich neu ist jedoch, dass wir heute von einem tendenziell gesamtgesellschaftlichen Problem sprechen müssen - Rassismus ist nicht mehr nur ein Randphänomen von rechtsorientierten Gruppierungen, sondern Charakteristikum vieler Bereiche der Gesellschaft (s. Kapitel 3, 3.1, 3.2). ${ }^{1081}$ Der uniforme, angeblich nur kulturell begründete sogenannte Neorassismus hat sich im 21. Jahrhundert in ein modernisiertes Rassismusphänomen gewandelt, welches sich aus vielfältigen Vorurteilen - insbesondere wieder mit direktem biologistischem Hintergrund - entwickelt. Diese Entwicklungen beschränken sich nicht nur auf die Bundesrepublik Deutschland, sondern sind innerhalb der gesamten Staatengemeinschaft der Europäischen Union als Phänomen der europäischen Entwicklung zu identifizieren (s. Kapitel 2, 3.6). ${ }^{1082}$

\subsection{4 ,Überflutung' und ,Überfremdung' Deutschlands? Einwanderung in Zahlen}

Die Dynamik von Einwanderung ist, wie die vorherigen Kapitel veranschaulichen, oftmals mit rassistischen Zuschreibungen verknüpft. Hier muss insbesondere auf den Wahlkampf im Rahmen der Europawahl 2014 verwiesen werden, den zahlreiche konservative sowie rechte Parteien für eine vehemente Warnung vor einer intensivierten Einwanderung in die EU nutzten. Deren Wahlerfolg symbolisiert den bevölkerungsweiten Zuspruch zu diesen fremdenfeindlichen und diskriminierenden Thesen. Das folgende Kapitel illustriert jedoch anhand eines kurzen Einblicks in die aktuelle Bevölkerungsentwicklung Deutschlands, dass populistischen ,Überflutungs-' sowie ,Überfremdungsszenarien' eine eindeutige Absage erteilt werden muss. ${ }^{1083}$ Belegt werden kann ebenfalls, dass die Klassifizierung von spezifischen Menschengruppen sich schon aufgrund statistischer Daten unwahrscheinlich zeigt. Statistisch gesehen muss beachtet werden, dass die deutsche Bevölke-

\footnotetext{
1080 Vgl. Buntenbach, Annelie (2001): Blicke auf Asylpolitik und Antidiskriminierungsgesetz - was tun gegen Rechtsextremismus und Rassismus, in: Arndt, Susan (Hrsg.): AfrikaBilder. Studien zu Rassismus in Deutschland, Münster, S. 405ff.

1081 Vgl. Buntenbach 2001, ebd., S. 407ff.

1082 Vgl. Balibar 1992, a. a. O., S. 10ff. | Vgl. Rieker, Peter (2007): Fremdenfeindlichkeit und Sozialisation in Kindheit und Jugend, in: Aus Politik und Zeitgeschichte, Beilage zur Wochenzeitung Das Parlament, 37/2007, 57. Jahrgang, Bonn, S. 31.

1083 Zur statistischen Visualisierung dieses Sachverhaltes wird auf die aktuellen Daten des Statistischen Bundesamtes DESTATIS zurückgegriffen.
} 
rung im Hinblick auf deren Migrationsstatus nur in ,Inländer und ,Ausländer`, im Gegensatz zum Begriff der ,Migranten‘, differenziert wird. ${ }^{1084}$

„Als Ausländer gelten alle Personen, die nicht Deutsche im Sinne von Art. 116 Abs. 1 GG sind, d. h. nicht die deutsche Staatsangehörigkeit besitzen, wobei zu den Ausländern auch Staatenlose zählen. Dies können direkt zugezogene Personen mit einer ausländischen Staatsangehörigkeit sein oder auch deren im Land geborene Nachkommen, die selbst keine Migranten sind, sofern sie nicht die deutsche Staatsangehörigkeit besitzen. "1085 „ZZur Bevölkerungsgruppe mit Migrationshintergrund zählen hingegen] neben allen nach Deutschland Zugewanderten und allen im Inland mit fremder Staatsangehörigkeit Geborenen auch die hier geborenen Deutschen mit zumindest einem Elternteil, der zugewandert ist oder als Ausländer in Deutschland geboren wurde. "1086

Diese definitorischen Einteilungen werden, insbesondere im Bereich Migration und Asyl, durch vielfältige gesetzliche Grundlagen verankert. ${ }^{1087}$

Wie in der nachfolgenden Grafik zu erkennen ist, kann seit dem Jahr 1995 keinesfalls mehr von einem enorm steigenden Wachstum der ausländischen Bevölkerung gesprochen werden. ${ }^{1088}$ Bis 1995 lässt sich statistisch gesehen ein kontinuierlich ansteigender Trend der ausländischen Bevölkerung in der Bundesrepublik Deutschland auf etwa 7,2 Millionen Menschen feststellen. ${ }^{1089}$ Auch der Bevölkerungsanteil der ausländischen Bevölkerung ist lediglich bis in das Jahr 1995 auf etwa 8,9 Prozent angestiegen - die einzige Abweichung bildet eine kurzzeitige

1084 Vgl. Schimany, Peter (2007): Migration und demographischer Wandel, Forschungsbericht 5, Nürnberg, S. 25.

Diese Begriffsdifferenzierung kann einscbränkend auch nur für die Bundesrepublik. Deutschland gelten, da eine international einheitliche Definition aufgrund der mangelnden, spracblichen Vergleichbarkeit der Begrifflichkeiten schwierig erscheint. Beachtet werden muss bei der Begriffsbestimmung des, Migrationshintergrundes" ₹usätzlich, dass dieser auch in der Bundesrepublik. Deutschland keinesfalls übereinstimmend geregelt ist, da die Definitionen der Bundesländer zum Teil von denen des Statistischen Bundesamtes DESTATIS variieren. Vgl. Borchers, Kevin/Breustedt, Wiebke (2008): Die Datenlage im Bereich der internationalen Migration. Europa und seine Nachbarregionen, Working Paper 18, Nürnberg, S. 24. Schimany 2007, ebd., S. 28.

1086 Grobecker, Claire/Krack-Rohberg, Elle (2008): Bevölkerungsstand und Bevölkerungsentwicklung, in: Statistisches Bundesamt Destatis (Hrsg.): Datenreport 2008. Ein Sozialbericht für die Bundesrepublik Deutschland, Bonn, S. 18.

1087 Bezüglich der umfangreichen Gesetze und Vorscbriften im Bereich der Asyl- und Zuwanderungspolitik - als exemplarische Beispiele seien bier Art. 16 a Abs. 1 GG, der sich mit der Aufnabme von Verfolgten als Asylberechtigte beschäftigt, und das novellierte Zuwanderungsgeset», in Kraft getreten am 01. Januar 2005, genannt - wird auch aufgrund der Komplexität von europäischen und bundesländerspezifischen Charakteristika auf die nachfolgende Literatur verwiesen. Vgl. Schneider 2009, a. a. O., S. $14 \mathrm{ff}$.

1088 Vgl. Grobecker/Krack-Rohberg 2008, a. a. O., S. 20. | Vgl. Statistisches Bundesamt Destatis (2011b): „Wanderungen von Deutschen/Ausländer/-innen zwischen Deutschland und dem Ausland ab 1991", in URL:

http://www.destatis.de/jetspeed/portal/cms/Sites/destatis/Internet/DE/Navigation/Statisti ken/Be-voelkerung/Wanderungen/Tabellen.psml <19.08.2012>.

1089 Vgl. Grobecker/Krack-Rohberg 2008, a. a. O., S. 20. | Vgl. Statistisches Bundesamt Destatis 2011b, a. a. O. 
Abnahme der Prozentwerte in den Jahren 1990 bis 1991, die dem Prozess der deutschen Wiedervereinigung geschuldet ist. ${ }^{1090}$

Seit dem Jahr 1995 lässt sich jedoch innerhalb der Bundesrepublik eine Stagnation der Zahl der ausländischen Mitbürgerinnen und Mitbürger diagnostizieren. ${ }^{1091}$ Darüber hinausgehend kann im Gegenteil sogar konstatiert werden: Zwischen den Jahren 2006 bis 2010 hat sich sowohl die Anzahl der ausländischen Menschen in Deutschland sowie deren Bevölkerungsanteil auf ungefähr 6,8 Millionen bzw. 8,2 Prozent abgesenkt. ${ }^{1092}$ Der leichte Aufschwung im Jahr 2011 ist hierbei statistisch tendenziell vernachlässigbar. Die novellierten Datengrundlagen auf der Basis des Zensus 2011 identifizieren sogar einen noch geringeren Anteil nichtdeutscher Bürgerinnen und Bürger von nur 7,9 Prozent. ${ }^{1093}$ Auf dieser Datenbasis lässt sich keinesfalls - zumindest nicht für die vergangenen 15 Jahre - eine vermeintlich ,gefährliche' Steigerung der ausländischen Bevölkerung mit der apokalyptischen Gefahr „Deutschland schaff[e] sich ab“1094 konstatieren. ${ }^{1095}$ Aufgrund der über den langen Zeitraum stattgefundenen Überlappungen, Verknüpfungen und Vermischungen der ausländischen Bevölkerung in Deutschland auf der Grundlage von Eheschließungen oder Familiengründungen können weiterhin keine spezifischen Menschengruppen - biologistisch als auch kulturell - differenziert werden.

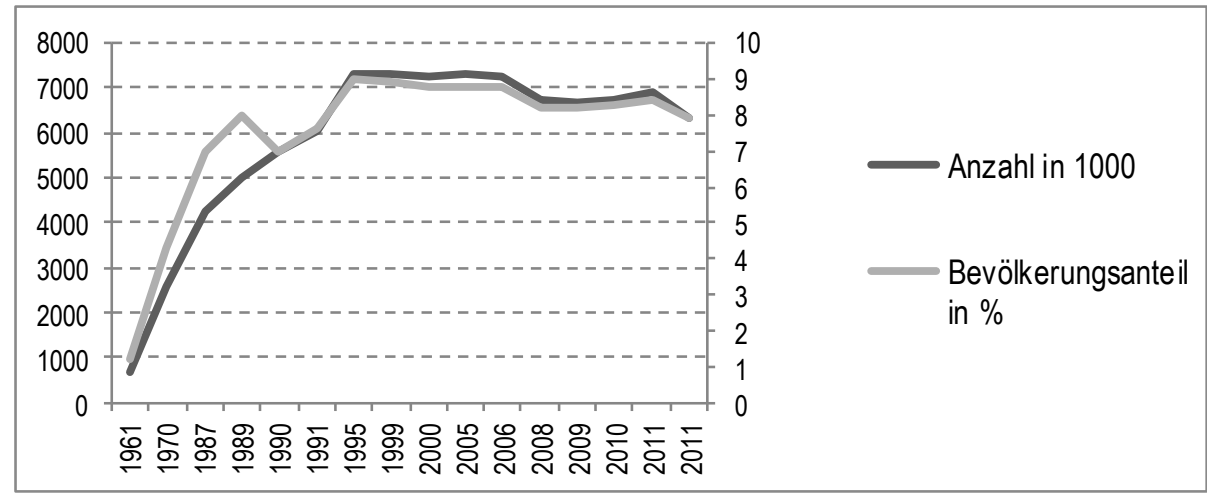

Abb. 10: Entwicklung der ausländischen Bevölkerung Deutschlands seit $1961^{1096}$

1090 Vgl. Grobecker/Krack-Rohberg 2008, a. a. O., S. 20. | Vgl. Statistisches Bundesamt Destatis 2011b, a. a. O.

1091 Vgl. Grobecker/Krack-Rohberg 2008, a. a. O., S. 20. | Vgl. Statistisches Bundesamt Destatis 2011b, a. a. O.

1092 Vgl. Grobecker/Krack-Rohberg 2008, a. a. O., S. 20. | Vgl. Statistisches Bundesamt Destatis 2011b, a. a. O.

1093 Vgl. Statistisches Bundesamt Destatis 2013b, a. a. O., S. 17.

1094 Sarrazin 2010, a. a. O., S. 7.

1095 Vgl. Grobecker/Krack-Rohberg 2008, a. a. O., S. 20. | Vgl. Statistisches Bundesamt Destatis 2011b, a. a. O.

1096 Eigene Darstellung nach: Vgl. Grobecker/Krack-Rohberg 2008, a. a. O., S. 20. | Vgl. Statistisches Bundesamt Destatis 2011b, a. a. O. | Vgl. Statistisches Bundesamt Destatis (2013b): Bevölkerung und Erwerbstätigkeit. Vorläufige Ergebnisse der Bevölkerungsfortschreibung auf der Grundlage des Zensus 2011, Wiesbaden, S. 17. 
Die obigen Erkenntnisse lassen sich ebenfalls zusätzlich durch weitere statistische Daten bestätigen. Konzentriert man sich beispielsweise auf die aktuellen Einbürgerungen in die Bundesrepublik Deutschland, wird man auch hier keineswegs dramatisch ansteigende Zahlen ermitteln, sondern gegenteilig einen absinkenden Trend der Einbürgerungen von ausländischen Mitbürgerinnen und Mitbürgern belegen können. ${ }^{1097}$ Die Einbürgerungen in die Bundesrepublik Deutschland sind vom Jahr 2000 bis zum Jahr 2008 um etwa die Hälfte auf circa 95.000 pro Jahr gesunken. ${ }^{1098}$ Das Statistische Bundesamt DESTATIS schlussfolgert aufgrund dessen in seinem Überblick 2009 treffend:1099

\section{„In Deutschland leben rund 7,2 Millionen Ausländerinnen und Ausländer. Viele sind als Gastarbeiter oder deren Angehörige nach Deutschland gekommen. Sie bereichern das Land mit ihrer Kultur und ihrem Wissen. Deutschland ist für viele ein Land der Mög- lichkeiten. Die Aussicht auf bessere Verdienstmöglichkeiten, aber auch der allgemeine Lebensstandard machen Deutschland für Einwanderer attraktiv. Besonders für Jüngere ist ein Gastaufenthalt in Deutschland erstrebenswert: Fast jede brw. jeder achte Studie- rende an deutschen Hochschulen kommt aus dem Ausland. " 1100}

Noch deutlicher werden die Einwanderungsbewegungen nach Deutschland, wenn man die Wanderungsbewegungen zwischen Deutschland und dem Ausland im zeitlichen Vergleich analysiert. Auch hier kann kein extremer Einwanderungstrend identifiziert werden. Enorme Einwanderungsraten von ausländischen Menschen sind schon seit den 1990 er Jahren nicht mehr zu diagnostizieren. ${ }^{1101}$ Ursache hierfür war der Zerfall der Sowjetunion sowie das Ende des Kommunismus, die mithilfe des sogenannten Eisernen Vorhangs ,[...] die traditionelle Migration auf der Ost-West-Achse [...]“1102 40 Jahre lang verhindert hatten. ${ }^{1103}$ Auch die zahlreichen Flüchtlinge des Jugoslawienkonfliktes in den 1990er Jahren müssen diesbezüglich beachtet werden. Die Anzahl von Zuzügen von ausländischen Bürgerinnen und

\footnotetext{
1097 Der Enwerb der deutschen Staatsangebörigkeit basiert beispielsweise auf der Geburt, auf der Bescheinigung des Spätaussiedlerstatus oder auf der Einbürgerung in die Bundesrepublik Deutschland. Beqüglich der detaillierten Voraussetzungen, von denen eine Einbürgerung in die Bundesrepublik Deutschland abbängt, sowie den organisatorischen und gesetzlichen Formalia zur Erlangung der deutschen Staatsangehörigkeit ist auf die folgende $L i$ teratur zu verweisen: Vgl. Worbs, Susanne (2008): Die Einbürgerung von Ausländern in Deutschland, Integrationsreport, Working Paper 17, 2. Auflage, Nürnberg, S. $11 \mathrm{ff}$.

1098 Statistisches Bundesamt Destatis (2009): Deutschland - Land und Leute, Wiesbaden, S. 32. Vgl. Statistisches Bundesamt Destatis (2011a): „Eingebürgerte Personen“, in URL: http://www.destatis.de/jetspeed/portal/cms/Sites/destatis/Internet/DE/Navigation/Statisti ken/Bevoelkerung/MigrationIntegration/Eingebuergerte/Eingebuergerte.psml $<19.08 .2012>$.
}

1099 Vgl. Statistisches Bundesamt Destatis 2009, a. a. O., S. 32.

1100 Statistisches Bundesamt Destatis 2009, a. a. O., S. 32.

1101 Vgl. Grobecker/Krack-Rohberg 2008, a. a. O., S. 17. | Vgl. Statistisches Bundesamt Destatis 2011 b, a. a. O.

1102 Heßler 1993b, a. a. O., S. 14.

1103 Vgl. Heßler 1993b, a. a. O., S. 14ff. 
Bürgern nach Deutschland hat sich vor diesem Hintergrund seit dem Jahr 2003 tendenziell zwischen 570.00 und 800.000 Einwanderern stabilisiert. ${ }^{1104}$

Tab. 14: Wanderungen zwischen Deutschland und dem Ausland ${ }^{1105}$

\begin{tabular}{|c|c|c|c|c|c|c|c|}
\hline & & Zuzüge & & & Fortzüge & & Saldo \\
\hline & $\begin{array}{c}\text { Insge- } \\
\text { samt }\end{array}$ & Deutsche & $\begin{array}{c}\text { Auslän- } \\
\text { der/ - } \\
\text { innen }\end{array}$ & $\begin{array}{c}\text { Insge- } \\
\text { samt }\end{array}$ & Deutsche & $\begin{array}{c}\text { Auslän- } \\
\text { der/ - } \\
\text { innen }\end{array}$ & $\begin{array}{c}\text { Insge- } \\
\text { samt }\end{array}$ \\
\hline $1950-1953$ & 374177 & - & - & 462279 & - & - & -88102 \\
\hline 1954-1959 & 1038759 & 477414 & 561345 & 955190 & 638657 & 316533 & 83569 \\
\hline $1960-1969$ & 6257185 & 724624 & 5532561 & 4239458 & 789119 & 3450339 & 2017727 \\
\hline $1970-1979$ & 7002667 & 783306 & 6219361 & 5439852 & 543843 & 4896009 & 1562815 \\
\hline $1980-1990$ & 7401367 & 1743637 & 5657730 & 5260310 & 744722 & 4515588 & 2141057 \\
\hline 1991-1995 & 6157185 & 1460428 & 4696757 & 3597562 & 577691 & 3019871 & 2559623 \\
\hline 1996 & 959691 & 251737 & 707954 & 677494 & 118430 & 559064 & 282197 \\
\hline 1997 & 840633 & 225335 & 615298 & 746969 & 109903 & 637066 & 93664 \\
\hline 1998 & 802456 & 196956 & 605500 & 755358 & 116403 & 638955 & 47098 \\
\hline 1999 & 874023 & 200150 & 673873 & 672048 & 116410 & 555638 & 201975 \\
\hline 2000 & 841158 & 191909 & 649249 & 674038 & 111244 & 562794 & 167120 \\
\hline 2001 & 879217 & 193958 & 685259 & 606494 & 109507 & 496987 & 272723 \\
\hline 2002 & 842543 & 184202 & 658341 & 623255 & 117683 & 505572 & 219288 \\
\hline 2003 & 768975 & 167216 & 601759 & 626330 & 127267 & 499063 & 142645 \\
\hline 2004 & 780175 & 177993 & 602182 & 697632 & 150667 & 546965 & 82543 \\
\hline 2005 & 707352 & 128051 & 579301 & 628399 & 144815 & 483584 & 78953 \\
\hline 2006 & 661855 & 103388 & 558467 & 639064 & 155290 & 483774 & 22791 \\
\hline 2007 & 680766 & 106014 & 574752 & 636854 & 161105 & 475749 & 43912 \\
\hline 2008 & 682146 & 108331 & 573815 & 737889 & 174759 & 563130 & -55743 \\
\hline 2009 & 721014 & 114700 & 606314 & 733796 & 154988 & 578808 & -12782 \\
\hline 2010 & 798283 & 114752 & 683530 & 670605 & 141000 & 529605 & 127677 \\
\hline 2011 & 958299 & 116604 & 841695 & 678969 & 140132 & 538837 & 279330 \\
\hline
\end{tabular}

Der massive Arbeitskräftebedarf aus den 1950er und 1960er Jahren aufgrund der „[...] fortschreitenden ökonomischen Expansion [... ["1106 der Bundesrepublik Deutschland ist heute nicht mehr anzutreffen, könnte aber in Zukunft aufgrund der tendenziell negativen demographischen Entwicklung der bundesrepublikanischen Gesellschaft eventuell wieder eine Rolle spielen. ${ }^{1107}$ Besonders in den Jahren

1104 Vgl. Grobecker/Krack-Rohberg 2008, a. a. O., S. 17. | Vgl. Statistisches Bundesamt Destatis 2012, a. a. O.

1105 Eigene Darstellung nach: Vgl. Grobecker/Krack-Rohberg 2008, a. a. O., S. 17. | Vgl. Statistisches Bundesamt Destatis 2011b, a. a. O. | Vgl. Statistisches Bundesamt Destatis (2012): „Bevölkerung und Erwerbstätigkeit. Wanderung 2011“, in URL:

https://www.destatis.de/DE/ZahlenFakten/GesellschaftStaat/Bevoelkerung/Wanderungen/ Tabellen/ZuwanderungsgruppenPDF.pdf?_blob=publicationFile $<05.07 .2013>$.

Zum begrifflichen Verständnis folgen hier die Begriffsbestimmungen von $\mathrm{Zu}$-und Abwanderung, angelehnt an die Empfeblungen der Vereinten Nationen: „Zuwanderung ist die Handlung, durch die eine Person ibren üblichen Aufenthaltsort für einen Zeitraum von mindestens zwölf Monaten bzw. von voraussicbtlich mindestens zwölf Monaten in das Hobeitsgebiet eines Mitgliedstaats verlegt, nachdem sie zuvor ibren üblichen Aufentbaltsort in einem anderen Mitgliedstaat oder einem Drittstaat hatte. Abwanderung ist die Handlung, durch die eine Person, die zuvor ibren üblichen Aufenthaltsort im Hobeitsgebiet eines Mitgliedstaats hatte, ibren üblichen Aufenthaltsort in diesem Mitgliedstaat für einen Zeitraum von mindestens zwölf Monaten bzw. von voraussichtlich mindestens zuölf Monaten aufgibt. "Schimany 2007, a. a. O., S. 84.

1106 Ganßloser 1992, a. a. O., S. 45.

1107 Vgl. Ganßloser 1992, a. a. O., S. 45ff. | Vgl. Funcke 1993, a. a. O., S. $21 \mathrm{ff}$. 
2008 und 2009 - Hintergrund könnte die vorherrschende Wirtschafts- und Finanzkrise sein - sind im Vergleich zu den Vorjahren deutlich erhöhte Abwanderungswerte festzustellen. ${ }^{1108}$ Die Folge: In den Jahren 2008 und 2009 lässt sich sogar ein tendenzieller Abwanderungstrend aus Deutschland heraus diagnostizieren. ${ }^{1109}$ Erst seit dem Jahr 2010 kann in Deutschland wieder ein positiver Einwanderungssaldo diagnostiziert werden, der auf eine intensivierte Einwanderung von ausländischen Menschen hinweist. ${ }^{1110}$

Nichtsdestotrotz lassen sich auf der Grundlage der Wanderungsstatistiken zwischen Deutschland und dem Ausland ebenfalls keinerlei Kennzeichen für eine zukünftige ,[...] weitere Massenimmigration von [...] Gruppen aus Afrika, aus Nah- und Mittelost [...]“1111 erkennen, wie beispielsweise Thilo Sarrazin suggeriert. Lediglich auf der gesamteuropäischen Ebene lässt sich ein positiver Einwanderungssaldo ermitteln. ${ }^{1112}$

Betrachtet man im weiteren Verlauf die Verteilung der ausländischen Bevölkerung auf die deutschen Bundesländer, so lassen sich einige länderspezifische Unterschiede feststellen. Die im bundesweiten Vergleich höchste Bevölkerungsdichte von ausländischen Mitbürgerinnen und Mitbürgern ist in den Stadtstaaten Berlin, Bremen, Hamburg sowie im Bundesland Hessen zu beobachten. ${ }^{1113}$ Jedoch lassen sich hierbei statistisch betrachtet mit 17 ausländischen Bürgerinnen und Bürgern pro 1000 Einwohner in Deutschland keine ,erschreckend' hohen Anteile innerhalb der bundesrepublikanischen Bevölkerung identifizieren, wie die populistische Darstellung moderner Rassisten dies vermuten lässt. ${ }^{1114}$ Insbesondere in den ostdeutschen Bundesländern fallen weiterhin die extrem niedrigen Raten ausländischer Bevölkerungsanteile auf, die jedoch durch die in den vorherigen Kapiteln skizzierten gesellschaftlichen Entwicklungen zu erklären sind (s. Kapitel 4.1.2, 4.1.3):1115 „[...] eines der Ergebnisse der DDR-Geschichte. “1116

1108 Vgl. Grobecker/Krack-Rohberg 2008, a. a. O., S. 17. | Vgl. Statistisches Bundesamt Destatis 2011b, a. a. O. | Vgl. Statistisches Bundesamt Destatis 2012, a. a. O.

1109 Vgl. Grobecker/Krack-Rohberg 2008, a. a. O., S. 17. | Vgl. Statistisches Bundesamt Destatis 2011b, a. a. O.

1110 Vgl. Statistisches Bundesamt Destatis 2012, a. a. O. | Vgl. Süddeutsche Zeitung (2013): „Massiver Anstieg bei Zuwanderung. Einwanderungsland Deutschland", in URL:

http://www.sueddeutsche.de/politik/massiver-anstieg-bei-zuwanderung-einwanderungslanddeutschland-1.1667070<14.07.2013>.

1111 Sarrazin 2010, a. a. O., S. 393.

1112 Vgl. Boutang, Yann Moulier (1997): Die Europäische Union als Einwanderungsregion: Probleme und Perspektiven, in: Weber, Albrecht (Hrsg.): Einwanderungsland Bundesrepublik Deutschland in der Europäischen Union, Osnabrück, S. 45.

Europa gilt insbesondere unter den Einwanderinnen und Einwandern als „Die Villa mit fünf Sternen“, als Wunschiziel vieler Migrationsbewegungen. Kiyak, Mely (2008): Europa: Die Villa mit fünf Sternen, in: Aus Politik und Zeitgeschichte, Beilage zur Wochenzeitung Das Parlament, 35-36/2008, 58. Jahrgang, Bonn, S. 3.

1113 Vgl. Statistisches Bundesamt Destatis 2013a, a. a. O.

1114 Vgl. Statistisches Bundesamt Destatis 2013a, a. a. O.

1115 Vgl. Statistisches Bundesamt Destatis 2013a, a. a. O. | Broszinsky-Schwabe 1990, a. a. O., S. $18 \mathrm{ff}$.

1116 Broszinsky-Schwabe 1990, a. a. O., S. 19. 


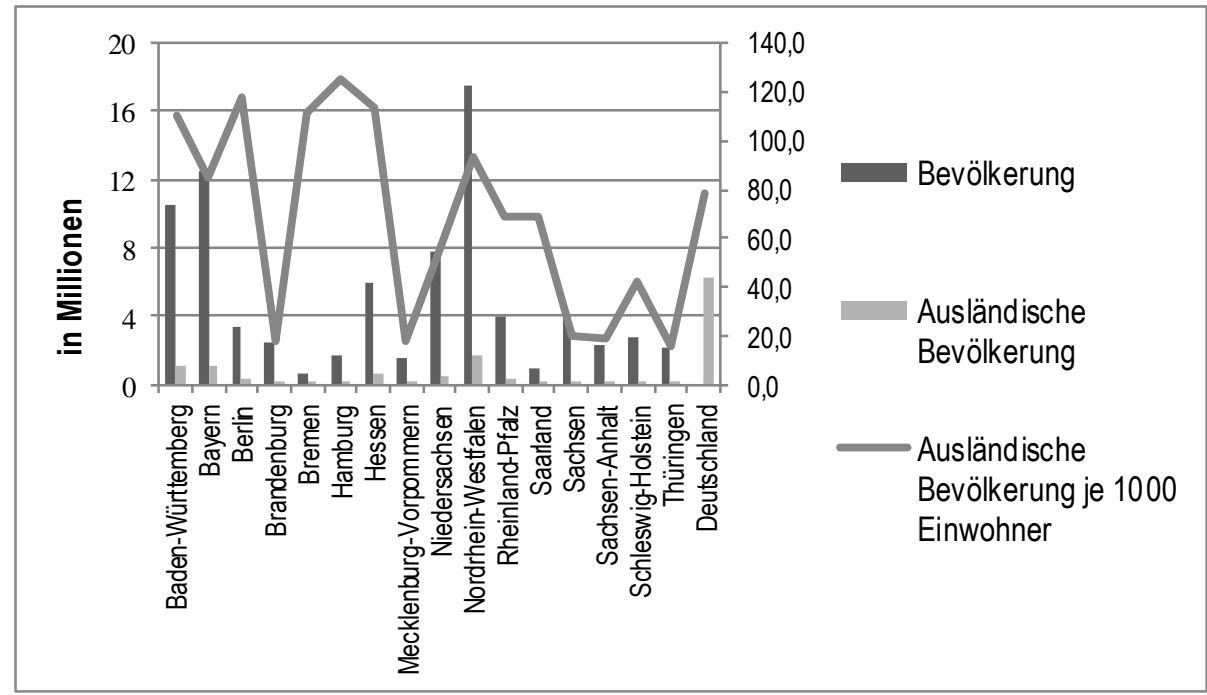

Abb. 11: Ausländische Bevölkerung ${ }^{1117}$

Auch vor dem Hintergrund der deutschen Wiedervereinigung muss so anerkannt werden, dass die „[...] Bundesrepublik [...] heute nicht jenes ökonomisch reiche Land [wäre], das sich das gigantische Experiment leisten [...] [konnte], einen bankrott gegangenen Staat zu übernehmen und dessen Wirtschaft und Infrastruktur binnen weniger Jahre auf das eigene Niveau zu katapultieren, wenn sie nicht von ihrem Beginn an ein Einwanderungsland gewesen wäre."1118 Über dieses bundesrepublikanische Beispiel hinaus muss aus der gegenwärtigen Perspektive anerkannt werden, dass „[d]ie internationale Migration [...] nahezu alle westeuropäischen Industrieländer einschließlich der Bundesrepublik Deutschland faktisch zu Einwanderungsländern gemacht [hat], auch wenn diese das Thema lange begrifflich verdrängt und tabuisiert haben." 1119 In diesem Zusammenhang wird gleichermaßen deutlich, dass sich die Bundesrepublik ihrer neu gewachsenen Verantwortung als Einwanderungsland auch im 21. Jahrhundert nicht entziehen kann. ${ }^{1120}$ „Nowadays almost all countries are affected by international population movements.“1121 Die Ursachenfaktoren für diese Wanderungsbewegungen zeigen sich

1117 Eigene Darstellung nach: Vgl. Statistisches Bundesamt Destatis 2013b, a. a. O., S. 17.

1118 Hoffmann 1993, a. a. O., S. 36.

1119 Weber, Albrecht (1997): Einwanderungsland Bundesrepublik Deutschland in der Europäischen Union - Bestandsaufnahme, Regelungselemente und europäischer Rahmen. Eine Einführung, in: ebd. (Hrsg.): Einwanderungsland Bundesrepublik Deutschland in der Europäischen Union, Osnabrück, S. 9.

1120 Vgl. Weber 1997, ebd., S. $10 \mathrm{ff}$.

1121 Lohrmann, Reinhard (1997): International Migration Dynamics and Immigration Policy in Europe: an Internationale Perspective, in: Weber, Albrecht (Hrsg.): Einwanderungsland Bundesrepublik Deutschland in der Europäischen Union, Osnabrück, S. 31. 
heute vielschichtig. ${ }^{1122}$ Für die zukünftigen Wanderungsbewegungen bleibt zu resümieren:
„Die Migrationsbewegungen in den letzten Jahren und in der Zukunft waren und wer- den nicht nur bedingt sein durch politische Verfolgung, Krieg und Bürgerkrieg. Hunger und Zerstörung der Umwelt werden in zunehmenden Maße Menschen zwingen, ibre an- gestammte Heimat zu verlassen. Daneben wird die Mobilität aber auch aus ökonomi- schen Gründen noch weiter steigen. Da viele Menschen im Osten und Süden in absehba- rer Zeit keine Chance für eine soziale und wirtschaftliche Besserung im Herkunftsstaat seben, werden sie sich auf den Weg in die reichen Länder des Westens und des Nordens machen. " "123

Die Bundesrepublik kann sich ihrer internationalen Aufgabe folglich nicht verweigern - die mit Migrationsprozessen einhergehenden Probleme bedürfen eines gemeinsamen Lösungsweges. ${ }^{124}$ Selbstverständlich benötigt dieser Integrationsprozess Zeit und vor allem das Verständnis der einheimischen Bevölkerung, denn „[...] Probleme der Ausländerfeindlichkeit, des Rassismus und der interethnischen Konflikte [...] [sind] nur auf [der] Gemeinschaftsebene [...]“1125 zu lösen. ${ }^{1126}$ Rassistische und pseudobiologische Forderungen nach einem Stopp der angeblichen ,Überfremdung' stellen vor diesem Hintergrund nur eines dar: Den Missbrauch bevölkerungsstatistischer und naturwissenschaftlicher Erkenntnisse sowie eine existenzielle Gefährdung des deutschen Wohlfahrts- und Sozialstaates.

Eine bisher unzureichend absolvierte Hauptaufgabe der Politik wird so insbesondere in Zukunft die Förderung der Integration mit dem Ziel des Abbaus von Fremdenfeindlichkeit und Rassismus sein. ${ }^{1127}$ Deutschland benötigt eine intensive Weiterentwicklung der Einwanderungs- und Migrationspolitik: „Es gilt, Vorurteile zu überwinden und die äußeren und inneren Voraussetzungen für Begegnung und Verständigung zu treffen." 1128 Die endgültige Durchsetzung der Diskriminierungsverbote nach Art. 3 GG sollte so eine vordringliche Aufgabe der politischen

1122 Vgl. Lohrmann 1997, a. a. O., S. $31 \mathrm{ff}$.

Eine detailliertere Diagnose der Hintergründe heutiger W anderungsbewegungen gibt Reinhard Lohrmann in der oben genannten Literaturempfeblung.

1123 Wollenschläger, Michael (1997): Rechtlicher Rahmen und Voraussetzungen einer Zuwanderungsgesetzgebung, in: Weber, Albrecht (Hrsg.): Einwanderungsland Bundesrepublik Deutschland in der Europäischen Union, Osnabrück, S. 198.

1124 Vgl. Lohrmann 1997, a. a. O., S. 31 f.

1125 Boutang 1997, a. a. O., S. 46.

1126 Vgl. Lohrmann 1997, a. a. O., S. 31-32, $39 \mathrm{ff}$.

1127 Vgl. Oberndörfer, Dieter (1993): Vom Nationalstaat zur offenen Republik - Zu den Voraussetzungen der politischen Integration von Einwanderung, in: Heßler, Manfred (Hrsg.): Zwischen Nationalstaat und multikultureller Gesellschaft. Einwanderung und Fremdenfeindlichkeit in der Bundesrepublik Deutschland, Berlin, S. 61.

1128 Funcke 1993, a. a. O., S. 27. | Vgl. Rahner 2011, a. a. O., S. 35. | Vgl. Lange, Jörg (2008): Migration und die Allgemeine Erklärung der Menschenrechte von 1948, in: Aus Politik und Zeitgeschichte, Beilage zur Wochenzeitung Das Parlament, 46/2008, 58. Jahrgang, Bonn, S. 21. 
Akteure darstellen. ${ }^{1129}$ Als Orientierung könnten die Vereinigten Staaten von Amerika dienen, die in den Einwanderern ,[...] vornehmlich die Chance [sehen] zu einer Regeneration der intellektuellen und ökonomischen Ressourcen ihres Landes. "1130 beizutragen. Für die zukünftigen Entwicklungsperspektiven der Bundesrepublik Deutschland bleibt so zu folgern:

„Republiken orientieren ibre Politik am Ziel der politischen Einheit aller Menschen. [...] Für [...] Deutschland und Europa bedeutet dies, dass sie in Zukunft die weltbürgerlichen Prämissen ibrer eigenen Verfassungen stärkere politische Gestalt gewinnen lassen müssen. [...] Die notwendige Verwirklichung einer [für Ausländer] offenen Republik wird sicherlich konfliktreich sein. Diese Konflikte können aber auch die Quelle neuer Dynamike und Vitalität werden. [...] Der Weg zur offenen Republik bedeutet für viele, vor allem ältere Deutsche, den Abschied von der überlieferten, ja Entfremdung von der sich verändernden politisch-kulturellen Heimat. Das Durchmessen dieses W eges wird lange Zeit brauchen und allen, den Altbürgern wie den Neubürgern, viel abverlangen." "1131

Deutschland gilt so im 21. Jahrhundert als weltweit etabliertes Einwanderungsland - eine Ablehnung oder gar Blockade - wie in den 1980er und 1990er Jahren geschehen - ist folglich politisch keine Option mehr. ${ }^{1132}$ Dies verdeutlicht auch der zehnte Migrationsbericht des Bundesamtes für Migration und Flüchtlinge: Deutschland ist ein attraktives Hauptzielland für Einwanderung und Migration in Europa. ${ }^{1133}$ „Deutschland ist heute ein Einwanderungsland“1134, so Staatsministerin Maria Böhmer in einer Presseerklärung im Januar 2013.

1129 Vgl. Oberndörfer 1993, a. a. O., S. $61 \mathrm{ff}$.

1130 Fanizadeh, Andreas (1992): Die multikulturellen Freunde und ihre Gesellschaft. Von der harten Flohmarktschule, in: Redaktion diskurs (Hrsg.): Die freundliche Zivilgesellschaft. Rassismus und Nationalismus in Deutschland, Berlin, S. 13.

Aus der Perspektive des 21. Jabrhunderts muss die gegenwärtige Einwanderungspolitik der US A jedoch auch kritisch betrachtet werden, da sich bier in den letziten Jabren deutliche Diskussionen zum Thema Zuwanderung identifizieren lassen. Hintergründe sind beispielsweise die Angst vor einem zu bohen Anteil der Bürgerinnen und Bürger lateinamerikanischer Herkunft oder Debatten um die Einbürgerung von Illegalen - die intensivierte Bewachung der US-amerikanisch-mexikanischen Grenze veranschaulicht die Konsequenzen dieser Diskussionen.

1131 Oberndörfer 1993, a. a. O., S. 65.

1132 Vgl. Funcke 1993, a. a. O., S. 25ff.

1133 Vgl. Rühl, Stefan/Brucker, Paul/Kohls, Martin/Lederer, Harald/Dabkowski, David (2013): Migrationsbericht des Bundesamtes für Migration und Flüchtlinge im Auftrag der Bundesregierung. Migrationsbericht 2011, Berlin.

1134 Presse- und Informationsamt der Bundesregierung (2013): „Böhmer: ,Deutschland ist ein Einwanderungsland. “", in URL:

http://www.bundesregierung.de/Content/DE/Pressemitteilungen/BPA/2013/01/2013-0130-boehmer-deutschland-einwanderungsland.html $<14.07 .2013>$. 


\subsubsection{Rassismus und Rechtspopulismus: Deutschland und Europa}

Die vorhergehenden Kapitel haben eindrücklich vergegenwärtigt, dass das Phänomen des Rassismus wieder einen Platz in der Mitte der Gesellschaft gefunden hat. Weiterhin wurde deutlich, dass die politische Arena in diesem Zusammenhang nicht von der Verantwortung für diese Entwicklung freigesprochen werden kann. Nichtsdestotrotz müssen in der heutigen Zeit ebenfalls die zahlreichen supra- und internationalen Verflechtungen der Bundesrepublik Deutschland beachtet werden, die den politischen, gesellschaftlichen und ökonomischen Alltag in Deutschland zusätzlich beeinflussen. Aufgrund dessen wird bezüglich der politischen Sphäre noch ein Blick auf mögliche Einflüsse der Europäischen Union geworfen: Welche Einflüsse der EU-Nachbarstaaten sind bezüglich des bundesrepublikanischen Rassismusphänomens zu beobachten?

In der schon angesprochenen Studie „Ist Europa auf dem ,rechten“ Weg?‘“1135 wird detailliert expliziert, dass fremdenfeindliche und rassistische Argumentationsmuster nicht nur auf die Gesellschaft der Bundesrepublik Deutschland begrenzt, sondern vermehrt in vielen Staaten der Europäischen Union zu verorten sind. Auf diese Erkenntnis weisen auch die Datensätze der ebenfalls vorgestellten Studie „Die Abwertung der Anderen“1136 hin (s. Kapitel 3.6). Zusätzlich stellen dies die Rassismuskommission sowie die jährlichen Diskriminierungsberichte der EU fest (s. Kapitel 1, 2).

Eigentlich galt das Phänomen des Rassismus in Europa spätestens seit dem Ende der Kolonialisierung als überholt und nicht mehr zeitgemäß. Im 21. Jahrhundert muss jedoch abermals konstatiert werden, dass rassistische Tendenzen in multiplen Teilen der europäischen Gesellschaften nationenübergreifend zu identifizieren sind. ${ }^{1137}$ Die Grundlagen hierfür stammen nicht nur aus dem 18. Jahrhundert - wie die vorherigen Kapitel illustriert haben -, sondern basieren insbesondere auch auf Ereignissen des 20. Jahrhunderts. ${ }^{1138}$ Vor allem die neue Entwicklung von rassistisch geprägten Politikstilen in vielen Staaten Europas hat dem Rassismusphänomen zu einer revitalisierten Bedeutung verholfen. „[...] Fragen nach Einwanderung und Rasse [... $]^{\text {"1139 }}$ haben in Politik und Gesellschaft scheinbar eine neue Bedeutung erlangt. Auch auf europäischer Ebene ist keineswegs mehr von einem rassistischen Randphänomen zu sprechen, sondern von einem sich aus der Mitte der Bevölkerung entwickelnden Rassismus, der in modernisiertem Gewand in flexiblen Ausprägungen - biologistisch oder kulturalistisch begründet auftaucht. ${ }^{1140}$ „Rassismus entsteht weder am Rand noch in der Mitte, sondern in breiten Bereichen der Gesellschaft [...]." 1141 Diese regenerierten, rassistischen

\footnotetext{
1135 Langenbacher, Nora/Schellenberg, Britta (2011): Ist Europa auf dem „rechten“ Weg? Rechtsextremismus und Rechtspopulismus in Europa, Berlin.

1136 Zick/Küpper/Hövermann 2011, a. a. O.

1137 Vgl. Bojadžijev/Demirović 2002, a. a. O., S. 21.

1138 Vgl. Solomos 2002, a. a. O., S. 162.

1139 Solomos 2002, a. a. O., S. 160.

1140 Vgl. Bojadžijev/Demirović 2002, a. a. O., S. 23.

1141 Bojadžijev/Demirović 2002, a. a. O., S. 23.
} 
Muster haben demnach auch mit zu einer Wiederbelebung des Rassismuskonstrukts geführt. ${ }^{1142}$ Dies veranschaulicht beispielsweise der gegenwärtige Trend des sogenannten Rechtspopulismus. ${ }^{1143}$ Dieser fokussiert zwar primär auf angebliche kulturelle Differenzen zwischen spezifischen Menschengruppen anhand derer Abwertungen und Diskriminierungen vorgenommen werden - der ,Rassebegriff sowie die biologistisch-naturalisierenden Argumentationsschemata sind jedoch indirekt immer noch präsent (s. Kapitel 2, 3). ${ }^{1144}$

Parallel zum Anstieg der rassistischen Ressentiments im wiedervereinigten Deutschland kann folglich - beginnend in den 1990er Jahren - auch auf der Ebene Europas die Entwicklung eines neuen Rassismusphänomens identifiziert werden. ${ }^{1145}$ Dazu beigetragen hat, wie auch in Deutschland, eine neue Dynamik Migration, die den Rassismus modifiziert und an aktuelle Bedürfnisse angepasst hat. ${ }^{1146}$

„Die Migrationsbewegungen nach Deutschland und nach Europa und die Kämpfe der Migration haben selbst zu Verschiebungen beigetragen, die den Rassismus sicherlich nicht aufgelöst, aber seine Reorganisierung befördert haben [...]. "1147

Die tendenziell zunehmende Fremdenfeindlichkeit bzw. der Anstieg von rassistischen Vorurteilen der europäischen Bevölkerung kann so gesehen auch als Folge der angeblich zunehmenden ,Befremdung ${ }^{6}$ verstanden werden. ${ }^{1148}$ Lediglich die einzelnen, nationalen Kontexte differieren heute zum Teil aufgrund von unterschiedlichen Verknüpfungen zwischen Migration und Rassismus. ${ }^{1149}$

Durch die zu Beginn des neuen Jahrtausends aufgekommenen, zahlreichen Evolutionsprozesse der Europäischen Union, haben sich die Entwicklungslinien des Rassismus verändert, was letztlich zu einer vielschichtigen „,...] Rekonfiguratio[n] des Rassismus [...]“1150 führte, wie beispielsweise die heute vorherrschende sogenannte Islamophobie eindrücklich demonstriert. ${ }^{1151}$ Insbesondere eine Diskriminierung und Abwertung von arabischen sowie türkischen Einwanderern ist

\footnotetext{
1142 Vgl. Solomos 2002, a. a. O., S. 161.

1143 Vgl. Bojadžijev/Demirović 2002, a. a. O., S. $21 \mathrm{ff}$.

1144 Vgl. Solomos 2002, a. a. O., S. 167 ff.

1145 Vgl. Müller 1992, a. a. O., S. 25.

1146 Vgl. Bojadžijev 2008, a. a. O., S. $278 f f$.

1147 Bojadžijev 2008, a. a. O., S. 278.

1148 Vgl. Heinrichs, Hans-Jürgen (1993): Von Fluten, Wellen und Strömen, in: Nirumand, Bahman (Hrsg.): Angst vor den Deutschen. Terror gegen Ausländer und der Zerfall des Rechtsstaates, Reinbek bei Hamburg, S. $42 \mathrm{ff}$.

1149 Vgl. Bojadžijev 2008, a. a. O., S. $278 \mathrm{ff}$.

1150 Bojadžijev 2008, a. a. O., S. 280.

1151 Vgl. Bojadžijev 2008, a. a. O., S. 279.

Im Rabmen der Evolutionsprozesse der EU ist insbesondere die Osterveiterung des Staatenbündnisses anzuführen: Im Mai 2004 traten Estland, Lettland, Litauen, Polen, Tschechien, Slowakei, Ungarn, Slowenien, Malta und Zypern der EU bei. Im Januar 2007 folgten Bulgarien und Rumänien, sowie im Juli 2013 Kroatien. Die damit zusammenhängenden Ängste der, Andersartigkeit' sowie der, Überflutung'Deutschlands mit billigen, ausländischen Arbeitskräften forcieren das Anwachsen rassistischer Ressentiments.
} 
verstärkt zu diagnostizieren. ${ }^{1152}$ Schon Ende der 1990 er Jahre wurde diese rassistische Tendenz auch auf europäischer Ebene identifiziert. ${ }^{1153}$ Folglich ist zu registrieren, dass das aktuelle Rassismusphänomen nicht nur allein auf die Bundesrepublik Deutschland begrenzt ist, sondern dass von einem europäischen Rassismus gesprochen werden muss: ${ }^{1154}$ Denn „Auch in Europa [...] geht das Gespenst des Rassismus um." $" 1155$

Um die Verbreitung des rassistischen Trends auf der europäischen Ebene zu ergründen, muss ebenfalls wieder ein Perspektivenwechsel in die Vergangenheit erfolgen, um die Hintergründe einerseits ursächlich verstehen und andererseits auf das 21. Jahrhundert fokussiert - als Erklärungshilfe anwenden zu können. In diesem Zusammenhang gilt insbesondere der Zusammenbruch der Sowjetunion auf europäischer Ebene als Ereignis mit historischer Tragweite bezüglich der Einwanderungsbewegungen. ${ }^{1156}$ Die zusätzlichen Einwanderungsbewegungen aus den ehemaligen Ostblockstaaten sowie die schon vorherrschenden multiplen Interessen und Politiken der einzelnen Mitgliedstaaten, führten in den 1990er Jahren zu einem gewaltigen Konfliktpotenzial.1157 „Europa ist nun der Ort, in dem sich die politischen Probleme der ganzen Welt kristallisieren [... $]^{\text {"1158, }}$, so Étienne Balibar - eine äußerst instabile Situationsanalyse. Zusätzlich galt auch noch das wiedervereinigte Deutschland als Zentrum von gesellschaftlichen und politischen Spannungen. ${ }^{1159}$ Vor diesem Hintergrund wird deutlich, dass sich Migration und Rassismus am Ende des 20. Jahrhunderts als Teile des ,Problems Europa' manifestierten. ${ }^{1160}$ Der Theologe Johann Baptist Metz stellt folglich schon 1993 fest, dass ,,[q]uer durch Europa [...] eine neue Fremdenfeindlichkeit und ein [...] angeschärfter Neorassismus [...]"1161 existent sind. Die Auswirkungen des heutigen Rassismusphänomens stellen demnach eine forcierte Weiterentwicklung der in den 1990er Jahren ausgelösten Krise dar. In diesem Zusammenhang könnte wieder die Frage nach einem politisch motivierten, einem sogenannten ,institutionellen Rassismus' auf EU-Ebene aufgeworfen werden. Diesbezüglich prognostizierte Sozialwissenschaftler Kees Groenendijk schon 1992 vorausblickend, dass das Schengener Zusatzabkommen aus dem Juni 1990 das europäische Rassismusproblem verschärfe:1162 Hier würde eindeutig zwischen Bürgerinnen und Bürgern der

\footnotetext{
1152 Vgl. Bojadžijev 2008, a. a. O., S. $278 f f$.

1153 Vgl. Balibar 1992, a. a. O., S. $27 \mathrm{ff}$.

1154 Vgl. Anthias 1992, a. a. O., S. 101.

1155 Veit/Wiebus 1993, a. a. O., S. 9.

1156 Vgl. Balibar 1992, a. a. O., S. $12 \mathrm{ff}$.

1157 Vgl. Balibar 1992, a. a. O., S. 14.

1158 Balibar 1992, a. a. O., S. 17.

1159 Vgl. Balibar 1992, a. a. O., S. $12 \mathrm{ff}$.

1160 Vgl. Balibar 1992, a. a. O., S. $12 \mathrm{ff}$.

1161 Metz, Johann Baptist (1993): Das Christentum und die Fremden. Perspektiven einer multikulturellen Religion, in: Balke, Friedrich et al. (Hrsg.): Schwierige Fremdheit. Über Integration und Ausgrenzung in Einwanderungsländern, Frankfurt/Main, S. 217.

1162 Vgl. Groenendijk, Kees (1992): Europa 1992: Realitäten, Mythen und Chancen, in: Institut für Migrations- und Rassismusforschung e. V. (Hrsg.): Rassismus und Migration in Europa. Bei-
} 
damaligen Europäischen Gemeinschaft und Nicht-Bürgerinnen und -Bürgern, also Ausländerinnen und Ausländern, differenziert. Darin sieht er ein zukünftiges Gesellschaftsproblem in der heutigen EU, sodass Bürgerinnen und Bürger zweiter oder dritter Klasse kategorisiert werden könnten, die aufgrund von Migrationsbestrebungen in die EU einwandern. ${ }^{1163}$ Aus heutiger Perspektive muss ihm teilweise zugestimmt werden, da der im 21. Jahrhundert in der europäischen Gesellschaft tendenziell verankerte kulturell und biologisch konnotierte Rassismus genau darauf abzielt.

Nichtsdestotrotz muss auch für die EU und Europa festgehalten werden, dass die europäischen Staaten von den vergangenen und anhaltenden Migrationsbewegungen immer noch profitieren. ${ }^{1164} \mathrm{Da}$ die Tendenzen eines demographischen Wandels nicht nur in der Bundesrepublik Deutschland bestehen, sondern ein insgesamt westliches Phänomen darstellen, kann nur mithilfe der Unterstützung von Einwanderern das heutige soziale, gesellschaftliche und ökonomische Potenzial konstant aufrecht erhalten werden.

Kulturalistischer und biologistischer Rassismus stellen sich also mitnichten als rein bundesrepublikanisches Phänomen dar. ${ }^{1165}$ Auch auf der europäischen Ebene sind rassistische Vorurteile in den verschiedenen europäischen Gesellschaften, im vielfältigen Medienangebot sowie auch auf der institutionalisierten, politischen Ebene zu identifizieren. ${ }^{1166}$ Vor diesem Hintergrund kann ein ,„[..] verinner-

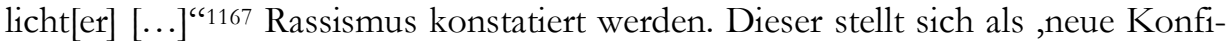
guration“ der rassistischen Ideologie dar, die jedoch definitorisch weit über die neorassistischen Entwicklungen der 1990er Jahre hinausgeht. ${ }^{1168}$ Der heutige Rassismus konstruiert sich aus der aktuellen Wirtschafts-, Finanz- und Eurokrisenkonstellation, einer gewissen rassistischen Tradition der europäischen Gesellschaft sowie einer teilweise institutionalisierten Struktur der gesellschaftlichen und politischen Diskriminierung von Einwanderern. ${ }^{1169}$

„Europas Establishments haben sich [...] darauf geeinigt, bestimmte Konflikte zu Tabus ₹u erklären und ihnen im politischen Diskurs keinen Zentimeter Raum zuzuerkennen. Dąu gehört die Frage auch der Einwanderung, die politisch und vor allem wirtschaftlich in bö̈hstem Grade erwünscht sein mag, aber bei zablreichen Menschen zu sebr

träge des Kongresses „Migration und Rassismus in Europa“ Hamburg, 26. bis 30. September 1990, Hamburg, S. 517.

1164 Vgl. Heinrichs 1993, a. a. O., S. $33 \mathrm{ff}$.

1165 Vgl. Institut für Sozialforschung (1992): Fremdenfeindlichkeit im vereinigten Deutschland. Memorandum, in: ebd. (Hrsg.): Aspekte der Fremdenfeindlichkeit. Beiträge zur aktuellen Diskussion, Frankfurt/Main u. a., S. 9.

1166 Vgl. Butterwegge 2001, a. a. O., S. $104 \mathrm{ff}$.

1167 Arndt 2001c, a. a. O., S. 9.

1168 Vgl. Balibar 1992, a. a. O., S. 18.

1169 Vgl. Balibar 1992, a. a. O., S. $18 \mathrm{f}$. 


\section{realen Alltagsproblemen wie [...] Diskriminierung oder einem Gefübl der Unsicherheit [...] fübrt. " 170}

Eine besorgniserregende Rolle nimmt in diesem Zusammenhang der sogenannte Rechtspopulismus ein, eine modernisierte rechte Bewegung, die nach Politikwissenschaftler Hans-Georg Betz ,[...] ganz darauf abgestellt [ist], in der Bevölkerung latent und offen vorhandene Ressentiments aufzugreifen, zu mobilisieren und emotional aufzuheizen und daraus politisches Kapital zu schlagen [...]“"1171. Dieser kann als neue politische und gesellschaftliche Strömung bezeichnet werden, ,[...] [die] im Namen der Freiheit Antisemitismus und Rassismus gegenüber Juden und Migranten in den Rang des guten und selbstverständlichen gesellschaftlichen Tons erhebt."1172 Der Rechtspopulismus greift folglich die lange Tradition des Rassismus wieder in neuem, modernisierten Gewand auf und re-etabliert ihn in breiten Bereichen der europäischen Gesellschaft. ${ }^{173}$ Hierbei greift er nicht nur auf kulturelle Begründungsparameter zurück, sondern integriert zunehmend biologisch-genetische Erklärungsstrukturen. Dabei bedient er sich sprachlicher Codes, wie die Benutzung des Begriffs ,Kultur ${ }^{6}$ anstatt ,Rasse`, oder die indirekte Artikulierung von Andeutungen und Unterschwelligkeiten, um nicht per se als eindeutig biologistisch-rassistisch klassifiziert zu werden. ${ }^{1174}$ Also wird hier das biologistisch-genetische Erklärungsmuster durch ein kulturalistisches Verständnis, das in weiten Teilen der Bevölkerung weniger Abwehrtendenzen produziert, verdeckt. Der Rechtspopulismus kreiert somit ein neues Bild der ,Anderen', die als Randgruppen im Sinne des gegenwärtigen Rassismus systematisch ausgegrenzt, abgewertet und diskriminiert werden. ${ }^{1175}$

Tab. 15: Kriterien des Rechtspopulismus ${ }^{1176}$

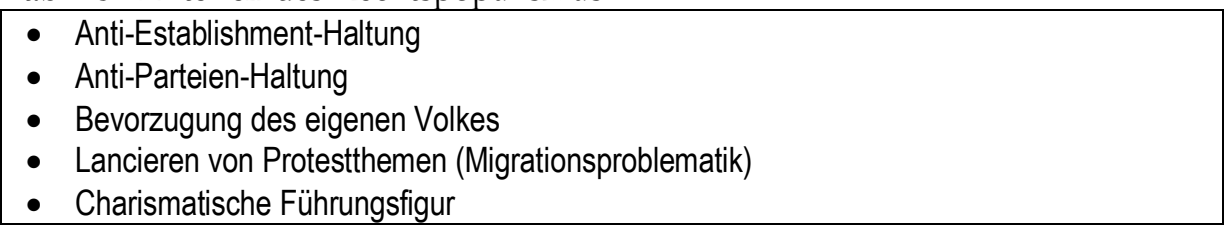

1170 Schümer, Dirk (2002): „Rechtspopulismus ist der neue Trend in Europa“, in: Frankfurter Allgemeine Zeitung Nr. 114, 18.05.2002, S. 45.

1171 Betz, Hans-Georg (1998): Rechtspopulismus: Ein internationaler Trend?, in: Aus Politik und Zeitgeschichte, Beilage zur Wochenzeitung Das Parlament, B 9-10, 3-12, Bonn, S. 5.

1172 Bojadžijev/Demirović 2002, a. a. O., S. 10.

1173 Vgl. Bojadžijev/Demirović 2002, a. a. O., S. 21.

1174 Vgl. Bailer, Brigitte (2004): Partei- statt Metapolitik. „Neue Rechte“ und FPÖ in Österreich, in: Gessenharter, Wolfgang/Pfeiffer, Thomas (Hrsg.): Die Neue Rechte - eine Gefahr für die Demokratie?, Wiesbaden, S. 167.

1175 Vgl. Kreisky, Eva (2002): In Konvergenz der Interessen: Neoliberale Praktiken und rechtspopulistische Regulierung sozialen Protestes, in: Bojadžijev, Manuela/Demirović, Alex (Hrsg.): Konjunkturen des Rassismus, Münster, S. 54.

1176 Eigene Darstellung nach: Reuter, Gerd (2009): Rechtspopulismus in Belgien und den Niederlanden. Unterschiede im niederländischsprachigen Raum, Wiesbaden, S. 39. 
Weiterhin profitiert er von der lange Zeit vorherrschenden politischen Konzeptlosigkeit in Bezug auf die Einwanderungs- und Ausländerpolitik - dieses ,politische Vakuum' konnte der Rechtspopulismus mithilfe seiner rassistischen Ideologien ausnutzen und „[...] nach dem stigmatisierenden Code: ,Ausländer ${ }^{6}$, ,kriminelle noch dazu'“"1177 bewerten. ${ }^{1178}$ Darüber hinaus sorgen auch die heutige Wirtschafts-, Finanz- und Schuldenkrise sowie die anhaltenden Einwanderungsbewegungen für eine Verbreitung der rechtspopulistischen Theoreme innerhalb der europäischen Gesellschaften. ${ }^{1179}$ Der Rechtspopulismus greift also vielfältige politische und gesellschaftliche Problemfelder auf und ideologisiert bzw. mobilisiert diese.

„All dies deutet darauf hin, dass [Rechts-]Populismus kein homogenes Politikkonzept darstellt, dass mit ihm im Gegenteil eine quiemlich inkohärente Palette von Phänomenen und Merkmalen angesprochen wird. "1180

Das große Problem im Vergleich zum Rechtsextremismus und Rechtsterrorismus ist jedoch, dass sich der Rechtspopulismus aufgrund seiner subtilen Mittel nicht einfach öffentlich dämonisieren bzw. bekämpfen lässt. ${ }^{1181}$ Rechtsextremistische Parteien gelten im 21. Jahrhundert größtenteils als nicht gesellschaftsfähig, rechtspopulistische Parteien hingegen schon. ${ }^{1182}$ Auch in der Bundesrepublik Deutschland sind diese rechtspopulistischen Ideen vermehrt vorhanden. Insbesondere das Parteienspektrum auf der Ebene der Bundesländer lässt populistischen Parteien einen ausreichenden Raum. ${ }^{1183}$ Jedoch wird auch vermehrt auf Bundesebene spekuliert, dass sich hier neue Möglichkeiten für die Etablierung einer rechtspopulistischen Partei eröffnen könnten, insbesondere durch den seit der (Wieder-)Übernahme von Regierungsverantwortung 2005 erfolgten ,Mitte-“ bzw. ,Linksruck' der Unionsparteien CDU und CSU (Christlich-Soziale Union). Eine

1177 Kreisky 2002, a. a. O., S. 55.

1178 Vgl. Kreisky 2002, a. a. O., S. 55.

1179 Vgl. Kreisky 2002, a. a. O., S. $70 f f$.

1180 Kreisky 2002, a. a. O., S. 72.

1181 Vgl. Birsl, Ursula (2002): Der Neoliberalismus in der politischen Mitte: ein gezähmter Rechtspopulismus?, in: Bojadžijev, Manuela/Demirović, Alex (Hrsg.): Konjunkturen des Rassismus, Münster, S. 30ff.

1182 Vgl. Birsl 2002, ebd., S. 35ff.

Berüglich einer Einfübrung in das rechtspopulistische Parteienspektrum Europas ist auf folgende Literaturempfehlungen zu verweisen: Vgl. Reuter 2009, a. a. O., S. 21 ff. | Vgl. Klein, Tanja (2012): Rechtspopulistische Parteien in Regierungsbildungsprozessen: Die Niederlande, Belgien und Schweden im Vergleich, Potsdam. | Vgl. Bathke, Peter/Hoffstadt, Anke (2013): Die neuen Rechten in Europa. Zwischen Neoliberalismus und Rassismus, Köln.

1183 Vgl. Birsl 2002, ebd., S. 31.

Als Beispiel sei bier der Aufstieg - und zugegebenermaßen der schnelle Zerfall - der rechtspopulistischen ,Partei Rechtsstaatlicher Offensive; , kury, Schill-Partei genannt, die 2001 in die Hamburger Bürgerschaft einziehen konnte. Durch eine Regierungskoalition mit der Hamburger CDU und FDP (Freie Demokratische Partei) wurde so dem Rechtspopulismus in Hamburg der Weg in die gesellschaftliche Normalität bzw. Mitte geebnet. Weiterbin kann als aktuelles Beispiel PRO NRW genannt werden, welche von dem forcierten Rassismusphänomen profitiert. Vgl. Birsl 2002, ebd., S. 37. | Vgl. Decker/Kiess/Brähler 2012, a. a. O., S. $13 \mathrm{f}$. 
rechtspopulistische Partei könnte so in Zukunft eine reale Chance haben, sich auch auf der Bundesebene zu etablieren und zu profilieren. ${ }^{1184}$ Darüber hinaus ist mit Politikwissenschaftlerin Ursula Birsl anzumerken:

„Die politische Mitte hat es bisher vermocht, die Existenz einer radikal rechten Partei mit größerer Ausstrablung zu verhindern, jedoch um den Preis, äußerst rechtes und rechtspopulistisches Denken zu integrieren und damit nach rechts zu erodieren. "1185

Diese Tendenz erscheint jedoch nicht überall: Die Neukonstellation einer ,entfesselten' rechtspopulistischen Partei - und damit rassistischer Trends - auf Bundesebene scheint denkbar. ${ }^{1186}$

Auf europäischer Ebene sind solche Konstellationen hingegen in vielen Nachbarstaaten schon Realität. In Österreich gelang im Februar 2000 eine Regierungskoalition zwischen der konservativen Österreichischen Volkspartei (ÖVP) unter Wolfgang Schüssel und der rechtspopulistischen FPÖ unter Jörg Haider. ${ }^{1187}$ Die FPÖ ist als „Sammelbecken“1188 verschiedener politischer Strömungen geprägt von einem kulturalistischen und insbesondere biologistischen Rassismus gegenüber Einwanderern, von einem grassierenden Antisemitismus sowie einer eindeutigen Einbindung der Parteistrukturen in rechtsextreme Lager. ${ }^{1189}$ Die FPÖ verfolgt demnach als angebliche ,[...] demokratische Mitte [...]"1190 eine eindeutig rechtspopulistische Strategie. Im Fokus steht zum einen die Ausländerfrage mit dem Ziel des „Stopp[s] der Überfremdung“"1191 sowie zum anderen die - nur vordergründig - kulturalistisch modernisierte Aktualisierung des Rassismusphänomens. ${ }^{1192}$ Auch die Politikerinnen und Politiker der FPÖ waren damals nur vordergründig demokratische Vertreterinnen und Vertreter, primär gehörten sie der rechtsextremistischen sowie rechtspopulistischen Szene an. ${ }^{1193}$ Das Merkmal der FPÖ in ihrer Regierungszeit war eine gewisse opportunistische Tendenz: Sie bündelte, artikulierte, profilierte und emotionalisierte rassistische Positionen. ${ }^{1194}$ Insbesondere Jörg Haider bediente sich „,[...] allen Regeln der modernen Manipulati-

1184 Diese Annabme wird einerseits durch die hoben Zustimmungswerte der bundesrepublikeanischen Bevölkerung zu rassistischen und fremdenfeindlichen Ressentiments unterstütat, die in großen Teilen auch vom Rechtspopulismus aufgegriffen werden (s. Kapitel 3.6). Andererseits zeigen auch die nicht zu vernachlässigenden Zustimmungswerte zur rechtsextremen NPD in Deutschland, dass diese ein gewisses Wählerpoteñial bindet, welches ansonsten eine rechtspopulistische Partei wählen würde. In diesem Zusammenhang sei auf die Zustimmungswerte in Meckelenburg-Vorpommern von 6,0\% (Landtagswabl 2011), in Sachsen von 5,6\% (Landtagswabl 2009), in Sachsen-Anbalt von 4,6\% (Landtagswabl 2011) oder in Thüringen von 4,3\% (Landtagswabl 2009) bingewiesen. Vgl. Bundeszentrale für politische Bildung 2013, a. a. O. Birsl 2002, a. a. O., S. 48.

1186 Vgl. Birsl 2002, a. a. O., S. 48.

1187 Vgl. Bojadžijev/Demirović 2002, a. a. O., S. 7 ff.

1188 Bailer 2004, a. a. O., S. 168.

1189 Vgl. Bojadžijev/Demirović 2002, a. a. O., S. 7 ff.

1190 Bojadžijev/Demirović 2002, a. a. O., S. $7 \mathrm{ff}$.

1191 Bailer 2004, a. a. O., S. 169.

1192 Vgl. Bailer 2004, a. a. O., S. 172.

1193 Vgl. Bojadžijev/Demirović 2002, a. a. O., S. 8ff.

1194 Vgl. Bojadžijev/Demirović 2002, a. a. O., S. $10 \mathrm{ff}$. 


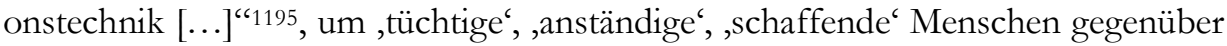
,raffenden', ,untüchtigen` Menschen auszuspielen. ${ }^{1196}$ Mit der Etablierung in der politischen Arena konnten folglich rechtsextremistische, rechtspopulistische und rassistische Ideologien auf politischer Ebene normalisiert und rassistische Ideen auf gesellschaftlicher Ebene forciert werden. ${ }^{1197}$

„Mit diesem Ereignis scheint erstmals in einem Mitgliedstaat der Europäischen Union das Tabu des antifaschistischen Nachkriegskonsenses gebrochen und eine den Nationalsozialismus relativierende, im übrigen vor allem rechtspopulistisch agierende Partei an der Regierungsmacht beteiligt. "198

Die Entwicklungen um die Jahrtausendwende in Österreich können so als ,Prototyp' für die Verbreitung von biologistisch-naturalisierenden, rassistischen und fremdenfeindlichen Potenzialen auf politischer Ebene gesehen werden. ${ }^{1199}$

Als weiteres Beispiel der Verbreitung des europäischen Rechtspopulismus und auch des europäischen Rassismus - kann Italien genannt werden. Auch hier hat sich die populistische Partei ,Popolo della Libertàc (PDL) Silvio Berlusconis durch eine gewisse Nähe zur organisierten Kriminalität und Korruption etabliert. ${ }^{1200}$ Ihr werden zusammen mit der ,Lega Nord' multiple rechtspopulistische Tendenzen vorgeworfen - beispielsweise die Abwertung von angeblichen ,Sozialschmarotzern' als ,Sündenböcke', oder die Hervorhebung von angeblich ethnischen Differenzen zwischen der italienischen Bevölkerung sowie den Bürgerinnen und Bürgern mit Migrationshintergrund. ${ }^{1201}$ Die ,Lega Nord‘ beruft sich offensichtlich auf biologistische Erklärungsmodi zur Diskriminierung der ,Fremden“.

„Von Beginn an setzten die regionalen Ligen und später die Lega [Nord] [...] auf die Verbreitung des Rassismus in der Gesellschaft - mal mehr, mal weniger. Soziale Diskriminierung und Rassismus charakterisiert ihr politisches Handeln, wobei die Lega

1195 Bailer 2004, a. a. O., S. 170.

1196 Vgl. Bailer 2004, a. a. O., S. 170.

1197 Vgl. Birsl 2002, a. a. O., S. $50 \mathrm{ff}$.

1198 Kreisky 2002, a. a. O., S. 50.

Beachtet werden muss jedoch, dass die Mitgliedstaaten der EU nach anfänglichem Zögern mithilfe von Sanktionen gegen Österreich bzw. die ÖVP-FPÖ-Koalition zumindest eingegriffen baben: Unter anderem wurden bilaterale Kontakte auf politischer Ebene zwischen den Mitgliedstaaten der EU und Österreich ausgesetżt. Zur vertieften Einarbeitung in den sperifisch österreichischen Recbtspopulismus der FPÖ/BZÖ (Bündnis Zukunft Österreich) ist exemplarisch auf folgende Literaturempfehlung zu verweisen: Vgl. Gessenharter, Wolfgang/Pfeiffer, Thomas (Hrsg.): Die Neue Rechte - eine Gefahr für die Demokratie?, Wiesbaden.

1199 Vgl. Kreisky 2002, a. a. O., S. $52 \mathrm{ff}$.

1200 Vgl. Bojadžijev/Demirović 2002, a. a. O., S. 17ff. | Vgl. Muzzupappa, Sergio (2013): Die Genese des Berlusconismus, in: Bathke, Peter/Hoffstadt, Anke (Hrsg.): Die neuen Rechten in Europa. Zwischen Neoliberalismus und Rassismus, Köln, S. 126-131. | Vgl. Priester, Karin (2013): Das Phänomen des Berlusconismus, in: Bathke, Peter/Hoffstadt, Anke (Hrsg.): Die neuen Rechten in Europa. Zwischen Neoliberalismus und Rassismus, Köln, S. 132-145.

1201 Vgl. Christen, Christian (2002): Italiens Regierung zwischen autoritärem Neoliberalismus und modernem Rechtsextremismus, in: Bojadžijev, Manuela/Demirović, Alex (Hrsg.): Konjunkturen des Rassismus, Münster, S. 113ff. 


\section{durchaus geschickt agiert, um nicht gänzlich als rassistisch zu gelten. In ibren Positionen zu Migration, sozialen und politischen Rechten für Ausländer finden sich die gleich lau- tenden rassistischen Positionen, wie sie auch von anderen rechten Parteien vertreten wer- den. " 202}

Insbesondere die ,Lega Nord' bedient sich des sozialbiologistischen bzw. sozialdarwinistischen Rassismus, vermischt und verdeckt mit kulturalistischen Elementen. ${ }^{1203}$ Hier wird die Gefahr einer, Verunreinigung، des Volkes durch die Einwanderer konstatiert sowie gar eine Gefährdung der „padanischen Rasse“1204. Rassistische und menschenverachtende Ansichten scheinen so in der ,Lega Nord“ etabliert zu sein. ${ }^{1205}$ Trotz dieser eindeutig rassistischen Tendenzen wird die ,Lega Nord' offiziell nicht als rassistisch, sondern zum Großteil ,nur als rechtspopulistisch klassifiziert. ${ }^{1206}$

Diese Liste der rechtspopulistischen und eindeutig rassistischen Parteien in Europa ließe sich nun noch beliebig weit fortführen und ausdifferenzieren (s. Kapitel 3.6). Resümierend kann konstatiert werden, dass sich Rassismus in Europa wieder in beunruhigendem Maße verbreitet. Schon im Jahr 1994 wurde notiert, dass ,,[d]er neu aufgeflammte Fremdenhass in Europa [...] höchst beunruhigend

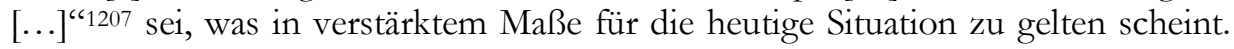
Die durch den Rassismus hervorgerufene „[...] Barbarei und Entmenschlichung

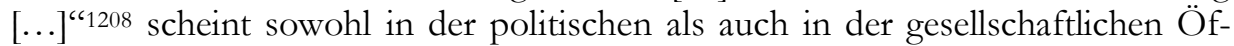
fentlichkeit wieder dauerhaft präsent zu sein. Auch was in Politik und Gesellschaft allgemein ,nur ${ }^{6}$ als fremdenfeindlich oder diskriminierend bezeichnet wird, verortet die „,[...] Rassismustheorie als rassistisch [...]"1209. Überlegungen bezüglich ,Rasse“ und Einwanderung erlangen in Europa eine neue Bedeutung, was der skizzierte Anstieg der zahlreichen rechtspopulistischen und offen rassistischen Bewegungen belegt: Ein Wiederaufstieg des direkt und indirekt biologisch konnotierten Rassismusphänomens ist in Europa zu beobachten. ${ }^{1210}$ Insgesamt kann so ansatzweise eine tendenzielle Bewegung des politischen Klimas in Richtung fremdenfeindlicher Argumentationen identifiziert werden. ${ }^{1211}$ Insbesondere die gesellschaftlichen Reaktionen auf die sich ausbreitende Euro- und Stabilitätskrise der EU könnten sich hier zukünftig zusätzlich negativ bemerkbar machen.

\footnotetext{
1202 Christen 2002, a. a. O., S. 119.

1203 Vgl. Christen 2002, a. a. O., S. 119.

1204 Christen 2002, a. a. O., S. 120.

Die ,Lega Nord' tritt für eine Unabhängigkeit Norditaliens - von der,Lega Nord' Padanien genannt - ein, unter anderem begründet mit einer anderen ,Rassenzugebörigkeit" der sogenannten Padanier.

1205 Vgl. Christen 2002, a. a. O., S. $120 \mathrm{ff}$.

1206 Vgl. Christen 2002, a. a. O., S. $121 \mathrm{ff}$.

1207 Renschler, Regula (1994): Wider das „Global village“. Plädoyer für eine Migrationspolitik, in: Rauchfleisch, Udo (Hrsg.): Fremd im Paradies. Migration und Rassismus, Basel, S. 220.

1208 Bojadžijev/Demirović 2002, a. a. O., S. 20.

1209 Bojadžijev/Demirović 2002, a. a. O., S. 20.

1210 Vgl. Solomos 2002, a. a. O., S. $160 \mathrm{ff}$.

1211 Vgl. Bojadžijev/Demirović 2002, a. a. O., S. 19 ff.
} 
Deutschland nimmt in Europa demzufolge keine Sonderstellung bezüglich der ansteigenden rassistischen Tendenzen ein - in ganz Europa ist Besorgnis angebracht. ${ }^{1212}$ Warum sollte sich ein ,[...] variiertes FPÖ-Phänomen [...]“1213 nicht auch in der Bundesrepublik Deutschland dauerhaft etablieren können? Das notwendige Potenzial zeigt sich jedenfalls vorhanden. Eines wird vorausblickend deutlich: Der rassistische Rechtspopulismus wird sich aus der Mitte der Gesellschaft heraus entwickeln (s. Kapitel 3). ${ }^{1214}$

Kann diesbezüglich nicht doch von einer europäischen Tradition des Rassismus gesprochen werden? ${ }^{1215}$ Ein Rückblick: Im Deutschen Reich galt der Fremdenhass als Mittel zur Herausbildung eines inneren, nationalen Zusammenhaltes der deutschen Bevölkerung. ${ }^{1216}$ Nach der scheinbaren ,Gewöhnung' der deutschen Bürgerinnen und Bürger an die ausländischen Arbeitsmigrantinnen und migranten folgte dann im Verlauf des Ersten Weltkrieges ein Höhepunkt der gewaltsamen Zwangsarbeit von ausländischen Mitmenschen. ${ }^{1217}$ In der Weimarer Republik entwickelte sich der unbegründete Antisemitismus in der deutschen Gesellschaft, der im Verlauf des nationalsozialistischen Regimes zum grauenhaften Höhepunkt der Vernichtung von ,Andersartigen' sowie zu den Schreckensszenarien des Zweiten Weltkrieges führte. ${ }^{1218}$ Jedoch bleibt das Vorhandensein von Fremdenfeindlichkeit sowie des Rassismusphänomens in der deutschen Gesellschaft nach 1945 bzw. 1949 bestehen. ${ }^{1219}$

Darüber hinaus sind die vielfältigen Einflüsse der politischen Ebene - national und supranational - in den vorausgegangenen Kapiteln deutlich geworden. Die fehlerhaften bzw. zögerlichen und unzureichenden Entscheidungen der politischen Arena haben das Phänomen des Rassismus insbesondere in Deutschland sicherlich forciert, so dass im 21. Jahrhundert wieder vor einem in der Mitte der deutschen und europäischen Gesellschaft etablierten Rassismusproblem gesprochen werden kann. Vor allem der überholt geglaubte biologistische Rassismustypus zeigt sich wieder direkt und indirekt auf der gesellschaftlichen und - wie im Falle des Rechtspopulismus - teilweise auf der politischen Agenda präsent. Demzufolge lässt sich auch vor dem Hintergrund „,[...] der kulturalistischen Argumentationen [...] relativ leicht das biologistische Moment freilegen."1220 Mit Ulrich Herbert bleibt zukunftsweisend festzustellen:

1212 Vgl. Kreisky 2002, a. a. O., S. $57 \mathrm{ff}$.

1213 Kreisky 2002, a. a. O., S. 61. | Vgl. Werner, Alban/Gebhardt, Richard (2013): Bedingt abkehrbereit. Warum es in der Bundesrepublik (noch) keine erfolgreiche rechtspopulistische Partei gibt, in: Bathke, Peter/Hoffstadt, Anke (Hrsg.): Die neuen Rechten in Europa. Zwischen Neoliberalismus und Rassismus, Köln, S. 201.

1214 Vgl. Kreisky 2002, a. a. O., S. 61ff.

1215 Vgl. Herbert 2003, a. a. O., S. $335 \mathrm{ff}$.

1216 Vgl. Herbert 2003, a. a. O., S. $335 \mathrm{ff}$.

1217 Vgl. Herbert 2003, a. a. O., S. 336ff.

1218 Vgl. Herbert 2003, a. a. O., S. $337 \mathrm{ff}$.

1219 Vgl. Herbert 2003, a. a. O., S. $339 \mathrm{ff}$.

1220 Bojadžijev/Demirović 2002, a. a. O., S. 16. 


\begin{abstract}
„Masseneinwanderungen, noch dazu in ein Land wie Deutschland, das Grenzen zu neun Nachbarländern hat und am östlichen Rand des europäischen Woblstandsgürtels liegt, sind ebenso wie die damit verbundenen innenpolitischen Auseinandersetzungen, insbesondere die Spannungen zwischen Zuwanderern und sozial schwachen Einheimischen, keine Sonderentwicklungen, sondern der Normalfall. Sich darauf einzustellen, ist weniger ein Gebot der Moral, sondern der Klugheit." "221
\end{abstract}

\title{
4.2 Ökonomie und Rassismus
}

Nach der Fokussierung der Zusammenhänge zwischen Politik und rassistischer Ideologie soll im weiteren Verlauf der Fokus auf mögliche Einflüsse der wirtschaftlichen Rahmenbedingungen sowie der ökonomischen Dynamik auf das Phänomen des Rassismus gelegt werden. Ebenfalls müssen die politischen Rahmenbedingungen mit beachtet werden, die eine soziale Marktwirtschaft ermöglichen.

Mithilfe der diskursanalytischen Aufbereitung von Interviews lässt sich die Angst der bundesrepublikanischen Bürgerinnen und Bürger vor ökonomischen Risiken durch die stattfindenden Einwanderungsbewegungen illustrieren. Die Ängste vor einem ökonomischen Abwärtstrend forcieren ,,[...] naturalisierend[e] und rassistisch[e] Grundhaltung[en] [... $]^{\text {"1222 }}$. Einwanderer gelten vor allem vor dem Hintergrund der vorhanden Arbeitslosigkeit oder aber auch in wirtschaftlichen Krisenzeiten als „Bedrohungen', die Arbeitsplätze blockieren und gefährden. ${ }^{1223}$ Dieser Befund kann auf die Gegebenheiten des 21. Jahrhunderts direkt und unmittelbar übertragen werden: Hier werden aufgrund der anhaltenden bzw. sich tendenziell ausweitenden europäischen Wirtschafts-, Finanz- und Eurokrise Sorgen bezüglich einer ökonomischen Rezession sowie einer finanziellen Inflation in Deutschland, und damit verbunden die Gefährdung unserer Wohlstands- und Wohlfahrtsgesellschaft, genährt. Für diese Sorgen und Ängste fungieren die ausländischen EU-Mitbürgerinnen und -Mitbürger wie schon so oft in der bundesrepublikanischen Geschichte als ,Sündenböcke', auf die die Schuld an den wirtschaftlichen Fehlentwicklungen projiziert werden kann. ${ }^{1224}$ Als Beispiel können die Bevölkerungen der hochverschuldeten Krisenstaaten des Euroraumes - allen voran Griechenland, Italien, Spanien und Portugal - angesehen werden, denen aufgrund der finanziellen Unterstützung durch den IMF (International Monetary Fund) sowie des Rettungsschirms der europäischen Staatengemeinschaft eine zu-

1221 Herbert 2003, a. a. O., S. 345.

1222 Jäger 1992b, a. a. O., S. 35.

1223 Vgl. Jäger 1992b, a. a. O., S. 36ff.

1224 Vgl. Höhler, Gerd (2011): „Der Euro entzweit Deutsche und Griechen. Ende einer Freundschaft", in URL: http://www.fr-online.de/schuldenkrise/der-euro-entzweit-deutsche-undgriechen--ende-einer-freundschaft,1471908,8583708.html <12.08.2013>. | Vgl. Berliner Morgenpost (2013): „Deutsche sind gegen neue Hilfen für Griechenland“, in:

http://www.morgenpost.de/politik/article111703137/Deutsche-sind-gegen-neue-Hilfen-fuerGriechenland.html <12.08.2013>. 
nehmende Abneigung gegenüber steht. Sie werden als faul, unprofitabel, unproduktiv, ,Parasiten' und ,Sozialschmarotzer' bezeichnet. Ein Blick in die Vergangenheit zeigt ein ähnliches Phänomen im Rahmen der deutschen Wiedervereinigung: Auch hier galten die sogenannten Ausländerinnen und Ausländer aus der Perspektive der ehemaligen Bürgerinnen und Bürger der DDR als Konkurrenten um Arbeitsplätze und den durch die Wiedervereinigung erhofften Wohlstand (s. Kapitel 4.1.2). ${ }^{1225}$ Schon in den 1990er Jahren wurde demnach wissenschaftlich validiert, dass Zeiten hoher Arbeitslosigkeit und die damit zusammenhängenden wachsenden Existenzängste in der Bevölkerung zu einer Rückkehr rassistischer Vorurteile und Ressentiments beitragen. ${ }^{1226}$ Die wirtschaftlichen Entwicklungen und deren Auswirkungen auf den bundesrepublikanischen Arbeitsmarkt scheinen also direkt mit dem Phänomen des Rassismus verknüpft zu sein.

Im Zuge eines Perspektivenwechsels auf die Seite der Einwanderer muss jedoch nachdrücklich konstatiert werden, dass diese positive Anreize für die bundesrepublikanische Wirtschaft ermöglicht haben. Sie eröffneten der Wirtschaft die Chance, jederzeit auf billige Arbeitskräfte zurückgreifen und diese als „Mobilitätsreserve“"1227 flexibel einsetzen zu können. ${ }^{1228}$ Insbesondere im Verlauf der sogenannten Gastarbeiterära in den 1960er und 1970er Jahren galten die ausländischen Arbeitskräfte als „[...] konjunkturelles Ausgleichsinstrument [...]“1229, als schnelle Reaktionsmöglichkeit auf sich verändernde ökonomische Bedingungen und einen sich verändernden Arbeitskräftebedarf. Die ausländischen Arbeitskräfte repräsentierten sozusagen einen flexibel einsetzbaren Arbeitskräftepool, eine „Flexibilitätsreserve“"1230, der für die bundesrepublikanische Wirtschaft eine durchweg kostengünstige Alternative darstellte, um auf den schwankenden Konjunkturverlauf optimiert zu reagieren. ${ }^{1231}$ Diese Tatsache gilt bis heute: ,[.....] viele ausländische Arbeitnehmer dienen [...] als Randbelegschaft zur Stabilisierung der Stammbelegschaft." ${ }^{232}$ Die Soziologin Cintia Meier-Mesquita geht diesbezüglich noch einen Schritt weiter und identifiziert den durch wirtschaftliche Flexibilität sowie Ausbeutung entstandenen Rassismus als moderne Sklaverei. ${ }^{1233}$ Der Begriff ,Sklaverei“ deutet hier schon auf die pseudobiologischen Rassismuscharakteristika hin, da hier

1225 Vgl. Poutrus et al. 2001, a. a. O., S. 197. | Vgl. Krüger-Potratz 1991b, a. a. O., S. 3.

Die skizzierten Entwicklungen sind jedoch - über Deutschland binaus gesehen - gerade in den genannten Staaten zu erkennen. Der beispielsweise in Griechenland vorberrschende Rassismus sowie die dort stattfindenden rassistisch motivierten Gewalttaten sind erschreckend. Bedenklich sind insbesondere die Wablerfolge der rassistischen sowie nationalistischen Partei, Goldene Morgenröte; die sogar im griechischen Parlament vertreten ist. Vgl. Zeit Online (2013): „Griechische Neonazis hetzen gegen Türkei“, in URL: http://www.zeit.de/politik/ausland/2013-05/griechenland-rassismus-neonazis <05.07.2013>. Vgl. Matter 1987, a. a. O., S. 223.

1227 Finkelstein 2006, a. a. O., S. 15.

1228 Vgl. Finkelstein 2006, a. a. O., S. 14ff.

1229 Finkelstein 2006, a. a. O., S. 16.

1230 Herbert 2003, a. a. O., S. 206.

1231 Vgl. Rürup/Sesselmeier 1993, a. a. O., S. 289.

1232 Rürup/Sesselmeier 1993, a. a. O., S. 289.

1233 Vgl. Meier-Mesquita 1994, a. a. O., S. 52. 
Menschengruppen aufgrund ihrer angeblichen biologischen, Minderwertigkeit ${ }^{6}$ als Arbeiterschicht ,zweiter Klasse diskriminiert und ausgegrenzt werden. ${ }^{1234}$

„Wie [...] geschildert, ist die koloniale oder neo-koloniale Arbeitskraft viel billiger als die europäische. So wird [...] der Kolonialisierte zum Untermensch degradiert: er ist im wörtlichen Sinne minderwertig, weil es seine Bestimmung ist, unter dem Wert seiner Arbeitskraft zu arbeiten; er ist Untermensch, weil die natürliche Grenze des Arbeitstages über ihr bistorisches Niveau erweitert werden muss. Hier erreichen wir die Nabtstelle [...] des Rassismus [...]؛ "“235

Vor diesem Hintergrund kann ein Ursprung des gegenwärtigen, europäischen Rassismusphänomens abermals in der Kolonialzeit verortet werden, die jedoch wie illustriert - auch zum heutigen gesellschaftlichen und politischen Kontext zahlreiche Parallelen aufweist (s. Kapitel 2.1, 2.3).

Das Rassismusprinzip besitzt - insbesondere in biologistischer Ausprägung für die Wirtschaft teilweise immer noch eine stabilisierende Funktion. ${ }^{1236}$ Denn auch im 21. Jahrhundert setzt man in Zeiten starker Konjunkturschwankungen auf billige Zeitarbeitskräfte - was auch für deutsche Mitarbeiterinnen und Mitarbeiter zutrifft -, die von Vermittlungsagenturen ohne umfangreiche betriebliche Mitbestimmungs- und Kündigungsrechte sowie mit mangelhafter sozialer Absicherung als günstige und äußerst flexibel einsetzbare Arbeitskräfte auf dem Arbeitsmarkt offeriert werden. Insbesondere die Automobilindustrie nutzt diese variabel anpassbare Arbeitskraftreserve intensiv, um die Marktinteressen jeweils flexibel bedienen zu können sowie keine großen Kapazitätsreserven bereitstellen zu müssen. Bei abfallenden Absatzzahlen können die Zeitarbeiter meist ohne großen finanziellen und personellen Aufwand gekündigt werden, obwohl sich deren Arbeitsverhältnis in den letzten Jahren partiell gebessert hat. Demnach sind die ausländischen Facharbeitskräfte folgerichtig auch für die Vergrößerung des gesamtwirtschaftlichen Angebotes mitverantwortlich und erhöhen gleichzeitig die konjunkturelle Nachfrage. ${ }^{1237}$ Insbesondere in den 1990er Jahren konnte mithilfe der Arbeitsmigrantinnen und -migranten eine enorme Produktivitätssteigerung in der deutschen Wirtschaft erreicht werden. ${ }^{1238}$ Vor dem Hintergrund des heutigen demographischen Wandels der bundesrepublikanischen Gesellschaft sind die ausländischen Mitbürgerinnen und Mitbürger für die bundesrepublikanische Wirtschaft noch wichtiger geworden - ohne diese wäre die herausragende ökonomische Stellung Deutschlands, vor allem nach den anhaltenden ökonomischen und fiskalen Krisenentwicklungen seit den Jahren 2007/2008, kaum denkbar. Insofern sind die Auswirkungen der Unterstützung durch ausländische Mitbürgerinnen und Mitbürger für die deutsche Wirtschaft auch noch im 21. Jahrhundert durchweg positiv. Ohne die Einwanderer wären die wirtschaftlichen Wachstumsraten der

1234 Vgl. Herbert 2003, a. a. O., S. 55.

1235 Meier-Mesquita 1994, a. a. O., S. 56.

1236 Vgl. Meier-Mesquita 1994, a. a. O., S. 60.

1237 Vgl. Rürup/Sesselmeier 1993, a. a. O., S. 285.

1238 Vgl. Rürup/Sesselmeier 1993, a. a. O., S. 290. 
letzten Jahrzehnte unmöglich gewesen. ${ }^{1239}$ Schon in den $1990 \mathrm{er}$ Jahren konnte was uneingeschränkt auch für das 21. Jahrhundert gilt - folglich auf wissenschaftlicher Ebene schlussfolgernd konstatiert werden:

„Aufgrund der [...] differenzierten und differierenden Ergebnisse wird man zu dem $\mathrm{Fa}$ zit gelangen müssen, dass die Einwanderungen der letzten 30 Jahre sich positiv auf die deutsche Volkeswirtschaft [...] ausgewirkt haben, einem Resümee, zu dem im übrigen auch fast alle einschlägigen internationalen Studien gelangen. "1240

Ein Exkurs in die deutsche Historie zeigt ähnliche Entwicklungen und bestätigt die hier getroffenen Erkenntnisse bezüglich der Verknüpfung von Ökonomie und rassistischer Ideologie. In den 1880er Jahren herrschte in der riesigen Landwirtschaft Ostpreußens ein Mangel an billigen Arbeitskräften für einfache Arbeitsaufgaben. Als ,Lösung' wurden ausländische Arbeitskräfte, zum Großteil polnische Bürgerinnen und Bürger, als Arbeiterinnen und Arbeiter ,zweiter Klasse` flexibel eingestellt. ${ }^{1241}$ Seitens der deutschen Bevölkerung entwickelte sich aufgrund der polnischen Einwanderungsraten Abwehrhaltungen gegenüber den ,Fremden'.1242 Die Arbeitsmigrantinnen und -migranten wurden als „,volkspolitisch“1243 gefährlich angesehen, als Gefährdung des kulturellen Niveaus der deutschen Gesellschaft sowie als Überfremdungsgefahr. ${ }^{1244}$ Diese angebliche ,[...] Überschwemmung unserer deutschen Lande mit Ausländern minderwertigen Charakters

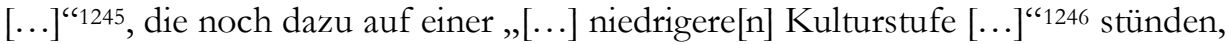
führte damals zu ,[...] wilden Eruptionen von Fremdenfeindlichkeit und Rassis-

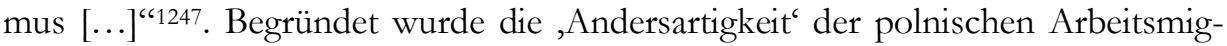
rantinnen und -migranten mit der Gefahr der gesellschaftlichen Vermischung mit „fremden Elementen“1248 - also mit naturalisierenden, biologistischen und ,rassischen' Argumentationen. Auch heute sind genau diese Argumentationsmuster wieder zunehmend in der Mitte der Gesellschaft etabliert, wie unter anderem die große Resonanz auf Thilo Sarrazins Theoriekonstrukt zeigt (s. Kapitel 3).

Die ökonomischen Entwicklungen haben demnach ebenfalls einen bedeutenden Anteil an der Entstehung und der Verbreitung der rassistischen Ideologie in der bundesrepublikanischen Gesellschaft. Insbesondere wirtschaftliche Krisenerscheinungen zeigen deutliche Verstärkereffekte auf das Phänomen des Rassismus - in den 1970er Jahren, den 1990er Jahren, wie auch heute. ${ }^{1249}$ Vor diesem Hintergrund sind die rassistischen Strömungen am Ende des ersten Jahrzehnts des

\footnotetext{
1239 Vgl. Rürup/Sesselmeier 1993, a. a. O., S. $293 \mathrm{ff}$.

1240 Rürup/Sesselmeier 1993, a. a. O., S. 300.

1241 Vgl. Herbert 2003, a. a. O., S. $15 \mathrm{ff}$.

1242 Vgl. Herbert 2003, a. a. O., S. $21 \mathrm{ff}$.

1243 Herbert 2003, a. a. O., S. $21 \mathrm{ff}$.

1244 Vgl. Herbert 2003, a. a. O., S. $21 \mathrm{ff}$.

1245 Herbert 2003, a. a. O., S. 30.

1246 Herbert 2003, a. a. O., S. 28.

1247 Herbert 2003, a. a. O., S. 30.

1248 Herbert 2003, a. a. O., S. 30.

1249 Vgl. Schiesser 1994, a. a. O., S. 72.
} 
21. Jahrhunderts überwiegend zu erklären. Schon 1994 wurde vermerkt, dass ökonomische Krisen „,[...] rassistische Denkweisen und Handlungen verstärk[en] (nicht entstehen lässt).“1250 Die nun schon seit dem Beginn der ursprünglichen Immobilienkrise im Jahr 2007 in den USA anhaltende Wirtschafts-, Finanz- und Eurokrise stellt einen bedeutenden Faktor des aktuellen Rassismusphänomens in der deutschen Gesellschaft dar - ein Grund für die zeitliche Eingrenzung dieser Untersuchung auf die Jahre 2007 bis 2013 (s. Kapitel 1.2). Hinzukommend muss beachtet werden, dass zurzeit keine endgültigen sowie nachhaltigen Lösungswege aus den ökonomischen und fiskalpolitischen Krisenentwicklungen sichtbar sind, im Gegenteil: Die Eurokrise zieht immer engere Kreise und bedroht in zunehmendem Maße die gesellschaftliche Stabilität in Europa. Aus der ursprünglichen Wirtschaftskrise entwickelte sich die internationale Finanzkrise. Heute stehen wir vor den Gegebenheiten einer europäischen Staatsschulden- und Eurokrise. Die Auswirkungen innerhalb der bundesrepublikanischen Gesellschaft sind offen erkennbar: Die EU-Staatsangehörigen der Krisenstaaten werden für die Entstehung der die Krise hervorgerufenen politischen und ökonomischen Fehlentscheidungen verantwortlich gemacht. Das Rassismusphänomen erlebt in diesem Zusammenhang seine europaweite Renaissance.

Abschließend kann dementsprechend resümiert werden, dass Einwanderer für die bundesrepublikanische Wirtschaft im 19., 20. als auch 21. Jahrhundert essentiell wichtig waren und weiterhin bleiben. Sie tragen auch in Zukunft mehr denn je einen unverzichtbaren Beitrag zur wirtschaftlichen Produktivität sowie zum Wohlstand der Bundesrepublik Deutschland bei. ${ }^{1251}$ Deutschland hat von der wirtschaftlichen Unterstützung durch ausländische Arbeitskräfte auf einzigartige Weise profitiert. ${ }^{1252}$ Exemplarisch hat so „[d]as Ruhrgebiet [...] seine Stärke gerade aus der Integration von Einwanderern gewonnen.“1253 Für die bundesrepublikanische Wirtschaft ist Migration heutzutage aufgrund des fortschreitenden demographischen Wandels der deutschen Bevölkerung gar unabdingbar, ansonsten wäre der wirtschaftliche Bedarf an Arbeitskräften nicht zu decken. ${ }^{1254}$ Trotzdem nehmen, wie skizziert, die wirtschaftlichen und ökonomischen Entwicklungen eine potenzielle Verstärkerrolle des Rassismusphänomens ein. Die „Wirtschaft [...] wende $[t]$ sich zwar verbal gegen Fremdenfeindlichkeit [und Rassismus], produzier[t] [...] [diese] aber mit ihrer volkswirtschaftlichen, Verrechnung' und, Vernutzung' der Fremden in ihrer einseitig an Effizienz und Produktionserfordernissen [...]“1255 orientierten Strategie, so Politikwissenschaftler Helmut Fröchling folgerichtig. Rassismus ist also in nicht $\mathrm{zu}$ verachtendem Maße von ökonomischen

1250 Kalpaka/Räthzel 1994c, a. a. O., S. 44.

1251 Vgl. Knight/Kowalsky 1991, a. a. O., S. 44ff.

1252 Vgl. Neubauer 1992, a. a. O., S. $196 \mathrm{ff}$.

1253 Behrens, Fritz (2004): Vorwort, in: Gessenharter, Wolfgang/Pfeiffer, Thomas (Hrsg.): Die Neue Rechte - eine Gefahr für die Demokratie?, Wiesbaden, S. 8.

1254 Vgl. Knight/Kowalsky 1991, a. a. O., S. 44ff. | Vgl. Rahner 2011, a. a. O., S. 29.

1255 Fröchling, Helmut (1994): Sozialwissenschaftliche Erklärungsansätze für fremdenfeindliche Einstellungen und Handlungen, in: Knortz, Heike (Hrsg.): Fremdenfeindlichkeit in Deutschland. Ein interdisziplinärer Diskussionsbeitrag, Frankfurt/Main u. a., S. 90. 
Entwicklungen abhängig bzw. beeinflusst, wird aber ebenfalls von anderen gesellschaftlichen sowie politischen Faktoren bestimmt. ${ }^{1256}$

\subsection{Die deutsche Gesellschaft im Umbruch?}

Letztlich muss die Frage nach der Beteiligung der bundesrepublikanischen Bevölkerung am heutigen Rassismusproblem detaillierter analysiert und erörtert werden.

Diesbezüglich wird einführend jedoch abermals konstatiert, dass das Phänomen des Rassismus in Deutschland schon längere Zeit Präsenz zeigt. ${ }^{1257}$ Festzuhalten ist so, dass ,[...] Rassismus in der bundesdeutschen Gesellschaft fest verwurzelt ist [...]“1258. „,...] Rassismus [ist] in der bundesdeutschen Gesellschaft

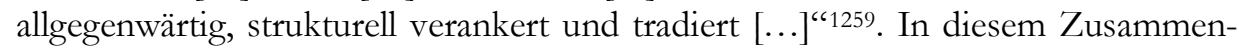
hang können hier als exemplarische Beispiele infrastrukturelle Maßnahmen, wie die Benennung von Straßen mit Namen von dem Rassismus nahestehenden Persönlichkeiten sowie die deutsche (Alltags-)Sprache, in der sich zahlreiche rassistische Assoziationen und Anfeindungen finden lassen, illustriert werden. ${ }^{1260} \mathrm{Neu}$ ist jedoch die Rückkehr der dezidiert biologisch-genetischen Argumentationsformen der rassistischen Ideologie. Vor diesem Hintergrund stellte Siegfried Jäger hinsichtlich der gesellschaftlichen Akteure schon im Jahr 2001 das fest, was auf die heutige Lage der Bundesrepublik Deutschland uneingeschränkt übertragen werden kann: ${ }^{1261}$

„[...] Rassismus [...] [ist] generell fortlaufend Bestandteil des öffentlichen und privaten Diskurses [...]. [...] Rassismus [...] und andere Ideologeme [...] sind weiterbin in dieser Gesellschaft insgesamt dauerhaft latent vorhanden und sie können - wie dies in den letzten Jahren mehrfach geschehen ist-jederzeit wieder an die gesellschaftliche Oberfläche treten. "I262

\footnotetext{
1256 Vgl. Kalpaka/Räthzel 1994c, a. a. O., S. $19 \mathrm{ff}$.

1257 Vgl. Butterwegge 2001, a. a. O., S. 102.

1258 Arndt 2001b, a. a. O., S. 10.

1259 Arndt 2001b, a. a. O., S. 11.

1260 Vgl. Arndt 2001b, a. a. O., S. 14, $24 \mathrm{ff}$.

In der deutschen Alltagssprache sind viele Wörter sowie Wortbedeutungen zu finden, die fremdenfeindliche sowie rassistische Assoziationen beinhalten. Das Wort ,Ausländer' impliziert beispielsweise eine Unterscheidung zwischen Inländern (Deutschen) und Fremden, die nicht aus Deutscbland kommen, sondern, außen vor stehen. Insbesondere vor dem Hintergrund der afrikanischen Bevölkerung existieren zablreiche Begrifflichkeiten, die zur Abwertung der dortigen Bevölkerung dienen: Hottentotten, Buschmänner oder Miscblinge. Auf der Grundlage dieser im Vergleich zu den Deutschen veränderten Wortbeschreibung werden nachfolgend unterschiedliche ,Rassen ' differenziert. Vgl. Arndt, Susan/Ofuatey-Alazard, Nadja (2011a): Wie Rassismus aus Wörtern spricht. (K)erben des Kolonialismus im Wissensarchiv deutsche Sprache. Ein kritisches Nachschlagewerk, Münster.

1261 Vgl. Jäger, Siegfried (2001): Rassismus und Rechtsextremismus in der deutschen Sprache. Einige Überlegungen zur Berichterstattung über Rassismus und Rechtsextremismus aus diskursanalytischer Sicht, in: Arndt, Susan (Hrsg.): AfrikaBilder. Studien zu Rassismus in Deutschland, Münster, S. $123 \mathrm{ff}$. 
Demzufolge kann von einem latenten Rassismusphänomen in erheblichen Teilen der deutschen Bevölkerung gesprochen werden (s. Kapitel 3). ${ }^{1263}$ Rassismus gehört ,[...] seit Jahrzehnten zum Alltag. “1264 und stellt dementsprechend ,[...] kein [grundsätzlich] neues Phänomen.“"1265 dar. Insofern muss im 21. Jahrhundert eine neue ,Konjunktur' des Rassismus deutschland- und europaweit identifiziert werden. ${ }^{1266} \mathrm{Im}$ weiteren Verlauf wird nun die Frage nach dem , Warum` zu klären sein: Welche spezifischen gesellschaftlichen Hintergründe haben zu seiner erneuten Etablierung - insbesondere mit biologistischem Schwerpunkt - geführt?

\subsubsection{Die ,Ängste` der bundesrepublikanischen Bürgerinnen und Bürger}

Seit den 1990er Jahren kann eine sukzessive Rückkehr rassistischer Argumentationsmuster in der deutschen Gesellschaft verortet werden. Hier scheint ein neues Zeitalter des Rassismus - zuerst der kulturell-naturalisierend begründeten neorassistischen Formen und im 21. Jahrhundert zunehmend auch wieder des direkt und indirekt biologistisch konnotierten Typus - zu entstehen: Rassismus stößt wieder auf eine breite Akzeptanz bei den Bürgerinnen und Bürgern (s. Kapitel 3). ${ }^{1267}$ Erschreckend zeigt sich in diesem Zusammenhang insbesondere der Anstieg des „[...] verdeckten Rassismus [...]“1268 in der deutschen Gesellschaft im letzten Jahrzehnt. Offiziell werden rassistische Stereotype und Ressentiments vordergründig abgelehnt, um persönlich eine ,weiße Weste` der akzeptierten, demokratischen Gesellschaftsnormen zu erhalten. Indirekt steht man ihnen jedoch verständnisvoll gegenüber. In den 1990er Jahren hat sich dieser Rassismus zumeist an ,den` Ausländern gezeigt, die für die politischen und wirtschaftlichen Probleme im Zuge der Wiedervereinigung verantwortlich gemacht wurden (s. Kapitel 4.1.2). ${ }^{1269}$ Hier wurden im Sinne der rassistischen Ideologie deutlich, die Anderen' differenziert, hierarchisiert, ausgegrenzt und als ,nicht zugehörig“ abgewertet - das ,Rassekonstrukt ${ }^{6}$ in verschleiertem Gewand. ${ }^{1270}$ Was sind die spezifischen gesellschaftlichen Erklärungsansätze dieses bis heute andauernden Rassismusphänomens innerhalb der deutschen Bevölkerung? Auf der einen Seite müssen an dieser Stelle sicherlich die in den vorherigen Kapiteln detailliert illustrierten Faktoren politischer sowie wirtschaftlicher Art beachtet werden. Vor dem Hintergrund zögerlicher bzw. fehlender politischer Entscheidungen und Rahmenbedingungen, greift insbesondere der aufstrebende sogenannte Rechtspopulismus Ängste und Sorgen

\footnotetext{
1263 Vgl. Trittin 1993, a. a. O., S. 73.

1264 Farin/Seidel-Pielen 1992, a. a. O., S. 9.

1265 Kleff, Sanem et al. (1990): Vorwort, in: ebd. (Hrsg.): BRD - DDR. Alte und neue Rassismen im Zuge der deutsch-deutschen Einigung, Frankfurt/Main, S. 2.

1266 Vgl. Bojadžijev 2008, a. a. O., S. $275 \mathrm{ff}$.

1267 Vgl. Gerhard, Ute (1993): „Fluten“, „Ströme“, „Invasionen“ - Mediendiskurs und Rassismus, in: Heßler, Manfred (Hrsg.): Zwischen Nationalstaat und multikultureller Gesellschaft. Einwanderung und Fremdenfeindlichkeit in der Bundesrepublik Deutschland, Berlin, S. $239 \mathrm{ff}$. Jäger 1992b, a. a. O., S. 9.

1269 Vgl. Jäger 1992b, a. a. O., S. 32.

1270 Vgl. Jäger 1992b, a. a. O., S. 32.
} 
der Bürgerinnen und Bürger auf und emotionalisiert diese - die durch die aktuelle Eurokrise ausgelösten Verunsicherungen und Zukunftssorgen bieten hierfür einen geradezu idealen Ansatzpunkt (s. Kapitel 4.1.5).1271 Auf der anderen Seite sehen auch viele Bürgerinnen und Bürger in der verstärkten Einwanderung nach Deutschland aus weltweiten Krisenregionen - wie beispielsweise den nordafrikanischen Staaten, dem Nahen Osten, dem Irak oder Afghanistan - in wirtschaftlichen Krisenzeiten eine Konkurrenz, die aufgrund unzureichender politischer Bemühungen bisher überwiegend nicht als unbegründet kommuniziert werden konnte. Die einwandernden Mitmenschen sind so schon verallgemeinernd von Vornherein seitens der bundesrepublikanischen Bevölkerung mit Vorurteilen behaftet. ${ }^{1272}$

Da politische, wirtschaftliche oder kulturelle Begründungszusammenhänge im Rahmen dieser Vorurteile größtenteils fehlen, bietet die Biologie als scheinbar unfehlbare sowie, einfache ${ }^{6}$ Wissenschaft die passende Legitimationsgrundlage: Nach dem Verlauf der 1990er Jahre, dem Zeitalter des sogenannten Neorassismus, fokussieren die gesellschaftlichen Argumentationen des gegenwärtigen Rassismusphänomens heute in zunehmendem Maße die originären, pseudobiologischen Ursprünge und Grundlagen des Rassismusbegriffes (s. Kapitel 2). ${ }^{1273}$ Besorgniserregend ist die zunehmende und daher tendenziell gesellschaftskonforme Verschleierung: 1274

„Bei genauerem Hinsehen zeigt sich, dass Rassismus vielfach nicht offen zugegeben wird, dass die Menschen teilweise subtile Strategien verwenden, um ibre rassistischen Einstellungen zu beschönigen bzw. um trotz ibrer rassistischen Einstellungen beim/bei der GesprächspartnerIn einen positiven Eindruck zu erwecken etc. Auch tritt Rassismus beute nicht mehr so grobschlächtig auf, wie dies früher meist der Fall gewesen ist, wo insbesondere oder auch ganz allein biologisch-genetisch verankerte oder als biologisch-genetische verankert unterstellte Eigenschaften Anlass zur Ablebnung und Verfolgung anderer Menschen waren. "1275

Gerade diese ,grobschlächtigen‘ biologisch-genetischen Vorurteile müssen jedoch im Untersuchungszeitraum dieser Arbeit wieder verortet werden. Nichtsdestotrotz gelingt es gesellschaftlichen Akteuren im Gegensatz zu früheren Konjunkturen des Rassismus heute effektiver, biologisch-rassistische Ressentiments subtil zu verpacken, um mögliche Normen- und Werteverletzungen zu vermeiden: Ein Hauptansatzpunkt bleibt die ,rassengeleitete ${ }^{6}$ Diskriminierung und Hierarchisierung von spezifischen Menschengruppen (s. Kapitel 2).1276 Der „[...] als fremd und andersartig wahrgenommene ,Kulturkreis` der Anderen $[\ldots]^{\text {“1277 }}$ dient über-

\footnotetext{
1271 Vgl. Institut für Sozialforschung 1992, a. a. O., S. $14 \mathrm{f}$.

1272 Vgl. Institut für Sozialforschung 1992, a. a. O., S. $14 f$.

1273 Vgl. Bojadžijev 2008, a. a. O., S. 25.

1274 Vgl. Jäger 1992b, a. a. O., S. $13 \mathrm{f}$.

1275 Jäger 1992b, a. a. O., S. 13, 14.

1276 Vgl. Jäger 1992b, a. a. O., S. 52, $180 \mathrm{ff}$.

1277 Jäger 1992b, a. a. O., S. 39.
} 
wiegend nur als verschleiernder sowie beschönigender Vorwand, um biologistische Begründungsmuster zu verdecken. Man bedient sich heutzutage demzufolge häufig ,,[...] Verharmlosungs- und Verdeckungsstrategien [...]“1278, beispielsweise geschickter Rede- und Präsentationsformen, mit denen man biologischrassistische „,...] Aussagen etwas abmildern, umschreiben, leugnen, relativieren, nachträglich einschränken möchte $[\ldots]^{\text {“1279. }}$

„Rassistische Einstellungen offen zuzugeben, wird denn auch tunlichst vermieden. Mit den verwendeten Verharmlosungs- und Verdeckungsstrategien reagieren viele Menschen demnach auf die heute verbreitete soziale Norm, dass es unanständig und undemokratisch ist, rassistisch zu sein. Diese Norm ist historisch, sozial und situativ jedoch erbeblichen Schwankungen unterworfen. Rassismus äußert sich je nach den Umständen mehr oder minder offen. Er kann auch durch bestimmte anerzogene Grundhaltungen [...] überdeckt sein. "280

In die Zukunft blickend bleibt an dieser Stelle die Frage unbeantwortet, ob aus diesem verdeckt vorhandenen Rassismus wieder offene, gewalttätige rassistische Einstellungen entstehen könnten, wie sie in den Folgejahren der deutschen Wiedervereinigung insbesondere in den neuen, ostdeutschen Bundesländern präsent waren. ${ }^{1281}$ Nichtsdestotrotz erscheint das gesellschaftlich verdeckte Rassismusphänomen noch gefährlicher sowie für Politik und Gesellschaft bedrohlicher, $\mathrm{da}$ dieses nur schwierig frühzeitig erkannt und präventiv bekämpft werden kann (s. Kapitel 3.7).1282 Selbst für die sozialwissenschaftliche Forschung scheint dies eine diffizile Situation, wie die für das 21. Jahrhundert zurzeit noch mäßige Forschungslage bestätigt.

Wie zeigt sich dieser neue gesellschaftliche Rassismus? Insbesondere der tendenziell wiederkehrende biologisch konnotierte Rassismustypus ist heute mit dem eher verharmlosenden Begriff der Fremdenfeindlichkeit verknüpft. ${ }^{1283}$ Gegenüber diesen ,Fremden' existieren wieder zahlreiche biologistische, vermeintlich einfach zu verstehende Vorurteile: Das Einbringen von Krankheiten in die Gesellschaft, die ,Verschlechterung ${ }^{6}$ des Genpools, eine höhere angeborene Kriminalitätsrate, eine niedrigere Produktivität, geringere kognitive Fähigkeiten und vieles mehr. ${ }^{1284}$ Die tiefergehende Frage, was diese angeblich ,Fremden` überhaupt charakterisiert, bleibt jedoch auch weiterhin offen. ${ }^{1285}$

,Die Fremden' erfüllen die ,Sündenbock'-Funktion nicht nur hinsichtlich der mangelhaften Einwanderungspolitik - trotz der novellierten Gesetzgebung im Jahr 2005 -, sondern auch bezüglich der schwierigen ökonomischen Lage, ausge-

\footnotetext{
1278 Jäger 1992b, a. a. O., S. 243.

1279 Jäger 1992b, a. a. O., S. 242.

1280 Jäger 1992b, a. a. O., S. 243.

1281 Vgl. Trittin 1993, a. a. O., S. 96ff.

1282 Vgl. Freyberg 1992, a. a. O., S. $71 \mathrm{ff}$.

1283 Vgl. Bojadžijev 2008, a. a. O., S. 26ff.

1284 Vgl. Bojadžijev 2008, a. a. O., S. 26ff.

1285 Vgl. Bojadžijev 2008, a. a. O., S. $27 \mathrm{ff}$.
} 
löst durch die Immobilien-, Wirtschafts- und Finanzkrise seit dem Jahr 2007.1286 Insbesondere die jüngeren Bürgerinnen und Bürger stehen den ausländischen Mitbürgerinnen und Mitbürgern vor diesem Hintergrund ablehnend gegenüber, wie Siegfried Jäger im Rahmen einer qualitativen Diskursanalyse feststellt (s. Kapitel 3). ${ }^{1287}$ „Der Ausländer gibt dem [...] Unglück einen Namen [...]“1288 visualisiert auch Sozialwissenschaftler Thomas von Freyberg.

„Der Fremde erfüllt als Angehöriger einer Minorität oft die Funktion eines Sünden-
bocks. Er ist gleichsam ,Blitzableiter' für alle unsere Enttäuschungen, unsere Wut, unse-
re Obnmacht und die tief in uns sitzende Angst. Diese Angst hat in der Gegenwart ver-
schiedene Quellen, von denen die für die Entstehung des Rassismus wichtigsten genannt
werden sollen: die Angst angesichts tiefgreifender politischer Veränderungen [...]; die
Angst vor sozialer und beruflicher Unsicherheit [...]; die Angst aufgrund von Orientie-
rungslosigkeit [...], von Unverbindlichkeit im familiären und weiteren sozialen Bereich
und von zunehmender Anonymität in der Gesellschaft; vielfältige aus der individuellen
Lebensgeschichte herrührenden Ängste aufgrund von emotionalen Mangelerfahrungen,
weltanschaulicher Verunsicherung sowie die traumatische Erfahrung selbsterlebter Ver-
letzungen und Ausgrenzungen [...]; eine weitere Quelle von Angst ist schließlich auch in
drohenden Umweltkatastrophen unvorstellbaren Ausmaßes zu sehen [...]. " "28s9

Ganz im Sinne des biologistischen Rassismusphänomens regenerieren sich zudem die Ideen der Gefahr einer angeblichen ,Durchrassung“ und ,Landnahme durch eingewanderte Personen. ${ }^{1290}$ Zusätzlich werden die Zukunftssorgen ebenfalls mit dem Bild des ,Überlaufens' der Bundesrepublik Deutschland sowie eines ,zu viel an zusammenlebenden Mitmenschen neu konstruiert. ${ }^{1291}$ Auch hierbei nutzt man intensiv die biologistische Trickkiste, um den eigenen Rassismus zu legitimieren: „[...] Ausländer [werden] gegen Deutsche [...]“1292 abgegrenzt, „[...] genetische Merkmale von EinwanderInnen [werden] mit bestimmte[n] negativen Charaktereigenschaften in Beziehung gesetzt [...]"1293 oder ,[...] kulturelle Eigenschaften

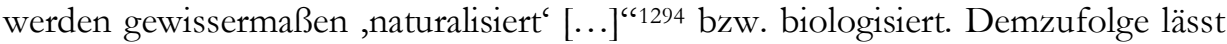
sich auch hieran wiederum tendenziell die wiederkehrende Etablierung biologistischer, rassistischer Ressentiments diagnostizieren.

\footnotetext{
1286 Vgl. Heßler 1993b, a. a. O., S. 8.

1287 Vgl. Jäger 1992b, a. a. O., S. 290.

1288 Freyberg 1992, a. a. O., S. 78.

1289 Rauchfleisch, Udo (1994): Offene und verdeckte Ausgrenzung und Diskriminierung. Rassismus aus psychologischer Sicht, in: ebd. (Hrsg.): Fremd im Paradies. Migration und Rassismus, Basel, S. 94, 95.

1290 Vgl. Franz, Fritz (1993): Schleusen und Schranken der Einwanderung nach Deutschland, in: Heßler, Manfred (Hrsg.): Zwischen Nationalstaat und multikultureller Gesellschaft. Einwanderung und Fremdenfeindlichkeit in der Bundesrepublik Deutschland, Berlin, S. 69. Vgl. Jäger 1992b, a. a. O., S. 61 ff. | Vgl. Tanner 1994, a. a. O., S. 14.

1292 Jäger 1992 b, a. a. O., S. 63.

1293 Jäger 1992b, a. a. O., S. 63.

1294 Jäger 1992b, a. a. O., S. 63.
} 
In diesem Zusammenhang steht insbesondere die Angst um die eigene berufliche, finanzielle und private Existenz sowie die eigene individuelle Freiheit im Vordergrund. ${ }^{1295}$ Der ,Fremde“ dient so als eine ideale „Projektionsfigur“"1296 für die persönlichen Ängste. Hauptverantwortliche Hintergründe für diese Ängste sind jedoch einerseits fehlende, unzureichende oder mangelhaft kommunizierte politische Rahmenbedingungen hinsichtlich Migration und Integration sowie andererseits die größtenteils ausschließlich auf die Produktivität der Arbeitnehmerinnen und Arbeitnehmer orientierte Wirtschaft. ${ }^{1297}$

Wie bereits im zweiten Kapitel hergeleitet, verdeutlichen auch die nachfolgenden Ergebnisse, dass es sich bei der Verwendung des ,Rassebegriffs' nicht um ein biologisches, sondern ein gesellschaftliches Konstrukt handelt (s. Kapitel 2, 5). Dessen angeblich naturalistischen sowie biologistischen Unterschiede werden missbraucht, um eine ,Rassenkonstruktion' zu generieren - auch dies unterstreicht nochmals die Verknüpfung des kulturell-naturalisierenden und des biologistischen Rassismustypus. ${ }^{1298}$ Das heißt, die kulturell konstruierten Unterschiede werden seitens der Gesellschaft auf angebliche naturwissenschaftliche Differenzen projiziert, um demnach mithilfe der Biologie unterschiedliche Eigenschaften zwischen spezifischen Menschengruppen legitimieren zu können. Der biologistisch begrün-

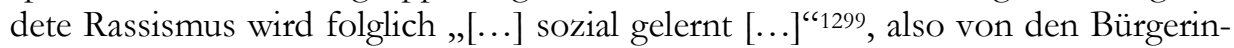
nen und Bürgern als Erklärungsmodell selbst (fort-)entwickelt, weil die biologischen Grundlagen ,einfach' sowie für jeden verständlich erscheinen. ${ }^{1300}$ Schlussfolgernd lässt sich so erkennen:

\section{„[...] Rassismus ist [...] nicht bloß ein Ausdruck von Vorurteilen und Diskriminie- rungen, sondern vielmehr ein Denksystem, das sich in einer Sozialstruktur eingebettet bat." 301}

Rassismus wird also nicht nur gefühlt institutionell, sondern auch seitens der Bevölkerung - , von unten' - generiert, platziert, stabilisiert und reproduziert. ${ }^{1302}$ Der modernisierte Rassismus des 21. Jahrhunderts basiert folglich auf einer gesellschaftlichen Konstruktion unter Verknüpfung von individuellen Ängsten und Zukunftssorgen. ${ }^{1303}$ Hieraus resultieren dann Ausgrenzung, Abwertung und Diskriminierung der ,Fremden`. In diesem Zusammenhang zeigt sich der Begriff der

\footnotetext{
1295 Vgl. Tanner 1994, a. a. O., S. $17 \mathrm{ff}$.

1296 Rauchfleisch 1994, a. a. O., S. 89.

1297 Vgl. Rauchfleisch 1994, a. a. O., S. $87 \mathrm{ff}$.

1298 Vgl. Jäger 1992b, a. a. O., S. $118 \mathrm{ff}$.

1299 Dijk, Teun A. van (1992a): Der Diskurs der Elite und seine Funktion für die Reproduktion des Rassismus, in: Institut für Migrations- und Rassismusforschung e. V. (Hrsg.): Rassismus und Migration in Europa. Beiträge des Kongresses „Migration und Rassismus in Europa“ Hamburg, 26. bis 30. September 1990, Hamburg, S. 290.

1300 Vgl. Dijk 1992a, a. a. O., S. 290ff. | Vgl. Farin/Seidel-Pielen 1992, a. a. O., S. 30.

1301 Meier-Mesquita 1994, a. a. O., S. 45.

1302 Vgl. Kalpaka/Räthzel 1994b, a. a. O., S. 9f.

1303 Vgl. Kalpaka/Räthzel 1994b, a. a. O., S. 13.
} 
,Fremden“ als extrem wandelbar und je nach Situation anpassungsfähig. ${ }^{1304}$ Diese sind nicht nur ausländische Mitbürgerinnen und Mitbürgern, sondern können auch multiple Gesellschaftsgruppen darstellen, die von einem sozialen Standard abweichen. Demzufolge ist nicht der rechtliche Status als In- bzw. Ausländer, sondern die gesellschaftliche Konstruktion von Fremdheit von Bedeutung. ${ }^{1305}$ So kann tendenziell von einer „Vergesellschaftung“1306 des heutigen Rassismusphänomens gesprochen werden.

Zurück zur Frage nach dem ,Warum' des heutigen, gesellschaftlichen Rassismus: Die gesellschaftlichen Entwicklungslinien dürfen, wie veranschaulicht, nicht isoliert betrachtet werden. Insbesondere die wirtschaftliche und fiskalpolitische Krisenlage seit 2007 sowie die zögerliche und mangelhaft kommunizierte Ausländerpolitik der bundesrepublikanischen Führung haben das Rassismusphänomen in der deutschen Bevölkerung forciert. Insofern kann der Rassismus auch ein Stück weit als Protest der Bürgerinnen und Bürger gegen politische und ökonomische Fehleinschätzungen bzw. -entscheidungen verstanden werden. ${ }^{1307}$

\subsubsection{Mediale Einflüsse auf Rassismus und Rassismuskritik}

Nicht unterschätzt werden darf vor diesem Hintergrund ebenfalls die Rolle der Medien bezüglich der Verbreitung und - partiell - der Verstärkung des Rassismus. Die Causa Sarrazin vergegenwärtigt, dass erst die mediale Unterstützung seiner Thesen sowie die populistische Inszenierung seines ,Skandal-Charakters' als angeblicher Klartext-Politiker die gesellschaftliche Aufmerksamkeit ermöglicht und hergestellt haben. ${ }^{1308}$ Schon vor der Veröffentlichung seines biologistischen Pamphlets intensivierten, polarisierten und inszenierten insbesondere die Printmedien, einzig mit dem Ziel der Auflagenhöhe, die gesellschaftliche Stimmung in besorgniserregendem Maße durch die Publikation von Vorabdrucken. ${ }^{1309}$ Vor allem viele Massenmedien spielen vor diesem Hintergrund, mit wenigen Ausnahmen, eine elementare Rolle für populistische, rassistische und rechtspopulistische Akteure: Sie setzen bzw. inszenieren gesellschaftliche Konflikte und Problemsituationen als wichtigen Alltagsdiskurs und bieten in diesem Rahmen vorgefertigte, unreflektierte sowie vorurteilsgeprägte Meinungs- und Interpretationsangebote für

\footnotetext{
1304 Vgl. Kleinert, Corinna (2004): FremdenFeindlichkeit. Einstellungen junger Deutscher zu Migranten, Wiesbaden, S. 53.

1305 Vgl. Kleinert 2004, a. a. O., S. 62f.

1306 Kalpaka/Räthzel 1994b, a. a. O., S. 77.

1307 Vgl. Demirović 1992b, a. a. O., S. 31.

1308 Vgl. Weiß 2011b, a. a. O., S. 8ff, $128 f$.

1309 Vgl. Bade 2013, a. a. O., S. 88ff.

Angemerk.t werden muss an dieser Stelle zwar, dass sich einige Printmedien, wie beispielsweise ,Die Zeit', im Laufe der Sarrazin-Debatte kritisch mit dessen Thesen auseinandersetzten und sich im Nachbinein auch davon distanzierten. Die ersten Vorabveröffentlichungen fast sämtlicher Printmedien steigerten jedoch die Popularität von Sarrazins Theoremen auf nachbaltige Weise.
} 
die medienkonsumierende Bevölkerung an. ${ }^{1310}$ Die Medien werden deshalb heutzutage auch oftmals aufgrund ihrer gesellschaftlichen und quasi-politischen Macht als sogenannte, vierte Gewalt' neben Legislative, Exekutive und Judikative deklariert, was ihren elementaren Einfluss auf Politik, Wirtschaft und Gesellschaft demonstriert. Festgestellt werden muss in diesem Zusammenhang, dass dieser medialen Gewalt eine direkte Mitverantwortung an der Verbreitung und Reproduktion des gegenwärtigen Rassismusphänomens zukommt, ausgelöst durch die „Sensationslust" 1311 und den Unterhaltungsdrang der medienkonsumierenden Bürgerinnen und Bürger. ${ }^{1312}$ Weiterhin unterstützen vor allem die Boulevard-Medien die gesellschaftliche Debatte um ,gute' bzw. ,schlechte' Einwanderer populistisch und skizzieren ebenfalls symbolisch eine Bedrohung durch die angebliche ,Überfremdung“ durch Einwanderer aus dem Ausland. ${ }^{1313}$ Gefördert wird dieser mediale Rassismus zusätzlich durch eine oftmalige Zweideutigkeit der Medien, die eine eindeutige Unterscheidung zwischen Rassismus und Antirassismus vermissen lassen. ${ }^{1314}$ Insbesondere viele Journalistinnen und Journalisten kennzeichnen Einwanderer in ihren Beiträgen oftmals als Menschen, die einzig Probleme verursachen und tragen folglich mit zur Stereotypisierung, Diskriminierung und Vorurteilsbildung bei. ${ }^{1315}$ Einzig der Begriff des Rassismus wird in der medialen Berichterstattung oftmals vermieden, so dass man eher verharmlosend und beschönigend von Fremdenfeindlichkeit spricht. ${ }^{1316}$ Dies beweist eine Art ungeschriebenen Konsens zwischen Politik, Medien und Gesellschaft: Aufgrund der historischen Schreckensereignisse des Zweiten Weltkriegs sowie der nationalsozialistischen Terrorherrschaft wird der Rassismusbegriff zugunsten einer weniger negativ konnotierten Begrifflichkeit ersetzt. Vor allem der in den vorherigen Kapiteln illustrierte Rechtspopulismus bedient sich dieser medialen Falschdarstellung und macht sich diese im Zeitalter der heutigen medialen Erlebnis-, Unterhaltungs- und Spaßgesellschaft für seine diskriminierende und teilweise offen rassistische Politik zunutze. ${ }^{1317}$ Demnach muss so konstatiert werden:

„Sicherlich tragen die Medien nicht die alleinige Schuld am Zustand der deutschen Republik; bescheinigt werden muss ihnen [...] jedoch eine erhebliche Mitverantwortung für die [...] ausländerfeindlichen Ereignisse. Sie haben dazu beigetragen, dass Flüchtlinge, die nach Deutschland kommen, oder solche Leute, die dort seit langem leben, aber von sogenannter deutscher Normalität abweichen, zu einer solch gravierenden Bedrohung hochstilisiert werden, dass der daraus resultierende Handlungsbedarf geradezu als zwin-

1310 Vgl. Virchow, Fabian (2013): Massendmedialer Rassismus und Rechtspopulismus, in: Bathke, Peter/Hoffstadt, Anke (Hrsg.): Die neuen Rechten in Europa. Zwischen Neoliberalismus und Rassismus, Köln, S. 231, 234f.

1311 Jäger 2001, a. a. O., S. 128.

1312 Vgl. Jäger 2001, a. a. O., S. $127 \mathrm{ff}$.

1313 Vgl. Jäger 2001, a. a. O., S. $129 \mathrm{ff}$.

1314 Vgl. Jäger 2001, a. a. O., S. 133.

1315 Vgl. Jäger 2001, a. a. O., S. $143 \mathrm{ff}$.

1316 Vgl. Jäger 2001, a. a. O., S. 147.

1317 Vgl. Kreisky 2002, a. a. O., S. 56. 
gend erscheint, und sie tragen weiterhin dazu bei, dass auch rechtsextreme Parteien und Organisationen [...] die Ernte in ibre Scheuer fahren können, die Medien und Politiker der Mitte gesät haben. "1318

Die spezifischen Hintergründe der rassistischen Tendenzen innerhalb der bundesrepublikanischen Gesellschaft gehen also auf vielfältige Entstehungszusammenhänge zurück: Politische und wirtschaftliche Faktoren, das gesellschaftliche Empfinden der Einwanderungs- und Migrationsdebatte sowie auch die Medien als zentraler Einflussfaktor forcieren das heutige Rassismusphänomen. Die dadurch ausgelösten Zukunftsängste um Arbeitsplatz, finanzielle Sicherheit, gesellschaftliche Stellung oder individuelle Macht werden auf ,die Fremden' als vermeintliche Sündenböcke übertragen. Von ausschließlich gesellschaftlichen Erklärungsansätzen zu sprechen ist demnach schwierig: Politik, Wirtschaft, Medien und Gesellschaft wirken wechselseitig aufeinander ein, jedes gesellschaftliche Subsystem ist mit den anderen mehr oder weniger direkt rückgekoppelt. Der CDU-Politiker Heiner Geißler warnte diesbezüglich schon in den 1990er Jahren treffend, dass „,[u]nsere Zukunft [...] nicht durch den Zuzug von Ausländern, sondern durch die Ressentiments und die Verbohrtheit ihnen gegenüber gefährdet [wird]."1319 Deutschland ist auf die Immigration angewiesen. Ein teilweise gesellschaftlich erwünschter Immigrationsstopp durch rigide Grenzkontrollen hätte zum einen fatale politische und wirtschaftliche Auswirkungen und wäre zum anderen faktisch fast unmöglich durchzusetzen, wie das folgende Gedankenspiel visualisiert.

„Voraussehbar ist jedoch, dass bei einer Verriegelung der Grenzen die Deutschen im Lande immer weniger werden und draußen vor den Toren die Menschbeit rasant zunimmt. Eine ausgebaute militärische Sicherung der Außengrenzen wäre nötig, einschließlich einer sündhaft teuren, hochtechnologischen Überwachungsanlage. Der Gedanke an die an Slums grenzenden Parkanlagen südamerikanischer Großgrundbesitzer wäre nicht abwegig. Wie an der [ehemaligen deutsch-deutschen] Mauer wären Tote zu vermelden, und ein Friede mit den Nachbarn wäre nicht zu erreichen, ganz abgesehen davon, dass die anderen europäischen Länder eine solche Politik ablehnen, aber eine einheitliche europäische Regelung gefunden werden muss. Darüber hinaus stellt sich die Frage, ob sich eine Exportnation wie die deutsche eine solche Politik überhaupt leisten kann, obne den bestehenden Woblstand zu gefährden. Zusätəliche Probleme brächte eine unzureichend genutrte Infrastruktur. " 320

Rückblickend bleibt so festzuhalten, dass kulturalistische als auch biologistische Vorurteile innerhalb großer Teile der bundesrepublikanischen Gesellschaft auf ein komplexes und vielschichtiges Erklärungsgefüge aufbauen. Erst das Zusammenspiel von mehreren Faktoren politischer, wirtschaftlicher und sozialer Natur allen voran die anhaltenden ökonomischen Krisenentwicklungen sowie unzureichende politische Entscheidungen - ermöglicht die erneute Renaissance der

\footnotetext{
1318 Jäger 2001, a. a. O., S. 138.

1319 Heßler 1993b, a. a. O., S. 10.

1320 Knight/Kowalsky 1991, a. a. O., S. 26.
} 
rassistischen Ideologie in Deutschland. ${ }^{1321}$ Eine gewichtige Rolle spielen diesbezüglich insbesondere der Vertrauensverlust zwischen den Bürgerinnen und Bürgern sowie der bundesrepublikanischen Politik, jedoch auch die im Zuge der Wirtschafts- und Eurokrise anhaltenden ökonomischen Unsicherheiten und Zukunftssorgen. ${ }^{1322}$ Ängste vor einer konjunkturellen Rezession scheinen darüber hinaus nicht unbegründet.

Auch eine Rückkehr biologistischer Argumentationen muss aufgrund multipler Ursachenstrukturen im 21. Jahrhundert bestätigt werden (s. Kapitel 3). ${ }^{1323}$

„Die Behauptung zudem, dass heute ein offen genetisch-biologistischer Rassismus zugunsten eines kulturalistischen Rassismus aufgegeben werde [...], muss [...] beqweifelt werden. Biologistische Markierungen von EinwanderInnen spielen nach wie vor eine große Rolle - nicht nur im Alltagsdiskurs. Ein Blick in rassistisch argumentierende Medien [...] zeigt, dass auch beute noch auf das andere Aussehen der EinwanderInnen und Flüchtlinge starker Nachdruck gelegt wird. "1324

Die Biologie ist als Naturwissenschaft also weiterhin ,willkommen` zur Erklärung von angeblich genetischen bzw. biologischen Differenzen zwischen vermeintlichen ,Menschenrassen', da die überragende Mehrheit der Bürgerinnen und Bürger auch genetisch bezogene Merkmale zur Unterscheidung von Bevölkerungsgruppen benutzt (s. Kapitel 3). ${ }^{1325}$ Die Biologie wird somit gesellschaftlich instrumentalisiert, um mit ihr - aufgrund der gefühlt fehlenden, politischen Unterstützung selbst ein Legitimationsgefüge für aktuelle Probleme und Missstände zu konstruieren. Schon während des Jahrtausendwechsels konnte verifiziert werden, dass sich der heutige Rassismus zwar von der „[...] plump biologistischen Rassenideologie

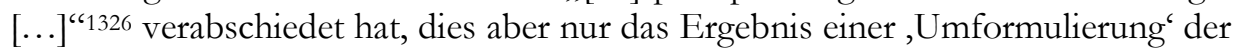
Begrifflichkeit darstellt. „Erklärten es alte rassistische Ideologien zur Aufgabe, die Erbsubstanz rein zu halten, soll nun die sogenannte ,kulturelle Identität ${ }^{`}$ der Völker [...] vor fremden Einflüssen geschützt werden."1327 - zwei Begriffe, eine Bedeutung. Die Frage nach einem heutigen, modernisierten Rassismus ohne ,Rassen“ kann also verneint werden, lediglich der ,Rassebegriff‘ wird heute durch beschönigende Wortformulierungen ersetzt. ${ }^{1328}$

1321 Vgl. Behrens 2004, a. a. O., S. 7.

1322 Vgl. Bischoff, Joachim et al. (2004b): Stichwort: Rechtsextremismus - Rechtspopulismus, in: ebd. (Hrsg.): Moderner Rechtspopulismus. Ursachen, Wirkungen, Gegenstrategien, Hamburg, S. 7. | Vgl. Bischoff, Joachim/Müller, Bernhard (2004a): Moderner Rechtspopulismus, in: Bischoff, Joachim et al. (Hrsg.): Moderner Rechtspopulismus. Ursachen, Wirkungen, Gegenstrategien, Hamburg, S. 10, 31.

1323 Vgl. Jäger 1992b, a. a. O., S. $221 \mathrm{ff}$.

1324 Jäger 1992b, a. a. O., S. 221.

1325 Vgl. Jäger 1992b, a. a. O., S. 222ff. | Vgl. Wachendorfer, Ursula (2001): Weiß-Sein in Deutschland. Zur Unsichtbarkeit einer herrschenden Normalität, in: Arndt, Susan (Hrsg.): AfrikaBilder. Studien zu Rassismus in Deutschland, Münster, S. 87. | Trittin 1993, a. a. O., S. 84.

1326 Trittin 1993, a. a. O., S. 84.

1327 Trittin 1993, a. a. O., S. 85, 86.

1328 Ergänzend kann ebenfalls notiert werden, dass der biologistische Rassismustypus schon immer in rassistischen Argumentationsstrukturen vorhanden war, auch in Zeiten des sogenannten Neorassismus. Hier konnten jedoch 
Abschließend muss dann vor der Gefahr möglicher neuer Konjunkturen des Rechtsextremismus und des Rechtspopulismus gewarnt werden. „Rassismus kann nämlich aufgrund seines biologistischen Gehalts und weil er insgesamt soziale Zusammenhänge naturalisiert, als Einfallstor für andere völkische und rechtsextreme Ideologeme fungieren." 1329 - insbesondere, da sich der Rassismus - wie gezeigt - dem ,[...] jeweiligen Denken der Zeit $[\ldots]^{] " 1330}$, der jeweiligen politischen, wirtschaftlichen und gesellschaftlichen Situation flexibel und kontinuierlich anpasst. Er inszeniert damit spezifische Ängste innerhalb der Gesellschaft.

\subsection{Zwischenfazit: Phänomenologie des Rassismus im 21. Jahrhundert}

Resümierend lässt sich konstatieren, dass das gegenwärtige Rassismusphänomen nicht auf einzelne Erklärungsansätze bzw. Hintergründe zurückzuführen ist. Verantwortlich für die aktuelle ,Konjunktur ${ }^{`}$ des tendenziell wieder biologistischen Rassismusphänomens im 21. Jahrhundert ist vielmehr ein komplexes Ursachengefüge, welches rassistische Ressentiments in erheblichen Teilen der Gesellschaft forciert hat (s. Kapitel 3). Auch dürfen die historisch-politischen Entwicklungsprozesse - insbesondere in den 1980er und 1990er Jahren - nicht übergangen werden, da auch sie Langzeitauswirkungen auf die aktuellen rassistischen Tendenzen haben, wie vor allem historisch argumentierende Analyseansätze der Rassismusforschung verdeutlichen. Politik, Wirtschaft, Medien und Gesellschaft haben in der Bundesrepublik Deutschland gemeinsam aufgrund vielfältiger Wechselwirkungen zum aktuellen Aufschwung rassistischer Ansichten beigetragen: Die politische Ebene vor allem aufgrund ihrer fehlenden und verzögerten Entscheidungen zur Ausländer-, Migrations- und Einwanderungspolitik am Ende des vergangenen Jahrhunderts sowie durch einen gefühlten institutionell verankerten Rassismus auf nationalstaatlicher Ebene; die ökonomischen Entwicklungen seit dem Jahr 2007, besonders die aktuelle Eurokrise und die scheinbar nur auf Produktivität ausgerichtete Zielorientierung, deren Auswirkungen die Bürgerinnen und Bürger direkt wahrnehmen; auch die bundesrepublikanische Gesellschaft hat durch vorschnelle Vorurteilsbildungen sowie durch die soziale Konstruktion des Rassismuskonstrukts einen entscheidenden Anteil. ${ }^{1331}$ Vor dem Hintergrund der politischen Fehlentwicklungen müssen insbesondere die mangelnde Ausländer- und Migrationspolitik bis ins 21. Jahrhundert, die fehlende gesellschaftliche Kommunikation und Transparenz dieser sowie die unstrukturierte Asyldebatte in den 1990er Jah-

kulturelle Aspekte die pseudobiologische Komponente zum Großteil vollständig verdecken. Vgl. Demirović, Alex (1992c): Vom Vorurteil zum Neorassismus. Das Objekt, Rassismus' in Ideologiekritik und Ideologietheorie, in: Redaktion diskurs (Hrsg.): Die freundliche Zivilgesellschaft. Rassismus und Nationalismus in Deutschland, Berlin, S. $87 \mathrm{ff}$. | Vgl. Bojadžijev 2008, a. a. O., S. 24f. Jäger 2001, a. a. O., S. 124.

1330 Veit/Wiebus 1993, a. a. O., S. 47.

1331 Vgl. Jäger/Jäger 2002, a. a. O., S. 219. | Vgl. Zick/Küpper/Hövermann 2011, a. a. O., S. 160f, 172ff, 184f. | Vgl. Groß/Zick/Krause 2012, a. a. O., S. 16. 
ren für die „Treibhausbedingungen“1332 und den darauf folgenden Anstieg des Rassismus bis heute verantwortlich gemacht werden. ${ }^{1333}$ Aufgrund der geschaffenen politischen Verunsicherungen bzw. der fehlenden politischen Rahmenbedingungen nahmen verschiedene Ebenen der Gesellschaft das Problem ,selbst in die Hand': Mithilfe der rassistischen Fremdgruppenabgrenzung und -abwertung wurde Einwanderung als nicht erwünscht kommuniziert. Ebenso hat die Tabuisierung des Rassismusbegriffs sowie das ,Nicht-wahr-haben-wollen' des Rassismus diesen in Politik und Gesellschaft verstärkt: Das „,...] Phänomen [wurde fälschlicherweise] zu einer reinen Randerscheinung einer ansonsten intakten Gesellschaft ,anständiger ${ }^{\star}$ Deutscher umdefiniert [...].“1334 Einer endgültigen Beseitigung des gesellschaftlich verankerten Rassismus stehen mehr denn je vielfältige Probleme im Weg. 1335

Auch die gesellschaftlichen Hintergründe des modernisierten Rassismusphänomens im 21. Jahrhundert sind tendenziell multiperspektivisch $\mathrm{zu}$ sehen: ${ }^{1336}$ Fremdenfeindliche Vorurteile und Stereotype, Fremdenhass, eine ,innere Leere', fehlende Zukunftsperspektiven, eine mangelnde Unterstützung durch die Politik, aber sicherlich auch die Bedeutung der gesellschaftlichen Gruppendynamik, die insbesondere durch die mediale Verstärkung des Rassismus hervorgerufen wird, haben einen gemeinsamen Anteil an der Renaissance des Rassismus. ${ }^{1337}$ Hier sei insbesondere auf den rassismustheoretischen Forschungsansatz von Robert Miles verwiesen, der diese genannte gesellschaftliche Dynamik mit der Konstruktion von Herrschaftsverhältnissen, der sogenannten ,Rassenkonstruktion', verknüpft und damit die hier exemplifizierten Annahmen bestätigt. Weiterhin spielen auch die Rückkehr der angeblich ,einfach verständlichen', biologisch-genetischen „Reinheitsidee“1338 von Populationen sowie die Differenzierung zwischen ,guten“ und ,weniger guten“ Mitmenschen im Rahmen der immer noch vorhandenen Einwanderungs- und Migrationsdebatte eine wichtige Rolle. ${ }^{1339}$ Der ,Rassebegriff scheint zusätzlich durch gesellschaftliche Konstruktionen wieder salonfähig zu werden, auch wenn er meist durch beschönigende Ersatztermini ausgetauscht wird. ${ }^{1340}$

Die Begrenzung auf eine ,kulturelle Andersartigkeit' sowie die kulturelle Identität, welche die kulturtheoretisch argumentierende Rassismusforschung fokussiert, wird heute zunehmend durch insbesondere ursächlich biologistisch begründete Rassismen durchbrochen: Der biologischen Herkunft, von Intelligenz und Bil-

1332 Bischoff/Müller 2004a, a. a. O., S. 39.

1333 Vgl. Bischoff/Müller 2004a, a. a. O., S. 13, 33 ff.

1334 Fröchling 1994, a. a. O., S. 89.

1335 Vgl. Jäger/Jäger 2002, a. a. O., S. 212.

1336 Vgl. Veit/Wiebus 1993, a. a. O., S. 157.

1337 Vgl. Veit/Wiebus 1993, a. a. O., S. 79ff. | Vgl. Grau/Heitmeyer, a. a. O., S. $150 \mathrm{ff}$.

1338 Veit/Wiebus 1993, a. a. O., S. 93.

1339 Vgl. Veit/Wiebus 1993, a. a. O., S. 93.

1340 Vgl. Kalpaka/Räthzel 1994c, a. a. O., S. 15. 
dungsstand oder dem physischen Aussehen. ${ }^{1341}$ Die biologistischen Rassismuskomponenten sind so keinesfalls in den Wirren des historischen Entwicklungsprozesses verschwunden, sondern im Alltag der bundesrepublikanischen Gesellschaft permanent vorhanden. ${ }^{1342}$ Auch kann keineswegs von einem rein auf Deutschland begrenzten Rassismusphänomen ausgegangen werden, im Gegenteil. Ebenfalls in vielen weiteren Staaten Europas sind rassistische Positionen, besonders im Zuge des Rechtspopulismus, vergleichsweise latent präsent, da Fragen um die Migration ein EU-weites, unzureichend gelöstes Problem - insbesondere in den südlichen Mitgliedstaaten - darstellen. ${ }^{1343}$ Darüber hinaus kann mit Blick auf Nicht-EU-Staaten davon ausgegangen werden, dass es sich um ein , ,[... globales Problem $[\ldots]$. ${ }^{\text {“1344 }}$ des wiedererstarkenden Rassismus handelt. ${ }^{1345}$

Das heutige Rassismusphänomen ist in Deutschland nicht neu oder plötzlich entstanden, sondern in den vergangenen Jahrzehnten durch verschiedene Ursachenkomplexe bis ins 21. Jahrhundert ,gewachsen'. Rassismus ist folglich je nach der ursächlichen ,Konjunktur ${ }^{`}$ des Phänomens unterschiedlich und flexibel modifizierbar. ${ }^{1346}$ Trotz zahlreicher wissenschaftlicher Gutachten über Hintergründe rassistischer Konzepte scheinen diese unterschiedliche Entwicklungslinien aufzugreifen, welche einen nachhaltigen Rückhalt in der bundesrepublikanischen Bevölkerung genießen. ${ }^{1347}$ Resümierend muss daher konstatiert werden, dass ,[d]ie Geschichte des Rassismus [...] schon mehrere hundert Jahre alt und auch heute noch sehr lebendig [ist].“"1348 Politik und Gesellschaft sollten perspektivisch für die bundesrepublikanische Zukunft „,...] nachhalti[g] über die Fragen von Rasse und Rassismus nachdenken." ${ }^{\text {1349 }}$

1341 Vgl. Veit/Wiebus 1993, a. a. O., S. 157. | Vgl. Runge 1990, a. a. O., S. 58f. | Vgl. Rahner 2011, a. a. O., S. 29. | Link, Jürgen (2002): „Rechtspopulismus“? Über einige diskurstaktische Probleme beim Bekämpfen des Neorassismus unter normalistischen Verhältnissen (mit neun diskurstaktischen Tipps), in: Bojadžijev, Manuela/Demirović, Alex (Hrsg.): Konjunkturen des Rassismus, Münster, S. 204f.

1342 Vgl. Castles, Stephen (1991): Weltweite Arbeitsmigration, Neorassismus und der Niedergang des Nationalstaats, in: Bielefeld, Uli (Hrsg.): Das Eigene und das Fremde. Neuer Rassismus in der Alten Welt?, Hamburg, S. 140f. Vgl. Veit/Wiebus 1993, a. a. O., S. 157.

1344 Farin/Seidel-Pielen 1992, a. a. O., S. 12.

1345 Vgl. Balke et al. 1993, a. a. O., S. VIII.

1346 Vgl. Bojadžijev/Demirović 2002, a. a. O., S. 25. | Vgl. Steins, Gisela/Rudolph, Udo (1994): Fremdenfeindlichkeit aus sozialpsychologischer Sicht: Vorauslaufende Bedingungen, Folgen, Interventionen, in: Knortz, Heike (Hrsg.): Fremdenfeindlichkeit in Deutschland. Ein interdisziplinärer Diskussionsbeitrag, Frankfurt/Main u. a., S. 101. | Vgl. Würtz, Stefanie (2000): Wie fremdenfeindlich sind Schüler? Eine qualitative Studie über Jugendliche und ihre Erfahrungen mit dem Fremden, Weinheim u. a., S. $239 \mathrm{ff}$.

Rassistische Ausdruckesformen können variabel an die aktuelle politische, wirtschaftliche und gesellschaftliche Lage angepasst werden, was zur beutigen Problemsituation fübrt.

1347 Vgl. Taguieff, Pierre-André (1994): Die Metamorphosen des Rassismus und die Krise des Antirassismus, in: Bielefeld, Uli (Hrsg.): Das Eigene und das Fremde. Neuer Rassismus in der Alten Welt?, Hamburg, S. 222f.

1348 Veit/Wiebus 1993, a. a. O., S. 88.

1349 Solomos 2002, a. a. O., S. 170. 



\section{Naturwissenschaften und Rassismus}

In den vorherigen Kapiteln wurden die vielfältigen Charakteristika des im 21. Jahrhundert auftretenden Rassismusphänomens innerhalb der bundesrepublikanischen Politik und Gesellschaft aus sozialwissenschaftlicher Perspektive analysiert. Der Fokus lag hierbei auf den vornehmlich biologistisch konnotierten Erklärungsund Argumentationsansätzen der rassistischen Ideologie. Bezugnehmend auf eine mögliche Definition des Rassismusbegriffes wurde demzufolge ein enggeführter, begrenzender Definitionsrahmen präferiert (s. Kapitel 2): Hier stehen vor allem morphologisch-physiognomische, genetische und kognitive Differenzen als „,...] biologische ,Basis' [...] ${ }^{\text {“1350 }}$ rassistischer Vorurteile im Mittelpunkt. ${ }^{1351}$ Denn die Biologie hat vor dem Hintergrund der Begründung rassistischer Ressentiments eine lange historische Tradition. ${ }^{1352}$ Ein sogenannter biologischer Determinismus zeigt sich demnach als immer noch vorhandener sozialer Stereotyp. ${ }^{1353}$ Folglich konzentriert sich auch der weitere Verlauf auf den schon in vorherigen Kapiteln präferierten, engen Rassismusbegriff nach Robert Miles, der vornehmlich biologistische sowie pseudogenetische Vorurteile fokussiert. Nur so kann ein abgrenzbarer Rahmen sowie eine gezielte Engführung des Forschungsvorhabens erreicht werden. Zusätzlich veranschaulicht gerade der biologische Schwerpunkt die be-

\footnotetext{
$1350 \quad$ Singer 1997, a. a. O., S. 56.

1351 Vgl. Singer 1997, a. a. O., S. 55f.

1352 Vgl. Gould, Jay Stephen (1983): Der falsch vermessene Mensch, Basel u. a., S. 26.

1353 Vgl. Gould 1983, ebd., S. 356.
} 
sondere Relevanz und Bedeutung dieser Arbeit, die aufgrund von bisher noch unzureichenden Forschungsansätzen einen Erkenntnisfortschritt erwarten lässt. Hierzu trägt die Kombination von Sozial- und Naturwissenschaften - fachlich als auch methodisch - in besonderer Weise bei.

Aufgrund dessen fokussieren die folgenden Kapitel einen Schwerpunkt dieser Arbeit: Die Diskussion bezüglich des pseudobiologisch begründeten Rassismustypus. Dieser soll aus der Perspektive molekulargenetischer Forschungserkenntnisse analysiert und auf seine Validität geprüft werden. Mithilfe der biologischen Forschungsbereiche der Anthropologie, der Bio-Psychologie, der Neurobiologie sowie der Molekular-, Verhaltens-, Evolutions- und Humangenetik soll verdeutlicht werden, dass die zahlreichen Deutungs- und Erklärungsschemata des biologisch konnotierten Rassismusphänomens nur eines darstellen: Einen Missbrauch naturwissenschaftlicher Forschungsbefunde zur Legitimation der rassistischen Ideologie. Eine Klassifizierung der Menschen in morphologisch und genetisch differierende ,reine Rassen“ ist nach heutigem Forschungsstand ebenso realitätsfern, wie unter Bezugnahme auf Charles Darwin - eine hierarchische Unterteilung der Menschheit in einerseits ,nützliche', ,höherwertigere' ${ }^{6}$ und intelligentere sowie andererseits scheinbar , unnützere', ,minderentwickelte`, ,dümmere 6 und den gesellschaftlichen Fortschritt blockierende Menschenpopulationen. Die im weiteren Verlauf diskutierten biologischen Forschungserkenntnisse visualisieren, dass alle Menschen aufgrund verschiedener biologisch-genetischer Mechanismen vollkommen verschieden sind. ${ }^{1354}$ Selbst bei eineiigen Zwillingen, die sich aus einer einzigen befruchteten Eizelle entwickeln, können beispielsweise Variationen in deren Erbinformationen vorhanden sein. ${ }^{1355}$ Grund dieser genetischen Variabilität und Vielfalt ist unter anderem die sogenannte Rekombination der Gene bei der geschlechtlichen Fortpflanzung, die in den folgenden Kapiteln noch detaillierter erörtert wird. ${ }^{1356}$ Darüber hinaus lassen sich einführend als weitere Beispiele der menschlichen Individualität die Existenz verschiedener Blutgruppen oder auch die Abstoßungs-Immunreaktion bei der Transplantation von nichteigenen Spenderorganen nennen. ${ }^{1357}$ Sogenannte Histokompatibilitäts-Gene ermöglichen die Transplantation in diesem Fall nur bei identischer Allel- bzw. Genkombination. ${ }^{1358}$

Der weitere Verlauf wird illustrieren, dass nicht nur die genetischen Grundlagen, sondern insbesondere auch die vielfältigen Umwelteinflüsse auf die menschliche Individualentwicklung für die Vererbung von Genen bzw. die Ausprägung

1354 Vgl. Dobzhansky, Theodosius (1973): Intelligenz, Vererbung und Umwelt. Die Antwort der Wissenschaft im Streit um vererbte und erworbene Intelligenz, München, S. 14ff.

1355 Vgl. Dobzhansky 1973, ebd., S. 15ff.

1356 Vgl. Dobzhansky 1973, ebd., S. 15ff.

1357 Vgl. Dobzhansky 1973, ebd., S. $15 \mathrm{ff}$.

1358 Vgl. Dobzhansky 1973, ebd., S. $15 \mathrm{ff}$.

Gene stellen spezifische Abschnitte der menschlichen Erbinformationen - der DNA (Desoxyribonucleic acid/Desoxyribonukleinsäure) - dar. Diese sind aus sogenannten Nukleotiden, den Grundbausteinen der menscblichen DNA, zusammengesetzt. Allele stellen demgegenüber unterschiedliche Zustandsformen eines Gens dar. Die Gesamtheit aller Allele einer Population wird als deren Genpool bezeichnet. Vgl. Markl, Jürgen (2006): Neil A. Campbell, Jane B. Reece. Biologie, 6. Auflage, München, S. 1496, 1511. 
von spezifischen Merkmalen verantwortlich sind: Kognitive Fähigkeiten, Bewegung oder musische Begabung sind hiervon abhängig. ${ }^{1359}$ Somit ist die rechtliche Gleichheit aller Menschen aus politikwissenschaftlicher Perspektive zwar eine alte Wahrheit - so Genetiker Luigi Luca Cavalli-Sforza -, wie beispielsweise Art. 3 Abs. 1 GG demonstriert, jedoch keinesfalls mit biologischen bzw. kognitiven Charakteristika gleichzusetzen (s. Kapitel 1, 5).1360

„Gleichbeit bedeutet, dass allen Menschen dieselben Chancen zugebilligt werden, ibre Fähigkeiten voll zu entfalten - nicht, dass ibre Fähigkeiten identisch wären. "I361

Der Genetiker Theodosius Dobzhansky sieht die rechtliche Gleichheit folglich mehr als ethisches Gebot - die biologische Verschiedenheit aller Menschen ist hingegen ein Faktum der Natur sowie der Evolution. ${ }^{1362}$ Demzufolge scheint die von der rassistischen Ideologie postulierte, angebliche Ungleichheit von spezifischen Menschengruppen lediglich eine gesellschaftliche Konstruktion und keine naturwissenschaftliche Tatsache, wie die nachfolgenden Kapitel detailliert vergegenwärtigen werden. ${ }^{1363}$

Die aktuelle, biologische Forschungslage bezüglich biologistischer sowie pseudogenetischer Argumentationen ist in weiten Teilen noch immer kontrovers diskutiert. Auf der einen Seite stehen die biologistisch argumentierenden Vertreter des Rassismus, die auch heute noch eine Höherwertigkeit der eigenen Bevölkerung bzw. Kultur sowie die Abwertung und Ausgrenzung ,der anderen' anhand amateur-biologischer Charakteristika festzustellen versuchen. Im 21. Jahrhundert stehen jedoch nicht mehr die Forschungsfelder der Kraniologie sowie der sogenannten ,Rassenforschung' im Fokus, sondern angeblich genetische und intelligenzbedingte Differenzen zwischen spezifischen Populationen von Menschen. Evolutionsbiologe Stephen Jay Gould, einer der größten Kritiker der Soziobiologie, konstatiert vor diesem Hintergrund schon in den 1980er Jahren treffend: ${ }^{1364}$

„Die Plumpheit des Schädelindex haben der Komplexität des Intelligenztests Platr gemacht. Die Zeichen der angeborenen Kriminalität werden nicht mehr in den Stigmata der groben Anatomie gesucht, sondern [...] in den Genen und der Feinstruktur des Gebirns." "365

1359 Vgl. Dobzhansky 1973, a. a. O., S. 17.

Vgl. Bundeszentrale für politische Bildung 2011, a. a. O., S. 13.

1360 Vgl. Dobzhansky 1973, a. a. O., S. 13. | Vgl. Cavalli-Sforza, Luigi Luca/Cavalli-Sforza, Francesco (1994): Verschieden und doch gleich. Ein Genetiker entzieht dem Rassismus die Grundlage, München, S. 9. | Vgl. Bundeszentrale für politische Bildung 2011, a. a. O., S. 13.

1361 Dobzhansky, Theodosius (1962): Dynamik der menschlichen Evolution. Gene und Umwelt, Hamburg, S. 29.

1362 Vgl. Dobzhansky 1962, a. a. O., S. 14.

1363 Vgl. Dobzhansky 1962, a. a. O., S. 14.

1364 Vgl. Richards, Robert J. (1987): Darwin and the emergence of evolutionary theories of mind and behavior, Chicago, S. 544.

1365 Gould 1983, a. a. O., S. 153. 
Hinzukommend fand zwar nach dem Zweiten Weltkrieg eine breite Abkehr der Biologie von der sogenannten ,Rassenforschung' statt, die jedoch vornehmlich auf politischen Anstrengungen basierte. Diesbezüglich sind insbesondere die 1950/1951 sowie 1952 stattgefundenen UNESCO-Konferenzen zu biologischen Grundlagen rassistischer Argumentationen - insbesondere bezüglich des sogenannten ,Rassebegriffs' - sowie die UNESCO-Erklärung aus dem November $1978 \mathrm{zu}$ nennen, die das pseudowissenschaftliche, biologistisch begründete Rassismusphänomen aus wissenschaftlicher Perspektive diskreditierten (s. Kapitel 1). 1366

Nichtsdestotrotz sind biologistisch-rassistische Forschungsansätze immer noch präsent, sogar im 21. Jahrhundert. Hier seien beispielsweise die Forschungen von Politikwissenschaftler Charles Murray und Psychologe Richard Herrnstein von der Harvard University genannt, die 1994 eine Studie zur angeblichen geistigen Benachteiligung von Menschen mit afrikanischer Herkunft publizierten. ${ }^{1367}$ Ebenfalls sei an die Veröffentlichung einer Sonderausgabe des Wissenschaftsmagazins ,Nature Genetics“ aus dem November 2004 zum Thema „Genetics for the human race“1368 erinnert, in dem namhafte und anerkannte Biologen und Genetiker das Vorhandensein von genotypischen Unterschieden zwischen Menschen sowie die Existenz von sogenannten ,Menschenrassen“ diskutierten. ${ }^{1369}$ Weiterhin findet

1366 Vgl. Kühl, Stefan (1999): Die soziale Konstruktion von Wissenschaftlichkeit und Unwissenschaftlichkeit in der internationalen eugenischen Bewegung, in: Kaupen-Haas, Heidrun/Saller, Christian (Hrsg.): Wissenschaftlicher Rassismus. Analysen einer Kontinuität in den Humanund Naturwissenschaften, Frankfurt/Main u. a., S. 116ff.

Vor dem Hintergrund der Schreckensszenarien des Zweiten Weltkrieges versuchte die UNESCO in den 1950er und 1960er Jabren auf verschiedenen Konferenzen mithilfe eines internationalen Wissenschaftlerteams den Rassismus- und primär den ,Rassebegriff, die maßgeblich zu den katastrophalen Ereignissen der nationalsozialistischen Terrorberrschaft beigetragen hatten, zu diskereditieren. Am Ende der Konferenzen von 1950/1951 wurde trotz kontroverser Diskussionen die gemeinsame Erklärung, The Race Question'verabschiedet. Diese stellte unter anderem fest, dass Menschen aufgrund von nur phänotypischen Unterschieden nicht in ,Rassen "klassifiziert werden können. Auch die willkïrliche Klassifizierung von Menschengruppen aufgrund sozialer und kultureller Aspekte wurde als Widerspruch zur biologischen Bedeutung des Begriffes identifiziert. Darüber hinaus wurde auch bezüglich, rassischer" Unterschiede von intellektuellen und geistigen Leistungen die feblende Beweislage festgestellt. Weiterbin konnte man sich biernach in einer Erklärung im Jahr 1952 zu der Empfeblung bewegen, den, Rassebegriff in Zukunft nicht mehr zu vervenden und - bei aller existierender Kritik - eher die Begrifflichkeit, ethnische Gruppen' zu präferieren. Darauffolgte 1965 die UN-

Rassendiskriminierungskonvention sowie 1978 die ,Erklärung über ,Rassen ' und rassistische Vorurteile' der UNESCO. Vgl. UNESCO 1950, a. a. O. | Vgl. Deutsche UNESCO-Kommission e. V. (1980): „Über ,Rassen“ und rassistische Vorurteile“, in URL: http://www.unesco.de/ erklaerung_rassist_vorurteile.html $<24.07 .2012>$.

1367 Vgl. Finzsch, Norbert (1999): Wissenschaftlicher Rassismus in den Vereinigten Staaten - 1850 bis 1930, in: Kaupen-Haas, Heidrun/Saller, Christian (Hrsg.): Wissenschaftlicher Rassismus. Analysen einer Kontinuität in den Human- und Naturwissenschaften, Frankfurt/Main u. a., S. $85 f$.

1368 Nature Publishing Group (2004): Nature Genetics. Genetics for the human race, Vol. 36 Nr. 11, Nov. 2004, London u. a.

1369 Der Begriff, Genotyp“ beschreibt die Gesamtheit aller Erbanlagen eines Lebewesens, also die gesamten, in der $D N A$ enthaltenen genetischen Informationen. Demgegenüber fokussiert der sogenannte ,Pbänotyp' das äußere Erscheinungsbild eines Lebewesens bzw. in diesem Fall eines Menschen: „[...] Die Ausprägung des Genotyps 
man auch vorausblickend in das Jahr 2014 Erbgutanalysen, die beispielsweise genetische Unterschiede zwischen verschiedenen mexikanischen Bevölkerungsgruppen mit physiologischen Merkmalen verknüpfen und darauf aufbauend eine neue genspezifische Gesundheitspolitik fordern. ${ }^{1370}$ Selbst in der wissenschaftlichen Lehr- und Fachliteratur finden sich zahlreiche Autoren, die sich immer noch ausgiebig mit der ,Rassenkunde' des Menschen beschäftigen. Hier sei als Beispiel der Anthropologe Rainer Knußmann genannt, der sich in seinem 1996 erschienenen Lehrbuch „Vergleichende Biologie des Menschen“1371 in mehreren Kapiteln mit der „Allgemeinen Rassenkunde“"1372 sowie der „Speziellen Rassenkunde“1373 des Menschen beschäftigt. ${ }^{1374}$ Auch der deutsche Genetiker Volkmar Weiss befasst sich primär mit der angeblich hauptsächlich genetischen Vererbung der sogenannten Intelligenz beim Menschen, wodurch rassistische Thesen bezüglich einer Erblichkeit von ,Dummheit‘ scheinbar bestätigt werden. Erst 2012 veröffentlichte Weiss mit „Die Intelligenz und ihre Feinde: Aufstieg und Niedergang der Industriegesellschaft ${ }^{\text {‘1375 }}$ ein weiteres Werk zu diesem Schwerpunkt. Ebenfalls die Thesen Thilo Sarrazins, der sich für eine hohe Erblichkeit der sogenannten Intelligenz sowie für das Vorhandensein von ethnisch - ,rassisch ${ }^{6}$ - unterschiedlichen Menschengruppen ausspricht, basieren auf lückenhaft recherchierten, biologisch-genetischen Forschungsergebnissen (s. Kapitel 3.1). Diesen Eindruck erzeugt zumindest seine semi-wissenschaftliche Beweisführung. Bezugnehmend auf Murray und Herrnstein ist so folgerichtig zu kritisieren: Sie ,[...] bewegen sich auf dem Gebiet der Intelligenzforschung so, als ob es die Forschungsergebnisse der Neurobiologie, Embryologie, kognitiven Psychologie, Entwicklungspsychologie, Entwicklungsbiologie und Genetik der letzten hundert Jahre nicht gegeben hätte."1376 Die nachfolgenden Kapitel werden diese Einschätzung bestätigen. Nichtsdestotrotz muss konstatiert werden, dass sich der große gesellschaftliche Rückhalt

bestimmt das Erscheinungsbild des Lebewesens (Phänotyp). Der Phänotyp bescbreibt alle Merkmale der Morphologie, Physiologie, Ökologie und des Verhaltens eines Organismus. Organismen zeigen den gleichen Phänotyp, wenn die Gene in ähnlicher Weise ausgeprägt werden. Da Umwelffaktoren auf die Ausprägung einwirken, gibt es keine phänotypisch exakt gleichen Individuen. Ein bestimmter Genotyp wird in der Regel also leicht verschiedene Pbänotypen hervorbringen. "Vgl. Janning, Wilfried/Knust, Elisabeth (2008): Genetik. Allgemeine Genetik - Molekulare Genetik - Entwicklungsgenetik, 2. Auflage, Stuttgart u. a., S. 491, 495. | Munk, Katharina (2010): Taschenlehrbuch Biologie. Genetik, Stuttgart, S. 254. Vgl. Spiegel Online (2014): „Überraschende Erbgutanalyse. Die Vielfalt der Mexikaner“, in URL: http://www.spiegel.de/wissenschaft/mensch/genetische-vielfalt-der-mexikanergroesser-als-angenommen-a-675031.html <16.06.2014>. | Vgl. Moreno-Estrada, Andrés et al. (2014): The genetics of Mexico recapitulates Native American substructure and affects biomedical traits, in: Science, Vol. 344, Washington u. a., S. 1280-1285. Knußmann, Rainer (1996): Vergleichende Biologie des Menschen. Lehrbuch der Anthropologie und Humangenetik, 2. Auflage, Stuttgart u. a.

1372 Knußmann 1996, ebd., S. 405.

1373 Knußmann 1996, ebd., S. 429.

1374 Vgl. Knußmann 1996, ebd., S. $405 \mathrm{ff}$.

1375 Weiss, Volkmar (2012): Die Intelligenz und ihre Feinde: Aufstieg und Niedergang der Industriegesellschaft, Graz.

1376 Finzsch 1999, a. a. O., S. 87. 
biologistisch-rassistischer Ressentiments auch auf die genannten pseudowissenschaftlichen Forschungsbefunde stützt.

Auf der - tendenziell größer werdenden - Gegenseite der Fachwissenschaften stehen zunehmend namhafte Genetiker aus dem 20. und 21. Jahrhundert, die sich aus verschiedenen biologischen Perspektiven sowie mit unterschiedlichsten Forschungsvorhaben mit den Themenbereichen der Erblichkeit von Genen, der Ausprägung von Merkmalen sowie der Entwicklung und Evolution des Menschen beschäftigen. Einen Vorteil stellt insbesondere der weitreichende Fortschritt der heutigen Genetik dar, der das Vordringen in neue wissenschaftliche Forschungsebenen überhaupt erst ermöglicht hat und so gleichzeitig die natürlichen Grenzen der Forschung immer weiter zurückdrängt. ${ }^{1377}$ Das Ziel biologischer Forschung war jedoch nur in den seltensten Fällen die Erlangung eines validen, wissenschaftlichen Beweises gegen die Theoreme der rassistischen Ideologie. Vielfältige Ergebnisse aus den genannten Untersuchungsbereichen können aber nach detaillierter Analyse und Aufbereitung dazu verwendet werden, die zahlreichen rassistischen Falschaussagen zu diskreditieren und fachlich zu korrigieren. Diesbezüglich sei vor allem auf einen der „[...] wichtigsten Genetike[r] unserer Tage [...]“ ${ }^{\text {‘1378, }}$, Luigi Luca Cavalli-Sforza, hingewiesen. Dieser beschäftigt sich insbesondere mit der evolutiven Entwicklung und Verbreitung des modernen Menschen ausgehend vom afrikanischen Kontinent, kurz: Mit der Geschichte des Menschen. Hier nutzt er vor allem den Zusammenhang zwischen Genen und dem Kommunikationsmittel Sprache, um Vererbungs- und Entwicklungslinien zwischen verschiedenen Populationen des Homo sapiens zu ermitteln sowie darauf aufbauend ein Evolutionsschema des modernen Menschen zu konstruieren. Anhand zahlreicher Parallelen zwischen Sprache und genetischer Ausstattung der Menschenpopulationen verschiedenster Kontinente belegt Cavalli-Sforza die weltweite Ähnlichkeit des modernen Menschen - gleichgültig, ob aus China, Australien, Europa, Südafrika oder Brasilien. Die Journalistin Kirsten Brodde charakterisierte ihn 1992 als „[...] in der Tradition von Charles Darwin [... “"1379 stehend, da auch dieser schon die Sprache als Schlüssel zur menschlichen Geschichte favorisierte. ${ }^{1380 ~ „ W i e ~ S c h l u ̈ s s e l ~}$ und Schloss pass[en] genetischer und sprachlicher Stammbaum der Menschen zueinander." "1381

Ein weiterer prominenter Vertreter der anti-rassistischen, biologischen Forschung ist Theodosius Dobzhansky, der sich primär mit den Abhängigkeiten von Genen und Umweltfaktoren im Verlauf des Vererbungsprozesses beschäftigt. Im Fokus seiner Forschung liegt der Nachweis, dass die sogenannte Intelligenz nicht,

\footnotetext{
1377 Vgl. Cavalli-Sforza, Luigi Luca et al. (1994): The History and Geography of Human Genes, Princeton u. a., S. IX.

1378 Finzsch 1999, a. a. O., S. 87.

1379 Brodde, Kirsten (1992): ,Ahnensuche in Sprachen und Genen. Von Afrika aus wurden zunächst Asien und dann die übrigen Kontinente besiedelt", in URL:

http://www.zeit.de/1992/02/ahnensuche-in-sprachen-und-genen <23.07.2012>.

1380 Vgl. Brodde 1992, a. a. O.

1381 Brodde 1992, a. a. O.
} 
wie von zahlreichen Vertretern der rassistischen Ideologie behauptet, mit spezifischen Prozentsätzen vererbt wird. Thilo Sarrazin spielt diesbezüglich beispielsweise mit verschiedensten Werten zwischen 20 und 80 Prozent (s. Kapitel 3.1). Auch die zahlreichen Datensätze aus teilweise methodisch unzuverlässigen Zwillingsund Adoptionsstudien sind nur mit Einschränkungen gültig bzw. vernachlässigbar. Darüber hinaus müssen diese Daten bei der Verwendung im Rahmen von Erblichkeitsschätzungen auch genetisch und statistisch korrekt ausgewertet sowie interpretiert werden, was zahlreiche PseudoWissenschaftler ebenfalls vernachlässigen. ${ }^{1382}$ Dobzhansky verdeutlicht mithilfe zahlreicher humangenetischer Analysen weiterhin, dass insbesondere die verschiedenen Umwelt- und Umgebungsfaktoren einen entscheidenden Einfluss auf die Ausbildung des Intelligenz-Phänomens zu haben scheinen. Nur im Zusammenspiel von genetischen Vererbungsmechanismen und den Einflüssen der unterschiedlichen Umwelten ist die generationenübergreifende Entwicklung von sogenannter Intelligenz zu erfassen, so seine Hypothese. Diese unterstützen zusätzlich die Befunde der biopsychologischen Forschung, die ebenfalls einen entscheidenden Einfluss der Umwelt auf die Vererbung von Genen sowie die Ausprägung von Merkmalen konstatieren.

Als weiterer Vertreter der naturwissenschaftlichen Anti-Rassismusforschung muss der Begründer der modernen Evolutionstheorie, Charles Darwin, genannt werden, der mit seinen oftmals missbrauchten Beobachtungen einen entscheidenden Beitrag zur Analyse der Evolution von Organismen sowie des modernen Menschen leistete. ${ }^{1383}$ Darwin wird häufig als Begründer des Sozialdarwinismus gebrandmarkt - der weitere Kapitelverlauf wird jedoch umfassend verdeutlichen, dass Darwin keinesfalls als Sozialdarwinist bzw. Rassist charakterisiert werden kann.

Rückblickend wird ersichtlich, dass im 21. Jahrhundert zahlreiche separate Ergebnisse aus verschiedenen Forschungsdisziplinen von Biologie und Psychologie existieren, die biologistisch-rassistischen Vorurteilen aufgrund validierter, wissenschaftlicher Forschungsbefunde widersprechen. Kritisch anzumerken bleibt jedoch, dass trotz aller widersprüchlichen Forschungserkenntnisse sowie der UNESCO-Deklarationen gegen die Verwendung des ,Rassebegriffes ‘ auch in den Naturwissenschaften immer noch auffällig viele Wissenschaftler - auch Luigi Luca Cavalli-Sforza und Theodosius Dobzhansky - den Terminus ,Rasse' verwenden. ${ }^{1384}$ Erst gegen Ende der 1990er Jahre hat sich Cavalli-Sforza in einigen öf-

1382 Erblichkeitsmessungen sind eine statistische Messmethode, mit deren Hilfe mittels prozentualer Berechnungen das relative Verbältnis von geno- zu phänotypischen Abweichungen in einer Population bestimmt werden kann. Ein ermittelter Geneinfluss bedeutet jedoch nicht, dass dieser die Zukunft bzw. das Schicksal eines Individuums unweigerlich bestimmt. Vgl. Plomin, Robert/DeFries, John C. (1998): The Genetics of Cognitive Abilities and Disabilities, in: Scientific American, May 1998, S. 66.

1383 Vgl. Meier-Mesquita 1994, a. a. O., S. 50.

1384 Luigi Luca Cavalli-Sforza und Theodosius Dobzhansky verwenden - trotz aller kritischen Einschränkungen ibrerseits - den ,Rassebegriff mehr oder weniger regelmäßig in ibren Veröffentlichungen. Im Folgenden einige Beispiele biervu: Vgl. Dobzhansky 1973, a. a. O., S. 65. | Vgl. Dunn, Leslie Clarence/Dobzhansky, Theodosius (1970): Vererbung, Rasse und Gesellschaft, Frankfurt/Main. | Vgl. Cavalli-Sforza/Cavalli-Sforza 1994, a. a. O., S. 203. 
fentlichen Interviews mehr oder weniger gegen den ,Rassebegriff ‘ ausgesprochen. ${ }^{1385}$ Auffällig ist weiterhin, dass insbesondere im 21. Jahrhundert bisher noch wenig an weiterführender Forschungsarbeit stattgefunden hat, insbesondere nach der Entschlüsselung des menschlichen Genoms im Rahmen des Human-GenomeProject (HUGO). ${ }^{1386}$ Das Thema Rassismus scheint für viele Naturwissenschaftler nicht mehr relevant zu sein. Der aktuelle gesellschaftliche Trend sowie einzelne Perspektiven der heutigen biologischen Forschungslandschaft illustrieren jedoch eine gegenteilige Entwicklung (s. Kapitel 3).

Die Ziele dieses Kapitels liegen in der Analyse der biologisch-genetisch konnotierten, rassistischen Ressentiments, die scheinbar auf validen, naturwissenschaftlichen Forschungserkenntnissen basieren. Wie der aktuelle Forschungsstand diesbezüglich schon verdeutlicht hat, existieren von biologischer Seite multiple Forschungsbefunde, die biologistisch-rassistische Vorurteile direkt oder indirekt berühren. Jedoch sind die einzelnen Forschungsergebnisse bisher zum Großteil abgegrenzt voneinander publiziert worden. Eine Disziplinen übergreifende Integration zu einem wissenschaftlichen Gesamtkonstrukt - welches sich eindeutig gegen den rassistischen Missbrauch naturwissenschaftlicher Datensätze stellt - fehlt bisher. Die Notwendigkeit und Relevanz dieses Kapitels bietet sich folglich in einer strukturierten Analyse, Verknüpfung, Koordination und Integration allgemeinbiologischer, genetischer, anthropologischer, evolutionsbiologischer sowie biopsychologischer Befunde, um hiermit einen nachhaltigen Beitrag zur eindeutigen Dekonstruktion der biologistischen Vorurteile des Rassismus zu realisieren: Diesem soll die Argumentationsgrundlage entzogen werden. Visualisiert werden soll unter anderem, dass...

- ...die Evolutionstheorie Charles Darwins von Seiten des Rassismus falsch interpretiert und missbraucht wird.

- ...das ,Rassekonstrukt $t^{6}$ im Zusammenhang mit der menschlichen Evolution keine Existenzberechtigung hat.

- ...das Zusammenspiel von Genen und Umweltfaktoren die Vererbung von Genen sowie die Ausprägung und Entwicklung von spezifischen Merkmalen nachhaltig bestimmt.

- ...die Ausprägung des sogenannten Intelligenz-Phänomens von individuellen Gen-, Umwelt- und Umgebungsfaktoren abhängig ist, jedoch keinesfalls generationen- oder lebenszeitübergreifend vererbbar bzw. statistisch quantifizierbar.

\footnotetext{
1385 Vgl. Zeit Online (1992): „Alle aus demselben Holz. Ein Gespräch über den Stammbaum der Menschheit mit dem Genetiker Luigi Luca Cavalli-Sforza", in URL: http://www.zeit.de/1992/07/alle-aus-demselben-holz <23.07.2012>.

1386 Das Human-Genome-Project war ein internationales Forschungsprojekt in den Jabren 1990 bis 2003. Ziel war die vollständige Entschlüsselung der DNA, des genetischen Codes des Menschen. Seit dem Abschluss des Projektes im Jabr 2003 gilt das menschliche Genom als vollkommen entscblüsselt. Folgeprojekte konzentrieren sich auf die Funktionsanalyse der einzelnen menscblichen Gene. Vgl. Strachan, Tom/Read, Andrew P. (2005): Molekulare Humangenetik, 3. Auflage, München, S. 238ff.
} 
Im Rahmen des vorgestellten, interdisziplinären Untersuchungskonzeptes dieser Arbeit wird insbesondere auf die Literatur der schon angesprochenen Wissenschaftler zurückgegriffen. Im Fokus stehen sowohl die zahlreichen Veröffentlichungen von Luigi Luca Cavalli-Sforza - zum Teil auch in Zusammenarbeit mit weiteren Genetikern - aus den 1960er bis 1990er Jahren zu den Themenbereichen Evolution und Verbreitung des modernen Menschen, die wegweisenden Arbeiten von Theodosius Dobzhansky aus den 1960er und 1970er Jahren zur Vererbung von sogenannter Intelligenz oder auch die bahnbrechenden Werke Charles Darwins aus dem 19. Jahrhundert zur Grundlagenforschung der Evolution. Zum Bereich des sogenannten Intelligenz-Phänomens und den damit zusammenhängenden Vererbungs- und Umweltanalysen wird insbesondere auf Arbeiten der Verhaltensgenetik sowie der Biopsychologie zurückgegriffen: Hier sind die Grundlagenwerke von Carole Wade und Carol Tavris, Robert Plomin, John DeFries, Gerald E. McClearn und Peter McGuffin, Ferdinand Merz und Ingeborg Stelzl, Joachim Grabowski sowie von Stephen Jay Gould zu nennen. ${ }^{1387}$ Aus dem Bereich der Anthropologie und der Evolutionsgenetik werden insbesondere die Forschungsansätze von Steve Olson, Michael Ruse, Bruno Streit, Winfried Henke und Hartmut Rothe sowie von Gisela Grupe erörtert.

Da das vorliegende Kapitel schwerpunktmäßig biologische sowie molekulargenetische Themenaspekte fokussiert, scheinen sozialwissenschaftliche Methoden zur Bearbeitung dieser nur eingeschränkt zielführend. Präferiert werden im nachfolgenden Kapitel folglich primär naturwissenschaftliche Forschungslayouts, die sich insbesondere auf quantitative Untersuchungsdesigns stützen. Zur Verständnisförderung wird versucht, naturwissenschaftliche Fachtermini reduziert zu verwenden und Begrifflichkeiten sowie methodische Vorgehensweisen gegebenenfalls einführend zu erläutern.

Vor dem Hintergrund des Missbrauchs der darwinistischen Evolutionstheorie durch zahlreiche rassistische Argumentationsmuster erfolgt anhand der beiden Hauptwerke Darwins zunächst eine Inhaltsanalyse zur Überprüfung der dargelegten Vorurteile. Die hier gewonnen Erkenntnisse sollen dann im weiteren Verlauf im Rahmen einer vergleichenden Inhaltsanalyse mit dem heute vorherrschenden Verständnis des Evolutionsmechanismus konfrontiert werden, um den essentiellen Beitrag Darwins gegen rassistische Theoreme zu verdeutlichen.

Da qualitative Untersuchungsmethoden am Menschen - im Gegensatz zu tierischen Versuchsansätzen - insbesondere im Bereich der Intelligenz- und Entwicklungsforschung nicht bzw. nur schwierig möglich erscheinen, stehen im weiteren Verlauf vor allem quantitativ-genetische Methoden im Mittelpunkt. Bezüglich der Frage nach einer ,Rassenentwicklung' des Homo sapiens wird auf quantitatives Datenmaterial der anthropologischen Forschung zur Entwicklung des Menschen zurückgegriffen, welches zur Erstellung einer Kontinent-übergreifenden Verbreitungsanalyse des modernen Menschen mit quantitativen Analysen der Desoxyri-

1387 Bezüglich der vollständigen Literaturangaben wird auf das Literaturverzeichnis am Ende dieser wissenschaftlichen Arbeit verwiesen. Hier sind unter den genannten Autoren die einzelnen Publikationen umfassend notiert. 
bonukleinsäure (DNA) verglichen werden soll. ${ }^{1388}$ Auch vor dem Hintergrund der Umwelteinwirkungen auf die DNA der menschlichen Zellen wird partiell auf quantitative Datensätze zu Auswirkungen von Umweltreizen bzw. zur Entstehung von Mutationen durch Umwelteigenschaften zurückgegriffen. ${ }^{1389}$ Ergänzt wird dies darüber hinaus durch DNA-Analysen des Menschen.

An das strukturierte, transparente und methodische Vorgehen ist auch die Gliederung dieses Kapitels angepasst. Der erste Teil des Kapitels fokussiert die Grundlagen der modernen Evolutionsbiologie und -genetik. Hier stehen folglich die Evolutionstheorie Charles Darwins und deren Missbrauch bzw. deren Falschinterpretation durch rassistische Theoreme im Mittelpunkt. In diesem Zusammenhang erfolgt ebenfalls ein Vergleich mit dem heute vorliegenden Synthetischen Evolutionskonzept sowie dessen möglicher Teilhabe an der Legitimierung biologistisch-rassistischer Ressentiments. Im weiteren Verlauf wird das ,Rassekonstrukt ${ }^{6}$ als Namensgeber und Basisbegriff des Rassismus untersucht. Ist der ,Rassebegriff' fachlich korrekt auf den Menschen übertragbar? Existieren verschiedene ,Rassen`von Menschen? Haben sich sogenannte ,Menschenrassen` schon während der evolutiven Entwicklung und Verbreitung des Homo sapiens auf der Erde differenzieren können? Einen weiteren Schwerpunkt bezüglich rassistischer Ressentiments bildet die molekulargenetische Perspektive. Diese soll vor allem auf der Basis einer strukturierten Auswertung der menschlichen DNA sowie einer Analyse der Chromosomen die natürlichen Unterschiede menschlicher Erbinformationen visualisieren. Diesbezüglich müssen auch die multiplen umweltbedingten Einflüsse Beachtung finden.

Der vierte Abschnitt des Kapitels beschäftigt sich letztlich mit einem von biologistisch-argumentierenden Theoretikern immer wieder vorgebrachten Vorurteil: Der angeblich genetisch verankerten Vererbung von erworbenen Genen bzw. Merkmalen - hier exemplarisch am Beispiel der sogenannten Intelligenz - von Generation zu Generation. Vor diesem Hintergrund muss insbesondere das vorherrschende Missverständnis bezüglich des Einflusses von Genen und Umwelten auf den Vererbungsprozess veranschaulicht werden. Abschließend folgen eine stichhaltige Zusammenfassung der wichtigsten Kernaussagen sowie eine Einordnung der zahlreichen Missverständnisse im Verhältnis von Biologie und Rassismus im Rahmen eines Zwischenfazits.

\subsection{Charles Darwin: Evolution und Rassismus}

Zahlreiche biologistisch-rassistische Vorurteile und Ressentiments beziehen sich direkt auf die von Naturforscher Charles Darwin 1859 veröffentlichte Evolutionstheorie aller Lebewesen. Die darwinschen Schlussfolgerungen des ,Kampfes ums Dasein' werden oftmals sowohl für die Einteilung der menschlichen Spezies in

\footnotetext{
1388 Vgl. Cavalli-Sforza/Cavalli-Sforza 1994, a. a. O.

1389 Vgl. Olson, Steve (2003): Herkunft und Geschichte des Menschen. Was die Gene über unsere Vergangenheit verraten, Berlin.
} 
sogenannte ,Rassen“ als auch für die Proklamation eines ,Rassenkampfes` von angeblich stärkeren, ,höherwertigeren' und intelligenteren Menschengruppen gegenüber scheinbar, minderwertigeren“ Menschengruppen missbraucht. Charles Darwin wird so indirekt als Mitbegründer von Rassismus und Sozialdarwinismus stilisiert. Der weitere Verlauf skizziert jedoch, dass Charles Darwin keinesfalls als Rassist charakterisiert werden kann, sondern dass seine Aussagen von Seiten der rassistischen Ideologie größtenteils falsch interpretiert und missbraucht worden sind.

„Charles Darwin selbst war kein Rassist, aber solche Vorstellungen wie ,natürliche Auslese' und ,Überleben des Tüchtigsten' wurden von Rassentheoretikern begierig übernommen. [...] Der Rassismus [...] vereinfachte Darwin, übernahm die in ihm beschriebenen, guten, verlässlichen Fakten“ und übertrug sie auf den Kampf ums Überleben und die Auslese der tüchtigsten Rasse. "1390

Die außerordentliche wissenschaftliche Leistung Darwins zeigt sich darin, dass die moderne Evolutionsbiologie „[...] ohne die Leistungen Darwins nicht denkbar."1391 wäre. Die weiterentwickelte aktuelle Synthetische Evolutionstheorie basiert auf Darwins Grundlagenforschung, geht jedoch aufgrund der dynamischen Wissenschaftsentwicklung heute weit über seine Erkenntnisse hinaus, bietet also folglich eine Erweiterung von Darwins Gedanken. ${ }^{1392}$ Trotz einiger Fehlschlüsse aufgrund der damaligen mangelnden Wissenslage gilt Darwin mehr denn je als ,[...] ein Wegweiser für die moderne Biologie [...]“1393.

„Seit Darwins Tod haben schon [...] [fünf] Generationen das Licht der Welt erblicktund noch immer bietet uns jenes Werk wichtige Leitlinien, noch immer steht es als gewaltige Enzyklopädie da. "1394

Ohne die drei Hauptwerke Darwins - „On the Origin of Species by Means of Natural Selection, or The Preservation of Favoured Races in the Struggle for Life“"1395 veröffentlicht im Jahr 1859, das auf den Menschen bezogene „The Descent of Man, and Selection in Relation to Sex“1396 von 1871 und „The Expression of the Emotions in Man and Animals“"1397 von 1882 - wäre der entscheidende Anstoß zur Entwicklung der Evolutionsbiologie nicht möglich gewesen. ${ }^{1398}$

\footnotetext{
1390 Mosse 1993, a. a. O., S. 95.

1391 Wuketits, Franz M. (1987): Charles Darwin. Der stille Revolutionär, München, S. 96.

1392 Vgl. Wuketits 1987, ebd., S. 96ff.

1393 Wuketits 1987, ebd., S. 96.

1394 Wuketits 1987, ebd., S. 98.

1395 Darwin, Charles (2000): Über die Entstehung der Arten durch natürliche Zuchtwahl oder die Erhaltung der begünstigten Rassen im Kampfe um's Dasein, Köln.

1396 Darwin, Charles (2002): Die Abstammung des Menschen, Stuttgart.

1397 Janich, Peter (2010): Der Mensch und andere Tiere. Das zweideutige Erbe Darwins, Berlin, S. 20 .

1398 Vgl. Engels, Eve-Marie/Betz, Oliver/Köhler, Heinz-R./Potthast, Thomas (2011): Charles Darwin und seine Bedeutung für die Wissenschaften - Eine Einführung in: ebd. (Hrsg.):

Charles Darwin und seine Bedeutung für die Wissenschaften, Tübingen, S. 11.
} 
Charles Darwin gewährte mit der Entthronung von Gott als ,Schöpfungswesen“ einen Wendepunkt der Biologie, indem er eine einzig auf die Naturwissenschaften beschränkte Theorie zur Entstehung und Entwicklung von Lebewesen generierte. ${ }^{1399}$ „Durch seinen Platz in einem Abstammungsgeschehen aus dem Tierreich erhält der Mensch eine Einordnung in die Natur [... "“1400. Schon 1857 stellt er seine Theorie in einem Brief an den Botaniker Asa Grey vor, erwähnt aber gleichzeitig einschränkend, dass seine Theorie der ,natürlichen Zuchtwahl' - die nur die besten Eigenschaften eines Lebewesens zur Fortpflanzung präferiert - nur ausgehend von der menschlichen Domestikation von Pflanzen und Tieren anwendbar sei, nicht jedoch auf den Menschen selbst. ${ }^{1401}$ Die modifizierte Anwendung seiner Evolutionstheorie auf die psychische und physische, menschliche Entwicklung erfolgt erst in seinem zweiten Hauptwerk $1871 .{ }^{1402}$

\subsubsection{Die Evolutionstheorie: Von Darwin bis in die Gegenwart}

Die Relevanz der darwinschen Evolutionstheorie liegt vornehmlich in der Ablösung der sogenannten Theorie der Artkonstanz durch das Konzept der Evolution aller Organismen. ${ }^{1403}$ Auch die weitere Übertragung des Evolutionsmechanismus auf den Menschen kann als Weltneuheit der damaligen Zeit identifiziert werden. ${ }^{1404}$ Im Zentrum der Evolutionstheorie Darwins steht das Konzept der ,natürlichen Zuchtwahl' bzw. der ,natürlichen Auslese' oder ,Selektion', von dem ausgehend die vier Hauptelemente seiner Theorie dargestellt werden können: Die gemeinsame Abstammung aller Organismen, die Theorie des Gradualismus, die Selektionstheorie sowie die Theorie der Speziation. ${ }^{1405}$ Im Rahmen der Abstammungs- bzw. Deszendenztheorie proklamierte Darwin die abgestufte, natürliche Verwandtschaft aller Organismen als Ausdruck unterschiedlicher genealogischer Beziehungen der einzelnen Arten. ${ }^{1406}$ Bahnbrechend war jedoch seine Behauptung

\footnotetext{
1399 Vgl. Engels et al. 2011, a. a. O., S. 11.

1400 Janich 2010, a. a. O., S. 20.

1401 Vgl. Darwin 2000, a. a. O., S. 17. | Vgl. Janich 2010, a. a. O., S. 19.

1402 Vgl. Darwin 2002, a. a. O., S. IX.

1403 Vgl. Bayertz, Kurt/Heidtmann, Bernhard/Rheinberger, Hans-Jörg (1982): Editorial, in: ebd. (Hrsg.): Darwin und die Evolutionstheorie, Köln, S. 8.

1404 Vgl. Shipman, Pat (1994): The Evolution of Racism. Human Differences and the Use and Abuse of Science, New York u. a., S. 24.

1405 Vgl. Engels et al. 2011, a. a. O., S. 13. | Vgl. Junker, Thomas (2011): Auf den Schultern von Riesen: Darwins Evolutionstheorie, in: Engels, Eve-Marie/Betz, Oliver/Köhler, HeinzR./Potthast, Thomas (Hrsg.): Charles Darwin und seine Bedeutung für die Wissenschaften, Tübingen, S. 39.

Die Theorie des Gradualismus besagt, dass die schrittweise Anbäufung von kleinen Variationen (beispielsweise Mutationen oder Rekombinationen der DNA) mit jeweils geringfügigen Abänderungen - gegenüber der Parentalgeneration aufsummiert - ̈̈̈ber einen längeren Zeitraum größere Varietäten zwischen Individuen einer Art ergeben, die für die Vielfalt der Lebewesen verantwortlich sind. Vgl. Markl 2006, a. a. O., S. 513.

1406 Vgl. Maier, Wolfgang (2011): Darwins Weltreise mit der HMS ,Beagle‘ (1831-1836) - Historische Geologie und die Entstehung der modernen Evolutionstheorie, in: Engels, EveMarie/Betz, Oliver/Köhler, Heinz-R./Potthast, Thomas (Hrsg.): Charles Darwin und seine Bedeutung für die Wissenschaften, Tübingen, S. 64ff.
} 
der Entstehung von neuen Arten durch die Abspaltung von bestehenden, variablen Arten. ${ }^{1407}$ Auch die Selektionstheorie bzw. die Theorie der ,natürlichen Auslese $^{6}$ eröffnete zahlreiche Diskussionen, an die insbesondere das heute wieder tendenziell biologistische Rassismusphänomen anknüpft. Darwin erkannte, dass jeweils die bestangepassten Individuen einer Population - Individuen mit der besten funktionellen Fitness - eine erhöhte Chance zum Überleben und zur Fortpflanzung - die sogenannte reproduktive Fitness - haben. ${ }^{1408}$ „Die ,evolutionäre Fitness' oder Darwin-Fitness ist der Beitrag eines Individuums zum Genpool der nächsten Generation im Verhältnis zu den Beiträgen anderer Individuen." 1409 , so Biologe Jürgen Markl aus der heutigen wissenschaftlichen Perspektive. Durch die dauerhafte Anpassung an veränderliche innere und äußere Lebens- und Umweltbedingungen - die sogenannten „,conditions of life“"1410 - erfolgt demzufolge über viele Generationen sowie große Zeitfenster hinweg eine schrittweise Veränderung von Arten. ${ }^{1411}$

„W as aber auch die Ursache des ersten kleinen Unterschiedes zwischen Eltern und Nachkommen sein mag, und eine Ursache muss für einen jeden da sein, so baben wir zu der Annahme Ursache, dass es doch nur die stete Häufung der für das Individuum nützlichen Verschiedenheit ist, welche alle jene bedeutungsvolleren Änderungen der Structur einer jeden Art in Bezug zu deren Lebensweise hervorgebracht hat. " "412

Das Einflussvermögen des Menschen auf diese natürliche Zuchtwahl schätzt Darwin vor dem Hintergrund der domestizierten Tier- und Pflanzenarten eher gering - die Selektion durch Natur und Umwelt bleibt unübertroffen. ${ }^{1413}$

„Aber die natürliche Zuchtwahl ist [...] eine unaufhörliche zur Thätigkeit bereite Kraft und des Menschen schwache Bemühungen so unermesslich überlegen, wie es die Werke der Natur überhaupt denen der Kunst sind. "1414

Diese Verschiedenheit der Individuen durch die ,natürliche Zuchtwahl' hat vielfältige Vorteile zur Folge: Organismen mit nützlichen Anpassungen haben größere Chancen sich erfolgreich fortzupflanzen und so ihre Variationen durch Vererbung an die kommenden Generationen weiterzugeben. Dieses ,Prinzip der Erhaltung des Überlebens des Passendsten“ wird darüber hinaus folglich ebenfalls durch die sogenannte ,sexuelle Zuchtwahl', die beispielsweise durch eine gezielte Partnerwahl den biologischen Evolutionsmechanismus beeinflusst, unterstützt: Die bes-

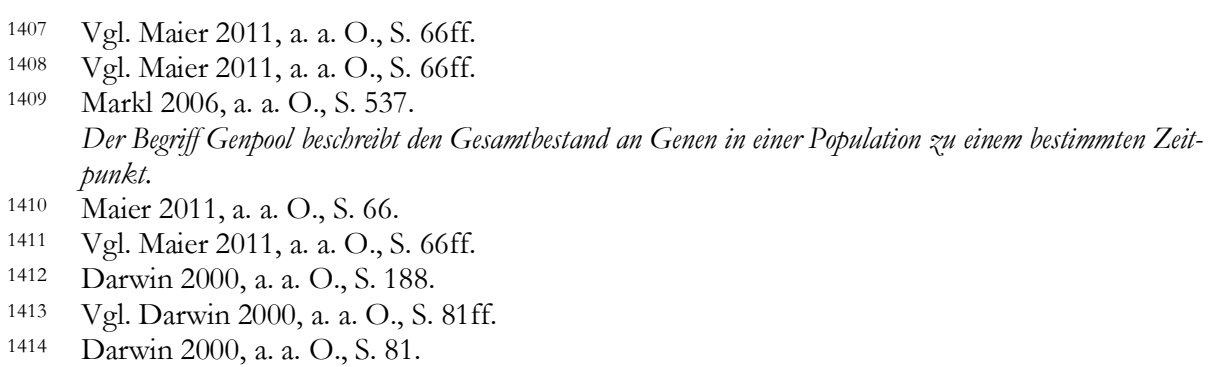


ser angepassten Organismen werden hier bevorzugt. ${ }^{1415}$ Aufgrund eines begrenzten Lebensraumes sowie limitierender abiotischer und biotischer Umweltfaktoren führt dies zur Schlussfolgerung, dass nicht alle Lebewesen gleichermaßen überleben können - die am besten angepassten Individuen haben aufgrund ihres durch ihre begünstigten Merkmale ausgelösten überdurchschnittlichen Fortpflanzungserfolges die größere Chance. ${ }^{1416}$ Insbesondere die Umweltfaktoren selektieren bzw. filtern so aus jeder Generation spezifische erbliche Varianten heraus und begünstigen einige von ihnen. ${ }^{1417}$ Dieses Prinzip ist nun auch für die menschliche Evolution gültig, was Darwin in seinem zweiten Hauptwerk 1871 illustriert. ${ }^{1418}$ Demnach kann subsummiert werden, dass viele Beziehungen zwischen den unterschiedlichen Organismen den ,Kampf ums Dasein` beeinflussen. ${ }^{1419}$

Die Evolutionstheorie Darwins stellt den Beginn der modernen Evolutionsbiologie dar, wie der Evolutionsbiologe Ralf Sommer eindrücklich feststellt. ${ }^{1420}$ Denn auch die im 21. Jahrhundert weit verbreitete, weiterentwickelte sogenannte Synthetische Evolutionstheorie basiert in weiten Teilen auf Darwins Grundlagenforschung und wird wie Darwins Werk auch heute noch partiell debattiert. Die Evolutionsfaktoren der heutigen Theorie bauen auf den darwinschen Grundlagen auf, ergänzen jedoch neueste Erkenntnisse aus dem Bereich der Genetik, von denen Charles Darwin aufgrund der eingeschränkten Forschungsmöglichkeiten des 19. Jahrhunderts noch nichts wissen konnte: „[...] nothing was known of modern genetics, DNA, or chromosomes [...]"1421. Die neuere Genetik ergänzt heute essentielle Evolutionsfaktoren: Zum einen das Phänomen der Mutationen zur Genese neuer genetischer Typen, das Prinzip des Gradualismus, die ,natürliche Selektion' zur Auswahl der am besten Angepassten, der Gendrift - welcher Zufallsgeschehen und statistische Fluktuationen integriert -, die Umwelt sowie zum anderen die sogenannte genetische Migration. ${ }^{1422}$

„Darwins Konzept von der Evolution durch Überleben der am besten Angepassten bedarf also [heute primär] der Ergänzung durch den Hinweis auf die Bedeutung des Zu-

1415 Vgl. Darwin 2002, a. a. O., S. 258ff.

Vgl. Darwin 2000, a. a. O., S. $150 \mathrm{ff}$.

1416 Vgl. Darwin 2000, a. a. O., S. 83ff.

Unter dem Begriff der sogenannten abiotischen Ökofaktoren werden alle chemischen sowie physikalischen Umweltfaktoren zusammengefasst, die das Leben von Organismen beeinflussen, beispielsweise das Nabrungsvorkommen, $W$ asser, Wind, Regen, die Temperatur, der $p H$-Wert oder der Salzgehalt. Die sogenannten biotischen ÖKofaktoren beschreiben bingegen alle Einflüsse, die von der belebten Natur ausgehen: Fressfeind-BeuteBeziehungen, Parasitismus, Symbiose oder Konkurrenzverbalten. Vgl. Smith, Thomas M./Smith, Robert L. (2009): Ökologie, 6. Auflage, München, S. 55ff, $139 \mathrm{ff}$.

1417 Vgl. Markl 2006, a. a. O., S. $512 \mathrm{ff}$.

1418 Vgl. Darwin 2000, a. a. O., S. 83ff.

1419 Vgl. Darwin 2000, a. a. O., S. 90.

1420 Vgl. Sommer, Ralf J. (2011): Zur wissenschaftlichen Vielfalt der modernen Evolutionsbiologie, in: Engels, Eve-Marie/Betz, Oliver/Köhler, Heinz-R./Potthast, Thomas (Hrsg.): Charles Darwin und seine Bedeutung für die Wissenschaften, Tübingen, S. 77.

1421 Shipman 1994, a. a. O., S. 21.

1422 Vgl. Cavalli-Sforza, Luigi Luca (1999): Gene, Völker und Sprachen. Die biologischen Grundlagen unserer Zivilisation, Darmstadt, S. 56ff. 


\section{falls, auf die der Genetiker Motoo Kimura mit der Formulierung Überleben der vom Glück Begünstigten aufmerksam gemacht hat. Die Evolution ist also das Überleben nicht nur der besser angepassten genetischen Typen, sondern auch derjenigen, die mehr Glück gehabt haben. "1423}

Zusätzlich muss auch der Zeitfaktor als unabdingbarer Evolutionsfaktor beachtet werden. ${ }^{1424}$ Denn die Evolution bezeichnet einen Prozess mit einer Dauer von mehreren Millionen Jahren, in deren Verlauf auch Zwischenformen von Arten entstehen und wieder aussterben können - der Zeitfaktor sollte folglich nicht unterschätzt werden. ${ }^{1425}$ Die Gesamtheit der bekannten Evolutionsfaktoren führt zur Weiterentwicklung, zur Evolution von Populationen, nicht jedoch von Individuen - die individuelle Abwertung von Menschen auf der Grundlage einer angeblich biologischen Beweisführung ist demnach hinfällig. ${ }^{1426}$ Die Hauptideen der Synthetischen Evolutionstheorie sind so folglich: Die Identifizierung von Populationen als Grundeinheiten der Evolution, die natürliche Selektion als wichtigster Mechanismus der Evolution sowie der Gradualismus als Erklärungsansatz für die Entstehung der Vielfalt des Lebens über einen langen Zeitraum. ${ }^{1427}$ Unter der Begrifflichkeit Population wird dabei eine lokal begrenzte Gruppe von Individuen derselben Art verstanden. ${ }^{1428}$

Auch der moderne, evolutionstheoretische Erklärungsansatz bleibt so ein Prozess, der von vielfältigen Faktoren und Wechselwirkungen - äußeren und inneren - bestimmt und beeinflusst wird. ${ }^{1429}$ Zur Vollständigkeit muss hinzugefügt werden, dass auch die moderne Evolutionstheorie in Zukunft einige „Schönheitsoperation[en]"1430 notwendig haben wird, da insbesondere im Verhältnis zwischen Mikro- und Makroevolution noch offene Erklärungsmodi vorhanden sind. ${ }^{1431}$ Trotzdem zeigt sich die Synthetische Evolutionstheorie weiterhin als pluralistische, synthetische Theorie, da „,[...] sie die Forschungsergebnisse aus praktisch sämtlichen biologischen Disziplinen zu einem Ganzen, zu einem Erklärungsgefüge, vereint." 1432 Sie stellt sozusagen ein Gesamtkonzept, bestehend aus Genetik, Kultur und Umwelt, zur Erläuterung des Evolutionsgeschehens dar. ${ }^{1433}$ Vorausblickend stellt Jürgen Markl folgerichtig fest:

„Die lebhafte Debatte um die Evolution des Lebens ist ein gesundes Zeichen; die Evolutionsbiologie ist eine lebendige Wissenschaft, die sich dynamisch weiterentwickelt. Die

Cavalli-Sforza 1999, a. a. O., S. 64.

Vgl. Shipman 1994, a. a. O., S. 23.

Vgl. Shipman 1994, a. a. O., S. 23.

Vgl. Markl 2006, a. a. O., S. $513 \mathrm{ff}$.

Vgl. Markl 2006, a. a. O., S. $524 f$.

Vgl. Markl 2006, a. a. O., S. 525.

Vgl. Wuketits 1987, a. a. O., S. 95.

Markl 2006, a. a. O., S. 564.

Vgl. Markl 2006, a. a. O., S. $563 f f$.

Wuketits 1987, a. a. O., S. 94.

Vgl. Dobzhansky 1962, a. a. O., S. 31. 
Diskussionen werden anbalten, solange wir nengierig sind auf unseren Ursprung und unsere Beziebungen zu der übrigen lebenden Welt. "“434

\subsubsection{Missbrauch der Evolutionstheorie im Rahmen des Rassismus}

Die Skizzierung der Entwicklung der Evolutionstheorie von Charles Darwin bis ins 21. Jahrhundert hat schon einführend verdeutlicht, dass das Konzept der Evolution weder von Darwin - bei Fokussierung auf sein Grundlagenwerk von 1859 noch von heutigen Evolutionsbiologen zur Erklärung rassistischen Verhaltens gedacht war bzw. ist. Demzufolge bezieht sich beispielsweise Darwins Grundlagenwerk aus dem Jahr 1859 in keinem Kapitel, Ausnahme ist ein einziger Satz am Ende des Werkes, auf den Menschen - Darwin zeichnet lediglich den Einfluss seines Evolutionskonzeptes auf Fauna und Flora nach. ${ }^{1435}$ Auch eine eindeutige Differenzierung der menschlichen Spezies in eine ,Rassenhierarchie ${ }^{6}$ sucht man vergeblich. Die rassistische Ideologie verfälscht Darwins Theoriegefüge folglich an entscheidenden Stellen bzw. interpretiert Darwins Schlussfolgerungen absichtlich falsch. Der „Kampf ums Dasein“ wird so zu einem ,Kampf der Menschengruppen', das ,Überleben der Angepassten' zum ,Überleben des Stärkeren' und das Prinzip der ,natürlichen Zuchtwahl' zur ,natürlichen Rassenwahl'. Demgegenüber muss korrigierend angemerkt werden, dass die These des ,Kampfes ums Dasein lediglich auf eine weit gefasste, metaphorische Bedeutung abhebt. ${ }^{1436}$ Wichtig ist einzig das Verhältnis, in dem sich Organismen zu vermehren streben, also der Erfolg des Hinterlassens einer Nachkommenschaft, wie Charles Darwin im folgenden Textauszug erläutert. ${ }^{1437}$

„Ich will vorausschicken, dass ich diesen Ausdruck [des Kampfes ums Dasein] in einem weiten und metaphorischen Sinne gebrauche [...] Man kann mit Recht sagen, dass zwei bundeartige Raubtiere in Zeiten des Mangels um Nabrung und Leben miteinander kämpfen. Aber man kann auch sagen, eine Pflanze kämpfe am Rande der Wüste um ibr Dasein gegen die Trocknis, obwobl es angemessener wäre zu sagen, sie bänge von der Feuchtigkeit ab. [...] Die Mistel ist vom Apfelbaum und einigen wenigen anderen Baumarten abhängig; doch kann man nur in einem weit hergeholten Sinne sagen, sie kämpfe mit diesen Bäumen; denn wenn zu viele dieser Schmarotzer auf demselben Baume wachsen, so wird er verkümmern und sterben. Wachsen aber mebrere Sämlinge derselben dicht auf einem Aste beisammen, so kann man in zutreffenderer Weise sagen, sie kämpfen miteinander. Da die Samen der Mistel von Vögeln ausgestreut werden, so bängt ibr Dasein mit von dem der Vögel ab, und man kann metaphorisch sagen, sie kämpfen mit anderen beerentragenden Pflanzen, damit sie die Vögel veranlasse, eher ibre Früchte zu verzebren und ibre Samen auszustreuen, als die der anderen. "438

1434 Markl 2006, a. a. O., S. 567.

1435 Vgl. Darwin 2000, a. a. O., S. 16. | Vgl. Janich 2010, a. a. O., S. 19.

1436 Vgl. Darwin 2000, a. a. O., S. 82.

1437 Vgl. Darwin 2000, a. a. O., S. 82ff.

1438 Darwin 2000, a. a. O., S. 82-83. 
„Kampf ums Dasein', ,natürliche Auslese' und ,survival of the fittest" sind so metaphorisch vielmehr als Anpassung an Lebensraum und Umwelt zu verstehen, denn als körperlicher oder physischer Kampf zwischen Organismen. ${ }^{1439}$

Hinzukommend sieht Darwin in der Vielfalt und Variabilität von Individuen einen außerordentlichen Vorteil - je mehr Variationen, auch bei menschlichen Individuen, vorkommen, desto größer ist die Chance, eine vorteilhafte Variation zu erlangen. ${ }^{1440}$ Als Hauptursache der Variationen identifiziert Darwin die zahlreichen Umwelteinflüsse, die die rassistische Ideologie fälschlicherweise in erbliche Eigenschaften uminterpretiert. ${ }^{1441}$ Dies ist übrigens die einzige Aussage in Darwins Standardwerk von 1859, die sich direkt auf den Menschen bezieht; alle anderen Behauptungen konzentrieren sich ausschließlich auf Tiere und Pflanzen. ${ }^{1442}$ Darwin und die moderne Evolutionstheorie sind also weit entfernt davon zu behaupten, dass ,reine Menschenrassen' existent seien bzw. präferiert werden müssten, wie das zahlreiche Theoretiker des biologistisch konnotierten Rassismuskonzepts konstatieren. Auch ein möglicher Grad an Verschiedenheit zwischen Individuen, wie die sogenannte ,Rassentheorie‘ mithilfe der hierarchischen Gliederung von angeblichen ,Menschenrassen` zu klassifizieren versucht, kann laut Darwin so nicht festgestellt werden. ${ }^{1443}$

Einschränkend muss jedoch auch festgehalten werden, dass insbesondere Darwins zweites Werk von 1871 mit Bezug auf die Abstammung des Menschen teilweise nicht frei von, undarwinistischen' Äußerungen ist: So wird unter anderem das Vorhandensein von Subspezies bzw. von ,Rassen' des Menschen sowie auch die europäische Bevölkerung als die am weitesten entwickelte menschliche Subspezies konstatiert, wobei Darwin versucht zwischen tiefer- - sogenannten wilden - und höherstehenden Menschen zu differenzieren. ${ }^{1444}$ Weiterhin folgert Charles Darwin ebenfalls bezüglich der Erblichkeit von intellektuellen Qualitäten eher fragwürdig. ${ }^{1445}$ Nichtsdestotrotz muss zur Richtigstellung gleichsam bemerkt werden, dass Darwin sehr wohl die Fehler bzw. das wissenschaftlich fragwürdige Konzept der Einteilung von Menschen in Subspezies erkannte: So erteilte er klaren Unterscheidungsmerkmalen zwischen Menschengruppen zur Klassifizierung dieser eine eindeutige Absage. ${ }^{1446}$

Darüber hinaus fehlen bei Darwin auch auf der Basis der menschlichen Evolution sämtliche Ansätze, die sich für eine unveränderliche Vererbung von erworbenen Eigenschaften - so wie dies vor ihm der französische Botaniker und Zoologe Jean-Baptiste de Lamarck konstatierte - aussprechen. Lamarck hatte in seiner 1809 veröffentlichten Vererbungstheorie das Konzept der speziellen Anpassung

\footnotetext{
1439 Vgl. Dobzhansky 1962, a. a. O., S. 26.

1440 Vgl. Darwin 2000, a. a. O., S. 57.

1441 Vgl. Mosse 1993, a. a. O., S. $96 f$.

1442 Vgl. Darwin 2000, a. a. O., S. 57.

1443 Vgl. Darwin 2000, a. a. O., S. 79.

1444 Vgl. Darwin 2000, a. a. O., S. XXVIII, 160.

1445 Vgl. Darwin 2000, a. a. O., S. XXIX.

1446 Vgl. Darwin 2000, a. a. O., S. 215ff, $226 \mathrm{ff}$.
} 
kreiert, welches unter anderem die Vererbung von erworbenen Merkmalen vorsah, was Lamarck bekanntermaßen am Beispiel des Wachstums eines Giraffenhalses illustrierte. ${ }^{1447}$ „Es gibt jedoch keine Hinweise darauf, dass erworbene Merkmale vererbt werden können."1448 Somit entfällt auch jegliche darwinsche Legitimationsbasis der rassistischen Ideologie für die unveränderliche Vererbung von spezifischen Genen bzw. Eigenschaften von Generation zu Generation - beispielsweise des sogenannten Intelligenz-Phänomens. Darwin konstatiert lediglich die Vererbung von Veränderungen der Geistesfähigkeit von sogenannten Instinkten als angeborene Verhaltensweise bei Tieren. ${ }^{1449}$ Den Menschen betrachtend detektiert er jedoch zukunftsweisend: „Ich werde [...] zu zeigen haben, dass in den geistigen Fähigkeiten kein fundamentaler Unterschied zwischen den Menschen $[. .$.$] besteht. “1450$

So kann schlussfolgernd festgehalten werden, dass die Evolutionstheorie Charles Darwins nicht direkt auf die menschlichen Entwicklungslinien übertragen werden kann. Darwin diagnostiziert lediglich, dass der Mensch von weniger hochentwickelten Lebewesen abstammt, was er embryonalen Vergleichsanalysen entnimmt, die viele Ähnlichkeiten zwischen den menschlichen Embryonen und denen anderer Säugetiere aufzeigen. ${ }^{1451}$ Das Konzept der ,natürlichen Zuchtwahl ${ }^{6}$ zeigt sich nach Darwin nur mit Einschränkungen beim Menschen wirksam, jedoch betont er individuelle, variable Verschiedenheiten. ${ }^{1452}$ Einzig das hypothetische Vorhandensein von Subkategorien des Menschen - nicht von ,Rassen ${ }^{6}$ - gibt Darwin zu bedenken. ${ }^{1453}$ Jedoch schränkt er gleichzeitig ein, dass aufgrund der vielen Übereinstimmungen des Homo sapiens weltweit eine Kategorisierung und Hierarchisierung in Subspezies erschwert werde, da die menschliche Spezies aufgrund ihrer vielfältigen Ähnlichkeiten von einem gemeinsamen Ursprung abstammen müsse. ${ }^{1454}$ Weiterhin sieht er die menschliche Sprache als essentiellen Ausdruck der gleichsam hohen Intelligenz aller Menschen. ${ }^{1455}$

Resümierend kann vor dem Hintergrund der darwinschen Evolutionstheorie demnach gefolgert werden, dass sowohl Rassismus als auch Sozialdarwinismus das Evolutionskonzept Charles Darwins sowie auch das heutige Konzept der Synthetischen Evolutionstheorie nicht nur aufgrund wissenschaftlichen Halbwissens falsch interpretieren und missverstehen. Sie passen das Gesamtkonstrukt der Evolution auch an die eigene Ideologie an und missbrauchen es fachlich. Theodosius Dobzhansky wirft dem Rassismus so folgerichtig eine Verdrehung und Verzer-

\footnotetext{
1447 Vgl. Markl 2006, a. a. O., S. 507.

1448 Markl 2006, a. a. O., S. 507.

1449 Vgl. Darwin 2000, a. a. O., S. 317.

1450 Darwin 2002, a. a. O., S. 79.

1451 Vgl. Darwin 2002, a. a. O., S. $262 \mathrm{ff}$.

1452 Vgl. Darwin 2002, a. a. O., S. 264ff. | Vgl. Bayertz, Kurt (1982): Darwinismus als Ideologie, in: Bayertz, Kurt/Heidtmann, Bernhard/Rheinberger, Hans-Jörg (Hrsg.): Darwin und die Evolutionstheorie, Köln, S. 111.

1453 Vgl. Darwin 2002, a. a. O., S. 265ff.

1454 Vgl. Darwin 2002, a. a. O., S. 265ff.

1455 Vgl. Darwin 2002, a. a. O., S. $267 \mathrm{ff}$.
} 
rung des eigentlichen Sinnzusammenhanges vor: Eine Verallgemeinerung des Evolutionskonzeptes auf Kultur, Politik und Nation ist keinesfalls realitätsnah. ${ }^{1456}$ Auch die Übertragung auf die gesellschaftliche Entwicklung zur „,...] Humanisierung des Daseinskampfes [... $]^{\text {"1457 }}$ ist fachlich falsch. ${ }^{1458}$ Der Sozialdarwinismus versucht ,[...] mit Parolen wie ,Kampf um das Dasein“ und ,Überleben des Tüchtigsten' die ungleiche Verteilung von materiellen Gütern, sozialen Lebenschancen und politischen Einflussmöglichkeiten als ,natürlich' [... “"1459 zu erklären. Diese Grundannahmen des Sozialdarwinismus sind mit den darwinschen Annahmen keineswegs vereinbar. ${ }^{1460}$ Die rassistischen Bestrebungen, , „...] den Darwinismus als Ideologie $[\ldots]^{“ 1461}$, ,...] über ihren fachbiologischen Anwendungskreis hinausgehend auch für die Lösung weltanschaulicher Probleme (z. B. die Stellung des Menschen in der Natur) fruchtbar zu machen [...]"1462, ist aus fachwissenschaftlicher Perspektive als zum Scheitern verurteilt zu diskreditieren. Die Biologie kann so folglich von Seiten Darwins keinesfalls als zusätzliche Legitimierung oder Begründung der rassistischen Ideologie instrumentalisiert werden. ${ }^{1463}$

\subsubsection{Charles Darwin - kein Rassist!}

Die beiden Hauptwerke Charles Darwins „On the Origin of Species by Means of Natural Selection, or The Preservation of Favoured Races in the Struggle for Life“"1464 sowie ,The Descent of Man, and Selection in Relation to Sex“"1465 können demnach nicht als Begründung biologistisch-rassistischer Argumentationsmuster herangezogen werden. Insbesondere ersteres gilt vielmehr als Wendepunkt der Biologie, der deren entwicklungsbedingten Fortschritt markiert. ${ }^{1466}$ „Darwin schuf der Biologie eine solide wissenschaftliche Grundlage [...]."1467 Die einzigartige Kernaussage seines Hauptwerkes von 1859 lautet, dass alle Lebewesen miteinander verwandt sind - das Konzept der Evolution. ${ }^{1468}$ Alle Individuen einer Spezies stammen von gemeinsamen Eltern bzw. Vorfahren ab und haben sich von einem ,Geburtsort' ${ }^{`}$ aus verbreitet. ${ }^{1469}$ Hiermit unterstützt Darwin schon nichtwissend die Vertreter des heutigen Out-of-Africa-Modells der Entwicklung des modernen Menschen, die der Existenz von unterschiedlichen ,Menschenrassen“ ebenfalls eine Absage erteilen, wie die nachfolgenden Kapitel erörtern.

\footnotetext{
1456 Vgl. Dobzhansky 1962, a. a. O., S. 28.

1457 Bayertz 1982, a. a. O., S. 107.

1458 Vgl. Bayertz 1982, a. a. O., S. $107 \mathrm{ff}$.

1459 Bayertz 1982, a. a. O., S. 110.

1460 Vgl. Bayertz 1982, a. a. O., S. $110 \mathrm{ff}$.

1461 Bayertz 1982, a. a. O., S. 113.

1462 Bayertz 1982, a. a. O., S. 113.

1463 Vgl. Geiss 1988, a. a. O., S. 171.

1464 Darwin 2000, a. a. O.

1465 Darwin 2002, a. a. O.

1466 Vgl. Marten 1983, a. a. O., S. 70.

1467 Markl 2006, a. a. O., S. 520.

1468 Vgl. Darwin 2000, a. a. O., S. 422.

1469 Vgl. Darwin 2000, a. a. O., S. 477 f.
} 
Dezidiert festzuhalten bleibt darüber hinaus, dass sich Darwin immer gegen die Politisierung seiner theoretischen Äußerungen wehrte und dies folglich auch im Laufe seiner Ausarbeitungen bestmöglich vermied. ${ }^{1470}$

\section{„Es ist wichtig zu betonen, dass Darwin mit seiner Theorie die Lösung einiger Probleme der Naturwissenschaften im Sinne batte und nicht gesellschaftspolitische Ziele, welcher Art auch immer, verfolgte. " 471}

Nichtsdestotrotz bieten Darwins Argumentationen aus der Perspektive des Rassismus gesehen vielfältige gesellschafts- und bevölkerungspolitische Anknüpfungspunkte, auch wenn diese seitens Charles Darwin nicht gewollt und diesen ausdrücklich widersprochen wurde. Gerade vor dem Hintergrund des rasanten Bevölkerungsanstieges, der Industrialisierung sowie des zunehmenden Nationalismus und Kolonialismus zum Zeitpunkt der Veröffentlichung Darwins im Jahr 1859 mitten im Zeitalter der Moderne, fand seine Theorie nicht nur aus evolutionsbiologischer Sicht große Zustimmung, sowohl in den Natur- als auch in den Sozialwissenschaften. Im Zusammenhang mit den skizzierten rapiden wirtschaftlichen und gesellschaftlichen Umbrüchen bot seine Evolutionstheorie nicht nur einen ersten naturwissenschaftlichen Erklärungsansatz der Entstehung des Lebens, sondern konnte selbstredend auch für eine Legitimation einer zukünftigen, Menschen diversifizierenden Bevölkerungspolitik nutzbar gemacht werden. Somit konnten die bisherigen Herrschaftsverhältnisse, die Berechtigung bzw. die Legitimation von ,Herrschenden' und ,Beherrschten', nicht mehr nur vor religiösem Hintergrund als ,gottgegeben', sondern auch vor wissenschaftlichem Hintergrund - die im Rahmen von Aufklärung und Moderne den Charakter einen neuen Religion übernahm - begründet und somit auch für die Zukunft weiter stabilisiert werden. Darwin muss so vor allem vor dem Hintergrund seines ersten Hauptwerkes als „,...] unfreiwilliger Kronzeuge $[\ldots]^{\text {“1472 }}$ rassistischer Argumentationen gesehen werden.

Charles Darwin kann so mitnichten als Mitbegründer des Sozialdarwinismus oder der rassistischen Ideologie diagnostiziert werden - er wollte seine naturwissenschaftliche Theorie niemals auf die Politik und das Gesellschaftssystem übertragen. ${ }^{1473}$ Eine Anwendung auf wirtschaftliche, politische und gesellschaftliche Gegebenheiten, wie sie unter anderem vom britischen Soziologen und Philosophen Herbert Spencer sowie dem Zoologen Ernst Haeckel vorgenommen wurde, war von Charles Darwin nicht vorgesehen. ${ }^{1474}$

\footnotetext{
1470 Vgl. Darwin 2000, a. a. O., S. XXXI.

1471 Wuketits 1987, a. a. O., S. 101.

1472 Patalong, Frank (2014): „Harte Zeiten für Rassisten“, in URL: http:/ / www.spiegel.de/wissenschaft/mensch/neandertaler-forschung-stellt-rassistischeweltbilder-auf-den-kopf-a-950848.html <28.05.2014>.

1473 Vgl. Wuketits 1987, a. a. O., S. 102 f.

1474 Vgl. Panahi 1980, a. a. O., S. 38f.
} 
„Der Sozialdarwinismus mit allen seinen grausamen Konsequenæen lässt sich also nicht als Forffübrung der Gedanken Darwins betrachten und schon gar nicht mit Darwins Werk identifizieren. " "475

Trotz einiger kritischer Aussagen spricht für Darwin, dass er in seinen Arbeiten immer wieder einschränkend den lückenhaften Wissensstand der Naturwissenschaften, die rudimentären Forschungsergebnisse sowie daraus resultierend sein mangelndes Vorwissen betont. ${ }^{1476}$ Weiterhin muss anerkannt werden, dass es sich bei Darwins Hypothese lediglich um eine naturwissenschaftliche Theorie, also um einen Versuch oder Vorschlag - keine Tatsache - handelt, das Evolutionsgeschehen mittels der natürlichen Selektion zu erläutern. ${ }^{1477}$ Charles Darwin ist sich so über den defizitären, bruchstückhaften und unvollkommenen Stand seiner Argumentationen vollkommen bewusst, wie er zum Schluss der ,Abstammung des Menschen“ illustriert: „Viele der Ansichten, die ich hier ausgesprochen habe, sind sehr spekulativ, und manche werden sich zweifellos als irrig erweisen $[\ldots]^{\text {“ } 1478}$. Durch Charles Darwin bleibt „,[d]ie Evolutionsforschung [...] lebendiger als je zuvor." "1479

Als Schlussbetrachtung hält Philosoph Kurt Bayertz die Vermutung fest, dass der Sozialdarwinismus bei der Nichtexistenz der darwinschen Evolutionstheorie sicherlich auch andere Theorien zur Legitimierung seiner pseudowissenschaftlichen Ansichten gefunden und herangezogen hätte. ${ }^{1480}$ Charles Darwins Evolutionstheorie bleibt so für die aktuelle und zukünftige biologische Forschung ebenso zukunfts- wie richtungsweisend. Ungeachtet dessen bleibt seine Evolutionstheorie jedoch auch weiterhin - wie auch schon vor der offiziellen Veröffentlichung 1859 - diskutiert. ${ }^{1481}$ Nichtsdestotrotz ist für die Biologie als Naturwissenschaft resümierend festzuhalten:

„Der Darwinismus ist keine Weltanschaunng, sondern eine wissenschaftliche Theorie.

Für die Biologie ist diese Theorie zu der zentralen Theorie überhaupt geworden. "1482

\subsection{Missbrauch eines biologischen Begriffes: Die sogenannte ,Rasse ${ }^{6}$}

Die Verwendung des sogenannten ,Rassekonzeptes' und dessen Übertragung auf den modernen Menschen im Rahmen des biologistisch konnotierten Rassismusphänomens kann, wie das vorherige Kapitel illustriert, keinesfalls von der

\footnotetext{
1475 Wuketits 1987, a. a. O., S. 109.

1476 Vgl. Darwin 2000, a. a. O.S. 478.

1477 Vgl. Markl 2006, a. a. O., S. 519.

1478 Darwin 2002, a. a. O., S. 262.

1479 Markl 2006, a. a. O., S. 520.

1480 Vgl. Bayertz 1982, a. a. O., S. 116.

1481 Vgl. Shipman 1994, a. a. O., S. 35.

1482 Darwin 2002, a. a. O., S. XLI.
} 
Evolutionstheorie Charles Darwins abgeleitet werden, auf die die rassistische Ideologie immer wieder rekurriert. Auch die folgenden Kapitel werden veranschaulichen, dass die Entleihung des ,Rassekonstrukts' aus der Biologie keineswegs fachlich übereinstimmend sowie korrekt stattgefunden hat, sondern dass es sich auch hier um eine bewusste Falschinterpretation, um eine Verdrehung wissenschaftlich validierter Systematiken sowie einen eindeutigen Missbrauch der Biologie als vermeintliche Legitimationsbasis des Rassismus handelt. Die nachfolgenden Kapitel konzentrieren sich jedoch eher auf die Perspektiven der Anthropologie, der Molekulargenetik sowie der Evolutionsbiologie: Mithilfe der evolutiven Entwicklung und Verbreitung des modernen Menschen über alle Kontinente der Erde - von Asien bis Afrika sowie von Europa bis Südamerika -, soll mithilfe des heutigen wissenschaftlichen Kenntnisstandes konkretisiert werden, dass eine Klassifizierung der Menschheit in sogenannte ,Rassen' nicht möglich erscheint.

Zur begrifflichen Einordnung muss einführend konstatiert werden, dass der ,Rassebegriff' als Grundlage und Namensgeber des Rassismus verstanden werden kann (s. Kapitel 2). Gleichzeitig stellt die angebliche Vererbung erworbener Eigenschaften - wie intellektuellen oder körperlichen Fähigkeiten, Mut oder Stärke und darauf aufbauend die Hierarchisierung und Klassifizierung der Menschheit in ,höherwertigere' und ,niedere' Rassen ein Grundkonzept des biologistisch konnotierten Rassismusphänomens dar. Die vorherigen Kapitel visualisieren, dass heute zwar partiell das Konzept der kulturellen und ethnischen Verschiedenheit im Mittelpunkt steht, jedoch generiert die ,Rassenklassifikation' weiterhin indirekt und unausgesprochen die Grundlage der rassistischen Ideologie. Die Biologie bleibt demnach auch weiterhin ein zentraler Baustein (s. Kapitel 1, 2). „Rasse wird so als eine die Individuen überdauernde körperlich-seelische Ganzheit verstanden."1483 Die biologische ,Rasse ${ }^{6}$ legt folglich scheinbar die körperlichen und geistigen Charakteristika der betreffenden menschlichen Individuen über Generationen hinweg konstant und unabänderlich fest. ${ }^{1484}$ Das an die Biologie angelehnte ,Rassekonzept ${ }^{6}$ bleibt demzufolge auch heute noch, trotz der unüberschaubaren Vielzahl von ,Rassetheorien', existent, insbesondere mit genetischer Konnotation.

Luigi Luca Cavalli-Sforza sieht die Einteilung der Menschen von drei bis in über 60 ,Rassen ' fachlich von vornherein als willkürlich. ${ }^{1485}$ Ungeachtet dessen scheinen jedoch auch in den biologischen Fachwissenschaften diesbezüglich noch viele Fragen offen, insbesondere die Evolution des Menschen und damit einhergehend eine mögliche Untergliederung des Homo sapiens betreffend. Der Anthro-

1483 Kattmann, Ulrich (1999): Warum und mit welcher Wirkung klassifizieren Wissenschaftler Menschen?, in: Kaupen-Haas, Heidrun/Saller, Christian (Hrsg.): Wissenschaftlicher Rassismus. Analysen einer Kontinuität in den Human- und Naturwissenschaften, Frankfurt/Main u. a., S. 76.

1484 Vgl. Kattmann 1999, ebd., S. 76ff.

1485 Vgl. Cavalli-Sforza/Cavalli-Sforza 1994, a. a. O., S. 356. 
pologe Winfried Henke spricht in diesem Zusammenhang von einem schrittweisen ,theoriegeleitete[n] Hypothesentesten“"1486.

\subsubsection{Rassismus und das Konzept der ,Rasse“}

Die Grundlagen der ,Rassifizierung` der menschlichen Spezies stammen vorrangig aus dem 19. Jahrhundert: Kraniologie und Schädelmessung haben sich jedoch beide als wissenschaftlich nicht valide und fachlich irreführend herausgestellt. Stephen Jay Gould gibt diesbezüglich in seinem Werk „The Mismeasure of Man“1487 einen eindrucksvollen Rückblick. Er identifiziert die Aufstellung einer Rangfolge von ,Menschenrassen“ nach der Durchschnittsgröße des Schädels oder des Schädelvolumens seit den Anfängen um den Anthropologen Samuel George Morton als ,[...] ein Mischmasch aus Pfusch und Mogelei, eindeutig vom Interesse an der Bestätigung vorgefasster Überzeugungen motiviert." ${ }^{1488}$ Bei Nachmessungen seinerseits habe er keine signifikanten Unterschiede feststellen können entweder seien die Werte so falsch oder verzerrt. ${ }^{1489}$ Auch die neuere Schädelkunde aus dem frühen 20. Jahrhundert ist durch multiple methodische Fehler und Fehlannahmen gekennzeichnet. Beispielsweise wurden hier vorgefertigte wissenschaftliche Erkenntnisse auf nur eine angeblich benachteiligte Gruppe von Menschen übertragen. Diese identifizierte man nachfolgend mit dem Stereotyp der Minderwertigkeit - das Prinzip des sogenannten biologischen Determinismus. ${ }^{1490}$ Die gesellschaftliche und soziale Struktur richtete sich demzufolge nach den Erkenntnissen der Natur und der Biologie, die unmittelbar auf die menschliche Gesellschaft übertragen wurden. ${ }^{1491}$ Vor diesem Hintergrund wertet Gould auch bezüglich der pseudowissenschaftlichen Erkenntnisse des Anthropologen und Arztes Paul Broca: „Broca pfuschte nicht an den Zahlen herum; er wählte bloß unter ihnen aus oder interpretierte um sie herum, um zu seinen gewünschten Schlussfolgerungen zu gelangen." "1492 Messungen von Gehirn und Schädelgröße stellen einen unzureichenden Index zur Bestimmung des kognitiven Potenzials von Menschen dar. ${ }^{1493}$ Insgesamt diagnostiziert Gould, dass die zahlreichen experimentellen Schlussfolgerungen nur durch vorgefasste Meinungen und Ansichten

\footnotetext{
1486 Henke, Winfried (2004): Evolution und Verbreitung des Genus Homo. Aktuelle Befunde aus evolutionsökologischer Sicht, in: Conard, Nicholas (Hrsg.): Woher kommt der Mensch?, Tübingen, S. 98.

1487 Gould 1983, a. a. O.

1488 Gould 1983, a. a. O., S. 54.

1489 Vgl. Gould 1983, a. a. O., S. 67.

1490 Vgl. Gould 1983, a. a. O., S. $81 \mathrm{ff}$.

Das Prinzip des biologischen Determinismus konstatiert, dass , [...] gemeinsame Verhaltensnormen und soziale und ökonomische Unterschiede zwischen Gruppen von Menschen - hauptsächlich zwischen Rassen, Klassen und Geschlechtern - [...] sich aus ererbten, angeborenen Unterschieden [ergäben], und die Gesellschaft sei in diesem Sinne ein genaues Spiegelbild der Biologie. "Gould 1983, a. a. O., S. 14.

1491 Vgl. Gould 1983, a. a. O., S. $81 \mathrm{ff}$.

1492 Gould 1983, a. a. O., S. 89.

1493 Vgl. Carroll, Sean B. (2003): Genetics and the making of Homo sapiens, in: Nature, Vol. 422, London u. a., S. 851.
} 
diktiert, nicht jedoch durch naturwissenschaftlich sowie experimentell bestätigte Zahlenbelege untersucht wurden. ${ }^{1494}$

\section{„Zablen und Grafiken gewinnen durch zunehmende Messgenauigkeit, Stichprobengröße oder Komplexität der Handhabung nicht an Autorität." "495}

Aufgrund des Fehlens jeglicher wissenschaftlicher Hintergrundinformationen, führte die mediale Inszenierung, Stilisierung und systematische Verunwissenschaftlichung zu einer gesellschaftsweiten Verbreitung der pseudowissenschaftlichen Befunde, da diese hierfür einen idealen Nährboden bot. ${ }^{1496}$

Für die Gegenwart kann ein Bedeutungsverlust der irreführenden, semiwissenschaftlichen Ergebnisse der Schädelkunde konstatiert werden, da deren Aussagen sukzessive falsifiziert wurden. ${ }^{1497}$ Dennoch muss insbesondere im Vorausblick auf das sogenannte Intelligenz-Phänomen aufgezeigt werden, dass die Anwendung der Erkenntnisse der Schädelforschung in Verbindung mit dem sogenannten IQ (Intelligenzquotient) immer noch vorhanden ist. ${ }^{1498}$ Darüber hinaus kann vornehmlich in den 1960 er Jahren für die ,Rassenforschung ${ }^{6}$ wieder eine Art Renaissance konstatiert werden, wie die Historie des bundesrepublikanischen Rassismusphänomens schon bemerkenswert deutlich demonstriert (s. Kapitel 3, 4). ${ }^{1499}$ Ungeachtet der Schreckensereignisse des Zweiten Weltkrieges zeigte sich noch auf den UNESCO-Konferenzen 1950/1951, die sich mithilfe wissenschaftlicher Experten mit der ,Rassenfrage' beschäftigten, dass ein diesbezüglicher, naturwissenschaftlicher Konsens hochumstritten ist: Trotz des gemeinsamen Bestreitens von geistigen Differenzen zwischen imaginären ,Menschenrassen ${ }^{6}$ in der Erklärung „The Race Question“ 1500 bleibt die Thematik weiterhin brisant diskutiert (s. Kapitel 1, 5). Paul Mecheril und Karin Scherschel bezeichnen das Ergebnis der UNESCO-Konferenzen so nur als „oberflächlichen Effekt"“1501. Jedoch kann in der Folge eine teilweise Verlagerung der sogenannten ,Rassentheoretiker ${ }^{6}$ in den Bereich der psychologischen Intelligenzforschung sowie der Anthropologie notiert werden, da sich die Humanbiologie durch die UNESCO-Erklärungen weitgehend von dem menschlichen ,Rassenkonzept ${ }^{\star}$ distanziert hat. ${ }^{1502}$

Nichtsdestotrotz bleibt das ,Rassekonzept ${ }^{`}$ nach wie vor aufgrund der Bezugnahme auf scheinbar biologisch validierte Forschungsbefunde existent. Luigi Luca Cavalli-Sforza gibt trotzdem immer wieder nachdrücklich zu bedenken, dass die morphologischen und genetischen Unterschiede zwischen verschiedenen Menschenpopulationen - beispielsweise im AB0- und Rhesus-Blutgruppensystem -

\footnotetext{
1494 Vgl. Gould 1983, a. a. O., S. 81.

1495 Gould 1983, a. a. O., S. 83.

1496 Vgl. Gould 1983, a. a. O., S. 83.

1497 Vgl. Gould 1983, a. a. O., S. 112.

1498 Vgl. Gould 1983, a. a. O., S. 112.

1499 Vgl. Kühl 1999, a. a. O., S. $117 \mathrm{ff}$

1500 UNESCO 1950, a. a. O.

1501 Mecheril/Scherschel 2009, a. a. O., S. 49.

1502 Vgl. Kühl 1999, a. a. O., S. $118 f f$.
} 
nur minimal sind. ${ }^{1503}$ Insbesondere die europäische Bevölkerung zeige sich diesbezüglich sehr homogen. ${ }^{1504}$ So sind beispielsweise auf genetischer Seite größere Differenzen innerhalb der bundesrepublikanischen Bevölkerung existent, als zwischen Deutschen und Franzosen. ${ }^{1505}$ Lediglich Unterschiede bei Haar-, Haut- und Augenfarbe sind aufgrund der Anpassung an vielfältige Umweltfaktoren sowie klimatische Verhältnisse tendenziell genetisch bedingt. Alle weiteren phänotypischen Merkmale und Unterschiede lassen sich größtenteils auf umweltbedingte und kulturelle Einflüsse bzw. Phänomene zurückführen.

„Wir halten [...] fest, dass die [...] Forschungen, die darauf abzielten, genetische Auswirkungen auf die einzelne Persönlichkeit festzustellen, unbaltbare oder jedenfalls sehr wenig überzengende Ergebnisse erbracht haben. "506

5.2.2 Biologischer Art- und Rassebegriff: Klassifikation in Botanik und Zoologie

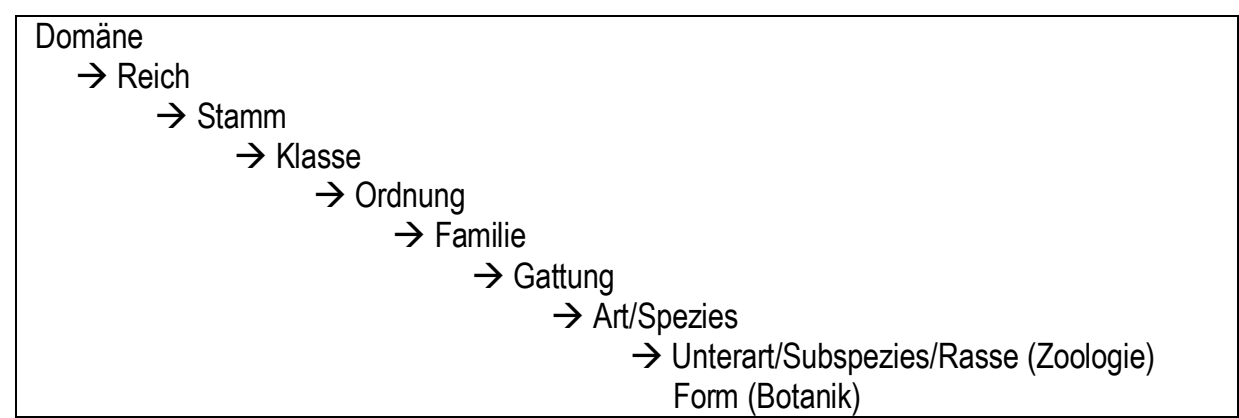

Abb. 12: Hierarchische Klassifizierung der Biologie ${ }^{1507}$

Wie in den vorherigen Kapiteln schon vergegenwärtigt wurde, handelt es sich bei dem auf den modernen Menschen übertragenen ,Rassebegriff' vornehmlich um eine kulturelle Charakterisierung. Da der Terminus jedoch ursprünglich aus dem Fachbereich der Biologie entnommen wurde und dieser immer noch als Argumentationsgrundlage dient, soll im Folgenden ein kurzer Blick auf das originäre, biologische Rassekonzept gelegt werden, das heißt auf die fachlich korrekte Verwendung der Begrifflichkeit einzig in der botanischen und zoologischen, nicht aber in der humanbiologischen Forschung. Im 21. Jahrhundert wird der biologische Rassebegriff größtenteils nur noch von Anthropologen und Haustierkundlern angewandt - in der allgemeinen Botanik und Zoologie wird die Begrifflichkeit aufgrund der illustrierten politischen und gesellschaftlichen Debatte einzig eingeschränkt benutzt (s. Kapitel 2). ${ }^{1508}$ Insbesondere vor dem Hintergrund der experimentellen Forschung mit von Menschen domestizierten Haustieren muss darauf

1503 Vgl. Cavalli-Sforza/Cavalli-Sforza 1994, a. a. O., S. $318 \mathrm{ff}$.

1504 Vgl. Cavalli-Sforza/Cavalli-Sforza 1994, a. a. O., S. $318 \mathrm{ff}$.

1505 Vgl. Cavalli-Sforza/Cavalli-Sforza 1994, a. a. O., S. $318 f f$.

1506 Cavalli-Sforza/Cavalli-Sforza 1994, a. a. O., S. 319.

1507 Eigene Darstellung nach: Vgl. Markl 2006, a. a. O., S. 581.

1508 Vgl. Kattmann 1999, a. a. O., S. 78. 
hingewiesen werden, dass deren Forschungsergebnisse nicht ohne weitere Präzisierungen auf natürliche Populationen übertragen bzw. verallgemeinert werden können, da diese genetisch vielfältig und keineswegs mit genetisch homogenen Haustieren vergleichbar sind. ${ }^{1509}$

Ebenfalls muss beachtet werden, dass beispielsweise verschiedene Hunderassen erst durch den Menschen enggezüchtet wurden - von einer natürlichen, evolutiven Unterteilung in ,Rassen“ kann demzufolge keine Rede sein. ${ }^{1510}$ Das „, [...] Benennen und Klassifizieren von Arten und Artengruppen." ${ }^{1511}$ in der Biologie wird durch die sogenannte Taxonomie repräsentiert. ${ }^{1512}$ Diese hatte ihren Beginn mit dem von Naturforscher Carl von Linné 1858/1859 veröffentlichten Hauptwerk ,Systema Naturae', das erstmals eine systematische Klassifizierung und Hierarchisierung der bisher bekannten Lebewesen vornahm. ${ }^{1513}$ Das auch heute noch verwendete Schema kennzeichnet sich durch eine hierarchische Einteilung von Lebewesen in immer größere Über-Gruppen von Lebewesen: Von der Art zur Domäne, wie die vorhergehende Grafik zeigt.1514 Für eine humanbiologische Verwendung der Unterart, Subspezies oder ,Rasse' sind keine wissenschaftlichen Beweise zu erbringen, wie auch der weitere Verlauf illustriert. Um dies noch mit taxonomischen Tatbeständen zu verifizieren, werden nun die für das weitere Vorgehen notwendigen Voraussetzungen zur Entstehung einer Art bzw. Unterart sowie die Frage nach der definitorischen Eindeutigkeit des Artbegriffs betrachtet. Denn ohne einen klaren Art-Begriff gestaltet sich auch die Begriffsbestimmung einer Unterart schwierig. Schon bei der Definition des Art-Begriffs lassen sich jedoch unterschiedliche Ansätze und Schwerpunkte erkennen, die es selbstredend weiterführend noch verkomplizieren, eine alternative sowie transparente Einteilung in Unterarten, beispielsweise des Menschen, zu ermöglichen. Schon Charles Darwin bemerkte hier bezüglich der verschiedenen Artdefinitionen, dass ,[...] keine derselben [...] bis jetzt alle Naturforscher befriedigt [...]"1515 hat. Die nachfolgende Tabelle gibt zur Verständnisförderung einen exemplarischen Überblick über die unterschiedlichen Artkonzepte der Biologie.

\footnotetext{
1509 Vgl. Kattmann 1999, a. a. O., S. 78.

1510 Vgl. Kattmann 1999, a. a. O., S. 78.

1511 Markl 2006, a. a. O., S. 581.

1512 Die Taxonomie ist das Forschungsgebiet der Biologie, welches sich mit der Benennung und Klassifizierung von Lebewesen befasst. Eine einheitliche, wissenschaftliche Gruppe von Lebewesen wird dabei als Taxon bezeichnet.

1513 Vgl. Markl 2006, a. a. O., S. 581.

1514 Vgl. Markl 2006, a. a. O., S. $581 \mathrm{ff}$.

Das taxonomische Schema kennzeichnet sich durch einen zweiteiligen Namen jeder Art: Den Gattungs- sowie den Artnamen. Am exemplarischen Beispiel des Menschen bedeutet dies wie folgt: Reich Metazoa (vielzellige Tiere) - Stamm Chordata (Chordatiere) - Klasse Mammalia (Sängetiere) - Ordnung Primates (Herrentiere) - Familie Hominidae (große Menschenaffen und Menschen) - Gattung Homo - Spezies Homo sapiens.

1515 Darwin 2000, a. a. O., S. 61.
} 
Tab. 16: Artkonzepte der Biologie (eigene Darstellung)

\begin{tabular}{|ll|}
\hline Biologisches Artkonzept & $\begin{array}{l}\text { „Arten sind Gruppen natürlicher Populationen, die sich tat- } \\
\text { sächlich oder potenziell untereinander kreuzen können und } \\
\text { von anderen solchen Gruppen reproduktiv isoliert sind. “1516 }\end{array}$ \\
\hline $\begin{array}{l}\text { Morphologisches Artkon- } \\
\text { zept }\end{array}$ & $\begin{array}{l}\text { [[...] Arten [sind] Lebensformen, die sich anhand ihrer mor- } \\
\text { phologisch-anatomischen Körpermerkmale deutlich von } \\
\text { anderen Lebensformen unterscheiden.“1517 }\end{array}$ \\
\hline Evolutionäres Artkonzept & $\begin{array}{l}\text { Eine Art ist ,[...] eine Abstammungsgemeinschaft aus einer } \\
\text { bis vielen Populationen in einer bestimmten Zeitspanne.“1518 }\end{array}$ \\
\hline Ökologisches Artkonzept & $\begin{array}{l}\text { [[...] Arten [sind] ökologische Einheiten, die sich durch ihre } \\
\text { jeweils spezifische ökologische Nische auszeichnen."1519 }\end{array}$ \\
\hline Genetisches Artkonzept & $\begin{array}{l}\text { Die Identität einer Art wird definiert ,[...] als Folge koadaptiv } \\
\text { aufeinander abgestimmter Gencluster."1520 }\end{array}$ \\
\hline Organismisches Artkonzept & $\begin{array}{l}\text { Das organismische/integrative Artkonzept integriert neben } \\
\text { den fünf genannten Definitionskriterien weitere Faktoren. }{ }^{1521}\end{array}$ \\
\hline
\end{tabular}

Wie kann es nun - trotz der unterschiedlichen Erklärungsansätze - zur Entwicklung neuer Arten sowie von Unterarten kommen? Notwendig ist die Überwindung sogenannter Isolationsbarrieren, die eine Reproduktion bzw. die Ausbildung neuer Arten verhindern. Hierfür kommen sowohl präzygotische Fortpflanzungsbarrieren, die eine Paarung bzw. die Befruchtung der Eizelle verhindern, als auch postzygotische Barrieren, die bei gelungener Befruchtung der Eizelle die Ausbildung von lebensfähigen Individuen verhindern, als Alternativen in Betracht. Die nachfolgende Tabelle skizziert die idealtypische Wirkung dieser Isolationsbarrieren bezüglich der Fortpflanzung und Neuentstehung von Arten sowie Unterarten.

Die internationale Wissenschaftsgemeinschaft präferiert insbesondere das biologische Artkonzept, da es vor allem die Grundprinzipien der Evolutionstheorie Charles Darwins nachdrücklich integriert. Jedoch ist das biologische Artkonzept nicht unumstritten, da es auf der einen Seite nicht auf alle Konstellationen anwendbar ist und sich auf der anderen Seite in vielen Fällen zur Abgrenzung von Arten als unbrauchbar erweist. ${ }^{1522}$ Trotz aller kritischen Einschränkungen der Artkonzepte illustrieren der biologische sowie der genetische Artbegriff jedoch eindrucksvoll, dass die menschliche Spezies Homo sapiens definitiv nur eine einzige Art repräsentiert, da alle menschlichen Individuen weltweit untereinander fort-

1516 Betz, Oliver (2011): Artentstehung, natürliches Aussterben und anthropogene Krise der Biodiversität. Darwins Theorie aus heutiger evolutionsbiologischer Sicht, in: Engels, Eve-

Marie/Betz, Oliver/Köhler, Heinz-R./Potthast, Thomas (Hrsg.): Charles Darwin und seine Bedeutung für die Wissenschaften, Tübingen, S. 103.

1517 Betz 2011, ebd., S. 105.

1518 Betz 2011, ebd., S. 106.

1519 Betz 2011, ebd., S. 106.

1520 Betz 2011, ebd., S. 106.

1521 Vgl. Betz 2011, ebd., S. 107.

1522 Vgl. Markl 2006, a. a. O., S. 549. 
pflanzungsfähig sind und ähnliche Gencluster - ohne maßgebliche, größere Unterschiede - aufweisen.

Tab. 17: Überblick über die Fortpflanzungsbarrieren zwischen Arten ${ }^{1523}$

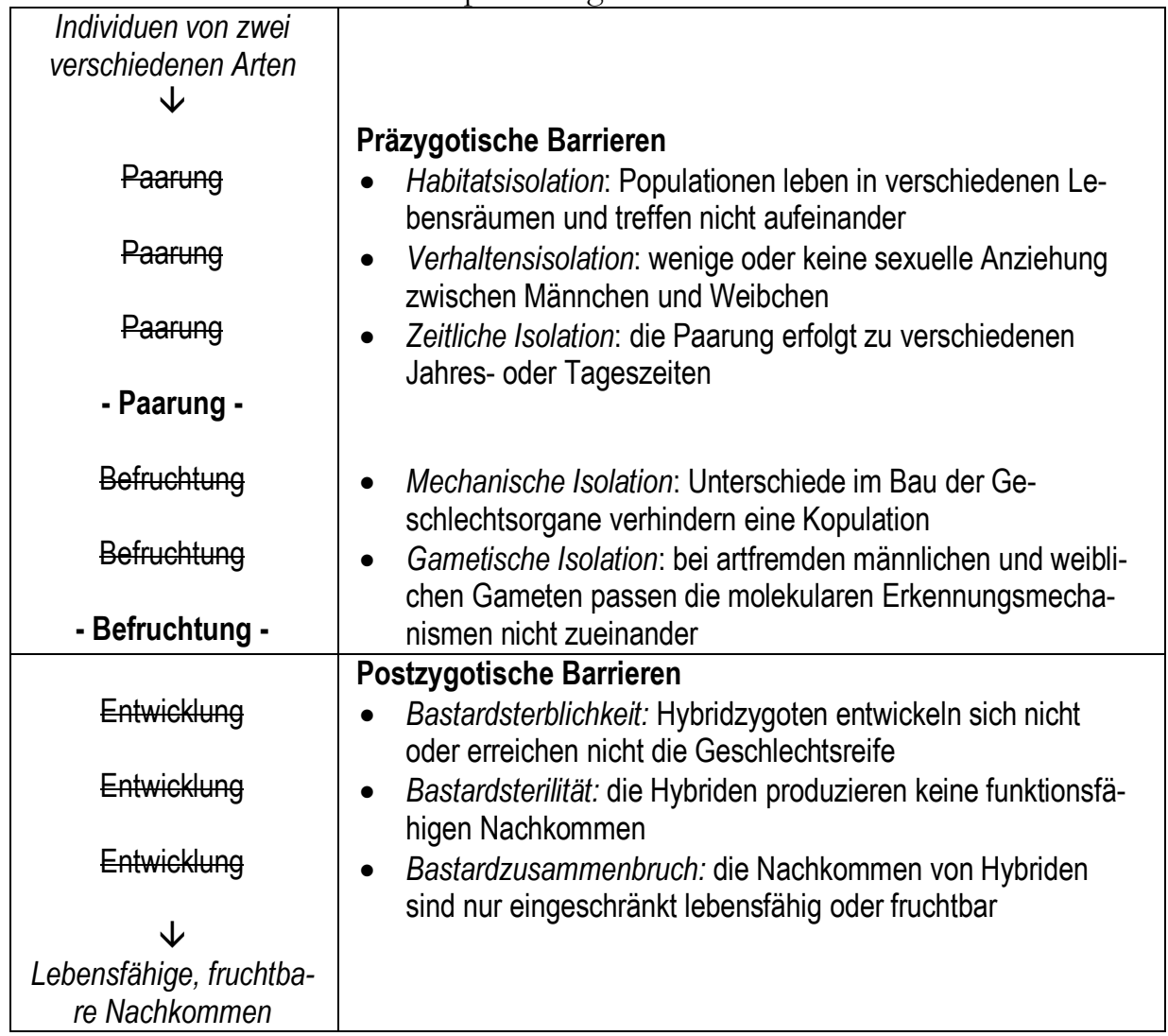

Unterarten bzw. Rassen weisen schon deutliche genotypische als auch phänotypische Differenzierungen untereinander auf. ${ }^{1524}$ Auch dies ist, wie das nachfolgende Kapitel demonstrieren wird, keinesfalls zutreffend. Darüber hinaus sind für die menschliche Entwicklung auch die Voraussetzungen der differenten Artentwicklung hin zu verschiedenen Subspezies nicht nachweisbar. Denn Grundlage der Art- bzw. Unterartbildung ist aus genotypischer Perspektive die Auftrennung des Genpools einer Art in separate, voneinander isolierte Genpools, sodass voneinan-

1523 Eigene Darstellung nach: Markl 2006, a. a. O., S. 549.

1524 Rasse/Unterart/Subsperies ist eine taxonomische Klassifikation unterbalb des Taxons Art. Mögliche Subspezies unterscheiden sich von der Hauptpopulation ibrer Art durch veränderte sonve abgewandelte genotypische und phänotypische Merkmale. Jedoch fehlt ein klares sowie objektives Klassifikationsmuster, ab wann Subspezies taxonomisch klassifiziert werden können. In der Biologie wird der Rassenbegriff heute meist nur noch in Verbindung mit sogenannte Kulturrassen, also vom Menschen gezü̈bteten und domestizierten Tieren und Pflanzen verwendet. 
der getrennte Evolutionsprozesse stattfinden können. ${ }^{1525}$ In der Folge differenzieren sich die beiden entstandenen Teilpopulationen voneinander genetisch immer weiter, sodass nach einem gewissen Zeitraum keine Fortpflanzung mehr zwischen den ursprünglichen Populationen möglich ist, außer bei Hybridisierungen. ${ }^{1526}$

Unterschieden werden können bei diesem Prozess der Artbildung grundsätzlich zwei Mechanismen, die teilweise auch auf die Unterartbildung zutreffen: Zum einen die sogenannte allopatrische Artbildung, bei der physikalische Barrieren wie die Entstehung von Gebirgen, die Neubildung von Flüssen, der Anstieg des Meeresspiegels, eine Vergletscherung als Folge von klimatischen Änderungen oder der Kontinentaldrift - entstehen, sowie die sympatrische Artbildung, bei der die Differenzierung von Arten vornehmlich aufgrund von Unterbrechungen des gemeinsamen Genflusses - beispielsweise durch Mutationen oder Rekombinationen - zu erklären sind. ${ }^{1527}$ Selbstverständlich werden die genannten Artbildungsprozesse auch von weiteren genetischen, ökologischen und umweltbedingten Charakteristika beeinflusst, die diese beschleunigen oder hemmen können. ${ }^{1528}$ Beispielsweise erschweren Temperaturreduzierungen, die zu Vergletscherungen und eiszeitlichen Bedingungen führen, vielfältige Lebensprozesse und verhindern damit auch die Neubildung von Arten aufgrund der mangelnden Nahrungs- sowie Lebensgrundlagen. Auch unterschiedliche Körpergrößen des modernen Menschen können beispielsweise mittels der differierenden Temperaturbedingungen erläutert werden: In Zentralafrika zeigt sich so oft das Phänomen der Kleinwüchsigkeit als Anpassung an die hiesige Lebensumwelt. Bei den dort während des Tages herrschenden hohen Temperaturen, bietet die geringe Körpergröße ein im Vergleich gesehen relativ kleines Körpervolumen zu einer relativ großen Körperoberfläche. ${ }^{1529}$ Diese große Oberfläche begünstigt und erhöht die Transpirations-

1525 Vgl. Betz 2011, a. a. O., S. $107 \mathrm{f}$

1526 Vgl. Betz 2011, a. a. O., S. 107 f.

Der Begriff Hybridisierung bedeutet, dass kurz nach der Bildung von Teilpopulationen auf dem Weg zur Artbildung aufgrund des ähnlichen Genpools der beiden Teilgruppen immer noch Paarungen zwischen beiden möglich sind - bierbei entstehen Hybride. Erst auf dem weiteren Weg der genotypischen und phänotypischen Differenzierung ist eine Paarung dann folgend nicht mehr möglich.

1527 Vgl. Betz 2011, a. a. O., S. $110 \mathrm{ff}$.

Im Zusammenhang mit der sympatrischen Artbildung muss auch die parapatrische Artbildung erwähnt werden, die auf der Veränderung von Umweltbedingungen in einem spesifischen Verbreitungsgebiet aufbaut. Auch die Bildung von Unterarten basiert auf der Isolation einer spezifischen Population einer Art, die mehr oder weniger als sich entwickelnde, neue Art verstanden werden kann. Unterschieden werden muss hierbei zwischen geographischen, biologischen und physiologischen Unterarten: Geographische Unterarten entstehen durch räumliche Isolation, nur an den Verbreitungsgrenzen kann es zur Ausbildung von Mischformen mit der ursprünglichen Art kommen (äbnlich dem Mechanismus der allopatrischen Artbildung); biologische Unterarten unterscheiden sich durch verschiedene Lebensweisen oder Erscheinungszeiten; physiologische Unterarten unterscheiden sich durch verschiedene Lebensäußerungen oder den Chromosomenbestand (beide äbnlich dem Mechanismus der sympatrischen Artbildung). Alle diese genannten Charakteristika treffen jedoch auf die Spezies Homo sapiens nicht zu - eine Bildung von ,Rassen' erscheint so unrealistisch. Vgl. Paululat, Achim/Purschke, Günter (2011): Wörterbuch der Zoologie, 8. Auflage, Heidelberg, S. $23 f$.

1528 Vgl. Betz 2011, a. a. O., S. $107 \mathrm{ff}$.

1529 Vgl. Cavalli-Sforza/Cavalli-Sforza 1994, a. a. O., S. 35. 
rate und folglich den Abkühlungseffekt des Körpers. ${ }^{1530}$ Auch das mit dem geringeren Körpervolumen in Zusammenhang stehende verringerte Gewicht, garantiert einen erniedrigten Energieverbrauch bei der Bewegung - alles umweltbedingte Anpassungen. ${ }^{1531}$

Tab. 18: Allopatrische und sympatrische Artbildung im Überblick ${ }^{1532}$

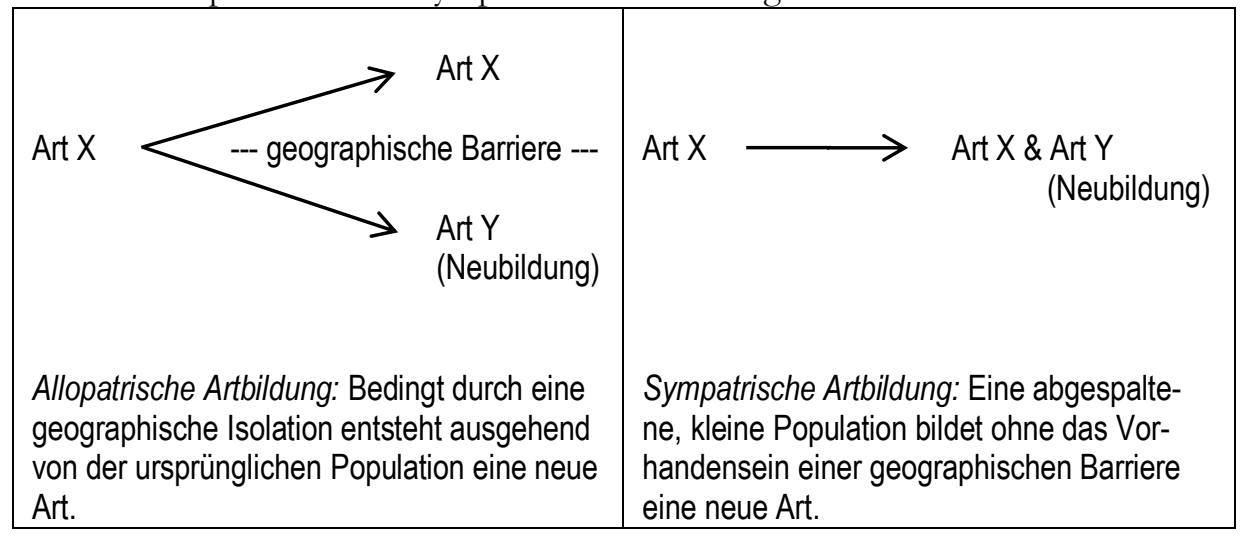

Auch aus dem Tierreich sind solche umweltbedingten Anpassungsmöglichkeiten bekannt, die in der sogenannten Bergmannschen Regel sowie der Allenschen Regel beschrieben werden. ${ }^{1533}$ Eine identische Übertragung dieser auf den modernen Menschen erscheint jedoch aufgrund dessen evolutiver Entwicklung wenn überhaupt nur eingeschränkt möglich. Da die menschliche Spezies in verschiedenen Populationen, auf unterschiedlichen Kontinenten sowie in differenten Nationen verteilt auftritt, könnten sich hypothetisch bei einer längeren gegenseitigen Isolation von mehreren 1.000 Jahren differente geno- und phänotypische Merkmale ausbilden, so dass von verschiedenen Unterarten, Subspezies oder Rassen gesprochen werden könnte. ${ }^{1534}$ Ursache hierfür könnten sowohl die genetische Drift, die ,natürliche Auslese،, Mutationen, Rekombinationen, geographische Isolation als auch verschiedene Umwelteinflüsse sein. ${ }^{1535}$ Wissenschaftlich problematisch ist

1530 Vgl. Cavalli-Sforza/Cavalli-Sforza 1994, a. a. O., S. 35.

1531 Vgl. Cavalli-Sforza/Cavalli-Sforza 1994, a. a. O., S. 35.

1532 Eigene Darstellung nach: Markl 2006, a. a. O., S. 550.

1533 Die Allensche Regel besagt, dass die Größe der Körperanbänge bei bomoiothermen (gleichwarmen) Tieren im Vergleich zu deren verwandten Arten in wärmeren Regionen tendenziell abnimmt. Dies fübrt zu einer Verkleinerung der Körperoberfläche in Relation zum Körpervolumen, was die Wärmeabgabe der in den källteren Regionen lebenden Tiere maßgeblich reduriert. Die Bergmannsche Regel konstatiert, dass homoiotherme Individuen relativ nab miteinander verwandter Arten in kälteren Regionen tendenziell größer und kompakter sind als deren Verwandte in wärmeren Regionen. Grundlage dessen ist die Tatsache, dass größere Tiere in Relation zu ibrem Körpervolumen nur eine relativ kleine Körperoberfläche, und daraus folgernd auch nur einen geringen Wärmeverlust durch Transpiration haben. Vgl. Munk, Katharina (2009): Taschenlehrbuch Biologie. Ökologie - Evolution, Stuttgart, S. 17.

1534 Vgl. Cavalli-Sforza/Cavalli-Sforza 1994, a. a. O., S. 171.

1535 Die genetische Drift bezeichnet Zufallsereignisse, die den Genpool kleiner Populationen verändern köonnen. 
jedoch, dass sich die Klassifizierung von Unterarten als schwierig möglich und sehr komplex darstellt. Außerdem sind keinerlei standardisierte biologische Gesetzmäßigkeiten, Anhaltspunkte oder Vergleichsgrundlagen vorhanden, lediglich ein allgemeines, lückenhaftes Beschreibungsprofil. 1536 Festzuhalten bleibt darüber hinaus, dass sich der Prozess der Artbildung bzw. Artabspaltung - demnach auch der Prozess der Bildung von Unterarten - über mehrere Millionen von Jahre hinzieht. Sie stellen also keinen Erklärungsansatz für eine ,Rassenbildung ${ }^{6}$ des modernen Menschen dar, da sich dieser erst vor etwa 100.000 Jahren entwickelt hat. ${ }^{1537}$ Der evolutionsbiologische Zeitfaktor bringt hier abermals die Annahme der rassistischen Ideologie zu Fall.

Aus der Perspektive der systematischen Taxonomie zeigen sich so das biologische und das genetische Artbildungskonzept, wie auch die geographische, biologische oder physiologische Unterartbildung für die Entwicklung des modernen Menschen als größtenteils untauglich, da die menschliche Spezies an sich schon vielfältige Varietäten - in der Gesamtbetrachtung nur von geringer Bedeutung mitbringt. Die Rassentaxonomie lässt sich demnach nur auf genetisch konstante sowie vererbbare Gene bzw. Eigenschaften von Tier- und Pflanzenarten anwenden. ${ }^{1538}$ Cavalli-Sforza bemerkt aber gleichzeitig korrigierend, dass aufgrund der Mechanismen der Evolution, die eine andauernde Weiterentwicklung, Variabilität und Heterogenität zur Folge haben, eine genetische Konstanz beim Menschen nicht erreicht werden kann und folglich auch nicht existiert - die weitere Unterklassifizierung des Taxons Art scheint also per se komplex und schwierig. ${ }^{1539}$ Cavalli-Sforza und Biologe Ulrich Kattmann notieren aufgrund dessen folgendes Fazit:

„Beim Menschen ist die Vielfalt innerhalb und swischen den Populationen so komplex, dass es unzweckmäßig ist, diese Art zoologisch weiter zu untergliedern. [...] Das Rassenkonzept ist einfach untauglich, die genetische Verschiedenheit der Menschen in ibrer individuellen und geographischen Vielfalt angemessen zu erfassen. "1540 "Aus all diesen Gründen ist die Klassifizierung von Rassen schwierig, wenn nicht gar ebenso unmöglich wie die Antwort auf zwei präzise Fragen: Gibt es eine italienische Rasse? Gibt es eine jüdische Rasse?" "541

Das biologische ,Rassekonzept ${ }^{t}$ ist bezüglich der Übertragung auf den modernen Menschen folglich zu einfach gedacht. ${ }^{1542}$ Alle Menschen sind zwar aufgrund indi-

1536 Vgl. Kattmann 1999, a. a. O., S. 79.

1537 Vgl. Betz 2011, a. a. O., S. 115.

1538 Vgl. Cavalli-Sforza/Cavalli-Sforza 1994, a. a. O., S. 355.

1539 Vgl. Cavalli-Sforza/Cavalli-Sforza 1994, a. a. O., S. 355.

1540 Kattmann 1999, a. a. O., S. 79.

1541 Cavalli-Sforza/Cavalli-Sforza 1994, a. a. O., S. 357.

1542 Vgl. Patrinos, Ari (2004): ,Race' and the human genome, in: Nature Genetics. Genetics for the human race, Vol. 36 Nr. 11, Nov. 2004, London u. a., S. 1. | Vgl. Royal, Charmaine D.

M./Dunston, Georgia M. (2004): Changing the paradigm of ,race' to human genome variation, in: Nature Genetics. Genetics for the human race, Vol. 36 Nr. 11, Nov. 2004, London u. a., S. 7. 
vidueller, genetischer Unterschiede einzigartig, bilden jedoch eine gemeinsame Spezies. ${ }^{1543}$

\subsubsection{Phylogenese des modernen Menschen: Das Out-of-Africa-Modell}

Auch die folgende, eher anthropologische Perspektive auf die evolutive Entwicklung und Verbreitung des modernen Menschen visualisiert, dass eine ,Rasseklassi-

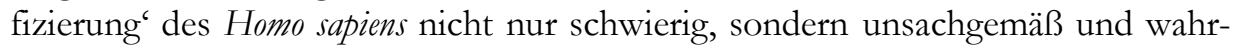
heitswidrig ist. Selbstverständlich existieren bezüglich der Evolution des modernen Menschen auch auf der naturwissenschaftlichen Ebene noch zahlreiche Meinungsverschiedenheiten. In den letzten Jahren zeigt sich aufgrund molekulargenetischer Untersuchungen jedoch immer deutlicher, dass der moderne Mensch monozentrischen Ursprungs, also nur an einem einzigen Ort gemeinsam entstanden, ist. Hier helfen insbesondere molekularbiologische Analysen der menschlichen DNA des Zellkerns, der mitochondrialen DNA (mtDNA) sowie der YChromosomen (s. Kapitel 5.3, 5.4). ${ }^{1544}$ Die Besonderheit der mtDNA ist, dass sie jeweils nur von der Mutter vererbt wird - sie ist also im Verlauf der Evolution weitgehend konstant geblieben und hat sich während der Fortpflanzungsprozesse nicht vermischt. Die Y-Chromosomen zeichnen sich dadurch aus, dass sie nur vom Vater weitergegeben werden - folglich sind auch sie im Laufe der Evolution weitgehend unverändert geblieben. Einzig während des Vorgangs der Reifeteilung, der sogenannten Meiose, können durch Rekombinationsereignisse Veränderungen an den Y-Chromosomen entstehen, die im weiteren Verlauf als genetische Marker zur eindeutigen Herkunftsbestimmung dienen. ${ }^{1545}$

Weiterhin bietet sich für genetische Verwandtschaftsanalysen die Untersuchung von Proteinen und deren Bausteinen, den sogenannten Aminosäuren, an: Je verschiedener zwei Organismen sind, desto unterschiedlicher ist meistens auch die Anzahl der Proteine sowie die der Aminosäuren, die untereinander differieren. ${ }^{1546}$ Mithilfe der genetischen Unterschiede kann in der Folge eine sogenannte ,Molekulare Uhr ${ }^{6}$ zur Berechnung der Evolutionszeiten zwischen den verglichenen Individuen erstellt werden. ${ }^{1547}$ Auf der Grundlage dieser Berechnungen wurde so bei-

1543 Vgl. Nature Publishing Group (2004): Editorial. The unexamined population, in: Nature Genetics. Genetics for the human race, Vol. 36 Nr. 11, Nov. 2004, London u. a., S. 3. | Vgl. Tishkoff, Sarah A./Kidd, Kenneth K. (2004): Implications of biogeography of human populations for ,race' and medicine, in: Nature Genetics. Genetics for the human race, Vol. $36 \mathrm{Nr}$. 11, Nov. 2004, London u. a., S. 22.

1544 Die Chromosomen enthalten in spiralisierter Form das Erbmaterial des Menschen, die DNA.

1545 Vgl. Markl 2006, a. a. O., S. 854.

Die sogenannte Meiose beschreibt den Vorgang der Kernteilung einer Zelle, bei der in zwei aufeinanderfolgenden, sogenannten Reifeteilungen die diploide Chromosomenzabl des Zellkerns auf die Hälfte - eine baploide Chromosomenzabl - reduziert wird. In der Folge enthält jeder der vier durch die Teilung entstandenen Zellkerne jeweils ein Chromosom von jedem Paar homologer Chromosomen, den Chromosomen von Mutter und Vater. Vgl. Janning/Knust 2008, a. a. O., S. 493.

1546 Vgl. Cavalli-Sforza/Cavalli-Sforza 1994, a. a. O., S. 69.

1547 Vgl. Cavalli-Sforza/Cavalli-Sforza 1994, a. a. O., S. $70 f f$. 
spielsweise festgestellt, dass sich Mensch und Schimpanse vor etwa fünf bis sieben Millionen Jahren stammesgeschichtlich getrennt haben, das heißt in diesem Zeitraum entwickelte sich der erste Vorfahre der Gattung Homo. ${ }^{1548}$

Die wichtigsten Entdeckungen menschlicher Überreste wurden in Afrika gemacht, was auch Darwin schon in seiner Arbeit konstatierte (s. Kapitel 5.1). ${ }^{1549}$ Aufgrund der erdrückenden Beweislage kann im 21. Jahrhundert dezidiert angenommen werden, dass alles Leben seinen Ursprung auf dem afrikanischen Kontinent hatte. ${ }^{1550}$ Insbesondere die Entwicklung des Homo sapiens betreffend liegen aus Afrika die überzeugendsten Belege vor:1551 „Afrika war die Wiege der Menschheit.“1552 „Im Grunde genommen sind wir alle Afrikaner.“1553 Hier kann ein gradueller Entwicklungsprozess von den früh-archaischen über die spätarchaischen Vorformen des modernen Menschen hin zum Homo sapiens konstruiert werden, der sich vor etwa 200.000-100.000 Jahren in Afrika entwickelte. ${ }^{1554}$ Eine Vermischung des Genpools von Homo sapiens mit seinen Vorformen scheint durch kurzzeitige Parallelexistenzen bis zu deren Ablösung möglich - nachfolgende genetische Vergleichsanalysen zwischen modernem Menschen und Neandertaler skizzieren jedoch ein differenzierteres Bild. ${ }^{1555}$

Die Verbreitung des Menschen über die verschiedenen Kontinente stellt eine der meist diskutierten Sachverhalte der Menschheitsevolution - zugleich eng verbunden mit rassistischen Theoremen - dar, wie die vorherige Tabelle erörtert. Denn eine polyzentrische Verbreitung des Menschen - der moderne Mensch wäre demnach multiregional auf den verschiedenen Kontinenten einzeln, separiert voneinander entstanden, eine Bildung von Unterarten deshalb wahrscheinlicher würde insbesondere Vorteile für das ,Rassekonzept ${ }^{`}$ des Rassismus ermöglichen. Vornehmlich das multiregionale Modell und das präferierte Out-of-Africa-Modell sind auch heute noch in der Anthropologie äußerst kontrovers diskutiert. ${ }^{1556}$ Die Genetik favorisiert eindeutig das monozentrische Entstehungsmodell des Men-

Die ,Molekulare Ubr' basiert auf der Annabme, dass einige Regionen des menschlichen Genoms mit konstanter Zeit evolvieren - diese dienen dann nachfolgend zur relativen Zeitmessung.

Vgl. Bräuer 2004, a. a. O., S. $165 f f$.

Für weitere Detailinformationen der Vorfabren des modernen Menschen wird auf die entsprechende Facbliteratur verviesen: Grupe, G. et al. (2005): Anthropologie. Ein einführendes Lehrbuch, Berlin u. a., S. 26ff.

1555 Vgl. Bräuer 2004, a. a. O., S. $166 f f$.

1556 Vgl. Henke, Winfried/Rothe, Hartmut (1999): Stammesgeschichte des Menschen, Berlin u. a., S. 281. 
schen. ${ }^{1557}$ Vor allem in Asien zeigt sich eine polyzentrische, regionale Evolution des modernen Menschen auf der Basis von DNA-Analysen als wenig wahrscheinlich. ${ }^{1558}$ Speziell die Aufrechterhaltung der Kontinuitätsmerkmale von Homo erectus, dem Vorläufer des modernen Menschen aus der Gattung Homo, bis hin zum Vorkommen des modernen Menschen erscheint unrealistisch. ${ }^{1559}$

Tab. 19: Herkunftsmodelle des anatomisch modernen Menschen ${ }^{1560}$

\begin{tabular}{|c|c|}
\hline Multiregionales Modell & $\begin{array}{l}\text { Die individuellen phänotypischen und genotypischen Merkma- } \\
\text { le von Menschen haben sich dort ausgebildet, wo sie noch } \\
\text { heute anzutreffen sind. }\end{array}$ \\
\hline Out-of-Africa-Modell & $\begin{array}{l}\text { Der moderne Mensch hatte seinen einzigen Ursprung auf dem } \\
\text { afrikanischen Kontinent. Eine Differenzierung in verschiedene } \\
\text { Menschenpopulationen mit teilweise unterschiedlichen Merk- } \\
\text { malen erfolgte erst später mit der Ausbreitung in andere Erd- } \\
\text { teile. }\end{array}$ \\
\hline Hybridisierungsmodell & $\begin{array}{l}\text { Das Hybridisierungsmodell sieht, ähnlich wie das multiregio- } \\
\text { nale Modell nur zeitlich später, eine Vernetzung der menschli- } \\
\text { chen Vorfahren miteinander und, als dessen Folge, eine Ent- } \\
\text { stehung des modernen Menschen vor. }\end{array}$ \\
\hline
\end{tabular}

Auch eine schon angesprochene multiregionale, fruchtbare sowie nachhaltige Paarung zwischen Populationen des Homo sapiens und dessen Vorfahren scheint, außer einzelner, unstrukturierter Paarungsereignisse, wenig wahrscheinlich - auch dies ein Beweis gegen die Existenz von genotypisch verschiedenen ,Menschenrassen'. Ein Beispiel: Der Neandertaler gilt noch bis etwa vor 27.000 Jahren als in Europa existent. ${ }^{1561}$ Vor etwa 35.000 Jahren verbreitete sich der moderne Mensch auf dem europäischen Kontinent - beide koexistierten also über einen gewissen Zeitraum.1562 Dies bestätigen auch Uran-Zerfallsanalysen zur Altersbestimmung. ${ }^{1563}$ Neuere Forschungsbefunde sehen den modernen Menschen hingegen schon vor etwa 45.000 Jahren in Europa angekommen, was Messungen in Apulien in Italien bestätigen. ${ }^{1564}$ Folglich bestanden zwischen Homo sapiens und Homo nean-

1557 Vgl. Cavalli-Sforza/Cavalli-Sforza 1994, a. a. O., S. 90.

1558 Vgl. Bräuer 2004, a. a. O., S. 174.

1559 Vgl. Bräuer 2004, a. a. O., S. 175.

1560 Eigene Darstellung nach: Vgl. Stringer, Christoph B. (1995): Die Herkunft des anatomisch modernen Menschen, in: Streit, Bruno (Hrsg.): Evolution des Menschen, Heidelberg u. a., S. $77 \mathrm{ff}$.

1561 Vgl. Stringer 1995, ebd., S. 81.

1562 Vgl. Stringer 1995, ebd., S. 81.

1563 Vgl. Stringer 1995, ebd., S. 81.

Die Uran-Zerfallsanalyse ist eine absolute Datierungsmethode zur Altersbestimmung von beispielsweise fossilen Funden. Hier werden die radioaktiven Zerfallsreiben des chemischen Elements Uran genutat, um Proben genau datieren zu können. Auf der Grundlage der Messung des Anteils der natürlich vorkommenden radioaktiven Uranelemente sowie ihrer Zerfallsprodukte kann mithilfe der bekannten Halbwertszeit von Uran somit das spezifische Alter berechnet werden.

1564 Vgl. Spiegel Online (2011c): „Zahnfunde: Moderner Mensch lebte bereits vor 45.000 Jahren in Europa“, in URL: http://www.spiegel.de/wissenschaft/mensch/zahnfunde-moderner- 
derthalensis etwa 5.000-10.000 Jahre der Koexistenz: „Der Kontakt zwischen den beiden Lebensformen [...] [ist] womöglich intensiver gewesen als bisher angenommen [...] Es gab genug Zeit für einen Austausch.“1565 Aufgrund kultureller Vorteile des Homo sapiens - wie die optimierte Nahrungsbeschaffung durch Ackerbau und Domestikation von Tieren oder die Sprache als Kommunikationsmittel wurde der Homo neanderthalensis einfach verdrängt. ${ }^{1566}$ Hinzukommend scheint der moderne Mensch auch an die zunehmenden Klimaschwankungen der damaligen Zeit besser angepasst gewesen zu sein. ${ }^{1567}$ So kann angenommen werden, dass die Einwanderung des modernen Menschen nach Europa für den Neandertaler „[...] üble Folgen [...] “1568 hatte: Das Aussterben der eigenen Art. Die Verbreitung des modernen Menschen bedeutete für den Neandertaler eine „,evolutionäre Sackgasse“1569. Dies illustrieren zusätzlich vergleichende Sequenzanalysen von menschlicher und neandertalensischer DNA, die für den modernen Menschen etwa 212 Sequenzvariationen aufweisen, von denen mindestens 20 eine positive Selektion gegenüber dem Neandertaler begünstigt haben dürften. ${ }^{1570}$ „Bestimmte Mutationen [...] könnten [...] letztlich zur Überlegenheit des [modernen] Menschen

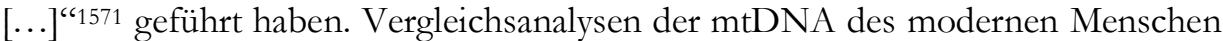
mit der mtDNA des Neandertalers zeigen zusätzlich keinerlei Übereinstimmungen: In der mtDNA des heutigen Homo sapiens sind - obwohl diese nur einen repräsentativen Bruchteil der gesamten DNA des Menschen darstellt - keine mtDNA-Reste bzw. -Bruchstücke des Neandertalers nachweisbar, was bei einer in der Vergangenheit erfolgten, vielfachen Paarung auch heute molekulargenetisch noch

mensch-lebte-bereits-vor-45-000-jahren-in-europa-a-795500.html <01.08.2012>. | Vgl. Higham, Tom/Compton, Tim/Stringer, Chris/Jacobi, Roger/Shapiro, Beth/Trinkaus, Erik/Chandler, Barry/Gröning, Flora/Collins, Chris/Hillson, Simon/O’Higgins, Paul/FitzGerald, Charles/Fagan, Michael (2011): The earliest evidence for anatomically modern humans in northwestern Europe, in: Nature, Vol. 479, London u. a., S. 521-524.

1565 Spiegel Online 2011c, a. a. O.

Diese Annabme der zeitweisen Koexitenz beider Spezies bestätigen weiterbin neuere Skelettfunde auf der Halbinsel Krim. Zablreiche Indizien weisen darauf hin, dass Homo sapiens und Homo neanderthalensis auch dort eine gewisse Zeit nebeneinander existiert baben. Vgl. Uthmeier, Thorsten (2013): „Auf den Spuren der letzten Neandertaler“", in URL: http://blogs.fau.de/news/2013/05/22/auf-den-spurender-letzten-neandertaler/ $<22.05 .2013>$.

1566 Vgl. Olson 2003, a. a. O., S. 132.

1567 Vgl. Spiegel Online (2012b): „Moderner Mensch verdrängte Neandertaler“, in URL: http://www.spiegel.de/wissenschaft/mensch/moderner-mensch-wurde-neandertaler-zumverhaengnis-a-845971.html <01.08.2012>. | Vgl. Lowe, John et al. (2012): Volcanic ash layers illuminate the resilience of Neanderthals and early modern humans to natural hazards, in: PNAS, July 23, Washington, S. 1-6. Spiegel Online 2012b, a. a. O.

1569 Markl 2006, a. a. O., S. 853.

1570 Vgl. Briseno, Cinthia (2010): „Wir sind alle ein bisschen Neandertaler“, in URL: http://www.spiegel.de/wissenschaft/ mensch/erbgut-entschluesselt-wir-sind-alle-einbisschen-neandertaler-a-692855.html $<01.08 .2012>$. 
sichtbar sein müsste. ${ }^{1572}$ Denn die mtDNA wird, wie schon erwähnt, jeweils nur von den weiblichen Partnern vererbt, bleibt also über einen langen Zeitraum größtenteils konstant erhalten. Lediglich in der DNA der Zellkerne menschlicher Zellen des Homo sapiens lassen sich Übereinstimmungen zwischen einem und vier Prozent ermitteln, die vom Homo neanderthalensis zu stammen scheinen, was auf einzelne, zufällige, nicht systematische Paarungen schließen lässt. ${ }^{1573} \mathrm{Im}$ Zuge der Entschlüsselung des vollständigen Erbguts des Neandertalers im Jahr 2010 konnte ein Leipziger Forscherteam diesbezüglich bestätigen, dass sich der moderne Mensch und der Neandertaler vor etwa 50.000 bis 100.000 Jahren einzeln gepaart haben müssen, da wenige identische DNA-Sequenzen existieren: „,Wir sind [folglich] alle [nur] ein bisschen Neandertaler." 1574 Darüber hinausgehend konnte festgestellt werden, dass die genannten ein bis vier Prozent der DNAÜbereinstimmungen nur für Menschen nichtafrikanischer Herkunft gelten. ${ }^{1575}$ Hierfür verglichen sie die genomische DNA eines Neandertalers mit der DNA von fünf modernen Menschen. ${ }^{1576}$ Dies stellt einen weiteren Beweis für die monozentrische Entstehung des modernen Menschen dar, der sich mit dem Neandertaler folglich erst nach dem Verlassen des afrikanischen Kontinents im Nahen Osten vor etwa 65.000 bis 90.000 Jahren zufällig paarte. ${ }^{1577}$ „Zugleich ähnelt das Neandertaler-Genom der Sequenz von Europäern ebenso sehr wie der von Ostasiaten. "1578 Schon aufgrund dieser entwicklungsgeschichtlichen Ähnlichkeit kann so ein weiterer Beweis gegen die Existenz von sogenannten ,Menschenrassen“ ausgesprochen werden, die sich beispielsweise nur durch isolierte und häufigere Paarungen mit dem Neandertaler eventuell hätten bilden können.

Auf der anderen Seite bestätigt jedoch auch die aufgrund molekulargenetischer, zeitlicher Bestimmungen verschiedener Neandertaler-Funde angenommene genetische Trennung zwischen Homo neanderthalensis und Homo sapiens vor etwa 90.000100.000 Jahren eindeutig, dass der Neandertaler trotz aller Ähnlichkeiten mit dem rezenten Menschen größtenteils isoliert und genetisch betrachtet keineswegs mit diesem identisch ist. ${ }^{1579}$ Biologe Günter Bräuer folgert vor diesem Hintergrund, „dass das Ausmaß an Genfluss zwischen Neandertalern und frühen modernen Populationen eher gering gewesen sein dürfte. In manchen Regionen Europas [...] haben neueste Untersuchungen nicht einmal Hinweise auf eine Koexistenz von Neandertalern und modernen Menschen liefern können." ${ }^{1580}$ Resümiert werden kann demnach:

\footnotetext{
1572 Vgl. Olson 2003, a. a. O., S. 124ff. | Vgl. Graw, Jochen (2010): Genetik, 5. Auflage, Heidelberg u. a., S. 768.

1573 Vgl. Ruse, Michael (2012): The Philosophy of Human Evolution, Cambridge u. a., S. 61.

1574 Briseno 2010, a. a. O.

1575 Vgl. Briseno 2010, a. a. O.

1576 Vgl. Graw 2010, a. a. O., S. 768f.

1577 Vgl. Grolle, Johann (2011): „,Rivalen um die Weltherrschaft“", in URL: http://www.spiegel.de/spiegel/a-784530.html <01.08.2012>.

1578 Briseno 2010, a. a. O.

1579 Vgl. Olson 2003, a. a. O., S. 128ff. | Vgl. Graw 2010, a. a. O., S. 762.

1580 Bräuer 2004, a. a. O., S. 174.
} 
„In Europa ist der Neandertaler ein Vorgänger des modernen Menschen; für etliche Jabrtausende bewohnten beide Arten denselben Lebensraum [...]. Die Analyse des mitochondrialen Genoms gibt keinen Hinweis darauf, dass es zu einer Durchmischung gekommen ist. Es gibt aber Hinweise auf eine Durchmischung aus einzelnen genomischen Regionen; der Gesamtbeitrag des Neandertalers am Genom des modernen Menschen wird auf $1-5 \%$ gescbätzt. "“581

Bei der Analyse der genetischen Auseinanderentwicklung des modernen Menschen in Folge dessen Verbreitung und Differenzierung über die einzelnen Kontinente lässt sich diagnostizieren, dass ab diesem Zeitpunkt genetische Informationen sowie auch Variationen in Form von Mutationen oder Rekombinationen unterschiedlich weitergegeben wurden. ${ }^{1582}$ Hier kann so ursprünglich eine ansatzweise genetische Auseinanderentwicklung des modernen Menschen identifiziert werden, die im Rahmen der Evolutionsprozesse zur heutigen Vielfalt führte. ${ }^{1583}$ Darüber hinaus demonstriert das folgende Beispiel unterstützend, dass aufgrund dieser molekularbiologischen Erkenntnisse jedoch keineswegs von einer tendenziellen Bildung verschiedener menschlicher Subspezies gesprochen werden kann. Hauptursache der vielfältigen genetischen Variationen sind Anpassungsmechanismen an die zahlreichen Klima- und Umweltverhältnisse der unterschiedlichen Lebensregionen.

„Die Ausbreitung vorteilhafter Mutationen spielte in der Menschbeitsgeschichte eine wichtige Rolle. Man nehme nur das Verbältnis von Hautfarbe und Kima. Für Menschen, die in der Äquatorregion leben, ist dunkle Haut ein großer Vorteil, weil sie weniger anfällig für Schäden durch ultraviolette Sonnenstrablung ist. Dunkle Haut bilft sowobl Krebs zu verbindern als auch starken Sonnenbrand, der zu schweren Infektionen fübren kann. [...] In Teilen der Welt, in denen die Sonneneinstrablung weniger intensiv ist, kann dunkle Haut jedoch ein Nacbteil sein. Unser Körper braucht ultraviolettes Licht, das die Haut durchdringt, um Vitamin D zu bilden. Ohne ausreichende Mengen an Vitamin D können die Knochen nicht richtig wachsen, was unter Umständen zur schmerz̧baften und entstellenden Racbitis führt. " "584

Durch zufällige, umweltbedingte Variationen der DNA verändern sich Gene und Genfunktionen der Menschen, die sich hierdurch genotypisch schrittweise in geringem Maße auseinander entwickeln. Der daraus entstehende genetische Abstand - der keineswegs ausreichend für eine ,Rassendifferenzierung ' ist - lässt demnach tendenziell differenzierte Gruppen entstehen. ${ }^{1585}$ Luigi Luca CavalliSforza stellt aufgrund dessen fest, dass der genetische Abstand zwischen Afrikanern und Nichtafrikanern nach der monozentrischen Verbreitung des Menschen logischerweise am größten ist, da diese die älteste Trennung des modernen Men-

\footnotetext{
1581 Graw 2010, a. a. O., S. 771.

1582 Vgl. Olson 2003, a. a. O., S. 64.

1583 Vgl. Olson 2003, a. a. O., S. 64.

1584 Olson 2003, a. a. O., S. 65-66.

1585 Vgl. Zeit Online 1992, a. a. O.
} 
schen darstellt - denn als erstes verließ der moderne Mensch Afrika. ${ }^{1586}$ Folglich sind aufgrund der zeitlich am weitesten zurückliegenden Teilung auch am meisten genetische Variationen möglich. Mithilfe von mtDNA-Analysen aufgrund von Mutationshäufigkeiten belegen auf der einen Seite der Genetiker Allan L. Wilson und die Biochemikerin Rebecca L. Cann an einem relativ kurzen Stück der mtDNA von nur 600 bis 700 Nukleotiden - Bausteinen der DNA - und Cavalli-Sforza mit DNA-Analysen auf der anderen Seite, dass diese Trennung vor etwa 100.000 Jahren stattfand: Nach Asien gelangte der Homo sapiens folglich vor etwa 100.000 Jahren, nach Australien vor etwa 55.000 Jahren, nach Europa vor etwa 35.000 Jahren und nach Amerika vor etwa 35.000-15.000 Jahren, was die folgende Grafik visualisiert. ${ }^{1587}$

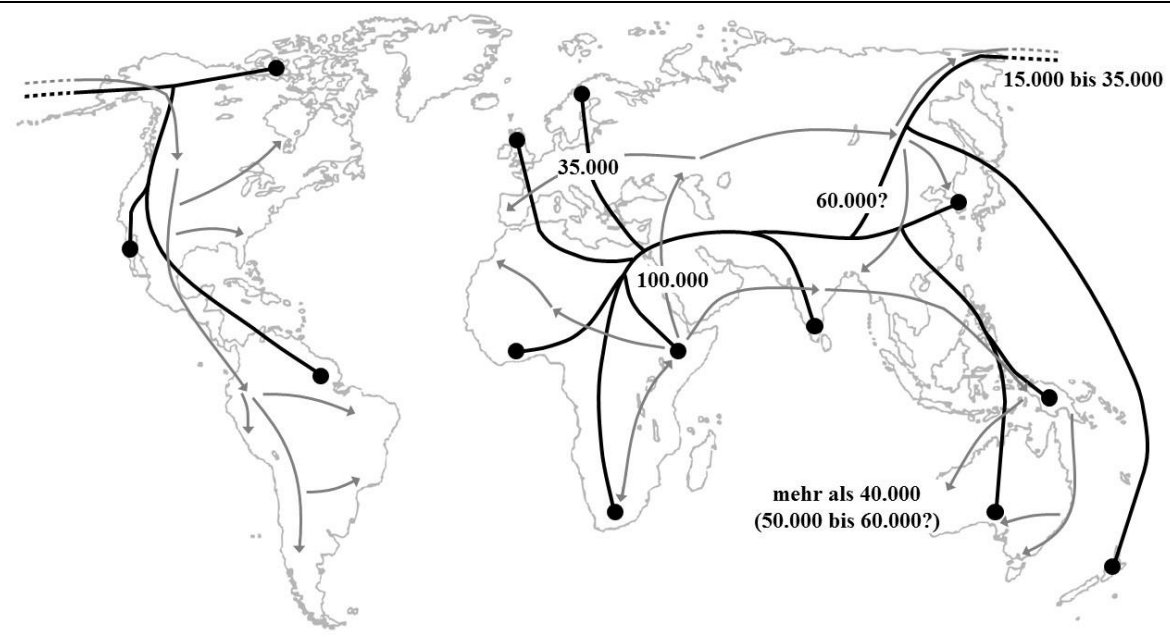

Rekonstruktion der Ausbreitung des Menschen in vorgeschichtlicher Zeit. Ein erster genetischer Stammbaum (schwarz) wurde derart auf eine Weltkarte projiziert, dass die Endpunkte der Zweige in den heutigen Regionen der einzelnen Populationen liegen. Das Ergebnis passt recht gut zu einer Rekonstruktion nach archäologischen und fossilen Funden (die Zahlen bezeichnen das Auftauchen des anatomisch modernen Menschen in Jahren vor der Gegenwart). Neuere genetische Untersuchungen (grau) lassen vermuten, dass der Homo sapiens auf zwei Routen nach Asien gelangte; die Details der Wege beruhen aber auf Spekulation.

Abb. 13: Wanderungsbewegungen des modernen Menschen ${ }^{1588}$

1586 Vgl. Cavalli-Sforza, Luigi Luca (1995): Stammbäume von Völkern und Sprachen, in: Streit, Bruno (Hrsg.): Evolution des Menschen, Heidelberg u. a., S. $121 \mathrm{ff}$. | Vgl. Zeit Online 1992, a. a. O.

1587 Vgl. Zeit Online 1992, a. a. O.

1588 Eigene Darstellung nach: Cavalli-Sforza 1995, a. a. O., S. 121. | With kind permission of Junker Verlag GmbH. Junker Verlag GmbH (2014): „Gratis Malvorlage Erde - Weltkarte“, in URL: http://arbeitsblaetter-kindergarten.de/component/content/article/81-ausmalbildertexte/90-gratis-malvorlage-erde-weltkarte <01.07.2014>. 
Dies bestätigen ebenfalls Analysen des Y-Chromosoms: Mithilfe von Mutationen als Zeitmarkern konnte die Abspaltung des Menschen vor etwa 100.000 Jahren datiert werden. ${ }^{1589}$ Die mtDNA-Analyse erfolgt dabei auf der Basis der sogenannten ,Molekularen Uhr' mithilfe einer Restriktionsanalyse. Bei dieser sogenannten Restriktionsfragment-Längenpolymorphismen-Analyse (RFLP, Restriction Fragment Length Polymorphism) werden die DNA-Abschnitte mit Restriktionsenzymen behandelt, die die DNA in unterschiedliche Restriktionsfragmente zerschneiden. Unterschiedliche DNA-Sequenzen zeigen in der Folge auch ein unterschiedliches Muster der Restriktionsfragmentlängen. Anhand der Übereinstimmung der Muster zweier DNA-Abschnitte kann so die Ähnlichkeit, also ein möglicher Verwandtschaftsgrad, identifiziert werden. Zeitlich gleichmäßig entstandene Mutationen auf der mtDNA werden mithilfe der RFLP bis zu dem Zeitpunkt zurückverfolgt, an dem sich zwei heute getrennte Populationslinien ursprünglich aufgespalten haben. ${ }^{1590}$ Mithilfe der mtDNA-Analysen kann ein ähnliches Verbreitungsschema des modernen Menschen generiert werden, welches ebenfalls den Ursprung des modernen Menschen in Afrika - trotz teilweiser methodischer Unsicherheiten sieht. 1591 Bei einer als gleich bzw. ähnlich angenommenen Mutationsrate der mtDNA aller menschlichen Populationen, lassen sich sowohl eine monozentrische Entwicklung des modernen Menschen als auch die tendenziell größeren genetischen Unterschiedlichkeiten afrikanischer Menschen erklären. Diese haben sich als erstes abgespalten, sind also auch genetisch am ältesten und weisen aufgrund der vergrößerten Zeitspanne logischerweise auch eine Mehrzahl an genetischen Variationen auf.1592 Unterstützt wird diese Annahme ebenfalls von der mithilfe der mtDNA-Analysen ermittelten - relativ engen Verwandtschaft von Europäern, Asiaten und den weiteren Pazifikvölkern. ${ }^{1593}$ Denn diese haben sich erst nach dem Verlassen Afrikas voneinander differenziert, sind also näher miteinander verwandt als mit der afrikanischen Bevölkerung, was die vorhergehende Grafik bestätigt. Doch trotz dieser ermittelten Unterschiede bleibt festzuhalten, dass sich die modernen Menschen weltweit genetisch dennoch sehr homogen darstellen - die genotypischen Varietäten können aus evolutionsbiologischer Per-

\footnotetext{
1589 Vgl. Markl 2006, a. a. O., S. 854.

1590 Vgl. Stringer 1995, a. a. O., S. $80 \mathrm{ff}$.

Mit Restriktionsfragment-Längenpolymorphismus bezeichnet man eine Veränderung einer Erkennungsstelle

für ein Restriktionsensym auf der DNA die zur Folge hat, dass die genannten Ensyme die sperifische DNA-

Stelle nicht mehr erkennen und zerschneiden können. Die darauf basierende RFLP-Methode ist eine biochemische Analysemethode zur Trennung und dem anschließenden Vergleich von DNA-Fragmenten. Die zu untersuchende DNA wird mithilfe von Restriktionsensymen, die die DNA an sperifischen Schnittstellen schneiden, in einzelne DNA-Fragmente zerteilt. Ist eine Schnittstelle wie oben bescbrieben individuell verändert, kann das Ensym dort nicht schneiden und das DNA-Fragment wird länger. Diese werden mittels einer weiteren analytischen Methode, der sogenannten Geleleketrophorese, ibrer Länge nach aufgeteilt und geordnet. So entsteht ein individuelles Bandenmuster der untersuchten DNA. So können beispielsweise im Rabmen von Vaterschaftstests DNA-Proben miteinander verglichen werden, um Aussagen über den Grad der Verwandtschaft treffen zu können. Vgl. Janning/Knust 2008, a. a. O., S. $307 \mathrm{ff}$.

1592 Vgl. Stringer 1995, a. a. O., S. $80 \mathrm{ff}$.

1593 Vgl. Stringer 1995, a. a. O., S. $81 \mathrm{ff}$.
} 
spektive vernachlässigt werden. ${ }^{1594}$ Weiterhin bestätigen dies zahlreiche molekulargenetische Untersuchungen, die anhand von mtDNA-Analysen annehmen, dass alle modernen Menschen der Spezies Homo sapiens von einer ursprünglichen Frau - angelehnt an den biblischen Schöpfungsmythos mit ,Ur-Eva' bezeichnet bzw. einer relativ kleinen Stammgruppe abstammen, die vor ungefähr 200.000 Jahren in Afrika lebte - ebenfalls ein Beweis gegen das polyzentrische, multiregionale Modell. 1595

Auch der Genetiker Jochen Graw resümiert demzufolge: „Die Entwicklung des modernen Menschen begann wohl im südlichen zentralen Afrika: Danach hat sich der Mensch in mehreren Wellen aus Afrika nach Asien, Europa und später Amerika ausgebreitet. Die Untersuchung verschiedener charakteristischer Genorte legt es nahe, auf allen Stufen dieser Entwicklung ein gewisses Maß an Durchmischung der verschiedenen Populationen anzunehmen." 1596 Die Ausbreitung des modernen Menschen von Afrika aus ist so nicht statisch, sondern mit einer Vielzahl von Vermischungen und Kreuzungen auf dem Verbreitungsweg verbunden. 1597

Zusätzlich belegt auch die Erforschung von genetischen Distanzen zwischen unterschiedlichen Populationen die skizzierten Ergebnisse. Je länger zwei ursprünglich zusammenhängende Populationen voneinander getrennt sind, desto größer werden die genetischen Unterschiede zur Ursprungspopulation - diese werden als genetische Distanzen gemessen. ${ }^{1598}$ Die ermittelten Unterschiede sind quantitativ relativ klein - viele Gene liefern darüber hinaus auch keine Informationen, da die genetische Distanz hier annähernd null beträgt. ${ }^{1599}$ Lediglich bei der Berechnung der genetischen Distanz des Rhesus-Gens in Europa liegen die Werte von 0,1 bis 31,7 Prozent relativ breit gestreut zwischen den einzelnen Staaten, was jedoch auch partiell auf technischen Komplikationen beruhen kann. ${ }^{1600}$ Für eine Bildung verschiedener Unterarten des Homo sapiens erscheinen diese genetischen Distanzen jedoch zu gering (s. Kapitel 5.2.2). Insgesamt ist so zu bemerken:

„Wir haben festgestellt, dass dabei [dennoch] zwischen den Genen wenig Variation besteht." "601

An dieser Stelle ist insbesondere auf die genetischen Vergleichsanalysen von Cavalli-Sforza zwischen verschiedenen Populationen des modernen Menschen zu

\footnotetext{
1594 Vgl. Wilson, Allac C./Cann, Rebecca L. (1995): Afrikanischer Ursprung des modernen Menschen, in: Streit, Bruno (Hrsg.): Evolution des Menschen, Heidelberg u. a., S. 90.

1595 Vgl. Stringer 1995, a. a. O., S. 86.

1596 Graw 2010, a. a. O., S. 765.

1597 Vgl. Graw 2010, a. a. O., S. $761 \mathrm{f}$.

1598 Vgl. Wilson/Cann 1995, a. a. O., S. 87.

1599 Vgl. Cavalli-Sforza 1999, a. a. O., S. 35

1600 Vgl. Cavalli-Sforza 1999, a. a. O., S. 35.

Das Rhesus-Gen ist für das Vorhandensein des sogenannten Rhesus-Faktors als Merkmal des menschlichen Blutgruppensystems verantwortlich. Feblt das Rhesus-Gen ist der entsprechende Mensch Rhesus-negativ, ist das Rhesus-Gen vorhanden ist der betroffene Mensch dementsprechend Rhesus-positiv.

1601 Cavalli-Sforza 1999, a. a. O., S. 38.
} 
verweisen, die die oben zitierten Befunde umfassend validieren: In „Genetics, Evolution, and Man“1602 sowie „The Genetics of Human Populations"1603 vergegenwärtigen Cavalli-Sforza und Genetiker W. F. Bodmer, dass zwar aufgrund des Evolutionsmechanismus Variationen zwischen Individuen bestehen, diese aber insgesamt betrachtet viel zu klein sind, um die Existenz von genetisch abgrenzbaren Populationen einer Art - von Subspezies oder ,Rassen ${ }^{6}$ - zu beweisen. Folglich bleibt die ,Rassifizierung' des Menschen nicht nur kompliziert und willkürlich, sondern wissenschaftlich eindeutig falsch. ${ }^{1604}$ Denn selbst zwischen naheliegenden Orten - exemplarisch beispielsweise Frankfurt am Main und Hanau, Köln und Leverkusen, Berlin und Potsdam oder Leipzig und Halle - sind genetische Distanzen vorhanden. ${ }^{1605}$ Oftmals sind sogar die genetischen Distanzen zwischen Individuen einer Population größer als zwischen Individuen zweier verschiedener Populationen. ${ }^{1606}$ Hinzukommend kann man mithilfe der Errechnung der genetischen Distanzen von Ureinwohnern der fünf Kontinente nochmals das monozentrische Out-of-Africa-Modell bestätigen und damit einen Beweis gegen die Existenz von unterschiedlichen menschlichen Subspezies - die sich durch eine zeitlich längerfristige, geographische bzw. regionale sowie genetische Isolation nach dem polyzentrischen Entwicklungsmodell des Menschen eventuell hätten differenzieren können - anführen, wie die nachfolgende Systematik visualisiert. Die folgenden Tabellen der genetischen Distanzen sowie der genetische Stammbaum belegen unzweideutig, dass sich zuerst die afrikanische Bevölkerung von allen anderen Menschenpopulationen getrennt hat, „[...] was die Hypothese bestätigt, dass der moderne Mensch aus Afrika stammt und sich von dort aus über die ganze Erde ausgebreitet hat.“1607

Tab. 20: Genetische Distanzen zwischen den Kontinenten ${ }^{1608}$

\begin{tabular}{|lcccc|}
\hline & Afrika & Ozeanien & Amerika & Europa \\
\hline Ozeanien & 24,7 & & & \\
Amerika & 22,6 & 14,6 & & \\
Europa & 16,6 & 13,5 & 9,5 & \\
Asien & 20,6 & 10,0 & 8,9 & 9,7 \\
\hline
\end{tabular}

1602 Bodmer, W. F./Cavalli-Sforza, Luigi Luca (1976): Genetics, Evolution, and Man, San Francisco.

1603 Bodmer, W. F./Cavalli-Sforza, Luigi Luca (1971): The Genetics of Human Populations, San Francisco.

1604 Vgl. Cavalli-Sforza 1999, a. a. O., S. 39.

1605 Vgl. Cavalli-Sforza 1999, a. a. O., S. $40 \mathrm{ff}$.

1606 Vgl. Cavalli-Sforza 1999, a. a. O., S. $40 \mathrm{ff}$.

1607 Cavalli-Sforza 1999, a. a. O., S. 54.

1608 Eigene Darstellung nach: Cavalli-Sforza 1999, a. a. O., S. 50. 


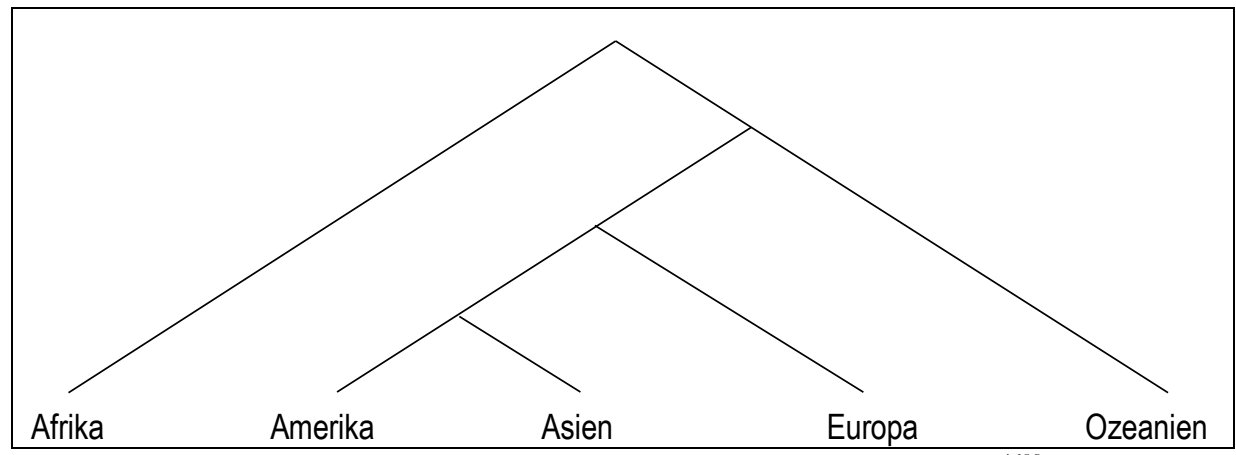

Abb. 14: Genetischer Stammbaum des modernen Menschen (ausgehend von Tab. 20)1609

Aus der vorhergehenden Tabelle kann ermittelt werden, dass die genetische Distanz zwischen Asien und Amerika am kleinsten ist, folglich muss auch die Aufteilung der asiatischen und amerikanischen Population zeitlich am spätesten stattgefunden haben, sodass aufgrund der zeitlichen Kürze im Vergleich zur Differenzierung seitdem nur wenige genetische Variationen möglich wurden. Demgegenüber zeigen sich die genetischen Distanzen zwischen Ozeanien und Amerika auf der einen Seite und Afrika auf der anderen Seite am größten - deren Differenzierung muss also zeitlich weit auseinander liegen. Von Afrika aus verbreitete sich der moderne Mensch demzufolge zuerst nach Asien - von dort aus nach Australien, Ozeanien, Alaska und Amerika - sowie über Westasien nach Europa. ${ }^{1610}$ Dies bestätigt ebenfalls der Vergleich der festgestellten genetischen Distanzen mit den Besiedlungsdaten der einzelnen Kontinente. Die genetische Distanz zwischen Afrika und Asien zeigt sich am größten - afrikanische und asiatische Populationen müssen sich also zeitlich gesehen als erstes differenziert haben, wie die Erstbesiedlungsdaten vor etwa 100.000 Jahren aufzeigen. Die letzte Aufteilung erfolgte bei der Besiedlung Amerikas von Asien aus vor etwa 50.000-15.000 Jahren - auch die genetische Distanz zwischen beiden Populationen zeigt sich hier am kleinsten, also zeitlich am jüngsten. Dies verifizieren ebenfalls die erörterten Datensätze. Aus biologischer Perspektive muss jedoch nochmals darauf hingewiesen werden, dass es sich hierbei lediglich um eine Hypothese handelt, eine hypothetische Lösung, die am besten mit den derzeit verfügbaren Daten übereinstimmt. ${ }^{1611}$ Optimierungen und Anpassungen sind jederzeit möglich. Ein aktuelles Forschungsprojekt der Biologen Peter Ralph und Graham Coop weist außerdem darauf hin, dass auch der Einfluss von Migration sowie von Wanderungsbewegungen zwischen einzelnen Menschenpopulationen nicht unterschätzt werden darf. Demnach haben alle heute in Europa lebenden Menschen gemeinsame bzw. ähnliche Vorfahren: Der Vergleich von Genomsequenzen visualisiert jedoch, dass beispielsweise deutsche und polnische Bürgerinnen und Bürger sich teilweise genotypisch ähnli-

1609 Eigene Darstellung nach: Cavalli-Sforza 1999, a. a. O., S. 52.

1610 Vgl. Cavalli-Sforza 1999, a. a. O., S. 80ff.

1611 Vgl. Markl 2006, a. a. O., S. 592. 
cher sind - also in mehr Gensequenzen Übereinstimmungen aufweisen - als die deutsche Bevölkerung untereinander. ${ }^{1612}$ Folglich dürfen auch die vielfältigen äuBeren Einflussfaktoren auf die Bewegung und Struktur von Populationen nicht unbeachtet bleiben.

Tab. 21: Zusammenhang zwischen genetischen Distanzen und Besiedlungsdaten ${ }^{1613}$

\begin{tabular}{|lcc|}
\hline Kontinente & Genetische Distanzen & $\begin{array}{c}\text { Datum der ersten Besiedlung } \\
\text { (in Jahrtausenden) }\end{array}$ \\
\hline Afrika-Asien & 206 & 100 \\
Asien-Australien & 101 & 55 \\
Asien-Europa & 97 & 43 \\
Asien-Amerika & 89 & $15-50$ \\
\hline
\end{tabular}

Darüber hinaus ist auch eine Abgrenzung von Populationen mittels geographischer oder sprachlicher Barrieren im Hinblick auf die moderne Menschheit nicht zielführend, da für eine Gebietsbestimmung kein umschlossener, abgrenzbarer Raum definierbar ist. ${ }^{1614}$ Denn selbst vor 50.000-15.000 Jahren ist es dem modernen Mensch schon gelungen, geographische Barrieren zu überwinden, um alle Kontinente der Erde zu besiedeln. Das eindrücklichste Beispiel ist hier die Besiedlung Amerikas von Asien aus über die heutige Beringstraße.

Die vom Out-of-Africa-Modell ausgehende Verbreitung des modernen Menschen über den Nahen Osten nach Europa kann weiterführend auch durch die Entstehung bzw. Übernahme des Ackerbaus und der Verbreitung der Sprache nachverfolgt werden. Denn insbesondere der Ackerbau stellt als regelmäßige und zuverlässige Nahrungsquelle den Grundstein für ein Anwachsen der Menschheit und deren Verbreitung aufgrund der Suche nach neuen Anbau- und Jagdgebieten, zusammen mit der beginnenden Domestikation von Pflanzen und Tieren, dar. So konstatiert Cavalli-Sforza, der sich in mehreren, sehr umfangreichen wissenschaftlichen Ausarbeitungen mit der Verbreitung des Homo sapiens aufgrund von Ackerbau und Sprache beschäftigt, dass die genetischen Differenzen zwischen den Menschenpopulationen des Nahen Ostens und Europas kontinuierlich abnehmen. ${ }^{1615}$ Dies bestätigt folglich die Tatsache, dass der moderne Mensch sich ausgehend vom Nahen Osten in Europa verbreitet hat: Je näher er in Richtung Naher Osten vorkommt, desto geringer werden die diesbezüglichen genetischen Unter-

1612 Vgl. Ralph, Peter/Coop, Graham (2013): The Geography of Recent Genetic Ancestry across Europe, in: PLoS Biol 11(5) e1001555. doi:10.1371/journal.pbio.1001555, Cambridge u. a. Ralph und Graham integrieren in ihr Forschungsprojekt Ergebnisse aus der Archäologie, der Linguistik, den Geschichtswissenschaften sowie der Molekularbiologie. Hauptsächlich verglichen sie mithilfe der Analyse von Genomsequenzen die genotypische Ähnlichkeit der heute in Europa lebenden Menschen: Je mehr Genomsequenzen zwischen verschiedenen Personen übereinstimmen bzw. je länger die übereinstimmenden Genomsequenzen sind, desto näher sind einzelne Personen miteinander verwandt.

1613 Eigene Darstellung nach: Cavalli-Sforza 1999, a. a. O., S. 81.

1614 Vgl. Cavalli-Sforza 1999, a. a. O., S. 41.

1615 Vgl. Cavalli-Sforza/Cavalli-Sforza 1994, a. a. O., S. 239. 
schiede. Auch dieses Faktum stellt so wiederum einen Beweis für die monozentrische Entwicklung des Menschen und damit gleichzeitig ein wichtiges Argument gegen die Wahrscheinlichkeit der Entstehung von unterschiedlichen ,Menschenrassen' dar. Denn sowohl die Menschenpopulationen im Nahen Osten als auch in Europa sind, trotz in der Gesamtbetrachtung zu vernachlässigender genetischer Unterschiede, genetisch nah verwandt. Dieses Ergebnis wird zusätzlich durch Analysen der menschlichen Sprachfähigkeit unterstützt: Diese ist bei allen Menschen in biologischer Hinsicht identisch. ${ }^{1616}$ Jeder Mensch besitzt folglich die gleiche Fähigkeit, eine komplexe Sprache in den ersten Lebensjahren zu erlernen, da bekanntermaßen die Fähigkeit zur Sprachadaption danach kontinuierlich nachlässt und verloren geht. ${ }^{1617}$ Demzufolge kann auch aufgrund der Sprachfähigkeit der Menschen aller Kontinente nur realitätsfern auf unterschiedliche kognitive Fähigkeiten spezifischer Menschenpopulationen gefolgert werden, da das Erlernen sowie die Kommunikation einer komplexen Sprache bei allen Menschen eine hohe kognitive Leistung voraussetzt. ${ }^{1618}$

Abschließend müssen noch einige weitere Faktoren bezüglich der menschlichen Verbreitung nach dem Out-of-Africa-Modell miteinbezogen werden: Der Aspekt des Zufalls sowie unsere kulturellen Präferenzen. ${ }^{1619}$ Diese beeinflussen die modernen Menschen beispielsweise bei der Partnerwahl aufgrund von phänotypischen Merkmalen, die je nach Kulturkreis stark divergieren. ${ }^{1620}$ Dies wirkt sich selbstverständlich gleichermaßen auf die Fortpflanzungswahrscheinlichkeit sowie die natürliche Selektion aus, die hierdurch beeinflusst werden. Demnach verdeutlicht auch diese Charakteristik, dass eine genetische Identität zwischen verschiedenen Individuen einer Population definitiv nicht realistisch ist, folglich auch keine sogenannten ,reinen Rassen', im Gegenteil: Die meisten Gruppen sind Produkte ihrer Kultur bzw. ihrer Gesellschaft (s. Kapitel 2, 4). ${ }^{1621}$ Vor diesem Hintergrund lässt sich wieder treffend der Beweis anführen, dass auch angebliche ,rassische“ Menschengruppen nichts anderes als Konstruktionen der Gesellschaft sind. ${ }^{1622}$ In diesem Zusammenhang kommentiert der Schriftsteller Steve Olson:

\section{„[Auch] [n] atürliche Selektion, genetischer Zufall und kulturelle Präferenzen bewirken, dass die körperlichen Merkmale verschiedener Gruppen sich auseinander entwickeln. [...] Unsere [heutige] DNA ist [folglich] ein Flickenteppich aus $\operatorname{der} D N A$ unserer Vorfabren." "623}

Weiterhin kann nun zusätzlich bestätigt werden, dass die Entwicklung des modernen Menschen im Vergleich zur Entwicklungszeit unserer archaischen Vorfahren

\footnotetext{
1616 Vgl. Cavalli-Sforza/Cavalli-Sforza 1994, a. a. O., S. 292 f.

1617 Vgl. Cavalli-Sforza/Cavalli-Sforza 1994, a. a. O., S. 292 f.

1618 Vgl. Cavalli-Sforza/Cavalli-Sforza 1994, a. a. O., S. 293.

1619 Vgl. Olson 2003, a. a. O., S. 67f.

1620 Vgl. Olson 2003, a. a. O., S. 68.

1621 Vgl. Olson 2003, a. a. O., S. 79.

1622 Vgl. Olson 2003, a. a. O., S. 79.

1623 Olson 2003, a. a. O., S. 68, 76.
} 
noch relativ jung ist und folglich noch in den ,Kinderschuhen' steckt. Auch für eine Ausbildung von Subspezies - um an das vorherige Kapitel anzuknüpfen fehlt bisher schlichtweg die Zeit für einen evolutiven Prozess der Differenzierung (s. Kapitel 5.2.2). Zusätzlich sind ebenso zwischen den einzelnen Menschenpopulationen weltweit zu viele genetische Verknüpfungen und Verbindungen - keinesfalls eine Isolation - zu identifizieren, was die hohe genetische Ähnlichkeit aller Menschen durch ständige Vermischungen des Genpools bestätigt. Geographische Barrieren können heute mit Flugzeugen, Schiffen, Automobilen oder dem Zugverkehr überwunden werden - Isolation ist nicht mehr existent, auch bei den letzten ,Ureinwohnern'.

„Die modernen Menschen sind jedoch als Spezies noch zu jung und baben sich allzu eifrig untereinander gekereuzt, um erhebliche genetische Unterschiede auszubilden. Genetiker haben zum Beispiel nie eine Mutation gefunden, die in einer ,Rasse' oder ethnischen Gruppe hundertprozentig vertreten wäre und in einer anderen bundertprozentig gefehlt bätte, und in Anbetracht unserer genetischen Geschichte werden sie eine solche auch nie finden. Genetisch gesehen existieren zwischen allen Menschen Überschneidungen. "1624

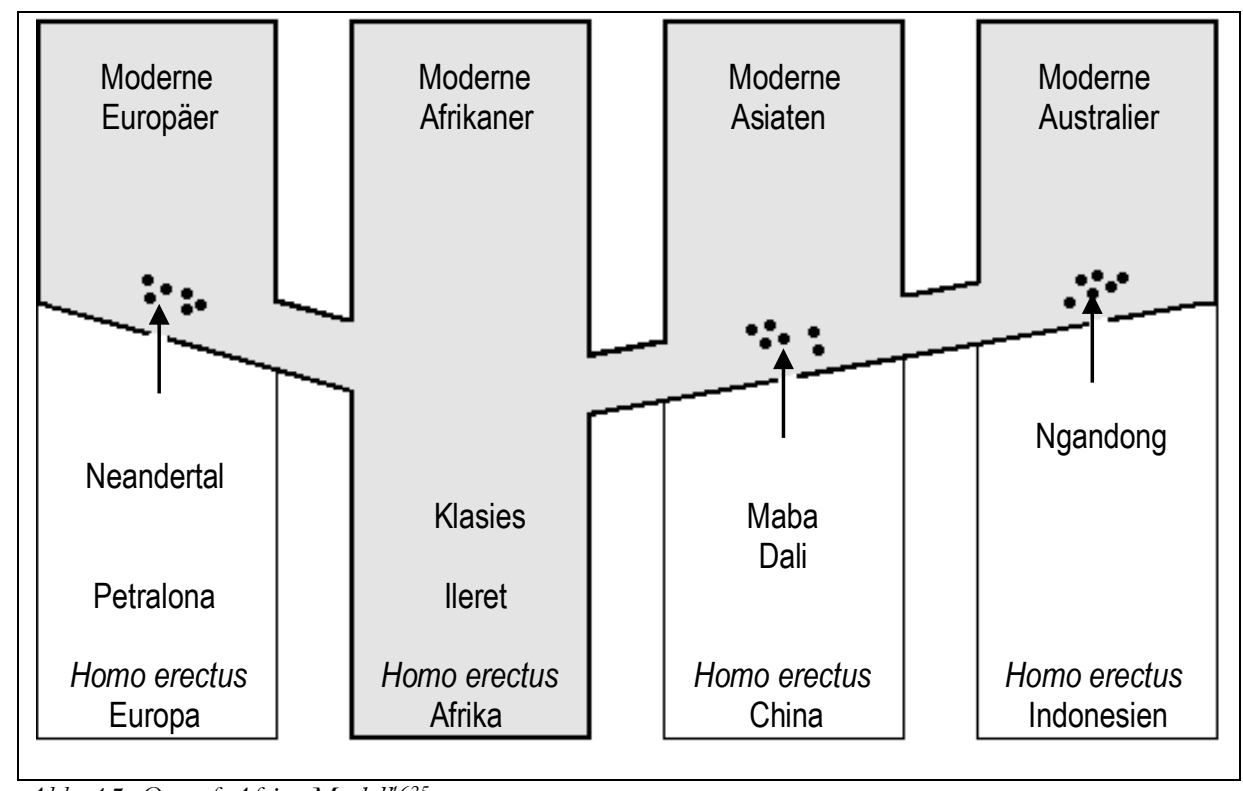

Abb. 15: Out-of-Africa-Modell ${ }^{1625}$

Die monozentrische Evolution des modernen Menschen ist demnach heute im Rahmen des Out-of-Africa-Modells am wahrscheinlichsten, obwohl diesbezüglich auch in Zukunft noch viele Forschungslücken zu schließen sind. ${ }^{1626}$ Zahlreiche

1624 Olson 2003, a. a. O., S. 79.

1625 Eigene Darstellung nach: Vgl. Bräuer 2004, a. a. O., S. 182.

1626 Vgl. Bräuer 2004, a. a. O., S. $182 \mathrm{f}$. 
genetische, serologische, biochemische und linguistische Daten sowie Stammbäume validieren diesen Befund aus wissenschaftlicher Perspektive. ${ }^{1627}$ Letztlich können diesbezüglich auch die zahlreichen Ausgrabungen in Süd- und Ostafrika als Beweismittel mit herangetragen werden, die aufgrund der Vielzahl sowie der zeitlichen Einordnung der Funde mithilfe biochemischer Analysen ebenfalls zu dem Fazit gelangen, dass sich ein monozentrischer Ursprung des Homo sapiens am wahrscheinlichsten darstellt. ${ }^{1628}$ Dies unterstützt darüber hinaus auch die vom modernen Menschen in den unterschiedlichen Kontinenten gezeigte hohe Anpassungsfähigkeit an verschiedene umweltbedingte Klimate. ${ }^{1629}$

Die vorhergehende Grafik visualisiert diese Erkenntnisse nochmals: Einzelne Vermischungen mit archaischen Vorfahren des modernen Menschen scheinen stattgefunden zu haben; der überwältigende Großteil des Homo sapiens stammt jedoch aus Afrika. Als Resümee folgt ein aus naturwissenschaftlicher Perspektive treffendes Fazit von Steve Olson:

„In gewisser Weise sind Details, wie es zur Entwicklung des modernen Menschen kam, unwichtig. Was als eine der tiefgreifendsten biologischen Erkenntnisse aller Zeiten zählen muss, ist die Einsicht in unsere bemerkenswerte genetische Ähnlichkeit. Etwa 7500 Generationen sind vergangen, seit unsere Vorfabren in der Savanne Ostafrikas lebten. In der Evolutionsgeschichte entspricht das einem kurzen Augenblick. Schon die Schimpansen, die auf einem einzigen Berg Afrikas leben, haben mebr als doppelt so viele $V$ arietäten in ibrer mitochondrialen $D N A$ als sämtliche [sieben] [...] Milliarden Menschen der Erde, weil es die heutigen Schimpansenarten schon wesentlich länger gibt als den modernen Menschen. [...] die Menschen [haben] sich im Laufe der vergangenen 150 000 Jahre nicht sonderlich verändert. Und ebendiese Schlussfolgerung haben die Genetiker aus unserer DNA gezogen. "1630

\subsection{4 ,Rasse ${ }^{6}$ - Missbrauch eines biologischen Fachbegriffs}

Die vorangegangenen Kapitel verdeutlichen, dass die genotypischen und phänotypischen Unterschiede zwischen einzelnen Menschenpopulationen nur als oberflächlich anzusehen sind, da die Spezies Homo sapiens untereinander tatsächlich relativ eng verwandt ist, trotz der Verteilung auf verschiedene Kontinente der Erde. ${ }^{1631}$ Nach dem Homo erectus vor etwa 1,5 Millionen Jahren gelang es dem Homo sapiens vor ungefähr 100.000 Jahren zum zweiten Mal, verschiedene Kontinente ausgehend von Afrika zu besiedeln. ${ }^{1632}$ Mit den archaischen Vorfahren gab es jedoch - wie das Beispiel des Neandertalers konkretisiert - wenn überhaupt nur wenige Vermischungen, demgegenüber aber vielfältige Überkreuzungen innerhalb der Populationen des modernen Menschen, was die heutige hohe Verwandt-

1627 Vgl. Henke/Rothe 1999, a. a. O., S. $283 \mathrm{ff}$.

1628 Vgl. Cavalli-Sforza/Cavalli-Sforza 1994, a. a. O., S. $98 \mathrm{ff}$.

1629 Vgl. Cavalli-Sforza/Cavalli-Sforza 1994, a. a. O., S. $100 f$.

1630 Olson 2003, a. a. O., S. 48, 51.

1631 Vgl. Olson 2003, a. a. O., S. 14.

1632 Vgl. Markl 2006, a. a. O., S. 852f. 
schaftsquote sowie die Vielfalt des Homo sapiens erklärt. ${ }^{1633}$ Selbstverständlich sind Differenzen zwischen einzelnen Menschen vorhanden - alle modernen Menschen sind genetisch gesehen Individuen, mit teilweiser Ausnahme genetisch eineiiger Zwillinge. Woher kommen diese Variationen? Eine wichtige Rolle spielen in diesem Zusammenhang genetische Komponenten, wie Mutation, Rekombination und die Einwirkung von Umwelteinflüssen (s. Kapitel 5.3, 5.4). Da die heutigen Menschen von der idealtypischen, evolutionsbiologischen Annahme der Panmixie weit entfernt sind, entstehen durch diesen kulturellen bzw. gesellschaftlichen Einfluss Unterschiede und Variationen in der Fortpflanzung. ${ }^{1634}$ Auch aufgrund des Fehlens von unüberwindbaren geographischen Isolationsbarrieren sowie unscharfen Grenzziehungen kommt es zur Vermischung von Genpools und damit zum Einbringen von immer neuen genetischen Variationen und Kombinationen. ${ }^{1635}$ Doch trotz des Vorhandenseins dieser genetischen Unterschiede - die aus der Perspektive des gesamten Evolutionsprozesses vollkommen unbedeutend erscheinen - gehören alle menschlichen Populationen zu den modernen, in der Gegenwart lebenden Menschen der Spezies Homo sapiens. ${ }^{1636}$ Weiterhin muss beachtet werden, dass ohne Variation und Diversität keine bzw. eine natürliche Selektion - Evolution - nur eingeschränkt möglich wäre. ${ }^{1637}$ Der moderne Mensch ist und bleibt ein Produkt der Evolution, wird jedoch ebenso maßgeblich beeinflusst von seiner menschlichen Sozialisation, seinem kulturellen Hintergrund sowie zahlreichen Umwelteinflüssen. ${ }^{1638}$ Insbesondere der kulturelle Hintergrund scheint für die Merkmalsentwicklung und -ausprägung des modernen Menschen entscheidend zu sein (s. Kapitel 2, 4). ${ }^{1639} \mathrm{Um}$ vor diesem Hintergrund wieder an die theoretischen Überlegungen Charles Darwins anzuknüpfen: Der Mensch gilt als der ,Angepasstere' seiner Umwelt, da er sich mithilfe seiner Erfindungen, seiner Entdeckungen, seines Fortschritts und seiner enormen geistigen Leistung an seine Lebenswelt angepasst hat - nicht weil er der physisch ,Stärkere“ ist, der im ,Kampf ums Dasein` gegenüber weiteren Organismen ,in der Schlacht' siegreich war. ${ }^{1640}$

Jeder Mensch ist und bleibt aufgrund der hier skizzierten phänotypischen und genotypischen, evolutionsbedingten Variationen einzigartig, was auch die heterogene Zusammensetzung der einzelnen Kontinente bestätigt. ${ }^{1641}$ Selbst die genetischen Informationen von Eltern und deren Nachkommen zeigen Unterschiede in mehreren Genen. Nicht vergessen werden darf in diesem Zusammenhang aber-

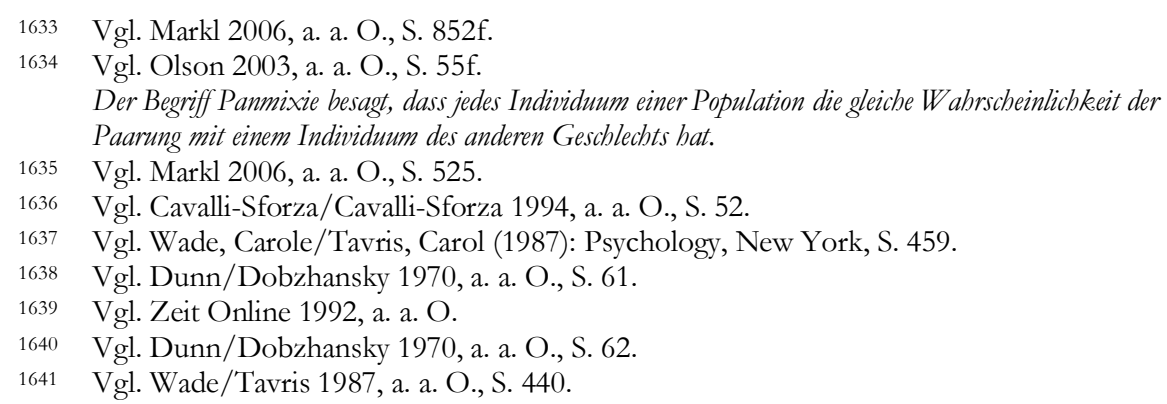


mals der Zeitfaktor: Da keine menschliche Population lange Zeit isoliert war und folglich auch keine schwerwiegenden Variationen ausbilden konnte, spricht auch der Zeitfaktor eindeutig gegen die Existenz menschlicher Subspezies. ${ }^{1642}$ Der moderne Mensch gilt vielmehr als ,[...] sehr junger Zweig am Stammbaum der Wirbeltiere“"1643. Vor diesem Hintergrund zeigt sich die irrige und vollkommen unrealistische Annahme der rassistischen Ideologie, den Menschen in einzelne Subspezies bzw. ,Rassen' zu klassifizieren: Da sich alle Menschen als Individuen genound phänotypisch voneinander unterscheiden, müsste jeder Mensch theoretisch eine eigene ,Rasse ${ }^{6}$ darstellen. ${ }^{1644}$, „[...] wenn man das aber einräumt, ist der Rassebegriff ad absurdum geführt. Es ist [folglich] nicht nur bei [menschlichen] Individuen, sondern auch bei ganzen Gruppen schwierig, sie einer Rasse zuzuordnen. "1645 Darüber hinaus fehlen eindeutige Kriterien der ,Rasse'-Klassifikation von Menschen - allein phänotypische Merkmale wie Haut-, Haar- oder Augenfarbe reichen hierfür nicht aus (s. Kapitel 5.2.2). ${ }^{1646}$ In der Folge zeigt sich abermals, dass eine Klassifizierung von Menschen in ,Rassen' nicht nur schwierig ist, sondern vollkommen an der Realität wissenschaftlicher Erkenntnisse vorbei geht. Hier wird seitens des biologistischen Rassismusphänomens - ob direkt oder indirekt - ein biologischer Fachterminus bewusst fehlinterpretiert und umgedeutet.

Die Annahme der Existenz von sogenannten ,reinen Rassen“ des Menschen kann ebenfalls auf den Scheiterhaufen der Naturwissenschaften verbannt werden. Es gab ursprünglich und wird auch in Zukunft nie eine Population von Menschen existieren, deren Allelkombinationen aller Gene vollkommen homozygot bzw. identisch sind. ${ }^{1647}$ Ein Rückblick auf die Weltgeschichte lässt sofort erkennen, dass auch bisher nur Mischungen von Menschengruppen existiert haben: „Die Menschheit war immer eine Mischlingsgesellschaft und ist es nach wie vor."1648 Auch Versuche der Inzucht, der Einheitlichkeit sowie der Erbkontrolle aus der Vergangenheit haben eindeutig bewiesen, dass die Existenz von ,reinen Rassen“ ein irreführendes Gedankenkonstrukt bleibt. ${ }^{1649}$ Somit ist die These der Existenz von sogenannten ,Volksgruppengenen', der sich unter anderem Thilo Sarrazin mit seinem sogenannten ,Basken-' bzw. ,Judengen' bedient, zum Scheitern verurteilt. ${ }^{1650}$ Alle menschlichen Populationen bewahren in ihrem Genpool Spielräume von genetischen Varianzen, die, wie eben schon bemerkt, den Evolutionsprozess

\footnotetext{
1642 Vgl. Zeit Online 1992, a. a. O.

1643 Markl 2006, a. a. O., S. 857.

1644 Vgl. Dunn/Dobzhansky 1970, a. a. O., S. 105.

1645 Dunn/Dobzhansky 1970, a. a. O., S. 105.

1646 Vgl. Cavalli-Sforza 1999, a. a. O., S. 43.

1647 Die Genetik differenziert zwischen homozygoten (reinerbigen) Allelkombinationen, bei denen die Allele auf dem mütterlichem sowie dem väterlichem Chromosom jeweils identisch sind, und heterozygoten Allelkombinationen, bei denen die Allele auf mütterlichem sowie väterlichem Chromosom jeweils differieren. Vgl. Janning/Knust 2008, a. a. O., S. $491 \mathrm{f}$.

1648 Dunn/Dobzhansky 1970, a. a. O., S. 106.

1649 Vgl. Dobzhansky 1973, a. a. O., S. 44.

1650 Vgl. Zeit Online 1992, a. a. O.
} 
auf der Grundlage der natürlichen Selektion erst ermöglichen. ${ }^{1651}$ Grundlage ist und bleibt der Polymorphismus, die genetische Vielfalt: Ein Gen existiert in mehreren Varianten. ${ }^{1652}$

Das ,Rassekonstrukt ${ }^{6}$ wird zusammenfassend also eindeutig durch die neuere anthropologische Forschung sowie die Molekulargenetik widerlegt und ihm auf der Grundlage der menschlichen Evolution das Existenzrecht abgesprochen. „Die Genforschung ist dabei, mit unserem althergebrachten, unseligen Rassenbegriff aufzuräumen." 1653 Aufgrund der vielfältigen Überlappungen ist eine eindeutige Kategorisierung des modernen Menschen unmöglich. Vor diesem Hintergrund ist auch die UNESCO-Empfehlung der Alternativbenennung von Menschengruppen in ,ethnische Gruppen' als tendenziell problematisch anzusehen, da dies eigentlich nur einen neuen Begriff ,im alten Gewand', eine begriffliche Verschleierung darstellt (s. Kapitel 1).

Festzuhalten bleibt demzufolge, dass sich die Evolutionsgeschichte des Menschen sehr viel komplexer darstellt, als es das sogenannte ,Rassekonzept ${ }^{6}$ vorsieht. ${ }^{1654}$ Um diesbezüglich mit den Worten Cavalli-Sforzas zu enden:

„Tatsächlich ist bei der Gattung Mensch eine Anwendung des Begriffs ,Rasse“ völlig unsinnig. "1655 „Für mich ist er völlig willkërrlich. Je nachdem, welche Kriterien man zugrunde legt, lässt sich behaupten, es gebe drei, zehn oder fünfiig Rassen. Vergleicht man die Gene verschiedener Populationen, so lassen sich keine Klaren, sauberen Abgrenzungen finden. Man beobachtet eine endlose Reibe von Variationen. Keine menschliche Gruppe ist biologisch rein [...]? Das gibt es nicht beim Menschen. Es gibt immer einen bestimmten Grad an Mischung. " "656

\subsection{Rassistische Ressentiments aus molekulargenetischer Perspektive}

Der wichtigste Beweis gegen biologistisch-rassistische Vorurteile ist im Grundbaustein des menschlichen Lebens, in unseren Erbinformationen - der DNA - zu finden. Diese enthält sämtliche Informationen den Aufbau, die Struktur, die Mechanismen und die vielfältigen Funktionen den menschlichen Organismus betreffend. Demzufolge ist die DNA nicht nur der Schlüssel zur Encodierung unserer vielfältigen Stoffwechsel- und Lebensvorgänge, sondern ebenfalls ein wichtiger Nachweisfaktor bezüglich der Vergangenheit und Geschichte der menschlichen Entwicklung. Immer neuere und modernere Untersuchungsmethoden haben es bis ins 21. Jahrhundert möglich gemacht, nun endlich ausgehend von der DNA Stoffwechselmechanismen, Krankheiten oder organische Störungen zu entschlüs-

1651 Vgl. Dobzhansky 1973, a. a. O., S. 44.

1652 Vgl. Cavalli-Sforza/Cavalli-Sforza 1994, a. a. O., S. 368.

1653 Olson 2003, a. a. O., S. 17.

1654 Vgl. Kattmann 1999, a. a. O., S. 78.

1655 Cavalli-Sforza/Cavalli-Sforza 1994, a. a. O., S. 367.

1656 Zeit Online 1992, a. a. O. 
seln, so dass diese gemildert oder sogar korrigiert und behoben werden können. Auf dieser Grundlage können viele grundsätzliche Theorien der biologischen Forschung heute mithilfe der molekularen Analyse der DNA endgültig validiert und bestätigt werden. „Die DNA ist [...] das genetische Material [...]“1657 sämtlicher lebender Organismen.

„Das Vorhandensein von Nucleinsäuren ist ein universelles Charakteristikum der belebten Natur. Obne Nucleinsäuren gibt es auf unserem Planeten kein Leben, ja man kann das Nucleinsäure Molekül als die Grundsubstanz bezeichnen, die Leben definiert." "658

Die DNA besteht aus einem Polymer von Einzel-Bausteinen, den sogenannten Nukleotiden. ${ }^{1659}$ Diese bilden durch Verknüpfungen die bekannte DoppelhelixStruktur der DNA, die erstmals von den Biochemikern Francis Crick und James Watson im Jahr 1953 wissenschaftlich bestätigt wurde. ${ }^{1660}$

Damit einhergehend können auf der DNA unterschiedliche Genorte, sogenannte Genloci, differenziert werden, die die Orte von spezifischen Genen in einer DNA-Sequenz darstellen. ${ }^{1661}$ „Ein Gen ist ein Abschnitt der DNA, der ein funktionelles Produkt codiert." 1662 Gene codieren bestimmte Proteine - Strukturund Baustoffe des Organismus -, wie beispielsweise Enzyme, Hormone oder Strukturproteine, die ihrerseits für die Ausbildung verschiedener geno- und phänotypischer Merkmale verantwortlich sind. Jedoch enthält die DNA neben den codierenden Sequenzen auch nicht-codierende Sequenzen. ${ }^{1663}$ Beispielsweise „Pseudogene sind nicht mehr funktionierende Gene, die ursprünglich durch Genduplikation entstanden sind und anschließend durch Mutationen [...] modifiziert wurden. Sie bilden sozusagen den ,Mülleimer der Evolution'“"1664 Darüber hinaus übernehmen die DNA bzw. die dort verorteten Gene noch weitere Aufgaben im Organismus, wie der folgende tabellarische Überblick exemplarisch illustriert.

1657 Markl 2006, a. a. O., S. 341.

1658 Buselmaier, Werner/Tariverdian, Gholamali (2007): Humangenetik, 4. Auflage, Heidelberg, S. 2.

1659 Die Nukleotide sind aus einer Phosphatgruppe, einem Pentosezucker - der sogenannten Desoxyribose - und einer stickstoffhaltigen Base - den Pyrimidinbasen Cytosin und Thymin sowie den Purinbasen Adenin und Guanin - aufgebaut. Jeweils zwei Phosphat-Pentose-Polymere sind miteinander antiparallel verknüpft. Die jeweils nach innen zeigenden Basen der beiden Polymere binden komplementär über sogenannte Wasserstoffbrückenbindungen. Eine Bindung erfolgt immer komplementär, entweder nur zwischen den Basen Adenin und Thymin - die zwei Wasserstoffbrückenbindungen ausbilden - oder nur zwischen den Basen Guanin und Cytosin-diese bilden drei Wasserstoffbrückenbindungen aus. Mitbilfe der W asserstoffbrückenbindungen entsteht so zwischen beiden Polymer-Strängen eine Art, Strickleiter; die durch ibre Windungen die bekannte Doppelhelix-Struktur der DNA konstruiert. Vgl. Markl 2006, a. a. O., S. $341 \mathrm{ff}$.

1660 Vgl. Markl 2006, a. a. O., S. 344.

1661 Vgl. Munk 2010, a. a. O., S. 254.

1662 Buselmaier/Tariverdian 2007, a. a. O., S. 9.

1663 Vgl. Buselmaier/Tariverdian 2007, a. a. O., S. 54ff.

1664 Buselmaier/Tariverdian 2007, a. a. O., S. 11. 
Tab. 22: Biologische Aufgaben der DNA ${ }^{1665}$

\begin{tabular}{|ll|}
\hline Replikation & Präzise Vervielfältigung der DNA während der Zellverdopplung \\
\hline Speicherung & Speicherung der gesamten notwendigen biologischen Funktion \\
\hline Weitergabe & Weitergabe der Information an die Zelle \\
\hline Stabilität & $\begin{array}{l}\text { Aufrechterhaltung der Strukturstabilität, um Erbänderungen (Mutationen) } \\
\text { zu minimieren }\end{array}$ \\
\hline
\end{tabular}

Die DNA hilft außerordentlich bei der Beweisführung gegen biologistische Argumentationen des Rassismus, wie die folgenden Kapitel schwerpunktmäßig anhand multipler Kriterien erörtern werden. Anhand des Aufbaus, der Struktur sowie der Replikations- und Vererbungsmechanismen der DNA kann unmissverständlich demonstriert werden, dass - mit Ausnahme von eineiigen Zwillingen sämtliche Menschen zum einen aufgrund von genetischen Variationen biologische Individuen darstellen und folglich zum anderen keine standardisierte und transparente Grundlage für eine Klassifizierung bzw. Hierarchisierung von Menschen in ,reine Rassen' erzeugt werden kann. Insbesondere die vielfältigen Wechselwirkungen zwischen Umwelt und Genen auf molekularer Ebene sollen aufzeigen, dass bei den meisten Vererbungsprozessen von Generation zu Generation nicht nur die genetischen Abläufe relevant sind, sondern ebenso die Einflüsse der umgebenden Umweltfaktoren. Diese Umweltfaktoren, die das menschliche Leben nachhaltig beeinflussen, erscheinen dabei vielfältig. Sie umfassen nach der quantitativ-genetischen Theorie definitorisch ein breites Spektrum: Abiotische - physikalische und chemische - und biotische - belebte - Umweltfaktoren gehören ebenso dazu, wie Sozialisation, Gesellschaft, familiäres Umfeld, Peergroups und viele weitere Aspekte. ${ }^{1666}$ Demnach sind auch aufgrund dieser variablen Umgebungsbedingungen jegliche nachhaltigen Klassifikationsversuche des Homo sapiens schon von Vornherein unrealistisch.

In diesem Zusammenhang ist insbesondere auf das Human-Genome-Project hinzuweisen. Das am 01. Oktober 1990 gestartete, internationale Projekt zur Entschlüsselung des menschlichen Genoms konnte am 14. April 2003 mit der Sequenzierung von 99,99 Prozent der 3,08 Milliarden Basen der menschlichen DNA abgeschlossen werden. ${ }^{1667}$ Der Abschlussbericht stellt fest: „Nach dem gegenwärtigen Stand unseres Wissens enthält das menschliche Genom 3,08 Milliarden Basen und 20.000 bis 25.000 proteinkodierende Gene." 1668 Vor diesem Hintergrund wurden im Rahmen von HUGO auch einige klassische Modellorganismen der Biologie sequenziert, wie beispielsweise das Bakterium Escherichia coli, die Taufliege Drosophila melanogaster oder die Hausmaus Mus musculus. ${ }^{1669}$ Darüber hinaus bestätigte HUGO eindrucksvoll, dass der Genotyp des modernen Menschen weltweit

\footnotetext{
1665 Eigene Darstellung nach: Vgl. Buselmaier/Tariverdian 2007, a. a. O., S. 7.

1666 Vgl. Plomin, Robert et al. (1999): Gene, Umwelt und Verhalten. Einführung in die Verhaltensgenetik, Bern u. a., S. 214.

1667 Vgl. Buselmaier/Tariverdian 2007, a. a. O., S. 4.

1668 Buselmaier/Tariverdian 2007, a. a. O., S. 4.

1669 Vgl. Buselmaier/Tariverdian 2007, a. a. O., S. 4.
} 
zu 99,9 Prozent identisch ist: ${ }^{1670}$ Elementare, pseudowissenschaftliche ,Rassenunterschiede' sind nicht existent! Viele rassistische Amateur-Wissenschaftler beziehen sich im 21. Jahrhundert bezüglich der Existenz von speziellen ,Volksgruppengenen' sowie menschengruppenspezifischen Genfunktionen auf die Projektergebnisse von HUGO. Diesbezüglich ist jedoch an dieser Stelle nachdrücklich darauf hinzuweisen, dass HUGO zwar für die Entschlüsselung des genetischen Codes des Menschen sowie für die weitere molekulargenetische Forschung essentielle Erkenntnisse gewonnen hat, jedoch nichts über Bedeutung, Regulation und Funktion der diagnostizierten Gene aussagt. ${ }^{1671}$ Behauptungen bezüglich der auf HUGO aufbauenden Lösung aller zukünftigen Erbkrankheiten - mit dem Ziel der ,reinen Rasse - gehören so zu pseudogenetischen Spekulationen. ${ }^{1672}$

Weiterhin können von Seiten der Molekulargenetik aufgrund neuerer Forschungserkenntnisse insgesamt fünf grundlegende, genetische Evolutionsfaktoren differenziert werden, die die Veränderung der Allelfrequenz eines Genpools, und damit einer Population, verursachen - die Mikroevolutionen. Die größte Bedeutung kommt der sogenannten genetischen Drift sowie der natürlichen Selektion zu, auf die in den vorherigen Kapiteln schon hingewiesen wurde (s. Kapitel 5.1). ${ }^{1673}$ Die natürliche Selektion verläuft dabei immer vorteilhaft: Vorteilhafte genotypische Veränderungen werden über mehrere Generationen angehäuft und können sich folglich mit größerer Wahrscheinlichkeit vermehren. ${ }^{1674}$ Die natürliche Selektion ist dabei der einzige genetische Evolutionsfaktor der ausschließlich vorteilhafte Anpassungen von Organismen an ihre Umwelt bewirkt - alle anderen Faktoren wirken entweder positiv, neutral oder negativ. ${ }^{1675}$ Die genetische Drift hingegen bezeichnet die zufällige Veränderung der Allelfrequenz einer Population durch Zufallsabweichungen: Je kleiner beispielsweise eine Stichprobe an Individuen einer Population ist, desto größer erscheinen Zufallsabweichungen von einem idealisierten Ergebnis; je größer die Population hingegen ist, desto genauer respektive identischer ist der Genpool bzw. desto identischer ist ein dort vorhandenes Individuum mit dem Genpool der Population, da relativ gesehen weniger Zufallsabweichungen vorhanden sind. ${ }^{1676}$ Im Zusammenhang mit der genetischen Drift ist exemplarisch noch der sogenannte Flaschenhalseffekt $\mathrm{zu}$ nennen, der durch Veränderungen der Umwelt - beispielsweise Überschwemmungen, Vergletscherungen oder Dürreereignisse - eine drastische Reduzierung einer Population und damit auch deren Genpool bewirkt, da im Verlauf dieser katastrophalen Ereignisse viele Individuen sterben, wie die folgende Grafik verbildlicht. Der Flaschenhalseffekt verändert so den Genpool für nachfolgende Generationen und damit

\footnotetext{
1670 Vgl. Buselmaier/Tariverdian 2007, a. a. O., S. 4.

1671 Vgl. Graw 2010, a. a. O., S. 619.

1672 Vgl. Graw 2010, a. a. O., S. 619.

1673 Vgl. Markl 2006, a. a. O., S. 528f.

1674 Vgl. Markl 2006, a. a. O., S. 529.

1675 Vgl. Markl 2006, a. a. O., S. 529.

1676 Vgl. Markl 2006, a. a. O., S. 529.
} 
zusammenhängend deren genetische Variabilität, da durch den Flaschenhalseffekt eine Vielzahl an Allelen verloren gegangen ist. ${ }^{1677}$

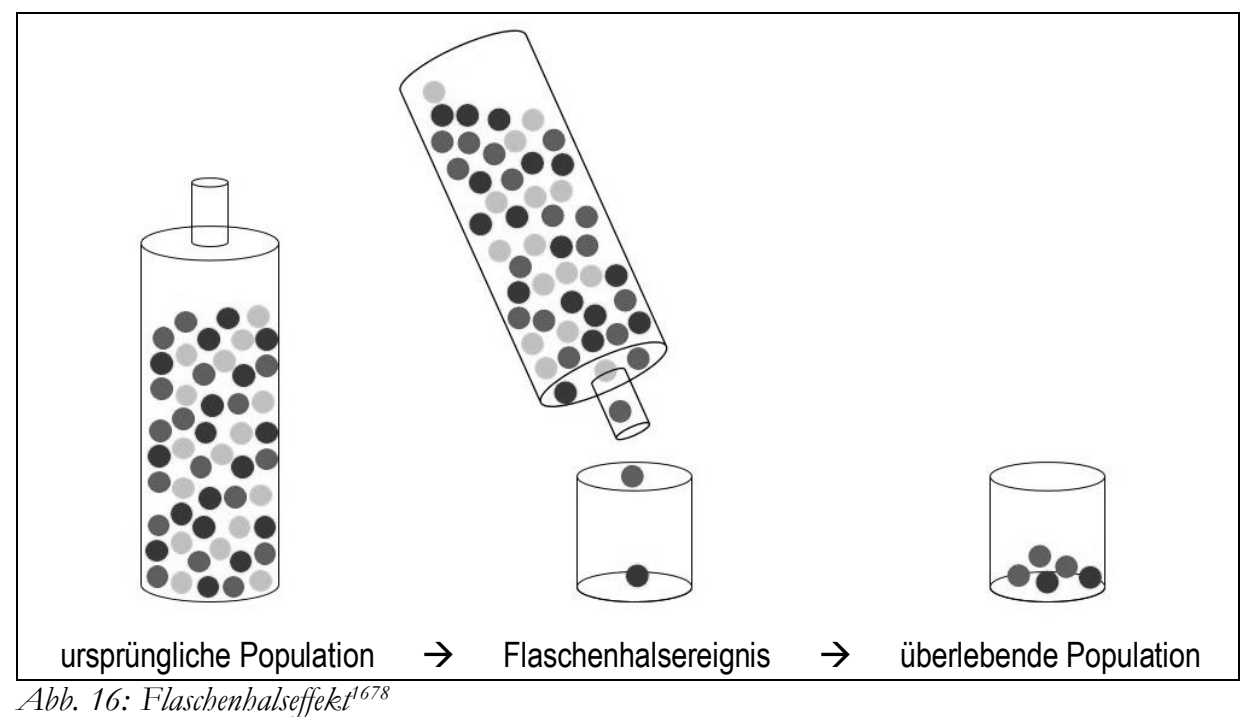

Der sogenannte Genfluss ist schließlich ein weiterer essentieller Evolutionsfaktor der Molekulargenetik. Er bezeichnet den genetischen Austausch von Allelen aufgrund von Wanderungsbewegungen zwischen Individuen oder Populationen. ${ }^{1679}$ Das Phänomen des Genflusses verringert so in der Folge des ständigen Austausches die genotypischen Unterschiede zwischen Populationen, was insbesondere auf die Evolution des Menschen zutrifft. Somit wäre ein weiteres Argument gegen den biologistischen Rassismustypus identifiziert: Menschen sind sich auf der Grundlage des Genflusses genotypisch untereinander sehr ähnlich. ${ }^{1680}$ Die ultimative Basis sämtlicher hier genannter Evolutionsfaktoren bleibt jedoch die Mutation als integrativer Grundbaustein sämtlicher Faktoren der Mikroevolution. Sowohl die natürliche Selektion, die genetische Drift, der Flaschenhalseffekt als auch der Genfluss sind nicht möglich ohne die ursächliche Entstehung von Variationen des Genpools durch den Prozess der Mutation.

„Sicherlich ist auf lange Sicht Mutation an sich sebr bedeutend für die Evolution, weil sie der Ursprung jener genetischen Vielfalt ist, die als Ausgangsmaterial für die natürliche Selektion [, den genetischen Drift und den Genfluss] dient. "1681

\footnotetext{
1677 Vgl. Markl 2006, a. a. O., S. 530.

1678 Eigene Darstellung nach: Vgl. Markl 2006, a. a. O., S. 530.

1679 Vgl. Markl 2006, a. a. O., S. 531.

1680 Vgl. Markl 2006, a. a. O., S. 531.

1681 Markl 2006, a. a. O., S. 531.
} 
Der weitere Verlauf wird sich ausführlich mit dem bedeutendsten molekulargenetischen Mechanismus der Evolution, der Mutation, auseinandersetzen, die zugleich die Vielfalt der modernen Menschen ermöglicht. Was sind Mutationen? Welche verschiedenen Mutationsmodi existieren? Wie generieren Mutationen genotypische Vielfalt und Individualität? Welche Bedeutung haben die unterschiedlichen Umwelten an der Entstehung und Vererbung von Mutationen bzw. der genetischen Information? In welchem Zusammenhang stehen rassistische Theorien und Mutationsereignisse? Im folgenden Abschnitt soll zuerst die Bedeutung von Mutationen für die Evolution, die Vielfalt und die Einzigartigkeit jedes Menschen grundlegend erläutert werden, um damit schon zu Beginn sämtliche biologistisch-rassistischen Forderungen nach einer Existenz von genetischen ,Rassen` als realitätsfern zu klassifizieren. Hiernach werden einzelne Alternativen visualisiert und diskutiert, die das Zustandekommen sowie das Wirkungsmuster von Mutationen analysieren. Abschließend liegt ein weiterer Fokus auf der Beteiligung und dem Einfluss der spezifischen Umwelten auf die Vererbung von Genen bzw. von genotypischen und phänotypischen Merkmalen und damit zusammenhängend auf der Frage der Existenz von sogenannten menschlichen ,Rassen“.

\subsubsection{Mendel-Regeln als theoretische Grundlage der modernen Genetik}

Als Basis der heutigen Vererbungslehre können die theoretischen Grundlagen von Naturforscher Johann Gregor Mendel zur Vererbung von Merkmalen - der GenBegriff war damals noch nicht existent - herangezogen werden. ${ }^{1682}$ Er erforschte „[...] die grundlegenden Prinzipien der Vererbung [... “"1683. Anhand dieser können im weiteren Verlauf Unregelmäßigkeiten und Abweichungen in Erbgängen illustriert werden. Mendel entdeckte, dass für alle Gene, welche beispielsweise die Augenfarbe eines Menschen codieren, zwei alternative Zustandsformen existieren, die sogenannten Allele. Sie entscheiden durch ihre Wechselwirkungen die Ausprägungsform eines bestimmten Merkmals. ${ }^{1684}$ Unterschieden werden können sogenannte dominante und rezessive Allele: „Wenn die beiden Allele unterschiedlich sind, dann wird eines, und zwar das dominante Allel voll exprimiert; das andere, das rezessive Allel, zeigt keinerlei Ausprägung. Man spricht in diesem Zusammenhang auch von einem dominant-rezessiven Erbgang.“1685 Johann Gregor Mendels Ergebnisse können auf die heutige molekulargenetische Forschung übertragen werden: Gene befinden sich auf vordefinierten Orten - sogenannten Loci - der

\footnotetext{
1682 Für detailliertere Beschreibungen und Erläuterungen zu den Vererbungsexperimenten Gregor Mendels sowie zu deren Ergänzungen des 20. und 21. Jabrhunderts ist auf die folgende Fachliteratur zu verweisen: Vgl. Janning/Knust 2008, a. a. O., S. 53ff. | Vgl. Munk 2010, a. a. O., S. 267ff. | Vgl. Markl 2006, a. a. O., S. 294ff. | Vgl. Graw 2010, a. a. O., S. 456ff.

1683 Markl 2006, a. a. O., S. 294.

1684 Vgl. Spiegel Online (2009): „Augenfarbe-Vorhersage: Ich schau Dir in die DNA, Kleines“, in URL: http://www.spiegel.de/wissenschaft/natur/augenfarbe-vorhersage-ich-schau-dir -indie-dna-kleines-a-612361.html <07.02.2013>.

1685 Markl 2006, a. a. O., S. 297.
} 
DNA bzw. der menschlichen Chromosomen. ${ }^{1686}$ Die DNA-Sequenz und somit auch der Informationsgehalt können an diesen Loci jedoch leicht variieren, so dass in der Folge unterschiedliche Eigenschaften induziert werden. ${ }^{1687}$

Somit konnte Mendel aufzeigen, dass das äußere Erscheinungsbild von Individuen, der sogenannte Phänotyp, nicht mit der genotypischen Ausstattung und Ausprägung identisch ist. Folglich können auch, auf die sogenannte ,Rasseproblematik' übertragen, mithilfe phänotypischer Merkmale von Menschen, wie Haar-, Haut- oder Augenfarbe, keine Rückschlüsse auf den Genotyp eines Individuums und damit auf eine angebliche ,Rasse ${ }^{6}$ ermöglicht werden. Hinzukommend muss aus der Perspektive des 21. Jahrhunderts eingrenzend konstatiert werden, dass die Mendelschen Vererbungsregeln nicht bei allen Vererbungsgängen identisch bzw. gleichmäßig angewandt werden können, da sich Johann Gregor Mendel vornehmlich auf einfache Genotyp-Phänotyp-Beziehungen konzentrierte. ${ }^{1688}$ Auch neue Erkenntnisse der Epigenetik lassen Abweichungen im mendelschen Vererbungsweg vermuten (s. Kapitel 5.3.5). Es zeigt sich so, dass die Vererbungssystematik nach Mendel vielfachen Einflüssen und Eventualitäten unterworfen ist, die zu genetischen Variationen führen können. Des Weiteren muss diesbezüglich abermals festgestellt werden, dass sich Mendels Versuche mit Nutzpflanzen keinesfalls ohne Modifizierungen auf den menschlichen Vererbungsweg übertragen lassen, wie die nachfolgenden Betrachtungen von Mutationserscheinungen aufzeigen. ${ }^{1689}$ Beispielsweise ist auch die Vererbung von menschlichen Erbkrankheiten nicht uneingeschränkt mit der mendelschen Systematik erklärbar. ${ }^{1690}$ Die von vielen biologistisch-rassistisch argumentierenden Theoretikern herangezogene Schlussfolgerung, dass Nachkommen die identischen bzw. ,reinen' Erbinformationen der Eltern übertragen bekommen, ist demzufolge schon aus der mendelschen Perspektive des 19. Jahrhunderts unrealistisch.

\subsubsection{Mutationen als Voraussetzung der Evolution}

Mithilfe der Molekulargenetik können die Grundlagen der Weiterentwicklung und Anpassung von Organismen an ihre Lebens- und Umweltbedingungen auf der molekularen Ebene unserer Erbinformationen veranschaulicht werden. Unsere

\footnotetext{
1686 Vgl. Markl 2006, a. a. O., S. 297.

1687 Vgl. Markl 2006, a. a. O., S. 297.

1688 Vgl. Markl 2006, a. a. O., S. 303.

Beispielsweise existiert das Phänomen der unvollständigen Dominanz, ausgelöst durch einen sogenannten intermediären Erbgang, der ein zwischen den beiden Allelen liegendes Erscheinungsbild zur Folge hat. Auch die Möglichkeit von sogenannten multiplen Allelen muss beachtet werden, bei der ein Gen mehr als zwei Ausprägungsformen enthält, wie beispielsweise beim ABO-Blutgruppensystem. Ebenfalls Pleiotropie - ein Gen zeigt demnach mehrere phänotypische Ausprägungen -, Epistase - die Überlagerung der phänotypischen Ausprägung eines Gens durch andere Gene -, die polygene Vererbung - mehrere Gene wirken bei der Vererbung sogenannter quantitativer Merkemale zusammen - oder die Umwelt beeinträchtigen die Mendel-Systematik. So folgen auch mtDNA, maternal vererbte Eigenschaften oder der meiotische Drift den Mendel-Regeln nur mit Abweichungen. Vgl. Markl 2006, a. a. O., S. $303 \mathrm{ff}$. 
DNA - und folglich auch die in ihr gespeicherten genetischen Informationen in Form unterschiedlicher Gene - verändert sich im Laufe der Zeit. Grundlage dieser Variationen sind Mutationen, beispielsweise Veränderungen der Nukleotidsequenz der DNA, die teilweise an die nachfolgenden Generationen vererbt werden können. ${ }^{1691}$

„Gene frequencies change over time. Mutations supply the raw material by generating new allels and even new genes, when whole regions are duplicated. Thus, mutation is a key ingredient of evolution. Without it, evolution would soon come to a standstill. "1692

Differenziert werden können allgemein gesehen sogenannte somatische Mutationen - Mutationen in unseren Körperzellen, die nicht an nachfolgende Generationen vererbt werden - und sogenannte generative Mutationen, das heißt Mutationen in unseren Geschlechtszellen, die an nachfolgende Generationen vererbt werden können, was oftmals im Phänotyp ersichtlich wird. ${ }^{1693}$ Die meisten somatischen Mutationen gehen folglich mit dem Tod eines Organismus verloren, da sie nicht vererbbar sind. ${ }^{1694}$ Wie Luigi Luca Cavalli-Sforza im vorangegangenen Zitat schon diagnostiziert, stellen Mutationen nicht nur bloße Veränderungen unserer DNA dar, sondern sind der eigentliche Schlüssel unserer evolutiven Geschichte. ${ }^{1695}$ Mutationen sind ursächlich dafür verantwortlich, dass sich der Genotyp von Organismen über Generationen hinweg durch einzelne Mutationsereignisse verändert, die in ihrer Gesamtheit den schrittweisen, evolutiven Veränderungs- und Weiterentwicklungsprozess von Organismen bedingen. Sie treten meist spontan und zufällig auf. ${ }^{1696}$

„Eine Mutation ist ein Schuss ins Blaue. Der Zufall bestimmt, wo er treffen und wie er ein Gen verändern wird. " 697

Alle Organismen sind demzufolge aufgrund der individuellen Abfolge von Mutationen einzigartig. Jedes neugeborene menschliche Kind weist in seiner DNA etwa 100 Mutationen im Vergleich zur ursprünglichen parentalen DNA aus Ei- und Samenzelle auf. 1698 Selbst einige eineiigen Zwillinge, die aus einer einzigen befruchteten Eizelle - der sogenannten Zygote - hervorgehen und folglich auch das identische Erbgut besitzen, weisen teilweise einzelne genotypische Mutationen auf. ${ }^{1699}$ Im weiteren Wachstums- und Lebensverlauf reproduzieren sich dann sowohl die von den Eltern vererbten Mutationen als auch die neu entstandenen Mutationen, was sowohl die Individualität jedes Menschen, als auch weiterfolgend die Individualität unserer Nachkommen konstruiert. ,Jedes Neugeborene ist daher

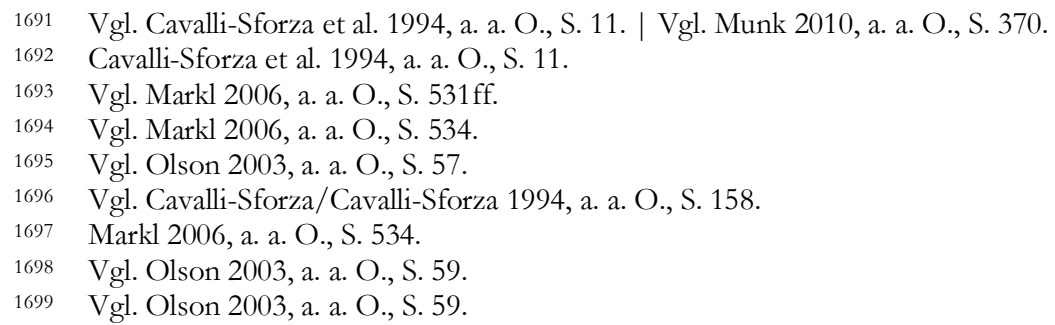


genetisch einzigartig [...]. “1700 Diese genetische Variabilität und Vielfalt des Genpools einer Population wird durch Mutation, sexuelle Rekombination sowie seltener durch den Zufall bestimmt. ${ }^{1701}$ Nichtsdestotrotz lassen sich selbstverständlich zwischen Eltern- und Filialgeneration zahlreiche geno- und phänotypische Ähnlichkeiten feststellen, wie Cavalli-Sforza exemplarisch visualisiert:

\begin{abstract}
„Zwischen Eltern und Kindern können wir manchmal beeindruckende Ähnlichkeiten feststellen. Sie weisen zum Beispiel den gleichen Haaransatz und die gleichen Haarwirbel und viele andere gemeinsame Merkmale und Verhaltensweisen auf, während die Eltern selbst offensichtlich voneinander verschieden sind. Wenn man Merkmal für Merkmal untersucht, Kann man herausfinden, dass das Kind einem der beiden Eltern ähnelt, eine Mischung zwischen den beiden ist oder sich von beiden unterscheidet. [...] Das beweist, wie stark das biologische Erbe sein kann. "7702
\end{abstract}

Insbesondere vor dem Hintergrund pseudobiologischer Theoreme bleibt so schon einführend festzustellen, dass alle modernen Menschen weltweit biologisch keineswegs identisch erscheinen, was zur Dekonstruktion des ,reinen Rassengedankens' beiträgt. ${ }^{1703}$ Wir sind und bleiben ein Produkt unserer vielfältigen Evolution.

„Die Erbanlage, die jeder von uns erbielt, besteht aus Mutationen, die bei unseren entfernten Vorfahren auftraten und sich als mehr oder weniger nützlich erwiesen haben. Denn gerade diese Akkumulation und Kombination nützlicher Mutationen hat unsere vormenschlichen Vorfahren in die Menschenspezies umgewandelt. "1704

Mutationen sind folglich die Quelle jeder Evolution, in dem sie von Generation zu Generation neue Variationen in den Genpool einer Population einbringen, was letztlich zur evolutiven, natürlichen Auslese führt. ${ }^{1705}$ Bedeutende Evolutionen der Geschichte des Menschen waren beispielsweise das Anwachsen von Umfang und Funktion des Gehirns vor etwa drei Millionen Jahren oder der fast vollständige Verlust der Körperbehaarung. ${ }^{1706}$ Mutationen dienen als Mechanismen der Vererbung, die darüber hinaus auch die genotypischen Differenzen zwischen verschiedenen Arten von Lebewesen generieren: ${ }^{1707}$ „Diese Mannigfaltigkeit wird durch den Mutationsprozess möglich gemacht, der das genetische Rohmaterial liefert, aus welchem dann die Diversität ,aufgebaut' werden kann. "1708 Die Umweltfaktoren bestimmen darauf aufbauend maßgeblich, ob sich die stattgefundenen Mutationen förderlich, neutral oder eher schädlich auswirken. ${ }^{1709}$ Die vorteilhafteren Mutationen werden sich im Laufe mehrerer Generationen aufgrund ihrer verbes-

\footnotetext{
1700 Olson 2003, a. a. O., S. 59.

1701 Vgl. Markl 2006, a. a. O., S. 534.

1702 Cavalli-Sforza/Cavalli-Sforza 1994, a. a. O., S. 127-128.

1703 Vgl. Dunn/Dobzhansky 1970, a. a. O., S. 73.

1704 Dunn/Dobzhansky 1970, a. a. O., S. 74.

1705 Vgl. Dunn/Dobzhansky 1970, a. a. O., S. 71.

1706 Vgl. Cavalli-Sforza/Cavalli-Sforza 1994, a. a. O., S. $169 f$.

1707 Vgl. Cavalli-Sforza/Cavalli-Sforza 1994, a. a. O., S. 128.

1708 Dunn/Dobzhansky 1970, a. a. O., S. 73.

1709 Vgl. Dunn/Dobzhansky 1970, a. a. O., S. 73 f.
} 
serten Überlebens-, Fortpflanzungs- und Anpassungsfähigkeit mit großer Wahrscheinlichkeit behaupten können. Die phänotypische Differenzierung des modernen Menschen auf den einzelnen Kontinenten stellt demnach ebenfalls lediglich einen mutationsbedingten Anpassungsprozess vor allem an die unterschiedlichen Umweltbedingungen dar, wie das folgende Beispiel zusätzlich bestätigt: ${ }^{1710}$
„In Europa hat sich mit der Entwicklung des Ackerbaus in den letzten 10000 Jahren die Verwendung von Getreide als Hauptnahrungsmittel verbreitet. Getreide enthält kein Vitamin D, wie etwa Fleisch und vor allem die Fischleber, aber ein Provitamin, das sich in Vitamin D verwandelt, sobald es der ultravioletten Strablung der Sonne ausgesetzt ist, die über die Haut absorbiert wird. Wenn wir Getreide essen, kann unser Organis- mus immer noch soviel Vitamin D produzieren, dass wir überleben und normal heran- wachsen können; Voraussetzung ist aber, dass unsere Haut bell ist, denn wenn sie dun- kel ist, dringen die ultravioletten Strablen nicht durch. Dagegen bedeutet dunkle Haut einerseits einen beträchtlichen Schutz, gegen die ultravioletten Strablen, die bei sehr star- ker Sonneneinwirkung Hautschäden verursachen können. Andererseits verbindert sie die Umwandlung des Provitamins. Solange man genügend Vitamin D in Form von Fleisch und Fisch zu sich nimmt, spielt das keine Rolle. Problematisch wird es aber in den nörd- lichen Regionen, wo die Sonne seltener scheint und ein Dunkelhäutiger nicht in ausrei- chender Menge ultraviolette Strahlen aufnehmen könnte. "1711

In der anthropologischen und evolutionsbiologischen Forschung werden Mutationen von mtDNA, Kern-DNA und Y-Chromosomen so beispielsweise als relative Zeitmesser genutzt, wie das vorherige Kapitel einführend illustriert hat (s. Kapitel 5.2): „Die Anzahl veränderter somatischer Zellen oder Keimzellen lässt Rückschlüsse auf den Zeitpunkt während der Entwicklung zu, an dem die Mutation erfolgt ist." 1712 So kann man mithilfe von Mutationen der Erbinformationen belegen, dass sich der moderne Mensch monozentrisch nach dem Out-of-AfricaModell einzig in Afrika entwickelt haben muss, da die ältesten vorkommenden Mutationen aus Afrika stammen. ${ }^{1713}$ Bei der Ausbreitung des Homo sapiens wurden nicht alle diese Mutationen genotypisch übernommen, so dass noch heute auf dem afrikanischen Kontinent - im Vergleich zu den übrigen Kontinenten - variantenreichere DNA-Mutationen existieren. ${ }^{1714}$ Mutationen sind folglich mehr als nur Veränderungen der DNA, sie dienen zusätzlich zur wissenschaftlichen Rekonstruktion der Menschheitsgeschichte.

„Mutationen sind ein Grundphänomen lebender Systeme. [...] Für die Evolution von Organismen sind sie unentbebrlich. "'715

\footnotetext{
1710 Vgl. Cavalli-Sforza/Cavalli-Sforza 1994, a. a. O., S. $160 f$.

1711 Cavalli-Sforza/Cavalli-Sforza 1994, a. a. O., S. 159.

1712 Graw 2010, a. a. O., S. 395.

1713 Vgl. Olson 2003, a. a. O., S. 62ff.

1714 Vgl. Olson 2003, a. a. O., S. 62ff.

1715 Graw 2010, a. a. O., S. 395.
} 
Das Mutations-Phänomen kann also neben der genetischen Drift, dem Zufall und der natürlichen Selektion als essentieller Faktor verstanden werden, der die Verschiedenheit von Individuen und Populationen ermöglicht. Der weitere Verlauf erörtert nun unterschiedliche Möglichkeiten von Mutationen bzw. Veränderungen der DNA, die in ihrer Gesamtheit die genotypische Individualität aller menschlichen Individuen bedingen. Selbstverständlich müssen in diesem Zusammenhang auch die sogenannten Umweltfaktoren dezidiert analysiert werden, die eine wichtige Rolle bei der Ausprägung von genotypischen sowie phänotypischen Merkmalen einnehmen.

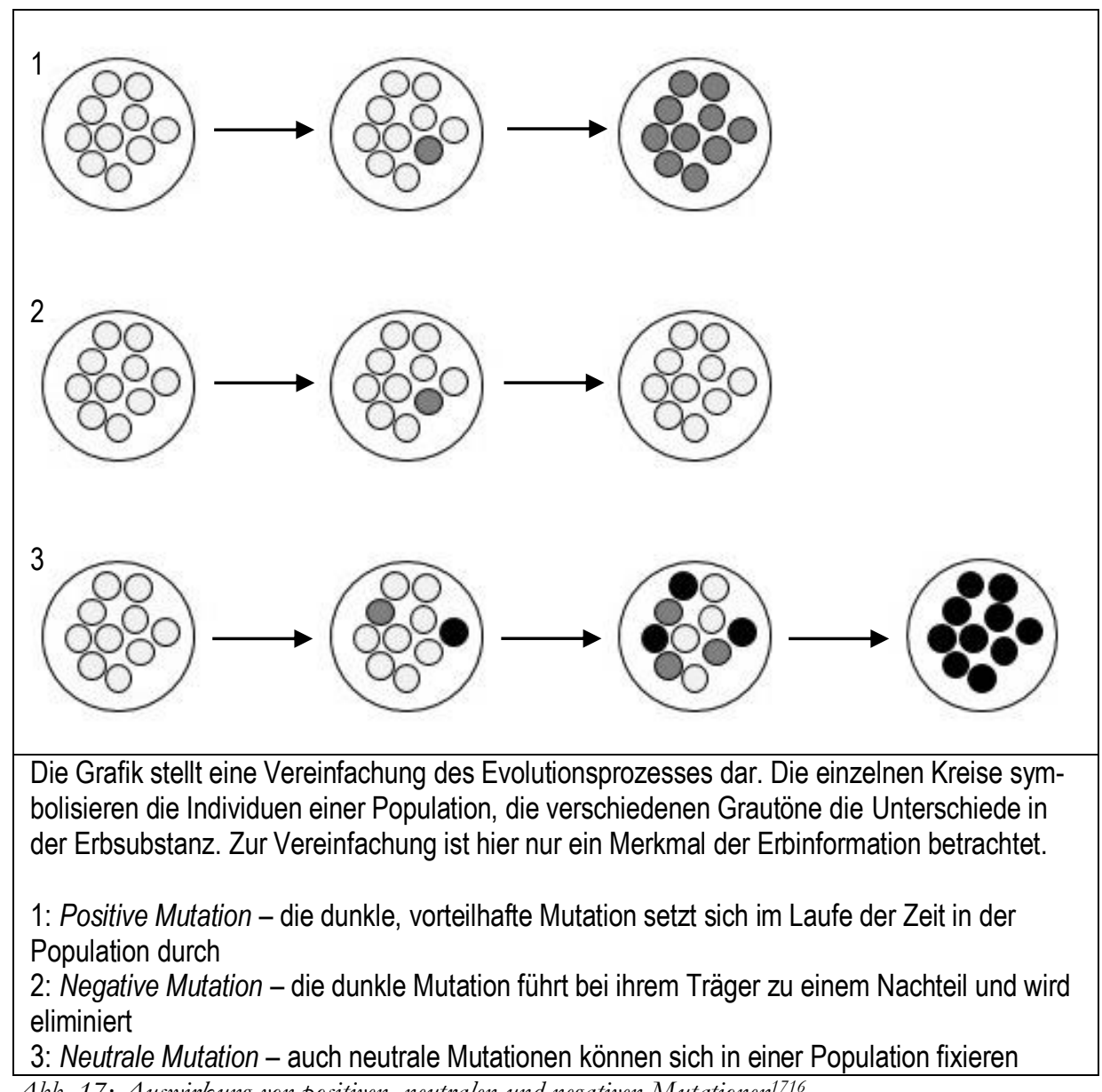
Abb. 17: Auswirkung von positiven, neutralen und negativen Mutationen ${ }^{1716}$

Wie schon angemerkt, werden positive, irrelevante und negative Mutationen unterschieden: „Es gibt relativ wenige vorteilhafte Mutationen, denn im Grunde sind

1716 Eigene Darstellung nach: Sommer 2011, a. a. O., S. 77. 
all jene Mutationen, die sich in der Vergangenheit als nützlich erwiesen haben, von der natürlichen Auslese längst zum genetischen Programm gemacht worden und damit bereits ein Teil von uns." 1717 Meist werden vorteilhafte Mutationen so über eine Vielzahl von Generationen in unsere DNA integriert, um im Rahmen der Evolution eine vorteilhafte Auslese zu ermöglichen. ${ }^{1718}$ Beispielsweise wurde die Laktosetoleranz von erwachsenen Menschen erst im Laufe der Zeit erworben, da erst vor etwa 10.000 Jahren mit der gerichteten Zucht von milchproduzierenden Rindern oder Schafen begonnen wurde, die nun auch Milch für Erwachsene als Nahrungsmittel zur Verfügung stellten. ${ }^{1719}$ Ursprünglich wiesen nur Säuglinge die Laktosetoleranz auf, da sie auf die mütterliche Milch als Nahrungsgrundlage angewiesen sind. Im Erwachsenenalter ging die Toleranzfähigkeit wieder verloren, was noch heute zahlreiche Fälle der Laktoseintoleranz beweisen, bei denen der Körper die Enzyme zum Milchabbau nicht bzw. nicht mehr produzieren kann. Erst mit dem Aufkommen des Milchverzehres auch von erwachsenen Menschen wurde die Laktosetoleranz nach und nach langfristig in unsere DNA integriert. Irrelevante Mutationen zeigen demgegenüber keine Auswirkungen auf den menschlichen Stoffwechsel. Negative Mutationen schließlich führen meist zu Beeinträchtigungen, Krankheiten oder zum Tod. ${ }^{1720}$

Aufgrund der Vielzahl von Veränderungen der DNA können das MutationsPhänomen betreffend verschiedene Klassifikationssysteme differenziert werden. Unterschieden werden allgemein sogenannte spontane sowie induzierte Mutationsursachen. Spontane Mutationen finden dabei, wie die begriffliche Bedeutung schon impliziert, spontan, ungerichtet, ungesteuert durch die chemischen Eigenschaften der Nukleotide, nicht von äußeren Faktoren induziert sowie mehr oder weniger zufällig statt. ${ }^{1721}$ Die meisten Mutationen entwickeln sich spontan - ihre Wirkung ist in der Folge nicht vorhersehbar. ${ }^{1722}$ „Alle Mutationen können [so] ohne ersichtlichen Auslöser auftreten." 1723 In diesem Zusammenhang können beispielsweise Basen der DNA ausgetauscht werden. ${ }^{1724}$ Auch Rekombinationsereignisse der DNA im Verlauf der Replikation - der Vervielfältigung der DNA oder der Meiose sind durch sogenannte Crossing-Over-Ereignisse möglich (s. Kapitel 5.3.5). Insbesondere „[b]ei der Replikation der DNA werden mit hohen Fehlerraten der DNA-Polymerase[, einem Enzym,] auch falsche Nucleotide eingebaut." ${ }^{1725}$ Als weitere Beispiele sind sogenannte Genkonversionen zu nennen, bei denen ganze Nukleotidcluster der DNA ausgetauscht werden, oder das soge-

1717 Cavalli-Sforza/Cavalli-Sforza 1994, a. a. O., S. 156.

1718 Vgl. Cavalli-Sforza/Cavalli-Sforza 1994, a. a. O., S. $157 \mathrm{ff}$.

1719 Vgl. Cavalli-Sforza/Cavalli-Sforza 1994, a. a. O., S. $157 \mathrm{ff}$.

1720 Vgl. Cavalli-Sforza/Cavalli-Sforza 1994, a. a. O., S. $154 \mathrm{ff}$.

1721 Vgl. Munk 2010, a. a. O., S. 382.

1722 Vgl. Munk 2010, a. a. O., S. 382.

1723 Munk 2010, a. a. O., S. 283.

1724 Vgl. Buselmaier/Tariverdian 2007, a. a. O., S. $76 \mathrm{ff}$.

Durch sogenannte Desaminierungen werden meist Thymin oder Uracil anstelle von Cytosin in die Basensequenz der $D N A$ integriert.

1725

Graw 2010, a. a. O., S. 409. 
nannte Polymeraseslippage, bei der das ,Wegrutschen' des Enzyms DNAPolymerase bei der Replikation der DNA zur Einfügung von kurzen Wiederholungssequenzen führt. ${ }^{1726}$ Hierdurch wird der Leserahmen der in der DNA codierten genetischen Informationen verändert. ${ }^{1727}$ Darüber hinaus sind weitere dynamische Mutationen, die zur Erhöhung von instabilen repetitiven DNA-Sequenzen führen, möglich. ${ }^{1728}$ Induzierte Mutationen sind hingegen insbesondere auf den mutationsfördernden Einfluss verschiedener physikalischer sowie chemischer Umweltfaktoren zurückzuführen (s. Kapitel 5.3.6, 5.3.7). ${ }^{1729}$ Abschließend muss vor dem Hintergrund der geschlechtlichen Fortpflanzung auch das Alter der Eltern, insbesondere des Vaters, herangezogen werden: Je älter vor allem der biologische Vater, desto höher die Mutationsrate des Genoms der Nachkommen. ${ }^{1730}$

Weiterhin können bezüglich der spontanen und induzierten Mutationen Punkt- bzw. Genmutationen - Veränderungen der Basenabfolge der DNA -, Chromosomenmutationen - einzelne Veränderungen der Chromosomenstruktur - sowie sogenannte Genommutationen - Veränderungen der Chromosomenzahl - differenziert werden, die in den folgenden Kapiteln detaillierter analysiert und mit den rassistischen Fehlinterpretationen der molekulargenetischen Forschung verknüpft werden. Die Mediziner Buselmaier und Tariverdian folgern vor diesem Hintergrund: „Die Mutationsraten für einzelne menschliche Gene liegen nach Berechnungen in der Größenordnung zwischen 10-4 und 10-6." "1731 Viele Gene weisen jedoch wesentlich geringere Mutationsraten auf. ${ }^{1732}$ Schlussfolgernd kann diagnostiziert werden:

„Mutationen, Veränderungen $\operatorname{der} D N A$, können spontan auftreten und durch Strahlung oder Chemikalien induigiert werden. Mutationen können nach ibrer Größe oder der Art ibrer DNA- beziehungsweise Chromosomenveränderung unterschiedlich klassifiziert werden." "1733

\subsubsection{Bedeutung von Genmutationen und Reparaturmöglichkeiten}

Genmutationen betreffen die Primärstruktur der DNA. Durch Mutationsereignisse können hier einzelne Basenpaarungen verändert werden. Deshalb spricht man auch von Punktmutationen, bei denen einzelne oder wenige, nebeneinander liegende Nukleotide verändert werden. Buselmaier und Tariverdian bezeichnen sie

\footnotetext{
1726 Vgl. Buselmaier/Tariverdian 2007, a. a. O., S. $76 \mathrm{ff}$.

1727 Vgl. Graw 2010, a. a. O., S. 409.

1728 Vgl. Graw 2010, a. a. O., S. 410 f.

1729 Vgl. Markl 2006, a. a. O., S. 330.

1730 Vgl. Buselmaier/Tariverdian 2007, a. a. O., S. 79.

1731 Buselmaier/Tariverdian 2007, a. a. O., S. 77.

1732 Vgl. Buselmaier/Tariverdian 2007, a. a. O., S. 77.

Je nach Auswirkung der einzelnen Mutationen können nochmals zwei verschiedene Untertypen differenziert werden: Sogenannte Nullmutationen, die den Ausfall einer Genfunktion - loss of function - zur Folge haben sowie sogenannte neomorphe Mutationen, in deren Folge ein Allel mit einer neuen Funktion aufgrund eines Mutationsereignisses - gain of function - entsteht. Vgl. Graw 2010, a. a. O., S. $394 \mathrm{f}$.

Graw 2010, a. a. O., S. 397.
} 
als „[...] mikroskopisch unsichtbare, kleine molekulare Änderungen."1734 Die spontane Mutationsrate für Punktmutationen, also die Häufigkeit von Punktmutationen, ist für jedes Gen unterschiedlich. ${ }^{1735}$ Jeder Mensch trägt in seinem Genom demnach etwa 50-100 Genmutationen für mögliche Erbkrankheiten mit sich, wie das internationale ,1000-Genom-Projekt' bestätigt. ${ }^{1736}$ Darüber hinaus konstatiert eine neue Pilotstudie, ,[...] dass jeder Mensch etwa 250 bis 300 Genveränderungen besitzt, die dazu führen, dass das jeweilige Gen nicht mehr richtig arbeiten kann."1737 Diese Variationen können sowohl Vor- als auch Nachteile für die menschliche Entwicklung sowie die der möglichen Nachkommen aufweisen, was vornehmlich von der Position der Mutation auf der DNA-Sequenz bzw. auf einem spezifischen Gen abhängig ist. ${ }^{1738}$ Die meisten Punktmutationen können jedoch als harmlos - ohne negative Wirkung - betrachtet werden, da ein Großteil der DNA nicht-proteincodierend ist, also für die Aufrechterhaltung der Stoffwechsel- und Körperfunktionen nur eine untergeordnete Rolle spielt. ${ }^{1739}$ Trotzdem sind auch vereinzelt negative Auswirkungen existent:

„Lebewesen sind hochkomplexe Systeme, entwickelt durch Selektion über Tausende vergangener Generationen, und eine zufällige Veränderung des Genoms wird den Organismus wahrscheinlich nicht mehr verbessern, als das blinde Abfeuern einer Gewehrkugel durch die Motorhaube eines Autos dessen Pferdestärken erböhen wird. "1740

Tab. 23: Mutationen am Beispiel der handschriftlichen Kopie von Gedichten ${ }^{1741}$

\begin{tabular}{|ccl|}
\hline Handschrift & Jahrhundert & \multicolumn{1}{c|}{ Anfang des Gedichts } \\
\hline 1 & IX & FORE THE'E NEIDFAERAE \\
2 & X & FORE THAE NEIDFAERAE \\
3 & XII & FORE TH-E NEIDFAERAE \\
4 & XII & FORE TH-E NEIDFAER-E \\
5 & XV & FORE TH-E NEYDFAER-E \\
6 & XIII & FORE TH-E NEIDFAOR-E \\
7 & XII & FORE TH-E NEIDFAOR-E \\
& & ,Vor der unvermeidlichen Reise $\ldots$ \\
\hline
\end{tabular}

Luigi Luca Cavalli-Sforza visualisiert die Entwicklung von Punktmutationen anhand des Kopierens von Handschriften aus dem kulturellen Milieu vergangener

1734 Buselmaier/Tariverdian 2007, a. a. O., S. 71.

1735 Vgl. Janning/Knust 2008, a. a. O., S. $188 \mathrm{ff}$.

1736 Vgl. Spiegel Online (2010): „DNA-Analyse. Genvarianten für Erbkrankheiten weit verbreitet“, in URL: http://www.spiegel.de/wissenschaft/ mensch/dna-analyse-genvarianten-fuererbkrankheiten-weit-verbreitet-a-725847.html <03.08.2012>. | Vgl. The 1000 Genomes Project Consortium (2010): A map of human genome variation from population-scale sequencing, in: Nature, Vol. 467, London u. a., S. 1061-1073.

1737 Spiegel Online 2010, a. a. O.

1738 Vgl. Cavalli-Sforza/Cavalli-Sforza 1994, a. a. O., S. 134ff.

1739 Vgl. Markl 2006, a. a. O., S. 534.

1740 Markl 2006, a. a. O., S. 534.

1741 Eigene Darstellung nach: Cavalli-Sforza/Cavalli-Sforza 1994, a. a. O., S. 136. 
Jahrhunderte, bei dem über Jahre hinweg ebenfalls sukzessive Fehler auftreten können.

Bezüglich der Punktmutationen lassen sich abermals verschiede Mutationstypen differenzieren. Grundsätzlich unterschieden werden Veränderungen einzelner Basenpaare bzw. Nukleotide. Als Substitution bezeichnet man demzufolge den allgemeinen Austausch von Basen einer DNA-Sequenz. ${ }^{1742}$ Dahingegen wird der Austausch einer Purin- gegen eine Pyrimidinbase - beispielsweise die Substitution von Adenin gegen Thymin - als Transversion benannt. ${ }^{1743}$ Darüber hinaus können Nukleotide in eine DNA-Sequenz zusätzlich eingefügt - die sogenannte Insertion - oder herausgenommen - die sogenannte Deletion - werden. ${ }^{174}$ Weiterhin ist es ebenfalls realisierbar, per Duplikation einzelne Basen bzw. kürzere Abschnitt der Basensequenz verdoppelt einzufügen. Ebenso möglich sind letztlich sogenannte Trinukleotidwiederholungen, bei denen sich ein aus drei Basen bestehendes, spezielles Basenmotiv zunehmend vermehrt. ${ }^{1745}$

Die präsentierten Mutationstypen können sich auf die genetischen Informationen auswirken, die in der Abfolge der Basenpaare der DNA gespeichert sind. Veränderungen der Basenpaarungen sind demnach exemplarisch zu einer Verschiebung des Leserasters einer proteincodierenden DNA-Sequenz in der Lage. ${ }^{1746}$ Im weiteren Verlauf könnte so der Mechanismus, welcher die in der DNA gespeicherten Informationen für den Aufbau eines Proteins codiert, durch sogenannte Rasterschub-Mutationen - frameshift mutations - erheblich beeinträchtigt werden, so dass das gebildete Protein Funktionsstörungen oder einen kompletten Funktionsausfall aufweist. ${ }^{1747}$ Punktmutationen des menschlichen Genoms zeigen also durchaus unterschiedliche Auswirkungen auf. $\mathrm{Zu}$ etwa 95 Prozent finden Punktmutationen jedoch als sogenannte stille Mutationen ohne weitere Folgewirkungen statt. ${ }^{1748}$ Bei der Veränderung einer längeren Nukleotidsequenz kann eine Missense-Mutation stattfinden, die für das entstandene Protein die oben genannten Auswirkungen zeigen kann. ${ }^{1749}$ Weiterhin möglich ist auch eine sogenannte Nonsense-Mutation, die für das zu codierende Protein meistens einen vollkommenen Funktionsdefekt zur Folge hat. ${ }^{1750}$ Dies kann fatale Auswirkungen für das menschliche Leben bedeuten: Grundlegende Lebens- und Stoffwechselprozesse können ebenso zum Stillstand gelangen, wie die Funktion einzelner Körperorgane und -gewebe. Vor dem Hintergrund des biologistischen Rassismustypus belegt das Phänomen der Genmutation jedoch abermals, dass identische Genotypen in einer

\footnotetext{
1742 Vgl. Munk 2010, a. a. O., S. $370 \mathrm{ff}$.

Der Austausch einer Pyrimidinbase durch die nicht-komplementäre Pyrimidinbase - beispielsweise der Austausch von Cytosin gegen Thymin - wird als Transition bezeichnet. Vgl. Munk 2010, a. a. O., S. $370 \mathrm{ff}$.

1743 Vgl. Munk 2010, a. a. O., S. $370 \mathrm{ff}$.

1744 Vgl. Buselmaier/Tariverdian 2007, a. a. O., S. $72 \mathrm{ff}$.

1745 Vgl. Buselmaier/Tariverdian 2007, a. a. O., S. $73 \mathrm{ff}$.

1746 Vgl. Munk 2010, a. a. O., S. 372.

1747 Vgl. Munk 2010, a. a. O., S. 372.

1748 Vgl. Munk 2010, a. a. O., S. $370 \mathrm{ff}$.

1749 Vgl. Munk 2010, a. a. O., S. $370 f f$.

1750 Vgl. Munk 2010, a. a. O., S. $370 f f$.
} 
Population, die zur Existenz von scheinbaren ,reinen Rassen' führen könnten, realitätsfern erscheinen. Denn demgegenüber steht eine Grundkomponente der Evolution: Das Prinzip der Mutation. Dies kann vorteilhafter oder negativer Art, vererbbar oder nicht vererbbar, mit Folgewirkungen oder ohne weitere Auswirkungen auftreten, ist größtenteils jedoch unvorhersehbar sowie zufällig. Obwohl Mutationen einzeln betrachtet relativ selten sind, akkumulieren sie sich im Laufe der Generationen, so dass über einen langen Zeitraum Anpassungsphänomene an Umwelt und Lebensraum aufgrund geno- und phänotypischer Veränderungen möglich sind. ${ }^{1751}$ Dies illustriert auf einzigartige Weise die DNA des Menschen: So existieren zwischen den einzelnen modernen Menschen etwa drei Millionen Unterschiede in den Basenpaarungen der DNA-Sequenz. ${ }^{1752}$ Auch dies belegt einerseits nochmals unzweideutig die genetisch bedingte Vielfalt und Verschiedenheit des Homo sapiens, die andererseits jedoch genotypisch betrachtet in ihrer Gesamtheit mit weniger als 0,1 Prozent des Genoms minimal ausfällt. Jürgen Markl sieht etwa Fehler in der Nukleotidsequenz der DNA nur mit einer Häufigkeit von 1:1 Milliarde, bei den Basenpaarungen jedoch von 1:10.000.1753 Die vorhandenen Unterschiede sind also nur quantitativer, nicht aber qualitativer Art. ${ }^{1754}$ Dies bestätigt Luigi Luca Cavalli-Sforza mithilfe der Analyse der Vorkommens-Häufigkeit von drei Genen in unterschiedlichen Menschenpopulationen. Die folgende tabellarische Übersicht illustriert, dass ,[...] [d]ie Schwankungen der Prozentsätze [...] zwischen den verschiedenen Populationen [...] minimal $[\ldots]^{\text {“ } 1755}$ sind. Einzig der Gentyp FY-0 zeigt in diesem Beispiel größere Differenzen auf: Dieser immunisiert seine Träger gegen einen in Afrika auftretenden Malariaparasiten, kommt dort auch relativ häufig vor, während er in anderen Kontinenten aufgrund der mangelnden Bedeutung fast vollständig fehlt. ${ }^{1756}$

Tab. 24: Häufigkeit von Genen ${ }^{1757}$

\begin{tabular}{|ccccccc|}
\hline Gene & Europa & $\begin{array}{c}\text { Afrika } \\
\text { (südlich } \\
\text { Sahara) }\end{array}$ & Indien & $\begin{array}{c}\text { Ferner } \\
\text { Osten }\end{array}$ & $\begin{array}{c}\text { Südameri- } \\
\text { ka }\end{array}$ & Australien \\
\hline GC-1 & $72 \%$ & $88 \%$ & $75 \%$ & $76 \%$ & $73 \%$ & $83 \%$ \\
GC-2 & $28 \%$ & $12 \%$ & $25 \%$ & $24 \%$ & $27 \%$ & $17 \%$ \\
HP-1 & $38 \%$ & $57 \%$ & $17 \%$ & $23 \%$ & $60 \%$ & $27 \%$ \\
FY-0 & $0,3 \%$ & $87 \%$ & $3 \%$ & $0 \%$ & $0,2 \%$ & $0 \%$ \\
\hline
\end{tabular}

Die Reparatur von Genmutationen ist zwar prinzipiell möglich, jedoch ist es unwahrscheinlich, dass sämtliche DNA-Variationen vollständig korrigiert werden können. So existiert auf molekulargenetischer Ebene zum einen die Fehlpaarungs-

1751 Vgl. Cavalli-Sforza/Cavalli-Sforza 1994, a. a. O., S. 141.

1752 Vgl. Cavalli-Sforza/Cavalli-Sforza 1994, a. a. O., S. 142f.

1753 Vgl. Markl 2006, a. a. O., S. 352.

1754 Vgl. Cavalli-Sforza/Cavalli-Sforza 1994, a. a. O., S. 204.

1755 Cavalli-Sforza/Cavalli-Sforza 1994, a. a. O., S. 205.

1756 Vgl. Cavalli-Sforza/Cavalli-Sforza 1994, a. a. O., S. 205 f.

1757 Eigene Darstellung nach: Cavalli-Sforza/Cavalli-Sforza 1994, a. a. O., S. 205. 
reparatur, die das Enzym DNA-Polymerase als Korrekturfunktion benutzt, um falsche Basen zu beseitigen und durch die korrekte, komplementäre Basenpaarung der DNA zu ersetzen. ${ }^{1758}$ Auch die sogenannte Mismatch-Reparatur entfernt mithilfe spezieller Enzyme falsche Basenpaarungen, sofern diese von der Fehlpaarungsreparatur nicht erkannt wurden. ${ }^{1759}$ Zum anderen ist es der sogenannten Excisionsreparatur möglich, eine defekte, kurze DNA-Sequenz per Enzym vollständig zu entfernen, um diese mithilfe der Enzyme DNA-Polymerase und DNALigase wieder in richtiger Reihenfolge aufzufüllen. ${ }^{1760}$ Letztlich kann beispielsweise noch die Sonnenstrahlung als DNA-Reparateur helfen, da diese im Rahmen der Photoreaktivierung mithilfe des Enzyms Photolyase spezielle Fehlpaarungen der DNA, sogenannte Pyrimidindimere, korrigieren kann. ${ }^{1761}$ Die Vielzahl der Reparaturmöglichkeiten von Genmutationen lässt schon darauf schließen, dass Fehlpaarungen der DNA-Sequenz keineswegs selten vorkommen. Diese Annahme bestätigt auch das Vorhandensein von 130 verschiedenen Reparaturenzymen beim Menschen. ${ }^{1762}$

\section{„Der Erhalt der in der DNA niedergelegten Information erfordert häufige Reparaturen verschiedenster Art. " "763}

Insbesondere die im weiteren Verlauf noch diskutierten Umwelteinflüsse, wie mutagene Chemikalien oder radioaktive Strahlung, tragen in hohem Maße zur Schädigung unserer Erbinformationen bei - und damit auch zur Veränderung unseres Genotyps. Unsere Gene befinden sich so in einem stetigen mutagenen Wandel, was einer standardisierten sowie feststehenden, genbasierten ,Rasseklassifikation' des Menschen diametral widerspricht.

\subsubsection{Chromosomen- und Genommutationen}

Die mendelschen Vererbungsgrundlagen konnten im Jahr 1902 zur sogenannten Chromosomentheorie der Vererbung zusammengeführt werden. ${ }^{1764}$ Diese umfasst die Erkenntnis, dass sämtliche Gene als Erbfaktoren auf unterschiedlichen Orten der Chromosomen gelagert sein müssen. ${ }^{1765}$ Chromosomen sind folglich die Träger der Gene. Für jeden menschlichen Chromosomensatz kann in der Folge eine Genkarte konstruiert werden, die die für jedes Chromosom charakteristischen Gene identifiziert und deren Genorte auf dem Chromosom lokalisiert. ${ }^{1766}$ Mithilfe der mendelschen Grundlagen der Vererbung „[...] können Gene einem bestimmten Chromosom des [...] Chromosomensatzes und dort einem Ort in der Genkar-

\footnotetext{
1758 Vgl. Markl 2006, a. a. O., S. 352.

1759 Vgl. Markl 2006, a. a. O., S. 352.

1760 Vgl. Markl 2006, a. a. O., S. 352.

1761 Vgl. Munk 2010, a. a. O., S. 107.

1762 Vgl. Markl 2006, a. a. O., S. 352.

1763 Markl 2006, a. a. O., S. 352.

1764 Vgl. Markl 2006, a. a. O., S. 320.

1765 Vgl. Markl 2006, a. a. O., S. 320.

1766 Vgl. Buselmaier/Tariverdian 2007, a. a. O., S. $46 f$.
} 
te zugeordnet werden." ${ }^{1767}$ Die DNA ist als Träger der Erbinformationen in verschiedene Chromosomen verpackt. Auf jedem dieser Chromosomen sind mehrere 100 bis 1.000 Gene gelagert. Diese nennt man gekoppelte Gene, da sie immer im Verband des Chromosoms zusammen vererbt werden. ${ }^{1768}$ Bezüglich des Menschen können Geschlechtschromosomen, sogenannte Gonosomen, sowie Autosomen unterschieden werden. ${ }^{1769}$

Auch Chromosomen sind von spontanen und induzierten Mutationen betroffen, die im Rahmen der sogenannten Chromosomenmutationen zu einer Strukturveränderung der Chromosomen führen. ${ }^{1770} \mathrm{Da}$ die meisten Mutationen mit der Trennung von Genorten verbunden sind, zeigen diese fast immer negative Auswirkungen auf die Entwicklung eines Individuums. ${ }^{1711}$ Lediglich bei vollkommen intakt bleibenden Genen verhalten sich die Veränderungen neutral oder selten auch positiv. ${ }^{1772}$ Die folgende Tabelle veranschaulicht mögliche Abweichungen sogenannte Aberrationen -, die zu einer Chromosomenmutation führen.

Tab. 25: Chromosomenmutationen ${ }^{1773}$

\begin{tabular}{|ll|}
\hline Deletion & Verlust eines Chromosomensegments \\
\hline Duplikation & Verdopplung eines Chromosomensegments \\
\hline Insertion & Inkorporation eines Chromosomensegments \\
\hline Inversion & Drehung eines Chromosomensegments um $180^{\circ}$ \\
\hline Translokation & Änderung der Position eines oder mehrerer Chromosomensegmente \\
\hline
\end{tabular}

Chromosomenmutationen sind grundsätzlich an jeder Stelle des Chromosoms möglich und können diese folglich an jeder Stelle modifizieren. Die Resultate sind jedoch unterschiedlich: Bei der Deletion können ganze Chromosomenbereiche mit mehreren funktionell wichtigen Genen verloren gehen, was in der Folge beispielsweise zu schweren Fehlbildungen oder einem erhöhten Tumorrisiko führen kann. ${ }^{1774}$ Auch als Folge von Duplikationen sind vielfältige genotypische Variationen möglich, die sich, je nach Ort der Veränderung auf dem Chromosom, eben-

1767 Janning/Knust 2008, a. a. O., S. 74.

1768 Vgl. Markl 2006, a. a. O., S. 322.

1769 Das menschliche Genom haploider - mit einem einfachen Chromosomensatz ausgestatteter - Geschlechtszellen, sogenannter Gameten, besteht aus 23 Chromosomen: 22 Autosomen und einem X-oder Y-Gonosom. Menschliche Körperzellen enthalten bingegen einen doppelten, sogenannten diploiden Chromosomensatz: 22 bomologe Autosomenpaare, von denen jeweils ein Chromosom von Mutter und V ater stammt, sowie ein Gonosomenpaar, von denen ebenfalls jeweils ein Gonosom von Vater und Mutter abstammt.

1770 Vgl. Janning/Knust 2008, a. a. O., S. 121.

1771 Vgl. Markl 2006, a. a. O., S. 534. | Vgl. Plomin, Robert/DeFries, John C./McClearn, Gerald E. (1990): Behavioral genetics. A Primer, 2. Auflage, New York, S. 127, $148 \mathrm{f}$.

Chromosomen-Anomalien sind als, normal' einzuordnen, kommen also häufiger vor. Im negativen Fall beeinflussen sie jedoch beispielsweise die kognitive Entwicklung oder das Körperwachstum von betroffenen Individuen in vielfältiger $W$ eise.

1772 Vgl. Markl 2006, a. a. O., S. 534.

1773 Eigene Darstellung nach: Buselmaier/Tariverdian 2007, a. a. O., S. 65.

1774 Vgl. Buselmaier/Tariverdian 2007, a. a. O., S. 65ff, 71. 
falls negativ auswirken können und beispielsweise zu Erbkrankheiten führen. ${ }^{1775}$ Die Duplikation von Chromosomenabschnitten führt jedoch meist zu negativen Auswirkungen. ${ }^{1776}$ Ebenfalls Translokationen können $\mathrm{zu}$ mehr oder weniger schweren Fehlbildungen führen, die im drastischsten Fall letale Folgen haben. ${ }^{1777}$ Chromosomenmutationen führen also, ebenso wie die Genmutationen, zu einer unglaublichen Vielfalt und Variabilität des menschlichen Genoms, sowohl positiv als auch negativ. Auch dies bestätigt wieder, dass alle modernen Menschen genotypisch gesehen Individuen darstellen, die aufgrund der Anfälligkeit der DNA für spontane und induzierte Mutationen nur realitätsfremd in genetisch identische ,Rassen` kategorisiert werden könnten. Die Auswirkungen dieser Mutationen sind nur selten prognostizierbar. Hinzukommend zeigt sich hier insbesondere, dass selbst menschliche Fähig- und Fertigkeiten - die mit hoher Wahrscheinlichkeit an die nachfolgenden Generationen vererbt werden - Variationen und Veränderungen aufweisen, also nicht identisch an die Nachkommen kopiert werden. So stellt sich auch die von biologistisch-rassistischen Theoremen oftmals propagierte, konstante Vererbung von Genen bzw. von erworbenen Eigenschaften, wie des Intelligenzphänomens, als fehlerhaft heraus (s. Kapitel 5.4).

Darüber hinaus tragen auch Genommutationen zur Vielfalt und Einzigartigkeit jedes menschlichen Genotyps bei. Diese betreffen jedoch die Veränderung der Anzahl ganzer Chromosomensätze. ${ }^{1778}$ Auf der einen Seite können Haploidisierungen entstehen, bei denen das Genom auf einen einfachen Chromosomensatz reduziert wird, sowie auf der anderen Seite sogenannte Polyploidisierungen, die den Chromosomensatz verdoppeln oder vervielfachen. ${ }^{1779}$ Weiterhin können durch Fehlverteilungen der Chromosomen während der Mitose - der Aufteilung der DNA einer Zelle auf zwei neu entstehende Tochterzellen - sowie während der Meiose sogenannte Non-disjunctions und numerische Chromosomenaberrationen, sogenannte Aneuploidien, entstehen. Hier wird die Anzahl einzelner Chromosomen verändert. ${ }^{1780}$

\section{„Genommutationen sind Veränderungen der Chromosomenzabl (Aneuploidien). “781}

Chromosomen- und Genommutationen visualisieren so beide auf eindeutige Weise, wie anfällig der menschliche Genotyp für Veränderungen und Variationen ist, die größtenteils spontan auftreten. Trotz aller negativen Folgen, die diese Mutationen hervorbringen können, belegen sie gleichzeitig die Vielfältigkeit der mensch-

\footnotetext{
1775 Vgl. Buselmaier/Tariverdian 2007, a. a. O., S. 65ff, 71.

Deletion und Duplikation sind beispielsweise ebenfalls bei dem Vorgang der chromosomalen Rekombination möglich, der während der Meiose auftreten kann (s. Kapitel 5.3.5). Vgl. Markl 2006, a. a. O., S. $331 \mathrm{ff}$.

1776 Vgl. Markl 2006, a. a. O., S. 354.

1777 Vgl. Buselmaier/Tariverdian 2007, a. a. O., S. 65ff, 71.

1778 Vgl. Munk 2010, a. a. O., S. 307.

1779 Vgl. Munk 2010, a. a. O., S. 379.

1780 Zellen, die nach Genommutationen ein oder mebrere Chromosomen zu viel aufweisen, werden als byperploid, Zellen, die nach Genommutationen ein oder mehrere Chromosomen zu wenig aufweisen, als bypoploid bezueichnet. Vgl. Buselmaier/Tariverdian 2007, a. a. O., S. 64. 
lichen Genotypen und damit der menschlichen Individuen. Genetisch homogene, ,reine ${ }^{6}$ Menschengruppen sind auf dieser Grundlage ebenso wenig zu erklären wie die Existenz von menschlichen Subspezies. Hierfür sind die genotypischen Unterschiede zwischen einzelnen Menschen statistisch gesehen mit 0,1 Prozent zu minimal.

\subsubsection{Rekombinationsereignisse als Ursache von Mutationen}

Einen weiteren entscheidenden Einfluss auf die genetische Vielfalt des modernen Menschen hat ursächlich der Mechanismus der sogenannten Rekombination. Im Fokus stehen diesbezüglich die Rekombinationsprozesse, also Neukombinationen von Chromosomenbestandteilen, während des Vorgangs der Meiose. ${ }^{1782}$ Insbesondere „[b]ei der geschlechtlichen Fortpflanzung werden Allele neu gemischt und nach dem Zufallsprinzip verteilt; auf diese Weise entstehen neue individuelle Genotypen."1783 Insgesamt können im Verlauf der Meiose drei Variabilitätsmechanismen differenziert werden, die zur Rekombination von genetischem Material führen: Zum einen kann es zu sogenannten Non-disjunctions kommen, einer Fehlverteilung der Chromosomen während der Meiose - diese werden als interchromosomale Rekombinationen bezeichnet. Die Chromosomen werden also frei neu kombiniert, was jedoch auch negative Auswirkungen, wie Aneuploidien, zur Folge haben kann. Die Verteilung respektive die Segregation von mütterlichen und väterlichen Chromosomen auf die Tochterzellen erfolgt dennoch vollkommen willkürlich - jede der neu entstehenden Tochterzellen stellt eine Neukombination der elterlichen Chromosomen dar, wie die nachfolgende Grafik vergegenwärtigt.

Insgesamt kann die Zahl der möglichen Rekombinationen für das Genom mit dem Faktor $2^{\text {n }}$ berechnet werden, wobei , $n^{6}$ die haploide Chromosomenzahl darstellt. Für den modernen Menschen würden sich so $2^{23}$, etwa 8 Millionen, Rekombinationsmöglichkeiten je Gamet ergeben. ${ }^{1784}$ Zum anderen können homologe Chromosomenpaare im Prozess des Crossing-Overs Chromosomenabschnitte Gene - untereinander austauschen, was als intrachromosomale Rekombination bezeichnet wird. ${ }^{1785}$ Hierbei werden die DNA-Stränge der Chromosomen gespalten und das Erbmaterial neu verknüpft. ${ }^{1786}$ Auch dies ist eine „,...] wichtige Quelle genetischer Variabilität.“'1787 Beim Vorgang des Crossing-Overs legen sich die homologen Chromosomen von Mutter und Vater aneinander und bilden eine

1782 Deren Ziel ist die Herstellung von haploiden Gameten aus diploiden Zellen, sodass nach der Verschmelzung von Eizelle und Spermium im Verlauf der Befruchtung wieder eine diploide Zygote entsteht, die den Ausgangspunket für die Entwicklung eines neuen Organismus darstellt. Die Meiose läuft hierzu in zwei Schritten, sogenannten Reifeteilungen, ab, in denen Rekombinationsereignisse stattfinden können. Vgl. Markl 2006, a. a. O., S. $281 \mathrm{ff}$.

1783 Markl 2006, a. a. O., S. 535. Auch bei der Mitose finden Rekombinationen statt, jedoch vergleichsweise etwa 100 bis 1.000 mal seltener. Vgl. Graw 2010, a. a. O., S. 183.

1784 Vgl. Markl 2006, a. a. O., S. 287.

1785 Vgl. Markl 2006, a. a. O., S. 535.

1786 Vgl. Munk 2010, a. a. O., S. 316.

1787 Markl 2006, a. a. O., S. 288. 
sogenannte Synapsis, die durch spezielle Proteine, den sogenannten Synaptonemalkomplex, ermöglicht wird. ${ }^{1788}$ Hierbei können Überkreuzungen von differenten homologen Chromosomen stattfinden, die als Chiasmata bezeichnet werden. ${ }^{1789}$ An diesen kann nun der Vorgang des Crossing-Overs, also der Austausch von Chromosomenstücken, stattfinden. Beim modernen Menschen finden im Durchschnitt etwa zwei bis drei dieser intrachromosomalen Rekombinationen pro homologem Chromosomenpaar statt. ${ }^{1790}$

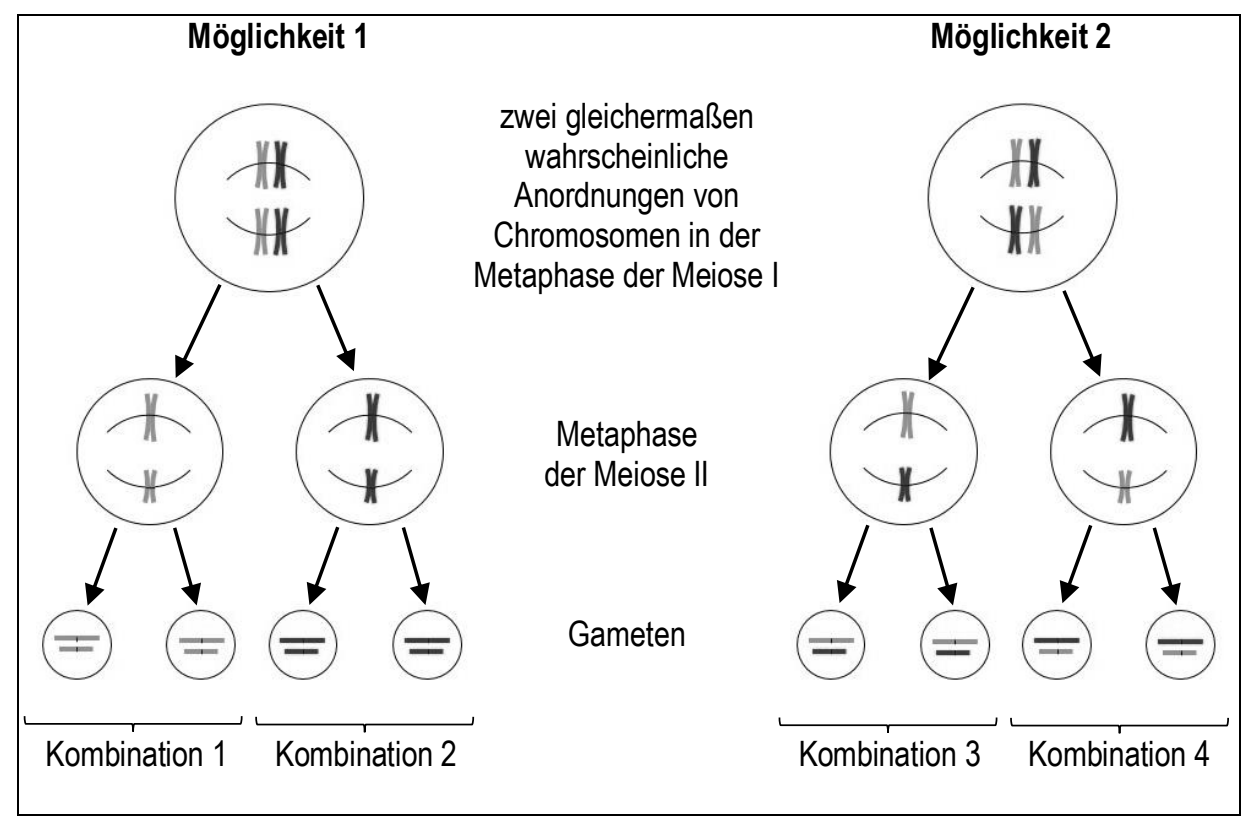

Abb. 18: Möglichkeiten der interchromosomalen Rekombination während der Meiose $e^{1791}$

Weiterhin ist die Zufälligkeit der Befruchtung als Variabilitätsereignis der Meiose aufzuführen. ${ }^{1792}$ Die interchromosomale Rekombination bescheinigt den männlichen und weiblichen Gameten das Vorhandensein von je 8 Millionen Rekombinationsmöglichkeiten. Bei der Verschmelzung von haploider Ei- und Samenzelle müssen die Wahrscheinlichkeiten beider Gameten nun multipliziert werden $\left(2^{23} \mathrm{x}\right.$ $2^{23}$ ), so dass für die Zygote schon etwa 64 Billionen mögliche diploide Rekombinationen existieren. ${ }^{1793}$ Kombiniert mit den Rekombinationsmöglichkeiten durch die intrachromosomale Rekombination, ergibt dies die unglaubliche Anzahl von über 70 Billionen Rekombinationsalternativen. ${ }^{1794}$ Jürgen Markl ist also vollkom-

\footnotetext{
1788 Vgl. Markl 2006, a. a. O., S. $281 \mathrm{ff}$.

1789 Vgl. Markl 2006, a. a. O., S. $281 \mathrm{ff}$.

1790 Vgl. Markl 2006, a. a. O., S. 288.

1791 Eigene Darstellung nach: Vgl. Markl 2006, a. a. O., S. 287.

1792 Vgl. Markl 2006, a. a. O., S. 287.

1793 Vgl. Markl 2006, a. a. O., S. $287 \mathrm{ff}$.

1794 Vgl. Markl 2006, a. a. O., S. 287ff.
} 
men zuzustimmen, wenn er diesbezüglich subsummiert: „Wir alle sind wahrlich einzigartig!"1795 Grundsätzlich bleibt anzumerken, dass die Rekombinationsfrequenz von zwei Genen umso höher liegt, je weiter diese voneinander entfernt auf dem Chromosom verortet sind, da so der größere Zwischenbereich gesteigerte, multiple Möglichkeiten für Veränderungen bietet. ${ }^{1796}$

Vor diesem Hintergrund visualisiert auch das Phänomen der Rekombination deutlich, dass das Genom jedes einzelnen Menschen von zahlreichen Varietäten geprägt ist: „[...] [es] ist ein Schlüssel zur Einzigartigkeit jedes Menschen.“1797 Auch die Rekombination erhöht so die Anzahl der möglichen Allelkombinationen der Nachkommen: „Durch Austausch von Chromosomenbereichen zwischen homologen Chromosomen (Rekombination) wird die Variationsbreite der genetischen Konstitution noch zusätzlich zur Zufallsverteilung der väterlichen und mütterlichen Chromosomen erhöht. “1798 Die Wahrscheinlichkeit, zwei Menschen mit dem identischen Genom anzutreffen, ist selbst bei eineiigen Zwillingen äußerst gering, da sich auch hier im Laufe der Entwicklung unterschiedliche Varietäten ausbilden können. Folglich illustriert auch der Mechanismus der Rekombination, dass alle Menschen genetisch einzigartig sind und sich durch Mutation und Rekombination mehr oder weniger voneinander unterscheiden, obwohl diese Unterschiede aus evolutionsgeschichtlicher Perspektive als nahezu irrelevant charakterisiert werden können. Neuere Forschungsbefunde haben darüber hinaus herausgefunden, dass der Rekombinationsmechanismus zum einen punktuell fokussiert arbeitet und zum anderen auch anfällig für Fehler - für Mutationen - ist, die insbesondere für das Entstehen von Krankheiten relevant sind. ${ }^{1799}$

„Beim Menschen ist diese Rekombination nicht gleichmäßig über das Genom verteilt,
sondern ereignet sich in Hotspots' [...]. Diese Hotspots umfassen demnach Abschnitte
im Erbgut von rund zweitausend DNA-Bausteinen. Darin sei die Cross[ing-]over-Rate
weit höher [...] als in den benachbarten DNA-Sequenzen [...]. " "1800

Somit können mithilfe von Mutation und Rekombination wiederum zahlreiche Vorurteile und Ressentiments von pseudogenetisch argumentierenden Rassisten entkräftet werden: Die genotypischen Charakteristika eines Menschen unterscheiden sich immer von denen der Eltern, sind also nie vollkommen identisch kopiert bzw. vererbt. Selbst wenn die Vererbung von genetisch erworbenen Merkmalen Ausnahme sind einzig angeborene Verhaltenseigenschaften wie Angst- oder Schutzreflexe - möglich ist, worauf neuere Erkenntnisse der sogenannten Epige-

1795 Markl 2006, a. a. O., S. 288.

1796 Vgl. Markl 2006, a. a. O., S. 325.

1797 Spiegel Online (2011a): „,Genkarte erstellt. Wo das Erbgut anfällig führ Fehler ist“, in URL: http://www.spiegel.de/wissenschaft/mensch/genkarte-erstellt-wo-das-erbgut-anfaellig-fuerfehler-ist-a-775714.html <04.08.2012>. | Vgl. Reich, David/Myers, Simon R. et al. (2011): The landscape of recombination in African Americans, in: Nature, Vol. 476, London u. a., S. $170-175$.

1798 Graw 2010, a. a. O., S. 179.

1799 Vgl. Spiegel Online 2011a, a. a. O.

1800 Spiegel Online 2011a, a. a. O. 
netik partiell hindeuten, würden auch hier kleinere Variationen auftreten, die möglicherweise weitreichende Folgen haben könnten. ${ }^{1801}$ „Jedes Spermium ist anders"1802 titelt ein Forschungsbericht der Stanford University im Juni 2012. Mithilfe der genetischen Kartierung von männlichen Spermien konnte hier festgestellt werden, dass zwischen jedem einzelnen Spermium eines Mannes deutliche genetische Differenzen existieren. ${ }^{1803}$ Zusätzlich konnten auch gegenüber der DNA normaler Körperzellen durchschnittlich 23 Variationen beobachtet werden. ${ }^{1804}$

„In jeder Spermienzelle fanden die Forscher [...] zwischen 25 und 36 Mutationen in einzelnen DNA-Bausteinen. Diese Veränderungen waren neu in den Zellen entstanden. Das Ergebnis hilft zu erklären, wie Eltern ihre Eigenschaften an ihre Kinder weitergeben - und warum Kinder keine Kopien ibrer beiden Elternteile sind. "1805

Die Existenz von ,reinen Rassen` bleibt folglich ebenso wie eine konstante, standardisierte ,Rassenklassifizierung' des modernen Menschen auch auf der Basis des Rekombinationsphänomens ein Phantasma. Hinzukommend erscheint es ebenfalls unrealistisch, anhand des Genotyps ,nützlichere‘ gegen ,unnützere‘ Menschen zu hierarchisieren. Denn sämtliche Gene, die als diesbezügliche spezifische ,Menschengruppengene' instrumentalisiert werden könnten, unterscheiden sich in mehr oder weniger weitgehenden Mutations- und Rekombinationsereignissen von Individuum zu Individuum. „Ausmaß und Art [...] [der] genetischen Mischung [durch Mutation und Rekombination sind] [...] dabei einzigartig für jedes Spermium und jede Eizelle. "1806, so der eben zitierte, aktuelle Forschungsbericht. Demnach bestätigen auch Mutation und Rekombination auf molekulargenetischer Ebene die

1801 Die sogenannte Epigenetik stellt eine der zentralen Themen der Genetik im 21. Jabrbundert dar. Sie beschäftigt sich mit Mechanismen und Konsequenzen vererbbarer Chromosomenmodifikationen sowie deren Wirkung auf den Phänotyp von Individuen. Welchen Einfluss haben beispielsweise entwicklungs- und umweltabhängige Veränderungen auf das Genom? Fachliche Grundlage ist die Annabme, dass Chromosomen durch chemische Modifikationen nachträglich verändert werden können, nicht jedoch die DNA-Sequenz selbst. Ziel der Forschung ist das vertiefte Verständnis der Steuerung der Genaktivität, beispielsweise der Funktionsweise der Genaktivierung und-abschaltung. Für den Menschen ist die Vererbung von Chromosomenmodifikationen jedoch schwierig nachweisbar, da sich qualitative Forschungsmethoden verbieten. Vgl. Hallgrímsson, Benedikt/Hall, Brain Keith (2011): Introduction, in: ebd. (Hrsg.): Epigenetics: Linking Genotype and Phenotype in Development and Evolution, Berkeley u. a., S. 1ff. | Vgl. Hallgrímsson, Benedikt/Hall, Brain Keith (2011): Epigenetics: The Context of Development, in: ebd.

(Hrsg.): Epigenetics: Linking Genotype and Phenotype in Development and Evolution, Berkeley u. a., S. $424 \mathrm{ff}, 435$.

1802 Spiegel Online (2012a): „Erbgut-Analyse. Jedes Spermium ist anders“, in URL: http://www.spiegel.de/wissenschaft/mensch/genetik-erbgut-in-samenzellen-eines-mannesunterscheidet-sich-stark-a-845469.html <04.08.2012>. | Vgl. Wang, Jianbin/Fan, Christina H./Behr, Barry/Quake, Stephen R. (2012): Genome-wide Single-Cell Analysis of Recombination Activity and De Novo Mutation Rates in Human Sperm, in: Cell, Vol. 150, München, S. 402-412. Vgl. Spiegel Online 2012a, a. a. O.

1804 Vgl. Spiegel Online 2012a, a. a. O.

1805 Spiegel Online 2012a, a. a. O.

1806 Spiegel Online 2012a, a. a. O. 
wirklichkeitsfremde Argumentations- und Erklärungsgrundlage des biologischgenetisch konnotierten Rassismusphänomens.

\subsubsection{Zusammenhang von induzierten Mutationen und Umweltfaktoren}

Die folgenden Kapitel visualisieren nun nochmals den Zusammenhang von Umweltfaktoren und Genotyp auf molekulargenetischer Ebene, um zu verdeutlichen, dass genotypische und phänotypische Informationen nicht unbeeinflusst vererbt werden können. Folglich ist auch die identische Ausprägung von Merkmalen - ob genetisch festgelegt oder nicht - von vielfältigen Umgebungsbedingungen abhängig, die eine identische Vererbung erworbener Eigenschaften als unrealistisch skizzieren. Hierzu illustriert das folgende Kapitel den unüberwindbaren Zusammenhang von abiotischen Umweltfaktoren und dem Zustandekommen von induzierten Mutationen. Die vorherigen Kapitel charakterisieren induzierte Mutationen schon als von außen gesteuerte bzw. von außen eingeleitete Mutationsereignisse, die im Gegensatz zum Großteil aller Mutationen eben nicht spontan entstehen.

Induzierte Mutationen treten demzufolge meist aufgrund des Einwirkens von mutagenen Agenzien - vielfältigen chemischen und physikalischen Umwelteinflüssen - auf. ${ }^{1807}$ Unterschieden werden können hierbei die ultraviolette Strahlung (UV-Strahlung), ionisierende Strahlung sowie chemische Mutagene. ${ }^{1808}$ Die UVStrahlung, insbesondere die UV-B-Strahlung, wirkt beispielsweise direkt auf die DNA ein und induziert dort, ausgelöst durch fotochemische Reaktionen, die Entstehung von anomalen DNA-Veränderungen. ${ }^{1809} \mathrm{UV}$-A-Strahlung führt dahingegen meist zu oxidativen Schäden der DNA, wie beispielsweise zur Entstehung von DNA-Strangbrüchen. ${ }^{1810}$ Aufgrund differierender theoretischer Schätzungen kann belegt werden, dass nach zwei Stunden intensivstem Sonnenkontakt, beispielsweise bei konzentriertem Sonnenkonsum, etwa 40 Prozent der Hautzellen geschädigt sind, was die Existenz der Vielzahl an Reparaturenzymen der DNA berechtigt (s. Kapitel 5.3.3).1811 Ionisierende Strahlung, wie Röntgenstrahlung, Protonen- und Neutronenstrahlung aus dem Weltall, radioaktive Strahlung oder $\gamma$ Strahlen, führen zum Großteil ebenfalls Einzel- und Doppelstrangbrüche der DNA oder Veränderungen einzelner Basen herbei. ${ }^{1812}$ Sie wirken direkt auf die Struktur der DNA ein. ${ }^{1813}$ Insbesondere die DNA-Strangbrüche erweisen sich meist spätestens nach der Mitose für die neu entstehenden Zellen als letal.1814

\footnotetext{
1807 Vgl. Graw 2010, a. a. O., S. 414.

1808 Vgl. Graw 2010, a. a. O., S. 414ff.

1809 Vgl. Graw 2010, a. a. O., S. 414ff. | Vgl. Munk 2010, a. a. O., S. $396 \mathrm{ff}$.

So entstehen beispielsweise sogenannte Pyrimidin-Dimere zwischen benachbarten Basen der DNA oder es folgen spontane Desaminierungen.

1810 Vgl. Graw 2010, a. a. O., S. $415 \mathrm{ff}$.

1811 Vgl. Knußmann 1996, a. a. O., S. 482.

Damit zusammen bängt auch die durch den übermäßigen Sonnenkonsum angestiegene Körpertemperatur, die bei über $45^{\circ} \mathrm{C}$ zunehmende Polyploidisierungen beschleunigt.

1812 Vgl. Graw 2010, a. a. O., S. $416 f$.

1813 Vgl. Munk 2010, a. a. O., S. 396.

1814 Vgl. Graw 2010, a. a. O., S. $416 f$.
} 
Wissenschaftlich noch nicht endgültig erforscht sind die Auswirkungen von konzentrierten elektromagnetischen Feldern auf den menschlichen Organismus, wie sie beispielsweise von Hochspannungsleitungen oder verschiedensten Haushaltsgeräten ausgehen. ${ }^{1815}$

„Energiereiche Strablung bewirkt vorwiegend Chromosomenbrüche. Diese Wirkung der Strablung berubt vor allem auf ibrer ionisierenden Eigenschaft. Durch Strablung entsteben auch freie Radikale und andere Oxidationsprodukte in der Zelle. Sie führen zu Basenveränderungen. " 816

Vor allem die ionisierende Strahlung nimmt in den letzten Jahrzehnten durch wirtschaftliche Weiterentwicklungen sowie durch den Prozess der Globalisierung stark zu, wie beispielsweise Strahlungen im medizinischen Bereich, radioaktive Strahlungsspitzen von Kernkraftwerken oder radioaktiver Fall-out von Kernwaffen(-experimenten). ${ }^{1817}$ Mit der Erhöhung der Strahlendosis steigt folglich auch die Mutationsrate. ${ }^{1818}$ Sowohl UV- als auch ionisierende Strahlung unterscheiden sich durch ihre Eindringtiefe in das menschliche Gewebe und die ausgelösten Schädigungen. Je tiefer die Strahlungen vordringen können, desto umfangreicher gestalten sich meist auch die stattfindenden zellulären Veränderungen.

„Schon eine einzige Ionisierung durch ein einriges Strahlungsquantum Kann einen genetischen Defekt verursachen. "1819

Zuletzt wirken sich auch zahlreiche chemische Mutagene negativ auf die Erbinformationen des Menschen aus, da auch sie zu Veränderungen der DNADoppelhelix führen. ${ }^{1820}$ Speziell im 21. Jahrhundert erlangen die chemischen $\mathrm{Mu}-$ tagene durch ihre zunehmende, weltweite Verbreitung sowie die durch den Menschen eigenständig betriebene Erzeugung dieser - beispielsweise durch die Nahrung, die Luft oder über die Haut - immer größere Bedeutung. ${ }^{1821}$ Sie übertreffen in großen Teilen die Wirkung von UV-Strahlen und ionisierender Strahlung, obwohl auch diese im Zuge der weltweiten Klimaveränderung an Intensität gewinnen. Viele chemische Mutagene weisen so eine hohe Kanzerogenität somatischer Zellen auf und führen in Verbindung mit generativen Zellen mit erhöhter Wahrscheinlichkeit zu Fehlbildungen während der Embryonal- und Fetalentwicklung nachfolgender Generationen. ${ }^{1822}$ Meist sind diese mutagenen Agenzien als integrative Bestandteile in Nahrungsmitteln vorhanden oder entstehen erst durch multip-

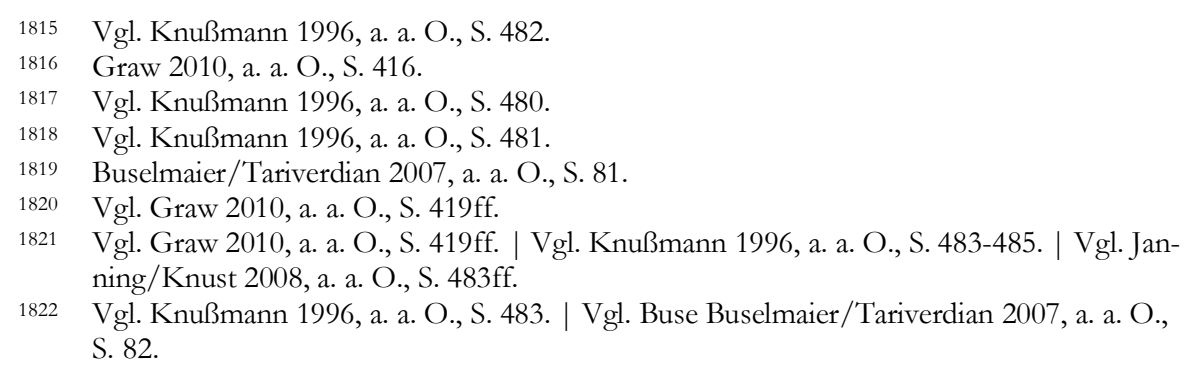


le Stoffwechselprozesse im menschlichen Organismus. ${ }^{1823}$ Die Genetiker Jochen Graw, Rainer Knußmann, Wilfried Janning und Elisabeth Knust zählen diesbezüglich jeweils eine beeindruckende Anzahl an chemischen Mutagenen auf, die bei genauerer Analyse in vielen Nahrungsmitteln und Alltagsstoffen anzutreffen sind. ${ }^{1824}$ Die Wirkungen chemischer Mutagene sind vollkommen unterschiedlich, zum Großteil jedoch auf die DNA beschränkt: Nukleinsäureantimetaboliten greifen beispielsweise direkt in den DNA-Stoffwechsel ein und verhindern dort die Proteinbiosynthese oder die DNA-Replikation. ${ }^{1825}$ Weiterhin können sogenannte Desaminierungen, die zu Veränderungen und Verschiebungen der Basenpaarungen der DNA durch das Einschieben von Molekülen führen, oder Chromosomenbrüche, die Chromosomenaberrationen zu Folge haben, entstehen. ${ }^{1826}$
„Basenveränderungen können sich spontan aufgrund der chemischen Eigenschaften (...) von Nucleinsäurekomponenten ereignen oder durch chemische Einflüsse von außen indu- ziert werden." "827 „[...] [Sie] fübren zu Veränderungen von Basenpaaren in Zusam- menhang mit der Replikation. "1828 „[Weitere] Folgen davon sind Fehlpaarungen von Basen während der Replikation, Hemmung der Replikation [...] und Chromosomenab- errationen." 829

Der Einfluss zahlreicher mutagener Umwelteinflüsse auf die molekulargenetische Ebene der Zelle illustriert folglich, dass die chemischen bzw. physikalischen Umweltfaktoren einerseits einen entscheidenden Beitrag bei der Ausbildung von Merkmalen sowie andererseits bei der Vererbung von spezifischen Charakteristika spielen. Aufgrund der angesprochenen ökonomischen Globalisierung werden diese umweltbedingten Einflüsse auf die menschliche DNA eher noch zunehmen als sich reduzieren. Spezifische Umweltfaktoren werden also auch weiterhin einen entscheidenden, wenn nicht sogar den entscheidenden Faktor für die generationenübergreifende, genotypische Weitergabe vielfältiger Charakteristika generieren. Das nachfolgende Kapitel wird diese Erkenntnisse im Zusammenhang mit dem Vererbungsprozess nochmals vertiefen. Grundsätzlich können jedoch schon an dieser Stelle abermals beispielsweise sämtliche pseudowissenschaftliche und rassistische Prozentberechnungen der angeblich konstanten Erblichkeit von menschlichen Merkmalen als gescheitert identifiziert werden, da es fast unmöglich bzw. unwahrscheinlich und unrealistisch erscheint, die zahlreichen Auswirkungen mutagener Umwelteinflüsse statistisch korrekt und umfänglich zu berücksichtigen.

\footnotetext{
1823 Vgl. Graw 2010, a. a. O., S. 420.

1824 Vgl. Graw 2010, a. a. O., S. 421 ff. | Vgl. Knußmann 1996, a. a. O., S. 483-485. | Vgl. Janning/Knust 2008, a. a. O., S. 198.

1825 Vgl. Knußmann 1996, a. a. O., S. 485.

1826 Vgl. Knußmann 1996, a. a. O., S. 485.

1827 Graw 2010, a. a. O., S. 422.

1828 Graw 2010, a. a. O., S. 423.

1829 Graw 2010, a. a. O., S. 424.
} 


\subsubsection{Umwelt und Gene}

Die vorherigen Kapitel illustrieren detailliert, dass genotypische Differenzen zwischen spezifischen Menschen auch von vielfältigen Umweltfaktoren beeinflusst sind. Unter ,Umwelt ${ }^{6}$ werden dabei alle nicht-erblichen Einflüsse auf die individuelle Entwicklung verstanden, welche individuell unterschiedlich wirken. ${ }^{1830}$ Diese ist folglich für die Ausbildung und Entwicklung vieler biologischer, psychischer und sozialer Eigenschaften des menschlichen Organismus hauptverantwortlich. Selbstverständlich erscheinen diese Variablen aus evolutionsbiologischer Perspektive minimal bis unbedeutend für die Entwicklung des modernen Menschen, denn auf die Evolution des Menschen zurückblickend müssen die zahlreichen genotypischen Gemeinsamkeiten des Homo sapiens von 99,9 Prozent hervorgehoben werden. 1831 Umwelteinflüsse und Gene tragen dennoch seitens der genetischen Forschung eher zur Unterschiedlichkeit zwischen einzelnen Individuen und weniger zur Ähnlichkeit dieser bei. ${ }^{1832}$ Jedoch operieren Umwelteinflüsse nicht selbstständig, sondern sind immer im Zusammenwirken mit den genotypischen Faktoren zu bewerten, wie der weitere Verlauf skizzieren wird. Von Vornherein muss dem weit verbreiteten Missverständnis entgegen getreten werden, welches entweder nur ,die Umwelt oder aber nur die Gene im Zusammenhang mit der Vererbung sieht; beide Faktoren sind für das Verständnis der Ausprägung von Fähig- und Fertigkeiten bedeutend. ${ }^{1833}$ Trotz der fraglichen Anwendung von prozentualen Hierarchisierungen zwischen Umwelt- und genetischem Einfluss bleibt demnach zu bemerken:

„Die Erblichkeit übersteigt selten 50 Prozent, was bedeutet, dass die ,Umweltbedingtbeit" selten weniger als 50 Prozent beträgt." "834

Charakteristisch an den Umwelteinflüssen auf den Genotyp jedes Individuums ist die - teilweise unbekannte - Vielfalt, Variabilität und Stärke, mit der die umweltassoziierten Faktoren die genetischen Informationen jedes Menschen zu beeinflussen ermöglichen. Ursache dessen ist, dass die multiplen Umwelten überwiegend individuell und menschenspezifisch ausgerichtet sind - jeder Mensch besitzt sein individuelles Setting an Umwelteinflüssen, selten bis nie werden diese spezifischen Umwelteinflüsse mit anderen Individuen oder gar Populationen geteilt. ${ }^{1835}$ Psychologe Robert Plomin diagnostiziert so unter anderem, dass „Umwelteinflüsse $[\ldots]$ weitgehend in nicht geteilter weise [wirken] und [dazu] führen [...], dass in derselben Familie aufwachsende Kinder sich voneinander unterscheiden." 1836 Genotypisch wirken Umweltfaktoren also spezifisch, so dass von einer „[...]

\footnotetext{
1830 Vgl. Dunn, Judy/Plomin, Robert (1996): Warum Geschwister so verschieden sind, Stuttgart, S. $54 f ., 60$.

1831 Vgl. Plomin et al. 1999, a. a. O., S. 67.

1832 Vgl. Plomin et al. 1999, a. a. O., S. 214. | Vgl. Dunn/Plomin 1996, a. a. O., S. 44.

1833 Vgl. Plomin/DeFries/McClearn 1990, a. a. O., S. $1 \mathrm{ff}$.

1834 Plomin et al. 1999, a. a. O., S. 214.

1835 Vgl. Plomin et al. 1999, a. a. O., S. 221.

1836 Plomin et al. 1999, a. a. O., S. 221.
} 
nichtgeteilte[n] Umwelt [...]“"1837 gesprochen werden kann. Insbesondere die abiotischen Umwelteinflüsse können jedoch auch lebensraumübergreifend wirken, wenn dieser homologe Umweltbedingungen für alle dort lebenden Individuen zur Verfügung stellt (s. Kapitel 5.3.6). Ein Beispiel stellt die unterschiedliche Hautpigmentierung des modernen Menschen je nach Kontinent und Klimazone dar: Alle Menschen gehören zur Spezies Homo sapiens und haben einen ähnlichen, fast identischen Genotyp. Die abiotische Umwelt formt jedoch mithilfe der Sonnenbzw. UV-Einstrahlung das phänotypische Aussehen individuell, gibt aufgrund dessen aber keinerlei Verwandtschaftsgrad zwischen einzelnen Individuen an. ${ }^{1838}$ Sämtliche Umwelteinflüsse - gleich ob chemisch-physikalischer, biologischer, sozialer oder kultureller Herkunft - wirken auf jeden Organismus individuell sowie auf Menschenpopulationen mit ähnlichen Umwelt- und Lebensbedingungen korrespondierend ein. Phänotypische Differenzen zeigen sich jedoch - im Gegensatz zu genotypischen Unterschieden - ausschließlich oberflächlich, beispielsweise anhand der unterschiedlichen Hautfärbung, die durch die differenzierte Einlagerung und Aktivierung von melaninhaltigen Zellen, sogenannten Melanozyten, ausgeprägt wird. ${ }^{1839}$

Die vielfältigen Umwelteinflüsse auf den Phäno- und insbesondere auf den Genotyp zeigen sich so scheinbar unendlich differenziert: Biologische, biomedizinische, chemische, physikalische, soziale oder kulturelle Faktoren scheinen zu interagieren. ${ }^{1840}$ Die Umwelt produziert folglich ,[...] ein ganz beachtliches Aktionsfeld. "1841 In der quantitativ-genetischen Theorie hat das Umweltphänomen dazu einen relativ breiten Definitionsrahmen: Von biotischen und abiotischen Umwelteinflüssen, der Sozialisation, dem familiären Umfeld, der Gesellschaft bis zu den ökonomischen Ressourcen sind vielfältige Einflussfaktoren existent. ${ }^{1842}$ Dies verdeutlicht die nachfolgende exemplarische Übersicht.

1837 Plomin et al. 1999, a. a. O., S. 68.

Differenziert werden muss in diesem Zusammenhang zwischen der sogenannten nicht-geteilten Individualumwelt (non-shared) sowie der geteilten Familienumwelt (shared). Beide sind für jedes Individuum sperifisch, auch bei monosygoten Zwillingen. Darüber hinaus bestätigen neuere Forschungsergebnisse auch die Altersabbängigkeit des Einflusses von Umweltfaktoren. Die nicht-geteilte Umwelt spielt demnach im Kindesalter eine untergeordnete Rolle, dominiert jedoch im Erwachsenenalter. Vgl. Zimmer, Dieter E. (2012): Ist Intelligenz erblich? Eine Klarstellung, Reinbek bei Hamburg, S. 168ff. | Vgl. Plomin/DeFries/McClearn 1990, a. a. O., S. 388ff. | Vgl. Bartels, M./Rietveld, M. J. H./Van Baal, G. C. M./Boomsma, D. I. (2002): Genetic and Environmental Influences on the Development of Intelligence, in: Behavior Genetics, Vol. 32, No. 4, Heidelberg u. a., S. 247.

Vgl. Olson 2003, a. a. O., S. 25.

Vgl. Dobzhansky 1962, a. a. O., S. 339.

Zimmer, Dieter E. (1975): Der Streit um die Intelligenz. IQ: ererbt oder erworben?, München u. a., S. 83.

1842 Vgl. Plomin et al. 1999, a. a. O., S. 214. 
Tab. 26: Umwelteinflüsse auf Weitergabe und Ausprägung von Eigenschaften ${ }^{1843}$

\begin{tabular}{|c|c|c|c|}
\hline \multicolumn{3}{|c|}{$\begin{array}{c}\text { Biologische, chemische und physikalische } \\
\text { Umweltfaktoren }\end{array}$} & \multirow{2}{*}{$\begin{array}{l}\text { Kulturelle \& soziale } \\
\text { Umweltfaktoren }\end{array}$} \\
\hline Biotisch & Abiotisch & Medizinisch & \\
\hline $\begin{array}{l}\text { Parasitismus } \\
\text { Symbiose } \\
\text { Konkurrenz } \\
\text { Fressfeind-Beute- } \\
\text { Beziehungen }\end{array}$ & $\begin{array}{c}\text { Strahlung } \\
\text { Temperatur } \\
\text { Wasser } \\
\mathrm{CO}_{2}, \mathrm{O}_{2} \\
\text { Nährstoffe } \\
\text { Mechanische Ein- } \\
\text { flüsse } \\
\text { Wind } \\
\text { Bodenstruktur } \\
\text { Chemische Kom- } \\
\text { ponenten } \\
\text { u. a. }\end{array}$ & $\begin{array}{c}\text { Unfälle } \\
\text { Prä- und perinatale } \\
\text { Schädigungen } \\
\text { Erkrankungen } \\
\text { Traumata } \\
\text { Kriege } \\
\text { u. a. }\end{array}$ & $\begin{array}{l}\text { Familiensituation } \\
\text { Peergroup } \\
\text { Schulische Bildung } \\
\text { Finanzielle Möglich- } \\
\text { keiten } \\
\text { Soziales Lebensum- } \\
\text { feld } \\
\text { Lebensstandard } \\
\text { Erziehung und Sozia- } \\
\text { lisation } \\
\text { u. a. }\end{array}$ \\
\hline
\end{tabular}

Wie lassen sich nun umweltbedingte und genotypische Einflüsse auf den Vererbungsprozess von Genen bzw. Merkmalen differenzieren? Sämtliche aus der Tierund Pflanzenzüchtung adaptierte Methoden bezüglich möglicher sogenannter Erblichkeitsschätzungen - die den genetischen Vererbungsanteil zu quantifizieren versuchen - zeigen sich für den Menschen nur eingeschränkt anwendbar, wie das nachfolgende Kapitel am Beispiel der Intelligenz erläutert (s. Kapitel 5.4). Viele quantitativ-genetische Methoden, wie die Zwillings- oder Adoptionsforschung, zeigen sich die Untersuchung des menschlichen Verhaltens und der Vererbung betreffend nur partiell geeignet. ${ }^{1844}$ Aussagekräftiger und datentechnisch verwertbarer wären experimentelle Inzuchtstudien oder genetische Manipulationsversuche ähnlich wie bei tierischen Forschungsansätzen, die jedoch auf Untersuchungen am Menschen in dieser Weise nicht übertragbar sind. ${ }^{1845}$

So stehen größtenteils nur die quasi-experimentellen und semi-validen Untersuchungen zum relativen Einfluss von Genen und Umwelt auf die Vererbung im Rahmen der Zwillings- und Adoptionsstudien zur Verfügung, die jedoch oftmals als absolute Einschätzungen präsentiert werden.1846 Die folgende Grafik veranschaulicht, dass sowohl Adoptions- als auch Zwillingsstudien gegebenenfalls nur Tendenzen bzw. relative Einschätzungen vornehmen, niemals jedoch mit absoluten Daten Genotyp versus Umwelt eindeutig klassifizieren können. So bemerkt unter anderem Robert Plomin bezüglich der Zwillingsstudien, dass bei einer an-

1843 Eigene Darstellung nach: Vgl. Zimmer 2012, a. a. O., S. 149. | Vgl. Dunn/Plomin 1996, a. a. O., S. $81 \mathrm{ff}, 111 \mathrm{ff}, 145 \mathrm{ff}$.

1844 Vgl. Plomin et al. 1999, a. a. O., S. 65.

Mithilfe von Zwillings- und Adoptionsstudien wird seitens der Molekular- und Verhaltensgenetik versucht festzustellen, in welchen relativen Anteilen Gene sowie Umwelten an der Vererbung von spezifischen Fäbigund Fertigkeiten verantwortlich sind.

1845 Vgl. Plomin et al. 1999, a. a. O., S. 65.

1846 Vgl. Plomin et al. 1999, a. a. O., S. 65. 
geblich höheren genetischen Beeinflussung eines Merkmals auch identische Umweltfaktoren - equal environments assumptions - verantwortlich sein können. ${ }^{1847}$

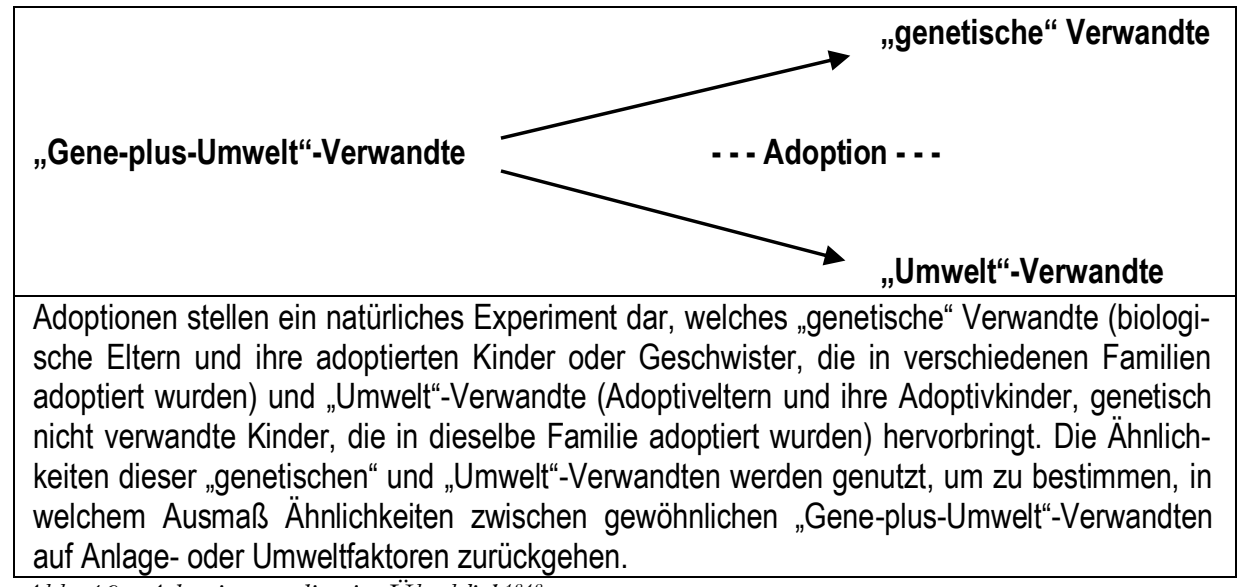

Abb. 19: Adoptionsstudien im Überblicke ${ }^{1848}$

Weiterhin müssen die charakteristischen Einschränkungen der Zwillingsmethode beachtet werden, die auf zwillingsspezifischen Besonderheiten beruhen: Unter anderem führen demzufolge genetische, medizinische aber auch psychologische Charakteristika von Zwillingen zu unterschiedlichen Ergebnissen und Bewertungen. ${ }^{1849}$ Auch die biologisch bedingt relativ geringe Probandenzahl stellt die Reliabilität und die Generalisierbarkeit der Untersuchungen in Frage, da die Zwillingsentstehung, insbesondere die von eineiigen Zwillingen, auch vom Einwirken von Umweltfaktoren abhängig ist. ${ }^{1850}$ Hinzukommend zeigen auch die genetischen Ergebniskorrelationen der Zwillingsstudien, dass hier lediglich von relativen Bewertungen gesprochen werden kann, die zum Teil grobe Schätzfehler enthalten und teilweise deutlich voneinander divergieren. ${ }^{1851}$

„Aus diesem Grund können Erblichkeitsschätzungen aufgrund einzelner Studien nur als äußerst grobe Schätzungen verstanden werden, die von einem großen Konfidenzintervall umgeben sind [...]. "1852

Mögliche Erblichkeitsschätzungen und -beiträge beziehen sich demnach lediglich auf denkbare interindividuelle, genotypische Unterschiede, die vor dem Hintergrund einer relativ großen Spannweite betrachtet werden müssen. ${ }^{1853}$ Definitive Aussagen bezüglich des Phänotyps sind jedoch nicht zulässig. Ein Beispiel:

1847 Vgl. Plomin et al. 1999, a. a. O., S. 71.

1848 Eigene Darstellung nach: Plomin et al. 1999, a. a. O., S. 66.

1849 Vgl. Buselmaier/Tariverdian 2007, a. a. O., S. $362 f$.

1850 Vgl. Graw 2010, a. a. O., S. 616.

1851 Vgl. Plomin et al. 1999, a. a. O., S. 75.

1852 Plomin et al. 1999, a. a. O., S. 75.

1853 Vgl. Plomin et al. 1999, a. a. O., S. 77. 


\begin{abstract}
„Die Erblichkeit des Merkmals Körpergröße beträgt beispielsweise etwa 90 Prozent. Dies bedeutet jedoch nicht, dass 90 Prozent der Größe einer bestimmten Person von genetischen Faktoren gesteuert wurden und die restlichen Zentimeter von der Umwelt hinzugefügt wurden. Es bedeutet vielmehr, dass ein Großteil der Unterschiede zwischen Personen im Merkmal Körpergröße auf genetische Unterschiede zwischen diesen Personen zurückegeht." "1854
\end{abstract}

Aufgrund dessen bleibt festzuhalten, dass sowohl Genotyp als auch Umwelt von entscheidender Bedeutung für die generationenübergreifende Weitergabe von Erbinformationen sowie für die Entwicklung und Ausprägung von menschlichen Eigenschaften sind. ${ }^{1855}$ Die Bedeutung von beiden Faktoren ändert sich jeweils nur, wenn genetische Einflüsse oder Umweltbedingungen variieren. ${ }^{1856}$ Demzufolge bleibt die Frage der Akzeptanz und der Beachtung der Ergebnisse von Zwillings- und Adoptionsstudien in der humanbiologischen Forschung auch weiterhin umstritten, insbesondere bezüglich der Generalisierbarkeit auf ganze Menschenpopulationen. ${ }^{1857}$ Aufgrund der molekulargenetischen Forschung des 21. Jahrhunderts kann jedoch eine Übertragbarkeit individueller genetischer Merkmale auf Menschengruppen ausgeschlossen werden. Die Ergebnisse der Erblichkeitsschätzungen beschreiben lediglich den Ist-Zustand zu einem festgelegten Untersuchungszeitpunkt, lassen jedoch keine Zukunftsprognosen bezüglich der weiteren Entwicklung zu. ${ }^{1858}$

\title{
„Die Erblichkeit ist ein statistischer Kennwert zur Beschreibung des Beitrags genetischer Unterschiede an beobachteten Unterschieden zwischen Individuen aus einer bestimmten Population und zu einer bestimmten Zeit. In unterschiedlichen Populationen oder zu ver- schiedenen Zeiten können sich Umwelteinflüsse oder genetische Faktoren unterscheiden, so dass sich auch die Erblichkeitsschätrungen in solchen Populationen unterscheiden können." "1859
}

Auch bei dem Beispiel Körpergröße ist nicht auszuschließen, dass die Umwelteinflüsse einen größeren Effekt auf das Wachstum zeigen könnten - die äußeren Bedingungen sind in der Lage, sich nach Zeit und Umgebung zu ändern. ${ }^{1860} \mathrm{Zu}$ sammenfassend ist festzuhalten, dass die Erblichkeitsschätzungen nicht mit genetischer Determiniertheit gleichgesetzt werden können, was die rassistische Ideologie vornehmlich versucht. ${ }^{1861}$ Umweltbedingte sowie genetische Veränderungen durch Mutationen und Rekombinationen sind jederzeit möglich.

Weiter geht Adolf Heschl, der die Ergebnisse der quantitativ-genetischen Forschung bezüglich der variablen Erblichkeitsschätzungen als tendenziell falsch

\footnotetext{
1854 Plomin et al. 1999, a. a. O., S. 77.

1855 Vgl. Plomin et al. 1999, a. a. O., S. 77.

1856 Vgl. Plomin et al. 1999, a. a. O., S. 78.

1857 Vgl. Plomin et al. 1999, a. a. O., S. 71.

1858 Vgl. Plomin et al. 1999, a. a. O., S. 78.

1859 Plomin et al. 1999, a. a. O., S. 77.

1860 Vgl. Plomin et al. 1999, a. a. O., S. 78.

1861 Vgl. Plomin et al. 1999, a. a. O., S. 79.
} 
charakterisiert. ${ }^{1862}$ Viele statistische Verfahren, wie beispielsweise auch die ZweiWeg-Varianzanalyse ANOVA (Analysis of Variance) seien nicht dafür geeignet, Erblichkeitswerte zu schätzen, da Gen-Umwelt-Interaktionen eben nicht ausgeschlossen werden können - deren Abhängigkeiten können statistisch nur unwahrscheinlich in die Berechnungen integriert werden. ${ }^{1863}$ Darüber hinaus kritisiert er, dass nicht spezifische, individuelle Verhaltensmuster auf genotypische und umweltbedingte Einflüsse überprüft würden, sondern nur hypothetische und unrealistische Verhaltensmuster zur Anwendung kämen. ${ }^{1864}$ Er bezeichnet die Erblichkeitsuntersuchungen und -ergebnisse so als ,[...] Realisierungswahrscheinlichkeiten von bereits vorhandener genetischer Information unter bestimmten Umweltbedingungen [...]. "1865 - je nach Milieu und Umgebung erfolgen unterschiedliche Ergebnisse. ${ }^{1866}$ Vor diesem Hintergrund schlussfolgert Heschl:

\section{„Ganz allgemein kann schließlich für die Gesamtheit der Ergebnisse aus der Erblich- keitsforschung gesagt werden, dass deren Vielfalt letztlich unerklärlich bleiben muss, da niemals eine echt kausale Begründung dafür angegeben werden kann, wieso gerade ein be- stimmter Prozentwert an Erblichkeit oder eben Umweltbedingtheit so ist, wie er eben ist. Der Befund, dass die Vorliebe für bzw. die (verbreitetere) Abneigung gegenüber Jazzmu- sik zu $45 \%$ vererbbar erscheint, ist zwar für sich genommen böchst amüsant, ist aber auch weiter nicht erk.lärbar. "1867}

Der komplexe Vererbungsprozess von Eigenschaften und Charakteristika des modernen Menschen ist also erstens nur im Zusammenspiel mit den vielfältig einwirkenden Umweltfaktoren zu verstehen und zweitens für eindeutig messbare Wahrscheinlichkeits- und Erblichkeitsschätzungen zu komplex. Der menschliche Genotyp gibt vielmehr verschiedene Reaktionsbreiten vor, innerhalb derer die endgültige Ausprägung eines Merkmals individuell eingeordnet und phänotypisch ausgebildet werden kann. Die Begrifflichkeit der Reaktionsbreite bzw. -norm (range of reaction) ist dabei schwierig zu beschreiben - hiermit kann keine Unteroder Obergrenze definiert werden. ${ }^{1868}$ Vielmehr stellt die Reaktionsbreite eine imaginäre Skala bzw. einen imaginären Raum dar, innerhalb dessen die Umwelt aktiv modifizierend eingreift, um die phänotypische Ausprägung festzulegen. ${ }^{1869}$ Die Reaktionsnorm ist ein „,[v]om Genotyp festgelegter Rahmen möglicher Phänotypen, Umweltfaktoren entscheiden [die] Merkmalsausprägung innerhalb dieses Rahmens.“1870 Vererbt wird also folglich auch nicht ein bestimmtes Gen bzw. Merkmal oder eine bestimmte Eigenschaft, sondern nur das Genom bzw. eine

\footnotetext{
1862 Vgl. Heschl, Adolf (1998): Das intelligente Genom. Über die Entstehung des menschlichen Geistes durch Mutation und Selektion, Berlin u. a., S. 130.

1863 Vgl. Heschl 1998, a. a. O., S. 130.

1864 Vgl. Heschl 1998, a. a. O., S. 131.

1865 Heschl 1998, a. a. O., S. 140.

1866 Vgl. Heschl 1998, a. a. O., S. $140 \mathrm{f}$.

1867 Heschl 1998, a. a. O., S. 133.

1868 Vgl. Dobzhansky 1973, a. a. O., S. 18.

1869 Vgl. Dobzhansky 1973, a. a. O., S. 18. | Vgl. Munk 2010, a. a. O., S. 261.

1870 Munk 2010, a. a. O., S. 263.
} 
Reaktionsnorm, auf deren Grundlage die multiplen Umweltfaktoren den Phänound Genotyp eines Individuums gestalten. ${ }^{1871}$ Individuell erworbene Merkmale können also nicht generationenübergreifend sowie statistisch messbar weitergegeben werden. ${ }^{1872}$ Der Genotyp eines menschlichen Individuums stellt dementsprechend nur die Primärwirkung dar, die endgültige Fixierung dessen findet jedoch erst im Laufe der Entwicklung und der Lebenszeit durch die unterschiedliche Ausprägung verschiedener Umweltfaktoren statt. ${ }^{1873}$

Die Diskussion um Umwelteinflüsse versus Erblichkeit lässt sich so mitnichten eindeutig in genetische und umweltbedingte Anlagen differenzieren. Beide Anteile sind vielfach überlappend und ineinander übergehend miteinander verwoben eine eindeutige, mathematische und absolute Bestimmung ihrer Anteile ist aktuell wissenschaftlich nicht realitätsnah, sämtliche Ergebnisse diesbezüglich zeigen sich als überwiegend fehlerbehaftet und wirklichkeitsfremd sowie größtenteils auf der Fantasie möglicher rassistischer PseudoWissenschaftler beruhend. ${ }^{1874}$ Dies gilt in außerordentlichem Maße für das Phänomen der sogenannten Intelligenz (s. Kapitel 5.4). Denn beispielsweise an der Gehirnentwicklung, die die Basis für das Vorhandensein sämtlicher kognitiver Fähigkeiten des menschlichen Organismus darstellt, sind über 1.000 verschiedene Gene beteiligt - manche noch unerforscht -, so dass es wissenschaftlich valide überhaupt nicht möglich ist, einzelne genetische Wirkungen gegenüber möglichen Umwelteinflüssen detailliert zu identifizieren. ${ }^{1875}$ Auch besondere Anfälligkeiten verschiedener Menschengruppen für spezifische Krankheiten sind demzufolge überwiegend auf das Einwirken von unterschiedlichen Umweltfaktoren zurückzuführen. ${ }^{1876}$ Steve Olson bemerkt so treffend, dass sich die Realität viel komplizierter und komplexer erweist als sämtliche halbwissenschaftliche und methodisch fragwürdige Korrelationsstudien diese darzustellen versuchen. ${ }^{1877}$ Jedoch bemerkt er einschränkend:

„Dennoch werden solche Bemühungen auf große Aufmerksamkeit stoßen, weil sie populären Vorurteilen entsprechen. " 878

Festzuhalten bleibt, dass sowohl genetische als auch umweltbedingte Einflüsse eine essentielle Rolle bei der Vererbung von Genen sowie bei der Ausbildung von Phäno- und Genotyp spielen. ${ }^{1879}$ Erbe und Umwelt sind zusammenhängende Faktoren, die bei der Ausprägung und Ausformung menschlicher Fähigkeiten

1871 Vgl. Merz, Ferdinand/Stelzl, Ingeborg (1977): Einführung in die Erbpsychologie, Stuttgart u. a., S. 20.

1872 Die Epigenetike siebt jedoch auf der Grundlage neuer Forschungserkenntnisse die Möglichkeit, dass Modifikationen von Chromosomen vererbt werden können (s. Kapitel 5.3.5).

1873 Vgl. Munk 2010, a. a. O., S. 261.

1874 Vgl. Olson 2003, a. a. O., S. 102.

1875 Vgl. Olson 2003, a. a. O., S. 102.

1876 Vgl. Olson 2003, a. a. O., S. 104.

1877 Vgl. Olson 2003, a. a. O., S. 103.

1878 Olson 2003, a. a. O., S. 103.

1879 Vgl. Plomin et al. 1999, a. a. O., S. 66. 
gemeinsam wirken. ${ }^{1880}$ Die genotypischen Eigenschaften des genetischen Codes, der DNA, stellen lediglich ein grundsätzliches Potenzial zur phänotypischen Entwicklung und Ausbildung eines Organismus dar. Die eigentliche Ausprägung geschieht jedoch in Abhängigkeit und in enger Zusammenarbeit mit den beteiligten Umweltfaktoren: „Die Gene sind nur ein Potenzial; es muss [erst] realisiert werden [...].“"1881 Dieses Zusammenspiel zu ergründen und zu analysieren ist auf biologischer Seite die Aufgabe der evolutionären Ökologie, die sich mit den Einflüssen von biotischen und abiotischen Umweltfaktoren auf die Evolution sowie die Entwicklung von Lebewesen - auch des Homo sapiens - beschäftigt. ${ }^{1882}$

Als Fazit bleibt folglich festzuhalten, dass sowohl die biologistisch-rassistische Fehlinterpretation und Falschauslegung molekulargenetischer Inhalte, fragwürdige Forschungsmethoden als auch unrealistische, experimentelle Ansätze zahlreiche Missverständnisse im Zusammenhang von Vererbung und Umwelt ausgelöst haben. Die relativen Erblichkeitsschätzungen beziehen sich nicht auf Individuen, sondern auf einzelne, untersuchte Populationen in einem bestimmten Zeitrahmen. Sämtliche generationenübergreifend festgelegte Prozentwerte, die eine absolute Messung der Genkoeffizienten am Prozess der Vererbung vorgeben, sind folglich auf den wissenschaftlichen Scheiterhaufen zu verbannen. Somit können mithilfe fehlinterpretierter Versuchsergebnisse keine validierten und verlässlichen Aussagen bezüglich möglicher Vererbungsunterschiede zwischen verschiedenen Menschengruppen postuliert werden. Denn Erblichkeit sowie Gene sind keine festgelegten oder statischen Faktoren. ${ }^{1883}$ Das Vorhandensein von regelmäßigen und vielfältigen, spontanen Gen-, Genom- und Chromosomenmutationen sowie Rekombinationen hat visualisiert, dass sowohl der Genotyp jedes Individuums als auch die einflussreichen Umweltfaktoren vollkommen variabel, flexibel und wandelbar existieren. Änderungen im Bereich der Umweltgestaltung wirken sich folglich auf den Genotyp eines Individuums genauso aus, wie der Genotyp eines Individuums im Gegenzug auf die äußere Umgebung einwirkt. Die Zusammensetzung der DNA sagt ebenso wie das Phänomen der Erblichkeit nichts über die Einflüsse und Effekte verschiedener Umweltfaktoren aus, die die Ausprägung und Entwicklung eines Individuums maßgeblich mitbestimmen. ${ }^{1884}$ Die Abhängigkeit von Umwelt und Genotyp widerlegt so die Interpretation biologistisch-rassistischer Ressentiments, die sowohl eine absolute Erblichkeit in jeder menschlichen Fähigund Fertigkeit sehen, als auch darauf basierend das Vorhandensein von menschlichen Subspezies in Form von unterschiedlichen, angeblich genetisch klar definierbaren ,Menschenrassen'. Die modernen Menschen unterscheiden sich zwar individuell in ihren Genomen, wie die molekulargenetischen Mechanismen von Mutation und Rekombination eindrücklich illustriert haben. Jedoch lassen sich auf-

\footnotetext{
1880 Vgl. Knoche, Werner (1977): Das Erbe-Umwelt-Problem, Frankfurt/Main, S. 35.

1881 Zimmer 1975, a. a. O., S. 88.

1882 Vgl. Sommer 2011, a. a. O., S. 83.

1883 Vgl. Grabowski, Joachim (2007): Atkinsons und Hilgards Einführung in die Psychologie, 14. Auflage, Berlin u. a., S. 581.

1884 Vgl. Grabowski 2007, a. a. O., S. 585.
} 
grund der variablen Umweltfaktoren zwar ähnliche Veränderungen einer Population, aber keine vollkommen identischen genotypischen Variationen diagnostizieren. Umwelt und Gene wirken bei der geno- und phänotypischen Ausprägung von Genen zusammen. ${ }^{1885}$ Der moderne Mensch bleibt demnach für sich biologisch gesehen ein sehr ähnliches, aber unterschiedliches Individuum. Evolutionsbiologisch, zeitlich sowie statistisch - mit einem differierenden Genotyp von 0,1 Prozent - gesehen lassen sich aufgrund dieser geringfügigen Unterschiede keine ,Rassen' - schon gar keine angeblich genetisch homogenen ,reinen Rassen' - nachweisen. Bedeutenden Anteil an diesem Fakt haben die hier vorgestellten Umweltfaktoren - diese sind maßgeblich am Zustandekommen der Variabilität und Einzigartigkeit der menschlichen Bevölkerung beteiligt. ${ }^{1886}$

„So entsteht der Organismus stets auf Grund eines Zusammenspiels von Erbe und Umwelt, und eine geeignete Umwelt ist gleichermaßen für die Entwicklung des Individuums unerlässlich wie ein geeignetes Erbgut. " 8887

\subsubsection{Molekulargenetik und biologisch-genetisch argumentierender Rassismus}

Die vorangegangenen Kapitel verdeutlichen, dass molekular- und humangenetische Prozesse sowie die den Menschen umgebenden Umwelten maßgeblich für die Weitergabe, Ausbildung und Ausprägung von Genen bzw. geno- und phänotypischen Eigenschaften verantwortlich sind. Die Evolutionsfaktoren natürliche Selektion, genetische Drift, Genfluss, Zufall und Mutationen ermöglichen auf molekularer Ebene erst die genetischen Prozesse, die für den von Charles Darwin beschriebenen Evolutionsvorgang notwendig sind. Insbesondere die genetische Drift ist nochmals als einer der Hauptfaktoren der genotypischen Entwicklung und Evolution von Individuen bezüglich des Erhalts, der Forcierung und der Ausbreitung von Mutationen zu nennen. ${ }^{1888}$ „Die genetische Drift ist für alle diese außergewöhnlichen Situationen verantwortlich, die durch Zufallseinwirkung entstanden sind, und [...] erstreckt sich auf alle erblichen Merkmale."1889 Für das 21. Jahrhundert kann die genetische Drift als Evolutionsfaktor jedoch tendenziell in den Hintergrund gerückt werden, da diese sich durch die Vervielfachung des Menschen in den vergangenen Jahrhunderten kaum noch auswirkt. ${ }^{1890}$ Auch der Faktor der natürlichen Auslese ist aufgrund des medizinischen Fortschritts eher als gering einzustufen. ${ }^{1891}$ So kommt den in den vorhergehenden Kapiteln beschriebenen Mutations- und Rekombinationsereignissen eine herausragende Bedeutung im Rahmen der Weiterentwicklung und Evolution des Menschen zu.

\footnotetext{
1885 Vgl. Munk 2010, a. a. O., S. 262.

1886 Vgl. Knußmann 1996, a. a. O., S. 27.

1887 Knußmann 1996, a. a. O., S. 27.

1888 Vgl. Cavalli-Sforza/Cavalli-Sforza 1994, a. a. O., S. 165.

1889 Cavalli-Sforza/Cavalli-Sforza 1994, a. a. O., S. 166.

1890 Vgl. Cavalli-Sforza/Cavalli-Sforza 1994, a. a. O., S. 388.

1891 Vgl. Cavalli-Sforza/Cavalli-Sforza 1994, a. a. O., S. 389.
} 
Gen-, Chromosomen-, Genommutationen und Rekombinationen sind der Ursprung der genetischen Vielfalt des Homo sapiens. ${ }^{1892}$ Sie sorgen - trotz zahlreicher bekannter auslösender Faktoren - meist spontan und ohne erkennbaren Grund für eine genotypische und biologische Individualität jedes modernen Menschen weltweit. 1893

„Eine weitere wesentliche Eigenschaft der Gene, obne die keine evolutionäre Weiterentwicklung denkbar ist, ist also die Fäbigkeit zur spontanen Änderung, zur Mutation. "' 894

Selbst bei - mit identischen genetischen Informationen ausgestatteten - eineiigen Zwillingen können im Laufe der Embryonal- und Fetalentwicklung sowie im Verlauf der weiteren Lebensphase deutliche genotypische Unterschiede auftreten, die durch spontane oder induzierte Mutationen - meist durch Umweltfaktoren begünstigt - hervorgerufen werden. Jeder Mensch ist demnach genetisch gesehen einzigartig, obwohl aus evolutionsbiologischer Sicht der durchschnittliche genotypische Unterschied von Mensch zu Mensch mit einer Nukleotiddiversität von 0,1 Prozent zu vernachlässigen ist. ${ }^{1895}$ Dies bedeutet nämlich, dass alle Menschen durchschnittlich auf 999 von 1.000 Stellen die gleichen Nukleotide aufweisen. 1896 Auch die Gendiversität zwischen modernen Menschen, also der durchschnittliche Prozentsatz der heterozygoten - differenten - Genloci, ist mit 14 Prozent relativ gering. ${ }^{1897}$ Hinzukommend sind nur wenige Prozentbereiche der menschlichen DNA proteincodierend notwendig. ${ }^{1898}$ In der Folge variieren auch die menschlichen Gameten mehr oder weniger stark in ihrer genetischen Ausstattung, so dass faktisch jede Zygote eine einzigartige Ansammlung von Allelen enthält. 1899 Nichtsdestotrotz: „Genetisch sind wir einander eindeutig äußerst ähnlich."1900 Dies illustriert vor dem Hintergrund der biologisch-genetisch rassistischen Vorurteile jedoch deutlich, dass die scheinbar biologische Grundlage der rassistischen Theoreme einzig pseudowissenschaftliche Falschinterpretationen von molekulargenetischen Befunden darstellen. Hier werden auf der einen Seite validierte, genetische Erkenntnisse variiert und angepasst, um die gewünschten Ergebnisse zu erhalten. Auf der anderen Seite werden Daten aus verhaltensbiologischen Zwillings- und Adoptionsstudien herangezogen, die als absolut anzusehende Datenreihen verallgemeinert auf sämtliche Menschenpopulationen übertragen werden. Die sogenannten Erblichkeitsschätzungen sind jedoch erstens primär im Bereich der Pflanzen- und Tierzüchtung sowie in der medizinischen Forschung uneinge-

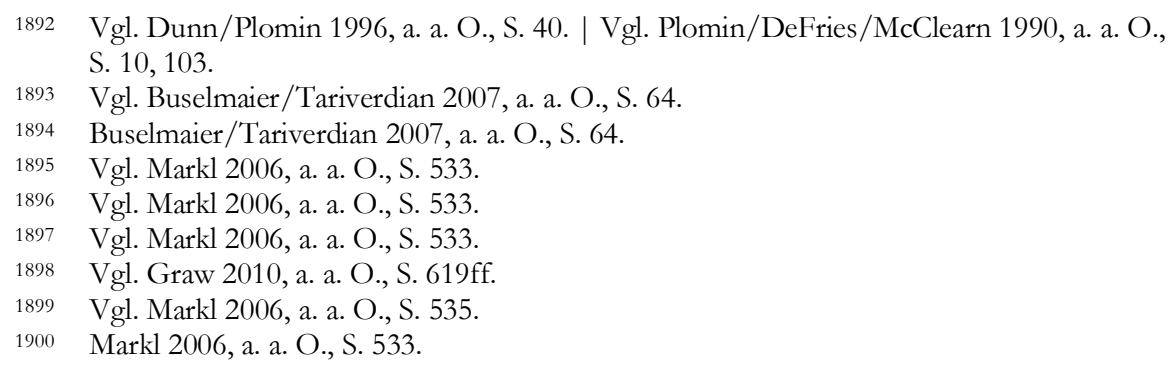


schränkt anwendbar sowie zweitens abhängig von der korrekten Interpretation und Auswertung der Ergebnisse. ${ }^{1901}$ In der Folge kann man von einem eindeutigen Missbrauch von molekular- und verhaltensgenetischem Datenmaterial sprechen, die der biologisch-genetische Rassismustypus für seine Zwecke zu instrumentalisieren versucht. Insofern können aufgrund der genotypischen Differenzen aller Menschen in keiner Weise menschliche ,Rassen“ - schon keinesfalls genetisch ,reine Rassen' - klassifiziert werden. Hierfür sind die modernen Menschen genotypisch aufgrund von andauernden Mutations- und Rekombinationsereignissen zu verschieden. Buselmaier und Tariverdian folgern so richtig:

„Man kann unter den Angehörigen einer Volksgruppe größere genetische Differenzen finden als zu Menschen, die einer ganz anderen Volksgruppe angehören und einen völlig anderen Lebensraum besitzen. Damit verschwinden sämtliche Rassenideen aus dem Orkus der Geschichte. "1902

Aufgrund klimatischer Veränderungen sowie der zunehmenden Belastung der Umwelt mit chemischen Mutagenen und DNA-schädigender Strahlung ist für die Zukunft von einer Zunahme der Mutations- und Rekombinationsereignisse beim Menschen auszugehen. So kann auch vor diesem Hintergrund trotz aller medizinischen Fortschritte, beispielsweise im Bereich der Pränataldiagnostik, keine genotypische Einheitlichkeit des Homo sapiens erreicht werden. Im Gegenteil, in den kommenden Jahrzehnten ist beim modernen Menschen eher eine Zunahme der Mutabilität zu erwarten. ${ }^{1903}$ Die Mutagene sind hierbei meist kanzerogen, das heißt meist über somatische Mutationen krebsauslösend, was zukünftig zu einem erhöhten Krebsrisiko führen dürfte. ${ }^{1904}$ Trotzdem ist es nicht möglich, diese geringen, aber vorhandenen, genotypischen Differenzen der Menschen als Legitimationsansatz für die Klassifizierung und Hierarchisierung des Menschen in mögliche Subspezies zu benutzen - spezifische Faktoren zur Bildung von Unterarten im Rahmen der menschlichen Evolution fehlen; 99,9 Prozent der DNA stimmen so überein. Dies belegen beispielsweise die bei allen Menschen im Wesentlichen identischen Chromosomenbandenmuster, die durch Färbung sichtbar werden. ${ }^{1905}$ Hier zeigen sich keine bedeutenden strukturellen oder numerischen Unterschiede. Alle Vertreterinnen und Vertreter des Homo sapiens haben folglich auch den gleichen Satz an Genen, die allenfalls aufgrund von Mutationen und Rekombinationen in leicht veränderten Varianten vorkommen, was die Einmaligkeit und Individualität jedes Menschen garantiert. ${ }^{1906}$ Darüber hinaus treten Mutationen zwar zwangsläufig zuerst bei Individuen auf, gehen dann aber im Verlauf der Produktion von

\footnotetext{
1901 Vgl. Munk 2010, a. a. O., S. 254.

1902 Buselmaier/Tariverdian 2007, a. a. O., S. 4.

1903 Vgl. Knußmann 1996, a. a. O., S. 480.

1904 Vgl. Knußmann 1996, a. a. O., S. 480.

1905 Vgl. Olson 2003, a. a. O., S. 28.

Durch das Anfärben eines Chromosoms mit der sogenannten Giemsa-Färbung entsteht für jedes Chromosom ein individuelles, charakteristisches Bandenmuster. Anhand dieser Musterung können so verschiedene Chromosomen unterschiedlicher Individuen miteinander auf ihre Ähnlichkeit bin verglichen werden. 
Nachkommen in die spezifische umgebende Menschenpopulation über, bis sie durch Vermischung der Menschen über die einzelnen Menschenpopulationen hinaus auf allen Kontinenten verteilt auftreten. ${ }^{1907}$ Der Genpool aller Menschen ist so eng und unweigerlich miteinander verbunden. ${ }^{1908}$ Der Informationsgehalt der zu Chromosomen spiralisierten DNA bleibt demnach trotz molekulargenetischer Variationen grundsätzlich gleich. Festzuhalten bleibt darüber hinaus nochmals, dass die Vererbung von geno- und phänotypischen Eigenschaften von den Vorfahren auf die nachfolgenden Generationen nie zu 100 Prozent stattfindet, da Genmutationen sowie die Neukombination des genetischen Materials zu leichten Veränderungen und Abweichungen - zur Vielfalt des Menschen - führen. ${ }^{1909}$ Dieser Prozess ist jedoch nicht nur eine molekulargenetische Erscheinung, sondern mit dem zu bezeichnen, was Charles Darwin 1859 das erste Mal treffend unter dem Begriff der Evolution subsummiert hat - diese dauert auch heute noch an. 1910

Weiterhin konnte im Verlauf der vorangegangenen Kapitel das Zusammenspiel zwischen genotypischen und umweltbedingten Einflüssen auf den molekulargenetischen Vererbungsprozess visualisiert werden. Menschliche Fähig- und Fertigkeiten gründen auf genetischen und nicht-genetischen Faktoren, die permanent miteinander interagieren. ${ }^{1911}$ Gene arbeiten nicht im Vakuum: Zur Proteinbiosynthese werden beispielsweise Aminosäuren aus der Nahrung - der Umwelt - benötigt. ${ }^{1912}$ Aufgrund der intensiven Wechselwirkungen kann jedoch nicht zwischen einem genotypischen bzw. einem Gen-bestimmten sowie einem umweltbestimmten Anteil differenziert werden. Versuche, die Grenzen von Genen und Umwelt statistisch zu quantifizieren bleiben so zum Scheitern verurteilt.

„Schließlich ist der Befund eines genetischen Einflusses auf komplexe Merkmale nicht gleichbedeutend damit, dass Umweltfaktoren unwichtig seien. Auf einfache monogeneti-

1907 Vgl. Olson 2003, a. a. O., S. 108.

1908 Vgl. Olson 2003, a. a. O., S. 109.

1909 Vgl. Dunn/Dobzhansky 1970, a. a. O., S. 50.

1910 Vgl. Dunn/Dobzhansky 1970, a. a. O., S. 55.

1911 Vgl. Euler, Harald A./Hoier, Sabine (2008): Die evolutionäre Psychologie von Anlage und Umwelt, in: Neyer, Franz J./Spinath, Frank M. (Hrsg.): Anlage und Umwelt. Neue Perspektiven der Verhaltensgenetik und Evolutionspsychologie, Stuttgart, S. 18. | Vgl. Asendorpf, Jens B. (2008): Verhaltensentwicklungsgenetik, in: Neyer, Franz J./Spinath, Frank M. (Hrsg.): Anlage und Umwelt. Neue Perspektiven der Verhaltensgenetik und Evolutionspsychologie, Stuttgart, S. 66, 81 .

Die Entwicklung und Ausprägung menschlicher Fähig- und Fertigkeiten ist ein lebenslanger (Lern-)Prozess, den Individuen in gewisser Weise mit bestimmen bzw. beeinflussen können. Das interaktionistische Menschenbild der Verbaltensgenetik, geht so davon aus, dass sowobl Interaktionen zwischen Genom und Umwelt als auch zwischen der sich entwickelnden Person und ihren genetischen sowie nicht-genetischen Entwicklungsbedingungen möglich erscheinen.

1912 Vgl. Penke, Lars/Denissen, Jaap J. A./Miller, Geoffrey F. (2008): Die Evolutionsgenetik der Persönlichkeit, in: Neyer, Franz J./Spinath, Frank M. (Hrsg.): Anlage und Umwelt. Neue Perspektiven der Verhaltensgenetik und Evolutionspsychologie, Stuttgart, S. $28 \mathrm{f}$. 
sche Störungen mögen Umwelteffekte geringen Einfluss haben. Für komplexe Merkmale sind Umwelteinflïsse aber in der Regel genauso bedeutsam wie genetische Einflüsse. "1913

Nicht vergessen werden dürfen in diesem Zusammenhang auch die schon mehrmals erwähnten Faktoren Zeit und Zufall. ${ }^{1914}$ Sämtliche molekulargenetischen Ereignisse benötigen Zeit, um sich endgültig ausdifferenzieren und entwickeln zu können. Genotypische Differenzen der menschlichen DNA benötigen Zeit, um sich im gesamten Genpool einer Menschenpopulation zu verbreiten. Auch umweltbedingte Faktoren benötigen Zeit, bis sich ihre mutagenen Auswirkungen auf genotypischer Ebene zu feststellbaren geno- und phänotypischen Auswirkungen potenzieren. Ebenfalls nicht vernachlässigt werden darf der Faktor Zufall: Wenig wahrscheinliche, unvorhersehbare sowie wenig bis nicht kontrollierbare Ereignisse - beispielsweise Mutationen - sind ebenfalls Ursachen für geno- bzw. phänotypische Differenzen. ${ }^{1915}$ „Verantwortlich ist das komplizierte Wechselspiel zwischen Erbanlagen und Umwelteinflüssen." ${ }^{1916}$ Der genetische Einfluss auf die Entwicklung und Ausprägung von menschlichen Eigenschaften und phänotypischen Merkmalen kann so eher als Neigung, als Tendenz verstanden werden, die eine gewisse Reaktionsbreite für die endgültige Ausprägung zur Verfügung stellt. ${ }^{1917}$ Die in der DNA gespeicherten Informationen sind also weder als festgelegtes Programm, noch als programmiertes Schicksal anzusehen: ${ }^{1918}$ „Genes do not determine one's destiny. “"1919

,Aus diesem Grund spiegeln genetische Einflïsse auf das Verhalten eher probabilistische

Neigungen wider als festgelegte Programme. Mit anderen Worten: Die Komplexität der

meisten Verhaltenssysteme bedingt, dass Gene sich nicht schicksalhaft auswirken. " "920

Es existieren also tendenziell auch keine ,schlechten' Gene, die für unterdurchschnittlich ausgeprägte Intelligenz, angeblich ,unnütze ' Verhaltensweisen oder spezifische ,Rassenzugehörigkeiten' verantwortlich gemacht werden könnten, womit die Theorie des angeblichen Vorhandenseins von ,Volksgenen', die zu einer in der gesamten Population verbreiteten ,schlechten' Leistung führen, falsifiziert wäre. ${ }^{1921}$ Darüber hinausgehend muss beachtet werden, dass die meisten Merkmale von mehreren Genen gemeinsam konstruiert werden, nicht nur von einzelnen Genen oder Genorten. ${ }^{1922}$ Unter anderem Robert Plomin resümiert so:

1913 Plomin et al. 1999, a. a. O., S. 79.

1914 Vgl. Cavalli-Sforza/Cavalli-Sforza 1994, a. a. O., S. 339. | Vgl. Dunn/Plomin 1996, a. a. O., S. 164.

1915 Vgl. Dunn/Plomin 1996, a. a. O., S. 164ff.

1916 Spiegel Online 2010, a. a. O. | Vgl. The 1000 Genomes Project Consortium 2010, a. a. O., S. 1061-1073.

1917 Vgl. Plomin et al. 1999, a. a. O., S. 79.

1918 Vgl. Plomin et al. 1999, a. a. O., S. 79. | Vgl. Plomin, Robert/DeFries, John C./McClearn, Gerald E./McGuffin, Peter (2008): Behavioral genetics, 5. Auflage, New York, S. 91.

1919 Plomin/DeFries/McClearn 1990, a. a. O., S. 9.

1920 Plomin et al. 1999, a. a. O., S. 79.

1921 Vgl. Plomin et al. 1999, a. a. O., S. 79.

1922 Vgl. Plomin et al. 1999, a. a. O., S. 79. 
„Genetische Einflüsse auf das Verbalten sind nichts anderes als genetische Einflüsse auf das Verhalten: ein Einfluss oder mitbestimmender Faktor, nichts Vorprogrammiertes oder deterministisches. Umwelteinflïsse sind in der Regel ebenso bedentsam wie genetische Einflüsse. [...] Die Würdigung individueller Differenzen, seien sie umweltbedingt oder genetischen Ursprungs, widerspricht [so] in keinster Weise dem Prinzip der Gleichbeit." "923

Als Zusammenfassung und gleichzeitig als Abschluss dieses Kapitels folgt eine treffende Bemerkung bezüglich des Zusammenspiels von Umwelt und Genen auf molekulargenetischer Ebene von den Psychologen Carole Wade und Carol Tavris:

„How do nature and nurture produce the many differences among us? We have seen that the answer is not so simple. Statistical estimates of the extent to which differences are 'beritable' or 'environmental' do not tell us how heredity and environment interact to produce each unique mixture of qualities that we call a buman being. This is because each of us is, in a sense, more than the sum of the individual influences on us. ""924

\subsection{Intelligenz-Phänomen im Kontext von Genen und Umwelt}

Die vorhergehenden Kapitel vergegenwärtigen mithilfe anthropologischer, evolutionsbiologischer, human- sowie molekulargenetischer Erkenntnisse, dass eine ,Rassifizierung' der Spezies Homo sapiens aufgrund des Evolutionskonzeptes von Charles Darwin als auch der aktuellen Synthetischen Evolutionstheorie unrealistisch ist. Die Analyse der biologischen Taxonomie sowie der Art- und Unterartbildung illustrieren eindeutig, dass der moderne Mensch nicht in ein ,Rassengefüge' klassifiziert bzw. hierarchisiert werden kann. Hierfür fehlen auf der einen Seite größere phänotypische und genotypische Differenzen, wie die Untersuchungen von DNA, mtDNA und Y-Chromosomen gezeigt haben, sowie auf der anderen Seite auch ein größeres Zeitfenster, welches zur Herausbildung unterschiedlicher Variationen von Menschenpopulationen benötigt worden wäre. Zusätzlich zeigen auch die Wanderungs- und Verbreitungsbewegungen des modernen Menschen keinerlei Abgrenzungs- oder Isolationstendenzen auf, die eine Bildung von Subspezies hätten forcieren können.

Das folgende Kapitel konzentriert sich auf einen weiteren pseudobiologischen Schwerpunkt rassistischer Argumentationen, der sich insbesondere im 21. Jahrhundert wieder größerer Beliebtheit erfreut: Die Debatte um die angebliche Vererbung erworbener Verhaltensmerkmale, wobei vor allem das IntelligenzPhänomen im Fokus steht (s. Kapitel 1, 2, 3). Spezifische Menschenpopulationen werden demzufolge aufgrund einer angeblich generationenübergreifenden Vererbung von ,dümmeren', ,unnützeren' Eigenschaften systematisch abgewertet und

1923 Plomin et al. 1999, a. a. O., S. 81.

1924 Wade/Tavris 1987, a. a. O., S. 458. 
diskriminiert. Damit einhergehend findet heutzutage die populistische Behauptung immer mehr Akzeptanz, dass aufgrund der Zunahme von ,dümmeren', ,minder qualifizierteren“ Menschen in der bundesrepublikanischen Gesellschaft die deutsche Bevölkerung im Durchschnitt immer ,dümmer ${ }^{6}$ werden, also an Qualität verlieren würde (s. Kapitel 3.1, 3.2). Existieren per se spezifische ,dümmere` sowie ,intelligentere' Menschengruppen, die aufgrund der vererbungsbedingten Weitergabe - der sogenannten biologischen Determination - des Intelligenz-Phänomens auch in Zukunft ,dumm ' oder ,intelligent' bleiben? Wird die sogenannte Intelligenz vollständig genetisch festgelegt oder existieren weitere Einflüsse auf deren Ausprägung? Wie können Intelligenz und der vielzitierte Intelligenzquotient begrifflich definiert werden? Kann die biologische Forschung die rassistischen Argumentationen validieren? Mit Hilfe der Human-, Molekular- und Verhaltensgenetik sowie der biopsychologischen Forschung soll sich den oben genannten Fragestellungen genähert werden.

Grundsätzlich muss schon zu Beginn festgehalten werden, dass sich die biologische Forschung das Intelligenz-Phänomen betreffend als höchst umstritten sowie kontrovers kennzeichnet (s. Kapitel 5.3). Auch im 21. Jahrhundert existieren mit Thilo Sarrazin oder Volkmar Weiss noch zahlreiche PseudoWissenschaftler, die diesbezüglich einen allein auf der Grundlage der Gene basierenden Vererbungsmechanismus konstatieren. Deren semi-wissenschaftlichen Theoreme finden einen unbestreitbaren gesellschaftlichen Rückhalt, wie die große Resonanz der Diskussionen in der bundesrepublikanischen Bevölkerung visualisiert (s. Kapitel 3). Adolf Heschl stellt diesen Bestrebungen der Erblichkeitsschätzungen und berechnungen des sogenannten Intelligenz-Phänomens jedoch korrekterweise schon im Voraus einen Totenschein aus:

„Mit der Zunahme [...] [von] Untersuchungen [...] wird dieser rein theoretische Forschungszweig rasch in jener Versenkung verschwinden, in die er schon längst bineingebört, denn je genauer wir Bescheid wissen über die exakten kausalen Zusammenhänge zwischen Genom und komplexen Verbaltensmustern, auch sogenannten gelernten, um so uninteressanter und irreführender werden uns solche Berechnungen vorkommen. Das teilweise Weiterbestehen des Erblichkeitskonzepts drückt also nichts anderes aus als unser zurzeit noch relativ großes Nichtwissen in diesem Bereich. "1925

Vor diesem Hintergrund sind auch die verschiedenen Intelligenzforscher der Gegenwart vor zahlreichen Gewissenskonflikten zu sehen, die von einer grundsätzlichen Bejahung der vollständigen Erblichkeit der sogenannten Intelligenz, über ein eventuelles, vielleicht' bis zu einer kategorischen Ablehnung reichen.1926 Einen internationalen Grundkonsens sucht man noch vergebens, wie das Vorhandensein von zahlreichen sogenannten Intelligenztheorien belegt. Schon in den 1980er Jahren zählte die Debatte bezüglich der genetischen oder umweltgesteuerten Weitergabe von geistigen sowie intellektuellen Leistungen zu den umstrittensten des

1925 Heschl 1998, a. a. O., S. 139.

1926 Vgl. Heschl 1998, a. a. O., S. 138. 
biologisch-psychologischen Forschungsbereiches. ${ }^{1927}$ In diesem Zusammenhang muss auch die außerordentliche politische Brisanz der Thematik, insbesondere für die Ausländer-, Migrations-, Integrations- und Sozialpolitik, beachtet werden. ${ }^{1928}$ Nichtsdestotrotz diagnostizieren schon die vorherigen Kapitel, dass die spezifische Ermittlung von angeblich erblichen Eigenschaften mittels individueller Statistiken in eine wissenschaftliche Sackgasse führt. Auch die kognitive Leistung von Individuen kann, nebensächlich ob von Umwelt oder genetischer Prädisposition bestimmt, nicht eindeutig ermittelt werden. ${ }^{1929}$ Luigi Luca Cavalli-Sforza gibt zu bedenken, dass mithilfe von genotypischen und phänotypischen Merkmalen zwar Rückschlüsse auf die evolutive Entwicklung des Menschen möglich sind, nicht aber Schlussfolgerungen die geistigen sowie intellektuellen Fähigkeiten von Individuen betreffend (s. Kapitel 5.1, 5.2, 5.3). ${ }^{1930}$

\subsubsection{Intelligenzbegriff in der Diskussion}

Da sich die weitere Diskussion auf das Phänomen der sogenannten Intelligenz konzentriert, muss einführend verdeutlicht werden, was unter der Begrifflichkeit Intelligenz definitorisch verstanden werden kann. Wie schon angesprochen ist dies kein einfaches Unterfangen, da diesbezüglich zahlreiche Theorien existieren, wie die nachfolgende tabellarische Auswahl exemplarisch aufzeigt. Intelligenz wird hier beispielsweise als Problemlösefähigkeit, als spezifischer Verarbeitungsmechanismus des Denkens, als Erfahrungsvergleich, als Kontextvergleich mit umweltbedingten Umgebungsbedingungen oder als biologisch begründetes Potenzial zum Erlernen von Wissen verstanden. ${ }^{1931}$ Der tabellarische Überblick könnte mit Intelligenztheorien verschiedener Jahrzehnte noch beliebig erweitert werden. Dies vergegenwärtigt die relativ schwierigen sowie komplexen Definitionsmöglichkeiten des Intelligenzbegriffs. Carole Wade und Carol Tavris bemerken dementsprechend: „[...] intelligence is highly valued but hard to define.“1932 Insbesondere traditionelle Definitionen lassen viele grundlegende Fähig- und Fertigkeiten des Intelligenz-Phänomens außen vor. ${ }^{1933}$ Eine transparente und zutreffende Definition steht so noch aus.

\footnotetext{
1927 Vgl. Rosemann, Hermann (1979): Intelligenztheorien. Forschungsergebnisse zum AnlageUmwelt-Problem im kritischen Überblick, Reinbek bei Hamburg, S. 20.

1928 Vgl. Rosemann 1979, ebd., S. 20.

1929 Vgl. Rosemann 1979, ebd., S. $17 \mathrm{ff}$.

1930 Vgl. Cavalli-Sforza/Cavalli-Sforza 1994, a. a. O., S. 193.

1931 Vgl. Grabowski 2007, a. a. O., S. 568ff.

1932 Wade/Tavris 1987, a. a. O., S. 426.

1933 Vgl. Gage, Nathaniel L./Berliner, David C. (1996): Pädagogische Psychologie, 5. Auflage, Weinheim, S. $51 \mathrm{f}$.
} 
Tab. 27: Exemplarischer Überblick über Intelligenztheorien ${ }^{1934}$

\begin{tabular}{|c|c|}
\hline Theorie & Beschreibung \\
\hline $\begin{array}{l}\text { Howard Gardners } \\
\text { Theorie }\end{array}$ & $\begin{array}{l}\text { Intelligenz ist eine Fähigkeit zur Lösung von Problemen oder zur } \\
\text { Erzeugung von Produkten, die in einer bestimmten Kultur als } \\
\text { wertvoll angesehen werden. }\end{array}$ \\
\hline Mike Andersons Theorie & $\begin{array}{l}\text { Intelligenz ist ein grundlegender Verarbeitungsmechanismus, } \\
\text { zusammen mit spezifischen Funktionsmodulen zum propositio- } \\
\text { nalen Denken sowie zum visuellen und räumlichen Denken. }\end{array}$ \\
\hline $\begin{array}{l}\text { Robert Sternbergs } \\
\text { triarchische Theorie }\end{array}$ & $\begin{array}{l}\text { Diese Theorie besteht aus drei Teiltheorien: der Komponenten- } \\
\text { theorie, die sich auf Mechanismen der internen Informationsver- } \\
\text { arbeitung konzentriert; der Erfahrungstheorie, welche die per- } \\
\text { sönlichen Erfahrungen mit einer Aufgabe oder einer Situation } \\
\text { berücksichtigt; und der Kontexttheorie, welche die Beziehung } \\
\text { zwischen der äußeren Umgebung und der Intelligenz einer } \\
\text { Person untersucht. }\end{array}$ \\
\hline $\begin{array}{l}\text { Stephen Cecis } \\
\text { bioökologische Theorie }\end{array}$ & $\begin{array}{l}\text { Intelligenz umfasst multiple kognitive Potenziale, die biologisch } \\
\text { begründet sind, deren Manifestation jedoch von Wissen ab- } \\
\text { hängt, welches sich eine Person in einem bestimmten Bereich } \\
\text { angeeignet hat. }\end{array}$ \\
\hline $\begin{array}{l}\text { Führende Anglo- } \\
\text { amerikanische Definition } \\
\text { (1994) }\end{array}$ & $\begin{array}{l}\text { Intelligenz ist ein sehr allgemeines geistiges Potenzial, das u. a. } \\
\text { die Fähigkeit zum schlussfolgernden Denken, zum Planen, zur } \\
\text { Problemlösung, zum abstrakten Denken, zum Verständnis kom- } \\
\text { plexer Ideen, zum schnellen Lernen und zum Lernen aus Erfah- } \\
\text { rung umfasst. }\end{array}$ \\
\hline
\end{tabular}

Vor diesem Hintergrund scheint auch die gängige Praxis der Intelligenztests schon qua Definition fragwürdig, wenn noch nicht einmal genau fixiert werden kann, was überhaupt gemessen werden soll. ${ }^{1935}$ Der Schriftsteller Hermann Rosemann konstatiert vor diesem Hintergrund, dass es ,die Intelligenz aufgrund der pluralen Sichtweisen auch zukünftig nicht geben werde. ${ }^{1936}$

„Sie ist kein Gegenstand, sondern eine Abstraktion, eine sprachliche Übereinkunft über einen nicht unmittelbar aufweisbaren Sachverhalt. Sie steht nach geläufiger Auffassung [lediglich] für bestimmte Verhaltensweisen, die mit Problemlösen, rascher Auffassung, Rechenfertigkeit, Worteinfall usw. in Zusammenhang stehen. "1937

Je nach beruflichem Arbeitsbild, kulturellem Hintergrund, sozialer Struktur, Lebenswelt sowie spezifischen gesellschaftlichen Konventionen kann Intelligenz demnach unterschiedlich definiert werden. Das Intelligenz-Phänomen ist somit kulturspezifisch. ${ }^{1938}$

\footnotetext{
1934 Eigene Darstellung nach: Grabowski 2007, a. a. O., S. 577. | Rost, Detlef H. (2009): Intelligenz. Fakten und Mythen, Weinheim u. a., S. 18.

1935 Vgl. Dobzhansky 1962, a. a. O., S. 116.

1936 Vgl. Rosemann 1979, a. a. O., S. $23 \mathrm{ff}$.

1937 Rosemann 1979, a. a. O., S. 23.

1938 Vgl. Gage/Berliner 1996, a. a. O., S. 53.
} 


\begin{abstract}
„Das schwarze Gettokind aus Harlem lebt in einer radikal anderen Lebensumwelt als das Kind eines weißen erfolgreichen Bankdirektors von der 61. Straße in New York. Das Gettokind hat andere Probleme zu bewältigen. Für dieses Kind herrschen andere Existenzgesetze. Es muss, will es sich behaupten, andere Denk-und Verhaltensstrategien sich aneignen. [...] Der Fließbandarbeiter steht anderen Forderungen gegenüber als der Deutschlehrer am Gymnasium. "1939
\end{abstract}

Das Phänomen der Intelligenz ist also, wie dessen Definitionsvielfalt illustriert, je nach Lebenssituation und -umwelt individuell $\mathrm{zu}$ charakterisieren und $\mathrm{zu}$ bewerten. Der im Beispiel genannte Deutschlehrer benötigt vor allem pädagogisches, fachdidaktisches sowie fachliches Wissen, ein Automechatroniker sieht demgegenüber eher ein fundiertes Fachwissen im Bereich Elektronik und Elektrotechnik als für ihn nützlich an. Intelligenz stellt sich folglich nicht als absolute, statistischmessbare oder vergleichbare Größeneinheit dar, sondern liegt vielmehr in den individuellen Lebensbedingungen und -umwelten jedes einzelnen Menschen begründet. ${ }^{1940}$ Das theoretische Gebilde der Intelligenz zeigt sich dementsprechend ebenfalls als variable und individualisierte Fähigkeit zur Lösung der eigenen Lebensprobleme, Lebensanforderungen und Veränderungen der Lebenswelt. ${ }^{1941}$ Intelligenz ist mit der Lebenswelt jedes einzelnen modernen Menschen individuell verbunden, wird aufgrund der Lebensbedingungen und des Lebensumfeldes jedes Einzelnen neu konstruiert und ist folglich auch nur vor diesem Hintergrund personalisiert messbar. ${ }^{1942}$ Zuzustimmen ist so Journalist Dieter E. Zimmer, der je nach Verwendung für eine detaillierte Beschreibung des Intelligenzbegriffes eintritt. ${ }^{1943}$

Das Phänomen der Intelligenz ist also von Individuum zu Individuum angesichts verschiedener lebensbedingter Voraussetzungen unterschiedlich. ${ }^{1944}$ Es besteht nicht nur aus einer einzelnen Fähigkeit, sondern aus mehreren Komponenten, sogenannten ,Primärfähigkeiten', die erst in ihrer Gesamtheit die kognitive Leistung von Individuen, und damit korrelierend den Intelligenzbegriff, bestim-

Die sperifische Kultur, der Kontext jedes Menschen, bestimmt die individuelle Entwicklung mit. Sie ist ein „, [...] integraler Bestandteil jedes Menschen. " und spielt insbesondere bei der Bestimmung der individuellen Unterschiede eine maßgebliche Rolle. Gage/Berliner 1996, a. a. O., S. 168.

Rosemann 1979, a. a. O., S. 24.

Vgl. Rosemann 1979, a. a. O., S. $25 \mathrm{ff}$.

Vgl. Rosemann 1979, a. a. O., S. 24ff. | Vgl. Krath, Stefanie/Hüther, Gerald (2013): Intelligenz ist eine Fähigkeit, Begabung ist ein Potenzial, in: Begegnung. Deutsche schulische Arbeit im Ausland, 3/2013, 34. Jahrgang, Köln, S. 26ff. | Vgl. Rost 2009, a. a. O., S. 16, 81ff. Der Neurobiologe Gerald Hüther favorisiert auf dieser Grundlage das Konzept der ,multiplen Intelligenzen nach Howard Gardner, welches die Existenz von unterschiedlichen Intelligenzen, wie beispielsweise der emotionalen oder der sozialen Intelligenz, konstatiert. Aufgrund der begrifflichen Ausweitung dieses Intelligenzkonzeptes zeigt es sich jedoch mit vielfacher fachlicher Kritik binsichtlich dessen definitorischer Unschärfe konfrontiert.

Vgl. Rosemann 1979, a. a. O., S. 24.

Vgl. Zimmer 2012, a. a. O., S. $56 \mathrm{ff}$.

Vgl. Rosemann 1979, a. a. O., S. 26. 
men. ${ }^{1945}$ Ein Vorschlag wäre so, den Intelligenzbegriff zukünftig eher durch ein Begriffssetting zu ersetzen, welches den kognitiven Prozess detailliert sowie fachlich korrekt beschreibt. ${ }^{1946}$ Der heutige Intelligenzbegriff als Grundlage für standardisierte Intelligenztests ist demnach anzuzweifeln, wie auch Theodosius Dobzhansky kritisiert. ${ }^{1947}$ Die Begrifflichkeit bleibt definitorisch äußerst schwierig zu fassen, was in der Folge auch für die darauf aufbauenden, standardisierten Messverfahren sowie Quotenbezeichnungen gilt. ${ }^{1948}$ Hierzu abschließend ein eindrückliches Beispiel des Psychologen Joachim Grabowski:

„Im Dezember 1856 wurde Tommy geboren. Er war der Sobn von Janet Woodrow [...] und Ruggles Wilson [...]. Tommys Eltern waren gebildete Leute, die das Lernen sehr hoch schätzten. Als Schulkind hatte Tommy jedoch große Schwierigkeiten beim Lesen. Trotz des Besuchs von speziellen Förderschulen konnte er bis in die späte Kindheit binein - mit etwa zehn bis elf Jahren - immer noch nicht lesen. [...] Aufgrund der bisberigen Informationen müsste man vorhersagen, dass Tommys Chancen auf ein erfolgreiches Leben nur mäßig waren. Wir würden wohl heute sagen, dass seine ,Papierform" eher schlecht war. Doch unsere bescheidenen Vorhersagen bezüglich Tommys Zukunft hätten sich als falsch erwiesen. Tommy war Thomas Woodrow Wilson. Nach seinem Abschluss in Princeton absolvierte er an der Universität von Virginia ein Jurastudium und erwarb an der John-Hopkins-Universität einen Doktorgrad in Politikwissenschaft. [...] 1912 kandidierte er gegen den Amtsinhaber, Präsident William Howard Taft, für die Präsidentschaft der Vereinigten Staaten von Amerika, gewann und wurde der 28. USPräsident. [...] Für seine Anstrengungen, die Gründung des Völkerbundes voranzutreiben, wurde ibm 1919 der Friedensnobelpreis verliehen. Auf Grund der Errungenschaften während seiner Lebenszeit würden die meisten Menschen behaupten, dass Thomas Woodrow Wilson ein intelligenter Mann war. Hätte er jedoch als Junge einen Intelligenztest oder eine andere Art von Eignungsprüfung gemacht, wäre er mit seinen Leistungen wobl nicht im ,intelligenten' Wertebereich gelandet. "1949

\subsubsection{Missverständnis Intelligenz: Intelligenztests und Intelligenzquotient}

Insbesondere im Lebensalltag der USA nimmt das Intelligenz-Phänomen auch heute noch einen bedeutenden Stellenwert ein. Sogenannte Eignungs- und Intelligenztests sind vor der Aufnahme in die Schule, das College oder die Universität, bei der Bewerbung um eine Arbeitsstelle oder auch beim Eintritt in die militärischen Streitkräfte obligatorisch. In Deutschland und Europa sind Intelligenztests von eher nachrangiger Bedeutung, obwohl beispielsweise auch verschiedene Unternehmen als Einstellungsgrundlage einen Intelligenztest zur angeblichen Vergleichbarkeit und Bestenauslese der Bewerberinnen und Bewerber präferieren.

\footnotetext{
1945 Vgl. Zimmer 1975, a. a. O., S. 30.

1946 Vgl. Plomin, Robert/DeFries, John C./Craig, Ian W./McGuffin, Peter (2003): Behavioral Genetics in the Postgenomic Era, Washington, S. XIX.

1947 Vgl. Dobzhansky 1973, a. a. O., S. 20ff.

1948 Vgl. Grabowski 2007, a. a. O., S. 557.

1949 Grabowski 2007, a. a. O., S. 557.
} 
Das Problem bezüglich der Testbarkeit und Identifizierung von Intelligenz wurde schon im vorigen Kapitel deutlich angesprochen: Wie kann ein Test auf der Basis eines Begriffes, der selbst in Wissenschaft und Forschung noch eingehend diskutiert und konsenslos ist, valide und von angemessener Reliabilität erscheinen? Wie kann weiterfolgernd ein scheinbar von unterschiedlichen, individuellen Lebensumwelten und Lebensbedingungen abhängiges Konstrukt als transparente und umfassend vergleichbare, statistische Größe ermittelt werden?

Ursprünglich stammt das Testinstrument des sogenannten Intelligenzquotienten vom Psychologen Alfred Binet, der auf Geheiß der französischen Regierung die Schulleistungen von tendenziell schlechteren Schülerinnen und Schülern bestimmen sollte, die eine zusätzliche schulische Betreuung benötigen würden. ${ }^{1950}$ Binet bemerkte jedoch schon zu Beginn seiner Arbeit einschränkend an, dass das Phänomen der menschlichen Intelligenz eigentlich zu komplex sei, um dieses mit einfachen, statistischen Zahlenwerten zu bestimmen - eine Aussage, die im 20. und 21. Jahrhundert oftmals nichtbeachtet überlesen wird. ${ }^{1951}$

\section{„Die Punktezahlen sind ein praktisches Hilfsmittel; sie untermanern keine Theorie geis- tiger Fähigkeiten. Sie definieren nichts Angeborenes oder Dauerhaftes. Wir dürfen das mit ibrer Hilfe Gemessene nicht als ,Intelligenz' oder als irgendeine andere verdinglichte Wesenheit bezeichnen. "1952}

Mit dieser Aussage konstatiert Binet explizit, dass die genannten Messwerte und Datensätze nur für die optimale, förderungsorientierte schulische Betreuung von Schülerinnen und Schülern angewandt werden dürfen. Eine Tatsache, die nicht nur zahlreiche darauf aufbauende Folgeuntersuchungen missachteten, sondern die auch von den Vertretern des biologistischen Rassismustypus systematisch umgedeutet und hinsichtlich einer manifesten, generationenübergreifenden Vererbung von ursprünglich erworbenen kognitiven Fähigkeiten absichtlich missinterpretiert wird. Diese Sachlage verdeutlicht auf einzigartige Weise die gesellschaftliche, wirtschaftliche und politische Annexion einer dezidiert nur für wissenschaftliche Zwecke konstruierten Forschungsmethode. Weiterhin werden hieran ebenfalls die skrupellose Umdeutung und der absichtlich fehlinterpretierte Transfer naturwissenschaftlicher Erkenntnisse $\mathrm{zu}$ pseudowissenschaftlichen, popularisierenden sowie angeblich die Sozialstruktur bestimmenden Theoremen deutlich. Binet kann - wie auch aus evolutionsbiologischer Perspektive Charles Darwin - nicht als Mitbegründer einer später, rassegeleiteten' Intelligenzforschung identifiziert werden. Auch er wurde Opfer der fälschlichen Politisierung und Vergesellschaftung seiner Ergebnisse. Denn er spricht mit der Präsentation des von ihm entwickelten Analyseinstrumentes diesem gleichsam explizit die Fähigkeit ab, anhand des sogenannten Intelligenzquotienten als statistischem, verallgemeinerbarem Wert, die Einordnung von Schülerinnen und Schülern nach ihren grundsätzlichen

\footnotetext{
1950 Vgl. Gould 1983, a. a. O., S. 162.

1951 Vgl. Gould 1983, a. a. O., S. $162 \mathrm{ff}$.

1952 Gould 1983, a. a. O., S. 167.
} 
kognitiven Fähigkeiten vorzunehmen. ${ }^{1953}$ In diesem Zusammenhang positioniert Binet ebenfalls ein gewichtiges Argument gegen die Differenzierung von Menschen in unterschiedliche Bevölkerungsgruppen aufgrund ihrer geistigen sowie intellektuellen Fähig- und Fertigkeiten. Wie auch das nachfolgende Zitat illustriert, warnt er eindeutig vor einem Missbrauch der Messwerte hinsichtlich einer Klassifikation von Schülerinnen und Schülern. Intelligenz ist nach Binet folglich einerseits kein feststehendes, statisches, unveränderliches Konstrukt sowie darüber hinausgehend andererseits auch keinesfalls eine verhaltensbiologischpsychologisch erworbene, vererbbare Eigenschaft, wie auch Stephen Jay Gould diagnostiziert. ${ }^{1954}$

„,...] [Die IQ-Skala] ist kein Mittel zur Aufstellung einer Rangordnung normaler Kinder. [...] Niedrige Werte sollten nicht benutzt werden, um Kinder als von Geburt an unfähig zu bezeichnen. "1955

Von vornherein steht der sogenannte Intelligenzquotient folglich auf wissenschaftlich fragwürdigen, tönernen Füßen. Theoretisch bezeichnet der ursprünglich von Psychologe William Stern konzipierte IQ eigentlich das Verhältnis von Intelligenzalter (IA) zu Lebensalter (LA), wie die folgende Berechnungsformel demonstriert: 1956

$$
I Q=\frac{I A}{L A} \times 100
$$

Heute werden zur Berechnung des IQ jedoch meist Tabellen herangezogen, mithilfe derer die getesteten Werte in standardisierte, vergleichbare Datensätze umgewandelt werden. ${ }^{1957}$ Der Multiplikator 100 bewirkt, dass der IQ auf einen Wert von 100 steigt, wenn IA und LA identisch erscheinen. ${ }^{1958}$ Bei einem kleineren IA sinkt der IQ unter 100, bei einem größeren IA steigt der IQ über 100. ${ }^{1959}$ Die populationsbedingten Häufigkeitsverteilungen der IQ-Werte nehmen statistisch meistens eine glockenförmige Kurve ein. Das bedeutet, dass die randständigen Extrembereiche nur sehr gering repräsentiert sind, wie die nachfolgende Grafik visualisiert. ${ }^{1960}$ Sogenannte, schwere bis schwerste Intelligenzminderungen' sowie ,deutlich überdurchschnittlich bis hochbegabt ${ }^{\star}$ kommen gesamtgesellschaftlich gesehen mit je 0,1 Prozent nur relativ selten vor. ${ }^{1961}$ Der durchschnittliche Anteil

\footnotetext{
1953 Vgl. Gould 1983, a. a. O., S. 163.

1954 Vgl. Gould 1983, a. a. O., S. 166.

1955 Gould 1983, a. a. O., S. 167.

1956 Vgl. Grabowski 2007, a. a. O., S. 561.

1957 Vgl. Grabowski 2007, a. a. O., S. 562. | Vgl. Gage/Berliner 1996, a. a. O., S. 55 ff.

1958 Vgl. Grabowski 2007, a. a. O., S. 561.

1959 Vgl. Grabowski 2007, a. a. O., S. 561.

1960 Vgl. Grabowski 2007, a. a. O., S. 562.

1961 Vgl. Grabowski 2007, a. a. O., S. 562.
} 
von 68,2 Prozent der untersuchten IQ-Werte liegt zwischen 85 und 115 Punkten, dem Durchschnittsbereich der sogenannten relativen Intelligenzverteilung. ${ }^{1962}$

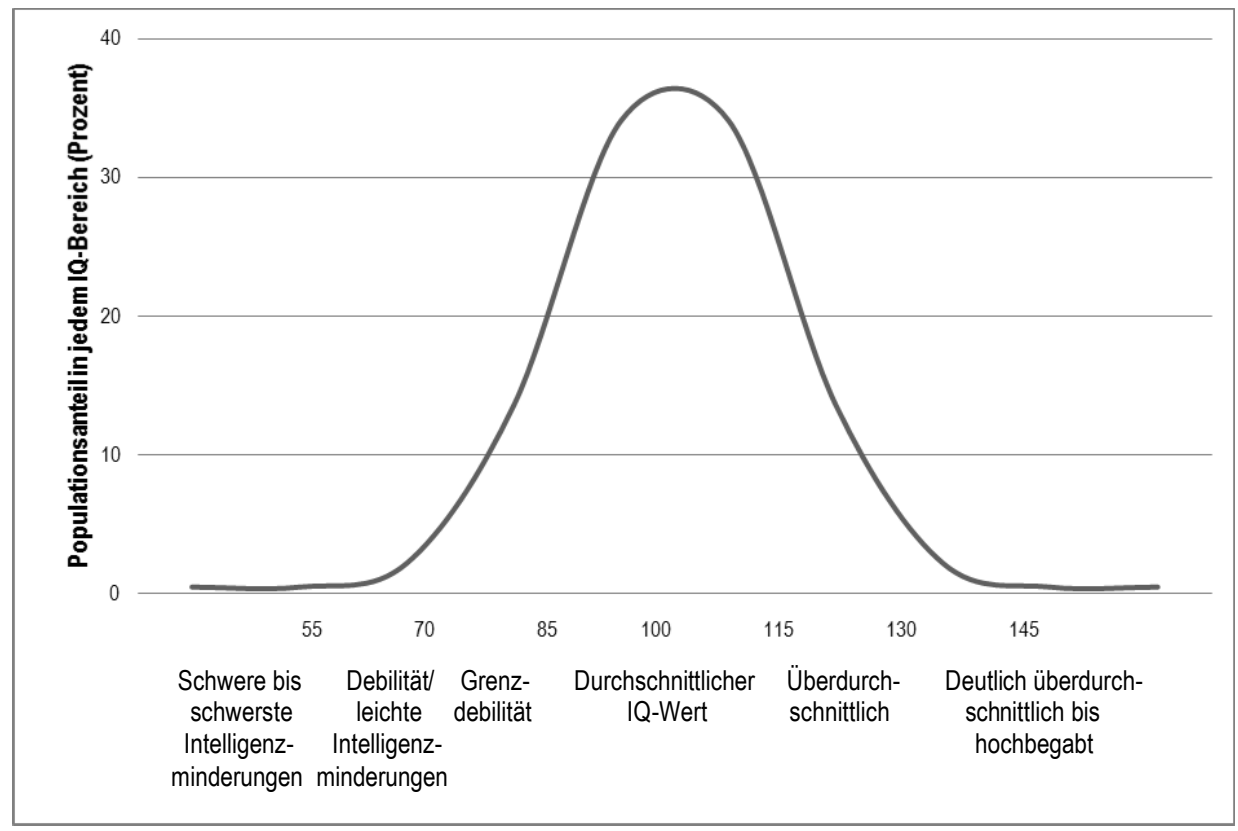

Abb. 20: Häufigkeitsverteilung der IQ-Werte ${ }^{1963}$

Errechnet wird hier jedoch nicht , die ' Intelligenz, sondern lediglich die sogenannte intellektuelle Grundfähigkeit , $\mathrm{g}^{6}$ (general cognitive ability), eine statistische Größe. ${ }^{1964}$ Diese wird oftmals fälschlicherweise mit Intelligenz übersetzt. Das Konzept der Erblichkeit bzw. von , $^{6}$ ist lediglich eine einfache Statistik, welche das relative Verhältnis von genotypischen zu phänotypischen Abweichungen darstellt. ${ }^{1965}$ Der Umweltbeitrag ist jeweils direkt analog bzw. entsprechend zu sehen. ${ }^{1966}$ Hierbei handelt es sich also, wie auch beim IQ, nicht um einen konstanten, unabänderlichen sowie individuellen Wert, sondern nur um eine beschreibende - und wie alle Statistiken mit Schwächen sowie Fehlern behaftete - Statistik (s. Kapitel 5.4.4). ${ }^{1967}$ Quantitative Korrelationen, wie beispielsweise zwischen IQ und schulischer Leis-

1962 Vgl. Grabowski 2007, a. a. O., S. 562.

1963 Eigene Darstellung nach: Vgl. Grabowski 2007, a. a. O., S. 562.

1964 Vgl. Zimmer 2012, a. a. O., S. 79ff. | Vgl. Plomin/DeFries/Craig/McGuffin 2003, a. a. O., S. 103. | Vgl. Plomin/DeFries/McClearn/McGuffin 2008, a. a. O., S. 147f. | Vgl. Spinath, Frank M./Deary, Ian J. (2008): Verhaltensgenetik und Intelligenz, in: Neyer, Franz J./Spinath, Frank M. (Hrsg.): Anlage und Umwelt. Neue Perspektiven der Verhaltensgenetik und Evolutionspsychologie, Stuttgart, S. 134.

1965 Vgl. Plomin/DeFries/McClearn 1990, a. a. O., S. 231. | Vgl. Plomin, Robert (1999): Genetics and general cognitive ability, in: Nature, Vol. 402, London u. a., S. C25.

1966 Vgl. Plomin/DeFries/McClearn 1990, a. a. O., S. 232.

1967 Vgl. Plomin/DeFries/McClearn 1990, a. a. O., S. 232. 
tung, weisen jedoch nicht notwendigerweise darauf hin, dass der IQ zwingend das schulische Leistungsniveau eines Individuums bestimmt: Korrelation bedeutet nicht gleichzeitig auch Kausalität. ${ }^{1968}$

Die Grundlage der auch im 21. Jahrhundert noch stark debattierten Ansicht der messbaren Erblichkeit des IQ ,[...] ist [zwar] ein heimisches Gewächs aus den USA.“1969, wurde jedoch schnell von biologistisch-rassistisch argumentierenden Theoretikern adaptiert. Oder, um mit den Worten Theodosius Dobzhanskys zu argumentieren: „Kein ernstzunehmender Wissenschaftler hält den IQ für einen Maßstab des generellen Wertes oder der Qualität von Menschen." 1970 Der IQ ist und bleibt qua ursprünglicher Definition ein rein mathematischer Diagnosewert. Nach Zimmer wäre es zielführend, diesen mathematischen Wert eher als analytische, abstrakte oder biometrische Intelligenz zu bezeichnen. ${ }^{1971}$ Diese kann keineswegs als umfassendes Prognoseinstrument zur Vorhersage von kognitiven Leistungen eines Individuums bzw. einer Menschengruppe benutzt werden, da vorhandene Korrelationen lückenhaft und unvollständig sind. ${ }^{1972}$ Darüber hinaus muss definitiv auch der im vergangenen Kapitel analysierte Umweltaspekt herangezogen werden, der ebenso wie die genetische Komponente einen essentiellen Einfluss auf die Ausprägung der kognitiven Fähig- und Fertigkeiten des modernen Menschen hat (s. Kapitel 5.3.7). ${ }^{1973}$ Der IQ steht - ausgehend von den neurobiologischen bzw. genetischen Grundstrukturen des Gehirns - lediglich für ein spezifisches Potenzial, eine relative Größe. ${ }^{1974}$ IQ und IQ-Messung bleiben so unzuverlässige sowie wenig aussagende Datensätze. ${ }^{1975}$

In diesem Zusammenhang konstatiert Luigi Luca Cavalli-Sforza, dass das Intelligenz-Konstrukt ein Produkt der persönlichen Lebensbedingungen und erfahrungen darstellt, die aufgrund von finanziellen, wirtschaftlichen, sozialen oder beispielsweise familiären Faktoren zwischen Individuen stark variieren. ${ }^{1976}$ Insbesondere die Qualität der schulischen Bildung, der außerfamiliären und außerschulischen Aktivitäten in Peergroups oder Familie sowie das gesellschaftliche und soziale Lebensumfeld generieren starke Einflussfaktoren auf die individuelle Entwicklung. Demzufolge zeigen sich auch bei Untersuchungen mit genetisch meist identischen, eineiigen Zwillingen, dass deren geistige Leistungen zwar ähnlich sind - also auf eine gewisse genetische Vererbungskomponente hindeuten -, dass es aber ebenso schwierig bleibt, die verschiedenen Milieufaktoren - abgegrenzt von

\footnotetext{
1968 Vgl. Gage/Berliner 1996, a. a. O., S. 59.

1969 Gould 1983, a. a. O., S. 170.

1970 Dobzhansky 1973, a. a. O., S. 21.

1971 Vgl. Zimmer 2012, a. a. O., S. 56.

1972 Vgl. Dobzhansky 1973, a. a. O., S. $20 \mathrm{ff}$.

1973 Vgl. Dobzhansky 1973, a. a. O., S. $20 \mathrm{ff}$.

1974 Vgl. Zimmer 2012, a. a. O., S. 124, $126 \mathrm{ff}$.

1975 Vgl. Tautz, Diethard (2012): Genetische Unterschiede? Die Irrtümer des Biologismus, in: Haller, Michael/Niggeschmidt, Martin (Hrsg.): Der Mythos vom Niedergang der Intelligenz. Von Galton zu Sarrazin: Die Denkmuster und Denkfehler der Eugenik, Wiesbaden, S. $133 f$.

Vgl. Cavalli-Sforza/Cavalli-Sforza 1994, a. a. O., S. $340 \mathrm{ff}$.
} 
möglichen Erbfaktoren - zu integrieren. ${ }^{1977}$ Nach Cavalli-Sforza bleibt demnach schlusszufolgern, dass für die Ausbildung der geistigen Fähigkeiten des modernen Menschen sowohl die genetischen Grundlagen, das Entwicklungsmilieu der Individuen - vor allem der Bildungsfaktor Schule - sowie das Lebensumfeld essentiell erscheinen. ${ }^{1978}$ Ergänzend ist hinzuzufügen, dass die genetischen Unterschiede zwischen einzelnen Menschen, wie auch schon die vorherigen Kapitel aufgezeigt haben, minimal, fast zu vernachlässigen sind - wichtig bleiben die Entwicklungsund vor allem die Bildungschancen durch Schullaufbahn und Schulqualität für die Ausprägung der geistigen Fähigkeiten des modernen Menschen. ${ }^{1979}$ Dies bestätigt ebenfalls Theodosius Dobzhansky nachdrücklich, der insbesondere das Entwicklungs- und Umweltmilieu als entscheidend für die Ausbildung der kognitiven Fähigkeiten charakterisiert. ${ }^{1980}$ Vorausblickend muss darüber hinaus schon konstatiert werden, dass nicht nur die sogenannte Intelligenz für den späteren Lebenserfolg in Schule und Beruf verantwortlich ist, wie das im vorigen Kapitel aufgezeigte Beispiel von Thomas Woodrow Wilson eindrucksvoll vergegenwärtigt (s. Kapitel 5.4.1). Nichts ist demnach wirklich und ausschließlich angeboren sowie von den Eltern uneingeschränkt vererbt. ${ }^{1981}$

Der IQ bleibt also ein auf vielfältigen Faktoren beruhendes, schwer zu interpretierendes Konstrukt.

„[...] [Der IQ] misst nicht die eigentliche Intelligenæ, die zu schwer zu definieren ist und viele Aspekte und verschiedene Fähigkeiten umfasst, sondern nur die Fähigkeit, bestimmte nummerische, geometrische, linguistische Analysen oder Analysen abstrakter Formen durchzufübren [...]. "9982

Tab. 28: Exemplarische Items aus dem Stanford-Binet-Intelligenztest ${ }^{1983}$

\begin{tabular}{|ll|}
\hline Verbales Schließen & Wortschatz, Verstehen, Absurditäten, Verbale Relationen \\
\hline Quantitatives Schließen & Mengen, Zahlenfolgen, Gleichungen \\
\hline Abstraktes/Visuelles Denken & Musteranalyse, Nachmalen \\
\hline Kurzzeitgedächtnis & $\begin{array}{l}\text { Perlengedächtnis, Satzgedächtnis, Zahlengedächtnis, Ob- } \\
\text { jektgedächtnis }\end{array}$ \\
\hline
\end{tabular}

Die sogenannte Intelligenz stellt, ähnlich wie die ,Rasseklassifizierung' des modernen Menschen, vorrangig eher ein kulturelles, soziales sowie gesellschaftliches Konstrukt dar, welches insbesondere auf verhaltensbiologische und biologischpsychologische Erkenntnisse zurückzuführen ist, um mithilfe derer die eigenen Fehlinterpretationen auf eine scheinbar naturwissenschaftlich validierte Grundlage zu heben. Denn einzig die Gesellschaftsordnung setzt vermeintlich ,gute, ,förder-

1977 Vgl. Cavalli-Sforza/Cavalli-Sforza 1994, a. a. O., S. 344.

1978 Vgl. Cavalli-Sforza/Cavalli-Sforza 1994, a. a. O., S. $346 f$.

1979 Vgl. Cavalli-Sforza/Cavalli-Sforza 1994, a. a. O., S. $346 f$.

1980 Vgl. Dobzhansky 1973, a. a. O., S. 32.

1981 Vgl. Cavalli-Sforza/Cavalli-Sforza 1994, a. a. O., S. 342.

1982 Cavalli-Sforza/Cavalli-Sforza 1994, a. a. O., S. 340.

1983 Eigene Darstellung nach: Vgl. Grabowski 2007, a. a. O., S. 563. 
liche', ,präferierte ${ }^{6}$ und ,hilfreiche` Fähigkeiten auf der einen Seite sowie ,nachteilige $^{6}$, ungewollte ${ }^{\varsigma}$ Eigenschaften auf der anderen Seite fest. ${ }^{1984}$ Diese eingegrenzte Reliabilität und Testbreite visualisiert die vorherige Tabelle mit einer exemplarischen Auswahl an in IQ-Tests verwendeten Items nochmals. Im Mittelpunkt stehen verbale Verständnisfragen, mathematische und geometrische Rechenaufgaben sowie am Kurzzeitgedächtnis orientierte Arbeitsaufträge.

Katastrophale Folge dieser gesellschaftlichen Engführung von Fähig- und Fertigkeiten ist, dass weitere, in bestimmten Lebensumwelten besser geeignete Eigenschaften nicht gemessen werden und das Ergebnisbild in der Folge verfälscht wird. ${ }^{1985}$ Welche Bedeutung haben so beispielsweise Kenntnisse über die pädagogische und erzieherische Betreuung von Vorschulkindern für einen ledigen Eisenbahner im Betriebsdienst, Fachrichtung Lokführer und Transport, nur weil diese von der Gesamtgesellschaft erwünscht sind? Welche Bedeutung kommt beispielweise von der Gesellschaft erwünschten Kenntnissen im Bereich der Geologie von Alpengesteinen für einen Facharzt der Chirurgie zu? An diesen Beispielen wird die eingeschränkte Normorientierung der Gesellschaft - größtenteils der gesellschaftlichen Mittelschicht - nochmals exemplarisch illustriert. Der Fokus liegt einzig auf der Lernfähigkeit der Individuen, auf einer quantitativen Reduzierung der Fähigkeiten des Menschen auf einen statistisch messbaren IQ-Wert, unter Ausblendung sämtlicher qualitativer Charakteristika sowie der komplexen Umwelten. ${ }^{1986}$ Die IQ-Tests messen folglich nicht die allgemeine Problemlösefähigkeit von Individuen, die die im vorherigen Kapitel gezeigten Intelligenztheorien zum Teil als Intelligenzbegriff definieren, sondern ausschließlich gesellschaftlich erwünschte Standards. ${ }^{1987}$ Hier wird der schon im Vorfeld zum Scheitern verurteilte Versuch unternommen, menschliche Individuen vollkommen unabhängig und isoliert von ihrer sozialen Umwelt und ihrem Lebensumfeld sowie unter Ausblendung der menschlichen Gefühlswelt - also der menschlichen Individualität - zu betrachten. ${ }^{1988}$ Das Konstrukt des IQ sowie die Vorgehensweise der IQ-Tests sind so nicht kulturunabhängig. ${ }^{1989}$ „Die heute gebräuchlichen Intelligenztests sagen wie eh und je nichts über die Entwicklung der geistigen Prozesse, die Kraft des Denkens oder die intellektuelle Analyse irgendeines Kindes aus. Tests haben weiterhin vordringlich die Aufgabe, Kinder zu klassifizieren oder in eine Rangreihe zu

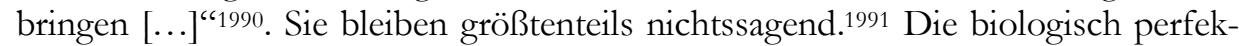
tionierten geistigen Fähigkeiten des modernen Menschen werden folglich auf gesellschaftlich standardisierte, messbare, reproduktive Leistungen gekürzt. ${ }^{1992}$ In der Folge sollten die statistischen Ergebnisse der IQ-Tests, so eindrücklich die nor-

\footnotetext{
1984 Vgl. Dobzhansky 1973, a. a. O., S. 50.

1985 Vgl. Dobzhansky 1973, a. a. O., S. 50.

1986 Vgl. Rosemann 1979, a. a. O., S. $26 \mathrm{ff}$.

1987 Vgl. Rosemann 1979, a. a. O., S. 34.

1988 Vgl. Rosemann 1979, a. a. O., S. $35 \mathrm{ff}$.

1989 Vgl. Grabowski 2007, a. a. O., S. 567.

1990 Rosemann 1979, a. a. O., S. 33.

1991 Vgl. Rosemann 1979, a. a. O., S. 35.

1992 Vgl. Rosemann 1979, a. a. O., S. $35 \mathrm{ff}$.
} 
mierten Auswertungen und Vergleichsanalysen auch erscheinen, nicht bedenkenlos akzeptiert werden. ${ }^{1993}$ Zusätzlich bleibt insbesondere vor dem Hintergrund der biologistisch-rassistischen Argumentationen zu erwähnen, dass die Ergebnisse der Intelligenzforschung lediglich Aussagen zu den spezifisch untersuchten Individuen oder vielmehr nur zu einer spezifisch untersuchten Menschengruppe zu dem originären Untersuchungszeitpunkt passen. ${ }^{1994}$ Eine Übertragung auf nachfolgende Generationen oder gar eine Verallgemeinerung auf die gesamte Menschheit ist vor dem Hintergrund der Reliabilität sowie der Validität ausgeschlossen. Ergebnisse, die sogenannte Intelligenz eines Individuums betreffend, können nicht auf eine ganze Menschengruppe, beispielsweise aus spezifischen Herkunftsländern, verallgemeinert und schon gar nicht als generationenübergreifend konstant interpretiert werden. Auch eine ,Rasseklassifizierung' von unterschiedlichen Menschengruppen aufgrund der IQ-Werte einzelner Gruppenmitglieder ist demzufolge wissenschaftlich und methodisch-analytisch schlichtweg falsch. Schlussfolgernd bleibt so zu diagnostizieren:

„[...] Andere, geistige‘ Persönlichkeitsmerkmale wie Ausdauer, Konzentration, Ehr-
geiz, Energie, Langzeitgedächtnis, Extra- und Introvertiertheit, Fantasie, Kreativität
[...] [misst der IQ] nur nebenbei und indirekt [...]. [B]ei den eigentlichen intellektuel-
len Fähigkeiten [...] [misst der IQ] nur einen Ausschnitt. Moralische Kriterien igno-
riert er vollständig [...]. Der IQ sagt nichts darüber, wie angenehm ein Mensch für seine
Mitwelt ist und wie nützlich für die Gesellschaft. Der Besitz selbst eines astronomischen
IQs ist keine Gewähr dafür, dass einer mit ihm auch etwas anzufangen weiß." "1995

IQ und Intelligenztest können so als „, ...] Artefakt[e] der Psycholog[ie] [...]“1996 bzw. als , „...] pragmatisch entwickelt[e] Kunstprodukt[e] der Psychologie [...]“1997 bezeichnet werden. Sie bleiben in der Verhaltensbiologie sowie in der biologischen Psychologie hochumstritten: Intelligenz als quantitatives Messergebnis der IQTests auf der einen Seite versus Intelligenz als individueller Pool an Fähig- und Fertigkeiten auf der anderen Seite. ${ }^{1998}$

\subsubsection{Intelligenz im Kontext von Verhaltens-, Molekular- und Humangenetik}

Die molekulargenetische Forschung zur Erblichkeit von kognitiven Fähigkeiten steht beim Menschen noch an den Anfängen. Die bisherigen Erkenntnisse sind demnach vielfach noch unstrukturiert. ${ }^{1999}$ Viele verhaltensbiologische Studien zur Bestimmung des Vererbungsanteils von intellektuellen bzw. geistigen Leistungen missverstehen beispielsweise das Konzept der Intelligenz, wie das vorige Kapitel

1993 Vgl. Gould 1983, a. a. O., S. 265.

1994 Vgl. Zimmer 1975, a. a. O., S. 57, 94.

1995 Zimmer 1975, a. a. O., S. 36.

1996 Zimmer 1975, a. a. O., S. 29.

1997 Zimmer 2012, a. a. O., S. 62.

1998 Vgl. Grabowski 2007, a. a. O., S. 557.

1999 Vgl. Devlin, B./Daniels, Michael/Roeder, Kathryn (1997): The heritability of IQ, in: Nature, Vol. 388, London u. a., S. 468, 470. 
verdeutlicht. Sämtliche statistischen Befunde bezüglich der sogenannten Intelligenz gelten nur relativ auf das einzelne Individuum bezogen, zeitlich begrenzt sowie nur für einen bestimmten Pool an - von der Gesellschaft festgelegten - normativen und standardisierten Fähigkeiten. Im Fokus der Forschung stehen hier die sogenannten Zwillings- und Adoptionsstudien, die insbesondere in den 1960er und 1970er Jahren des vergangenen Jahrhunderts mit Nachdruck betrieben wurden, jedoch auch im 21. Jahrhundert wieder an Bedeutung erlangen, wenn es um die Diskussion des Intelligenz-Phänomens geht.

Bei den sogenannten Zwillingsstudien werden standardisierte geistige Fähigkeiten von Zwillingen überprüft und verglichen. „Die Zwillingsmethode ist [scheinbar] geeignet, um den genetischen Anteil an der Ausprägung eines Merkmals quantitativ abzuschätzen, ohne dass man die dafür verantwortlichen Erbanlagen kennen muss.“"2000 Auf der einen Seite stehen die sogenannten zweieiigen, dizygoten Zwillinge, die sich, wie Einzelkinder ebenfalls, genetisch deutlich voneinander unterscheiden, da sie sich aus zwei verschiedenen befruchteten Eizellen - Zygoten - und damit aus zwei getrennten embryonalen Entwicklungsprozessen entwickeln. Die zahlreichen möglichen Variationen während dieses Entwicklungsprozesses verdeutlicht der bisherige Verlauf (s. Kapitel 5.3). Auf der anderen Seite stehen die sogenannten eineiigen, monozygoten Zwillinge, die sich aus einer gemeinsamen befruchteten Eizelle entwickeln, welche sich nach der Befruchtung geteilt hat, sodass zwei erbgleiche, lebensfähige Individuen entstehen konnten. Die Teilung erfolgt im frühen Embryonalstadium sehr wahrscheinlich aufgrund kurzfristiger Störungen. ${ }^{2001} \mathrm{Da}$ sich beide Organismen aus der gleichen Eizelle entwickeln, also auch einen identischen Genpool aufweisen, ist ihre DNA meistens vollkommen identisch. ${ }^{2002}$ Dizygote Zwillinge weisen hingegen - mit Ausblendung von zusätzlichen genetischen Variationen - zu etwa 50 Prozent die gleichen Gene auf. ${ }^{2003}$ Großeltern und deren Enkel weisen demgegenüber beispielsweise nur noch eine genetische Übereinstimmung von etwa 25 Prozent auf.2004 Unter verschiedenen umweltbedingten Testbedingungen können nun die geistigen Fähigkeiten von eineiigen und zweieiigen Zwillingen rudimentär verglichen werden. Höhere Korrelationen bei beiden eineiigen Zwillingen deuten auf einen gröBeren Erblichkeitsfaktor hin, höhere Korrelationen bei den zweieiigen Zwillingen insbesondere auf die Bedeutung der identischen Umgebungs- und Umweltbedingungen während des Wachstums- und Entwicklungsprozesses.

\footnotetext{
2000 Buselmaier/Tariverdian 2007, a. a. O., S. 352.

2001 Vgl. Buselmaier/Tariverdian 2007, a. a. O., S. 352 f.

2002 Jedoch treten auch bei monosygoten Zwillingen genotypische V ariationen auf, sodass deren genetische Korrelation nie 1 beträgt. Trotz der hohen genetisch übereinstimmenden Komponenten sorgen die differierenden Umwelten für geno- sowie phänotypische Unterschiede (s. Kapitel 5.3). Vgl. Zimmer 2012, a. a. O., S. $50 \mathrm{ff}$.

Vgl. Dobzhansky 1973, a. a. O., S. 24.

2004 Vgl. Dobzhansky 1973, a. a. O., S. 24.
} 


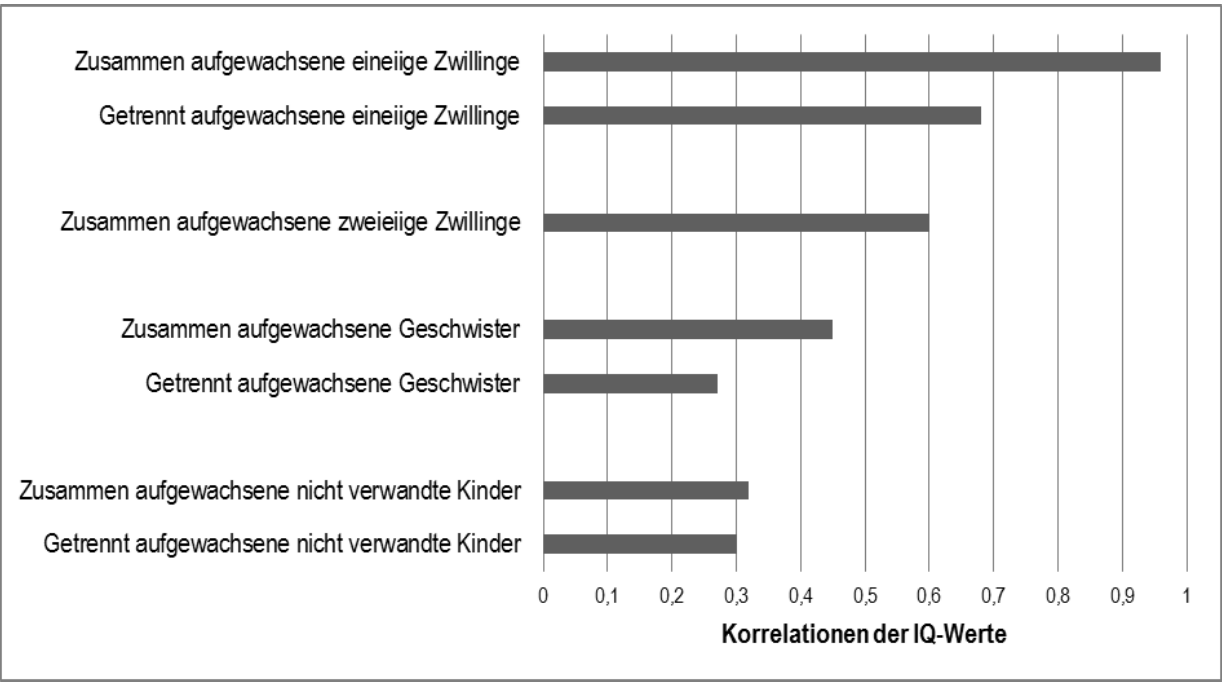

Abb. 21: IQ-Daten aus Zwillingsstudien ${ }^{2005}$

Ein ähnliches Prinzip verfolgen auch die sogenannten Adoptionsstudien, bei denen die kognitiven Leistungen eines adoptierten Kindes bei seinen Adoptiveltern - also seinen nicht-biologischen Eltern, mit denen es prinzipiell keinerlei genetische Informationen teilt bzw. vererbt bekommen hat - mit den geistigen Fähigkeiten der biologischen Eltern verglichen werden. Hier zeigen Analysen, dass der IQ der Kinder eher mit dem der biologischen Eltern korrelieren könnte. ${ }^{2006}$ In dieser Weise können aufgrund von Adoptionsstudien Aussagen bezüglich möglicher Umwelteinflüsse oder möglicher genetischer Prädispositionen getroffen werden. Die offene Frage bleibt jedoch, ob bzw. wo definitorisch die Grenze der chemisch-physikalischen, biologischen, sozialen und kulturellen Umwelten bzw. der Erblichkeit festgesetzt wird - diese bleibt oftmals willkürlich und verschwommen.

Die Problematik bei den von vielen Wissenschaftlern präferierten Zwillingsund Adoptionsstudien ist jedoch vielschichtig. Insbesondere genetische, medizinische und psychologische zwillingsspezifische Besonderheiten sind bei deren Anwendung und Interpretation zu beachten. ${ }^{2007}$ Weiterhin ist beispielsweise die Anzahl der monozygoten Zwillinge, die als Probanden in das Untersuchungsdesign passen, prinzipiell biologisch begrenzt, so dass hier meist nur 10-20 Untersuchungspersonen gefunden werden können. ${ }^{2008}$ Denn im Durchschnitt liegen die Zwillingsgeburten beispielsweise in Mitteleuropa nur bei etwa einem Prozent aller

2005 Eigene Darstellung nach: Vgl. Grabowski 2007, a. a. O., S. 581.

2006 Vgl. Dobzhansky 1973, a. a. O., S. 24.

2007 Vgl. Buselmaier/Tariverdian 2007, a. a. O., S. 362f.

2008 Vgl. Rosemann 1979, a. a. O., S. 128. 
Geburten, wie die nachfolgende Tabelle verbildlicht. ${ }^{2009}$ Hiervon sind etwa 40 Prozent monozygot und 60 Prozent dizygot. ${ }^{2010}$

Tab. 29: Häufigkeit von Zwillingsgeburten pro 1000 Geburten ${ }^{2011}$

\begin{tabular}{|lccc|}
\hline \multicolumn{1}{|c}{ Herkunft } & Periode & $\begin{array}{c}\text { ZZ/1000 } \\
\text { Geburten }\end{array}$ & $\begin{array}{c}\text { EZ/1000 } \\
\text { Geburten }\end{array}$ \\
\hline Spanien & $1951-1953$ & 5,9 & 3,2 \\
Portugal & $1955-1956$ & 6,5 & 3,6 \\
Frankreich & $1946-1951$ & 7,1 & 3,7 \\
Österreich & $1952-1956$ & 7,5 & 3,4 \\
Schweiz & $1943-1948$ & 8,1 & 3,6 \\
Bundesrepublik Deutschland & $1950-1955$ & 8,2 & 3,3 \\
Schweden & $1946-1955$ & 8,6 & 3,2 \\
Italien & $1949-1955$ & 8,6 & 3,7 \\
England und Wales & $1946-1955$ & 8,9 & 3,6 \\
Kalifornien: & & & \\
• US-Weiße & $1905-1959$ & 6,1 & 3,9 \\
• US-Farbige & $1905-1959$ & 11,0 & 3,9 \\
• US-Chinesen & $1905-1959$ & 2,2 & 4,8 \\
• US-Japaner & $1905-1959$ & 2,1 & 4,6 \\
Japaner & $1955-1962$ & 2,4 & 4,0 \\
\hline ZZ = Zweieiige Zwillinge; EZ = Eineiige Zwillinge & & \\
\hline
\end{tabular}

Von einem Prozent Bevölkerungsanteil auf die Gesamtbevölkerung zu schließen, scheint sehr gewagt und unrealistisch. Darüber hinaus stammen die ZwillingsProbanden meist auch aus ausschließlich selektiv ausgewählten bzw. vorsortierten Mittelschichtfamilien der hellhäutigen Bevölkerung, die sich durch ähnliche Umwelten charakterisieren und so folglich auch ähnlichere umweltbedingte Erblichkeitsschätzungen erlangen. ${ }^{2012}$ Vor diesem Hintergrund kommt es zu Verzerrungen und Fehlinterpretationen der einzelnen Studien durch ihre geringe Repräsentativität. Vornehmlich die fehlende Standardisierung der variablen, flexiblen Umweltbedingungen tragen zu einem an Validität mangelnden Ergebnis bei. ${ }^{2013}$ In der Folge unterscheiden sich auch die gewonnenen Datensätze von Studie zu Studie teilweise erheblich, was in der Konsequenz zu differenten, partiell gegensätzlichen Ergebnisinterpretationen führt. ${ }^{2014}$ Zusätzlich sind die erhaltenen Ergebnisse auch äußerst schwierig zu bewerten und zu interpretieren, wie das Beispiel ,g'verdeutlicht (s. Kapitel 5.4.2).2015

\footnotetext{
2009 Vgl. Buselmaier/Tariverdian 2007, a. a. O., S. $352 \mathrm{f}$.

2010 Vgl. Buselmaier/Tariverdian 2007, a. a. O., S. 354.

2011 Eigene Darstellung nach: Buselmaier/Tariverdian 2007, a. a. O., S. 355.

2012 Vgl. Dobzhansky 1973, a. a. O., S. 28. | Vgl. Plomin/DeFries/McClearn 1990, a. a. O., S. 360.

2013 Vgl. Rosemann 1979, a. a. O., S. $128 \mathrm{ff}$.

2014 Vgl. Wade/Tavris 1987, a. a. O., S. 462f.

2015 Vgl. Wade/Tavris 1987, a. a. O., S. 462.
} 
„Evidence from adoption and twin studies is often construed as strong support for the heritability of intelligence. However, heritability estimates vary widely from study to study. The degree to which heredity accounts for variations in intelligence within a population remains controversial." 2016

Vor allem die Zwillingsforschung im Rahmen der Verhaltensgenetik bleibt ein äußerst „sensibles Gebiet“2017. Denn die ermittelten Datensätze von Zwillingsund Adoptionsstudien illustrieren mittels ihrer begrenzten Aussagekraft nur, dass nicht nur die Gene des modernen Menschen, sondern ebenfalls die zahlreichen Umwelteinflüsse für die Entwicklung und Ausprägung des sogenannten Intelligenz-Phänomens aussagekräftig sind. ${ }^{2018}$

Tab. 30: Beispiele von Heritabilitätsschätzungen bei Tieren und Pflanzen2019

\begin{tabular}{|lc|}
\hline \multicolumn{1}{|c|}{ Organismus und Merkmal } & Heritabilität \\
\hline Fleckung bei Frisian-Rindern & 0,95 \\
Schlachtgewicht bei Rindern & 0,85 \\
Körperhöhe beim Menschen & 0,81 \\
IQ beim Menschen & 0,81 \\
Körpergewicht beim Menschen & 0,78 \\
Schädelindex beim Menschen & 0,75 \\
Pflanzenhöhe bei Mais & 0,70 \\
Eigewicht bei Geflügel & 0,60 \\
Gewicht der Bewollung bei Schafen & 0,40 \\
Milchproduktion bei Rindern & 0,30 \\
Kornertrag bei Mais & 0,25 \\
Eiproduktion bei Geflügel & 0,20 \\
Eiproduktion bei Drosophila & 0,20 \\
Ährenlänge bei Mais & 0,17 \\
Wurfgröße bei Mäusen & 0,15 \\
Reaktion auf Licht bei Drosophila & 0,09 \\
Empfängnisrate bei Rindern & 0,05 \\
Reaktion auf Schwerkraft bei Drosophila & 0,04 \\
\hline
\end{tabular}

Mitnichten wird jedoch ein festes, unabänderliches Verhältnis zwischen Umwelteinflüssen und Erblichkeit konstruiert, so dass beispielsweise ein fixiertes Zahlenverhältnis von Umwelt zu Genen von genau 20 zu 80 Prozent präsentiert werden könnte, wie dies beispielsweise Rainer Knußmann konstatiert. ${ }^{2020}$ Einige Studien quantifizieren die Erblichkeit der sogenannten Intelligenz demzufolge beispielsweise mit etwa 0,81, also 81 Prozent, wie die vorhergehende vergleichende Tabelle aus den 1960er Jahren visualisiert. Sie illustriert eine Hauptproblematik der Erblichkeitsschätzungen beim Menschen: Die dargestellten Forschungsdesigns sind

2016 Wade/Tavris 1987, a. a. O., S. 462.

2017 Buselmaier/Tariverdian 2007, a. a. O., S. 363.

2018 Vgl. Rosemann 1979, a. a. O., S. 132.

2019 Eigene Darstellung nach: Dobzhansky 1973, a. a. O., S. 29.

2020 Vgl. Knußmann 1996, a. a. O., S. $114 \mathrm{ff}$. 
eigentlich keinesfalls für die Anwendung am modernen Menschen vorgesehen, sondern primär für die landwirtschaftliche Züchtung möglichst ertragreicher, effizienter und resistenter Nutzpflanzen oder für die möglichst vorteilhafte Domestikation von Tieren und deren tierischer Nahrungsprodukte. Mithilfe der Forschungsbefunde können jeweils die Pflanzen und Tiere mit den präferierten und erwünschten Eigenschaften selektiert und nur diese in der Folge weiter gezüchtet werden. So kommen die präferierten Eigenschaften immer deutlicher zur Geltung: Die Erreichung eines möglichst hohen Schlachtgewichtes bei Tieren für eine möglichst große Fleischausbeute, eine möglichst große Milchproduktion bei Rindern zur anschließenden industriellen Milchverwertung oder der größtmögliche Kornertrag bei Mais zur Erlangung der optimalen Ernte. Können diese Untersuchungsdesigns und -befunde ohne Modifikationen auf den Homo sapiens übertragen werden? Zumindest die für quantitative und qualitative Tierexperimente geltenden Untersuchungsergebnisse können für menschliche Analysen nicht übernommen werden, wie auch die diesbezügliche Interpretationsvielfalt beweist. ${ }^{2021}$ Auch die Übertragung der tierischen, experimentellen Erkenntnisse auf den Menschen ohne weitere Verifizierung erscheint nicht realistisch. ${ }^{2022}$ Denn zu den biologischen Entwicklungsprozessen von Fauna und Flora kommen beim Menschen noch gesellschaftliche, soziale und kulturelle Entwicklungsfaktoren hinzu, die maßgeblich für die Sozialisation der menschlichen Individuen verantwortlich sind. 2023

„Die Heritabilität im engeren Sinne dient vor allem zur Prognostizierung des Nutzens, der aus einer Selektion zu erwarten ist, wie sie die Züchter von domestizierten Tieren oder Pflanzen betreiben: beispielsweise einer Selektion zur Steigerung der Legeleistung von Hennen oder des Milchertrags von Kühen. Beim Menschen sind solche Prognosen [...] nicht praktikabel [...]. "2024

Demzufolge verbietet sich eigentlich eine exakte Übertragung der Untersuchungsbedingungen, der Forschungsdesigns und der Forschungsbefunde von Pflanzen und Tieren auf den modernen Menschen kategorisch. ${ }^{2025}$ Folglich können auch die in der präsentierten Tabelle illustrierten Erblichkeitsfaktoren bezüglich des modernen Menschen als höchst zweifelhaft identifiziert werden, da dieser hier ohne methodische Anpassungen in das tierische sowie pflanzliche Untersuchungskonzept integriert wird. Für eine exakte Bestimmung der Vererbung der sogenannten Intelligenz wäre jedoch, wie bei Tierversuchen üblich, unter für den Menschen möglicherweise letalen Laborbedingungen zu arbeiten, was die gesellschaftliche und ethische Praxis verbietet. ${ }^{2026}$ Einzig kann von den tierischen und pflanzlichen Experimenten abstrahierend vermutet werden, dass allein das menschliche Ge-

\footnotetext{
2021 Vgl. Rosemann 1979, a. a. O., S. 151.

2022 Vgl. Rosemann 1979, a. a. O., S. 156.

2023 Vgl. Rosemann 1979, a. a. O., S. 309.

2024 Dobzhansky 1973, a. a. O., S. 27.

2025 Vgl. Rosemann 1979, a. a. O., S. 309.

2026 Vgl. Zimmer 1975, a. a. O., S. 56.
} 
nom nicht für die Ausbildung und Entwicklung des individuellen, menschlichen Verhaltens verantwortlich sein kann, sondern immer nur das Zusammenspiel zwischen genetischen und umweltbedingten Faktoren. ${ }^{2027}$ Insofern wird einzig die Komplexität und Vielschichtigkeit der Wechselbeziehungen zwischen humanbiologischen und umgebungsspezifischen Faktoren beim modernen Menschen bestätigt. 2028

Festgehalten werden kann demzufolge nur, dass die sogenannte Intelligenz sicherlich nicht unabhängig von Umweltfaktoren ausgebildet wird - inwieweit die Modifizierung durch umweltbedingte Reize jedoch stattfindet bleibt offen. ${ }^{2029}$ Hermann Rosemann konstatiert so sowohl für die Zwillingsstudien als auch für die Adoptionsstudien grundsätzlich erhebliche methodische Mängel.2030 „Zwillings-Studien zur IQ-Vererbung umweht seit jeher ein Ruch von Betrug. "2031, so auch Claus-Peter Sesín. Falsche Interpretationen der Ergebnisse, vielfältige Ergebnisverzerrungen, methodische Probleme sowie eine realitätsferne Überschätzung der Erblichkeitswerte lassen die Zwillingsstudien als höchst fragwürdig erscheinen. ${ }^{2032}$ Bisher ist es ihnen nachweislich nicht gelungen, genetische und umweltbedingte Einflüsse eindeutig voneinander zu trennen. ${ }^{2033}$ Bezüglich der Verwandtschaftsstudien sind also ausgeprägte Grenzen vorhanden, die unbedingt beachtet und akzeptiert werden müssen. ${ }^{2034}$ Darüber hinaus verdeutlichen auch die mit starken Einschränkungen und Zweifeln belasteten Intelligenz- und IQKonzepte, dass Befunde aus Zwillings- und Adoptionsstudien schon von Beginn an nur mit Einschränkungen beachtet werden dürfen (s. Kapitel 5.4.3). Die gemessenen Erblichkeitswerte lassen nur eingeschränkt Rückschlüsse auf das Phänomen der Intelligenz zu. ${ }^{2035}$ Weiterhin muss nochmals ergänzt werden, dass auch die möglichen Ergebnisse dieser Erblichkeitsschätzungen nur für die untersuchte Menschenpopulation sowie ausschließlich nur für das Zeitfenster der Analyse gelten dürfen. Eine Übertragung und Verallgemeinerung der Ergebnisse auf weitere Populationen oder gar die gesamte Menschheit weltweit über mehrere Generationen hinweg stellt eine Missachtung der Forschungsbedingungen dar, da repräsentative Samples bisher nicht existieren. ${ }^{2036}$

Vgl. Rosemann 1979, a. a. O., S. 155.

Vgl. Rosemann 1979, a. a. O., S. 154.

Vgl. Dobzhansky 1973, a. a. O., S. 26.

Vgl. Rosemann 1979, a. a. O., S. 147.

Sesín 2012, a. a. O., S. 35.

Vgl. Knebel, Leonie/Marquardt, Pit (2012): Vom Versuch, die Ungleichwertigkeit von Menschen zu beweisen, in: Haller, Michael/Niggeschmidt, Martin (Hrsg.): Der Mythos vom Niedergang der Intelligenz. Von Galton zu Sarrazin: Die Denkmuster und Denkfehler der Eugenik, Wiesbaden, S. $119 \mathrm{ff}$.

Vgl. Knebel/Marquardt 2012, ebd., S. 120.

Vgl. Dobzhansky 1973, a. a. O., S. 23.

Vgl. Zimmer 2012, a. a. O., S. 127.

Vgl. Dobzhansky 1973, a. a. O., S. 28ff. | Vgl. Zimmer 2012, a. a. O., S. 126. | Vgl.

Plomin/DeFries/McClearn 1990, a. a. O., S. 320. 
Grundlegend belegen die methodisch fragwürdigen Zwillings- und Adoptionsstudien des Menschen demnach, dass nicht nur die DNA bzw. die Gene jedes Menschen, sondern auch zahlreiche weitere Faktoren für die Ausbildung und Entwicklung des Menschen verantwortlich sind (s. Kapitel 5.3). „Each of us is a product of biological inheritance and experience." 2037 , folgern so Carole Wade und Carol Tavris. Hierbei sind unter anderem in der Kindheit die Nahrungsaufnahme, der Kontakt mit möglichen Giftstoffen oder Toxinen, die mentale Stimulation durch das Lernen, die Anzahl der Eltern-Kind-Interaktionen - gemeinsame Spiele, das Lesen von Büchern, gemeinsame Ausflüge oder das regelmäßige Antworten auf Fragen - sowie die Familiengröße anzuführen. ${ }^{2038}$

„In general, personality seems to be only moderately heritable. However, nervous habits and mannerisms, mood, and fearfulness all seem to have some genetic basis. Children are born with characteristic temperaments, or ways of reacting, that can influence their subsequent development. The consistency of temperaments across childhood depends in part on the ,fit' between the child's way of reacting and the parents'. '2039

Insbesondere die familiäre Umwelt bewirkt einen entscheidenden Einfluss auf die Entwicklung von Kindern, vor allem auf die geistige sowie intellektuelle Entfaltung. ${ }^{2040}$ Diese steht nicht isoliert dar, sondern ist mit vielfältigen weiteren Faktoren verbunden. ${ }^{2041}$ Speziell die Umweltfaktoren sind an dieser Stelle nochmals zu nennen: Insbesondere die Ernährung als Grundlage des menschlichen Stoffwechsels sowie der körpereigenen Energieversorgung - zugleich auch Kennzeichen des Lebendigen - ist essentiell für die Ausprägung sämtlicher Merkmale und Fähigkeiten des modernen Menschen. ${ }^{2042}$ Nur eine ausgewogene, qualitativ hochwertige Nahrung ermöglicht bei regelmäßiger Nahrungszufuhr die optimale energetische Versorgung aller Körperzellen und -gewebe mit Nährstoffen zum Erhalt und zum Wachstum dieser. Mangelernährung oder Nährstoffmangel führen demgegenüber insbesondere in der Wachstumsphase zu Störungen, die auch negative Auswirkungen auf die (kognitive) Entwicklung des Menschen haben können. Vor allem das Gehirn, welches etwa ein Viertel des menschlichen Energiehaushalts beansprucht, wird in der Folge unterdurchschnittliche Entwicklungs- und Verarbeitungsprozesse aufzeigen. Mangelnde Nährstoffversorgung führt hier beispielsweise zu Störungen des Nervensystems, zur Fehlentwicklung und mangelnden Funktionsfähigkeit des Gehirns, zu lokalen Schädigungen, zu fehlenden Synapsen und Dendriten zwischen den Nervenzellen - die die schnelle Informationsweiterleitung und -verarbeitung garantieren - oder zu einer Beeinträchtigung der Entwicklung der Neurone. ${ }^{2043}$ Dies kann in einer langsameren Informationsweiterleitung

2037 Wade/Tavris 1987, a. a. O., S. 424.

2038 Vgl. Wade/Tavris 1987, a. a. O., S. $450 \mathrm{ff}$.

2039 Wade/Tavris 1987, a. a. O., S. 462.

2040 Vgl. Merz/Stelzl 1977, a. a. O., S. 68.

2041 Vgl. Rosemann 1979, a. a. O., S. 168.

2042 Vgl. Rosemann 1979, a. a. O., S. 166.

2043 Vgl. Rosemann 1979, a. a. O., S. $170 \mathrm{ff}$. 
und folglich einer verminderten Reaktions-, Lern- und Leistungsfähigkeit resultieren. ${ }^{2044}$ Die Ernährung bildet so exemplarisch eine zusätzliche, grundlegende Ebene der Wechselbeziehungen zwischen Organismus und Umwelt sowie zugleich eine essentielle Vorbedingung für die korrekte Entwicklung des menschlichen Gehirns. ${ }^{2045}$

Eher untergeordnet scheinen demgegenüber die wirtschaftlichen und sozioökonomischen Voraussetzungen im Elternhaus, bezüglich derer nur ein schwacher Zusammenhang mit der geistigen Reifung diagnostizierbar ist. ${ }^{2046}$ Unterschiedliche Intelligenzwerte sind so - trotz aller begrifflichen Unschärfe - nicht nur genetisch- und umgebungsbedingt, sondern auch von den kulturellen, sozialen und gesellschaftlichen Umwelten, insbesondere von der familiären Umwelt in Elternhaus und Familie, abhängig. ${ }^{2047}$ Schlussfolgernd gesehen spielen die Umweltbedingungen für die humanbiologische Entwicklung des Gehirns und des Nervensystems während der Embryonal- und Fetalentwicklung des Kindes - die maßgeblich die spätere geistige Systemleistung bedingen - sowie ebenso nach der Geburt eine herausragende Rolle. Sie beeinflussen demnach auch die in der DNA des Menschen festgelegte Individualentwicklung. ${ }^{2048}$ Neuere Forschungserkenntnisse zeigen, dass die Bedeutung der Umweltfaktoren hinsichtlich des Verhaltens bzw. der kognitiven Fähigkeiten nach der Kindheit abnimmt. ${ }^{2049}$ Im Laufe des Lebens werden hingegen die genetischen Anlagen immer wichtiger, wie die nachfolgenden Grafiken visualisieren.

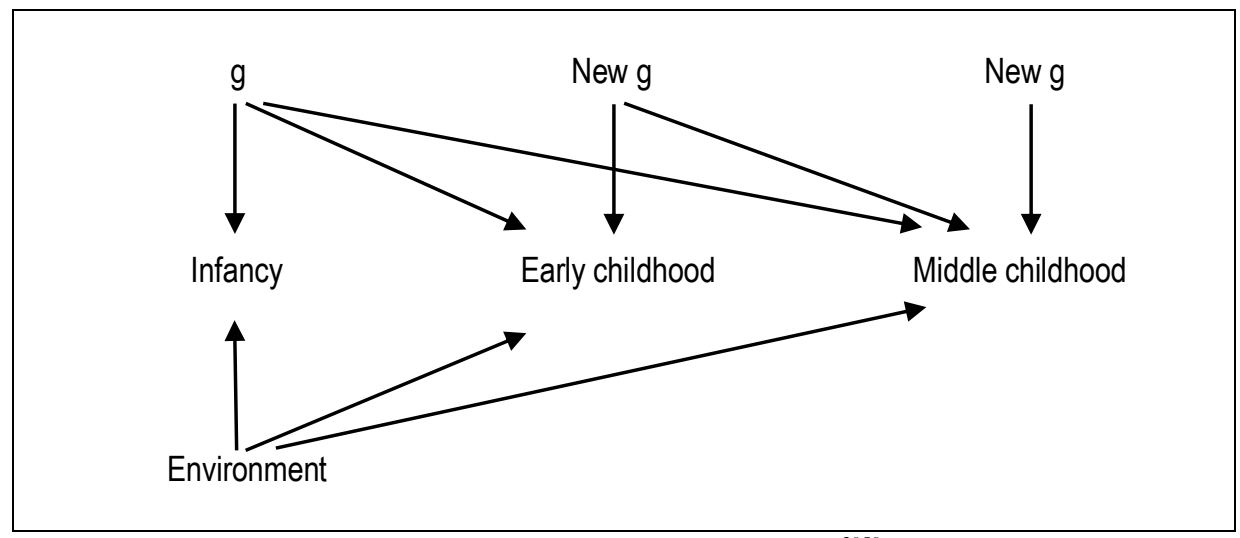

Abb. 22: Gen- und Umwelteinfluss während der Individualentwicklung ${ }^{2050}$

$\begin{array}{ll}2044 & \text { Vgl. Rosemann 1979, a. a. O., S. 170ff. } \\ 2045 & \text { Vgl. Rosemann 1979, a. a. O., S. 173ff. } \\ 2046 & \text { Vgl. Merz/Stelzl 1977, a. a. O., S. 70. } \\ 2047 & \text { Vgl. Dobzhansky 1973, a. a. O., S. } 20 . \\ 2048 & \text { Vgl. Grabowski 2007, a. a. O., S. 74. } \\ 2049 & \text { Vgl. Plomin/DeFries/McClearn/McGuffin 2008, a. a. O., S. 163ff. | Vgl. Plom- } \\ & \text { in/DeFries/McClearn 1990, a. a. O., S. 531ff. } \\ 2050 & \text { Eigene Darstellung nach: Plomin/DeFries/McClearn/McGuffin 2008, a. a. O., S. 167. | Vgl. } \\ & \text { Bartels/Rietveld/Van Baal/Boomsma 2002, a. a. O., S. 237ff. | Vgl. Plomin, Robert/Spinath, }\end{array}$ 


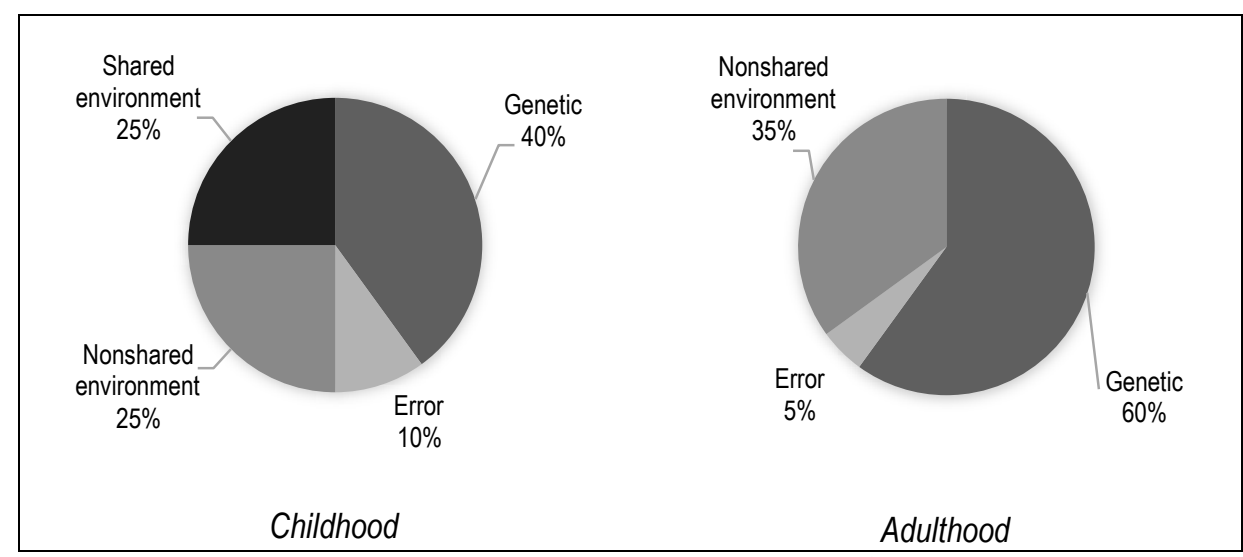

Abb. 23: Gen- und Umwelteinfluss im Kindes- und Erwachsenenalter 2051

Demnach gehen heute viele Wissenschaftler von einer beteiligten Erbkomponente bezüglich des Intelligenz-Phänomens aus - diese wirkt über die gesamte Lebenszeit auf die kognitive Entwicklung ein. ${ }^{2052}$ Adoptions- und Zwillingsstudien vergegenwärtigen darüber hinaus die Variabilität von Gen- und Umweltanteil: Im Kindesalter überwiegen die Umwelteinflüsse, im weiteren Lebensweg wird jedoch der genetische Einfluss stärker, wie die oben stehenden Ergebnisse zu zeigen vermögen. Auch Joachim Grabowski folgert so:

„,[Geistiges] Verhalten hängt von der Interaktion zwischen Anlage und Umwelt ab: Die Gene eines Individuums begrenzen das persönliche Potenzial, doch was mit diesem Potenzial tatsächlich geschieht, hängt von der Umwelt ab, in der dieser Mensch aufwächst." 2053

Darüber hinausgehend muss konstatiert werden, dass nicht nur ein Gen für die Entwicklung des sogenannten Intelligenz-Phänomens verantwortlich gemacht werden kann, sondern dass insbesondere für dieses komplexe Konstrukt der geistigen sowie intellektuellen Fähigkeiten eine Vielzahl von Genen - sogenannte Quantitative Trait Loci (QTLs) - erst im Zusammenspiel die individuelle Leistungsfähigkeit des Gehirns moderner Menschen bedingen. ${ }^{2054}$ Einen vielversprechenden Nachweis lieferten hier QTL-Analysen an Tiermodellen, die erste Hinweise zum Verständnis von Lernen und Gedächtnis auf genomischer Ebene erbrin-

Frank M. (2002): Genetics and general cognitive ability (g), in: TRENDS in Cognitive Sciences, Vol. 6, No. 4, München u. a., S. 169.

2052 Vgl. Plomin/DeFries/McClearn 1990, a. a. O., S. 365ff. | Vgl. Bartels/Rietveld/Van Baal/Boomsma 2002, a. a. O., S. 245.

2054 Vgl. Gould 1983, a. a. O., S. 177. | Vgl. Spinath/Deary 2008, a. a. O., S. 133. | Vgl. Plomin/DeFries/McClearn/McGuffin 2008, a. a. O., S. 353.

Mit QTL wird der Abschnitt eines Chromosoms - also ein brw. mehrere Gene auf einem Chromosom bezeichnet, die nachweislich für die Ausprägung bestimmter quantitativer Merkmale verantwortlich sind. 
gen. ${ }^{2055}$ Auch das G2C-Programm (Genes to Cognition Programme), welches genetische Informationen mit einem Set von Methoden - mit dem Ziel eines neuromolekularen Einblicks in das menschliche Verhalten - kombiniert, weist erste dahingehende Erkenntnisse auf. ${ }^{2056}$ Beide dienen zur Diagnose und Therapie, aber auch zum Verständnis von menschlichen Verhaltensweisen auf molekularer, zellulärer und neurosystematischer Ebene - dem größten biologischen Ziel des 21. Jahrhunderts: „Perhaps the greatest biological challenge of the 21 st century is to understand the mechanisms of human behavior. "2057 Nichtsdestotrotz steht die diesbezügliche Forschung erst an den Anfängen, insbesondere die Erforschung am Menschen gestaltet sich schwierig. ${ }^{2058}$ Hier ist zukünftig noch ein großes Potenzial im quantitativ-genetischen Bereich vorhanden, um den Zusammenhang von Genen und Gehirn im Rahmen der , functional genomics' zu verstehen. ${ }^{2059}$ Die kognitiven Fähigkeiten sind resümierend - wie auch weitere Teile des menschlichen Verhaltens - gleichsam hoch polygenetisch wie auch von nicht-genetischen Faktoren bestimmt. ${ }^{2060}$ Ein genetischer Determinismus bzw. eine direkte Abhängigkeit ist jedoch nicht nachweisbar. ${ }^{2061}$

Demzufolge gibt es auch kein spezifisches ,Dummheits'-Gen, welches die angeblich kategorisch niedrigere geistige Leistungsfähigkeit von einzelnen Menschenpopulationen erklären könnte, wie es beispielsweise Thilo Sarrazin mit dem „Basken-' und ,Judengen` zu propagieren versucht. Die sogenannte Intelligenz ist durch eine vielschichtige Dynamik geprägt und wird sowohl polygenetisch - über viele Gene verteilt - als auch über deren Interaktion mit der Umwelt festgelegt. ${ }^{2062}$ Auch die Identifizierung der intelligenzassoziierten Gene ist bisher wenig ertragreich, wie die vorher genannten QTL- und G2C-Analysen bestätigen. ${ }^{2063}$ Der Genotyp determiniert folglich keinen festen IQ. ${ }^{2064}$

2055 Vgl. Plomin/DeFries/Craig/McGuffin 2003, a. a. O., S. 118. | Vgl.

Plomin/DeFries/McClearn/McGuffin 2008, a. a. O., S. 117.

2056

Vgl. Plomin/DeFries/McClearn/McGuffin 2008, a. a. O., S. 136.

2058 Vgl. Plomin/DeFries 1998, a. a. O., S. 68f. | Vgl. Plomin/DeFries/McClearn/McGuffin 2008, a. a. O., S. 172.

2059 Vgl. Plomin/DeFries/McClearn/McGuffin 2008, a. a. O., S. 10ff, 190ff, 533ff. | Vgl. Deary, Ian J./Soinath, Frank M./Bates, Timothy C. (2006): Genetics of Intelligence, in: European Journal of Human Genetics, 14, London u. a., S. 698. | Vgl. Butcher, Lee M./Kennedy, Joanna K. J./Plomin, Robert (2006): Generalist genes and cognitive neuroscience, in: Current Opinion in Neurobiology, 16, München u. a., S. 150. | Vgl. Plomin, Robert/Owen, Michael J./McGuffin, Peter (1994): The Genetic Basis of Complex Human Behaviors, in: Science, Vol. 264, Washington u. a., S. 1739.

Der Fokus zukünftiger Forschungsfragen liegt auf der Integration der bisher individuellen Forschungsbereiche Quantitative Genetik, Molekulargenetik. und functional genetics, um von gemeinsamen Synergieeffekten - methodisch und technologisch - zu profitieren.

2060 Vgl. Plomin/DeFries/McClearn 1990, a. a. O., S. 247.

2061 Vgl. Plomin/DeFries/McClearn 1990, a. a. O., S. 247.

2062 Vgl. Grabowski 2007, a. a. O., S. 78. | Vgl. Zimmer 1975, a. a. O., S. 58ff. | Vgl. Dobzhansky 1973, a. a. O., S. 39. | Vgl. Tautz 2012, a. a. O., S. $131 \mathrm{ff}$.

2063 Vgl. Spinath/Deary 2008, a. a. O., S. 136.

2064 Vgl. Dobzhansky 1973, a. a. O., S. 51. | Vgl. Zimmer 2012, a. a. O., S. 150. 
Aus der Perspektive der Humanbiologie bleibt so eine eindeutige Prognose der Intelligenzentwicklung des modernen Menschen auch aufgrund zahlreicher methodisch fragwürdiger, experimenteller Ansätze komplex. Des Weiteren ist die Anwendung der schon vorgestellten Mendelschen Regeln als Grundkonzept der Vererbung von Merkmalen bzw. Genen insbesondere bezüglich des IntelligenzPhänomens schwierig, da es sich hier um eine polygenetische Eigenschaft handelt (s. Kapitel 5.3).2065

Resümierend bleibt festzuhalten, dass eine genetische Komponente der sogenannten Intelligenz durch die Zwillings- und Adoptionsstudien tendenziell nachgewiesen wurde. ${ }^{2066} \mathrm{Zu}$ kritisieren bleiben jedoch die zahlreichen instabilen Versuchsbedingungen der Studien, die in der Folge zu verfälschten Befunden führen können. 2067 Insofern sind Fragen bezüglich der geistigen Leistungsfähigkeit von Individuen nur eingeschränkt zu beantworten, gar verallgemeinerbare Erkenntnisse nicht nachhaltig identifizierbar. ${ }^{2068}$ Darüber hinaus belegen schon Studien mit Kindern aus den Jahren 1932 und 1947 eindeutig, dass jede biologischwissenschaftliche Grundlage für einen tendenziellen Intelligenzverlust der Gesellschaft - für eine, Verdummung' bzw. ein ,Abschaffen' der eigenen Nation, um mit den Worten Thilo Sarrazins zu sprechen - aufgrund biologischer Charakteristika fehlt: , ,...] so gibt es doch sicher keine Grundlage dafür zu glauben, die in unserer Gesellschaft wirkenden biologischen Kräfte führten zu einem drastischen Intelligenzabfall. Es gibt mehrere Lücken in jener Argumentation, die manche Leute dazu bringt, einen solche[n] Rückgang zu erwarten." ${ }^{\text {"2069 }}$

\subsubsection{Intelligenzforschung und Statistik}

Wie viele Forschungsbereiche stützt sich die Intelligenzforschung neben neurobiologischen und molekulargenetischen Erkenntnissen in großen Teilen auf statistische Datensätze, aus denen unterschiedliche Abhängigkeiten, Korrelationen und Kausalzusammenhänge bezüglich des Intelligenz-Phänomens erstellt werden (s. Kapitel 5.4.2, 5.4.3). Der Statistik wird in Gesellschaft und Wissenschaft als quantitativer Forschung ein enormes Vertrauen aufgrund ihrer Unabhängigkeit, Neutralität und Objektivität entgegen gebracht. Inwieweit erfüllt sie jedoch diese $\mathrm{Zu}$ schreibungen wirklich? Denn wie in vielen Forschungsbereichen hängt die Auswertung und Interpretation der Ergebnisse auch von den auswertenden Personen ab. Unabdinglich sind detaillierte fachliche sowie methodische Vorkenntnisse zur Analyse der gewonnenen Datenmaterialien. ${ }^{2070}$ Zusätzlich beeinflussen individuelle Vorurteile in entscheidendem Maße die Irrtumswahrscheinlichkeit bei der Datenauswertung - eine vollkommen wertfreie Betrachtung erscheint schwierig,

\footnotetext{
2065 Vgl. Knoche 1977, a. a. O., S. 52. | Vgl. Sesín 2012, a. a. O., S. 41.

2066 Vgl. Dunn/Dobzhansky 1970, a. a. O., S. 90.

2067 Vgl. Knoche 1977, a. a. O., S. 56 f.

2068 Vgl. Knoche 1977, a. a. O., S. 57f.

2069 Dunn/Dobzhansky 1970, a. a. O., S. 91.

2070 Vgl. Beck-Bornholdt, Hans-Peter/Dubben, Hans-Hermann (2008): Der Schein der Weisen.

Irrtümer und Fehlurteile im täglichen Denken, 6. Auflage, Reinbek bei Hamburg, S. 254.
} 
sodass die statistischen Interpretationen von PseudoTheoretikern wie Thilo Sarrazin oder Volkmar Weiss per se kritisch zu bewerten sind (s. Kapitel 3.1). ${ }^{2071}$ Eine statistische Datenanalyse erfordert demnach intensive fachliche Kenntnisse von Thematik sowie Methodik und ist darüber hinaus primär von deren definitorischen Grundlagen abhängig. ${ }^{2072}$ Das Beispiel , $\mathrm{g}^{6}$ in der Intelligenzforschung visualisiert, dass gerade hier oftmals mangelhafte Interpretationen zustande kommen, da der grundlegende Sachverhalt - in diesem Beispiel der Definitionsrahmen von , $\mathrm{g}^{6}$ - nicht bzw. absichtlich missverstanden wird.

Grundlegend erscheint neben den korrekten fachlichen Vorkenntnissen auch die richtige Durchführung der statistischen Mess- und Testverfahren. Erste Manipulationen sind diesbezüglich schon bei der Auswahl der Vergleichsdaten möglich, auf die sich beispielsweise bei einem zeitlichen Vergleich von Datensätzen bezogen wird. ${ }^{2073}$ Auch bei den ermittelten Datenmaterialien existieren vielfältige Fälschungsmöglichkeiten, um die gestellte Forschungshypothese zu validieren bzw. zu falsifizieren: Das Ignorieren von Messergebnissen, das Einfügen von alternativen, geschönten Zahlen oder das Aussortieren und Fälschen von Daten. ${ }^{2074}$ Weiterhin ermöglicht auch die grafische Darstellung von Messergebnissen vielfältige „,...] optische Täuschung[en] [...]“2075, wie das Abschneiden oder Strecken von Skalen, das Erstellen von unsinnigen Korrelationen oder das unzulässige Verschieben und Gruppieren von spezifischen Datensätzen. ${ }^{2076}$ Bei Thilo Sarrazin kann beispielsweise oftmals beobachtet werden, dass Korrelationen mit Kausalitäten gleichgesetzt werden, obwohl diese keine Zusammenhänge aufweisen (s. Kapitel 3.1). Darüber hinaus führt auch die Anwendung von unzulässigen Stichproben bei repräsentativen Studien - beispielsweise durch die Vorauswahl dieser - zu einer fehlerhaften Test- bzw. Messdurchführung. ${ }^{2077}$ Diesbezüglich dienen die Zwillings- und Adoptionsstudien im Rahmen der Intelligenzforschung als anschauliches Beispiel.

2071 Vgl. Beck-Bornholdt/Dubben 2008, a. a. O., S. 229.

2072 Vgl. Krämer, Walter (2008): So lügt man mit Statistik, 10. Auflage, München, S. 148.

2073 Vgl. Krämer 2008, ebd., S. 29ff.

2074 Vgl. Bosch, Karl (2002): Statistik. Wahrheit und Lüge, München u. a., S. 151f. | Vgl. Dubben, Hans-Hermann/Beck-Bornholdt, Hans-Peter (2007): Der Hund, der Eier legt. Erkennen von Fehlinformationen durch Querdenken, 2. Auflage, Reinbek bei Hamburg, S. $85 \mathrm{ff}, 98$.

2075 Bosch 2002, ebd., S. 153.

2076 Vgl. Dubben/Beck-Bornholdt 2007, ebd., S. 161ff, 182ff, 222. | Vgl. Krämer 2008, ebd., S. $51 \mathrm{ff}, 61 \mathrm{ff}, 87 \mathrm{ff}$.

Zusätzlich ist anzumerken, dass das Erstellen von Korrelationen nicht immer zielfübrend sowie keineswegs mit vorbandenen Kausalitäten gleichzusetzen ist. Auch die Arbeit mit Prozenten muss keritisch betrachtet werden: Obwohl Prozentwerte oftmals für Glawbwürdigkeit, Gewißheit und Objektivität stehen muss für deren Anwendung deutlich sein, was diese überhaupt darstellen bəw. sind. Äbnliches gilt für die Benutzung von Mittelwerten, die vielfach statistische Ungleichbeiten und Streunngen verschleiern, da Abweichungen ausgeblendet werden. Dies gilt ebenso für die Verwendung von synthetischen Superlativen, bei denen desöfteren die Vergleichbasis ausgeblendet wird bzw. nicht existent ist.

2077 Vgl. Bosch 2002, ebd., S. 154f. | Vgl. Krämer 2008, ebd., S. 97. 
Die scheinbar objektive Statistik bietet demnach multiple Möglichkeiten der Falschinterpretation, der Lüge sowie des Betrugs von ermittelten Datensätzen. ${ }^{2078}$ Sie generiert lediglich eine „Scheinpräzision“2079. Hier kann eine fehlende Beachtung der Grundsätze guter wissenschaftlicher Praxis identifiziert werden. Darüber hinausgehend fördert der Drang zu ständigen Neuerscheinungen voreilige Publikationen - allein die Quantität steht im Fokus, obwohl Qualität, also bessere Forschung, gefragt ist. ${ }^{2080}$ Die Sicherung der Eindeutigkeit der Ergebnisse durch Testwiederholungen wird in vielen Wissenschaftszweigen aufgrund des Zeitdrucks nicht beachtet. ${ }^{2081}$ Mehr Sachlichkeit sowie „[...] weniger Sensations- und Katastrophengeilheit $[\ldots]^{\text {“ } 2082}$ ist demnach insbesondere im Bereich der hochemotionalen Intelligenzdebatte notwendig. Die skizzierten Manipulations- und Verzerrungsmöglichkeiten gehören demnach „[...] in den Giftschrank des Statistikers." ${ }^{2083}$ Die statistische Forschung bietet lediglich einen kurzfristigen Trend als Zukunftsorientierung, kein deterministisches Konzept. ${ }^{2084}$ Die Entwicklungswege der Zukunft können also auch durch statistische Intelligenzauswertungen sowie mittels Zwillings- und Adoptionsstudien nicht als endgültig fixiert verstanden werden. ${ }^{2085}$

\subsubsection{Biologische Forschung und Intelligenzphänomen}

Die vorausgegangenen Kapitel veranschaulichen, dass einer eindeutigen, statistischen Bestimmung der genetischen bzw. umweltbedingten Entwicklungsanteile des Intelligenz-Phänomens, trotz der zahlreichen wissenschaftlichen Diskussionen, tendenziell eine Absage zu erteilen ist. Nichtsdestotrotz ist die DNA als Handbuch und Bauplan des menschlichen Organismus an der Ausbildung einzelner Merkmale und Fähigkeiten beteiligt, bzw. hat diesbezügliche Informationen gespeichert. Die Ausbildung der intellektuellen Fähigkeiten hängt letztlich von den neurobiologischen Eigenschaften des Gehirns ab: Der Anzahl der Nervenzellen, der Vielfalt der Synapsen oder der Isolierung der Axone bzw. Nervenfasern zur schnellen Informationsweiterleitung. ${ }^{2086}$ Gemeinsam bedingen sie beispielsweise die Geschwindigkeit und das Aktualisierungsvermögen des Gedächtnisses. ${ }^{2087}$ Wie diese zelluläre Zusammenarbeit aussieht, ist bisher noch nicht erforscht. Das $H u$ man-Brain-Project (HBP) versucht aktuell mithilfe eines computergestützten Modells

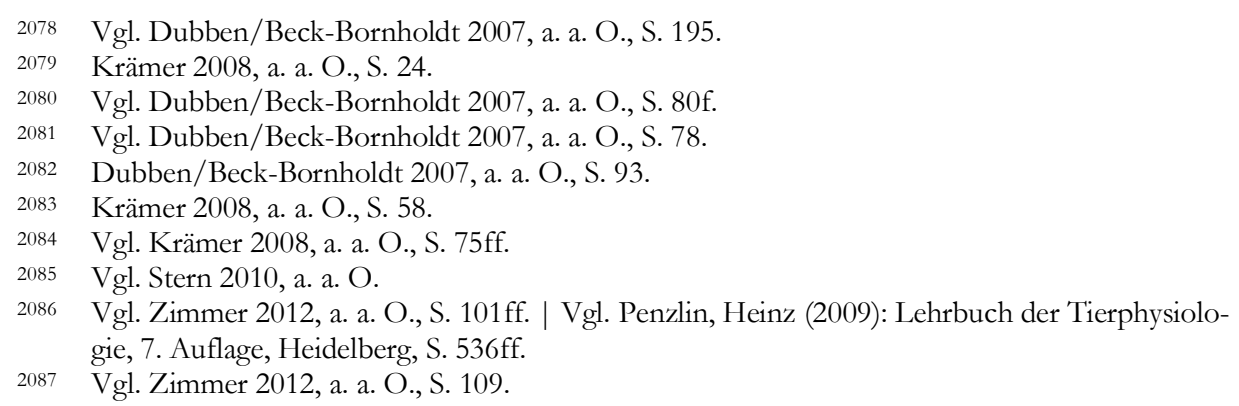


ein Rattengehirn zu simulieren. ${ }^{2088}$ Eine Simulation des menschlichen Gehirns und damit eine valide Aussage der neurologischen Fähigkeiten eines Menschen ist jedoch aufgrund dessen Komplexität sowie dessen enormer Speicherleistung selbst mit einem Hochleistungscomputer noch nicht möglich. ${ }^{2089}$ Insofern dürfen die genotypisch induzierten neuroanatomischen sowie -physiologischen Grundlagen keinesfalls außer Acht gelassen werden, da erst auf der Basis des von ihnen geschaffenen neurobiologischen Potenzials die multiplen Umwelten wirken können. Nichtsdestotrotz demonstrieren selbst die methodisch fragwürdigen Zwillings- und Adoptionsstudien deutlich, dass die zahlreichen Umweltfaktoren biologischer, chemisch-physikalischer, kultureller und sozialer Art - an der Ausgestaltung und Entwicklung der Fähigkeiten und Fertigkeiten eines Individuums maßgeblich beteiligt sind. In diesem Zusammenhang wurden bisher über 100.000 Personen in unterschiedlichen Testvarianten untersucht - ein einheitliches, aussagekräftiges Ergebnis fehlt aber weiterhin. ${ }^{2090}$ Die DNA gibt lediglich eine Reaktionsbreite vor, innerhalb derer sich die kognitiven Leistungen von Individuen ausbilden können - wie sich diese letztlich ausbilden, bleibt jedoch von vielfältigen genetischen und nicht-genetischen Einflüssen abhängig. Genetische und umweltbedingte Elemente bestimmen demzufolge gemeinsam die Ausprägung der individuellen sogenannten Intelligenz:2091 „Auch Intelligenz ist eine Sache der Interdependenz von Genen und Gelegenheiten." 2092

„Historically, debates about genetic and environmental influences on mental ability have sometimes sounded like a boxing match: ,In this comer, we have Heredity, and in this corner, we have Environment. Okay, you guys, come out fighting. 'The complicated findings of adoption and twin studies, however, show that in this contest, there can be no clear winner. Heredity might impose some limits on IQ and intellectual performance. But for any given genetic background, the reaction range, or range of potential reactions to the environment, is broad. "2093

Bei allen Problemen und Fragwürdigkeiten bezüglich des instabilen Intelligenzund IQ-Konzeptes bleibt insofern festzuhalten, dass die sogenannte Intelligenz nicht als „Schicksal“ 2094 bezeichnet werden kann, sondern von multiplen Einflussfaktoren konstruiert wird. ${ }^{2095}$ Beim sogenannten IQ handelt es sich lediglich um

2088 Vgl. Dambeck, Holger (2013): „Human Brain Project. Der Gehirn-Simulator von Jülich“, in URL: http://www.spiegel.de/wissenschaft/mensch/gehirn-simulation-neuronen-stattneutronen-a-903567.html <09.07.2013>. | Vgl. Human Brain Project (2013): ,The Human Brain Project. Vision“, in URL: http://www.humanbrainproject.eu/vision.html $<09.07 .2013>$.

2089 Vgl. Dambeck 2013, ebd.

2090 Vgl. Knußmann 1996, a. a. O., S. 120.

2091 Vgl. Dobzhansky 1962, a. a. O., S. 38. | Vgl. Knoche 1977, a. a. O., S. 35. | Vgl. Zimmer 2012, a. a. O., S. 250.

2092 Zimmer 1975, a. a. O., S. 79.

2093 Wade/Tavris 1987, a. a. O., S. 452.

2094 Dobzhansky 1973, a. a. O., S. 19.

2095 Vgl. Dobzhansky 1973, a. a. O., S. 19. 
einen relativen Zahlenwert, der nichts über die kognitiven Leistungen eines Individuums, wie Gedächtnis- oder Lernprozesse, aussagt. ${ }^{2096}$ Folglich zeigen sich auch die Vorurteile und Ressentiments des biologisch-genetisch konnotierten Rassismus als hinfällig, die auf eine ,rassengeleitete ${ }^{6}$ Vererbung der sogenannten Intelligenz zielen: Eine fixe, genetische Determination existiert nicht. Allein „,[d]as Genom ist die erste und entscheidende Bedingung menschlicher Existenz" "2097, nicht das Vorhandensein von spezifischen, ererbten Eigenschaften. Gene generieren keine spezifischen Fähig- und Fertigkeiten oder gar Vorlieben für bestimmte Hobbies; ihre Informationen dienen einzig der Produktion von Proteinen und Enzymen, sie sind jedoch nicht direkt für spezifische Verhaltensmuster verantwortlich. ${ }^{2098}$ Demzufolge kann auch das Vorurteil der ,reinen Rassen' in diesem Zusammenhang abermals als gescheitert entkräftet werden: Aufgrund der vielfältigen Umweltfaktoren, die auf die Entwicklung und Ausbildung der kognitiven Fähigkeiten variabel einwirken, stellen die modernen Menschen ebenfalls bezüglich der Intelligenz Individuen dar.

So bleibt festzuhalten, dass die Erbinformationen des Menschen eine Rolle unter vielen bei der Ausprägung der sogenannten Intelligenz spielen, da sie primär das grundlegende neurobiologische Potenzial bereitstellen. ${ }^{2099}$ Die Quantifizierung der Intelligenz des modernen Menschen mittels vielfältiger IQ-Testverfahren muss als zu einfach sowie methodisch und wissenschaftlich komplex klassifiziert werden - die Realität ist komplizierter. ${ }^{2100}$ Statistische Quantifizierungen bleiben ein „methodisches Kunstprodukt “2101 bzw. ein rein mathematisches Modell:

„Die herkömmliche Zwillingsmethode, die als Königsweg zur Erforschung der Bedeutung der Anlagen gilt, bleibt an der Oberfläche der Phänomene haften, d. h., sie ist nicht in der Lage, den real ablaufenden Entwicklungsprozess aufzuschlüsseln. Die Zwillingsforschung verfolgt darüber binaus einen mechanistischen und pessimistischen Ansatz: Sie versucht, die intellektuellen Unterschiede in mechanischer Form zu zerlegen: in einen Umweltanteil und in einen genetischen. Sowenig, wie es einen reinen genetischen Beitrag gib, gibt es einen reinen Umweltbeitrag. Beide Entwicklungsfaktoren wirken allemal zusammen, lassen sich im Prinzip nicht voneinander abgrenzen. "2102

Neuere Forschungserkenntnisse weisen sogar darauf hin, dass die analytische Intelligenz bzw. der IQ eines Menschen sich im Verlauf des Entwicklungsprozesses verändert: „Die biometrische Intelligenz altert.“2103 Darüber hinausgehend muss

\footnotetext{
2096 Vgl. Dunn/Plomin 1996, a. a. O., S. 27.

2097 Propping 1992, a. a. O., S. 114.

2098 Vgl. Zimmer 2012, a. a. O., S. 51.

2099 Neuere experimentelle Daten konstatieren, dass biometrische Intelligenzunterschiede bei Erwachsenen zu 60 bis 75 Prozent, bei Kindern zu unter 40 Prozent auf divergierende Gene zurück.zuführen sind. Auch individuelle Differenzen der abstrakt-analytischen Intelligenz, werden teilweise auf genbedingte Verschiedenheiten zurückgeführt. Vgl. Zimmer 2012, a. a. O., S. 28, 124, 250.

2100 Vgl. Zimmer 1975, a. a. O., S. 35. | Vgl. Zimmer 2012, a. a. O., S. 130.

2101 Rosemann 1979, a. a. O., S. 316.

2102 Rosemann 1979, a. a. O., S. 316.

2103 Zimmer 2012, a. a. O., S. 131.
} 
wiederholend angemerkt werden, dass sich alle Menschen genetisch zu ähnlich sind, um statistisch eindeutige, abgrenzbare Intelligenzunterschiede messen zu können. ${ }^{2104}$ Insbesondere zwischen unterschiedlichen Menschenpopulationen erscheint dies komplex: So existieren etwa 85 Prozent der genetischen Differenzen zwischen Individuen nur innerhalb einzelner Populationen, verschiedene Populationen unterscheiden sich im Durchschnitt jedoch nur um ungefähr 15 Prozent. ${ }^{2105}$ Dies visualisiert die große Spannweite sowie die differierenden Häufigkeitsverteilungen der gemessenen Durchschnittswerte. ${ }^{2106}$ Bezüglich des ,Rassekonzeptes' kann folglich auch diesbezüglich wieder illustriert werden, dass die genetischen Unterschiede auch am Beispiel der geistigen Fähigkeiten zwischen spezifischen Menschengruppen einfach zu gering sind, um Subspezies klassifizieren zu können. Hierfür müsste die genetische Differenz schätzungsweise mindestens 25-30 Prozent übersteigen, was aufgrund der kurzen Evolutionszeit des Menschen unwahrscheinlich erscheint. ${ }^{2107}$

Zwar haben fast alle menschlichen Fähig- und Fertigkeiten eine „[...] gene-

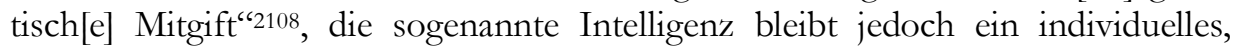
variables und dynamisches Entwicklungsprodukt. ${ }^{2109}$ Demzufolge muss bezüglich des Intelligenz-Phänomens nicht von einer ,Erbtheorie, , sondern von einer ,[...] Erbe-plus-Umwelt-Theorie $[\ldots]^{\text {“2110 }}$ gesprochen werden.

\subsection{Zwischenfazit: Biologie contra Rassismus}

Die vorangegangenen Kapitel verdeutlichen mithilfe unterschiedlicher Forschungsdisziplinen der Biologie, dass sämtliche biologistisch-rassistischen Theoreme zusätzlich zur sozialwissenschaftlichen Falsifizierung in den vorherigen Kapiteln keineswegs mithilfe der Biologie als Wissenschaft bestätigt oder validiert werden können. Die Fachdisziplinen der Biologie, wie die Humanbiologie und die Humangenetik, die Verhaltens- und Molekulargenetik, die Evolutionsbiologie, die Anthropologie sowie die biopsychologische Forschung werden durch pseudowissenschaftliche Argumentationen missinterpretiert und fehlgedeutet. Insbesondere die Ergebnisse der molekulargenetischen Forschung des 21. Jahrhunderts illustrieren eindeutig, dass mithilfe der DNA des Menschen keine bedeutenden, bzw. wenn nur evolutionsbiologisch zu vernachlässigende Unterschiede zwischen verschiedenen Menschenpopulationen nachweisbar sind - keinesfalls kann von verschiedenen ,Rassen“ gesprochen werden. Auch spezifische Intelligenzverteilungen sowie statistisch feste Vererbungswahrscheinlichkeiten der geistigen Leistungen können biologisch nur schwerlich bestätigt werden. Der pseudobiologische Ras-

2104 Vgl. Olson 2003, a. a. O., S. 100.

2105 Vgl. Olson 2003, a. a. O., S. 100.

2106 Vgl. Zimmer 2012, a. a. O., S. 197.

2107 Vgl. Olson 2003, a. a. O., S. 101.

2108 Zimmer 2012, a. a. O., S. 123.

2109 Vgl. Rosemann 1979, a. a. O., S. 241.

2110 Zimmer 2012, a. a. O., S. 121. | Vgl. Plomin/DeFries/McClearn 1990, a. a. O., S. $349 f f$. 
sismustypus basiert folglich einzig auf willentlichen Fehlinterpretationen der Naturwissenschaften, wie die folgenden Untersuchungsergebnisse nochmals zusammenfassend visualisieren.

Charles Darwin kommt demnach als Begründer der modernen Evolutionsbiologie eine herausragende Bedeutung in den Naturwissenschaften zu. Seine zukunftsweisende Evolutionstheorie markiert den Grundstein für eine ausnahmslos biologische Untersuchung der Entwicklung aller Lebewesen. Mit seinen zwei zentralen Komponenten, erstens der Evolution als Erklärungsmöglichkeit für Gemeinsamkeiten und Vielfalt der Organismen und zweitens dem Konzept der natürlichen Auslese als Ursache der Evolution, bricht Darwin mit dem vorherigen göttlichen Mythos der Artkonstanz. ${ }^{211}$ Jedoch kann der Prozess der natürlichen Selektion nicht als ,Kampf um das Überleben', als ,Überleben des Stärkeren“ oder als ,künstlich induzierte Bestenauslese‘ verstanden werden. Die natürliche Selektion zielt auf den unterschiedlichen Überlebens- und Fortpflanzungserfolg von Individuen aufgrund der Anpassung an deren Umwelten ab. ${ }^{2112}$ „Die natürliche Selektion erfolgt durch eine Wechselwirkung zwischen der Umwelt und der unter den einzelnen Organismen einer Population vorhandenen Variabilität."2113 Das heißt folglich, dass nicht der physisch Stärkere als Sieger der natürlichen Selektion hervorgeht, sondern das aufgrund vorteilhafter Variationen am besten an die gegebenen biotischen und abiotischen Umweltfaktoren angepasste Individuum. Das biologistisch-rassistische Prinzip des ,Überlebens der Stärkeren' respektive der angeblich ,nützlicheren', ,intelligenteren' und ,besseren' Menschenpopulationen kann so als wissenschaftlicher Unfug charakterisiert werden. Auch eine auf dem Evolutionskonzept Charles Darwins aufbauende ,Rassenklassifikation“ des modernen Menschen scheint aus der Perspektive der heutigen Evolutionsbiologie als unwahrscheinlich und realitätsfremd. Darwin kann folglich nicht als mit verschiedenen Rassentheoretikern und Sozialdarwinisten in einer Tradition stehend gesehen werden. Er stellt weder einen Mitbegründer des Rassismus noch des Sozialdarwinismus dar. Hier handelt es sich um unzulässige Adaptionen eines biologischen Konzepts auf gesellschaftliche und politische Verhältnisse, vor denen Darwin immer gewarnt und diese kategorisch abgelehnt hat. Rassismus und Sozialdarwinismus können so aus darwinistischer Sicht als Fehldeutung biologischer Theorien identifiziert werden. ${ }^{2114}$ Hier werden pseudowissenschaftliche Theorien ideologisiert, die mit der auf die Naturwissenschaften bezogenen Theorie der natürlichen Auslese nicht vereinbar sind. 2115

„Wir müssen uns vergegenwärtigen, dass der ganze [Rassismus und] Sozialdarwinismus mit seinen praktischen Auswirkungen eine pseudowissenschaftliche Doktrin ist, die sich

\footnotetext{
2111 Vgl. Markl 2006, a. a. O., S. $510 \mathrm{ff}$.

2112 Vgl. Markl 2006, a. a. O., S. 512.

2113 Markl 2006, a. a. O., S. 512.

2114 Vgl. Wuketits 1987, a. a. O., S. 109.

2115 Vgl. Wuketits 1987, a. a. O., S. 110.
} 
mit der streng auf das Naturwissenschaftliche bezogenen Theorie der natürlichen Auslese nicht vereinbaren lässt. "2116

Auch die moderne Synthetische Evolutionstheorie sieht - trotz teilweise kontroverser Inhalte - eine ,rassische' Evolution des Homo sapiens als unrealistisch an, insbesondere die Behauptung der Existenz von ,reinen Rassen ' des modernen Menschen. Denn alle Menschen sind, bis auf wenige Ausnahmen, genotypische und phänotypische Individuen. Sie unterscheiden sich weltweit durch geringfügige Variationen, die sich jedoch aus der Perspektive der Evolution als unbedeutend erweisen. Insofern sind die Evolutionsfaktoren, wie Gen-Neukombination, Mutation, Selektion, Isolation, Gendrift und Genfluss, die bedeutendsten Ursachenfaktoren des Evolutionsprozesses. Insbesondere Mutationen gelten als „[...] das dynamische, diskontinuierliche Element und liefern sozusagen das Rohmaterial für die Weiterentwicklung. “2117 Sämtliche Evolutionsfaktoren sorgen so für mehr oder weniger zufällige Variationen zwischen Individuen, so dass auch vor diesem Hintergrund die Existenz einer genotypisch vollkommen homogenen, ,reinen“ Menschenpopulation als unrealistisch identifiziert werden kann. Darüber hinaus sind auch Zufall und Zeit als Evolutionsfaktoren zu beachten. Genotypische und phänotypische Variationen kommen beim Menschen - bei Ausblendung der künstlichen, genetischen Klonierung - überwiegend zufällig zustande, können also folglich auch nicht vorbestimmt werden. ${ }^{2118}$ Vor allem aber muss die Zeit als maßgeblicher Einfluss auf das Evolutionsgeschehen berücksichtigt werden. Die Evolution ist ein Mechanismus, der Lebewesen über Millionen von Jahre verändert, anpasst, modifiziert und optimiert. Der moderne Mensch existiert in Europa beispielsweise erst seit etwa 35.000 Jahren - für uns gefühlsmäßig eine unendlich lange Zeitspanne, für den Prozess der Evolution sowie für die biologische Weltgeschichte jedoch nur ein zu vernachlässigender Bruchteil der Entwicklungshistorie. Aufgrund dieser erst relativ kurzen Existenz des Menschen hat der Zeitraum bisher nicht ausgereicht, um größere, aussagekräftigere und eindeutigere Variationen zwischen unterschiedlichen Menschenpopulationen zu generieren. Auch vor diesem Hintergrund zeigt sich so eine ,Rassenklassifikation' des Homo sapiens als utopisch und realitätsfremd. Darüber hinaus muss letztlich zusätzlich die Kultur als „,superorganischer“2119 Evolutionsaspekt beachtet werden: Diese beeinflusst und kontrolliert die Umwelten des Menschen, wird jedoch nicht genetisch vererbt. ${ }^{2120}$ Zugleich ist diese Kultur das entscheidende Kriterium, welches die übrige Fauna und Flora vom modernen Menschen unterscheidet.

„Die menschliche Evolution hat zwei Komponenten, die biologische oder organische und die kulturelle oder überorganische. Diese Komponenten schließen sich weder gegenseitig aus noch sind sie unabhängig voneinander, sondern miteinander verknüpft und interde-

2116 Wuketits 1987, a. a. O., S. 110.

2117 Feustel, Rudolf (1990): Abstammungsgeschichte des Menschen, 6. Auflage, Jena, S. 23.

2118 Vgl. Feustel 1990, ebd., S. 24ff.

2119 Dobzhansky 1973, a. a. O., S. 121.

2120 Vgl. Dobzhansky 1973, a. a. O., S. $121 \mathrm{ff}$. 
pendent. Menschliche Evolution kann nicht einæig als biologischer Prozess verstanden werden, noch kann sie in zureichender Weise als Kulturgeschichte beschrieben werden. Sie ist die Wechselwirkung von Biologie und Kultur. Zwischen biologischen und kulturellen Prozessen besteht eine Rückkopplung. "2121

Auch die anthropologische und molekulargenetische Forschung unterstützt die getroffenen Argumente gegen eine naturwissenschaftliche Begründung der biologistisch-rassistischen Ideologie. Wie mithilfe von DNA-, mtDNA- und YChromosomen-Analysen bestätigt werden konnte, hat sich der moderne Mensch ursprünglich monozentrisch in Afrika entwickelt. Erst im weiteren Entwicklungsverlauf hat er sich ausgehend von Afrika auf den weiteren Kontinenten der Erde verteilt. Zu Isolationsprozessen kam es vor diesem Hintergrund jedoch genauso wenig, wie zu einer nachhaltigen Vermischung mit archaischen Vorformen des modernen Menschen. Somit rückt sowohl eine mögliche Abspaltung von neuen Spezies des Menschen als auch die Ausdifferenzierung in unterschiedliche Subspezies in weite Ferne. Dies bestätigen ebenfalls Untersuchungen der sprachlichen Entwicklungs- und Verbreitungslinien sowie der Ausweitung des Ackerbaus auf verschiedene Kontinente, wie besonders Luigi Luca Cavalli-Sforza prägnant illustriert. Steve Olson folgert so treffend:

„Dennoch vermittelt unsere DNA eine klare Botschaft. Jeder Mensch, der heute lebt, ist entweder Afrikaner oder stammt von Afrikanern ab. Menschen verschiedener Kontinente besitzen keine unterschiedliche Evolutionsgeschichte. Die Entwicklung des modernen Menschen war bereits weitgehend abgeschlossen, bevor er auszog, um die Welt zu besiedeln. ${ }^{\prime 2122}$

Auch bezüglich der heutigen Bevölkerung der Bundesrepublik Deutschland kann so aufgrund der genotypischen Evolutionsbewegungen keinesfalls eine identische, gemeinsame Abstammung identifiziert werden. Die vorherigen Kapitel haben diesbezüglich schon vor allem den Wandel der bundesrepublikanischen Bevölkerung zu einer multikulturellen Gesellschaft präsentiert, sodass aufgrund von Einwanderungs- und Migrationsbewegungen heute nicht von einer genetisch homogenen Bevölkerung gesprochen werden kann (s. Kapitel 4). ${ }^{2123}$ Dies trifft jedoch nicht nur für das 21. Jahrhundert zu, sondern kann schon im Verlauf der vorhergehenden Jahrhunderte für den gesamten europäischen Kontinent beobachtet werden. Trotz dieser geringfügigen genotypischen Unterschiede zwischen den modernen Menschen können jedoch keine ,Menschenrassen“ klassifiziert und hierarchisiert werden - die genotypischen Differenzen zwischen möglichen Subspezies wären zu gering. Darüber hinaus lassen sich aufgrund der genetischen Variationen ebenfalls keine sogenannten ,Rassengene،, die sich von Population zu

2121 Dobzhansky 1962, a. a. O., S. 34.

2122 Olson 2003, a. a. O., S. 63.

2123 Vgl. Bielefeld, Uli (1991): Einleitung, in: ebd. (Hrsg.): Das Eigene und das Fremde. Neuer

Rassismus in der alten Welt?, Hamburg, S. 12. 
Population unterscheiden, identifizieren. ${ }^{2124}$ Diese bleiben ebenso wie die Existenz von multiplen ,Menschenrassen' ein Irrglaube der biologistisch-rassistischen Ideologie. Menschenpopulationen und nationale Bevölkerungsgruppen überlappen sich gegenseitig und sind durch einen andauernden, gegenseitigen genetischen Austausch charakterisiert. ${ }^{2125}$ Auch die genotypische und phänotypische Ausstattung einzelner Menschenpopulationen zeigt vielfältige Interdependenzen ,Volksgene' sind hier jedoch nicht diagnostizierbar. Schon Charles Darwin charakterisierte die Unterschiede zwischen den von ihm noch fälschlicherweise akzeptierten ,Menschenrassen“ aufgrund der großen Übereinstimmungen als unwichtig. ${ }^{2126}$ Hinzukommend muss ergänzt werden, dass der moderne Mensch in erster Ebene ein gesellschaftliches Produkt darstellt, da die gesellschaftlichen Normenund Wertvorstellungen das menschliche Individuum nachhaltig formen und beeinflussen. ${ }^{2127}$ Die Gesellschaft ist so insbesondere für die Übertragung und Prägung von sozialen Eigenschaften verantwortlich. ${ }^{2128}$ Sozialisation wird demzufolge nicht vererbt, sondern individuell erworben. So kann abermals festgehalten werden, dass erworbene Merkmale, wie soziale Eigenschaften oder kognitive Fähigkeiten, definitiv nicht vollkommen als erblich angesehen werden können. ${ }^{2129}$ Dies trifft hinzukommend selbstverständlich auch für weitere Attribute, wie Charakter und Persönlichkeit, zu - diese sind überwiegend durch die Sozialisation des Menschen bedingte Kennzeichen. ${ }^{2130}$ Sie werden durch Lernprozesse sowie Nachahmungen im Laufe des Wachstums- und Entwicklungsvorganges übernommen und ausgebildet. ${ }^{2131}$ Vor diesem Hintergrund folgert auch Cavalli-Sforza, dass die natürliche Auslese nur von der Natur, die kulturelle Auslese jedoch, wie beispielsweise die Aufnahme von neuen Wörtern oder Sprachbestandteilen in den Sprachpool, von der Gesellschaft vorgenommen wird. ${ }^{2132}$ Nicht zuletzt Theodosius Dobzhansky stellt diesbezüglich treffend fest: „Heute kann nicht entschieden genug betont werden, dass das, was biologisch vererbt wird, nicht fix und fertig von den Ahnen übernommen wurde. “2133 Hier muss eindeutig zwischen genetischen, vererbbaren und kulturell erworbenen Charakteristika differenziert werden.

\section{„Das Wechselspiel zwischen den biologischen und den kulturellen Komponenten der menschlichen Evolution kann vielleicht am klarsten aufgezeigt werden, wenn wir im Au- ge behalten, dass sie derselben grundlegenden Funktion dienen - der Anpassung an die menschliche Umwelt und der Kontrolle der menschlichen Umwelt. "2134}

\footnotetext{
2124 Vgl. Gould 1983, a. a. O., S. 358.

2125 Vgl. Cavalli-Sforza et al. 1994, a. a. O., S. 19.

2126 Vgl. Cavalli-Sforza et al. 1994, a. a. O., S. $17 \mathrm{ff}$.

2127 Vgl. Feustel 1990, a. a. O., S. 10.

2128 Vgl. Cavalli-Sforza 1999, a. a. O., S. 192.

2129 Vgl. Dobzhansky 1962, a. a. O., S. 23.

2130 Vgl. Dobzhansky 1962, a. a. O., S. 30.

2131 Vgl. Dobzhansky 1962, a. a. O., S. 36.

2132 Vgl. Cavalli-Sforza/Cavalli-Sforza 1994, a. a. O., S. 298.

2133 Dobzhansky 1962, a. a. O., S. 23.

2134 Dobzhansky 1962, a. a. O., S. 36-37.
} 
Vornehmlich die Molekulargenetik beschäftigt sich mit der Frage, woher die zahlreichen genotypischen und phänotypischen Variationen des Menschen letztlich stammen. Grundlage sind im Bereich der Klassischen Genetik zum einen die Ergebnisse der Vererbungsexperimente Gregor Mendels, die den grundlegenden Erbgang bezüglich weniger Merkmale von der Parental- zu den einzelnen nachfolgenden Filialgenerationen skizzieren. Zum anderen müssen diesbezüglich die genotypischen Eigenschaften der menschlichen DNA beachtet werden, die sich durch teilweise umweltbedingte Mutationen oder Rekombinationen in somatischen und generativen Zellen sukzessive verändern, da nicht alle Variationen durch selbstgesteuerte Reparaturmechanismen wieder vollständig korrigiert werden können. Nichtsdestotrotz ergibt sich gerade aus dieser genetischen Vielfalt ein essentieller Vorteil für eine verbesserte Umweltanpassung sowie die Weiterentwicklung und die Evolution des modernen Menschen. ${ }^{2135}$

\section{„Die genetische Verschiedenheit des Menschen ist kein unglücklicher Zufall oder Defekt der menschlichen Natur. Sie ist ein unschätzbarer Vorzug, mit dem der Evolutionspro- zess die menschliche Art ausgestattet hat." 2136}

Hauptfaktor der genetischen Verschiedenheit des modernen Menschen bleibt also das Vorhandensein von zufälligen, nicht steuerbaren, mehr oder weniger vorteilhaften genetischen Mutationen.
„Mutationen geschehen ziellos, in gewisser Beziehung zufällig, sind also nicht auf die $V$ erbesserung schon bestehender Anpassungen an die Umwelt oder Erzengung neuer Anpassungen gerichtet, sondern können, neutral' erscheinen, nützlich oder schädlich sein. "2137

Die erblichen und nicht-erblichen Variationen verändern sich in Anzahl und Vielfalt von Zeit zu Zeit, von Merkmal zu Merkmal oder von Population zu Population - ein Kennzeichen der Evolution. ${ }^{2138}$ Sämtliche statistisch-mathematischen Datensätze zur Bestimmung und Evaluierung von Erblichkeit bleiben so auch vor diesem Hintergrund eine fragwürdige, relative Komponente. ${ }^{2139}$ Sie geben wenn überhaupt, wie bei der Intelligenzforschung, lediglich eine relative Entwicklungsrichtung vor, sind jedoch keinesfalls auf einzelne Individuen oder gar die gesamte moderne Menschheit übertragbar. ${ }^{2140}$ Die DNA aller Menschen ist so zu eng miteinander vernetzt, sodass biologische Unterschiede aufgrund ihrer Variabilität nicht gerechtfertigt werden können: ${ }^{2141}$

„Unsere DNA ist zu eng verflochten, als dass man Unterschiede biologisch rechtfertigen könnte, die im Grunde gesellschaftlich bedingt sind. Unsere Vorlieben, unser Charakter

\footnotetext{
2135 Vgl. Dobzhansky 1973, a. a. O., S. 56 f.

2136 Dobzhansky 1973, a. a. O., S. 56.

2137 Feustel 1990, a. a. O., S. 24.

2138 Vgl. Zimmer 1975, a. a. O., S. 63.

2139 Vgl. Zimmer 1975, a. a. O., S. 64.

2140 Vgl. Zimmer 1975, a. a. O., S. 81.

2141 Vgl. Olson 2003, a. a. O., S. 353.
} 
und unsere Fäbigkeiten sind nicht von der biologischen Geschichte unserer Vorfahren bestimmt, sondern bängen von unseren individuellen Eigenschaften, Fäbigkeiten, Erfahrungen und Entscheidungen ab. In dem Maße, wie diese unausweicbliche Erkenntnis sich durchset:t, wird unsere genetische Geschichte zwangsläufig an Bedeutung verlieren. Wenn wir einen anderen Menschen anschauen, werden wir nicht mebr denken: ein Asiate, ein Schwarzer oder Weißer. Wir werden einfach denken: ein Mensch. "2142

Um an diese Schlussfolgerung von Steve Olson anzuschließen, kann weiterführend festgehalten werden, dass sich die modernen Menschen genetisch nur geringfügig - für die Evolution unbedeutend - unterscheiden, so dass die Existenz von ,Menschenrassen ${ }^{6}$ abermals eindeutig verneint werden kann. ${ }^{2143}$ Genotypische und phänotypische Differenzen folgen lediglich Anpassungen an Umwelt- und Lebensbedingungen der unterschiedlichen Menschenpopulationen. ${ }^{2144}$ Es kann so höchstens von quantitativen Varietäten zwischen Menschengruppen gesprochen werden, jedoch keineswegs von qualitativen. ${ }^{2145}$ Auch vor diesem Hintergrund muss die Existenz von sogenannten, Volksgenen' eindeutig abgestritten werden: „Es gibt keine Gene, die jemanden zu einem Maler, zu einem Staatsmann oder zu einem Gangster machen [...].“2146 Gene rechtfertigen folglich keinerlei Diskriminierung.

Resümierend steht ein Rückblick zur Fragestellung die Ursachen der menschlichen Variationen betreffend: Wie kommen genotypische und phänotypische, sichtbare und unsichtbare Variationen zwischen verschiedenen Populationen des Menschen zustande?

- Faktor eins ist die Anpassung an unterschiedliche umweltbedingte Klimate nach der Ausbreitung des modernen Menschen von Afrika aus auf die verschiedenen Kontinente. ${ }^{2147}$ Die Folge war eine erste genetische Differenzierung, die zahlreiche morphologische Unterschiede, wie die Anpassung von Haut-, Haar- oder Augenfarbe, der Körperbehaarung oder der differenzierte Körperbau illustrieren. ${ }^{2148}$

- Faktor zwei zeigt, dass die gruppenbezogene Anpassung an das Klima relativ homogen verlaufen ist und nur wenige individuelle Unterschiede anzutreffen sind. ${ }^{2149}$ Folglich bedingen einzig die unterschiedlichen klimatischen Lebensbedingungen zwischen verschiedenen Menschenpopulationen die differenten umweltbedingten Anpassungen. ${ }^{2150}$

2142 Olson 2003, a. a. O., S. 353.

2143 Vgl. Cavalli-Sforza/Cavalli-Sforza 1994, a. a. O., S. 203.

2144 Vgl. Cavalli-Sforza/Cavalli-Sforza 1994, a. a. O., S. 203. | Vgl. Zimmer 2012, a. a. O., S. 199. Menschen haben zwar gleiche Gene, diese unterscheiden sich jedoch durch die verschiedenen Ausprägungsformen, die Allele, sind also nicht vollkommen identisch.

2145 Vgl. Cavalli-Sforza/Cavalli-Sforza 1994, a. a. O., S. 204.

2146 Dobzhansky 1962, a. a. O., S. 378.

2147 Vgl. Cavalli-Sforza 1999, a. a. O., S. 22.

2148 Vgl. Cavalli-Sforza 1999, a. a. O., S. 23.

2149 Vgl. Cavalli-Sforza 1999, a. a. O., S. 24.

2150 Vgl. Cavalli-Sforza 1999, a. a. O., S. 24. 
- Drittens sind die Merkmale der klimabedingten Anpassungen meist nur auf der Körperoberfläche zu sehen, da diese die Verbindungsstelle zwischen Umwelt und Organismus darstellt. ${ }^{2151}$

- Vor dem Hintergrund des biologisch-genetischen Rassismustypus ist viertens die Ausweitung und Übertragung der umweltbedingten Variationen auf andere genotypische sowie phänotypische Merkmale fehlerhaft und utopisch. ${ }^{2152}$ So kann das Vorhandensein von sogenannten ,Menschenrassen' als Falschaussage abgewiesen werden: Allein aufgrund von phänotypischen Unterschieden können keine angeblich verschiedenen ,reinen Rassen konstruiert werden, da keine genetischen Polymorphismen, sondern genotypische Homogenität vorherrscht. ${ }^{2153}$

Auch Luigi Luca Cavalli-Sforza bestätigt diesbezüglich nochmals die enge genetische Verwandtschaft aller modernen Menschen weltweit:

„Diese unsichtbare Variation ist in jeder Gruppe, sei es die eines Kontinents, einer Region, einer Stadt oder eines Dorfes, immer groß, und sie ist größer als die zwischen Kontinenten, Regionen, Städten und Dörfern. Die Rassenreinheit ist also inexistent, unmöglich und überhaupt nicht erstrebenswert. "2154

Des Weiteren vergegenwärtigt die Molekulargenetik auch eindeutig, dass eine spezifische Unterscheidung zwischen genetischen und umweltbedingten Einflüssen auf den Vererbungsprozess nicht zielführend erscheint. Wie schon mehrmals angesprochen, können beide Komponenten nur schwerlich voneinander abgegrenzt werden, da sie sich gegenseitig beeinflussen, bedingen und von vielfältigen Wechselwirkungen geprägt sind. ${ }^{2155}$ Die genetisch festgelegten, vererbbaren Faktoren offerieren ein bestimmtes Potenzial, auf dessen Grundlage die biologischen, chemisch-physikalischen, sozialen und kulturellen Umwelten ,[...] zusammen

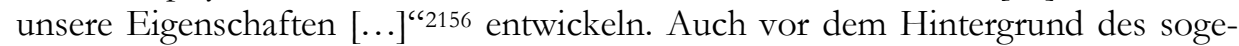
nannten Intelligenzbegriffes sowie der Erforschung und Einordnung von Individuen anhand des sogenannten IQ kann dementsprechend konstatiert werden, dass die geistigen Fähigkeiten der Menschen - trotz der Notwendigkeit von neurobiologischen sowie genetischen Voraussetzungen - auch maßgeblich durch die verschiedenen Umwelten geprägt werden. ${ }^{2157}$ Sie sind nicht von Geburt an durch Determinierung unveränderbar festgelegt, wie zahlreiche Zwillings- und Adoptionsstudien aufgrund unzulänglich interpretierter Testergebnisse sowie einer Vielzahl methodischer Fehler verdeutlichen wollen. ${ }^{2158}$ Es existiert zwar eine geneti-

\footnotetext{
2151 Vgl. Cavalli-Sforza 1999, a. a. O., S. 25.

2152 Vgl. Cavalli-Sforza 1999, a. a. O., S. 25.

2153 Vgl. Cavalli-Sforza 1999, a. a. O., S. $25 \mathrm{f}$.

2154 Cavalli-Sforza 1999, a. a. O., S. 26.

2155 Vgl. Dunn/Dobzhansky 1970, a. a. O., S. 5. | Vgl. Spinath/Deary 2008, a. a. O., S. 141.

Die Grenzen der relativen Erblichkeit sind so aktuell nicht möglich zu identifizieren.

2156 Dunn/Dobzhansky 1970, a. a. O., S. 13, 17.

2157 Vgl. Dunn/Dobzhansky 1970, a. a. O., S. 26.

2158 Vgl. Dunn/Dobzhansky 1970, a. a. O., S. $26 f f$.
} 
sche Grundlage, diese determiniert jedoch keinen festen IQ. ${ }^{2159}$ „People differ

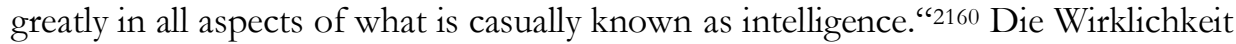
ist so weit komplexer sowie wissenschaftlich bisher nur rudimentär erforscht. Eine absolute Berechnung von Gen- und Umweltanteil hinsichtlich der Vererbung des Intelligenz-Phänomens zeigt sich demnach aufgrund der bisherigen, lückenhaften Forschungslage als sinnlos. ${ }^{2161}$ Die im Laufe einer Generation erworbenen Fähigund Fertigkeiten können nicht identisch an die nachfolgenden Filialgenerationen weiter vererbt werden. Vererbbar sind einzig die DNA bzw. die Gene des Menschen, die den Bauplan für den menschlichen Organismus, insbesondere der Vielzahl menschlicher Zellen, enthalten. ${ }^{2162}$ Gerade die Chromosomentheorie der Vererbung lässt der erblichen Weitergabe von erworbenen Eigenschaften keine Option - die Eizellen der weiblichen Individuen sind beispielsweise schon vor der Geburt angelegt und folglich im weiteren Lebensverlauf nicht mehr änderbar. ${ }^{2163}$ Die Evolutionstheorie Jean-Baptiste de Lamarcks hat sich demzufolge eindeutig als falsch erwiesen. ${ }^{2164}$

\section{„Viele wissenschaftliche Untersuchungen haben keinerlei Beweis erbracht, dass körperli- che oder geistige Merkmale, die sich die Eltern erworben haben, durch biologische Verer- bung an die Kinder weitergegeben werden. Wie wir wissen, bestimmt die Erbanlage ein Merkmal nicht ausschließlich. Sie gibt vielmehr eine gewisse Streubreite der Ausprä- gungsmöglichkeiten; die Umwelt bewirkt die Verwirklichung einer dieser Möglichkei- ten. "2165}

Der Homo sapiens zeigt sich so als integrierter Bestandteil seiner Umwelten, beeinflusst diese durch seinen evolutiven Fortschritt, wird jedoch auch selbst von diesen regelmäßig tangiert. ${ }^{2166}$ Aus der Perspektive der Molekulargenetik kann dementsprechend konstatiert werden, dass bezüglich der Erblichkeit von menschlichen Merkmalen und Fähigkeiten vielfältige Missverständnisse existieren, wie die Ressentiments des biologisch-genetisch konnotierten Rassismusphänomens bestätigen. ${ }^{2167}$

Resümierend zeigt sich, dass für die Mehrheit der Wissenschaftler sämtlicher biologischer Fachdisziplinen das ,Rassekonzept ${ }^{\star}$ und damit einhergehende Prämissen denkbar ungeeignet sind, um die genotypische und phänotypische Vielfalt des modernen Menschen in adäquater und valider Weise darzustellen. ${ }^{2168}$

\footnotetext{
2159 Vgl. Zimmer 2012, a. a. O., S. 150.

2160 Plomin/DeFries 1998, a. a. O., S. 62.

2161 Vgl. Gage/Berliner 1996, a. a. O., S. $61 \mathrm{ff}$.

2162 Vgl. Zimmer 1975, a. a. O., S. $57 \mathrm{ff}$.

2163 Vgl. Merz/Stelzl 1977, a. a. O., S. 13.

2164 Vgl. Dunn/Dobzhansky 1970, a. a. O., S. 94.

2165 Dunn/Dobzhansky 1970, a. a. O., S. 93.

2166 Vgl. Dobzhansky 1962, a. a. O., S. 114.

2167 Vgl. Grabowski 2007, a. a. O., S. $581 \mathrm{ff}$.

2168 Vgl. Kattmann 1999, a. a. O., S. 65.
} 


\begin{abstract}
„Die Vielfalt der Menschen wird der Einfalt der Typen geopfert: Jede Rassenklassifikation simplifiziert die Vielfalt in unzulässiger Weise, indem sie die Betrachtung auf eine mehr oder weniger große Anzabl von Gruppen reduziert und dabei (kleine) Gruppenunterschiede höher bewertet als (größere) zwischen den Individuen ein und derselben Gruppe. Das Klassifizieren wird so - obne Rücksicht auf die tatsächlich beobachtete V ariation zum Selbstzweck." "2169
\end{abstract}

Auch vor dem Hintergrund der geschichtlichen Entwicklung des sogenannten ,Rassebegriffes' kann keine erkennbare Grundlinie identifiziert werden. ${ }^{2170}$ Somit kann aufgrund der fehlenden Begründ- und Überprüfbarkeit eine naturwissenschaftliche Grundlage der ,Rasseklassifizierung' des modernen Menschen definitiv verneint werden. ${ }^{2171}$ Das Phänomen der ,Rasse' ist folglich kein biologisches Konzept, welches auf den modernen Menschen übertragen werden könnte. Allein die Beachtung kultureller Ähnlichkeiten als Hinweis für eventuelle genetische Übereinstimmungen zwischen Menschengruppen reicht nicht aus. ${ }^{2172}$ Luigi Luca Cavalli-Sforza diskreditiert die Klassifizierung und Diskriminierung von Menschen aufgrund ihrer angeblichen ,Rasse“ so folgerichtig als ,[...] Geschichte, von einem Narren [...]“2173. Auch Erika Dettmar identifizierte das ,Rassekonzept ${ }^{`}$ schon als sozialen Mythos. ${ }^{2174}$ Gesellschaftliche und politische Verhältnisse aufgreifend, ordnet ebenfalls John Solomos das ,Rassekonstrukt ${ }^{\star}$ als kulturelles Produkt der rassistischen Ideologie sowie ,[...] als falsch und irreführend [...], in manchen Fällen als politisch desaströs." 2175 ein. ${ }^{2176}$ Die evolutive Entwicklung der Spezies Homo sapiens ist zwar in der menschlichen Entwicklungsgeschichte festgeschrieben, jedoch kann der moderne Mensch eigenständig bestimmen, handeln und entscheiden. ${ }^{2177}$ Den modernen Menschen zeichnen in seinen verschiedenen Populationen mehr Eigenschaften und Charakteristika ähnlicher, als ihn voneinander trennen. ${ }^{2178}$ In die Zukunft blickend ist so zu folgern:
„Diese Vielfalt [der Menschen] - ein Beweis für unsere Fähigkeit, Veränderungen zu bewältigen, uns an unterschiedliche Umgebungen anzupassen und eigenständige Lebens- weisen zu entwickeln - ist die beste Garantie für die Zukunft der Gattung Mensch. "2179

Die molekular-, verhaltens- und humangenetischen Forschungsbefunde visualisieren demnach ebenso wie die evolutionsbiologischen, anthropologischen und biopsychologischen Erkenntnisse des 21. Jahrhunderts, dass die angeblich biologi-

\footnotetext{
2169 Kattmann 1999, a. a. O., S. 68-69.

2170 Vgl. Kattmann 1999, a. a. O., S. 69.

2171 Vgl. Kattmann 1999, a. a. O., S. 69.

2172 Vgl. Cavalli-Sforza/Cavalli-Sforza 1994, a. a. O., S. 211.

2173 Cavalli-Sforza/Cavalli-Sforza 1994, a. a. O., S. 206.

2174 Vgl. Dettmar 1987, a. a. O., S. 45.

2175 Solomos 2002, a. a. O., S. 160.

2176 Vgl. Solomos 2002, a. a. O., S. 160 f.

2177 Vgl. Cavalli-Sforza/Cavalli-Sforza 1994, a. a. O., S. 13 f.

2178 Vgl. Cavalli-Sforza/Cavalli-Sforza 1994, a. a. O., S. 13.

2179 Cavalli-Sforza/Cavalli-Sforza 1994, a. a. O., S. 13.
} 
schen Grundlagen des enggeführten Rassismusbegriffes keinerlei Zusammenhänge mit der wissenschaftlichen Realität aufweisen - weder in den Sozial-, noch in den Naturwissenschaften. In der Folge können aus der Perspektive der neueren biologischen Forschung die Existenzgrundlagen, Vorurteile und Ressentiments des biologisch-genetisch konnotierten Rassismus nachdrücklich angezweifelt werden. „So stell[t] sich die Kampagne, Menschenrassen zu definieren, als das heraus, was sie war: ein irregeleiteter Versuch, wissenschaftliche Methoden zu missbrauchen, um das Unentschuldbare zu entschuldigen. "2180 Die Hauptnachricht der modernen Verhaltens- und Molekulargenetik lautet: „,...] each of us is an individual.“2181 Die Zukunft ist auf der Basis des Genoms nicht vorhersagbar, auch nicht für das zukünftige Intelligenz- oder Wissensprofil eines Individuums. ${ }^{2182}$ Steve Olson geht diesbezüglich sogar noch einen Schritt weiter, wenn er den Genetiker Himla Soodyall wie folgt zitiert:

„Diese Daten bergen das Potenzial, Rassismus abzuschaffen. Rasse ist ausschließlich durch die Umstände bedingt. Sie etabliert eine soziale Hierarchie, die Menschen ausnutzen können, um andere auszubeuten. Aber diese Hierarchie hat keine biologische Grundlage." 2183

Abschließend bleibt jedoch anzumerken, dass biologistisch- sowie genetischrassistische Vorurteile trotz aller eindeutigen und umfassenden wissenschaftlichen Forschungsergebnisse auf der gesellschaftlichen und politischen Ebene immer noch präsent sind (s. Kapitel 2, 3). Gerade hinsichtlich der neueren genetischen Forschung müssen hier, um den Biologen Svante Pääbo zu zitieren, vielfache ,Wild-Western-DNA-Analysen' kritisiert werden, die durch ihre mangelnde Beachtung von wissenschaftlichen Protokollen oder Standards biologistischen Interpretationen eine neue Plattform bieten. ${ }^{2184}$ Für die Biologie bedeutet dies, in Zukunft noch große Forschungslücken zur detaillierten Beweisführung gegen pseudobiologische Argumentationen zu füllen. ${ }^{2185}$ Insbesondere im Bereich der neurobiologischen Forschung sind noch enorme Potenziale hinsichtlich der Leistungsfähigkeit des menschlichen Nervensystems notwendig. Nichtsdestotrotz: „Das Scheitern einer wissenschaftlichen Rassendefinition hat dem Rassismus [...] kein Ende gesetzt. Im Gegenteil, die Äußerungen rassistischer Organisationen und Einzelner sind so bigott wie eh und je.“2186 Folglich bleibt festzuhalten:

\footnotetext{
2180 Olson 2003, a. a. O., S. 97.

2181 Plomin/DeFries/McClearn 1990, a. a. O., S. 400.

2182 Vgl. Plomin/DeFries/Craig/McGuffin 2003, a. a. O., S. XVIII.

2183 Olson 2003, a. a. O., S. 63.

2184 Vgl. Gee, Henry (2014): The human puzzle, in: Nature, Vol. 506, London u. a., S. 30.

2185 Vgl. Weber, Nina (2012). „Fünf Gene beeinflussen unser Gesicht“, in URL: http://www.spiegel.de/wissenschaft/mensch/erbgut-studie-fuenf-gene-beeinflussenentwicklung-der-gesichtszuege-a-855105.html $<09.02 .2013>$. 
„Wir alle gehören einer einzigen Menschenfamilie an, sind Produkte genetischer Notwendigkeit und genetischen Zufalls, die unaufhörlich in eine ungewisse Zukunft geboren werden. "2187 



\section{Fazit}

Die vorherigen Kapitel haben vielfältige Facetten des bundesrepublikanischen Rassismusphänomens des 21. Jahrhunderts aus sozial- und naturwissenschaftlicher Perspektive verdeutlicht. Am Ende dieser Untersuchung sollen nun einerseits die hier erarbeiteten Kernelemente und -ergebnisse dieser Rassismusanalyse dargestellt sowie andererseits ein umfassendes Resümee der skizzierten Entwicklungen getroffen werden. Ebenfalls nicht fehlen darf eine Prognose des zukünftigen Trends hinsichtlich des gegenwärtigen Rassismusphänomens in Deutschland.

Die in der Einleitung präsentierte Fragestellung dieser Arbeit lautet: Analyse des gegenwärtigen Rassismus - Wie stellen sich Verbreitung, Hintergründe und wissenschaftliche Realität des biologisch-genetischen Rassismus im heutigen Deutschland dar? Dieser Frage folgend, wurde im Verlaufe der vorangegangenen Kapitel detailliert erörtert, dass der biologisch konnotierte Rassismus im 21. Jahrhundert keineswegs eine längst überwundene und überholte Ideologie darstellt, sondern heute mehr denn je in unterschiedlichen - sämtliche gesellschaftliche Sphären umfassenden - Ebenen der bundesrepublikanischen Bevölkerung zu identifizieren ist. Insbesondere die Kernelemente des biologisch-genetisch konnotierten ,Rassenrassismus' sind wieder nachhaltig existent, auch wenn sie vornehmlich indirekt, verschleiert und verdeckt auftauchen, um vordergründig dem gesellschaftlichen Normen- und Wertesystem zu entsprechen. Die in den 1990er Jahren von Étienne Balibar und Stuart Hall prognostizierte Ära des kulturell basierten ,Rassismus ohne Rassen' scheint für das 21. Jahrhundert tendenziell weniger zutreffend zu sein. Der Kulturbegriff dient einerseits meist lediglich - wie auch weitere assoziierte Ersatzbegriffe des 
Rassismus - zur Tarnung und Verschleierung biologistischer Charakteristika der rassistischen Ideologie: Aus ,Rasse w wird Kultur oder Ethnie, aus Rassismus Fremden- oder Ausländerfeindlichkeit, aus Blut und Genen eine spezifische kulturelle oder soziale Herkunft. Andererseits werden kulturelle Zuschreibungen oftmals naturalisiert und dadurch für pseudobiologische Belege nutzbar gemacht: Aus der sozialen Herkunft werden beispielsweise spezifische Genkombinationen oder Vererbungswahrscheinlichkeiten, um sich dem scheinbar endgültigen Charakter der naturwissenschaftlichen Forschung zu bedienen. Die Biologie und insbesondere die Genetik bleiben insofern auch weiterhin ein essentieller Grundbaustein zur Begründung und Legitimation des Rassismus. Die in diesem Forschungsprojekt vorgenommene Engführung des Rassismusbegriffes auf biologisch-genetische Charakteristika erweist sich so als zielführend und dem gegenwärtigen Rassismustrend folgend.

Vor diesem Hintergrund zeigen sich die eingangs vorgestellten Ziele dieser Untersuchung deutlich. Die Erarbeitung dieser ist im Rahmen der vorliegenden Arbeit in ein überwiegend neuartiges Forschungskonzept eingebunden worden: Der Kombination von sozial- und naturwissenschaftlichen Forschungsansätzen - fachlich, methodisch und strukturell. Dieses Untersuchungsschema zeigt sich im Rückblick hinsichtlich der Analyse des gegenwärtigen Rassismusphänomens als passend. Notwendigkeit und Legitimation dieses Konzeptes ergeben sich aus der Aktualität sowie der Dringlichkeit der Erforschung des gesellschaftsweit etablierten, heutigen Rassismuskonstrukts zur Zukunftssicherung unserer Gesellschaft (s. Kapitel 1).

Zunächst wurde versucht, in kurzen Strichen verschiedene biologischgenetisch konnotierte Rassismusbegriffe wiederzugeben, um im Anschluss aus dieser Auswahl einen wissenschaftlichen Arbeitsbegriff vorzustellen, der das Vorhaben dieser Arbeit untermauert. Ebenso waren demnach eine empirischtheoretische sowie eine historische Betrachtung des Rassismusbegriffes unerlässlich. Aufbauend auf dieses theoretische Grundlagenkonzept kristallisieren sich nun die in der zentralen Fragestellung dieser Forschungsarbeit integrierten Zielsetzungen und Zielformulierungen heraus. Im Zentrum steht einerseits aus der Perspektive der sozialwissenschaftlichen Forschung die übergreifende Frage nach dem modernisierten, biologistischen Rassismusphänomen in der Bundesrepublik Deutschland des 21. Jahrhunderts: Können biologisch-genetisch begründete Vorurteile und Ressentiments in der deutschen Gesellschaft ermittelt werden? In welchen gesellschaftlichen Ebenen sind biologistische Erklärungs- und Argumentationsstrukturen etabliert? Inwieweit kann von einem neuerlichen biologischgenetisch begründeten Rassismusproblem in Deutschland gesprochen werden?

Andererseits steht aus der biologischen Perspektive dieser Untersuchung die Analyse der naturwissenschaftlichen Realität biologisch-genetisch begründeter, rassistischer Argumentationsstrukturen als primäre Zielsetzung im Mittelpunkt. Trotz intensiver evolutions- und verhaltensbiologischer, molekulargenetischer sowie biopsychologischer Grundlagenforschung in den 1970er und 1980er Jahren, sind mögliche Zusammenhänge zwischen biologischer Forschung und der sozial- 
wissenschaftlichen Rassismusanalyse bis heute nicht endgültig erörtert. Insbesondere vor dem Hintergrund der modernen molekular- und verhaltensgenetischen Forschung auf der Grundlage der menschlichen DNA drängt sich demnach die hier vorgenommene neuerliche Betrachtung biologisch-rassistischer Zusammenhänge aus der Perspektive der heutigen Forschung auf: Kann die Existenz von menschlichen Subspezies vom aktuellen wissenschaftlichen Kenntnisstand eindeutig widerlegt werden? Welche Bedeutung kommt in diesem Zusammenhang den vielfach zitierten Forschungsergebnissen Charles Darwins und Johann Gregor Mendels zu? Welche neuen Erkenntnisse illustriert die Encodierung der menschlichen DNA? Zeigen sich erworbene Eigenschaften und Merkmale - bzw. Gene als generationenübergreifend identisch vererbbar?

Dieses Fazit soll mithilfe dieser - nochmals wiederholend dargestellten - Fragestellungen demonstrieren, dass die Theoreme des heutigen biologisch-genetisch konnotierten Rassismusphänomens auf der einen Seite nicht auf validierten, wissenschaftlichen Forschungserkenntnissen beruhen, sondern lediglich Falschinterpretationen von wissenschaftlichen Datensätzen darstellen. Rassistischen Falschinterpretationen soll aufgrund dessen eine eindeutige Absage erteilt werden. Auf der anderen Seite soll das Fazit ebenfalls den Erfolg der hier durchgeführten Kombination von sozial- und naturwissenschaftlicher Forschung herausstellen, um deren Ziel, Sinn und Notwendigkeit nochmals eindeutig zu visualisieren.

\subsection{Rückblick}

Zur Fokussierung der Kernresultate der Fragestellung dieser Arbeit folgt nun ein Blick auf deren grundlegende Ergebnisse und Erkenntnisse.

Die Untersuchung zeigt, dass die biologistischen Elemente und Charakteristika der rassistischen Ideologie eine lange Tradition haben - nicht nur in Deutschland, sondern in ganz Europa, wie Kapitel zwei beweist (s. Kapitel 2). Die originären Grundlagen rassistischer Vorstellungen und Handlungsweisen sind direkt mit dem Zeitalter des europäischen Kolonialismus und des Imperialismus verbunden. ${ }^{2188}$ Hier sind beispielsweise die zahlreichen Reiseberichte hervorzuheben, die die nicht-europäische Bevölkerung als „[...], weniger hervorragend[e] Völker der Erde $^{6}[\ldots]^{\text {“2189 }}$ mit , [...] als abnorm empfundenen Charakterzüge[n] [...]“2190 darstellten. Die ,Anderen' galten demnach als wild, brutal, unzivilisiert, barbarisch, vormodern und unaufgeklärt, was im Rahmen der Zivilisierung als Erklärungsgrundlage für rassistisch motivierte Gewaltverbrechen sowie Massen- und Völkermorde herangezogen wurde. ${ }^{2191}$ Hier entwickelte sich erstmals die Vorstellung von - im Gegensatz zur fortschrittlichen europäischen Bevölkerung - ,minderwertigen', außer-europäischen Zivilisationen, ein Vorläufer des als angeboren,

\footnotetext{
2188 Vgl. Barth 2010, a. a. O.

2189 Miles 1999, a. a. O., S. 31.

2190 Miles 1999, a. a. O., S. 31.

2191 Vgl. Hong 2011, a. a. O., S. 40.
} 
unveränderlich und hierarchisch geltenden ,Rassekonzeptes‘. ${ }^{2192}$ Das gegenwärtige Rassismusphänomen des 21. Jahrhunderts kann bereits mit diesen anfänglichen rassistischen Tendenzen in Verbindung gebracht werden. Das angebliche Bedrohungsszenario durch geno- und phänotypisch ,andersartige“ Mitmenschen erscheint vor diesem Hintergrund im 21. Jahrhundert nicht neu. ${ }^{2193}$ Die Entstehung des biologistischen ,Rassenrassismus“ muss letztlich im Zeitalter der Aufklärung verortet werden, welches als Zäsur in der Entwicklung der rassistischen Ideologie verstanden werden kann. ${ }^{2194}$ Das Rassismuskonzept wird hier durch neue, naturwissenschaftliche Erkenntnisse mithilfe der ,Rasseklassifizierung' erstmals - weg von der ursprünglichen Differenzierungsgrundlage der Religion - auf eine wissenschaftliche Basis gestellt. ${ }^{2195}$

Das grundlegende Charakteristikum des Rassismusbegriffes ist demnach die sogenannte ,Rassenkonstruktion', von Robert Miles als racialization beschrieben. ${ }^{2196}$ Diese klassifiziert Menschen anhand scheinbar differenter biologischer Merkmale in ein hierarchisch strukturiertes Kategoriensystem, welches sich biologisch unveränderlich reproduziere. ${ }^{2197}$ Diese ,Rassenkonstruktion“ gilt sowohl als Grundlage des Sozialdarwinismus, der rassistischen Ideologie als auch des Nationalsozialismus. ${ }^{2198}$

Auch in der Gegenwart kann das biologistische Prinzip der rassistisch motivierten ,Rassenkonstruktion“ identifiziert werden, meist verschleiert und verdeckt durch unpassende Ersatztermini. Die historische Entwicklung des Rassismusphänomens zeigt somit, dass allein aufgrund der Anzahl von Ausprägungen rassistischer Phänomene auch eine unüberblickbare Vielzahl an definitorischen Ansätzen möglich und realitätsnah ist. Dies führt zur grundlegenden Problemstellung, dass eine einheitliche, definitorisch transparente sowie umfassende Rassismusdefinition bis heute noch nicht gefunden ist. ${ }^{2199}$ Diese Ausarbeitung favorisiert aufgrund des

2192 Vgl. Miles 1999, a. a. O., S. 26ff, $39 \mathrm{ff}$.

Rassismusäbnliche Tendenzen können jedoch unter anderem schon in der griechischen Antike, dem römischen Imperium oder im Mittelalter identifiziert werden. Im Mittelalter bezog sich die Idee des ,Fremden 'bzw. ,der Anderen' aber fast ausschließlich religiös motiviert auf die Bevölkerung der arabischen Welt. Diese galt als ,fremd' außerbalb der Grenzen des europä̈schen Kontinents. Demzufolge wurden schon damals Nicht-Deutsche bəw. Nicht-Europäer aufgrund angeblicher religiöser, kultureller oder phänotypischer Unterscbiede und Abweichungen von einer imaginären europäischen Normvorstellung ausgegrenzt sowie diskriminiert. In diesem $\mathrm{Zu}$ sammenhang können erste Parallelen zum heutigen europäischen Rassismusphänomen identifiziert werden, das ebenfalls in der islamischen Bevölkerung der arabischen Welt eine Gefabr bžw. Instabilität für Europa siebt. Vgl. Miles 1999, a. a. O., S. 29.

2194 Vgl. Barth 2010, a. a. O.

2195 Vgl. Hong 2011, a. a. O., S. 41. Der eigentliche Rassismusbegriff etablierte sich jedoch erst im Zuge des Nationalsozialismus. Die Ideologie sowie die theoretischen Überlegungen rassistischer Theoreme sind so historisch gesehen zwar älter, der heute aktuelle Rassismusbegriff demgegenüber zeitlich relativ jung. Vgl. Miles 1999, a. a. O., S. 58f. | Vgl. Barth 2010, a. a. O.

2196 Vgl. Miles 1999, a. a. O., S. 99.

2197 Vgl. Miles 1999, a. a. O., S. $99 \mathrm{ff}$.

2198 Vgl. Bensch, Margrit (2009): Rassismus als kulturelle Entwicklungstheorie. Formen biologischen Denkens im Sozialdarwinismus, Diss. Technische Universität, Berlin, S. 5, 8, 11.

Vgl. Barth 2010, a. a. O. 
sozialwissenschaftlich-biologischen Schwerpunktes der Rassismusanalyse die weithin akzeptierte, enggefasste und präzise Rassismusdefinition von Robert Miles, der das Rassismusphänomen in direkter Verbindung mit dem biologischen ,Rassediskurs‘ sieht. 2200 Miles blendet damit mögliche kulturelle Erklärungsschemata bewusst aus, da er hierin einen tendenziell überdehnten Rassismusbegriff sieht, der aufgrund seiner wissenschaftlichen und definitorischen Unschärfe nur von begrenztem analytischem Wert sei.2201 Folglich ist die Orientierung an der Rassismusdefinition nach Robert Miles aufgrund ihrer definitorischen Präzision und inhaltlichen Passung für diesen Forschungsansatz prädestiniert.

Dass biologistische Vorurteile und Ressentiments in der bundesrepublikanischen Bevölkerung des 21. Jahrhunderts einen breiten Rückhalt genießen, zeigen die in Kapitel drei aus sozialwissenschaftlicher Perspektive fokussierten qualitativen und quantitativen Datenmaterialien (s. Kapitel 3).2202 Ein nicht zu verachtender Anteil der deutschen sowie der europäischen Bürgerinnen und Bürger vertritt implizit und explizit rassistisch motivierte, negative Einstellungen gegenüber ,Fremden“ - eine besorgniserregende und zugleich gefährliche Tendenz für die gesellschaftliche Integrität und Stabilität. ${ }^{2203}$ Dies zeigen insbesondere die hohen Zustimmungswerte der bundesrepublikanischen Gesellschaft zu den rassistischen und teilweise eugenischen Theoremen Thilo Sarrazins. Deutschland befindet sich hierbei immer noch im Spitzenfeld. ${ }^{2204}$ Dies bestätigt auch der europaweite Anstieg des sogenannten Rechtspopulismus, der partiell als Warnsignal der Wiederkehr rassistischer Ansichten auch auf politischer Ebene verstanden werden muss. ${ }^{2205}$ Obwohl auf nationalstaatlicher Ebene aktuell noch keine rechtspopulistische Partei vorzufinden ist, „[...] mangelt es keineswegs an der Mobilisierbarkeit für die typischen rechtspopulistischen Themen [... “"2206. In den 1990er Jahren führte die rassistisch geprägte Debatte um die Einwanderung in Deutschland zu einem Aufkommen des Rechtsextremismus - im 21. Jahrhundert folgen die europaweiten Strukturen des Rechtspopulismus diesem Trend. ${ }^{2207}$ Vollkommen ver-

2200 Vgl. Miles 1999, a. a. O., S. 130.

2201 Vgl. Miles 1999, a. a. O., S. 83.

Siegfried Jäger konstatiert darüber hinaus unterstützend, dass auch der kulturell konnotierte Rassismus nach Étienne Balibar und Stuart Hall mit dem Natur-Mythos operiere, indem er kulturelle Eigenschaften und Charakteristika naturalisiere - die Biologie zeige demnach auch bier eine elementare Präsen₹. Vgl. Jäger, Siegfried (1993): Rassismus und Rechtsextremismus - Gefahr für die Demokratie, in: Friedrich-Ebert-Stiftung (Hrsg.): Entstehung von Fremdenfeindlichkeit. Die Verantwortung von Politik und Medien, Bonn, S. 26.

2202 Hingewiesen werden muss diesbezüglich nochmals auf die - bier beachtete - Notwendigkeit der kritischen und differenzierten Betrachtung der unterschiedlichen Datensätze. Sowobl bei qualitativen als auch bei quantitativen Daten muss auf die möglichen Probleme und Schwierigkeit bei der Neuanalyse von vorbandenen Datensätzen unter newen Schwerpunkten geachtet werden. Vgl. Winkler 2003, a. a. O., S. 34.

2204 Vgl. Winkler 2003, a. a. O., S. 38.

2205 Vgl. Spier 2006, a. a. O., S. 46ff.

2206 Spier 2006, a. a. O., S. 212.

2207 Vgl. Jaschke 2006, a. a. O., S. $16 f$. 
gessen wird hingegen, dass das Phänomen Einwanderung für die ökonomische Vorreiterrolle der Bundesrepublik Deutschland unerlässlich war und aufgrund des demographischen Wandels mehr denn je auch in Zukunft unerlässlich sein wird, um die weltweite politische sowie ökonomische Spitzenstellung Deutschlands forcieren und stabilisieren zu können. Die in Zeiten von Wirtschafts-, Finanz- und Eurokrise ökonomische sowie fiskalpolitische, internationale Spitzenposition Deutschlands wäre ohne die ausländischen Mitbürgerinnen und Mitbürger undenkbar.

Dieses Ergebnis unterstützen die Phänomenologie und die aktuellen Erklärungsansätze des gegenwärtigen, biologisch konnotierten Rassismusphänomens in Deutschland: Kapitel vier identifiziert multiple Hauptmerkmale, die zur nachhaltigen Verbreitung rassistischer Argumentationen in Teilen der deutschen Bevölkerung des 21. Jahrhunderts beigetragen haben (s. Kapitel 3, 3.1, 4). Seitens der politischen Ebene muss insbesondere die zögerliche, fehlerhafte und unkoordinierte Ausländer-, Einwanderungs-, Integrations- und Migrationspolitik der deutschen Bundesregierungen von den 1970er Jahren bis in die Gegenwart nachdrücklich kritisiert werden. Für die bundesrepublikanische Bevölkerung bedeutete dies vor allem eines: Zukunftsängste den eigenen Wohn- und Lebensstandard betreffend sowie die Manifestierung und Engführung dieser Sorgen auf die nach Deutschland zugewanderte, ,fremde', andersartige ${ }^{`}$ Bevölkerung - die Biologie bietet hier die nötigen Anknüpfungspunkte - für die zahlreichen politischen und wirtschaftlichen Fehlentwicklungen. Auch die negativen Folgen der deutschen Wiedervereinigung müssen hier beachtet werden. ${ }^{2208}$ Darüber hinaus sind ebenfalls zahlreiche institutionelle Faktoren zu benennen, die auf politischer Ebene fremdenfeindliche und rassistische Einstellungen förderten bzw. fördern: Die gesetzliche Einordnung der Gastarbeiterinnen und Gastarbeiter als Stammarbeitsplätze gefährdender Wirtschaftspuffer, die lange ungeklärte Frage nach deren Staatsbürgerschaft, die gesetzlichen Differenzen zwischen In- und Ausländern oder das kulturelle Werte-, Normen- und Moralsystem, welches die eigene Kulturgemeinschaft bzw. Nation kulturell von ausländischen Nationen abgrenzt. ${ }^{2209}$ Dies führte zwar nicht direkt zum heutigen wieder tendenziell biologistisch konnotierten Rassismusphänomen, forcierte die gesellschaftliche Entwicklung und Etablierung jedoch sukzessive bis ins 21. Jahrhundert. Angemerkt werden muss an dieser Stelle abermals, dass die Migration in Deutschland keine neue, plötzliche Entwicklung darstellt. ${ }^{2210}$ Auch in

Rassistisches Denken, rassistische Argumentationen sowie rassistisches Verbalten können demnach auch beute noch als essentielles „Einfallstor" für rechtsextreme und rechtspopulistische Bewegungen identifiziert werden. (Vgl.) Jäger 1993, a. a. O., S. 1, 1 ff.

2208 Vgl. Jäger 1993, a. a. O., S. $30 \mathrm{ff}$.

2209 Vgl. Terkessidis 2004, a. a. O., S. $101 \mathrm{ff}$

2210 Vgl. Galtung, Johan (2009): Globale Migration, in: Butterwegge, Christoph/Hentges, Gudrun (Hrsg.): Zuwanderung im Zeichen der Globalisierung. Migrations-, Integrations- und Minderheitenpolitik, 4. Auflage, Wiesbaden, S. 11. 
der Vergangenheit lassen sich zahlreiche Einwanderungsbewegungen verorten. ${ }^{2211}$ Trotzdem werden Einwanderer sowie auch Flüchtlinge heute wie damals noch meist als sogenannte ,underclass“2212 diffamiert, deren Aufstiegs- und Integrationschancen in Deutschland fragwürdig erscheinen. ${ }^{2213}$ Die gesellschaftliche Rassismuswelle in Deutschland ab den 1960er Jahren ist so mit zahlreichen Parallelen auch im 21. Jahrhundert ähnlich zu verorten. ${ }^{2214}$

Darüber hinaus zeigen sich vielfältige ökonomische Entwicklungszusammenhänge für das Wiedererstarken des Rassismusphänomens im 21. Jahrhundert verantwortlich. Die bundesrepublikanische Wirtschaft war einerseits in der zweiten Hälfte des 20. Jahrhunderts während der Zeit des sogenannten Wirtschaftswunders und ist andererseits auch heute weiterhin an billigen, flexiblen Arbeitskräften sowie fast ausschließlich an deren Produktivität interessiert. Die hohen bundesrepublikanischen Sozialstandards kommen hier nicht bzw. nur teilweise zur Anwendung. Aufgrund dessen konstruieren Wirtschafts- und Industriebetriebe die gesellschaftlichen Ängste um unsichere, gefährdete Arbeitsplätze sowie den fragwürdigen Wohlstand mit, da die bundesrepublikanischen Bürgerinnen und Bürger gezwungen werden, in den Wettbewerb um billige Arbeitskräfte und Arbeitsplätze einzusteigen. Als ,Sündenbock ${ }^{\varsigma}$ und zuständiger Entscheidungsträger wird aber nicht das verantwortliche Management der Unternehmen kritisiert, sondern vielmehr die zugewanderten Mitbürgerinnen und Mitbürger als angebliche Verursacher des vermeintlichen ,Übels‘. Die gegenwärtige, rassistisch motivierte Abwertung, Ausgrenzung und Diskriminierung von Einwanderern resultiert demnach ebenfalls aus dem durch die Wirtschaft forcierten, sozioökonomischen Kampf um Arbeitsplätze, Einkommen, Wohlstand und damit zusammenhängend auch um den sozialen Status, die Wohnung, das Prestige und letztlich die individuelle gesellschaftliche Macht. ${ }^{2215}$ Des Weiteren müssen im ökonomischen Bereich aktuell noch die Auswirkungen der seit 2007 andauernden Wirtschafts-, Finanz- und Eurokrise ergänzt werden, die zur Unsicherheit bezüglich der gesellschaftlichen, sozialen und individuellen Zukunft beitragen.

Darüber hinaus muss auch die gesellschaftliche Arena bezüglich der Reproduktion des heute wieder zunehmend manifestierten Rassismusphänomens inkludiert werden. Eine bedeutende Rolle kommt in diesem Zusammenhang beispielsweise der

2211 Vgl. Galtung 2009, ebd., S. 15. | Vgl. Scholz, Antonia (2013): Warum Deutschland? Einflussfaktoren bei der Zielsuche von Asylbewerbern - Ergebnisse einer Expertenbefragung, Nürnberg, S. $161 \mathrm{ff}$.

Die Ursachen und Hintergründe dieser Zwwanderungs- und Migrationsbewegungen zeigen sich vielfältig: Die wirtschaftliche Schwäche der Heimatstaaten, politische Feblentwicklungen, kulturelle Schwächen oder Verletzungen der Menschenrecbte.

2212 Kühne, Peter (2009): Flüchtlinge und der deutsche Arbeitsmarkt. Dauernde staatliche Integrationsverweigerung, in: Butterwegge, Christoph/Hentges, Gudrun (Hrsg.): Zuwanderung im Zeichen der Globalisierung. Migrations-, Integrations- und Minderheitenpolitik, 4. Auflage, Wiesbaden, S. 255.

2213 Vgl. Kühne 2009, ebd., S. 255ff.

2214 Vgl. Terkessidis 2004, a. a. O., S. 16.

2215 Vgl. Winkler 2003, a. a. O., S. 35. 
gesellschaftlichen Umwelt - Elternhaus, Großeltern, Freunden, Verwandten und Peergroups - sowie der Erziehung, Sozialisation und Integration von Kindern in das gesellschaftliche Leben zu. ${ }^{2216}$ Vor diesem Hintergrund muss zusätzlich die Bedeutung der Medien an der Rückkehr rassistischer Einstellungen und Verhaltensweisen notiert werden: Auch „[...] die Medien tragen eine erhebliche Mitverantwortung dafür, dass in der Bundesrepublik der Rassismus eine solche Hochkonjunktur erfährt.“2217 Als Beispiel kann hier die Wochen andauernde Inszenierung und Stilisierung der biologistischen Thesen Thilo Sarrazins genannt werden. Diese wurden sowohl in den alten als auch in den neuen Medien mit anhaltender Aufmerksamkeit ausgiebig präsentiert und debattiert. 2218 Demzufolge muss bezüglich der medialen Gewalt tendenziell ein latenter Rassismus sowie ein teilweise „[...] praktizierte[r] Sozialdarwinismus“2219 festgestellt werden.2220 Mit Margret Jäger kann deshalb subsummiert werden:

\section{„Sicherlich tragen die Medien nicht die alleinige Schuld am Zustand unserer Republik, bescheinigt werden muss ibnen [...] jedoch eine erhebliche Mitschuld an de[r] [rassisti- schen Realität] [...7. "2221}

Die Analyse der Erklärungsansätze des biologisch-genetischen Rassismusphänomens in der Bundesrepublik Deutschland des 21. Jahrhunderts identifiziert aus sozialwissenschaftlicher Perspektive schlussfolgernd gesehen verschiedene Wirkungs- und Einflussbereiche. Politische, institutionelle, ökonomische, gesellschaftliche und mediale Faktoren aus mehreren Jahrzehnten bundesrepublikanischer Entwicklung tragen gemeinsam zur heutigen Rassismusproblematik bei. ${ }^{2222}$ Pseudobiologische Argumentationen offerieren diesbezüglich eine einfache Argumentations- und Legitimationsgrundlage. Forciert werden diese Entwicklungen seit dem Jahr 2007 durch die anhaltenden wirtschaftlichen, fiskalpolitischen und wäh-

2216 Vgl. Gehrs 2012, a. a. O., S. 7.

2217 Jäger, Margret (1993): BrandSätze und SchlagZeilen. Rassismus in den Medien, in: FriedrichEbert-Stiftung (Hrsg.): Entstehung von Fremdenfeindlichkeit. Die Verantwortung von Politik und Medien, Bonn, S. 74.

2218 Darüber hinaus konstruieren sie bierzu bedrobliche Wortbülsen und Metaphern, wie beispielsweise das Wellenbəw. Flutszenario der 1970er und 1980er Jahre - die Gefahr der angeblichen, Überflutung 'Deutschlands mit einer ,Welle' von ausländischen Mitmenschen - bis hin zum Szenario eines möglichen Bürgerkrieges. Aus der Perspektive des 21. Jabrbunderts kann ebenso das Überfremdungs- und Untergangsszenario ergänzt werden: Deutschland schaffe sich ab. Auch können die heute eher negativ besetzten Begriffe, Ausländer', ,Fremder' oder ,Asylant' als Ursache der medialen Falschinterpretation encodiert werden. Vgl. Jäger 1993, ebd., S. $75 \mathrm{ff.}$ Gehrs 2012, a. a. O., S. 9.

2220 Vgl. Jäger 1993, ebd., S. 75.

2221 Jäger 1993, ebd., S. 88.

2222 Sicherlich stehen einzelne Teilbereiche eher im Fokus als andere, eine primärer bəw. favorisierter Erklärungsansatz ist jedoch aufgrund der vielfältigen Überschneidungen und gegenseitigen Beeinflussungen nur schwierig zu identifizieren. Im Zentrum stehen die durch politische und ökonomische Feblentwicklungen sowie Feblentscheidungen ausgelösten Unsicherbeiten, Ängste, Arbeitsplatæsongen und Vertrauenskrisen der bundesrepublikanischen Bürgerinnen und Bürger. Der Versuch der eindeutigen Differeñierung von politischen, wirtschaftlichen und gesellschaftlichen Problemfeldern zeigt sich demnach rückblickend - auch vor dem Hintergrund der Verständnis- und Strukturierungsförderung - nur partiell erfolgsversprechend. Vgl. Zick/Küpper/Hövermann 2011, a. a. O., S. 145-184. 
rungspolitischen Krisenentwicklungen, die multiple Zukunftsängste und -sorgen in der Bevölkerung auslösen, welche nach dem ,Sündenbock'-Schema wieder biologisch stilisiert und in der Person der ,Fremden' kanalisiert werden. Notwendig ist mehr denn je ein politischer und gesellschaftlicher Kurswechsel. ${ }^{2223}$

Die sozialwissenschaftliche Analyse des gegenwärtigen Rassismusphänomens zeigt folglich einerseits die bedrohlichen Ausmaße der Problemstellung, andererseits jedoch auch die fehlenden politikwissenschaftlichen Grundlagen bzw. die falschen Annahmen der rassistischen Ideologie.

In Kapitel fünf wird nun deutlich, dass selbst die biologischen Grundlagen rassistischer Argumentationen aus heutiger Forschungsperspektive von Genetik, Evolutions- und Humanbiologie fachlich mitnichten zutreffend sind (s. Kapitel 5). Ein Ergebnis, welches durch die Verknüpfung von sozialwissenschaftlicher und biologischer Forschung eindeutig herausgestellt werden konnte. Hierbei handelt es sich einzig um die absichtliche Missinterpretation und Falschauslegung naturwissenschaftlicher Forschungserkenntnisse. Vor diesem Hintergrund kann beispielsweise die vielfach kritisierte Evolutionstheorie Charles Darwins keinesfalls als Anknüpfungspunkt der rassistischen Ideologie gesehen werden. ${ }^{2224} \mathrm{Zu}$ keinem Zeitpunkt hat Darwin seine Theorie der Entstehung und Entwicklung aller Lebewesen willentlich direkt auf die gesellschaftliche Situation sowie das Zusammenleben aller Menschen übertragen, insbesondere wenn man sein Grundlagenwerk von 1859 betrachtet. $^{2225}$ Hierbei handelt es sich einzig um eine fälschliche, pseudobiologische Interpretation sozialer Problemlagen, die das scheinbare Vorhandensein von biologisch ,minderwertigen' bzw. ,höherwertigeren' Menschenpopulationen suggeriert, um Fehlentwicklungen, Missstände und sozialen Problemlagen der gesellschaftlichen Realität zu begründen. ${ }^{2226}$ Darauf basierend wird im sarrazinschen Sinne vor dem Hintergrund der Vermehrung und Weitergabe von sogenannten degenerativen Merkmalen ein Zusammenbruch der deutschen Gesellschaft prognostiziert. 2227 Darwins Theorie kann zwar als Zäsur bzw. als biologische Revolution des religiös geprägten Weltbildes sowie des religiös-kulturell motivierten, vormodernen Rassismus angesehen werden, Darwin war aber kein Rassist. $^{2228}$ Vermutet werden kann lediglich, dass Darwin die Missinterpretation seiner Lehre durch rassistische bzw. ,rassische ' Theoretiker eventuell vorausgesehen und deswegen mit der Veröffentlichung seiner Hauptwerke so lange gezögert haben könnte. ${ }^{2229}$ Mit Nachdruck muss diesbezüglich jedoch herausgestellt werden, dass die gesellschaftliche Realität dem biologischen Evolutions- und Selektionsprozess nicht unterworfen ist. Trotzdem versucht die rassistische Ideologie auch im 21.

\footnotetext{
2223 Vgl. Bade 2013, a. a. O., S. 373.

2224 Vgl. Becker 1990, a. a. O., S. 589.

2225 Vgl. Becker 1990, a. a. O., S. 589.

2226 Vgl. Bensch 2009, a. a. O., S. 15, 87ff. | Vgl. Weingart 1992, a. a. O., S. 23, 25.

2227 Vgl. Weingart 1992, a. a. O., S. 24.

2228 Vgl. Barth 2010, a. a. O.

2229 Vgl. Becker 1990, a. a. O., S. 589.
} 
Jahrhundert weiterhin, eine Biologisierung der Gesellschaft im darwinschen Sinne des ,Kampfes ums Dasein' zu propagieren. ${ }^{2230}$ Insofern scheinen die biologischgenetischen Theoreme der nationalsozialistischen Ära nur vordergründig verschwunden bzw. tabuisiert, im verdeckten, verborgenen Rahmen sind sie jedoch immer noch präsent. ${ }^{2231}$ Auch der hiermit korrelierende ,Rassenbegriff' ist trotz zahlreicher Ersatztermini weiterhin vorhanden.2232 Als exemplarisches Beispiel seien hier wiederum die Äußerungen Thilo Sarrazins zu nennen, der die Ursache von gesellschaftlichen Missständen unter anderem in Qualitäts-, Gen- und Intelligenzunterschieden zwischen deutschen Bürgerinnen und Bürgern sowie Einwanderern sieht.

Der heutige Rassismus integriert aus biologischer Perspektive jedoch nicht nur fälschlicherweise die Evolutionstheorie Charles Darwins in seinen pseudowissenschaftlichen Argumentationsrahmen, sondern bedient sich noch weiterer biologistischer Elemente. ${ }^{2233}$ Thilo Sarrazin knüpft so irrigerweise an Darwins theoretische Arbeiten im Rahmen der angeblichen Vererbung des Intelligenz-Phänomens an ein grundsätzlich falscher Ansatz, da Charles Darwin lediglich Spekulationen bezüglich der menschlichen Entwicklung geäußert, jedoch hierzu nicht theoretisch geforscht hat, wie vergleichsweise im Bereich von Fauna und Flora. ${ }^{2234}$ Auch zeigt es sich als biologisch inakzeptabel, den Genpool einer Gesellschaft mit dem nationalen Genpool eines Staates gleichzusetzen, da dieser über die gesellschaftlichen und nationalen bzw. territorialen Grenzen weit hinausgeht. ${ }^{2235}$

Kritisiert werden muss jedoch auch die naturwissenschaftliche Forschung. Nur durch ihren naiven und nicht durchdachten Umgang mit biologisch-geprägten Gesellschafts-Konnotationen, wie dem ,Rassebegriff ${ }^{`}$ zu Beginn des 20. Jahrhunderts, erlangten Biologie und Genetik in bevölkerungs- und evolutionspolitischen Untersuchungen eine essentielle Bedeutung im Rahmen der rassistischen Ideologie. ${ }^{2236}$ Gerade die Adaption des biologischen ,Rassebegriffes‘ sowie dessen Übertragung auf die menschliche Spezies im Rahmen sozialpolitischer Überlegungen hat den sogenannten ,Rassenrassismus' gefördert und forciert. In der Folge ging der notwendige, enggeführte Definitionsrahmen des biologischen ,Rassekonzeptes $^{6}$ verloren bzw. wurde von der rassistischen Ideologie uminterpretiert. ${ }^{2237} \operatorname{Im} 21$. Jahrhundert ist der von Seiten der politischen und gesellschaftlichen Führung zwar tabuisierte, aber wieder explizit und implizit weit verbreitete ,Rassegedanke

2230 Vgl. Bensch 2009, a. a. O., S. 87 ff.

2231 Vgl. Bensch 2009, a. a. O., S. 88ff.

2232 Vgl. Bensch 2009, a. a. O., S. 90.

2233 Vgl. Lipphardt, Veronika (2008): Biologie der Juden. Jüdische Wissenschaftler über „Rasse“ und Vererbung. 1900-1935, Göttingen, S. 40.

2234 Vgl. Haller/Niggeschmidt 2012, a. a. O., S. 13.

2235 Vgl. Haller/Niggeschmidt 2012, a. a. O., S. 24.

2236 Vgl. Barth 2010, a. a. O.

2237 Die mit der Kolonialisierung entstandene, Rassenkunde' sorgte mit ibrer unsicheren und unscharfen Differenzierung von angeblichen ,Unterrassen " und ,Großrassen' für eine wissenscbaftsferne Inflation der Begrifflichkeit. Die Festlegung und Einteilung von scheinbaren, Rassenmerkmalen' war und ist auch beute noch größtenteils von Zufall und Willkër geprägt. Vgl. Becker 1990, a. a. O., S. 514ff. 
im Kern immer noch ein pseudobiologisches Produkt. Die Hauptcharakteristika der ,Rasseklassifikation" sind immer noch auf biologisch-genetische Merkmale zurückzuführen. ${ }^{2238}$ Nichtsdestotrotz bleibt das vor allem in der Tierzüchtung zur Taxierung angewandte, Rassekonzept ${ }^{\varsigma}$ auch zukünftig nicht auf den modernen Menschen anwendbar.

„Modern buman biological variation is not structured into phylogenetic subspecies (,races'), nor are the taxa of the standard anthropological, racial' classifications breeding populations. The ,racial taxa' do not meet the phylogenetic criteria. "2239

Der Homo sapiens erfüllt die naturwissenschaftlichen Nomenklatur-Kriterien an eine Subspezies bzw. Unterart nicht. So können beispielsweise zwischen unterschiedlichen Menschenpopulationen verschiedener Kontinente keine größeren genotypischen Differenzen identifiziert werden, im Gegenteil:

„This means that individuals from one, race' may be overall more similar to individuals in one of the other, races" than to other individuals in the same, race. "2240

Die vorhandenen phänotypischen Unterschiede sind zum überwiegenden Teil als Anpassung an bestehende Umwelt- und Klimafaktoren zu betrachten - eine genetische Prädisposition ist nur in den seltensten Fällen beobachtbar. Insbesondere bezüglich der phänotypischen Differenzen spielen multiple Umwelteinflüsse eine essentielle Rolle. ${ }^{2241}$ Der im Rahmen des gegenwärtigen Rassismusphänomens indirekt angewandte ,Rassebegriff' ist demnach auch im 21. Jahrhundert keinesfalls - ebenso wie aus sozialwissenschaftlicher Perspektive - mithilfe neuester, biologischer Forschungserkenntnisse zu belegen, sondern einzig als gesellschaftliche Konstruktion zu identifizieren. ${ }^{2242}$

„Race' denotes socially constructed units as a function of the incorrect usage of the term. [...] demographic units are not, races! But social units were politically constructed from the somatically defined, races' of classical anthropology. In addition, rules of descent were created that delimited group membership, based on some notion of desirability by those who created the laws. " 2243

Sämtliche pseudobiologischen Grundlagen auf bevölkerungspolitischer Ebene stellen folglich einen dezidierten Missbrauch naturwissenschaftlicher Konzepte

2238 Vgl. Collins, Francis S. (2004): What we do and don't know about, race', ,ethnicity', genetics and health at the dawn of the genome era, in: Nature Genetics. Genetics for the human race, Vol. 36 Nr. 11, Nov. 2004, London u. a., S. 13.

Andere Elemente des Rassismuskonstrukts, wie Kultur, Geschichte, Sozialisation, Politik oder Ökonomie generieren das heutige, Rassekon₹ept" ebenfalls mit, da sie alle auf biologische Kernkomponenten zurückzuführen sind.

2239 Keita, S. O. Y. et al. (2004): Conceptualizing human variation, in: Nature Genetics. Genetics for the human race, Vol. 36 Nr. 11, Nov. 2004, London u. a., S. 18.

2240 Keita et al. 2004, ebd., S. 18.

2241 Vgl. Cavalli-Sforza et al. 1994, a. a. O., S. IX.

2242 Vgl. Keita et al. 2004, ebd., S. 18.

2243 Keita et al. 2004, a. a. O., S. 18. 
dar. Das auf den Menschen übertragene ,Rassenkonzept ${ }^{6}$ bleibt auch in Zukunft ein Mythos, der einzig der Legitimation von Abwertung und Diskriminierung dient. $^{2244}$

\section{„[...] alle Menschen gebören einer einzigen Spezies an, und es gibt keine Unterteilung zwischen den Arten von Menschen, die jenen Schranken entsprächen, durch welche ein- zelne Tierspezies voneinander getrennt sind. "2245 „Es gibt keinen Zweifel, dass die all- gemeine Vorstellung von Rasse [...] ungültig sind [...]. "2246}

Leider ist diese wissenschaftliche Tatsache in der bundesrepublikanischen Bevölkerung keineswegs präsent, wie die weit verbreitete Ausdehnung von rassistischen, ,rassischen' und diskriminierenden Argumentations- und Verhaltensweisen im 21. Jahrhundert vergegenwärtigt (s. Kapitel 3). Das ,Rassekonstrukt‘ bleibt zwar seit den Schreckensszenarien des Zweiten Weltkrieges sowie des nationalsozialistischen Terrorregimes politisch und gesellschaftlich offiziell tabuisiert - in der verdeckten, verschleierten und eher indirekten gesellschaftlichen Realität zeigt es sich jedoch weiterhin - quasi subkutan - präsent. ${ }^{2247}$ Auch in der naturwissenschaftlichen Forschung bleibt der ,Rassediskurs' weiterhin von Bedeutung, obwohl er als nicht mehr zeitgemäß diskreditiert wurde (s. Kapitel 1, 5). Er wird in der humangenetischen Forschung partiell immer noch kritisch diskutiert. ${ }^{2248}$ Rassistische Ideologie und Naturwissenschaft scheinen folglich eine Art ,Verbindung ${ }^{6}$ aufzuweisen, ohne die das Konzept des Rassismus nicht möglich wäre - eine weitere Bestätigung der fachlichen und methodischen Notwendigkeit der Disziplinen übergreifenden Vorgehensweise im Rahmen dieser Arbeit. ${ }^{2249}$

Inwiefern die Vererbungswahrscheinlichkeit von spezifischen Fähig- und Fertigkeiten bzw. Genen von genotypischen oder umweltbedingten Einflüssen abhängt, kann auch im 21. Jahrhundert nur teilweise diagnostiziert werden, da die diesbezügliche Forschung nach der Entschlüsselung des genetischen Codes des Menschen im Jahr 2003 heute noch an den Anfängen steht, wie die nachfolgende Übersicht skizziert. Jedoch kann für viele Eigenschaften und Verhaltensweisen des Homo sapiens heute schon konstatiert werden, dass diese polygenetisch vererbt werden. Beispielsweise für den von Thilo Sarrazin forcierten, kryptischen Begriff der Intelligenz ist nicht nur ein Abschnitt auf der menschlichen DNA - ein Gen für dessen Ausprägung verantwortlich, sondern mehrere Gene, die in einem komplexen Zusammenspiel gemeinsam mit multiplen Umweltfaktoren ein grundlegendes Potenzial für die kognitiven Fähigkeiten des Homo sapiens bereitstellen.2250 Diese sogenannte multifaktorielle Vererbung ermöglicht es aktuell nur teilweise,

2244 Vgl. Kühl 1999, a. a. O., S. 116.

2245 Dunn/Dobzhansky 1970, a. a. O., S. 100.

2246 Dunn/Dobzhansky 1970, a. a. O., S. 103.

2247 Vgl. Terkessidis 2004, a. a. O., S. 73.

2248 Vgl. Terkessidis 2004, a. a. O., S. 75.

2249 Vgl. Kaupen-Haas, Heidrun (1999): Nachwort, in: Kaupen-Haas, Heidrun/Saller, Christian (Hrsg.): Wissenschaftlicher Rassismus. Analysen einer Kontinuität in den Human- und Naturwissenschaften, Frankfurt/Main u. a., S. 425. 
Variabilitäten einzelner Merkmale der genotypischen bzw. der umweltbedingten Seite differenziert zuzuordnen. ${ }^{2251}$ Eine eindeutige Differenzierung erscheint nur selten generierbar und biologisch sinnvoll. 2252

Tab. 31: Current understanding of genetic contribution to group differences ${ }^{2253}$

\begin{tabular}{|ll|}
\hline \multicolumn{1}{|c|}{ Trait category } \\
\hline $\begin{array}{l}\text { DNA sequence varia- } \\
\text { tion }\end{array}$ & Very detailed. \\
\hline Mendelian diseases & $\begin{array}{l}\text { Detailed. Most mutations are rare and are specific to regions or } \\
\text { groups, reflecting the timing of mutations and human population } \\
\text { history, including founder effects, genetic drift more generally and, } \\
\text { in some cases, natural selection. }\end{array}$ \\
\hline $\begin{array}{l}\text { Physical traits (skin, } \\
\text { hair and eye color, } \\
\text { hair form, body shape) }\end{array}$ & Modest. Presumed polygenic with few genes identified. \\
\hline Complex diseases & $\begin{array}{l}\text { Limited. Partial evidence for a few diseases where some variants } \\
\text { are group-specific and others are more broadly distributed, possi- } \\
\text { bly at different frequencies in different groups. }\end{array}$ \\
\hline Behavior & Very limited. Based only in within-group heritability studies. \\
\hline
\end{tabular}

Die dargestellten multiplen Variations-, Modifikations- und Mutationsmöglichkeiten der menschlichen DNA beweisen vor diesem Hintergrund zusätzlich, dass eine vollkommen identische Vererbung von Genen an die nachfolgenden Generationen sowie die eindeutige mathematische Berechnung dieser Wahrscheinlichkeiten realitätsfern ist. ${ }^{2254}$ „Erblichkeitsschätzungen unterliegen verschiedenen Fehlermöglichkeiten [...]“2255, so auch der Verhaltensbiologe David McFarland. Die Wechselwirkungen zwischen Genotyp und multiplen Umwelteinflüssen erzeugen eine unglaubliche Variabilität, die für Individuen nur schwer abzuschätzen ist, keinesfalls jedoch auf ganze Populationen von Menschen generalisierend übertragen werden kann. ${ }^{256}$ Zusätzlich ergeben sich beim Homo sapiens weitere spezifische Charakteristika, die eine Aussage bezüglich der Erblichkeit unrealistisch erscheinen lassen: Die nicht-zufällige Paarbildung beim Menschen, die nicht steuerbare, umweltbedingte Varianz, die soziale und familiäre Situation oder beispiels-

2251 Vgl. Propping 1992, a. a. O., S. 115.

2252 Vgl. Propping 1992, a. a. O., S. $118 \mathrm{ff}$.

2253 Eigene Darstellung nach: Vgl. Mountain, Joanna L./Risch, Neil (2004): Assessing genetic contributions to phenotypic differences among, racial' and ,ethnic' groups, in: Nature Genetics. Genetics for the human race, Vol. 36 Nr. 11, Nov. 2004, London u. a., S. 50.

2254 So stellen sich beispielsweise Chromosomenmutationen als relativ bäufig dar: Ungefähr 20 Prozent der menschlichen Zygoten weisen chromosomale Anomalien auf. Auch zeigt sich eine bomoaygote Weitergabe von angeblich ,vorteilhaften ' $b$ zw. ,minderwertigen' genetischen Prädispositionen im heutigen globalisierten, multikulturellen Bevölkerungsalltag unmöglich. Vgl. Propping 1992, a. a. O., S. 118, 125.

2255 McFarland, David (1999): Biologie des Verhaltens. Evolution, Physiologie, Psychologie, 2. Auflage, Heidelberg u. a., S. 44.

2256 Vgl. McFarland 1999, a. a. O., S. 44f. 
weise spezifische ökonomische Faktoren. ${ }^{2257}$ Problematisch daran bleibt die häufige - willentlich oder nicht - Verwechslung von umweltbedingten und genetisch vererbten Merkmalen - ein ungelöstes Problem der Biologie. ${ }^{2258}$ Das Genom darf zwar keinesfalls vernachlässigt werden, jedoch sind und bleiben ,[...] Erblichkeitsschätzungen kein brauchbarer Maßstab für die relative Bedeutung von angeborenen und erworbenen Eigenschaften $[\ldots]^{\text {“2259 }}$. Insbesondere das Phänomen der sogenannten Intelligenz verdeutlicht - trotz der begrifflichen Unschärfe - den heute wieder weit verbreiteten, rassistischen Irrglauben der Vererbung von erworbenen Fähig- und Fertigkeiten an nachfolgende Generationen, um damit eine deterministische, genotypische ,Rassenkonstruktion“ auf bevölkerungspolitischer Ebene zu legitimieren. ${ }^{2260}$ Von Seiten der Molekulargenetik fehlt bis heute jegliche wissenschaftliche Grundlage für eine ausschließlich genetische Basis der kognitiven Fähigkeiten - ein bevölkerungsspezifisches ,Intelligenzgen‘, um mit Thilo Sarrazin zu sprechen, entbehrt folglich jeglicher wissenschaftlicher Realität. ${ }^{2261}$

Ebenso wird vor dem Hintergrund zahlreicher differenter Praktiken und Rahmenbedingungen sogenannter Intelligenztestsettings deutlich, dass hier versucht wird ein Phänomen statistisch zu bestimmen, wobei jedoch keinesfalls deutlich ist, was hier überhaupt gemessen werden soll. ${ }^{2262}$ Intelligenz und IQ bleiben demnach auch in Zukunft lediglich ein kritisch debattiertes, relatives, theoretisches Konstrukt der biopsychologischen sowie verhaltensbiologischen Forschung, welches von vielfachen Fehlern, Schwächen und ebenso unterschiedlichen äußeren Faktoren, wie Sozialisation, Erziehung oder Bildungsweg, beeinflusst wird. ${ }^{2263}$ Demzufolge kann auch den Rassisten des 21. Jahrhunderts eine Falschinterpretation und Fehlauslegung biologisch-genetischer Erkenntnisse vorgeworfen werden. Sowohl der Bezug auf Darwins Evolutionstheorie, die Einbeziehung der Vererbungsregeln Gregor Mendels als auch die Integration hochspekulativer Forschungsarbeiten von Charles Murray und Richard Herrnstein mit „The Bell Curve“2264 bestätigen die keineswegs wissenschaftlichen Theorie-Konstrukte des Rassismus.2265 Vor allem die Forschungsergebnisse des letzten Jahrzehnts bekräftigen aufgrund der bedingt durch den wissenschaftlichen Fortschritt - erweiterten Analysemöglichkeiten eindeutig, dass Evolutions- und Verhaltensbiologie, Human- und Moleku-

2262

2263

2264

2265
Vgl. McFarland 1999, a. a. O., S. 44 f.

Vgl. McFarland 1999, a. a. O., S. 45.

McFarland 1999, a. a. O., S. 45.

Vgl. Sesín 2012, a. a. O., S. 40.

Die Intelligenz betreffend existieren zablreiche Definitionen und Begriffsbestimmungen unterschiedlicher wissenschaftlicher Fachdis:iplinen, die dem Intelligenz-Begriff verschiedene begriffliche Schwerpunkte zuschreiben. Der Intelligen zbegriff bleibt folglich ebenso wie die Praxis des sogenannten Intelligenrquotienten eine indirekte, an definitorischer Klarheit und Transparenz mangelnde Größe.

Vgl. Weingart 2012, a. a. O., S. 24.

Vgl. Knebel/Marquardt 2012, a. a. O., S. 107.

Vgl. Knebel/Marquardt 2012, a. a. O., S. 114, 117.

Herrnstein, Richard J./Murray, Charles (1996): The Bell Curve. Intelligence and Class Struc-

ture in American Life, New York u. a.

Vgl. Haller/Niggeschmidt 2012, a. a. O., S. 13. 
largenetik sowie die Biopsychologie in keiner Weise als theoretische oder fachwissenschaftliche Grundlage rassistischer Theoreme zu betrachten sind. ${ }^{2266}$ Die Bezugnahme des Rassismus auf Biologie und Genetik zur Zukunftsprognose der gesellschaftlichen Entwicklungsmöglichkeiten sowie deren Übertragung auf einzelne Menschenpopulationen ist in der Folge mehr denn je als ideologischer Irrweg zu klassifizieren. ${ }^{2267}$ Eine Naturalisierung des Sozialen sowie eine Übertragung von angeblich biologischen Ungleichheiten auf als natürlich gegebene, gesellschaftliche Ungleichwertigkeiten verbietet die moderne genetische Forschung. ${ }^{2268}$ Insbesondere Theoretiker wie Thilo Sarrazin sollten die wissenschaftliche Realität endgültig anerkennen. ${ }^{2269}$ Der weitere Missbrauch neuester biologisch-genetischer Untersuchungsergebnisse könnte nämlich gegenteilig sogar die Gefahr bergen, dass das gesellschaftliche Vertrauen in die biologische Forschung und in die Forschungsnotwendigkeit der Genetik verloren ginge. 2270

Zeigt sich das Rassismusphänomen nach Luigi Luca Cavalli-Sforza so als nicht ausrottbar? ${ }^{2271}$ Tendenziell kann sich seiner Einschätzung angeschlossen werden: „[...], wie wertvoll wissenschaftliche Argumente auch sein mögen, ich fürchte, dass der Rassismus noch gefährliche Gelegenheiten finden wird, sein hässliches Gesicht zu zeigen." 2272

\subsection{Bewertung}

Die Untersuchungsbefunde verdeutlichen eindrücklich, dass eine Rassismusanalyse des 21. Jahrhunderts - der Forschungszeitraum von 2007 bis 2013 als Schwerpunkt - mit vielfältigen Herausforderungen verknüpft ist. Sowohl eine eindeutige Definition des Rassismusphänomens im 21. Jahrhundert, eine klare und transparente Identifizierung der Hintergründe des heutigen Rassismusproblems als auch eine klare Abgrenzung der biologischen Zustandsbeschreibungen des Rassismus von kulturellen bzw. sozialen Ressentiments schien zu Beginn als sehr komplex. $^{2273}$

Das Forschungsdesign dieser Arbeit hat sich jedoch gerade vor dem Hintergrund dieser skizzierten Schwierigkeiten und Herausforderungen als zielorientiert und passend bestätigt. Die Fokussierung auf die biologische Rassismuskomponente sowie die detaillierte Analyse eines Phänomens, welches nicht nur auf sozial-

\footnotetext{
2266 Vgl. Propping 1992, a. a. O., S. 115.

2267 Vgl. Bensch 2009, a. a. O., S. 60.

2268 Vgl. Bensch 2009, a. a. O., S. 75.

2269 Die originären Eugeniker am Beginn des 20. Jabrbunderts hatten aufgrund feblender methodischer Vorgebensweisen selbstverständlich keine Vorstellung der durch Molekularbiologie und -genetik ermittelten geno- und phänotypischen Variabilität des Homo sapiens: Vgl. Propping 1992, a. a. O., S. 126.

2270 Vgl. Cho, Mildred K./Sankar, Pamela (2004): Forensic genetics and ethical, legal and social implications beyond the clinic, in: Nature Genetics. Genetics for the human race, Vol. $36 \mathrm{Nr}$. 11, Nov. 2004, London u. a., S. 11.

2271 Vgl. Cavalli-Sforza/Cavalli-Sforza 1994, a. a. O., S. 371.

2272 Zeit Online 1992, a. a. O.

2273 Vgl. Bensch 2009, a. a. O., S. 2.
} 
und politikwissenschaftlichen, sondern auch auf biologischen Themenaspekten basiert, ergibt nur Sinn bzw. kann nur dann erfolgreich sein, wenn es eben diese unterschiedlichen Forschungsfelder kombiniert. Diese Vorgehensweise wurde im Rahmen der aktuellen Rassismusforschung erstmals durch eine dezidierte Verknüpfung von sozial- und naturwissenschaftlichen Forschungsansätzen auf fachlicher, methodischer und struktureller Ebene verwirklicht.

Der wissenschaftliche Mehrwert dieser Integration verschiedener biologischer Forschungsdisziplinen in den Untersuchungsrahmen dieser Arbeit zeigt sich in der von biologischer Seite eindeutigen Diskreditierung sämtlicher biologischrassistischer Argumentationen. Zwar weisen schon die sozialwissenschaftlichen Befunde dieser Arbeit auf die Fraglichkeit dieser rassistischen Theoreme hin; aus biologischer Perspektive können die Falschauslegungen und Missinterpretationen der rassistischen Ideologie jedoch nun zusätzlich als fachlich eindeutig falsch identifiziert werden. Insbesondere die neuere genetische Forschung seit dem Erfolg von HUGO beweist auf theoretisch-genetischer und quantitativ-genetischer Ebene, dass Behauptungen hinsichtlich der Existenz unterschiedlicher, biologischer ,Menschenrassen', spezifischer Vererbungsschemata, fester Erblichkeitswahrscheinlichkeiten, eines deterministischen Genpools oder der Unwichtigkeit von Umwelteinflüssen auf den Vererbungsvorgang eine biologische Utopie darstellen. So kann eindeutig herausgestellt werden, dass nicht nur die politikwissenschaftlich-rassistischen Argumentationen auf der Basis von beispielsweise Bevölkerungsund Einwanderungsstatistiken nicht stimmig sind, sondern dass selbst die angeblich validen, manifesten und unfehlbaren biologischen Grundlagen jeglicher wissenschaftlicher Realität entbehren. Diese Feststellung ist vor allem durch die Einbeziehung der Biologie - trotz der auch in den Naturwissenschaften existierenden Diskussionen um ,Rasse“ und Vererbung - im Rahmen dieses sozialwissenschaftlichen Forschungsansatzes treffbar, was Sinn und Bedeutung dieser Vorgehensweise unterstreicht.

Schon die sozialwissenschaftliche Analyse des Rassismusphänomens der Jahre 2007 bis 2013 stellte so dar, dass sich die gegenwärtig in der bundesrepublikanischen Bevölkerung weit verbreiteten, rassistischen Argumentationen teilweise gegenseitig widersprechen bzw. im Argumentationsverlauf nicht vollkommen übereinstimmen. Die Inhaltsanalyse von Thilo Sarrazins Bestseller konkretisierte diese sozialpolitischen und sozialbiologischen Aussagen hinsichtlich der Überfremdung, Überflutung und des Untergangs der deutschen Kultur bzw. ,Rasse'. Mithilfe bevölkerungsstatistischer Datensätze konnte zusätzlich schon ein erster Hinweis auf die Unzulänglichkeit der rassistischen Argumentationen ermittelt werden. Die naturwissenschaftliche Überprüfung konnte diese Aussagen jedoch, insbesondere mithilfe quantitativ-genetischer Methoden, endgültig der Realitätsferne überführen. Die Untersuchungsergebnisse von sozial- und naturwissenschaftlichem Forschungsdesign stimmen so überein.

Insofern könnte an dieser Stelle jedoch auf mögliche Lern- und Optimierungschancen der sozialwissenschaftlichen Forschung durch die naturwissenschaftliche Untersuchungsmethodik hingewiesen werden. Gerade die durch biologische Ana- 
lyseansätze erreichte Objektivität und Validität - methodische Grenzen sind natürlich auch hier existent - könnte den Sozialwissenschaften eventuell neue Impulse und Chancen in der empirischen Forschung geben. Andererseits erscheint gerade auch die qualitative Sozialforschung wichtige Chancen für die Naturwissenschaften zu offerieren, wie die Methoden der Text- oder Inhaltsanalyse, aber auch die sozialwissenschaftlich-qualitativen Vorgehensweisen gezeigt haben. Quantitativ-genetische Daten zeigen sich zwar überwiegend objektiv, reliabel und valide; wie schon mehrmals angemerkt, könnte jedoch ein qualitativer Analyseansatz gerade in der biologischen Rassismusforschung weitergehende Erkenntnisse versprechen. Dementsprechend bietet die Verknüpfung von sozial- und naturwissenschaftlicher Forschung nicht nur fachliche Vorteile sowie gegenseitige methodische Ergänzungen - die jeweiligen methodischen Vorteile der Fachdisziplinen können in passender, vorteilhafter Weise kombiniert werden -, sondern auch einen dezidiert methodischen Mehrwert hinsichtlich neuer Chancen in der Rassismusforschung.

Der Erfolg dieser Untersuchung muss demzufolge dokumentiert werden: Durch die Fokussierung auf die biologisch orientierte, enggeführte Rassismusdefinition von Robert Miles gelingt es, die biologistische Variante der rassistischen Ideologie bestmöglich abzugrenzen und zu identifizieren. Dies illustriert im Besonderen die naturwissenschaftliche Analyse des biologistischen Rassismusphänomens (s. Kapitel 5). Das biologisch-genetisch geprägte Kernelement der rassistischen Ideologie zeigt sich in der Mitte der bundesrepublikanischen Bevölkerung etabliert - dies verdeutlicht die sozialwissenschaftliche Datenanalyse bzw. Datenzusammenstellung. Der biologische Forschungsansatz bestätigt darüber hinausgehend die fachliche Unstimmigkeit rassistischer Theoreme. Die heutigen Ausdrucksformen des Rassismus unterscheiden sich zwar von den rassistisch motivierten Vorkommnissen der 1980er und 1990er Jahre, haben sich jedoch lediglich an das gegenwärtige politische und gesellschaftliche Normen- und Wertesystem angepasst. Sozialwissenschaftliche Rassismus- und biologische ,Rassediskussionen bleiben aber auf repräsentativer Ebene weiterhin aufgrund der nationalsozialistischen Vergangenheit Deutschlands tabuisiert und verdrängt. Im Vordergrund stehen verniedlichende, verharmlosende und beschönigende Worthülsen bzw. Ersatzbegriffe, wie Fremdenfeindlichkeit, Ausländerfeindlichkeit, Ethnie oder Kultur, die aus sozial- und naturwissenschaftlicher Perspektive mitnichten das Phänomen des Rassismus treffen, wie die Ergebnisse dieser Arbeit verdeutlichen. 2274 Genau dies macht die Identifizierung gegenwärtiger rassistischer Verhal-

2274 Die vordergründig eingesetżten, verharmlosenden Begrifflichkeiten stellen lediglich kulturell-naturalisierende und -biologisierende Ersat_termini dar. Die pseudobiologische Begründung des Rassismus stïtrt - wie der Name verdentlicht - immer noch auf die wissenschaftlich falsifizierte, Rassenbiologie' des 20. Jabrbunderts. Moderne Psendotheoretiker nutzen - wie die Analyse der Theoreme Thilo Sarrazins gezeigt hat - diese Grundlage in modernisiertem Gewand, indem sie vor einer angeblichen biologischen, Überfremdung' durch, die Anderen " warnen sowie einen scheinbaren Intelligenz- und Genverlust durch, die Fremden' propagieren. Der , Rassebegriff" kommt zwar nur selten offen vor, steht jedoch bintergrïndig als Grundgedanke rassistischer Argumentationen weiterbin im Zentrum, wie die qualitativen und quantiativen Datenauswertungen belegen. Vgl. Schott 1992, a. a. O., S. $10 \mathrm{ff}$. 
tensweisen innerhalb des gesellschaftlichen Umfeldes jedoch seitens sozialwissenschaftlich-empirischer Methoden problematisch, da von Seiten der befragten Bürgerinnen und Bürger versucht wird, sich in eine scheinbar dem politischen und gesellschaftlichen Normensystem entsprechende Position zu lancieren (s. Kapitel 3). Diese Verdeckung und Verschleierung der biologistischen Kernelemente des Rassismus werden es in Zukunft prognostisch noch schwieriger machen, rassistische Phänomene in der Gesellschaft zu identifizieren. Sozialdarwinistische und eugenische Konzeptionen sind demnach im 21. Jahrhundert immer noch existent. 2275

Genau diese zentrale Erkenntnis beweist diese Arbeit mithilfe ihres Forschungsdesigns. Bisherige Untersuchungen fokussierten vornehmlich den angeblichen Kultur-Aspekt des Rassismus bzw. analysierten das Rassismusphänomen nur aus rein politikwissenschaftlicher Perspektive. Dieser Analyseansatz bestätigt jedoch die essentielle Erkenntnis, dass Biologie und Rassismus, trotz der eindeutigen Diskreditierung durch die Sozial- und Naturwissenschaften, in vielen gesellschaftlichen und politischen Ebenen akzeptiert und präsent sind. Somit können die in der Einleitung formulierten forschungsleitenden Hypothesen vollständig bestätigt sowie validiert werden (s. Kapitel 1.2). Das Ziel dieser Untersuchung, Hintergründe, Verbreitung und wissenschaftliche Realität des heutigen, biologisch-genetisch konnotierten Rassismusphänomens in Deutschland zu analysieren, ist demnach erreicht worden: Rassismus muss in seiner biologistischen Ausprägung wieder als Bestandteil vieler Ebenen der bundesrepublikanischen Gesellschaft festgehalten werden (s. Kapitel 3, 3.1). Eine allein sozialwissenschaftliche Auswertung und Interpretation der Datensätze - jeder einzeln für sich betrachtet - hätte diese Lage beispielsweise nicht in diesem Ausmaße realisieren können, da insbesondere die biologische Zentrierung zur Objektivitäts- und Validitätssteigerung gefehlt hätte.

Aufgrund der hier identifizierten, neuen Erkenntnisse bleibt abschließend warnend zu resümieren: Die moderne Gesellschaft reproduziert und regeneriert biologisch-rassistische Vorurteils- und Diskriminierungsstrukturen. ${ }^{2276}$

\subsection{Ausblick: Rassismusforschung in Deutschland}

Rückblick und Bewertung der Forschungsergebnisse das modernisierte, vornehmlich biologistische Rassismusphänomen des 21. Jahrhunderts betreffend illustrie-

2275 Vgl. Bensch 2009, a. a. O., S. 2.

2276 Jedoch dürfen nicht nur die gesellschaftlichen Fehlentwicklungen in den Fokus gerückt werden, denn auch politische und ökonomische Feblentscheidungen sowie ein gewisser institutioneller Rassismus kereieren Ungleichheit, Diskeriminierung, Ausgrenzung und Abwertung - kurz: Sie konstruieren das Wesen der, Anderen', der „Fremden' (s. Kapitel 4). Die Vertreter der rassistischen Ideologie nutzen diese Unsicherbeiten und Ängste, um diese kulturellen und sozialen Ungleichheiten als ,natürliches Phänomen " unterschiedlicher - , höherwertiger" und ,minderwertiger"-Menschengruppen darzustellen. Der heutige Rassismus nutzt so insbesondere die aktuelle sozialpolitische Schwäche, ausgelöst durch die vor allem Europa betreffende Wirtschafts- und Finanzkrise. Vgl. Terkessidis 2004, a. a. O., S. 96. 
ren, dass für die kommenden Jahre noch ein großes Forschungspotenzial hinsichtlich der heutigen rassistischen Ideologie existiert. Fokus und Zielsetzung dieser Untersuchung lagen in der Analyse des biologisch-genetisch begründeten Rassismuskonstrukts im heutigen Deutschland. Vergangene, historische Entwicklungen des Rassismus bieten jedoch, wie auch die zukünftigen Perspektiven, noch ein gewaltiges Forschungspotenzial, was insbesondere zur Aufklärung und Prävention auf allen gesellschaftlichen Ebenen führen muss. Denn ohne eine intensivierte Aufarbeitung und Reflexion des Rassismusphänomens besteht die Gefahr, diesem in der Öffentlichkeit auch für die Zukunft - beispielhaft ausgedrückt - weiter lebenserhaltende Maßnahmen bzw. „Überlebenshilfe“‘2277 zu geben.

„Die Geschichte des Rassismus bietet nach wie vor ein breites Feld für künftige Forschungen. Besonders Gender-Perspektiven, die sich in allen rassistischen Vorstellungen und Gesellschaftssystemen f[i]nden, sind [beispielsweise] erst seit kurzem in den Fokus der Analyse geraten und bieten erhebliches Potenzial für zukünftige Fragestellungen. "2278

Das politikwissenschaftliche Wissen bezüglich des heute wieder etablierten Rassismusphänomens bleibt aktuell noch vielfach lückenhaft, was beispielsweise die Definitionsschwierigkeiten sowie die erschwerte Fokussierung und Zentrierung des Rassismusbegriffes illustrieren. ${ }^{2279}$ Es fehlt weiterhin an einer umfassenden, weitgehend akzeptierten Rassismusdefinition auf sozialwissenschaftlicher Ebene, die sowohl engere als auch breitere Begriffscharakteristika integriert. Die im Rahmen dieser Analyse präferierte Rassismusdefinition von Robert Miles spiegelt den biologischen Fokus dieser Untersuchung treffend wieder und passt deshalb auch ideal zum gewählten Forschungsschwerpunkt. Nichtsdestotrotz charakterisiert sich der heutige Rassismustypus durch vielfältige Anpassungen an die gesellschaftliche Lage des 21. Jahrhunderts, wie die vorausgegangenen Untersuchungen neu bestätigen. Auf der Grundlage der hier getroffenen Forschungsergebnisse könnte eine modifizierte, an das biologisch-genetische Rassismuskonstrukt der Gegenwart angepasste Definition demnach wie folgt aussehen: Rassismus beschreibt ein gesellschaftliches Phänomen, welches mithilfe von biologistischen Merkmalen des ,Rassekonzeptes" sowie pseudogenetischen Charakteristika spezifische Menschengruppen konstruiert bzw. differenziert. Es zeigt sich im 21. Jabrbundert als flexibles, wandlungsfähiges Konzept zur Diskriminierung und Hierarchisierung unterschiedlicher Menschengruppen.

Für die Erforschung der eher kulturellen bzw. sozialen Komponenten des Rassismus bietet sich jedoch beispielsweise für zukünftige Forschungen alternativ ein weiteres Definitionsspektrum an, trotz der biologisch-naturalisierenden Basiskonzepte des Rassismusphänomens. Zukünftige Forschungs- und Analyseansätze sind demnach vielfach existent. Selbstverständlich bedürfen diese jedoch eines durch-

2277 Arndt, Susan (2011): Rassismus, in: Arndt, Susan/Ofuatey-Alazard, Nadja (Hrsg.): Wie Rassismus aus Wörtern spricht. (K)erben des Kolonialismus im Wissensarchiv deutsche Sprache. Ein kritisches Nachschlagewerk, Münster, S. 37.

2279 Vgl. Terkessidis 2004, a. a. O., S. 214. 
dachten Analyse- sowie Lösungsansatzes, um das Rassismusphänomen durch anknüpfende Untersuchungsprojekte nicht neuerlich zu reproduzieren.2280

Auch von Seiten der Naturwissenschaften ist noch ein gewisses Potenzial an Grundlagenforschung notwendig, um heutigen, genetisch argumentierenden Theoretikern den Missbrauch biologischer Theorien weiter zu erschweren. Selbstverständlich haben Molekulargenetik und Evolutionsbiologie in den letzten Jahrzehnten gewichtige Fortschritte vollbracht, jedoch fehlen zur umfassenden, wissenschaftlichen Falsifizierung der rassistischen Ressentiments noch zusätzliche Forschungsansätze, insbesondere im Bereich der neurobiologischen Forschung: Wie beeinflussen genotypische bzw. umweltbedingte Eigenschaften die Entwicklung und Ausprägungen der kognitiven Funktionen des Menschen? Wie gestaltet sich das Zusammenspiel von Genen und Genfunktionen im menschlichen Organismus? Diese und weitere Fragestellungen umreißen für die Zukunft in vielen Bereichen der Molekulargenetik noch ein enormes Forschungspotenzial, welches nicht nur eine fachliche, sondern vor allem auch eine gesellschaftliche und antirassistische Relevanz enthält. Der hier angewandte Kombinationsansatz von Sozial- und Naturwissenschaften bietet sich demzufolge an. Insbesondere der Einfluss genotypischer Eigenschaften auf die Ausbildung und Ausprägung menschlicher Gehirnfunktionen bzw. auf die kognitive Leistung des heutigen Homo sapiens offenbart gewaltige Forschungslücken, die gegenwärtige Theoretiker immer noch gekonnt auszunutzen wissen. 2281

Zukünftige Forschungsoptionen sind folglich sowohl auf sozial- als auch auf naturwissenschaftlicher Ebene durchaus vorhanden - das Ziel: Die weitere Einschränkung des Potenzials des Rassismus. Nur so können die wirklichkeitsferne Enteignung wissenschaftlich validierter Tatbestände sowie deren Missbrauch, deren Fehl- und Falschinterpretation verhindert werden. Hier zeigt sich auch die Notwendigkeit weiterer Forschung: Die aktuelle gesellschaftliche Situation in Deutschland das Rassismusphänomen betreffend zeigt sich als gefährlich. Um die zunehmende Verbreitung rassistischer Vorurteile und Ressentiments jedoch in der Mitte der Gesellschaft präventiv anzugehen, müssen Politik, Gesellschaft und die Wissenschaftsgemeinschaft gemeinsam agieren. Einzig so ergibt sich die Möglichkeit, Deutschland in eine multikulturelle, offene, freundliche, aufnahmebereite sowie dynamische Nation zu verwandeln, um damit das Bild der rassistischen, fremdenfeindlichen Bevölkerung für immer auf den Scheiterhaufen der deutschen Geschichte zu verbannen.

\subsection{Ausblick: Biologie und Rassismus}

Abschließend ein Blick auf die biologischen Kernergebnisse dieser Untersuchung zur Prognose der zukünftigen Entwicklungen Biologie und Rassismus betreffend. Vor dem Hintergrund der heutigen evolutions- und verhaltensbiologischen, hu-

2280 Vgl. Arndt/Ofuatey-Alazard 2011b, a. a. O., S. 16.

2281 Vgl. Propping 1992, a. a. O., S. 127. 
man- und molekulargenetischen sowie biopsychologischen Forschung bleibt als Ergebnis dieser interdisziplinären Analyse herauszustellen, dass alle Menschen genetisch einer einzigen Fortpflanzungsgemeinschaft angehören: der Art Homo sapiens. 2282 Hierarchisierte Unterarten bzw. Subspezies, wie es das rassistische ,Rassekonzept ${ }^{`}$ Glauben machen möchte, sind aus der Perspektive der Forschungserkenntnisse des 21. Jahrhunderts definitiv nicht vorhanden. ${ }^{2283}$ Die in der Einleitung formulierte, diesbezügliche Forschungshypothese kann demnach bestätigt werden (s. Kapitel 1.2): „There is no scientific basis to the belief of genetically determined ,superiority" of one population over another." 2284 Die Falschinterpretation des Rassismus besteht gegenwärtig darin, dass er mit methodischen Vorgehensweisen aus der Nutztierzucht sowie der falschen Auswertung und Interpretation der gewonnenen, quantitativ-genetischen Erkenntnisse argumentiert, um die Ungleichheit und Ungleichwertigkeit von verschiedenen Menschenpopulationen und damit das Vorhandensein von sogenannten ,Menschenrassen` zu beweisen. Zwillings- und Adoptionsstudien zeigen sich jedoch insbesondere im Bereich der Intelligenzforschung zwar als einzige quantitativ-genetische Forschungsmethode, sind insgesamt aber nur eingeschränkt zielführend. Eine Übertragung zoologischer Forschungserkenntnisse auf soziale und gesellschaftliche Gegebenheiten verbietet sich eindeutig. Ebenso die im Rahmen der eugenischen und sozialdarwinistischen Ideologie propagierte ,Auslese' von einerseits ,vorteilhafteren', ,nützlicheren' und andererseits, wertlosen' Menschen anhand pseudogenetischer Vererbungsschemata kann demnach als nicht zutreffend identifiziert werden.

„Es ist biologisch sinnlos und ethisch unvertretbar, beim Menschen in derartig eindimensionaler Weise wie in der Nutztierzucht ein Züchtungsziel zu definieren. Die beim Menschen i. a. als ,positiv' eingestuften Fähigkeiten und Eigenschaften, ₹. B. Körpergröße, Intelligenz, körperliche Fähigkeiten, hohe Lebenserwartung, werden genetisch multifaktoriell (polygen) determiniert. Monogen erbliche Merkmale sind allenfalls neutral für die Gesundheit der Menschen [...]. "2285

Vor diesem Hintergrund ist folgerichtig von einem eindeutigen Missbrauch der neueren biologisch-genetischen sowie biopsychologischen Forschungserkenntnisse im Rahmen der rassistischen Ideologie zu sprechen.

„Die Vertreter der Rassenhygiene [und des Rassismus] haben soziale und demographische Entwicklungen auf eine heute grotesk anmutende Weise biologisch zu interpretieren versucht, wobei sie persönliche Vorurteile ganz unkritisch in ibre Aussage haben einflieBen lassen. "2286

Die biologisch-genetische Forschung hat mit der rassistischen Ideologie des 21. Jahrhunderts keine Parallelen. Ebenso wie die sogenannte ,Rassenkunde` am Be-

\footnotetext{
2282 Vgl. Propping 1992, a. a. O., S. 122.

2283 Vgl. Propping 1992, a. a. O., S. 122.

2284 Cavalli-Sforza et al. 1994, a. a. O., S. 19.

2285 Propping 1992, a. a. O., S. 126.

2286 Propping 1992, a. a. O., S. 123.
} 
ginn des 20. Jahrhunderts nicht von der Biologie forciert und gestützt, sondern durch irrige sowie fehlgeleitete Wissens- und Glaubenstheoreme konstruiert wurde. ${ }^{2287}$ Das Konzept des Rassismus bietet auf der Grundlage von biologistischen Ressentiments sowie eines systematischen Abgrenzungs-, Abwertungs- und Diskriminierungsgefüges lediglich ein Gegenbild an, auf das seitens der Bevölkerung ein ,Sündenbock' projiziert werden kann. ${ }^{2288}$ Die Gefahr hieran skizziert Neurologe und Genetiker Peter Emil Becker:

„Rassismus kann als seelische Epidemie sich ausbreiten und weite Kreise ziehen [...].

[...] Rassismus kann [folglich] Züge einer Diesseitsreligion aufweisen. "2289

Essentiell erscheint vor diesem Hintergrund aus sozial- als auch aus naturwissenschaftlicher Perspektive die Beibehaltung des originären, biologisch konnotierten Rassismusbegriffes für den aktuellen Zustand in Deutschland (s. Kapitel 6.3).2290 Verharmlosende und beschönigende Ersatzbegrifflichkeiten sollten verbannt werden - die Probleme müssen mit dem eigentlichen Namen angesprochen werden, dem Rassismus.2291 Robert Miles identifiziert den originären Rassismusbegriff demnach folgerichtig als „[...] Schlüsselkonzept für die Sozialwissenschaften [...]“2292. Denn einzig der Begriff des Rassismus verdeutlicht den gefährlichen Charakter der biologisch-rassistischen Ideologie, wie die vorherigen Untersuchungen deutlich erkennen lassen: Die Reproduktion und Regeneration des ideologischen Rahmens durch ihre Anhänger, die Zusammenhänge zwischen Existenz und Verbreitung des Rassismus und den vorhandenen politisch-ökonomischen Verhältnissen sowie die „Vieldimensionalität“2293 des Rassismusphänomens. ${ }^{2294}$

Nichtsdestotrotz gelingt es Theoretikern sowohl aus den Sozial- als auch aus den Naturwissenschaften im 21. Jahrhundert immer noch mittels populistischer Methoden, biologisch eigentlich falsifizierte Tatbestände medienwirksam an die Öffentlichkeit zu tragen - eine Renaissance des biologistischen Rassismusphänomens. Die Frage nach der Vererbung von erlernten Fähigkeiten und Merkmalen bzw. von Genen -, der ,Rassenkonstruktion', der Brisanz der Evolutionstheorie Charles Darwins sowie der Vererbungstheorie Johann Gregor Mendels scheint auf ein großes Interesse zu stoßen, wie die vorhergehenden Kapitel bestätigen (s. Kapitel 5).

Zur scheinbaren Einhaltung der gesellschaftlichen und politischdemokratischen Werte- und Normensysteme werden biologisch-rassistische ÄuBerungen, Einstellungen und Verhaltensweisen heute jedoch meist verdeckt, verschleiert, verkleidet und indirekt - aber sozial akzeptiert - präsentiert, um einen

\footnotetext{
2287 Vgl. Becker 1990, a. a. O., S. 524.

2288 Vgl. Becker 1990, a. a. O., S. 524f.

2289 Becker 1990, a. a. O., S. 524, 525.

2290 Vgl. Miles 1999, a. a. O., S. 172.

2291 Vgl. Miles 1999, a. a. O., S. 172.

2292 Miles 1999, a. a. O., S. 172.

2293 Miles 1999, a. a. O., S. 174.

2294 Vgl. Miles 1999, a. a. O., S. $172 \mathrm{ff}$.
} 
quasi-demokratischen bzw. quasi-legalen Schein zu wahren. ${ }^{2295}$ Rassistische Vorurteile und Ressentiments werden so meist nach der Phrase ,Ich bin nicht rassistisch, aber ich kann verstehen, dass...' verdeckt und geleugnet. ${ }^{2296}$ Hier kann von einem manifestierten „Alltagsrassismus“2297 innerhalb der deutschen Gesellschaft gesprochen werden.

„Rassismus spiegelt sich [heute] als Selbstverständlichkeit in alltäglichen Handlungspraxen und Vorstellungen wider und durchdringt alle sozialen Strukturen und Diskurse. [...] Aufgrund des auf allen Ebenen der Gesellschaft verankerten Rassismus ist niemand daran unschuldig. "2298

Der offene biologisch-genetisch konnotierte Rassismus, der partiell die mediale Öffentlichkeit erreicht und empört, ist daher nach Siegfried Jäger lediglich „,[...] die Spitze des Eisbergs." 2299 Dies zeigen insbesondere die quantitativen Datenanalysen dieser Arbeit. Auch die politische Tabuisierung des Rassismus - zur Vermeidung sämtlicher Parallelen zur nationalsozialistischen Ära - trägt dazu bei. ${ }^{2300}$ Einzig im Zusammenhang mit prä-nationalsozialistischen sowie nationalsozialistischen Verbrechen wird der Begriff des Rassismus erwähnt - somit wird das heutige Problem des gesellschaftlichen Rassismus als nicht existent, als historisches Randphänomen angesehen. ${ }^{2301}$ Diese bundesrepublikanische Reduzierung des Rassismusbegriffs auf Nationalsozialismus und Rechtsextremismus muss als schwerwiegender Fehler kritisiert werden. ${ }^{2302}$ Bis ins 21. Jahrhundert konnten sich somit biologistische Vorurteilsstrukturen wieder unbemerkt etablieren sowie weiter entwickeln, da sie aus sozial- und naturwissenschaftlicher Perspektive fälschlicherweise als tendenziell nicht mehr existent galten. ${ }^{2303}$ Der spätestens seit dem Ende des Zweiten Weltkrieges bestehende, offizielle Konsens der Verurteilung aller rassistischen Äußerungen aufgrund deren wissenschaftlicher Diskreditierung sowie der offenen Identifizierung deren unmoralischer Charakteristika, zeigen sich

2295 Vgl. Jäger 1993, a. a. O., S. 8. | Vgl. Hong 2011, a. a. O., S. $60 \mathrm{ff}$.

2296 Vgl. Jäger 1993, a. a. O., S. 8 ff.

2297 Hong 2011, a. a. O., S. 66.

2298 Hong 2011, a. a. O., S. 66.

2299 Jäger 1993, a. a. O., S. 8.

2300 Vgl. Hong 2011, a. a. O., S. 4, 70f. | Vgl. Jäger 1993, a. a. O., S. 8. | Vgl. Shooman 2012, a. a. O., S. 53.

Jedoch zeigen sich Ersatzbegriffe wie ,Ausländerfeindlichkeit' oder ,Fremdenfeindlichkeit' einerseits wissenschaftlich und definitorisch vollkommen ungeeignet das Rassismusphänomen ₹u repräsentieren und sind andererseits selbst als tendeñiell diskriminierend zu klassifizieren, da bier eine Differenzierung zwischen In-und Ausländern aufgrund kultureller sowie biologischer Charakteristika vorgenommen wird. Zusätəlich lässt sich aus sozialwissenschaftlicher Sicht partiell auch die Ära des sogenannten Neorassismus als Ursprung der Verkleidung des biologisch-genetischen Rassismustypus identifirieren, da im Zuge dessen einzig kulturelle Elemente des Rassismuskonstrukts fokussiert brw. natïrliche Komponenten kulturalisiert wurden. Jedoch blieb das biologische Kermelement der rassistischen Ideologie weiterbin bestehen. Der kulturell orientierte ,Rassismus obne Rassen“ der 1990er Jabre kann demnach eher als „Modernisierungsstrategie“ verstanden werden, die zur Verschleierung des biologistischen Rassismuskerns fübrte. Shooman 2012, a. a. O., S. 53. Vgl. Shooman 2012, a. a. O., S. $53 \mathrm{ff}$.

2302 Vgl. Arndt 2011, a. a. O., S. 38.

2303 Vgl. Hong 2011, a. a. O., S. 71. 
im Untersuchungszeitraum von 2007 bis 2013 als lückenhaft und brüchig. ${ }^{2304}$ Insbesondere die heute immer noch vorhandene ,Rasse ${ }^{6}-$ bzw. ,rassische ${ }^{6}$ Intelligenzforschung verschiedener Naturwissenschaftler bestätigt diese Einschätzung. Die partielle Uneinigkeit der Fachwissenschaften zeigt sich hierbei folglich als zusätzlich problematisch: Es ,[...] hat sich zwar mittlerweile die wissenschaftliche ,Rassenkonzeption' als falsch erwiesen, und dennoch werden ihre Schlüsselideen in unterschiedlicher Form von einer ganzen Reihe von Wissenschaftlern weiterhin vertreten." ${ }^{2305}$ Eine gefährliche Rolle spielen in diesem Zusammenhang selbsternannte sogenannte Klartextpolitiker wie Thilo Sarrazin, die die bedrohliche gesellschaftliche Lage durch unzulässige politisch-biologische Vermischungen weiter destabilisieren. ${ }^{2306}$

$$
\begin{aligned}
& \text { "Aus alldem ergibt sich [trotzdem]: Thilo Sarrazins Äußerungen sind ein Aufguss älte- } \\
& \text { rer, längst diskreditierter Mythen [...]. "2307 }
\end{aligned}
$$

Doch stehen gegenwärtig weniger die sogenannten Gastarbeiterinnen und Gastarbeitern der 1950er und 1960er Jahre im rassistischen Fokus, sondern eher die Religionsgemeinschaft des Islam. ${ }^{2308}$ Muslime werden heute im Rahmen der pseudobiologischen, rassistischen Ideologie oftmals ,rassifiziert ${ }^{6}$ sowie als biologische Waffe, als Angriff des Islams auf die westliche Welt, als Unterwanderung und biologisch-kulturelle ,Überfremdung' Deutschlands positioniert. ${ }^{2309}$ Auch zukünftig wird so biologisches Halbwissen dazu missbraucht werden, um das Schreckgespenst einer ,biologischen Überfremdung' bzw. einer, genetischen Verunreinigung durch die angebliche Gefahr der Vermischung verschiedener ,Menschenrassen` zu regenerieren. ${ }^{2310}$ Vor dem Hintergrund dieser Untersuchungsergebnisse kann so tendenziell von einem ,[...], zweite[n] Zeitalter der Biologie $[\ldots]^{“ 2311}$ gesprochen werden, wobei es sich eigentlich nur um das ,[...] Repertoire neu aufgekochter Vorurteile aus dem 19. Jahrhundert [... “"2312 handelt. ${ }^{2313}$ Leider ist diese Erkenntnis größtenteils nur unter sozial- und naturwissenschaftlichen Experten verbrei-

2304 Vgl. Miles 1999, a. a. O., S. 10. | Vgl. Hong 2011, a. a. O., S. 2.

2305 Miles 1999, a. a. O., S. 50.

2306 Fragwürdigerweise konstatiert Sarrazin so beispielsweise in einem Schülerinterview im September 2011 bezüglich seines Buches: „Nach einem Jahr Diskussion stelle ich fest, dass die in meinem Buch grundlegend analysierten Fakten alle noch genauso stehen wie am Anfang der Diskussion. Ich habe auch noch keinen wesentlichen Denkfebler erkannt. "Anzumerken bleibt, dass erstens sämtliche seiner angeblichen Fakten aus der biologischen Mottenkiste größtenteils wissenschaftlich falsifiziert wurden sowie zweitens sein Buch keinesfalls als eine grundlegende, faketenorientierte Analyse gelten kann. Buchmann, et al. 2011, a. a. O., S. 4-5. | Vgl. Hong 2011, a. a. O., S. 60f.

2307 Gilman, Sander L. (2012): Sind Juden genetisch anders?, in: Haller, Michael/Niggeschmidt, Martin (Hrsg.): Der Mythos vom Niedergang der Intelligenz. Von Galton zu Sarrazin: Die Denkmuster und Denkfehler der Eugenik, Wiesbaden, S. 82.

2308 Vgl. Shooman 2012, a. a. O., S. 54.

2309 Vgl. Shooman 2012, a. a. O., S. $54 \mathrm{ff}$.

2310 Vgl. Hong 2011, a. a. O., S. 64.

2311 Gilman 2012, a. a. O., S. 71.

2312 Gilman 2012, a. a. O., S. 72.

2313 Vgl. Gilman 2012, a. a. O., S. 74ff. 
tet. ${ }^{2314}$ Der Rassismus und die neuere Biologie bleiben auch zukünftig in keiner Weise miteinander vereinbar. ${ }^{2315}$ Der Biologie Diethard Tautz und der Schriftsteller Steve Olson folgern exemplarisch vor dem Hintergrund der IntelligenzDebatte treffend:

„Welcher Anteil der ,Intelligenz' durch Umwelt (oder Kultur) bedingt ist, bängt zudem auch von dem gewählten Messverfabren ab. Aus Sicht der Genetik ist es unsinnig, mit solchen Prozentzablen zu hantieren, wenn noch nicht mal geklärt ist, über was genau man eigentlich spricht." 2316

„Menschen neigen dazu, den Forschungsergebnissen der Genetiker große Bedeutung beizumessen. Aber eigentlich bebt die verblïffende Homogenität unserer $D N A$ die zentrale Bedeutung hervor, die der Erfahrung des Einzelnen und der Gruppe für unsere Prägung zukommt. Jeder ist das Produkt einer bestimmten Menschbeits- und Gengeschichte. Doch diese Geschichte ist eine gemeinsame und zugleich einzigartige, eine universelle und zugleich individuelle. "2317

Der wissenschaftliche Fortschritt dieser Forschungsarbeit vergegenwärtigt: In der bundesrepublikanischen Gesellschaft werden wir auch zukünftig mit einem bevölkerungsübergreifenden Rassismusproblem zu kämpfen haben. ${ }^{2318}$ Biologistischrassistische Vorurteile bleiben im alltäglichen Arbeits- und Lebensumfeld weit verbreitet. ${ }^{2319}$ Der Rassismus des 21. Jahrhundert bleibt dabei nicht nur ein Problem für die diskriminierten Menschengruppen, sondern ein Integritäts- und Stabilitätsproblem für die gesamte Gesellschaft. ${ }^{2320}$ Besorgniserregend bleibt in diesem Zusammenhang vor allem die Flexibilität, Wandelbarkeit, Anpassungsfähigkeit und Variabilität des Rassismusphänomens, welches sich zeitgemäß mit neuen, modernisierten Formen der gegenwärtigen Lage anpasst. ${ }^{2321}$ Die Erklärungsansätze des heutigen Rassismusphänomens bleiben dabei vielseitig und variabel. ${ }^{2322}$

Zusammenfassend gibt der Kombinationsansatz dieser Arbeit einen zukunftsweisenden Beitrag zum Fortschritt und zur Weiterentwicklung der Minderheiten-, Diskriminierungs- und Rassismusforschung aus sozial- und naturwissenschaftlicher Perspektive. Hervorzuheben bleibt insbesondere der Disziplinen übergrei-

2314 Vgl. Schüller, Christian (1999): Ausnahmen sind die Regel. Die moderne Genetik widerlegt den Rassismus, in: Schüller, Christian/van der Let, Petrus (Hrsg.): Rasse Mensch. Jeder Mensch ist ein Mischling, Aschaffenburg, S. 18.

2315 Vgl. Gilman 2012, a. a. O., S. $73 \mathrm{ff}$.

2316 Tautz 2012, a. a. O., S. 132.

2317 Olson 2003, a. a. O., S. 110-111.

2318 Vgl. Hong 2011, a. a. O., S. 62ff. | Vgl. Krause-Vilmar 2006, a. a. O.

2319 Vgl. Hong 2011, a. a. O., S. $67 \mathrm{ff}$.

2320 Vgl. Miles 1999, a. a. O., S. 18.

2321 Vgl. Hong 2011, a. a. O., S. 65ff.

2322 Vgl. Krause-Vilmar 2006, a. a. O.

Das Rassismusphänomen greift sowobl politische Feblentscheidungen, zögerndes politisches Handeln sowie verantwortungsloses, skandalöses Verbalten der Politik, die Folgen der Globalisierungstendenzen als auch die klassischen Problemsituationen multikultureller und multiethischer Gesellschaften als Anknüpfungspunkte auf. 
fende Ansatz von sozialwissenschaftlichen und naturwissenschaftlichen Untersuchungsdesigns. Selbstverständlich handelt es sich bei den hier erarbeiteten, analysierten und visualisierten Erkenntnissen um keine für die Zukunft unumstößlichen Konzepte. Vor dem Hintergrund der molekulargenetischen Forschung werden in den kommenden Jahren noch viele Beobachtungen erwartet, die der rassistischen Ideologie zusätzlich ihre Falsch- und Missinterpretationen biologisch-genetischer Zusammenhänge aufzeigen werden. Auch auf der Ebene der Sozialwissenschaften müssen beispielsweise die anhaltenden Auswirkungen der europäischen Wirtschafts- und Finanzkrise eventuell in Zukunft neu bewertet werden, da diese sich immer weiter in Richtung einer akuten Staatenkrise entwickeln könnten. In diesem Zusammenhang sind die perspektivischen Auswirkungen auf die Integrität und Stabilität der bundesrepublikanischen Gesellschaft heute nur partiell skizzierbar.

Auffällig ist insbesondere, dass das biologische Taxon der ,Rasse', trotz der bisherigen Erfolge der molekulargenetischen, anthropologischen und evolutionsbiologischen Forschung sowie der offiziellen Diskreditierung durch Bundesregierung und Vereinte Nationen in mehreren Erklärungen und Schriftsätzen als auf den modernen Menschen nicht anwendbar, im gesellschaftlichen Alltagsleben keineswegs verschwunden ist. ${ }^{2323}$ Eugenik und ,Rassenideologie' sind zwar im 21. Jahrhundert durch die Erkenntnisse der neueren biologischen Forschung überholt. ${ }^{2324}$ „Das soziale und politische Konstrukt der ,Rasse“ wirkt [jedoch] implizit fort und ist mittlerweile untrennbar mit kulturellen und religiösen Zuschreibungen verbunden. “2325 Die Untersuchungsergebnisse skizzieren nach wie vor:

„Rassenhygiene oder Eugenike ist einer der Mythen, die den phantastischen Weg in die Zukunft einer gesünderen und tüchtigeren Menschheit mit bengalischem Licht beleuchten, verführerisch den ,neuen Menschen'verheißend, vertrauend auf das suspekte Wort vom Gemeinnutz, der vor Eigennutz, gebt. "2326

Man sollte der Empfehlung Steve Olsons folgen und den ,Rassebegriff endgültig aus der wissenschaftlichen Forschung verbannen: „Je eher man ihn aus dem Wortschatz streicht, desto besser.“2327 „Der Mensch ist [und bleibt] eine der genetisch homogensten Spezies, die es auf der Erde gibt.“2328 Der Genpool aller menschlichen Populationen ist nur sehr geringfügig diversifiziert. ${ }^{2329}$ Dies bestätigen die in den vorherigen Kapiteln herausgearbeiteten evolutions- und humanbiologischen Analysen der menschlichen Kern-DNA sowie die Untersuchung der mitochondrialen DNA (s. Kapitel 5.3). Die Genetik liefert demnach keine Erkenntnisse, die für eine Differenzierung und Hierarchisierung verschiedener Menschenpopulationen sprechen, auch nicht aufgrund der unterschiedlichen geogra-

2323 Vgl. Shooman 2012, a. a. O., S. 53ff. | Vgl. Becker 1990, a. a. O., S. 615.

2324 Vgl. Becker 1990, a. a. O., S. 616ff.

2325 Shooman 2012, a. a. O., S. 53.

2326 Becker 1990, a. a. O., S. 615.

2327 Olson 2003, a. a. O., S. 55.

2328 Tautz 2012, a. a. O., S. 127.

2329 Vgl. Tautz 2012, a. a. O., S. $128 f f$. 
phischen Verteilung auf verschiedenen Kontinenten der Erde. ${ }^{2330}$ Stephen Jay Gould resümiert folgerichtig: „Ich würde lieber das ganze Unterfangen, Gruppen nach ihrem biologischen Wert einzuordnen, als das brandmarken, was es ist: als irrelevant, geistig unredlich und in höchstem Maße schädlich. “2331 In diesem Zusammenhang ist es auch realitätsfern, die Existenz von angeblich manifest vererbbaren Genen, wie des Konstrukts der sogenannten Intelligenz, zu behaupten: ,Gene-plus-Umwelt' heißt die heutige Forschungstheorie. Diesbezüglich steckt die molekular- und humangenetische Forschung jedoch noch in den Anfängen. Etabliert und verifiziert ist einzig die Tatsache, dass Intelligenz eine polygenetische Eigenschaft darstellt, demnach also nicht von einem einzigen Gen abhängig ist und ebenfalls nicht nach den Mendelschen Vererbungsregeln charakterisiert werden kann. ${ }^{2332}$ Das von Thilo Sarrazin wieder auf die gesellschaftliche Tagesordnung gesetzte sogenannte ,Juden-' bzw. ,Bevölkerungsgen' ist und bleibt demnach auch in Zukunft ein „Phantom-Gen“2333. Die von Sarrazin konstatierte Abwicklung der deutschen Bevölkerung aufgrund einer zunehmenden biologischen ,Überfremdung' wegen zu wenig „,...] richtige[r] Geburten [...]“2334 bleibt ebenfalls ein Hirngespinst, wie die bevölkerungsstatistischen Datenauswertungen bestätigen.

Die Diversifizierung und Multikulturalisierung der Bundesrepublik Deutschland wird und muss auch in Zukunft weiter zunehmen. ${ }^{2335}$ „Deutschland war schon immer ein Land voller Vielfalt." 2336 Grund und Ursache der prognostisch zunehmenden Migrationsbewegungen in Richtung der nordwestlichen Welt, Europa und Nordamerika wird zukünftig insbesondere die zunehmende Überbevölkerung der südlichen Kontinente sein. ${ }^{2337}$ Dies zeigt der stetige Flüchtlingsstrom aus den nordafrikanischen Staaten in die EU. Hinzu kommen Flüchtlinge aus Krisenstaaten, die als ausländische Facharbeiterinnen und Facharbeiter mit einem größtenteils hohen fachlichen Qualifikationsniveau willkommen sind, da von ihnen vor allem die deutsche Exportwirtschaft abhängig ist. ${ }^{2338}$ Für diese zukünftigen Entwicklungen ist jedoch auf EU-Ebene eine modernisierte Einwanderungs-, Asyl- und Migrationsgesetzgebung notwendig, die die zurzeit relativ hohen juristischen sowie bürokratischen Barrieren für die ordentliche Teilnahme am Arbeits-

\footnotetext{
2330 Vgl. Tautz 2012, a. a. O., S. $128 \mathrm{ff}$.

2331 Gould 1983, a. a. O., S. 112.

2332 Vgl. Tautz 2012, a. a. O., S. $127 \mathrm{ff}$.

Eindeutige, wissenschaftlich validierte Aussagen den Zusammenhang von Gen, Genfunktion und Vererbungsweg betreffend gibt es bisher nur bei wenigen Eigenschaften, beispielsweise bezüglich der Hautfarbe, der Laktoseintoleranz oder der Resisten zegen spezifische Krankheitserreger. Vgl. Tautz 2012, a. a. O., S. $129 \mathrm{ff}$.

2333 Tautz 2012, a. a. O., S. 130.

2334 Buchmann et al. 2011, a. a. O., S. 4-5.

2335 Vgl. Dettling, Daniel/Gerometta, Julia (2007): Einleitung, in: ebd. (Hrsg.): Vorteil Vielfalt. Herausforderungen und Perspektiven einer offenen Gesellschaft, Wiesbaden, S. 11. Böhmer, Maria (2007): Für eine Kultur der Vielfalt in Wirtschaft, Gesellschaft und Staat, in: Dettling, Daniel/Gerometta, Julia (Hrsg.): Vorteil Vielfalt. Herausforderungen und Perspektiven einer offenen Gesellschaft, Wiesbaden, S. 17.

2337 Vgl. Galtung 2009, a. a. O., S. 21. | Scholz 2014, a. a. O., S. $161 \mathrm{ff}$.

2338 Vgl. Kühne 2009, a. a. O., S. 257.
} 
markt erleichtern. ${ }^{2339}$ Genau diese Entwicklungen könnten jedoch die tendenziell rassistische Grundhaltung der bundesrepublikanischen Gesellschaft weiter verstärken - hier ist demnach eine politisch transparente Arbeit gefragt.

Die nachhaltige Verbreitung von biologisch-genetisch konnotierten, rassistischen Einstellungen, Vorurteilen und Ressentiments - trotz der wissenschaftlichen Falsifizierung der pseudobiologischen Theoreme - skizziert ein besorgniserregendes, wenn nicht gar gefährliches Zukunftsbild für die bundesrepublikanische Gesellschaft. ${ }^{2340}$ Die Kombination von sozial- und naturwissenschaftlicher Forschung vergegenwärtigt, dass die Biologie im Rahmen des rassistischen Ideologiekonzeptes - trotz falscher fachlicher Darstellungen - wieder deutlich erkennbar ist, was die in der Einleitung aufgestellte Forschungshypothese validiert: Rassistische Vorurteile zeigen sich insbesondere in biologisch-genetischer Ausprägung im Deutschland des 21. Jahrhunderts auf allen gesellschaftlichen Ebenen etabliert. ${ }^{2341}$ Der vordergründig kulturelle Anstrich dient lediglich als Tarnung biologischgenetischer Zusammenhänge, wie die qualitativen und quantitativen Datenmaterialien dieser Arbeit erkennen lassen. Folglich muss die von Peter Emil Becker in den 1990er Jahren geäußerte Zukunftsprognose aufgrund der ermittelten Untersuchungsergebnisse leider bestätigt werden: Auch die Erkenntnisse und Ergebnisse der neueren genetischen Forschung werden weiterhin von Seiten der rassistischen Ideologie absichtlich fehlinterpretiert, umgedeutet und missbraucht. ${ }^{2342}$ Der biologische Rassismustypus knüpft flexibel und anpassungsfähig immer wieder an weitere populistische und extremistische Strömungen an, wie der Rechtsextremismus der 1990er Jahre oder der Rechtspopulismus des 21. Jahrhunderts bestätigen. ${ }^{2343}$ Die biologistisch-rassistische Ideologie bleibt der theoretische Mittelpunkt abwertender, ausgrenzender sowie diskriminierender Praktiken und Verhaltensweisen. ${ }^{2344}$ Erschreckend dabei scheinen aus heutiger Perspektive die tiefen Wurzeln, die biologistisch-rassistische sowie partiell nationalsozialistische und eugenische Theoreme in der deutschen Gesellschaft aufweisen, wie diese Untersuchung vergegenwärtigt. ${ }^{2345}$ Hier kann keineswegs mehr von einem Randphänomen gesprochen werden, wie Politik und gesellschaftliche Eliten lange Zeit illustrieren wollten: Rassismus ist in biologistischer bzw. naturalisierender Konnotation wieder ein Bestandteil des Lebensalltages in der deutschen Gesellschaft. Gegenwärtig kann demnach eine neue „Salonfähigkeit“2346 des biologisch-genetisch begründeten Rassismus in Deutschland diagnostiziert werden. ${ }^{2347}$ Vor dem Hintergrund

2339

2340 Rassismus ist jedoch nicht nur in Deutschland, sondern in ganz Europa wieder weit etabliert (s. Kapitel 3). Vgl. Zick/Küpper/Hövermann 2011, a. a. O., S. 192ff.

2341 Vgl. Zick/Küpper/Hövermann 2011, a. a. O., S. 192.

2342 Vgl. Becker 1990, a. a. O., S. 618.

2343 Vgl. Jaschke 2006, a. a. O., S. $75 \mathrm{ff}$.

2344 Vgl. Krause-Vilmar 2006, a. a. O.

2345 Vgl. Becker 1990, a. a. O., S. 619.

2346 Robertson-von-Trotha 2011, a. a. O., S. 13.

2347 Vgl. Robertson-von-Trotha 2011, a. a. O., S. 13ff. 
dieses sozialwissenschaftlich-naturwissenschaftlichen Forschungskonzeptes bleibt abschließend mit Christian Delacampagne festzuhalten:

„[...] der Rassismus wird nicht dank der Fortschritte [...] der Biologie verschwinden, sondern nur dann, wenn die Menschbeit verstanden hat, dass er keine und zwar überhaupt keine adäquate Antwort auf die vielfältigen Herausforderungen darstellt, mit denen wir in unserer Gesellschaft konfrontiert werden. "2348 



\section{Literaturverzeichnis}

Ackerknecht, Erwin (1985): Kurze Geschichte der Psychiatrie, 3. Auflage, Stuttgart.

Agentur der Europäischen Union für Grundrechte (2010): Jahresbericht 2010. Konferenzausgabe, Wien.

Agentur der Europäischen Union für Grundrechte (2012): Die Richtlinie zur Gleichbehandlung ohne Unterschied der Rasse: Anwendung und Herausforderungen, Wien.

Ahlheim, Klaus (2011): Sarrazin und der Extremismus der Mitte. Empirische Analysen und pädagogische Reflexionen, Hannover.

Anthias, Floya (1992): Parameter kollektiver Identität: Ethnizität, Nationalismus und Rassismus, in: Institut für Migrations- und Rassismusforschung e. V. (Hrsg.): Rassismus und Migration in Europa. Beiträge des Kongresses „Migration und Rassismus in Europa“ Hamburg, 26. bis 30. September 1990, Hamburg, S. 88-103.

Appiah, Kwame Anthony (1990): Racisms, in: Goldberg, David Theo (Hrsg.): Anatomy of racism, Minneapolis, S. 3-17.

Arndt, Susan (2001a): AfrikaBilder. Studien zu Rassismus in Deutschland, Düsseldorf. 
Arndt, Susan (2001b): Impressionen. Rassismus und der deutsche Afrikadiskurs, in: ebd. (Hrsg.): AfrikaBilder. Studien zu Rassismus in Deutschland, Münster, S. 11-70.

Arndt, Susan (2001c): Vorbemerkung, in: ebd. (Hrsg.): AfrikaBilder. Studien zu Rassismus in Deutschland, Münster, S. 9-10.

Arndt, Susan (2011): Rassismus, in: Arndt, Susan/Ofuatey-Alazard, Nadja (Hrsg.): Wie Rassismus aus Wörtern spricht. (K)erben des Kolonialismus im Wissensarchiv deutsche Sprache. Ein kritisches Nachschlagewerk, Münster, S. 37-43.

Arndt, Susan/Ofuatey-Alazard, Nadja (2011a): Wie Rassismus aus Wörtern spricht. (K)erben des Kolonialismus im Wissensarchiv deutsche Sprache. Ein kritisches Nachschlagewerk, Münster.

Arndt, Susan/Ofuatey-Alazard, Nadja (2011b): Zum Geleit, in: ebd. (Hrsg.): Wie Rassismus aus Wörtern spricht. (K)erben des Kolonialismus im Wissensarchiv deutsche Sprache. Ein kritisches Nachschlagewerk, Münster, S. 11-17.

Asendorpf, Jens B. (2008): Verhaltensentwicklungsgenetik, in: Neyer, Franz J./Spinath, Frank M. (Hrsg.): Anlage und Umwelt. Neue Perspektiven der Verhaltensgenetik und Evolutionspsychologie, Stuttgart, S. 61-84.

Ayim, May (2001): Die afro-deutsche Minderheit, in: Arndt, Susan (Hrsg.): AfrikaBilder. Studien zu Rassismus in Deutschland, Münster, S. 71-86.

Bade, Klaus J. (1990): Die Einwanderungssituation: Erfahrungen - Probleme - Perspektiven, in: Beauftragte der Bundesregierung für die Integration der ausländischen Arbeitnehmer und ihrer Familienangehörigen (Hrsg.): Bericht '99. Zur Situation der ausländischen Arbeitnehmer und ihrer Familien - Bestandsaufnahme und Perspektiven für die 1990er Jahre, 2. Auflage, Bonn, S. 307-316.

Bade, Klaus J. (1992a): Einführung: Das Eigene und das Fremde - Grenzerfahrungen in Geschichte und Gegenwart, in: ebd. (Hrsg.): Deutsche im Ausland - Fremde in Deutschland. Migration in Geschichte und Gegenwart, München, S. 15-28.

Bade, Klaus J. (1992b): Einheimische Ausländer: ,Gastarbeiter ${ }^{\varsigma}$ - Dauergäste Einwanderer, in: ebd. (Hrsg.): Deutsche im Ausland - Fremde in Deutschland. Migration in Geschichte und Gegenwart, München, S. 393-400.

Bade, Klaus J. (2013): Kritik und Gewalt. Sarrazin-Debatte, ,Islamkritik` und Terror in der Einwanderungsgesellschaft, Schwalbach/Taunus.

Bailer, Brigitte (2004): Partei- statt Metapolitik. „Neue Rechte“ und FPÖ in Österreich, in: Gessenharter, Wolfgang/Pfeiffer, Thomas (Hrsg.): Die Neue Rechte - eine Gefahr für die Demokratie?, Wiesbaden, S. 163-174. 
Balibar, Étienne (1992): „Es gibt keinen Staat in Europa“. Rassismus und Politik im heutigen Europa, in: Institut für Migrations- und Rassismusforschung e. V. (Hrsg.): Rassismus und Migration in Europa. Beiträge des Kongresses „Migration und Rassismus und Europa“ Hamburg, 26. bis 30. September 1990, Hamburg, S. 10-30.

Balke, Friedrich/Habermas, Rebekka/Nanz, Patrizia/Sillem, Peter (1993): Vorwort, in: ebd. (Hrsg.): Schwierige Fremdheit. Über Integration und Ausgrenzung in Einwanderungsländern, Frankfurt/Main, S. VII-XII.

Banton, Michael (1987): Racial theories, Cambridge u. a.

Bartels, M./Rietveld, M. J. H./Van Baal, G. C. M./Boomsma, D. I. (2002): Genetic and Environmental Influences on the Development of Intelligence, in: Behavior Genetics, Vol. 32, No. 4, Heidelberg u. a., S. 237-249.

Barth, Boris (2010): „Rassismus“, in URL: http://www.ieg-ego.eu/de /threads/europa-und-die-welt/rassismus/boris-barth-rassismus $<23.09 .2012>$.

Barth, Fredrik (1998): Ethnic Groups and Boundaries. The Social Organization of Culture Difference, Long Grove/Illinois.

Bathke, Peter/Hoffstadt, Anke (2013): Die neuen Rechten in Europa. Zwischen Neoliberalismus und Rassismus, Köln.

Bayertz, Kurt (1982): Darwinismus als Ideologie, in: Bayertz, Kurt/Heidtmann, Bernhard/Rheinberger, Hans-Jörg (Hrsg.): Darwin und die Evolutionstheorie, Köln, S. 105-120.

Bayertz, Kurt/Heidtmann, Bernhard/Rheinberger, Hans-Jörg (1982): Editorial, in: ebd. (Hrsg.): Darwin und die Evolutionstheorie, Köln, S. 5-9.

Beck-Bornholdt, Hans-Peter/Dubben, Hans-Hermann (2008): Der Schein der Weisen. Irrtümer und Fehlurteile im täglichen Denken, 6. Auflage, Reinbek bei Hamburg.

Becker, Peter Emil (1990): Sozialdarwinismus, Rassismus, Antisemitismus und Völkischer Gedanke. Wege ins Dritte Reich. Teil II, Stuttgart u. a.

Behnke, Joachim/Baur, Nina/Behnke, Nathalie (2010): Empirische Methoden der Politikwissenschaft, 2. Auflage, Paderborn.

Behrens, Fritz (2004): Vorwort, in: Gessenharter, Wolfgang/Pfeiffer, Thomas (Hrsg.): Die Neue Rechte - eine Gefahr für die Demokratie?, Wiesbaden, S. $7-10$.

Bendel, Petra (2009): Die Migrationspolitik der Europäischen Union. Inhalte, Institutionen und Integrationsperspektiven, in: Butterwegge, Christoph/Hentges, Gudrun (Hrsg.): Zuwanderung im Zeichen der Globalisierung. Migrations-, Integrations- und Minderheitenpolitik, 4. Auflage, Wiesbaden, S. 123-135. 
Benedict, Ruth (1983): Race and racism, London.

Bensch, Margrit (2009): Rassismus als kulturelle Entwicklungstheorie. Formen biologischen Denkens im Sozialdarwinismus, Diss. Technische Universität, Berlin.

Bergmann, Werner (1993): Antisemitismus und Ausländerfeindlichkeit - Eine empirische Überprüfung ihres Zusammenhangs, in: Heßler, Manfred (Hrsg.): Zwischen Nationalstaat und multikultureller Gesellschaft. Einwanderung und Fremdenfeindlichkeit in der Bundesrepublik Deutschland, Berlin, S. 115-132.

Berliner Morgenpost (2013): „Deutsche sind gegen neue Hilfen für Griechenland“, in: http://www.morgenpost.de/politik/article111703137/Deutsche -sind-gegen-neue-Hilfen-fuer-Griechenland.html <12.08.2013>.

Betz, Hans-Georg (1998): Rechtspopulismus: Ein internationaler Trend?, in: Aus Politik und Zeitgeschichte, Beilage zur Wochenzeitung Das Parlament, 9-10/1998, Bonn, S. 3-12.

Betz, Oliver (2011): Artentstehung, natürliches Aussterben und anthropogene Krise der Biodiversität. Darwins Theorie aus heutiger evolutionsbiologischer Sicht, in: Engels, Eve-Marie/Betz, Oliver/Köhler, HeinzR./Potthast, Thomas (Hrsg.): Charles Darwin und seine Bedeutung für die Wissenschaften, Tübingen, S. 89-120.

Bielefeld, Uli (1991): Einleitung, in: ebd. (Hrsg.): Das Eigene und das Fremde. Neuer Rassismus in der alten Welt?, Hamburg, S. 9-22.

Birsl, Ursula (2002): Der Neoliberalismus in der politischen Mitte: ein gezähmter Rechtspopulismus?, in: Bojadžijev, Manuela/Demirović, Alex (Hrsg.): Konjunkturen des Rassismus, Münster, S. 30-49.

Bischoff, Joachim/Müller, Bernhard (2004a): Moderner Rechtspopulismus, in: Bischoff, Joachim/Dörre, Klaus/Gauthier, Elisabeth et al. (Hrsg.): Moderner Rechtspopulismus. Ursachen, Wirkungen, Gegenstrategien, Hamburg, S. 9-44.

Bischoff, Joachim/Müller, Bernhard (2004b): Stichwort: Rechtsextremismus Rechtspopulismus, in: Bischoff, Joachim/Dörre, Klaus/Gauthier, Elisabeth et al. (Hrsg.): Moderner Rechtspopulismus. Ursachen, Wirkungen, Gegenstrategien, Hamburg, S. 7-8.

Blohm, Michael (2011): „Allgemeine Informationen zum ALLBUS“, in URL: http://www.gesis.org/allbus/allgemeine-informationen/ <31.07.2011>.

Blohm, Michael/Wasmer, Martina (2008): Einstellungen und Kontakte zu Ausländern, in: Statistisches Bundesamt Destatis/Gesellschaft Sozialwissenschaftlicher Infrastruktureinrichtungen/Wissenschaftszentrum Berlin für Sozialforschung (Hrsg.): Datenreport 2008. Ein Sozialbericht für die Bundesrepublik Deutschland, Bonn, S. 208-214. 
Blohm, Michael/Wasmer, Martina (2011): Einstellungen und Kontakte zu Ausländern, in: Statistisches Bundesamt Destatis/Gesellschaft Sozialwissenschaftlicher Infrastruktureinrichtungen/Wissenschaftszentrum Berlin für Sozialforschung (Hrsg.): Datenreport 2011. Ein Sozialbericht für die Bundesrepublik Deutschland. Band I, Bonn, S. 200-206.

Bodmer, W. F./Cavalli-Sforza, Luigi Luca (1971): The Genetics of Human Populations, San Francisco.

Bodmer, W. F./Cavalli-Sforza, Luigi Luca (1976): Genetics, Evolution, and Man, San Francisco.

Böhmer, Maria (2007): Für eine Kultur der Vielfalt in Wirtschaft, Gesellschaft und Staat, in: Dettling, Daniel/Gerometta, Julia (Hrsg.): Vorteil Vielfalt. Herausforderungen und Perspektiven einer offenen Gesellschaft, Wiesbaden, S. 17-21.

Bojadžijev, Manuela (2008): Die windige Internationale. Rassismus und Kämpfe der Migration, Münster.

Bojadžijev, Manuela/Demirović, Alex (2002): Vorwort, in: ebd. (Hrsg.): Konjunkturen des Rassismus, Münster, S. 7-29.

Borchers, Kevin/Breustedt Wiebke (2008): Die Datenlage im Bereich der internationalen Migration. Europa und seine Nachbarregionen, Working Paper 18, Nürnberg.

Bosch, Karl (2002): Statistik. Wahrheit und Lüge, München u. a.

Boutang, Yann Moulier (1997): Die Europäische Union als Einwanderungsregion: Probleme und Perspektiven, in: Weber, Albrecht (Hrsg.): Einwanderungsland Bundesrepublik Deutschland in der Europäischen Union, Osnabrück, S. 45-62.

Bräuer, Günter (2004): Das Out-of-Africa-Modell und die Kontroverse um den Ursprung des modernen Menschen, in: Conard, Nicholas (Hrsg.): Woher kommt der Mensch?, Tübingen, S. 164-187.

Brauner, Detlef Jürgen/Vollmer, Hans-Ulrich (2006): Erfolgreiches wissenschaftliches Arbeiten. Seminararbeit. Diplomarbeit. Doktorarbeit, Sternenfels.

Briseno, Cinthia (2010): „Wir sind alle ein bisschen Neandertaler“, in URL: http://www.spiegel.de/wissenschaft/mensch/erbgut-entschluesselt-wirsind-alle-ein-bisschen-neandertaler-a-692855.html <01.08.2012>.

Brodde, Kirsten (1992): „Ahnensuche in Sprachen und Genen. Von Afrika aus wurden zunächst Asien und dann die übrigen Kontinente besiedelt", in URL: http://www.zeit.de/1992/02/ahnensuche-in-sprachen-undgenen <23.07.2012>. 
Broszinsky-Schwabe, Edith (1990): Die DDR-Bürger im Umgang mit „Fremden“ - Versuch einer Bilanz der Voraussetzungen für eine Leben in einer multikulturellen Welt, in: Kleff, Sanem/Broszinsky-Schwabe, Edith/Albert, Marie-T./Marburger, Helga/Karsten, Marie E. (Hrsg.): BRD - DDR. Alte und neue Rassismen im Zuge der deutsch-deutschen Einigung, Frankfurt/Main, S. 18-44.

Brumlik, Micha (1990): Die Entwicklung der Begriffe „Rasse“, „Kultur“ und „Ethnizität“ im sozialwissenschaftlichen Diskurs, in: Dittrich, Eckhard J./Radtke, Frank-Olaf (Hrsg.): Ethnizität. Wissenschaft und Minderheiten, Opladen, S. 179-190.

Buchmann, Jonas/Buchmann, Konstantin/Diehl, Marisa/Donnerstag, Lucas/Gerke, Anna-Lena/Haase, Léon/Mußler, Marie/Neumann, Holly Ann/Privitera, Daniel/Siech, Carolin/Wenz, Sebastian (2011): „Sind Deutsche klüger als Türken?“, in: Frankfurter Neue Presse, 66. Jahrgang Nr. 223, 24.11.2011, S. 4-5.

Bukow, Wolf-Dietrich (1992): Ethnisierung und nationale Identität, in: Institut für Migrations- und Rassismusforschung e. V. (Hrsg.): Rassismus und Migration in Europa. Beiträge des Kongresses „Migration und Rassismus in Europa“ Hamburg, 26. bis 30. September 1990, Hamburg, S. 133-146.

Bullion, Constanze von (2010): Am warmen Ofen der Völkerfreundschaft, in: Deutschlandstiftung Integration (Hrsg.): Sarrazin. Eine deutsche Debatte, München, S. 14-15.

Bundesministerium des Innern (2012): Verfassungsschutzbericht 2011. Vorabfassung, Berlin.

Bundeszentrale für politische Bildung (2008): Vertrag von Lissabon. Mit einer Einführung von Elmar Brok und Jo Leinen, Bonn.

Bundeszentrale für politische Bildung (2011): Grundgesetz für die Bundesrepublik Deutschland, Bonn.

Bundeszentrale für politische Bildung (2013): „Parteiprofile. Wer steht zur Wahl“, in URL: http://www.bpb.de/politik/wahlen/wer-steht-zur-wahl/ $<04.07 .2013>$.

Buntenbach, Annelie (2001): Blicke auf Asylpolitik und Antidiskriminierungsgesetz - was tun gegen Rechtsextremismus und Rassismus, in: Arndt, Susan (Hrsg.): AfrikaBilder. Studien zu Rassismus in Deutschland, Münster, S. 405-419.

Buselmaier, Werner/Tariverdian, Gholamali (2007): Humangenetik, 4. Auflage, Heidelberg.

Bussink-Becking, Elke Marie (2013): Identitäten in Bewegung. Ausländische Adoptierte, Rassismus und hybride kulturelle Identität. Eine biographieanalytische Studie, Diss. Universität Göttingen, Göttingen. 
Butcher, Lee M./Kennedy, Joanna K. J./Plomin, Robert (2006): Generalist genes and cognitive neuroscience, in: Current Opinion in Neurobiology, 16, München u. a., S. 145-151.

Butterwegge, Christoph (1993): Der Funktionswandel des Rassismus und die Erfolge des Rechtsextremismus, in: Butterwegge, Christoph/Jäger, Siegfried (Hrsg.): Rassismus in Europa, 2. Auflage, Köln, S. 181-199.

Butterwegge, Christoph (2001): Rassismus und Rechtsextremismus im Zeichen der Globalisierung, in: Arndt, Susan (Hrsg.): AfrikaBilder. Studien zu Rassismus in Deutschland, Münster, S. 102-122.

Butterwegge, Christoph (2013): Sarrazynismus. Eine Katastrophe für die politische Kultur der Bundesrepublik und eine Gefahr für die Demokratie, in: Bathke, Peter/Hoffstadt, Anke (Hrsg.): Die neuen Rechten in Europa. Zwischen Neoliberalismus und Rassismus, Köln, S. 206-219.

Butterwegge, Christoph/Jäger, Siegfried (1993): Einleitung, in: ebd. (Hrsg.): Rassismus in Europa, 2. Auflage, Köln, S. 13-18.

Callaway, Ewen (2012): Economics and genetics meet in uneasy union, in: Nature, Vol. 490, London u. a., S. 154-155.

Carroll, Sean B. (2003): Genetics and the making of Homo sapiens, in: Nature, Vol. 422, London u. a., S. 849-857.

Castles, Stephen (1991): Weltweite Arbeitsmigration, Neorassismus und der Niedergang des Nationalstaats, in: Bielefeld, Uli (Hrsg.): Das Eigene und das Fremde. Neuer Rassismus in der Alten Welt?, Hamburg, S. 129-158.

Cavalli-Sforza, Luigi Luca (1995): Stammbäume von Völkern und Sprachen, in: Streit, Bruno (Hrsg.): Evolution des Menschen, Heidelberg u. a., S. $118-125$.

Cavalli-Sforza, Luigi Luca (1999): Gene, Völker und Sprachen. Die biologischen Grundlagen unserer Zivilisation, Darmstadt.

Cavalli-Sforza, Luigi Luca/Cavalli-Sforza, Francesco (1994): Verschieden und doch gleich. Ein Genetiker entzieht dem Rassismus die Grundlage, München.

Cavalli-Sforza, Luigi Luca/Menozzi, Paolo/Piazza, Alberto (1994): The History and Geography of Human Genes, Princeton u. a.

Cho, Mildred K./Sankar, Pamela (2004): Forensic genetics and ethical, legal and social implications beyond the clinic, in: Nature Genetics. Genetics for the human race, Vol. 36 Nr. 11, Nov. 2004, London u. a., S. 8-12.

Christen, Christian (2002): Italiens Regierung zwischen autoritärem Neoliberalismus und modernem Rechtsextremismus, in: Bojadžijev, Manuela/Demirović, Alex (Hrsg.): Konjunkturen des Rassismus, Münster, S. $112-135$. 
Claussen, Detlev (1994): Was heißt Rassismus?, Darmstadt.

Cohen, Philip (1994): Gefährliche Erbschaften: Studien zur Entstehung einer multirassistischen Kultur in Großbritannien, in: Kalpaka, Annita/Räthzel, Nora (Hrsg.): Die Schwierigkeit, nicht rassistisch zu sein. Rassismus in Politik, Kultur und Alltag, Köln, S. 81-143.

Collins, Francis S. (2004): What we do and don't know about ,race', ,ethnicity', genetics and health at the dawn of the genome era, in: Nature Genetics. Genetics for the human race, Vol. 36 Nr. 11, Nov. 2004, London u. a., S. 13-15.

Committee on the Elimination of Racial Discrimination (2013): „Communication No. 48/2010. Opinion adopted by the Committee at its eighty second (11 February to 8 March 2013)“, in URL: http://www2.ohchr.org/ English/bodies/cerd/docs/CERD-C-82-D-48-2010-English.pdf $<07.07 .2013>$.

Dambeck, Holger (2013): „Human Brain Project. Der Gehirn-Simulator von Jülich“, in URL: http://www.spiegel.de/wissenschaft/mensch/gehirnsimulation-neuronen-statt-neutronen-a-903567.html <09.07.2013>.

Darwin, Charles (2000): Über die Entstehung der Arten durch natürliche Zuchtwahl oder die Erhaltung der begünstigten Rassen im Kampfe um's Dasein, Köln.

Darwin, Charles (2002): Die Abstammung des Menschen, Stuttgart.

Deary, Ian J./Soinath, Frank M./Bates, Timothy C. (2006): Genetics of Intelligence, in: European Journal of Human Genetics, 14, London u. a., S. 690-700.

Decker, Frank (2006): Die populistische Herausforderung. Theoretische und länderübergreifende Perspektiven, in: ebd. (Hrsg.): Populismus in Europa. Gefahr für die Demokratie oder nützliches Korrektiv?, Bonn, S. 9-32.

Decker, Oliver/Brähler, Elmar (2006): Vom Rand zur Mitte. Rechtsextreme Einstellungen und ihre Einflussfaktoren in Deutschland, Berlin.

Decker, Oliver/Kiess, Johannes/Brähler, Elmar (2012): Die Mitte im Umbruch. Rechtsextreme Einstellungen in Deutschland 2012, Bonn.

Decker, Oliver/Rothe, Katharina/Weissmann, Marliese/Geißler, Norman/Brähler, Elmar (2008): Ein Blick in die Mitte. Zur Entstehung rechtsextremer und demokratischer Einstellungen in Deutschland, Berlin.

Decker, Oliver/Weißmann, Marliese/Kiess, Johannes/Brähler, Elmar (2010): Die Mitte in der Krise. Rechtsextreme Einstellungen in Deutschland 2010, Berlin.

Delacampagne, Christian (2005): Die Geschichte des Rassismus, Düsseldorf u. a. 
Demirović, Alex (1992a): Vom Vorurteil zum Neorassismus. Das Objekt ,Rassismus' in Ideologiekritik und Ideologietheorie, in: Jäger, Siegfried/Januschek, Franz (Hrsg.): Der Diskurs des Rassismus. Ergebnisse des DISS-Kolloquiums November 1991, Osnabrück, S. 13-36.

Demirović, Alex (1992b): Vom Vorurteil zum Neorassismus. Das Objekt „Rassismus“ in Ideologiekritik und Ideologietheorie, in: Institut für Sozialforschung (Hrsg.): Aspekte der Fremdenfeindlichkeit. Beiträge zur aktuellen Diskussion, Frankfurt/Main u. a., S. 21-54.

Demirović, Alex (1992c): Vom Vorurteil zum Neorassismus. Das Objekt ,Rassismus' in Ideologiekritik und Ideologietheorie, in: Redaktion diskurs (Hrsg.): Die freundliche Zivilgesellschaft. Rassismus und Nationalismus in Deutschland, Berlin, S. 73-94.

Dernbach, Andrea (2013): „Bundesregierung antwortet auf Sarrazin-Kritik der UN", in URL: http://www.zeit.de/politik/deutschland/2013-07/sarrazinun-bundesregierung $<23.07 .2013>$.

Dettling, Daniel/Gerometta, Julia (2007): Einleitung, in: ebd. (Hrsg.): Vorteil Vielfalt. Herausforderungen und Perspektiven einer offenen Gesellschaft, Wiesbaden, S. 11-14.

Dettmar, Erika (1987): Rassismus, Vorurteile, Kommunikation. Afrikanischeuropäische Begegnung in Hamburg, Berlin u. a.

Deutsche UNESCO-Kommission e. V. (1980): „Über ,Rassen“ und rassistische Vorurteile“, in URL: http://www.unesco.de/erklaerung_rassist_ vorurteile.html $<24.07 .2012>$.

Deutscher Taschenbuch Verlag (2010): Bürgerliches Gesetzbuch, 66. Auflage, München.

Devlin, B./Daniels, Michael/Roeder, Kathryn (1997): The heritability of IQ, in: Nature, Vol. 388, London u. a., S. 468-471.

Dijk, Teun A. van (1991): Rassismus heute: Der Diskurs der Elite und seine Funktion für die Reproduktion des Rassismus, 2. Auflage, Duisburg.

Dijk, Teun A. van (1992a): Der Diskurs der Elite und seine Funktion für die Reproduktion des Rassismus, in: Institut für Migrations- und Rassismusforschung e. V. (Hrsg.): Rassismus und Migration in Europa. Beiträge des Kongresses „Migration und Rassismus in Europa“ Hamburg, 26. bis 30. September 1990, Hamburg, S. 289-313.

Dijk, Teun A. van (1992b): Rassismus-Leugnung im Diskurs, in: Jäger, Siegfried/Januschek, Franz (Hrsg.): Der Diskurs des Rassismus. Ergebnisse des DISS-Kolloquiums November 1991, Osnabrück, S. 103-129.

Dijk, Teun A. van (1993): Subtiler Rassismus in westlichen Parlamenten, in: Butterwegge, Christoph/Jäger, Siegfried (Hrsg.): Rassismus in Europa, 2. Auflage, Köln, S. 200-212. 
Dittrich, Eckhard J./Radtke, Frank-Olaf (1990): Der Beitrag der Wissenschaften zur Konstruktion ethnischer Minderheiten, in: ebd. (Hrsg.): Ethnizität. Wissenschaft und Minderheiten, Opladen, S. 11-42.

Dobzhansky, Theodosius (1962): Dynamik der menschlichen Evolution. Gene und Umwelt, Hamburg.

Dobzhansky, Theodosius (1973): Intelligenz, Vererbung und Umwelt. Die Antwort der Wissenschaft im Streit um vererbte und erworbene Intelligenz, München.

Drechsler, Hanno/Hilligen, Wolfgang/Neumann, Franz (2003): Art. „Rasse/Rassismus", in: ebd. (Hrsg.): Gesellschaft und Staat. Lexikon der Politik, 10. Auflage, München, S. 802-803.

Dubben, Hans-Hermann/Beck-Bornholdt, Hans-Peter (2007): Der Hund, der Eier legt. Erkennen von Fehlinformationen durch Querdenken, 2. Auflage, Reinbek bei Hamburg.

Dunn, Judy/Plomin, Robert (1996): Warum Geschwister so verschieden sind, Stuttgart.

Dunn, Leslie Clarence/Dobzhansky, Theodosius (1970): Vererbung, Rasse und Gesellschaft, Frankfurt/Main.

Elfferding, Wieland (1989): Funktion und Struktur des Rassismus. Eine Theorieskizze, in: Autrata, Otger/Kaschuba, Gerrit/Leiprecht, Rudolf (Hrsg.): Theorien über Rassismus. Eine Tübinger Veranstaltungsreihe, 3. Auflage, Hamburg, S. 101-112.

Elitz, Ernst (2010): Abregen, anpacken, in: Deutschlandstiftung Integration (Hrsg.): Sarrazin. Eine deutsche Debatte, München, S. 49.

Elsner, Eva-Maria/Elsner, Lothar (1993): Ausländerpolitik und Ausländerfeindlichkeit in der DDR, in: Heßler, Manfred (Hrsg.): Zwischen Nationalstaat und multikultureller Gesellschaft. Einwanderung und Fremdenfeindlichkeit in der Bundesrepublik Deutschland, Berlin, S. 185-210.

Engels, Eve-Marie/Betz, Oliver/Köhler, Heinz-R./Potthast, Thomas (2011): Charles Darwin und seine Bedeutung für die Wissenschaften - Eine Einführung in: ebd. (Hrsg.): Charles Darwin und seine Bedeutung für die Wissenschaften, Tübingen, S. 9-26.

Etzemüller, Thomas (2012): Die Angst vor dem Abstieg - Malthus, Burgdörfer, Sarrazin: eine Ahnenreihe mit immer derselben Botschaft, in: Haller, Michael/Niggeschmidt, Martin (Hrsg.): Der Mythos vom Niedergang der Intelligenz. Von Galton zu Sarrazin: Die Denkmuster und Denkfehler der Eugenik, Wiesbaden, S. 157-184.

Euler, Harald A./Hoier, Sabine (2008): Die evolutionäre Psychologie von Anlage und Umwelt, in: Neyer, Franz J./Spinath, Frank M. (Hrsg.): Anla- 
ge und Umwelt. Neue Perspektiven der Verhaltensgenetik und Evolutionspsychologie, Stuttgart, S. 1-26.

Fanizadeh, Andreas (1992): Die multikulturellen Freunde und ihre Gesellschaft. Von der harten Flohmarktschule, in: Redaktion diskurs (Hrsg.): Die freundliche Zivilgesellschaft. Rassismus und Nationalismus in Deutschland, Berlin u. a., S. 13-24.

Farin, Klaus/Seidel-Pielen, Eberhard (1992): Rechtsruck. Rassismus im neuen Deutschland, 3. Auflage, Berlin.

Feustel, Rudolf (1990): Abstammungsgeschichte des Menschen, 6. Auflage, Jena.

Finkelstein, Kerstin E. (2006): Eingewandert. Deutschlands „Parallelgesellschaften", Bonn.

Finzsch, Norbert (1999): Wissenschaftlicher Rassismus in den Vereinigten Staaten - 1850 bis 1930, in: Kaupen-Haas, Heidrun/Saller, Christian (Hrsg.): Wissenschaftlicher Rassismus. Analysen einer Kontinuität in den Human- und Naturwissenschaften, Frankfurt/Main u. a., S. 84-110.

Flick, Uwe (2009): Sozialforschung. Methoden und Anwendungen. Ein Überblick für die BA-Studiengänge, Reinbek bei Hamburg.

Frankenberg, Günter (1992): Drinnen vor der Tür. Stichworte zur Asyldebatte, in: Institut für Sozialforschung (Hrsg.): Aspekte der Fremdenfeindlichkeit. Beiträge zur aktuellen Diskussion, Frankfurt/Main u. a., S. 91-100.

Franz, Fritz (1993): Schleusen und Schranken der Einwanderung nach Deutschland, in: Heßler, Manfred (Hrsg.): Zwischen Nationalstaat und multikultureller Gesellschaft. Einwanderung und Fremdenfeindlichkeit in der Bundesrepublik Deutschland, Berlin, S. 67-90.

Freyberg, Thomas von (1992): Anmerkungen zur aktuellen Welle von Fremdenhass, in: Institut für Sozialforschung (Hrsg.): Aspekte der Fremdenfeindlichkeit. Beiträge zur aktuellen Diskussion, Frankfurt/Main u. a., S. 71-90.

Fröchling, Helmut (1994): Sozialwissenschaftliche Erklärungsansätze für fremdenfeindliche Einstellungen und Handlungen, in: Knortz, Heike (Hrsg.): Fremdenfeindlichkeit in Deutschland. Ein interdisziplinärer Diskussionsbeitrag, Frankfurt/Main u. a., S. 81-100.

Funcke, Liselotte (1993): Konzept für eine zusammenhängende Migrationsund Integrationspolitik, in: Heßler, Manfred (Hrsg.): Zwischen Nationalstaat und multikultureller Gesellschaft. Einwanderung und Fremdenfeindlichkeit in der Bundesrepublik Deutschland, Berlin, S. 21-28.

Gage, Nathaniel L./Berliner, David C. (1996): Pädagogische Psychologie, 5. Auflage, Weinheim. 
Galtung, Johan (2009): Globale Migration, in: Butterwegge, Christoph/Hentges, Gudrun (Hrsg.): Zuwanderung im Zeichen der Globalisierung. Migrations-, Integrations- und Minderheitenpolitik, 4. Auflage, Wiesbaden, S. 11-22.

Ganßloser, Dagmar (1992): „Wir riefen Arbeitskräfte, es kamen Menschen“. Migrationspolitik und verschärftes Ausländergesetz in der BRD, Berlin u. a.

Gee, Henry (2014): The human puzzle, in: Nature, Vol. 506, London u. a., S. 30-31.

Gehrs, Oliver (2012): Fremdenfeindlichkeit ist die Einstiegsdroge, in: fluter. Magazin der Bundeszentrale für politische Bildung, Frühling 2012/Nr. 42, Bonn, S. 5-9.

Geiger, Klaus (1992): Nationalistische und postnationalistische Diskurse im Verteilungskampf der Bundesrepublik Deutschland, in: Institut für Migrations- und Rassismusforschung e. V. (Hrsg.): Rassismus und Migration in Europa. Beiträge des Kongresses „Migration und Rassismus in Europa“ Hamburg, 26. bis 30. September 1990, Hamburg, S. 273-288.

Geiss, Imanuel (1988): Geschichte des Rassismus, Frankfurt/Main.

Gerhard, Ute (1993): „Fluten“, „Ströme“, „Invasionen“ - Mediendiskurs und Rassismus, in: Heßler, Manfred (Hrsg.): Zwischen Nationalstaat und multikultureller Gesellschaft. Einwanderung und Fremdenfeindlichkeit in der Bundesrepublik Deutschland, Berlin, S. 239-254.

GESIS Leibniz-Institut für Sozialwissenschaften (2011): „Supplement zur Fragebogendokumentation ALLBUS 2010", in URL: Anforderung via http://www.gesis.org/allbus (Originaldatensatz, <30.07.2011>).

GESIS Leibniz-Institut für Sozialwissenschaften (2013): „Supplement zum Variable Report ALLBUS 2012. Nach Geschlecht getrennte Auszählungen. Studien-Nr. 4614, Version: 1.1.0, doi: 10.4232/1.11634“, in URL: Anforderung via http://www.gesis.org/allbus (Originaldatensatz, <26.05. 2013>).

Gessenharter, Wolfgang/Pfeiffer, Thomas (Hrsg.): Die Neue Rechte - eine Gefahr für die Demokratie?, Wiesbaden.

Geulen, Christian (2007): Geschichte des Rassismus, Bonn.

Geyer, Oliver (2012): Du Grammatik-Hitler, in: fluter. Magazin der Bundeszentrale für politische Bildung, Frühling 2012/Nr. 42, Bonn, S. 16-17.

Gilman, Sander L. (2012): Sind Juden genetisch anders?, in: Haller, Michael/Niggeschmidt, Martin (Hrsg.): Der Mythos vom Niedergang der Intelligenz. Von Galton zu Sarrazin: Die Denkmuster und Denkfehler der Eugenik, Wiesbaden, S. 71-86. 
Glanninger, Peter (2009): Rassismus und Rechtsextremismus. Rassistische Argumentationsmuster und ihre historischen Entwicklungslinien, Frankfurt/Main u. a.

Goldberg, David Theo (1990): Anatomy of racism, Minneapolis.

Gould, Jay Stephen (1983): Der falsch vermessene Mensch, Basel u. a.

Grabowski, Joachim (2007): Atkinsons und Hilgards Einführung in die Psychologie, 14. Auflage, Berlin u. a.

Grau, Andreas/Heitmeyer, Wilhelm (2013): Menschenfeindlichkeit in Städten und Gemeinden, Bielefeld.

Graw, Jochen (2010): Genetik, 5. Auflage, Heidelberg u. a.

Grobecker, Claire/Krack-Rohberg, Elle (2008): Bevölkerungsstand und Bevölkerungsentwicklung, in: Statistisches Bundesamt Destatis/Gesellschaft Sozialwissenschaftlicher Infrastruktureinrichtungen/Wissenschaftszentrum Berlin für Sozialforschung (Hrsg.): Datenreport 2008. Ein Sozialbericht für die Bundesrepublik Deutschland, Bonn, S. 11-26.

Groenendijk, Kees (1992): Europa 1992: Realitäten, Mythen und Chancen, in: Institut für Migrations- und Rassismusforschung e. V. (Hrsg.): Rassismus und Migration in Europa. Beiträge des Kongresses „Migration und Rassismus in Europa" Hamburg, 26. bis 30. September 1990, Hamburg, S. 515-528.

Grolle, Johann (2011): „Rivalen um die Weltherrschaft“, in URL: http://www.spiegel.de/spiegel/a-784530.html <01.08.2012>.

Groß, Eva/Zick, Andreas/Krause, Daniela (2012): Von der Ungleichwertigkeit zur Ungleichheit: Gruppenbezogene Menschenfeindlichkeit, in: Aus Politik und Zeitgeschichte, Beilage zur Wochenzeitung Das Parlament, 1617/2012, 62. Jahrgang, Bonn, S. 11-18.

Grupe, Gisela/Christiansen, Kerrin/Schröder, Inge/Wittwer-Backofen, Ursula (2005): Anthropologie. Ein einführendes Lehrbuch, Berlin u. a.

Guillaumin, Colette (1991): Rasse. Das Wort und die Vorstellung, in: Bielefeld, Uli (Hrsg.): Das Eigene und das Fremde. Neuer Rassismus in der Alten Welt?, Hamburg, S. 159-174.

Guillaumin, Colette (1992): Zur Bedeutung des Begriffs „Rasse“, in: Institut für Migrations- und Rassismusforschung e. V. (Hrsg.): Rassismus und Migration in Europa. Beiträge des Kongresses „Migration und Rassismus in Europa“ Hamburg, 26. bis 30. September 1990, Hamburg, S. 77-87.

Haller, Michael/Niggeschmidt, Martin (2012): Einführung, in: ebd. (Hrsg.): Der Mythos vom Niedergang der Intelligenz. Von Galton zu Sarrazin: Die Denkmuster und Denkfehler der Eugenik, Wiesbaden, S. 7-18. 
Hallgrímsson, Benedikt/Hall, Brain Keith (2011): Epigenetics: The Context of Development, in: ebd. (Hrsg.): Epigenetics: Linking Genotype and Phenotype in Development and Evolution, Berkeley u. a., S. 424-438.

Hallgrímsson, Benedikt/Hall, Brain Keith (2011): Introduction, in: ebd. (Hrsg.): Epigenetics: Linking Genotype and Phenotype in Development and Evolution, Berkeley u. a., S. 1-8.

Hebel, Stephan (2010): Der Ruf des Rattenfängers, in: Deutschlandstiftung Integration (Hrsg.): Sarrazin. Eine deutsche Debatte, München, S. 69-71.

Hecking, Claus (2013): „Britische Geheimprotokolle. Kohl wollte offenbar jeden zweiten Türken loswerden“, in URL: http://www.spiegel .de/politik/deutschland/kohl-wollte-jeden-zweiten-tuerken-in-deutsch land-loswerden-a-914318.html <03.08.2013>.

Heinrichs, Hans-Jürgen (1993): Von Fluten, Wellen und Strömen, in: Nirumand, Bahman (Hrsg.): Angst vor den Deutschen. Terror gegen Ausländer und der Zerfall des Rechtsstaates, Reinbek bei Hamburg, S. 28-51.

Heitmeyer, Wilhelm/Zick, Andreas/Groß, Eva/Krause, Daniela/Küpper, Beate/Klein, Anna/Mansel, Jürgen (2012): „Das Projekt Gruppenbezogene Menschenfeindlichkeit in Deutschland. Eine 10-jährige Langszeituntersuchung mit einer fährlichen Bevölkerungsumfragezur Abwertung und Ausgrenzung von schwachen Gruppen“, in URL: http://www.unibielefeld.de/\%28de\%29/ikg/projekte/GMF/index.htm <01.08.2013>.

Henke, Winfried (2004): Evolution und Verbreitung des Genus Homo. Aktuelle Befunde aus evolutionsökologischer Sicht, in: Conard, Nicholas (Hrsg.): Woher kommt der Mensch?, Tübingen, S. 98-135.

Henke, Winfried/Rothe, Hartmut (1999): Stammesgeschichte des Menschen, Berlin u. a.

Herbert, Ulrich (2003): Geschichte der Ausländerpolitik in Deutschland, München.

Herrnstein, Richard J./Murray, Charles (1996): The Bell Curve. Intelligence and Class Structure in American Life, New York u. a.

Heschl, Adolf (1998): Das intelligente Genom. Über die Entstehung des menschlichen Geistes durch Mutation und Selektion, Berlin u. a.

Heßler, Manfred (1993a): Ausländerbeschäftigung, Ausländerpolitik und Einstellungswandel, in: ebd. (Hrsg.): Zwischen Nationalstaat und multikultureller Gesellschaft. Einwanderung und Fremdenfeindlichkeit in der Bundesrepublik Deutschland, Berlin, S. 133-168.

Heßler, Manfred (1993b): Einleitung, in: ebd. (Hrsg.): Zwischen Nationalstaat und multikultureller Gesellschaft. Einwanderung und Fremdenfeindlichkeit in der Bundesrepublik Deutschland, Berlin, S. 7-20. 
Higham, Tom/Compton, Tim/Stringer, Chris/Jacobi, Roger/Shapiro, Beth/Trinkaus, Erik/Chandler, Barry/Gröning, Flora/Collins, Chris/ Hillson, Simon/O’Higgins, Paul/FitzGerald, Charles/Fagan, Michael (2011): The earliest evidence for anatomically modern humans in northwestern Europe, in: Nature, Vol. 479, London u. a., S. 521-524.

Hoffmann, Lutz (1993): Nationalstaat, Einwanderung und „Ausländerfeindlichkeit, in: Heßler, Manfred (Hrsg.): Zwischen Nationalstaat und multikultureller Gesellschaft. Einwanderung und Fremdenfeindlichkeit in der Bundesrepublik Deutschland, Berlin, S. 29-52.

Höhler, Gerd (2011): „Der Euro entzweit Deutsche und Griechen. Ende einer Freundschaft", in URL: http://www.fr-online.de/schuldenkrise/der-euroentzweit-deutsche-und-griechen--ende-einer-freundschaft,1471908,85837 08.html <12.08.2013>.

Hong, Eun-Young (2011): Rassismus als Problem kritischer Bildung. Widersprüche von Aufklärung, Solidarität und Vielfalt, Diss. Pädagogische Hochschule, Karlsruhe.

Human Brain Project (2013): „The Human Brain Project. Vision“, in URL: http://www.humanbrainproject.eu/vision.html <09.07.2013>.

Hund, Wulf D. (2007): Rassismus, Bielefeld.

Huntington, Samuel P. (2007): Kampf der Kulturen. Die Neugestaltung der Weltpolitik im 21. Jahrhundert, Hamburg.

Institut für Sozialforschung (1992): Fremdenfeindlichkeit im vereinigten Deutschland. Memorandum, in: ebd. (Hrsg.): Aspekte der Fremdenfeindlichkeit. Beiträge zur aktuellen Diskussion, Frankfurt/Main u. a., S. 9-20.

Jäger, Margret (1993): BrandSätze und SchlagZeilen. Rassismus in den Medien, in: Friedrich-Ebert-Stiftung (Hrsg.): Entstehung von Fremdenfeindlichkeit. Die Verantwortung von Politik und Medien, Bonn, S. 73-100.

Jäger, Margret/Jäger, Siegfried (2000): Rassistische Alltagsdiskurse, in: Räthzel, Nora (Hrsg.): Theorien über Rassismus, Hamburg, S. 278-291.

Jäger, Siegfried (1992a): Alltäglicher Rassismus in Deutschland. Erste Ergebnisse einer diskursanalytischen Studie, in: Jäger, Siegfried/Januschek, Franz (Hrsg.): Der Diskurs des Rassismus. Ergebnisse des DISSKolloquiums November 1991, Osnabrück, S. 130-147.

Jäger, Siegfried (1992b): BrandSätze. Rassismus im Alltag, Duisburg.

Jäger, Siegfried (1993): Rassismus und Rechtsextremismus - Gefahr für die Demokratie, in: Friedrich-Ebert-Stiftung (Hrsg.): Entstehung von Fremdenfeindlichkeit. Die Verantwortung von Politik und Medien, Bonn, S. 7-34. 
Jäger, Siegfried (2001): Rassismus und Rechtsextremismus in der deutschen Sprache. Einige Überlegungen zur Berichterstattung über Rassismus und Rechtsextremismus aus diskursanalytischer Sicht, in: Arndt, Susan (Hrsg.): AfrikaBilder. Studien zu Rassismus in Deutschland, Münster, S. 123-142.

Jäger, Siegfried/Jäger, Margarete (2002): Das Dispositiv des Institutionellen Rassismus. Eine diskurstheoretische Annäherung, in: Bojadžijev, Manuela/Demirović, Alex (Hrsg.): Konjunkturen des Rassismus, Münster, S. 212-225.

Jäger, Siegfried/Januschek, Franz (1992): Einleitung: ,Der Diskurs des Rassismus', in: ebd. (Hrsg.): Der Diskurs des Rassismus. Ergebnisse des DISS-Kolloquiums November 1991, Osnabrück, S. 5-12.

Janich, Peter (2010): Der Mensch und andere Tiere. Das zweideutige Erbe Darwins, Berlin.

Janning, Wilfried/Knust, Elisabeth (2008): Genetik. Allgemeine Genetik Molekulare Genetik - Entwicklungsgenetik, 2. Auflage, Stuttgart u. a.

Jaschke, Hans-Gerd (2006): Politischer Extremismus, Wiesbaden.

Jörges, Hans-Ulrich (2010): Ein Ungeheuer wird freigesetzt, in: Deutschlandstiftung Integration (Hrsg.): Sarrazin. Eine deutsche Debatte, München, S. 154-156.

Junker Verlag GmbH (2014): „Gratis Malvorlage Erde - Weltkarte“, in URL: http://arbeitsblaetter-kindergarten.de/component/content/article/81ausmalbilder-texte/90-gratis-malvorlage-erde-weltkarte $<01.07 .2014>$.

Junker, Thomas (2011): Auf den Schultern von Riesen: Darwins Evolutionstheorie, in: Engels, Eve-Marie/Betz, Oliver/Köhler, Heinz-R./Potthast, Thomas (Hrsg.): Charles Darwin und seine Bedeutung für die Wissenschaften, Tübingen, S. 27-42.

Kähler, Wolf-Michael (2011): Statistische Datenanalyse. Verfahren verstehen und mit SPSS gekonnt einsetzen, 7. Auflage, Wiesbaden.

Kalpaka, Annita/Räthzel, Nora (1994a): Die Schwierigkeit, nicht rassistisch zu sein. Rassismus in Politik, Kultur und Alltag, Köln.

Kalpaka, Annita/Räthzel, Nora (1994b): Vorwort, in: ebd. (Hrsg.): Die Schwierigkeit, nicht rassistisch zu sein. Rassismus in Politik, Kultur und Alltag, Köln, S. 9-11.

Kalpaka, Annita/Räthzel, Nora (1994c): Wirkungsweisen von Rassismus und Ethnozentrismus, in: ebd. (Hrsg.): Die Schwierigkeit, nicht rassistisch zu sein. Rassismus in Politik, Kultur und Alltag, Köln, S. 12-80.

Kalpaka, Annita/Räthzel, Nora (2000): Die Schwierigkeit, nicht rassistisch zu sein, in: Räthzel, Nora (Hrsg.): Theorien über Rassismus, Hamburg, S. $177-190$. 
Kattmann, Ulrich (1999): Warum und mit welcher Wirkung klassifizieren Wissenschaftler Menschen?, in: Kaupen-Haas, Heidrun/Saller, Christian (Hrsg.): Wissenschaftlicher Rassismus. Analysen einer Kontinuität in den Human- und Naturwissenschaften, Frankfurt/Main u. a., S. 65-83.

Kaupen-Haas, Heidrun (1999): Nachwort, in: Kaupen-Haas, Heidrun/Saller, Christian (Hrsg.): Wissenschaftlicher Rassismus. Analysen einer Kontinuität in den Human- und Naturwissenschaften, Frankfurt/Main u. a., S. 425-429.

Keita, S. O. Y./Kittles, R. A./Royal, C. D. M./Bonney, G. E./Furbert-Harris, P./Dunston, G. M./Rotimi, C. N. (2004): Conceptualizing human variation, in: Genetics. Genetics for the human race, Vol. 36 Nr. 11, Nov. 2004, London u. a., S. 17-20.

Kemper, Andreas (2012): Sarrazins deutschsprachige Quellen, in: Michael/Niggeschmidt, Martin (Hrsg.): Der Mythos vom Niedergang der Intelligenz. Von Galton zu Sarrazin: Die Denkmuster und Denkfehler der Eugenik, Wiesbaden, S. 49-70.

Kerner, Ina (2009): Differenzen und Macht. Zur Anatomie von Rassismus und Sexismus, Frankfurt/Main u. a.

Kiyak, Mely (2008): Europa: Die Villa mit fünf Sternen, in: Aus Politik und Zeitgeschichte, Beilage zur Wochenzeitung Das Parlament, 35-36/2008, 58. Jahrgang, Bonn, S. 3-6.

Kleff, Sanem (1990): „Wir sind auch das Volk!“ Die letzten zwölf Monate des geteilten Berlin aus der Sicht nicht-deutscher Berlinerinnen, in: Kleff, Sanem/Broszinsky-Schwabe, Edith/Albert, Marie-T./Marburger, Helga /Karsten, Marie E. (Hrsg.): BRD - DDR. Alte und neue Rassismen im Zuge der deutsch-deutschen Einigung, Frankfurt/Main, S. 3-17.

Kleff, Sanem/Broszinsky-Schwabe, Edith/Albert, Marie-T./Marburger, Helga/Karsten, Marie E. (1990): Vorwort, in: ebd. (Hrsg.): BRD - DDR. Alte und neue Rassismen im Zuge der deutsch-deutschen Einigung, Frankfurt/Main, S. 1-2.

Klein, Tanja (2012): Rechtspopulistische Parteien in Regierungsbildungsprozessen: Die Niederlande, Belgien und Schweden im Vergleich, Potsdam.

Kleinert, Corinna (2004): FremdenFeindlichkeit. Einstellungen junger Deutscher zu Migranten, Wiesbaden.

Knebel, Leonie/Marquardt, Pit (2012): Vom Versuch, die Ungleichwertigkeit von Menschen zu beweisen, in: Haller, Michael/Niggeschmidt, Martin (Hrsg.): Der Mythos vom Niedergang der Intelligenz. Von Galton zu Sarrazin: Die Denkmuster und Denkfehler der Eugenik, Wiesbaden, S. 87-126. 
Knight, Ute/Kowalsky, Wolfgang (1991): Deutschland nur den Deutschen? Die Ausländerfrage in Deutschland, Frankreich und den USA, 2. Auflage, Erlangen u. a.

Knoche, Werner (1977): Das Erbe-Umwelt-Problem, Frankfurt/Main.

Knußmann, Rainer (1996): Vergleichende Biologie des Menschen. Lehrbuch der Anthropologie und Humangenetik, 2. Auflage, Stuttgart u. a.

Koller, Christian (2009): Rassismus, Paderborn.

Krämer, Walter (2008): So lügt man mit Statistik, 10. Auflage, München.

Krath, Stefanie/Hüther, Gerald (2013): Intelligenz ist eine Fähigkeit, Begabung ist ein Potenzial, in: Begegnung. Deutsche schulische Arbeit im Ausland, 3/2013, 34. Jahrgang, Köln, S. 26-31.

Krause-Vilmar, Dietfrid (2006): „Rechtspopulismus als Herausforderung“, in URL: http://kobra.bibliothek.uni-kassel.de/handle/urn:nbn:de:hebis:34$2006112115754<30.08 .2012>$.

Kreisky, Eva (2002): In Konvergenz der Interessen: Neoliberale Praktiken und rechtspopulistische Regulierung sozialen Protestes, in: Bojadžijev, Manuela/Demirović, Alex (Hrsg.): Konjunkturen des Rassismus, Münster, S. 50-89.

Krieger, Regina (2012): „Lukratives Buch. Wie Sarrazin Millionär wurde“, in URL: http://www.handelsblatt.com/unternehmen/it-medien/lukrativesbuch-wie-sarrazin-millionaer-wurde/6647994.html <03.07.2013>.

Krüger, Karen (2010): Er ist nur eine Stimme unter vielen, in: Deutschlandstiftung Integration (Hrsg.): Sarrazin. Eine deutsche Debatte, München, S. 63-65.

Krüger-Potratz, Marianne (1991a): Anderssein gab es nicht. Ausländer und Migranten in der DDR, Münster u. a.

Krüger-Potratz, Marianne (1991b): Das hässliche Gesicht der einen Welt Zur Einleitung, in: ebd. (Hrsg.): Anderssein gab es nicht. Ausländer und Minderheiten in der DDR, Münster u. a., S. 1-58.

Krüger-Potratz, Marianne (1991c): Ihre Sorgen - unsere Sorgen, in: ebd. (Hrsg.): Anderssein gab es nicht. Ausländer und Minderheiten in der DDR, Münster u. a., S. 223-225.

Krüger-Potratz, Marianne/Jasper, Dirk (1991): Vorwort, in: Krüger-Potratz, Marianne (Hrsg.): Anderssein gab es nicht. Ausländer und Minderheiten in der DDR, Münster u. a., S. I-II.

Kühl, Stefan (1999): Die soziale Konstruktion von Wissenschaftlichkeit und Unwissenschaftlichkeit in der internationalen eugenischen Bewegung, in: Kaupen-Haas, Heidrun/Saller, Christian (Hrsg.): Wissenschaftlicher Ras- 
sismus. Analysen einer Kontinuität in den Human- und Naturwissenschaften, Frankfurt/Main u. a., S. 111-121.

Kühne, Peter (2009): Flüchtlinge und der deutsche Arbeitsmarkt. Dauernde staatliche Integrationsverweigerung, in: Butterwegge, Christoph/Hentges, Gudrun (Hrsg.): Zuwanderung im Zeichen der Globalisierung. Migrations-, Integrations- und Minderheitenpolitik, 4. Auflage, Wiesbaden, S. 253-267.

Lamnek, Siegfried (2010): Qualitative Sozialforschung. Lehrbuch, 5. Auflage, Weinheim.

Lange, Jörg (2008): Migration und die Allgemeine Erklärung der Menschenrechte von 1948, in: Aus Politik und Zeitgeschichte, Beilage zur Wochenzeitung Das Parlament, 46/2008, 58. Jahrgang, Bonn, S. 21-27.

Langenbacher, Nora/Molthagen, Dietmar (2010): Rechtsextremismus? Nicht mit mir! Grundwissen und Handwerkzeug für Demokratie, Berlin.

Langenbacher, Nora/Schellenberg, Britta (2011): Ist Europa auf dem „rechten" Weg? Rechtsextremismus und Rechtspopulismus in Europa, Berlin.

Laqueur, Walter (2006): Gesichter des Antisemitismus. Von den Anfängen bis heute, Berlin.

Leakey, Richard/Lewin, Roger (1996): Wie der Mensch zum Menschen wurde, Hamburg.

Leggewie, Claus (1992): ,Stolz, ein Deutscher zu sein... - die neue Angst vor den Fremden, in: Bade, Klaus J. (Hrsg.): Deutsche im Ausland - Fremde in Deutschland. Migration in Geschichte und Gegenwart, München, S. 423-429.

Leggewie, Claus (1993): Vom Deutschen Reich zur Bundesrepublik - und nicht zurück. Zur politischen Gestalt einer multikulturellen Gesellschaft, in: Balke, Friedrich/Habermas, Rebekka/Nanz, Patrizia/Sillem, Peter (Hrsg.): Schwierige Fremdheit. Über Integration und Ausgrenzung in Einwanderungsländern, Frankfurt/Main, S. 3-20.

Leo, Gerhard (2001): Tausende Ausländer/innen in Abschiebehaft. Gedanken zu einem Gefängnis besonderer Art in Berlin, in: Arndt, Susan (Hrsg.): AfrikaBilder. Studien zu Rassismus in Deutschland, Münster, S. 381-392.

Link, Jürgen (2002): „Rechtspopulismus“? Über einige diskurstaktische Probleme beim Bekämpfen des Neorassismus unter normalistischen Verhältnissen (mit neun diskurstaktischen Tipps), in: Bojadžijev, Manuela/Demirović, Alex (Hrsg.): Konjunkturen des Rassismus, Münster, S. 197-211.

Lipphardt, Veronika (2008): Biologie der Juden. Jüdische Wissenschaftler über „Rasse“ und Vererbung. 1900-1935, Göttingen. 
Lohrmann, Reinhard (1997): International Migration Dynamics and Immigration Policy in Europe: an Internationale Perspective, in: Weber, Albrecht (Hrsg.): Einwanderungsland Bundesrepublik Deutschland in der Europäischen Union, Osnabrück, S. 31-44.

Lowe, John et al. (2012): Volcanic ash layers illuminate the resilience of Neanderthals and early modern humans to natural hazards, in: PNAS, July 23, Washington, S. 1-6.

Maier, Wolfgang (2011): Darwins Weltreise mit der HMS ,Beagle‘ (1831-1836) - Historische Geologie und die Entstehung der modernen Evolutionstheorie, in: Engels, Eve-Marie/Betz, Oliver/Köhler, Heinz-R./Potthast, Thomas (Hrsg.): Charles Darwin und seine Bedeutung für die Wissenschaften, Tübingen, S. 43-76.

Marburger, Helga (1990): Interkulturelles Lernen in Europa - Aufgaben und Ansätze, in: Kleff, Sanem/Broszinsky-Schwabe, Edith/Albert, MarieT./Marburger, Helga/Karsten, Marie E. (Hrsg.): BRD - DDR. Alte und neue Rassismen im Zuge der deutsch-deutschen Einigung, Frankfurt/Main, S. 62-78.

Markl, Jürgen (2006): Neil A. Campbell, Jane B. Reece. Biologie, 6. Auflage, München.

Marten, Heinz-Georg (1983): Sozialbiologismus. Biologische Grundpositionen der politischen Ideengeschichte, Frankfurt/Main u. a.

Matter, Max (1987): Fremde im eigenen Land. Zur Situation türkischer Arbeitnehmer und ihrer Familien nach der Rückkehr aus der Bundesrepublik Deutschland, in: Kuntz, Andreas/Pfleiderer, Beatrix (Hrsg.): Fremdheit und Migration, Berlin u. a., S. 221-252.

Mayring, Philipp (2000): Qualitative Inhaltsanalyse, in: Forum Qualitative Sozialforschung/Forum Qualitative Social Research, Volume 1 No. 2, Art. 20, http://nbn-resolving.de/urn:nbn:de:0114-fqs0002204.

Mayring, Philipp (2002): Einführung in die qualitative Sozialforschung. Eine Anleitung zu qualitativem Denken, Weinheim u. a.

Mayring, Philipp (2013): Qualitative Inhaltsanalyse, in: Flick, Uwe/Kardorff, Ernst von/Steinke, Ines (Hrsg.): Qualitative Forschung. Ein Handbuch, 10. Auflage, Reinbek bei Hamburg, S. 468-475.

McFarland, David (1999): Biologie des Verhaltens. Evolution, Physiologie, Psychologie, 2. Auflage, Heidelberg u. a.

Mecheril, Paul/Melter, Claus (2009): Rassismustheorie und -forschung in Deutschland. Kontur eines wissenschaftlichen Feldes, in: ebd. (Hrsg.): Rassismuskritik. Band 1: Rassismustheorie und -forschung, Schwalbach/Taunus, S. 13-24. 
Mecheril, Paul/Scherschel, Karin (2009): Rassismus und „Rasse“, in: Melter, Claus/Mecheril, Paul (Hrsg.): Rassismuskritik. Band 1: Rassismustheorie und -forschung, Schwalbach/Taunus, S. 39-58.

Meier-Mesquita, Cintia (1994): Rasse, Rassismus und Rassentheorien. Die Entstehung des Rassismus und das Bild der außereuropäischen Völker in Europa, in: Rauchfleisch, Udo (Hrsg.): Fremd im Paradies. Migration und Rassismus, Basel, S. 45-60.

Melzer, Ralf/Serafin, Sebastian (Hrsg.): Rechtsextremismus in Europa. Länderanalysen, Gegenstrategien und arbeitsmarktorientierte Ausstiegsarbeit, Berlin.

Memmi, Albert (1992): Rassismus, Hamburg.

Merz, Ferdinand/Stelzl, Ingeborg (1977): Einführung in die Erbpsychologie, Stuttgart u. a.

Messerschmidt, Astrid (2009): Rassismusanalyse in einer postnationalsozialistischen Gesellschaft, in: Melter, Claus/Mecheril, Paul (Hrsg.): Rassismuskritik. Band 1: Rassismustheorie und -forschung, Schwalbach/Taunus, S. 59-74.

Metin, Mehmet (1990): Rassismus in der Sprache, Frankfurt/Main.

Metz, Johann Baptist (1993): Das Christentum und die Fremden. Perspektiven einer multikulturellen Religion, in: Balke, Friedrich/Habermas, Rebekka/Nanz, Patrizia/Sillem, Peter (Hrsg.): Schwierige Fremdheit. Über Integration und Ausgrenzung in Einwanderungsländern, Frankfurt/Main, S. 217-228.

Miles, Robert (1991): Die Idee der „Rasse“ und Theorien über Rassismus: Überlegungen zur britischen Diskussion, in: Bielefeld, Uli (Hrsg.): Das Eigene und das Fremde. Neuer Rassismus in der Alten Welt, Hamburg, S. 189-220.

Miles, Robert (1993): Racism after ,race relations', London.

Miles, Robert (1999): Rassismus. Einführung in die Geschichte und Theorie eines Begriffs, 3. Auflage, Hamburg.

Miles, Robert (2000): Bedeutungskonstitution und der Begriff des Rassismus, in: Räthzel, Nora (Hrsg.): Theorien über Rassismus, Hamburg, S. 17-33.

Minkenberg, Michael (2013): Die europäische radikale Rechte und Fremdenfeindlichkeit in West und Ost: Trends, Muster und Herausforderungen, in: Melzer, Ralf/Serafin, Sebastian (Hrsg.): Rechtsextremismus in Europa. Länderanalysen, Gegenstrategien und arbeitsmarktorientierte Ausstiegsarbeit, Berlin, S. 9-38.

Moebius, Stephan (2008): Macht und Hegemonie: Grundrisse einer poststrukturalistischen Analytik der Macht, in: Moebius, Stephan/Reckwitz, Andre- 
as (Hrsg.): Poststrukturalistische Sozialwissenschaften, Frankfurt/Main, S. 158-174.

Moebius, Stephan/Reckwitz, Andreas (2008): Einleitung: Poststrukturalismus und Sozialwissenschaften: Eine Standortbestimmung, in: ebd. (Hrsg.): Poststrukturalistische Sozialwissenschaften, Frankfurt/Main, S. 7-23.

Moreno-Estrada, Andrés et al. (2014): The genetics of Mexico recapitulates Native American substructure and affects biomedical traits, in: Science, Vol. 344, Washington u. a., S. 1280-1285.

Mosse, George L. (1993): Die Geschichte des Rassismus in Europa, Frankfurt/Main.

Mountain, Joanna L./Risch, Neil (2004): Assessing genetic contributions to phenotypic differences among, racial' and, ethnic' groups, in: Nature Genetics. Genetics for the human race, Vol. 36 Nr. 11, Nov. 2004, London u. a., S. 48-53.

Mühlen, Patrik von zur (1977): Rassenideologien. Geschichte und Hintergründe, Berlin u. a.

Müller, Jost (1992): Rassismus und die Fallstricke des gewöhnlichen Antirassismus, in: Redaktion diskurs (Hrsg.): Die freundliche Zivilgesellschaft. Rassismus und Nationalismus in Deutschland, Berlin u. a., S. 25-44.

Müller-Jung, Joachim (2010): „Sarrazins Biologismus. Phantasma ,JudenGen“", in URL: http://www.faz.net/aktuell/feuilleton/debatten/2.1763 /die-thesen/sarrazins-biologismus-phantasma-juden-gen-11028466.html $<09.02 .2013>$.

Munk, Katharina (2009): Taschenlehrbuch Biologie. Ökologie - Evolution, Stuttgart.

Munk, Katharina (2010): Taschenlehrbuch Biologie. Genetik, Stuttgart.

Muzzupappa, Sergio (2013): Die Genese des Berlusconismus, in: Bathke, Peter/Hoffstadt, Anke (Hrsg.): Die neuen Rechten in Europa. Zwischen Neoliberalismus und Rassismus, Köln, S. 126-131.

Nature Publishing Group (2004): Editorial. The unexamined population, in: Nature Genetics. Genetics for the human race, Vol. 36 Nr. 11, Nov. 2004, London u. a., S. 3.

Nature Publishing Group (2004): Nature Genetics. Genetics for the human race, Vol. 36 Nr. 11, Nov. 2004, London u. a.

Neubauer, Ralf (1992): Fremdenhass als Konjunkturbremse, in: Nirumand, Bahman (Hrsg.): Angst vor den Deutschen. Terror gegen Ausländer und der Zerfall des Rechtsstaates, Reinbek bei Hamburg, S. 193-201. 
Nohlen, Dieter/Schultze, Rainer-Olaf/Schüttemeyer, Suzanne (1998): Art. „Rassismus“, in: ebd. (Hrsg.): Lexikon der Politik. Band 7. Politische Begriffe, München, S. 530-531.

Oberndörfer, Dieter (1993): Vom Nationalstaat zur offenen Republik - Zu den Voraussetzungen der politischen Integration von Einwanderung, in: Heßler, Manfred (Hrsg.): Zwischen Nationalstaat und multikultureller Gesellschaft. Einwanderung und Fremdenfeindlichkeit in der Bundesrepublik Deutschland, Berlin, S. 53-66.

OECD (2010): PISA 2009 Ergebnisse. Was Schülerinnen und Schüler wissen und können: Schülerleistungen in Lesekompetenz, Mathematik und $\mathrm{Na}$ turwissenschaften, Paris.

Olson, Steve (2003): Herkunft und Geschichte des Menschen. Was die Gene über unsere Vergangenheit verraten, Berlin.

Panahi, Badi (1980): Vorurteile. Rassismus, Antisemitismus, Nationalismus... in der Bundesrepublik heute. Eine empirische Untersuchung, Frankfurt/Main.

Patalong, Frank (2014): „Harte Zeiten für Rassisten“, in URL: http:// www.spiegel.de/wissenschaft/mensch/neandertaler-forschung-stelltrassistische-weltbilder-auf-den-kopf-a-950848.html <28.05.2014 $>$.

Patrinos, Ari (2004): ,Race ${ }^{6}$ and the human genome, in: Nature Publishing Group (Hrsg.): Nature Genetics. Genetics for the human race, Vol. 36 Nr. 11, Nov. 2004, London u. a., S. 1-2.

Paululat, Achim/Purschke, Günter (2011): Wörterbuch der Zoologie, 8. Auflage, Heidelberg.

Penke, Lars/Denissen, Jaap J. A./Miller, Geoffrey F. (2008): Die Evolutionsgenetik der Persönlichkeit, in: Neyer, Franz J./Spinath, Frank M. (Hrsg.): Anlage und Umwelt. Neue Perspektiven der Verhaltensgenetik und Evolutionspsychologie, Stuttgart, S. 27-60.

Penzlin, Heinz (2009): Lehrbuch der Tierphysiologie, 7. Auflage, Heidelberg.

Plomin, Robert (1999): Genetics and general cognitive ability, in: Nature, Vol. 402, London u. a., S. C25-C29.

Plomin, Robert/DeFries, John C. (1998): The Genetics of Cognitive Abilities and Disabilities, in: Scientific American, May 1998, S. 62-69.

Plomin, Robert/DeFries, John C./Craig, Ian W./McGuffin, Peter (2003): Behavioral Genetics in the Postgenomic Era, Washington.

Plomin, Robert/DeFries, John C./McClearn, Gerald E. (1990): Behavioral genetics. A Primer, 2. Auflage, New York.

Plomin, Robert/DeFries, John C./McClearn, Gerald E./McGuffin, Peter (2008): Behavioral genetics, 5. Auflage, New York. 
Plomin, Robert/DeFries, John C./McClearn, Gerald E./Rutter, Michael (1999): Gene, Umwelt und Verhalten. Einführung in die Verhaltensgenetik, Bern u. a.

Plomin, Robert/Owen, Michael J./McGuffin, Peter (1994): The Genetic Basis of Complex Human Behaviors, in: Science, Vol. 264, Washington u. a., S. 1733-1739.

Plomin, Robert/Spinath, Frank M. (2002): Genetics and general cognitive ability (g), in: TRENDS in Cognitive Sciences, Vol. 6, No. 4, München u. a., S. 169-176.

Plümecke, Timo (2013): Rasse in der Ära der Genetik. Die Ordnung des Menschen in den Lebenswissenschaften, Bielefeld.

Poliakov, Léon (1993): Der arische Mythos. Zu den Quellen von Rassismus und Nationalismus, Hamburg.

Poliakov, Léon/Delacampagne, Christian/Girard, Patrick (1992): Rassismus. Über Fremdenfeindlichkeit und Rassenwahn, Hamburg u. a.

Poutrus, Patrice G./Behrends, Jan C./Kuck, Dennis (2001): Fremd-Sein in der sozialistischen Diktatur. Zu historischen Ursachen von Fremdenfeindlichkeit und rassistischer Gewalt in den Neuen Bundesländern, in: Arndt, Susan (Hrsg.): AfrikaBilder. Studien zu Rassismus in Deutschland, Münster, S. 184-204.

Presse- und Informationsamt der Bundesregierung (2013): „Böhmer: ,Deutschland ist ein Einwanderungsland.“, in URL: http://www. bundesregierung.de/Content/DE/Pressemitteilungen/BPA/2013/01/2013-01-

30-boehmer-deutschland-einwanderungsland.html <14.07.2013>.

Priester, Karin (2013): Das Phänomen des Berlusconismus, in: Bathke, Peter/Hoffstadt, Anke (Hrsg.): Die neuen Rechten in Europa. Zwischen Neoliberalismus und Rassismus, Köln, S. 132-145.

Propping, Peter (1992): Was müssen die Wissenschaft und die Gesellschaft aus der Vergangenheit lernen? Die Zukunft der Humangenetik, in: Propping, Peter/Schott, Heinz (Hrsg.): Wissenschaft auf Irrwegen. Biologismus - Rassenhygiene - Eugenik, Bonn u. a., S. 114-135.

Quadflieg, Dirk (2008): Sprache und Diskurs: Von der Struktur zu différance, in: Moebius, Stephan/Reckwitz, Andreas (Hrsg.): Poststrukturalistische Sozialwissenschaften, Frankfurt/Main, S. 93-107.

Quent, Matthias (2012): Rechtsextremismus - ein ostdeutsches Phänomen?, in: Aus Politik und Zeitgeschichte, Beilage zur Wochenzeitung Das Parlament, 16-17/2012, 62. Jahrgang, Bonn, S. 38-42.

Radtke, Frank-Olaf (1993): Multikulturalismus - Ein Gegengift gegen Ausländerfeindlichkeit und Rassismus?, in: Heßler, Manfred (Hrsg.): Zwischen 
Nationalstaat und multikultureller Gesellschaft. Einwanderung und Fremdenfeindlichkeit in der Bundesrepublik Deutschland, Berlin, S. 91-104.

Rahner, Sven (2011): Fachkräftebedarf und Zuwanderung: Geschichte und Perspektiven, in: Aus Politik und Zeitgeschichte, Beilage zur Wochenzeitung Das Parlament, 43/2011, 61. Jahrgang, Bonn, S. 29-35.

Ralph, Peter/Coop, Graham (2013): The Geography of Recent Genetic Ancestry across Europe, in: PLoS Biol 11(5) e1001555. doi:10.1371/journal. pbio.1001555, Cambridge u. a.

Räthzel, Nora (1992): Vorwort, in: Institut für Migrations- und Rassismusforschung e. V. (Hrsg.): Rassismus und Migration in Europa. Beiträge des Kongresses „Migration und Rassismus und Europa“ Hamburg, 26. bis 30. September 1990, Hamburg, S. 7-9.

Rauchfleisch, Udo (1994): Offene und verdeckte Ausgrenzung und Diskriminierung. Rassismus aus psychologischer Sicht, in: ebd. (Hrsg.): Fremd im Paradies. Migration und Rassismus, Basel, S. 85-98.

Redaktion diskurs (1992): Die freundliche Zivilgesellschaft. Rassismus und Nationalismus in Deutschland, Berlin u. a.

Reich, David/Myers, Simon R. et al. (2011): The landscape of recombination in African Americans, in: Nature, Vol. 476, London u. a., S. 170-175.

Reinfeldt, Sebastian/Schwarz, Richard/Foucault, Michel (1993): Bio-Macht, 2. Auflage, Duisburg.

Renschler, Regula (1994): Wider das „Global village“. Plädoyer für eine Migrationspolitik, in: Rauchfleisch, Udo (Hrsg.): Fremd im Paradies. Migration und Rassismus, Basel, S. 191-224.

Reuter, Gerd (2009): Rechtspopulismus in Belgien und den Niederlanden. Unterschiede im niederländischsprachigen Raum, Wiesbaden.

Rex, John (1990): „Rasse“ und „Ethnizität“ als sozialwissenschaftliche Konzepte, in: Dittrich, Eckhard J./Radtke, Frank-Olaf (Hrsg.): Ethnizität. Wissenschaft und Minderheiten, Opladen, S. 141-154.

Richards, Robert J. (1987): Darwin and the emergence of evolutionary theories of mind and behavior, Chicago.

Rieger, Günter (2005): Art. „Rassismus“, in: Nohlen, Dieter/Schultze, RainerOlaf (Hrsg.): Lexikon der Politikwissenschaft. Band 2 N-Z. Theorien, Methoden, Begriffe, 3. Auflage, München, S. 810-815.

Rieker, Peter (2007): Fremdenfeindlichkeit und Sozialisation in Kindheit und Jugend, in: Aus Politik und Zeitgeschichte, Beilage zur Wochenzeitung Das Parlament, 37/2007, 57. Jahrgang, Bonn, S. 31-38.

Rittershofer, Christian (2007): Art. „Rasse/Rassismus“, in: ebd. (Hrsg.): Lexikon Politik, Staat, Gesellschaft, München, S. 563-564. 
Robertson-von-Trotha, Caroline Y. (2011): Rechtsextremismus in Deutschland und Europa. Einleitende Anmerkungen, in: ebd. (Hrsg.): Rechtsextremismus in Deutschland und Europa. Rechts außen - Rechts ,Mitte?, Baden-Baden, S. 11-20.

Rommelspacher, Birgit (2009): Was ist eigentlich Rassismus?, in: Mecheril, Paul/Melter, Claus (Hrsg.): Rassismuskritik. Band 1: Rassismustheorie und -forschung, Schwalbach/Taunus, S. 25-38.

Rosemann, Hermann (1979): Intelligenztheorien. Forschungsergebnisse zum Anlage-Umwelt-Problem im kritischen Überblick, Reinbek bei Hamburg.

Rost, Detlef H. (2009): Intelligenz. Fakten und Mythen, Weinheim u. a.

Royal, Charmaine D. M./Dunston, Georgia M. (2004): Changing the paradigm of ,race' to human genome variation, in: Nature Genetics. Genetics for the human race, Vol. 36 Nr. 11, Nov. 2004, London u. a., S. 5-7.

Ruf, Christoph (2010): „Studie zu deutschen Einstellungen. Wie groß Sarrazins Basis wirklich ist", in URL: http://www.spiegel.de/politik/ deutschland/0,1518,druck-722789,00.html <25.07.2011>.

Ruf, Werner (1989): Ökonomie des Rassismus, in: Autrata, Otger/Kaschuba, Gerrit/Leiprecht, Rudolf (Hrsg.): Theorien über Rassismus. Eine Tübinger Veranstaltungsreihe, 3. Auflage, Hamburg, S. 63-84.

Rühl, Stefan/Brucker, Paul/Kohls, Martin/Lederer, Harald/Dabkowski, David (2013): Migrationsbericht des Bundesamtes für Migration und Flüchtlinge im Auftrag der Bundesregierung. Migrationsbericht 2011, Berlin.

Runge, Irene (1990): Ausland DDR. Fremdenhass, Berlin.

Rürup, Bert/Sesselmeier, Werner (1993): Einwanderung: Die wirtschaftliche Perspektive, in: Balke, Friedrich/Habermas, Rebekka/Nanz, Patrizia/Sillem, Peter (Hrsg.): Schwierige Fremdheit. Über Integration und Ausgrenzung in Einwanderungsländern, Frankfurt/Main, S. 285-304.

Ruse, Michael (2012): The Philosophy of Human Evolution, Cambridge u. a.

Salzborn, Samuel (2010): Antisemitismus als negative Leitidee der Moderne. Sozialwissenschaftliche Theorien im Vergleich, Frankfurt/Main u. a.

Salzborn, Samuel (2014): Rechtsextremismus, Baden-Baden.

Sarrazin, Thilo (2010): Deutschland schafft sich ab. Wie wir unser Land aufs Spiel setzen, 13. Auflage, München.

Scherr, Albert (2009): Rassismus oder Rechtsextremismus? Annäherung an eine vergleichende Betrachtung zweier Paradigmen jenseits rhetorischer Scheinkontroversen, in: Melter, Claus/Mecheril, Paul (Hrsg.): Rassismuskritik. Band 1: Rassismustheorie und -forschung, Schwalbach/Taunus, S. 75-97. 
Schiesser, Giaco (1994): Lust auf Leben, gefesselt. Der ganz alltägliche Rassismus als blinder Fleck des Antirassismus, in: Rauchfleisch, Udo (Hrsg.): Fremd im Paradies. Migration und Rassismus, Basel, S. 61-84.

Schimany, Peter (2007): Migration und demographischer Wandel, Forschungsbericht 5, Nürnberg.

Schirrmacher, Frank (2010): Ein fataler Irrweg, in: Deutschlandstiftung Integration (Hrsg.): Sarrazin. Eine deutsche Debatte, München, S. 22-28.

Schmidt, Christoph M. (2010a): Falsch verstandene Statistik und Rassismus, in: Deutschlandstiftung Integration (Hrsg.): Sarrazin. Eine deutsche Debatte, München, S. 132-136.

Schmidt, Manfred G. (2007): Das politische System Deutschlands, München.

Schmidt, Manfred G. (2010b): Art. „Rassismus“, in: ebd. (Hrsg.): Wörterbuch zur Politik, 3. Auflage, Stuttgart, S. 656-657.

Schneider, Jan (2009): Die Organisation der Asyl- und Zuwanderungspolitik in Deutschland, Paper 25, Nürnberg.

Scholz, Antonia (2013): Warum Deutschland? Einflussfaktoren bei der Zielsuche von Asylbewerbern - Ergebnisse einer Expertenbefragung, Nürnberg.

Schott, Heinz (1992): Die Stigmen des Bösen - kulturgeschichtliche Wurzeln der Ausmerze-Ideologie, in: Propping, Peter/Schott, Heinz (Hrsg.): Wissenschaft auf Irrwegen. Biologismus - Rassenhygiene - Eugenik, Bonn u. a., S. 9-22.

Schubarth, Wilfried (1993): Woher kommt der jugendliche Rechtsextremismus in Ostdeutschland?, in: Heßler, Manfred (Hrsg.): Zwischen Nationalstaat und multikultureller Gesellschaft. Einwanderung und Fremdenfeindlichkeit in der Bundesrepublik Deutschland, Berlin, S. 169-184.

Schubert, Klaus/Klein, Martina (2011): Art. „Ideologie“, in: ebd. (Hrsg.): Das Politiklexikon. Begriffe, Fakten, Zusammenhänge, 5. Auflage, Bonn, S. 142-143.

Schubert, Klaus/Klein, Martina (2011): Art. „Theorie“, in: ebd. (Hrsg.): Das Politiklexikon. Begriffe, Fakten, Zusammenhänge, 5. Auflage, Bonn, S. 297.

Schüller, Christian (1999): Ausnahmen sind die Regel. Die moderne Genetik widerlegt den Rassismus, in: Schüller, Christian/Let, Petrus van der (Hrsg.): Rasse Mensch. Jeder Mensch ist ein Mischling, Aschaffenburg, S. 15-30.

Schümer, Dirk (2002): „Rechtspopulismus ist der neue Trend in Europa“, in: Frankfurter Allgemeine Zeitung Nr. 114, 18.05.2002, S. 45.

Seibel, A./Schuhmacher, H./Fahrun, J. (2010): „Mögen Sie keine Türken, Herr Sarrazin“, in URL: http://www.welt.de/politik/deutschland/ 
article9255898/Moegen-Sie-keine-Tuerken-Herr-Sarrazin.html $\quad<10.02$. $2013>$.

Sesín, Claus-Peter (2012): Sarrazins dubiose US-Quellen, in: Haller, Michael/Niggeschmidt, Martin (Hrsg.): Der Mythos vom Niedergang der Intelligenz. Von Galton zu Sarrazin: Die Denkmuster und Denkfehler der Eugenik, Wiesbaden, S. 27-48.

Shipman, Pat (1994): The Evolution of Racism. Human Differences and the Use and Abuse of Science, New York u. a.

Shooman, Yasemin (2012): Das Zusammenspiel von Kultur, Religion, Ethnizität und Geschlecht im antimuslimischen Rassismus, in: Aus Politik und Zeitgeschichte, 16-17/2012, 62. Jahrgang, Bonn, S. 53-57.

Silbermann, Alphons/Hüsers, Francis (1995): Der „normale“ Hass auf die Fremden. Eine sozialwissenschaftliche Studie zu Ausmaß und Hintergründen von Fremdenfeindlichkeit in Deutschland, München.

Singer, Mona (1997): Fremd. Bestimmung. Zur kulturellen Verortung von Identität, Tübingen.

Skutnabb-Kangas, Tove/Phillipson, Robert (1992): Linguizismus, in: Institut für Migrations- und Rassismusforschung e. V. (Hrsg.): Rassismus und Migration in Europa. Beiträge des Kongresses „Migration und Rassismus in Europa" Hamburg, 26. bis 30. September 1990, Hamburg, S. 204-215.

Smith, Thomas M./Smith, Robert L. (2009): Ökologie, 6. Auflage, München.

Solomos, John (2002): Making sense of racism: Aktuelle Daten und politische Realitäten, in: Bojadžijev, Manuela/Demirović, Alex (Hrsg.): Konjunkturen des Rassismus, Münster, S. 157-172.

Sommer, Ralf J. (2011): Zur wissenschaftlichen Vielfalt der modernen Evolutionsbiologie, in: Engels, Eve-Marie/Betz, Oliver/Köhler, HeinzR./Potthast, Thomas (Hrsg.): Charles Darwin und seine Bedeutung für die Wissenschaften, Tübingen, S. 77-88.

Sontheimer, Kurt/Bleek, Wilhelm/Gawrich, Andrea (2007): Grundzüge des politischen Systems Deutschlands, München u. a.

Spiegel Online (2009): „Augenfarbe-Vorhersage: Ich schau Dir in die DNA, Kleines“, in URL: http://www.spiegel.de/wissenschaft/natur/augenfarbe -vorhersage-ich-schau-dir-in-die-dna-kleines-a-612361.html $<07.02 .2013>$.

Spiegel Online (2010): „DNA-Analyse. Genvarianten für Erbkrankheiten weit verbreitet“, in URL: http://www.spiegel.de/wissenschaft/mensch/dnaanalyse-genvarianten-fuer-erbkrankheiten-weitverbreitet-a-725847.html $<03.08 .2012>$. 
Spiegel Online (2011a): „Genkarte erstellt. Wo das Erbgut anfällig führ Fehler ist", in URL: http://www.spiegel.de/wissenschaft/mensch/genkarteerstellt-wo-das-erbgut-anfaellig-fuer-fehler-ist-a-775714.html $<04.08 .2012>$.

Spiegel Online (2011b): „Studie in acht Ländern. Europa der Intoleranten“, in URL: $\quad$ http://www.spiegel.de/politik/ausland/0,1518,750172,00.html $<30.07 .2011>$.

Spiegel Online (2011c): „Zahnfunde: Moderner Mensch lebte bereits vor 45.000 Jahren in Europa“, in URL: http://www.spiegel.de/wissenschaft /mensch/zahnfunde-moderner-mensch-lebte-bereits-vor-45-000-jahrenin-europa-a-795500.html <01.08.2012>.

Spiegel Online (2012a): „Erbgut-Analyse. Jedes Spermium ist anders“, in URL: http://www.spiegel.de/wissenschaft/mensch/genetik-erbgut-insamenzellen-eines-mannes-unterscheidet-sich-stark-a-845469.html $<04.08 .2012>$.

Spiegel Online (2012b): „Moderner Mensch verdrängte Neandertaler“, in URL: http://www.spiegel.de/wissen schaft/mensch/moderner-menschwurde-neandertaler-zum-verhaengnis-a-845971.html <01.08.2012>.

Spiegel Online (2013): „Rassismusvorwürfe wegen Sarrazin: Uno rügt Deutschland - und setzt Ultimatum“, in URL: http://www.spiegel.de /politik/deutschland/uno-ruegt-deutschland-wegen-sarrazin-und-setztultimatum-a-895208.html <07.07.2013>.

Spier, Tim (2006): Populismus und Modernisierung, in: Decker, Frank (Hrsg.): Populismus in Europa. Gefahr für die Demokratie oder nützliches Korrektiv?, Bonn, S. 33-58.

Spinath, Frank M./Deary, Ian J. (2008): Verhaltensgenetik und Intelligenz, in: Neyer, Franz J./Spinath, Frank M. (Hrsg.): Anlage und Umwelt. Neue Perspektiven der Verhaltensgenetik und Evolutionspsychologie, Stuttgart, S. 129-148.

Statistisches Bundesamt Destatis (2009): Deutschland - Land und Leute, Wiesbaden.

Statistisches Bundesamt Destatis (2011a): „Eingebürgerte Personen“, in URL: http://www.destatis.de/jetspeed/portal/cms/Sites/destatis/Internet/DE /Navigation/Statistiken/Bevoelkerung/MigrationIntegration/Eingebuerg erte/Eingebuergerte.psml <19.08.2012>.

Statistisches Bundesamt Destatis (2011b): „Wanderungen von Deutschen/Ausländer/-innen zwischen Deutschland und dem Ausland ab 1991“, in URL: http://www.destatis.de/jetspeed/portal/cms/Sites /destatis/Internet/DE/Navigation/Statistiken/Bevoelkerung/Wanderun gen/Tabellen.psml <19.08.2012>. 
Statistisches Bundesamt Destatis (2012): „Bevölkerung und Erwerbstätigkeit. Wanderung 2011“, in URL: https://www.destatis.de/DE/ZahlenFakten /GesellschaftStaat/Bevoelkerung/Wanderungen/Tabellen/Zuwanderung sgruppenPDF.pdf?_blob=publicationFile $<05.07 .2013>$.

Statistisches Bundesamt Destatis (2013a): „Ausländische Bevölkerung. Ausländische Bevölkerung am 31.12.2011“", in URL: https://www.destatis.de/ DE/ZahlenFakten/GesellschaftStaat/Bevoelkerung/MigrationIntegration /AuslaendischeBevolkerung/Tabellen/Bundeslaender.html $<13.01 .2013>$.

Statistisches Bundesamt Destatis (2013b): Bevölkerung und Erwerbstätigkeit. Vorläufige Ergebnisse der Bevölkerungsfortschreibung auf der Grundlage des Zensus 2011, Wiesbaden.

Statistisches Bundesamt Destatis/Gesellschaft Sozialwissenschaftlicher Infrastruktureinrichtungen/Wissenschaftszentrum Berlin für Sozialforschung (2008a): Datenreport 2008. Ein Sozialbericht für die Bundesrepublik Deutschland, Bonn.

Statistisches Bundesamt Destatis/Gesellschaft Sozialwissenschaftlicher Infrastruktureinrichtungen/Wissenschaftszentrum Berlin für Sozialforschung (2008b): Einleitung, in: ebd. (Hrsg.) Datenreport 2008. Ein Sozialbericht für die Bundesrepublik Deutschland, Bonn, S. 8-9.

Statistisches Bundesamt Destatis/Wissenschaftszentrum Berlin für Sozialforschung/Sozioökonomisches Panel (2011): Datenreport 2011. Ein Sozialbericht für die Bundesrepublik Deutschland. Band I, Bonn.

Staud, Toralf (2012): „Generation Nazi“, in URL: http://www.zeit.de/ 2012/45/NSU-Sozialisation <13.08.2013>.

Stefanowitsch, Anatol (2012): Sprache und Ungleichheit, in: Aus Politik und Zeitgeschichte, Beilage zur Wochenzeitung Das Parlament, 16-17/2012, 62. Jahrgang, Bonn, S. 27-33.

Steins, Gisela/Rudolph, Udo (1994): Fremdenfeindlichkeit aus sozialpsychologischer Sicht: Vorauslaufende Bedingungen, Folgen, Interventionen, in: Knortz, Heike (Hrsg.): Fremdenfeindlichkeit in Deutschland. Ein interdisziplinärer Diskussionsbeitrag, Frankfurt/Main u. a., S. 101-120.

Stern, Elsbeth (2010): „Was heißt hier erblich? Die Intelligenzforscherin Elsbeth Stern widerspricht der Verdummungsthese", in URL: http://www.zeit.de/2010/36/Intelligenz-Sarrazin <09.08.2013>.

Strachan, Tom/Read, Andrew P. (2005): Molekulare Humangenetik, 3. Auflage, München.

Stringer, Christoph B. (1995): Die Herkunft des anatomisch modernen Menschen, in: Streit, Bruno (Hrsg.): Evolution des Menschen, Heidelberg u. a., S. 77-85. 
Süddeutsche Zeitung (2011): „Studie. Europas Sehnsucht nach dem ,starken Mann“", in URL: http://www.sueddeutsche.de/politik/studie-europassehnsucht-nach-dem-starken-mann-1.1070820 <25.08.2011>.

Süddeutsche Zeitung (2013): „Massiver Anstieg bei Zuwanderung. Einwanderungsland Deutschland“, in URL: http://www.sueddeutsche.de/politik /massiver-anstieg-bei-zuwanderung-einwanderungsland-deutschland$1.1667070<14.07 .2013>$.

Taguieff, Pierre-André (1994): Die Metamorphosen des Rassismus und die Krise des Antirassismus, in: Bielefeld, Uli (Hrsg.): Das Eigene und das Fremde. Neuer Rassismus in der Alten Welt?, Hamburg, S. 221-268.

Taguieff, Pierre-André (2000): Die Macht des Vorurteils. Der Rassismus und sein Double, Hamburg.

Tanner, Jakob (1994): Nationalmythos und „Überfremdungsängste“. Wie und warum die Immigration zum Problem wird, dargestellt am Beispiel der Schweizer Geschichte des 19. und 20. Jahrhunderts, in: Rauchfleisch, Udo (Hrsg.): Fremd im Paradies. Migration und Rassismus, Basel, S. 11-26.

Tautz, Diethard (2012): Genetische Unterschiede? Die Irrtümer des Biologismus, in: Haller, Michael/Niggeschmidt, Martin (Hrsg.): Der Mythos vom Niedergang der Intelligenz. Von Galton zu Sarrazin: Die Denkmuster und Denkfehler der Eugenik, Wiesbaden, S. 127-134.

Terkessidis, Mark (1998): Psychologie des Rassismus, Opladen u. a.

Terkessidis, Mark (2004): Die Banalität des Rassismus. Migranten zweiter Generation entwickeln eine neue Perspektive, Bielefeld.

Terwey, Michael/Baltzer, Stefan (2013): „GESIS-Variable Reports 2013/16. ALLBUS 2012 - Variable Report. Studien-Nr. 4614, Version: 1.1.0, doi: 10.4232/1.11634“, in URL: Anforderung via http://www.gesis.org/allbus $<26.05 .2013>$.

The 1000 Genomes Project Consortium (2010): A map of human genome variation from population-scale sequencing, in: Nature, Vol. 467, London u. a., S. 1061-1073.

Thierse, Wolfgang (1992): Deutsch-deutsche Gewalt, in: Nirumand, Bahman (Hrsg.): Angst vor den Deutschen. Terror gegen Ausländer und der Zerfall des Rechtsstaates, Reinbek bei Hamburg, S. 67-75.

Tishkoff, Sarah A./Kidd, Kenneth K. (2004): Implications of biogeography of human populations for ,race' and medicine, in: Nature Genetics. Genetics for the human race, Vol. 36 Nr. 11, Nov. 2004, London u. a., S. 21-27.

Trittin, Jürgen (1993): Gefahr aus der Mitte. Die Republik rutscht nach rechts, Göttingen. 
UN (1966): „Internationales Übereinkommen zur Beseitigung jeder Form von Rassendiskriminierung", in URL: http://www.auswaertiges-amt.de/cae /servlet/contentblob/360838/publicationFile/3632/BeseitigungRassendi skr.pdf $<25.11 .2012>$.

UNESCO (1950): „The race question“, in URL: http://unesdoc.unesco.org/ images/0012/001282/128291eo.pdf <25.11.2012>.

UNESCO (1978): „Erklärung über ,Rassen“ und rassistische Vorurteile“, in URL: http://www.unesco.de/erklaerung_rassist_vorurteile.html $<25.11$. $2012>$.

Uthmeier, Thorsten (2013): „Auf den Spuren der letzten Neandertaler“, in URL: http://blogs.fau.de/news/2013/05/22/auf-den-spuren-der-letztenneandertaler/ <22.05.2013>.

Veit, Barbara/Wiebus, Hans-Otto (1993): Hass macht die Erde kalt. Die Wurzeln des Rassismus, Wuppertal.

Vesper, Karlen (2010): Eine Gefahr für die Demokratie, in: Deutschlandstiftung Integration (Hrsg.): Sarrazin. Eine deutsche Debatte, München, S. 102-104.

Virchow, Fabian (2013): Massendmedialer Rassismus und Rechtspopulismus, in: Bathke, Peter/Hoffstadt, Anke (Hrsg.): Die neuen Rechten in Europa. Zwischen Neoliberalismus und Rassismus, Köln, S. 230-236.

Vorsamer, B. (2010): „Gutachten zu Thilo Sarrazin. Rassistisch, elitär und herabwürdigend", in URL: http://www.sueddeutsche.de/politik /gutach ten-zu-thilo-sarrazin-rassistisch-elitaer-und-herabwuerdigend-1.58130 $<17.06 .2011>$.

Wachendorfer, Ursula (2001): Weiß-Sein in Deutschland. Zur Unsichtbarkeit einer herrschenden Normalität, in: Arndt, Susan (Hrsg.): AfrikaBilder. Studien zu Rassismus in Deutschland, Münster, S. 87-101.

Wade, Carole/Tavris, Carol (1987): Psychology, New York.

Wagner, Bernd (2001): Zu rechtsextremen Entwicklungen in den neuen Bundesländern, in: Arndt, Susan (Hrsg.): AfrikaBilder. Studien zu Rassismus in Deutschland, Münster, S. 166-183.

Wang, Jianbin/Fan, Christina H./Behr, Barry/Quake, Stephen R. (2012): Genome-wide Single-Cell Analysis of Recombination Activity and De Novo Mutation Rates in Human Sperm, in: Cell, Vol. 150, München, S. 402-412.

Weber, Albrecht (1997): Einwanderungsland Bundesrepublik Deutschland in der Europäischen Union - Bestandsaufnahme, Regelungselemente und europäischer Rahmen. Eine Einführung, in: ebd. (Hrsg.): Einwanderungsland Bundesrepublik Deutschland in der Europäischen Union, Osnabrück, S. 9-30. 
Weber, Nina (2012). „Fünf Gene beeinflussen unser Gesicht“, in URL: http://www.spiegel.de/wissenschaft/mensch/erbgut-studie-fuenf-genebeeinflussen-entwicklung-der-gesichtszuege-a-855105.html <09.02.2013>.

Weingart, Peter (1992): Politik und Vererbung, in: Propping, Peter/Schott, Heinz (Hrsg.): Wissenschaft auf Irrwegen. Biologismus - Rassenhygiene Eugenik, Bonn u. a., S. 23-43.

Weingart, Peter (2012): Ist Sarrazin Eugeniker?, in: Haller, Michael/Niggeschmidt, Martin (Hrsg.): Der Mythos vom Niedergang der Intelligenz. Von Galton zu Sarrazin: Die Denkmuster und Denkfehler der Eugenik, Wiesbaden, S. 19-26.

Weingart, Peter/Kroll, Jürgen/Bayertz, Kurt (1988): Rasse, Blut und Gene. Geschichte der Eugenik und Rassenhygiene in Deutschland, Frankfurt/Main.

Weiß, Anja (2013): Rassismus wider Willen. Ein anderer Blick auf eine Struktur sozialer Ungleichheit, 2. Auflage, Wiesbaden.

Weiß, Ulrich (2011a): Art. „Ideologie“, in: Nohlen, Dieter/Grotz, Florian (Hrsg.): Kleines Lexikon der Politik, 5. Auflage, München, S. 257-258.

Weiß, Volker (2011b): Deutschlands neue Rechte. Angriff der Eliten - Von Spengler bis Sarrazin, Paderborn.

Weiss, Volkmar (2012): Die Intelligenz und ihre Feinde: Aufstieg und Niedergang der Industriegesellschaft, Graz.

Werner, Alban/Gebhardt, Richard (2013): Bedingt abkehrbereit. Warum es in der Bundesrepublik (noch) keine erfolgreiche rechtspopulistische Partei gibt, in: Bathke, Peter/Hoffstadt, Anke (Hrsg.): Die neuen Rechten in Europa. Zwischen Neoliberalismus und Rassismus, Köln, S. 191-205.

Widmann, Arno (2010): Wider den Rassendünkel, in: Deutschlandstiftung Integration (Hrsg.): Sarrazin. Eine deutsche Debatte, München, S. 88-89.

Wilson, Allac C./Cann, Rebecca L. (1995): Afrikanischer Ursprung des modernen Menschen, in: Streit, Bruno (Hrsg.): Evolution des Menschen, Heidelberg u. a., S. 86-93.

Winkler, Jürgen R. (2003): Ursachen fremdenfeindlicher Einstellungen in Westeuropa, in: Aus Politik und Zeitgeschichte, Beilage zur Wochenzeitung Das Parlament, 26/2003, Bonn, S. 33-38.

Wollenschläger, Michael (1997): Rechtlicher Rahmen und Voraussetzungen einer Zuwanderungsgesetzgebung, in: Weber, Albrecht (Hrsg.): Einwanderungsland Bundesrepublik Deutschland in der Europäischen Union, Osnabrück, S. 197-224.

Worbs, Susanne (2008): Die Einbürgerung von Ausländern in Deutschland, Integrationsreport, Working Paper 17, 2. Auflage, Nürnberg. 
Wuketits, Franz M. (1987): Charles Darwin. Der stille Revolutionär, München.

Würtz, Stefanie (2000): Wie fremdenfeindlich sind Schüler? Eine qualitative Studie über Jugendliche und ihre Erfahrungen mit dem Fremden, Weinheim u. a.

Zaimoglu, Feridun (2010): Saubermann als Brandstifter, in: Deutschlandstiftung Integration (Hrsg.): Sarrazin. Eine deutsche Debatte, München, S. 56.

Zeit Online (1992): „Alle aus demselben Holz. Ein Gespräch über den Stammbaum der Menschheit mit dem Genetiker Luigi Luca CavalliSforza“, in URL: http://www.zeit.de/1992/07/alle-aus-demselben-holz $<23.07 .2012>$.

Zeit Online (2013): „Griechische Neonazis hetzen gegen Türkei“, in URL: http://www.zeit.de/politik/ausland/2013-05/griechenland-rassismusneonazis $<05.07 .2013>$.

Zerger, Johannes (1997): Was ist Rassismus? Eine Einführung, Göttingen.

Zick, Andreas/Küpper, Beate/Hövermann, Andreas (2011): Die Abwertung der Anderen. Eine europäische Zustandsbeschreibung zu Intoleranz, Vorurteilen und Diskriminierung, Berlin.

Zick, Andreas/Küpper, Beate/Wolf, Carina (2010): „Das Projekt Gruppenbezogene Menschenfeindlichkeit in Europa. Eine kulturvergleichende Untersuchung mit einer Bevölkerungsumfrage in acht europäischen Ländern zur Abwertung und Ausgrenzung von schwachen Gruppen", in URL: http://www.uni-bielefeld.de/\%28de\%29/ikg/projekte/GMF/index.htm $<01.08 .2013>$.

Zimmer, Dieter E. (1975): Der Streit um die Intelligenz. IQ: ererbt oder erworben?, München u. a.

Zimmer, Dieter E. (2012): Ist Intelligenz erblich? Eine Klarstellung, Reinbek bei Hamburg. 
Kaum ein anderes Thema polarisierte die bundesrepublikanische Öffentlichkeit in den vergangenen Jahren so nachhaltig wie die Veröffentlichung der tendenziell rassistischen Theoreme Thilo Sarrazins im Sommer 2010. Rassistische Ressentiments zeigten sich hier wieder als in vielen Teilen der deutschen Gesellschaft etabliert und debattiert, wie der Verkaufserfolg von Sarrazins Bestseller „Deutschland schafft sich ab" demonstriert. Die vorliegende Arbeit fokussiert dieses gegenwärtige, insbesondere biologisch-genetische Rassismusphänomen in der bundesrepublikanischen Gesellschaft im Zeitraum von 2007 bis 2013. Sie analysiert die Verbreitung, die Entstehungsbedingungen sowie die naturwissenschaftliche Realität biologistischer, rassistischer Argumentationen in Deutschland. Hierfür nutzt diese Arbeit einen kombinierten Forschungsansatz von Sozial- und Naturwissenschaften, um das gegenwärtige Rassismusphänomen sowohl aus sozialwissenschaftlicher als auch aus biologischer Perspektive zu analysieren und zu beurteilen. 